ERNEST GRLANDQ LAWRENCE

BERRELEY NATIDNAL LABGRATGRY $4 \because \therefore$

Pretest Analysis of the Thermal-Hydrological Conditions of the Drift Scale Test at Yucca Mountain

J.T. Birkholzer and Y.W. Tsang

Earth Sciences Division

June 1997
RECEIVED

MAR 29 9999 


\section{DISCLAIMER}

This document was prepared as an account of work sponsored by the United States Government. While this document is believed to contain correct information, neither the United States Government nor any agency thereof, nor The Regents of the University of California, nor any of their employees, makes any warranty, express or implied, or assumes any legal responsibility for the accuracy, completeness, or usefulness of any information, apparatus, product, or process disclosed, or represents that its use would not infringe privately owned rights. Reference herein to any specific commercial product, process, or service by its trade name, trademark, manufacturer, or otherwise, does not necessarily constitute or imply its endorsement, recommendation, or favoring by the United States Government or any agency thereof, or The Regents of the University of California. The views and opinions of authors expressed herein do not necessarily state or reflect those of the United States Government or any agency thereof, or The Regents of the University of California.

This report has been reproduced directly from the best available copy.

Available to DOE and DOE Contractors

from the Office of Scientific and Technical Information

P.O. Box 62, Oak Ridge, TN 37831

Prices available from (615) $576-8401$

Available to the public from the

National Technical Information Service

U.S. Department of Commerce

5285 Port Royal Road, Springfield, VA 22161

Ernest Orlando Lawrence Berkeley National Laboratory is an equal opportunity employer. 


\section{DISCLAIMER}

Portions of this document may be illegible in electronic image products. Images are produced from the best available original document. 


\title{
Pretest Analysis of the Thermal-Hydrological Conditions of the Drift Scale Test at Yucca Mountain
}

\author{
J.T. Birkholzer and Y.W. Tsang \\ Earth Sciences Division \\ Ernest Orlando Lawrence Berkeley National Laboratory \\ University of California \\ Berkeley, California 94720
}

June 1997. through the U.S. Department of Energy under Contract No. DE-AC03-76SF00098. 


\section{Pretest Analysis of the Thermal-Hydrological Conditions of the Drift Scale Test at Yucca Mountain}

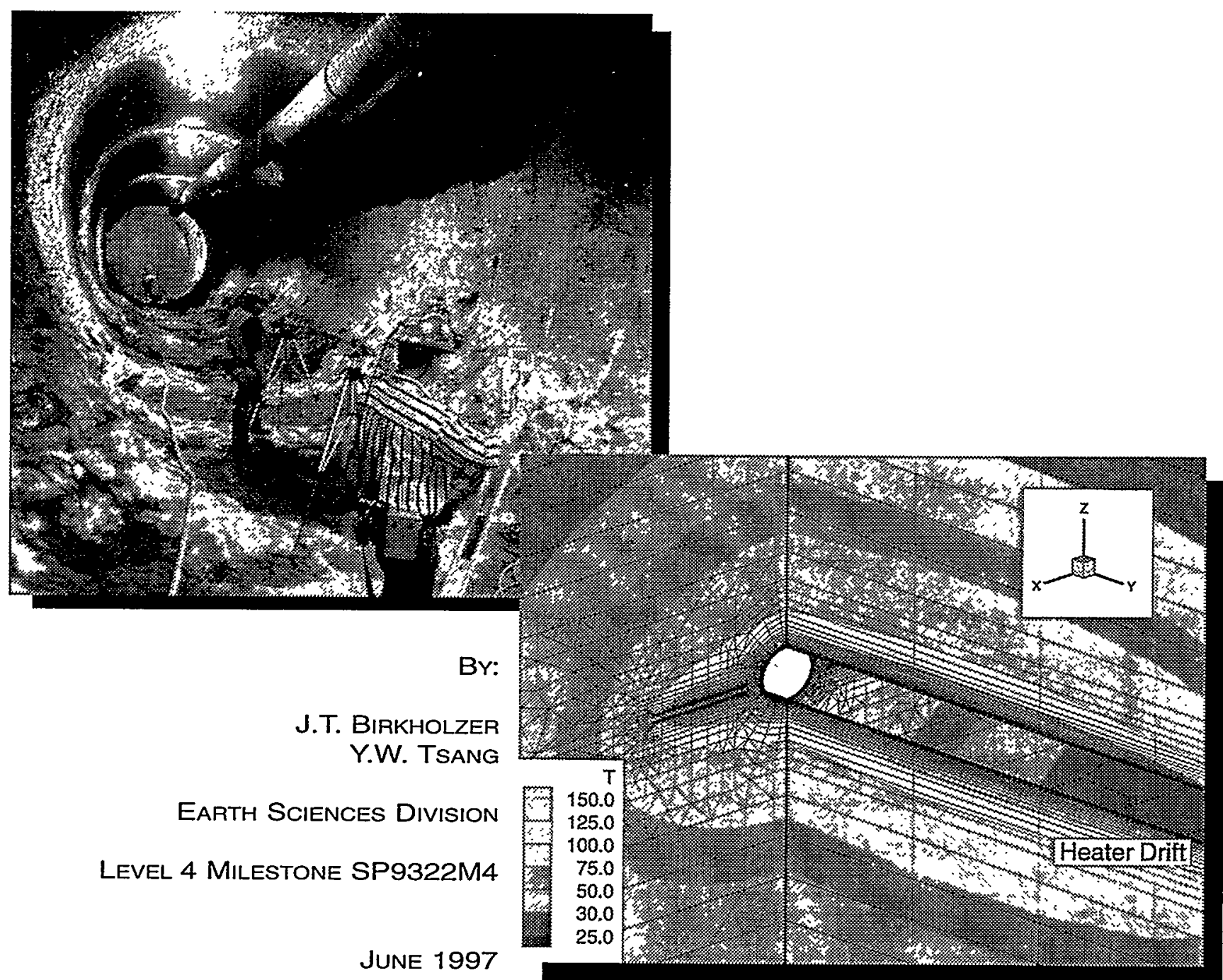




\section{Table of Contents}

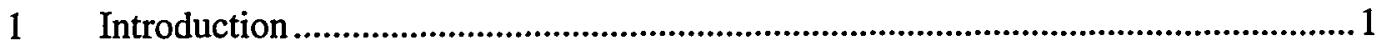

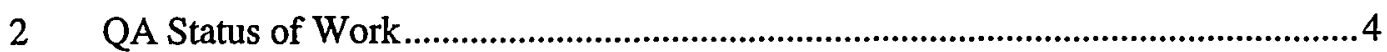

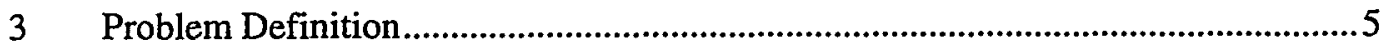

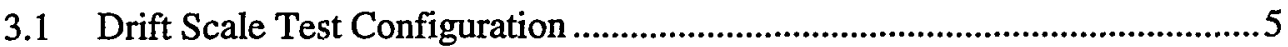

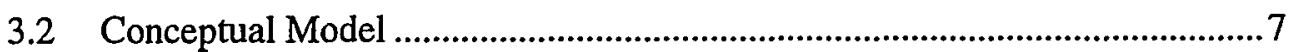

$4 \quad$ Model Concepts, Assumption and Parameters ......................................................11

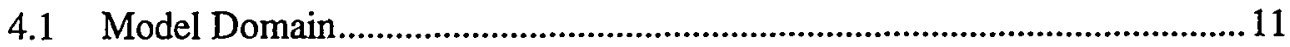

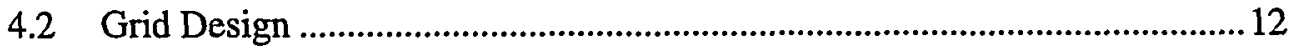

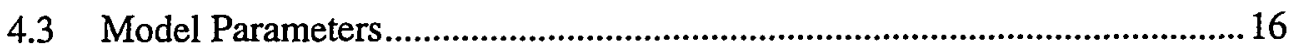

4.4 Boundary and Initial Conditions ............................................................21

$5 \quad$ Three-dimensional Thermal-Hydrological Simulation Results..............................23

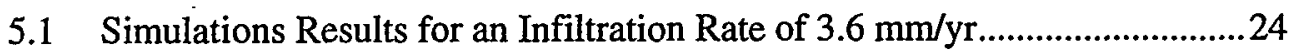

5.2 Simulations Results for an Infiltration Rate of $0.36 \mathrm{~mm} / \mathrm{yr} \ldots \ldots \ldots \ldots \ldots . . . . . . . . . .30$

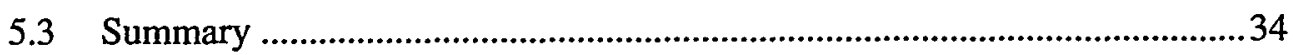

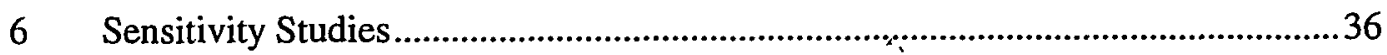

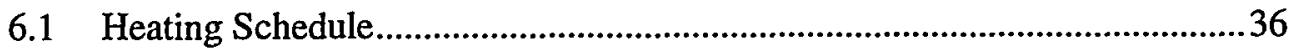

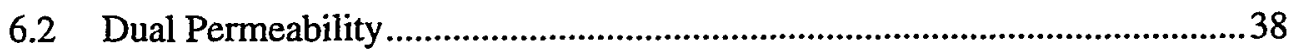

$7 \quad$ Prediction of Sensor Readings in Hydrology Holes ................................................42

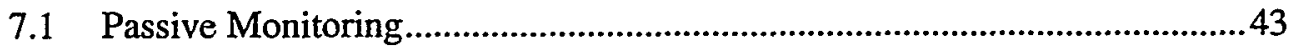

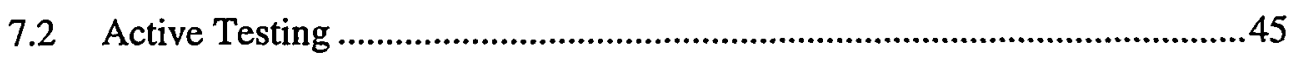

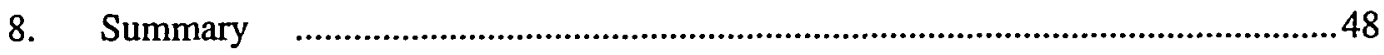

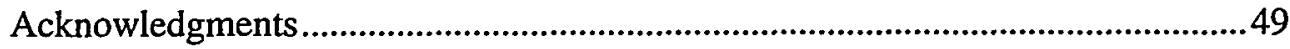

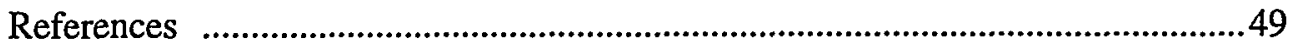

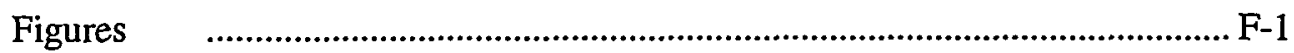

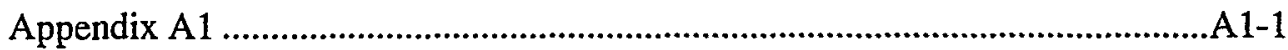

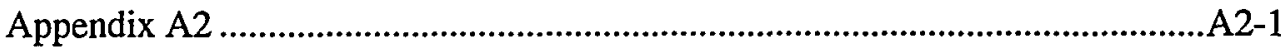




\section{Pretest Analysis of the Thermal-Hydrological Conditions of the ESF Drift} Scale Test

Level 4 Milestone SP9322M4

J. T. Birkholzer and Y.W. Tsang

Earth Sciences Division, LBNL

1 Cyclotron Road, Mailstop: 90-1116

Berkeley CA 94720

\section{Introduction}

In this report, we present the results of the modeling of both the heating and cooling phases of the Drift Scale Test (DST) in the Exploratory Studies Facility (ESF). We analyze the temporal evolution and spatial variation of the thermal-hydrological conditions in the rock mass and evaluate the impact of different input parameters such as heating rates and schedules, and different percolation fluxes at the test horizon. Furthermore, alternative conceptualization of the various physical processes are expected to play an equally important role in affecting the modeled thermal-hydrological responses of the rock mass. Therefore, the issue of conceptual model uncertainty is also addressed in this report. In particular, the processes examined are (1) alternative conceptualization of the matrix-fracture interaction, such as the effective continuum model (ECM) and the dual permeability formulation (DKM), and (2) the effect of radiative heat exchange in the Heater Drift.

The DST is currently under construction in Alcove 5 of the ESF. The heating phase of the multiyear test is scheduled to commence in December of 1997. The DST is the second of the two insitu heater tests being carried out in the ESF thermal alcove, and is an integral component of the overall thermal testing strategy (DOE-YMSCO/003, 1995). This strategy involves a multifaceted approach in which laboratory testing, field thermal tests, modeling analyses, and natural analog studies play important, interrelated roles. The DST is considerably larger in spatial scale than the Single Heater Test (SHT), and much longer in duration. While the heating element in the SHT is $5 \mathrm{~m}$ long and is emplaced in a borehole of $9.6 \mathrm{~cm}$ in diameter, the canister heaters in the DST will be emplaced in a heated drift $47.5 \mathrm{~m}$ in length and $5 \mathrm{~m}$ in diameter. The heat in the Single Heater Test was turned off on May 28, 1997, after nine months of heating. The heating phase of the DST is expected to be 4 years, in order to obtain adequate information on the coupled thermal-hydrological response of the rock mass to the heat, as shall be illustrated in 
simulations presented here. The SHT and DST are expected to provide the majority of sitespecific data on heat-driven near-field processes in the License Application time frame.

The most prominent thermal-hydrological response of the rock mass to the heater power output is the drying of the rock mass surrounding the heat source, the carrying away of moisture in the form of vapor from the heated area, and the subsequent condensation of the vapor in the cooler regions of the rock mass farther away from the heat source. After the heat source is removed and the rock mass starts to cool off, rewetting occurs as water moves back to the vicinity of the heaters. To ensure that a large enough volume of water is heated to above boiling, and that the dominant drift-scale thermal-hydrological processes expected in a repository can be monitored in the DST within a reasonable time frame, the DST has both canister heaters that will heat up the entire length $(47.5 \mathrm{~m})$ of the drift and wing heaters emplaced in 50 boreholes, orthogonal to and flanking the Heater Drift. The power of all canister and wing heaters can be varied within its full range. One objective for the pre-test calculations in this report is to provide input for arriving at an appropriate heating schedule for the DST. One main criterion governing the heating schedule is based on one of the thermal goals of the repository design, namely that the temperatures at the drift wall should not exceed $200^{\circ} \mathrm{C}$.

To monitor the thermal-hydrological evolution in the DST test block, various measuring systems will be installed in boreholes drilled from the Heater Drift, as well as from the Observation Drift parallel to the Heater Drift. In particular, there are twelve "hydrology holes," $40 \mathrm{~m}$ in length, and in three arrays of 5, 5 and 2 boreholes drilled from the Observation Drift. Each of these arrays of hydrology holes forms a fan in a plane orthogonal to the Heater Drift and brackets it. Each hydrology hole will be segregated by high-temperature inflatable packers into four zones, and each zone will be instrumented with sensors to monitor the temperature, relative humidity, and pressure. In addition to passive monitoring, active testing will be performed. This involves the injection of air in the individual zone isolated by packers, and the monitoring of the pressure response in all other packed zones in the hydrology holes, at different stages of the DST. These tests will help in understanding how the gas-phase permeability of the rock changes in time during heating and cooling, and in turn delineate the time evolution of the condensation zones. In this report's presentation of DST simulated results, particular attention will be paid to the predictions of the readings of the sensors in the twelve hydrology holes.

The numerical simulations presented in this report are performed in three dimensions with the multi-component, multi-phase flow simulator TOUGH2 (Pruess, 1987 and 1991; Pruess et al., 1996; Wu et al., 1996). The configuration, parameters, and initial and boundary conditions of the numerical model developed in this study are designed to resemble the Drift Scale Test as closely as possible. Furthermore, all site-specific characterization data such as laboratory measurements of thermal and hydrological properties of cores from the Drift Scale Test block, in-situ air permeability characterization, and borehole video logs are incorporated into the 
conceptual model of the Drift Scale Test. Even so, due to the complexity of the multiple physical processes, the uncertainty in key input parameters such as fracture properties, and in particular the fact that complete as-built data of the borehole and sensor locations are as yet unknown, it can be expected that the predictions from simulations as reported here will deviate from actual data. However, the presented model provides insight into DST performance and serves as an excellent baseline that can later be refined and calibrated against measured data. 
Pretest Analysis of the Thermal-Hydrological Conditions of the ESF Drift Scale Test

\section{QA Status of Work}

The work performed in this study is documented in Yucca Mountain Project Scientific Notebook YMP-LBNL-JBH-2. For input to this study, LBNL has used data collected under an approved YMP QMP. The software packages used in this study include standard spreadsheets and visualization and plotting programs. Such programs are not subject to QA requirements under QARD Rev. 7. The software used to simulate thermal-hydrological conditions in the Drift Scale Test with effective continuum and dual permeability formulation is the TOUGH2 code (Pruess, 1987, 1991). This program has been qualified under an approved YMP QAP (Pruess et al., 1996; Wu et al., 1996). Inversion is performed with the qualified calibration code ITOUGH2 (Finsterle, 1993; Finsterle et al., 1996).

The conclusions of this report are mainly based on qualified data and qualified software. The data used for the 1-D SD-9 calibration are Q, as are most of the additional hydrological and thermal data needed for the DST model. Site-specific data of the thermal testing area are incorporated whenever possible, and are mostly $\mathrm{Q}$. The stratigraphic layering at the DST is based on the UZ site-scale flow model, and is non-Q (Bodvarsson et al., 1997). All data on the specific geometry of the drift scale test configuration, including the borehole configuration, are non-Q. The DST is still under construction, and therefore the geometry used in the model represents design coordinates, not as-built coordinates. 


\section{Problem Definition}

\subsection{Drift Scale Test Configuration}

Figure 3.1-1 shows a plan view of the Drift Scale Test area. Figure 3.1-2 depicts a vertical profile of the test area along Section A-A, chosen as indicated in the plan view and facing approximately east. Figure 3.1-3 shows a small insert of the plan view and a vertical profile along Section B-B facing approximately north. All dimensions are given as designed (since the DST is still under construction), and minor deviations are to be expected from the final as-built configuration. The Heater Drift extends approximately in east-west direction, parallel to the Observation Drift, which connects the test area with the ESF main drift. A 2.0-m-deep bulkhead with low thermal conductivity separates the Heater Drift into a hot and a cold section, with the heated section extending $47.5 \mathrm{~m}$ from the bulkhead to the west. On the cold side of the bulkhead, the unheated section of the Heater Drift extends $9.0 \mathrm{~m}$ to the Connecting Drift. The horizontal distance between the south wall of the Heater Drift and the north wall of the parallel Observation Drift is $27.0 \mathrm{~m}$. The Heater Drift is designed perfectly horizontal, with a circular shape of $5.0 \mathrm{~m}$ in diameter. The Observation Drift gradually declines from the ESF main drift towards the test area, with a slope of $11.5 \%$. It is $5.0 \mathrm{~m}$ wide by $5.0 \mathrm{~m}$ high, measured from the invert to the crown. The Connecting Drift is $4.5 \mathrm{~m}$ wide; its height varies, as its invert is gradually declining from the Observation Drift to the Heater Drift.

All coordinates in this report are given in a local Cartesian coordinate system, relative to the location of the Heater Drift. The origin of the coordinate system is located on the hot side of the bulkhead, in the center of the drift (see Figure 3.1-1). The positive $x$-axis points horizontally approximately north (transverse to the Heater Drift); the positive y-axis points horizontally along the Heater Drift approximately west; and the positive z-direction points vertically upward from the origin. The origin of the local coordinate system relates to the Nevada State Plane Coordinates as follows: $234,059.95 \mathrm{~m}$ North, $171,431.99 \mathrm{~m}$ East, $1052.86 \mathrm{~m}$ NN Elevation (D. Weaver, personal communication).

Nine heater canisters will be placed into the Heater Drift, with a maximum power of $7.5 \mathrm{KW}$ each. However, the power of each of the heat canisters can be regulated in intervals of $250 \mathrm{~W}$, which essentially allows one to operate the heaters at any desired output level. Additional to the in-drift heaters, a total number of 50 wing heaters will be placed into 50 horizontal boreholes uniformly distributed along both sides of the Heater Drift. The lateral distance between the wing heaters is $1.83 \mathrm{~m}$, with the heater hole centerlines $25 \mathrm{~cm}$ below the $\mathrm{z}=0.0 \mathrm{~m}$ level. Each of the wing heaters has a $4.75-\mathrm{m}$-long inner section and a $4.75-\mathrm{m}$-long outer section, which operate on different power levels. The near end of the inner heater is located $2.0 \mathrm{~m}$ from the drift wall, 
while the far end of the outer heater is located at the bottom of the boreholes, $11.5 \mathrm{~m}$ from the drift wall. The wing heaters are represented by the shaded area in Figure 3.1-1. The maximum power of each wing heater is $1.145 \mathrm{KW}$ for the inner part and $1.716 \mathrm{KW}$ for the outer part. The power can be regulated in 5\% intervals; however, the $2 / 3$ power ratio between inner and outer heater must be maintained. Altogether, the in-drift heaters have a total maximum power of $67.5 \mathrm{KW}$, while the 50 wing heaters have a total maximum power of $143.05 \mathrm{KW}$.

Numerous sensors are installed in over 80 instrument boreholes in the DST to monitor the thermal, mechanical, hydrological, and chemical responses of the test. Radial arrays of $20 \mathrm{~m}$ long boreholes intended for closely spaced temperature sensors are drilled from the Heater Drift. Similar radial arrays of shorter boreholes (15 $\mathrm{m}$ in length) are located along the Heater Drift for monitoring mechanical rock displacement. Four long boreholes, drilled from the Connecting Drift and parallel to the Heater Drift, are designed for measuring temperature and rock mass displacement. There are also three horizontal boreholes, drilled from the Observation Drift towards the Heater Drift, for measuring displacement. The other 36 boreholes that originate from the Observation Drift are oriented south/north toward the Heater Drift and have incline angles ranging from $+24^{\circ}$ to $-22^{\circ}$ from the horizontal, so that different rock portions above and below the Heater Drift are covered. They are all $40 \mathrm{~m}$ in length and form spatial clusters of two to five boreholes. These clusters of boreholes serve different purposes. Ten boreholes are designed for moisture measurements with neutron probes, four boreholes are designed for performing electrical resistivity tomography measurements, ten boreholes are designed for chemical analysis, and twelve boreholes are particularly designed for capturing thermal-hydrological behavior ("hydrology holes").

The hydrology holes will be installed with high-temperature packers, high-temperature pressure transducers, and humicaps that measure both the relative humidity and the temperature. They are arranged in three arrays of 5, 5 and 2 boreholes. hydrology holes 57, 58, 59, 60 and 61 are located at $y=10.06 \mathrm{~m}$ measured from the bulkhead, hydrology holes 74, 75, 76, 77 and 78 at $y=30.18 \mathrm{~m}$, and hydrology holes 185 and 186 at $\mathrm{y}=44.8 \mathrm{~m}$, close to the western terminus of the Heater Drift. Each of these arrays forms a fan in a plane orthogonal to and brackets the Heater Drift. The borehole configuration is illustrated in Figures 3.1-2, showing cross-sections transverse to the Heater Drift axis at $y=10.06 \mathrm{~m}$ and $\mathrm{y}=30.18 \mathrm{~m}$, respectively. Table 3.1 summarizes the borehole layout of the DST. 
Table 3.1-1: Geometry of Wing Heater and hydrology holes

\begin{tabular}{|c|c|c|c|c|c|c|c|}
\hline Borehole \# & Purpose & \multicolumn{5}{|c|}{ Collar } & Orientation \\
$\mathbf{( d e g})$ & $\begin{array}{c}\text { Diameter } \\
(\mathbf{c m})\end{array}$ & $\begin{array}{c}\text { Length } \\
(\mathbf{m})\end{array}$ \\
\hline $83-107$ & Wing Heater & -2.5 & $*$ & -0.25 & 0.0 & 9.6 & 11.5 \\
\hline $108-132$ & Wing Heater & 2.5 & $*$ & -0.25 & 0.0 & 9.6 & 11.5 \\
\hline 57 & Hydrology & -29.5 & 10.06 & 4.45 & 24.0 & 7.57 & 40.0 \\
\hline 58 & Hydrology & -29.5 & 10.06 & 3.95 & 14.0 & 7.57 & 40.0 \\
\hline 59 & Hydrology & -29.5 & 10.06 & 3.45 & 6.0 & 7.57 & 40.0 \\
\hline 60 & Hydrology & -29.5 & 10.06 & 2.95 & -15.0 & 7.57 & 40.0 \\
\hline 61 & Hydrology & -29.5 & 10.06 & 2.45 & -22.0 & 7.57 & 40.0 \\
\hline 74 & Hydrology & -29.5 & 30.18 & 6.77 & 20.0 & 7.57 & 40.0 \\
\hline 75 & Hydrology & -29.5 & 30.18 & 6.27 & 10.0 & 7.57 & 40.0 \\
\hline 76 & Hydrology & -29.5 & 30.18 & 5.77 & 1.0 & 7.57 & 40.0 \\
\hline 77 & Hydrology & -29.5 & 30.18 & 5.27 & -20.0 & 7.57 & 40.0 \\
\hline 78 & Hydrology & -29.5 & 30.18 & 477 & -26.0 & 7.57 & 40.0 \\
\hline 185 & Hydrology & -29.5 & 44.80 & 8.0 & 6.8 & 7.57 & 40.0 \\
\hline 186 & Hydrology & -29.5 & 44.80 & 7.0 & -29.4 & 7.57 & 40.0 \\
\hline
\end{tabular}

* wing heater boreholes are uniformly distributed along Heater Drift, with a separation distance of $1.83 \mathrm{~m}$

\subsection{Conceptual Model}

While the dimensions and locations of drifts and boreholes are fixed, there remain many degrees of freedom to modeling the Drift Scale Test. This section outlines the rationale behind the choice of model domain, properties of stratigraphic units, percolation flux(es) at the DST horizon, and different conceptualizations of fracture-matrix interaction such as Effective Continuum Model (ECM) and Dual Permeability Model (DKM).

The Drift Scale Test block is located in the Topopah Spring Middle Non-lithophysal unit at Yucca Mountain (tptpmn), the average thickness of which is on the order of $40 \mathrm{~m}$ in the DST area. Scoping calculations show that with the design heat load, the spatial extent of the thermalhydrological perturbation from the applied heat at the end of four years of heating can be well beyond the boundaries of the tptpmn stratigraphic unit. Therefore, stratigraphic units other than tptpmn need to be included in the modeling of DST. The UZ site-scale flow model (Bodvarsson et al., 1997) forms the basis for the matrix and fracture properties to be applied to the different 
stratigraphic units. Hydrologic properties in the UZ site-scale flow model are obtained from calibration against all available data, including liquid saturation, moisture tension, perched water, pneumatic pressures, temperature, etc. Since SD-9 is the well closest to the DST area, properties used in the DST model correspond specifically to parameters derived from calibration against data in Borehole SD-9. As site-specific characterization data are being collected in the thermal alcove, including the DST area, these will be incorporated as much as possible in our numerical model.

The percolation flux at the DST horizon has a significant impact on the thermal-hydrological response of the rock formation to the applied heat, in that a higher flux can give rise to lower temperature and a larger extent of the condensation zone. Since the percolation flux is related to the surface infiltration flux, which is one of the most uncertain parameters at Yucca Mountain, the numerical model presented here shall be exercised for two different infiltration rates - the best estimate of $3.6 \mathrm{~mm} / \mathrm{yr}$, and one only one-tenth of the expected estimate, $0.36 \mathrm{~mm} / \mathrm{yr}$ - in order to include a full range of plausible responses. Infiltration is assumed to be constant in time; no episodic events are considered.

One of the key parameters in controlling the thermal-hydrological response of the welded tuff in the DST is the fracture permeability. It affects the temperature through heat convection, and it impacts the time evolution and spatial redistribution of moisture through the transport of water vapor and liquid water. Moreover, it is the gas-phase permeability that is of particular importance since the liquid-phase permeability is typically very low in the welded tuff units at ambient state. Site-specific characterization of the gas-phase permeability in the DST area was carried out (Tsang and Cook, 1997) while the Heater Drift was still under construction, and hence none of the wing heater and temperature boreholes originating from the Heater Drift were available for testing. Prior to April 1997, fourteen 40-m boreholes originating from the Observation Drift had been drilled. Each borehole was separated by three inflatable packers into approximately $12-\mathrm{m}$ zones, and a pressure sensor was installed in each packed-off zone. Air injection tests were carried out in each packed-off zone, and the pressure responses in the injection zone and all monitoring zones were monitored. The steady-state pressure response in the injection zone gives the local permeability, and the interference pressure response in all monitored zone gives the connectivity characteristics. Consistent with the borehole videos, which indicate that all the boreholes are intercepted by numerous fractures, the interference air permeability data indicate that the fractures are well connected, in that pressure response is obtained in most monitoring zones. However, the magnitude of the pressure response is typically small in the monitored zones as compared to that in the injection zone, and a direct connection between two packed-off zones by a large fracture such as that found in the SHT block test (Birkholzer and Tsang, 1996) is not evidenced here. 
These findings from air permeability tests are consistent with results from Sonnenthal et al. (1997) who reviewed and analyzed fracture mappings from the entire ESF to determine the properties and distribution of fractures. They showed that more than half of the mapped fractures have lengths below $1 \mathrm{~m}$ and an average spacing of $0.5 \mathrm{~m}$. While the lengths of the fractures range to greater than $18 \mathrm{~m}$, the spacing of the fractures increases quickly with their lengths. In fact, the mean spacing between fractures longer than $7 \mathrm{~m}$ is $11 \mathrm{~m}$ (with a standard deviation of $13 \mathrm{~m}$ ), and the mean spacing between fractures longer than $10 \mathrm{~m}$ is $21 \mathrm{~m}$ (with a standard deviation of $25 \mathrm{~m}$ ). Based on the fracture mapping analysis and the findings of the above mentioned air permeability tests, the DST block may be conceptualized as a fracture continuum formed by well-connected and mostly "short" fractures. The estimated local permeability of the 48 packed off zones range from a high of $2.02 \times 10^{-12} \mathrm{~m}^{2}$ to a low of $8.8 \times 10^{-16} \mathrm{~m}^{2}$, with a median value of $1.4 \times 10^{-13} \mathrm{~m}^{2}$ and a geometric mean of $1 \times 10^{-13} \mathrm{~m}^{2}$ (Tsang and Cook, 1997). Since a discrete large permeability feature is not found in the set of 14 boreholes tested, and since in a continuum the fluid flow will seek out the least resistive path while avoiding the low permeability regions, it is a good first approximation to model the fractures in the DST area as a homogeneous continuum with an average permeability of $1 \times 10^{-13} \mathrm{~m}^{2}$. As more characterization data become available, the conceptual model may need to be refined by incorporating heterogeneity in the fracture continuum.

Other than assigning the appropriate permeability to the fracture and matrix continua, it is also important to account for the interaction between the matrix and fractures. Previous experience with the modeling of the Single Heater Test (Birkholzer and Tsang, 1996) shows that the dual permeability conceptualization of the matrix-fracture interaction gives rise to higher liquid saturation in the fractures than the effective continuum model, and results in larger gravitydriven downward flow. The difference in the modeled behavior from the two conceptualizations is in the dynamics, and is not readily captured by passive monitoring data such as temperature and relative humidity. However, the higher liquid saturation and perhaps larger condensation zone below the horizon of the heaters may give rise to different air permeability signatures when air injection tests are performed in the 12 hydrology holes during the heater test. In this study, the dual permeability model is applied to the DST, and its effect on the modeled behavior is assessed. Also it is discussed, if the air permeability test results can possibly indicate the validity of the ECM and the DKM formulation, respectively.

The mechanism of enhanced vapor diffusion has often been included in previous thermalhydrological simulations (Pruess and Tsang, 1994; Birkholzer and Tsang, 1996). Since the enhanced vapor diffusion serves mainly to move moisture away from the heater area, it is to be expected that it will cause a larger dry-out zone around the heat source while reducing the extent of the condensation zone. Although the phenomenon of enhanced vapor diffusion is documented in the soil literature (Jury and Letey, 1979), there is no direct experimental evidence that it exists in porous rocks (Ho and Webb, 1996). Therefore, in the present study for the DST, our model 
includes the binary vapor-air diffusion rather than the enhanced vapor diffusion. The diffusion coefficient $\mathrm{D}_{\mathrm{va}}$ for the vapor-air mixture in a porous medium is calculated by (Vargaftik, 1975; Walker et al., 1981)

$$
\mathrm{D}_{\mathrm{va}}=\tau \phi S_{\mathrm{g}} \mathrm{D}_{\mathrm{va}}^{\mathrm{o}} \frac{\mathrm{P}_{\mathrm{o}}}{\mathrm{P}}\left[\frac{\mathrm{T}}{\mathrm{T}_{\mathrm{o}}}\right]^{\theta}
$$

Here, $D_{v a}^{\circ}$ is the free-space diffusion coefficient, $\theta$ is a factor for temperature dependence, $\phi$ is the porosity, $S_{8}$ is the gas saturation, $\tau$ is the tortuosity factor, $T$ is temperature, $P$ is pressure, and $T_{o}$ and $P_{o}$ are standard conditions of $0{ }^{\circ} \mathrm{C}$ and 1 bar. The parameter group $\tau \phi S_{g}$ represents the reduction of diffusion strength in a porous medium and is usually on the order of 0.01 .

For the modeling of the DST, the effect of vapor pressure lowering due to capillary and phase adsorption effects is included. This effect is represented by Kelvin's equation (Edlefsen and Anderson, 1943)

$$
f_{\mathrm{vPL}}=\frac{P_{v}\left(T, S_{1}\right)}{P_{\text {sat }}(T)}=\exp \left(\frac{m_{1} P_{c}\left(S_{1}\right)}{\rho_{1} R(T+273.15)}\right)
$$

where $f_{v P L}$ is the vapor pressure lowering factor, $P_{v}$ is vapor pressure, $P_{\text {sat }}$ is saturated vapor pressure of bulk liquid, $P_{c}$ is the difference between liquid and gas-phase pressures, $m_{l}$ is the molecular weight of the liquid, $R$ is the universal gas constant, and $\mathrm{T}$ is temperature in ${ }^{\circ} \mathrm{C}$. The definition of the vapor pressure lowering factor $f_{v P L}$ is identical to the definition of relative humidity. For the duration of the DST, there will be a large volume of rock in the dry-out region where the capillary pressure $P_{c}$ attains a very strong negative value. The readings in the relative humidity sensor will serve to monitor the evolution of the dry-out zones in the DST. 


\section{$4 \quad$ Model Concepts, Assumptions and Parameters}

Three-dimensional and two-dimensional thermal-hydrological simulations of the Drift Scale Test are performed with the Integrated Finite Difference Code TOUGH2 (Pruess, 1987, 1991). TOUGH2 is a numerical simulation program for non-isothermal flows of multicomponent, multiphase fluids in porous and fractured media. The TOUGH2-EOS4 module is used which accounts for the non-isothermal two-phase flow of components water and air, including vapor pressure lowering effects. The effective continuum approach is applied to account for the combined effect of the matrix and the fracture continua (Wu et al., 1996). A dual permeability formulation is used for certain runs to study the sensitivity of model results to the modeling concept.

\subsection{Model Domain}

The computational domain for the thermal-hydrological simulations includes the thermal testing area plus significant rock volumes added in all directions to guarantee a proper definition of boundary conditions. Since the thermal-hydrological impact of heating extends over different stratigraphic layers in the Topopah Spring geological formation, the vertical extent of the model area includes the Topopah Spring Middle Non-Lithophysal unit (tptpmn), where the Heater Drift resides, the overlying layer, the Topopah Spring Upper Lithophysal unit (tptpul), and the underlying layer, the Topopah Spring Lower Lithophysal unit (tptpll).

The thickness of the geological layers is interpolated from the UZ site-scale model (Hinds et al., 1997), specifically, from the model grid columns $242, \mathrm{E} 69$, and $\mathrm{H} 26$, which are the closest to the thermal test area. Due to the dipping of the geological units, the thickness and elevation of the tptpmn above the Heater Drift is not uniform; e.g. the elevation at the interface between the tptpmn and the tptpul units gradually increases from the bulkhead side to the western terminus by about $10 \%$. However, in order to limit the complexity of the 3-D grid design, a constant thickness and elevation for the geological layers in the model area is assumed, interpolated for one representative location in the middle of the heated section of the Heater Drift (i.e. $x=0.0 \mathrm{~m}$, $y=23.75 \mathrm{~m}$ in local coordinates). Table 4.1-1 gives the interpolated vertical elevation of the different model layers in global and local coordinates. The interfaces of the tptpmn to the upper and lower layers are estimated from the UZ site-scale flow model to be at $\mathrm{z}=+14.0 \mathrm{~m}$ and at $z=-26.58 \mathrm{~m}$, respectively. Note that these values might have to be adjusted when detailed sitespecific information about the near-drift geologic layering becomes available.

As listed in Table 4.1-1, the top and bottom boundaries of the model domain are $99.39 \mathrm{~m}$ and $156.76 \mathrm{~m}$ from the centerline of the Heater Drift; this is sufficiently far that they safely represent 
Pretest Analysis of the Thermal-Hydrological Conditions of the ESF Drift Scale Test

the boundary at infinity (i.e., constant primary variables). The northern lateral boundary is $90.0 \mathrm{~m}$ north of the centerline of the Heater Drift; the southern lateral boundary is $90.0 \mathrm{~m}$ south of the centerline of the Heater Drift. The eastern lateral boundary is $90.0 \mathrm{~m}$ east of the hot side of the bulkhead, $88.0 \mathrm{~m}$ east of the cold side of the bulkhead and $74.5 \mathrm{~m}$ east of the Connecting Drift. The western lateral boundary is $90.0 \mathrm{~m}$ west of the western terminus of the Heater Drift, $137.5 \mathrm{~m}$ from the hot side of the bulkhead. The overall north-south extension is $180.0 \mathrm{~m}$ and the overall east-west extension is $227.5 \mathrm{~m}$.

Table 4.1-1: Vertical Layering of the Model Domain

\begin{tabular}{|c|c|c|c|c|c|c|}
\hline $\begin{array}{c}\text { Geological } \\
\text { Unit }\end{array}$ & $\begin{array}{c}\text { Formation } \\
\text { Name }\end{array}$ & Thickness & \multicolumn{2}{|c|}{ Bottom Elevation } & \multicolumn{2}{c|}{ Top Elevation } \\
\cline { 4 - 7 } & $(\mathrm{m})$ & $\begin{array}{c}\text { global } \\
(\mathrm{m} \mathrm{NN})\end{array}$ & $\begin{array}{c}\text { local } \\
(\mathrm{m})\end{array}$ & $\begin{array}{c}\text { global } \\
\text { (in m NN) }\end{array}$ & $\begin{array}{c}\text { local } \\
(\mathrm{m})\end{array}$ \\
\hline $\begin{array}{c}\text { Topopah } \\
\text { Spring }\end{array}$ & tptpul & 85.39 & 1066.86 & 14.00 & 1152.25 & 99.39 \\
\hline $\begin{array}{c}\text { Topopah } \\
\text { Spring }\end{array}$ & tptpmn & 40.68 & 1026.18 & -26.68 & 1066.86 & 14.00 \\
\hline $\begin{array}{c}\text { Topopah } \\
\text { Spring }\end{array}$ & tptpll & 130.08 & 896.10 & -156.76 & 1026.18 & -26.68 \\
\hline
\end{tabular}

\subsection{Grid Design}

Grid generation is an important part of developing a complex 3-D model. The aim of grid generation is to achieve a proper balance between desired numerical accuracy and computational time, both of which are controlled by the total number of grid blocks. In the DST, the grid must be compatible with sharp gradients of temperature, saturation and pressure which may occur at different distances from the heat source as time progresses. At the same time, major hydrogeological features must be captured, and the special geometry of the test area (including tunnels, decline of the drifts and boreholes of interest) must be realistically represented. All these objectives were met by the grid designed as described in this section.

Several automatic grid generation modules have been developed to allow for accurate and efficient generation of 2-D and 3-D grids. In a first step, a 2-D vertical mesh is designed within the local xz-plane, i.e., orthogonal to the Heater Drift centerline. Local mesh refinement is particularly important in this plane, as most of the heat produced by the in-drift heaters and the wing heaters is released transverse to the Heater Drift centerline. In a second step, the complete 3-D DST grid is created by appropriately extending several vertical 2-D planes into the third 
dimension and merging them. This merging procedure maintains the refined 2-D mesh structure in all the planes incorporating the heated section of the drift; however, when moving outward from the heated section, the local mesh refinement is gradually reduced by combining small elements. This is important because (1) it improves the numerical accuracy by reducing the element aspect ratio and (2) it improves the numerical efficiency by decreasing the total number of grid blocks.

The grid generation modules used for creating the 2-D vertical grid are used as follows: Module 1 automatically generates $2-\mathrm{D}$ radial symmetric grids that at some given radius are converted gradually into Cartesian grids. Module 2 automatically generates rectilinear grids that may be locally refined in certain subregions. Module 3 automatically merges subgrids that have been generated by either Module 1 or 2 . In case these subgrids overlap, Module 3 will apply different criteria, such as the grid block volume ratio, or the minimal grid block length ratio etc., to decide which one of the overlapping grid blocks is to be maintained. Module 3 will also design adequate gridding along interfaces between different subregions and eventually create the complete 2-D finite difference mesh. Finally, Module 4 is applied to add boundary elements to the grid and write a MESH input file for the TOUGH2 simulator.

Figure 4.2-1 shows the entire 2-D vertical grid in a typical $\mathrm{xz}$-cross section intersecting the Heater Drift at $y=10.06 \mathrm{~m}$ (i.e., in the plane of hydrology holes 57 through 61 ), facing approximately west in positive y-direction. As already mentioned, the model area includes three geological layers of the Topopah Spring unit, the Upper and Lower Lithophysal, and the Middle Non-Lithophysal unit, which hosts the heater test area.' The grid was designed such that the interfaces between layers are represented by grid block interfaces (i.e., grid block interfaces are maintained at $\mathrm{z}=+14.0 \mathrm{~m}$ and $\mathrm{z}=-26.68 \mathrm{~m}$ ). Figure 4.2.-2 shows the same cross section in a close-up view of the rock areas adjacent to the Heater Drift and the wing heaters. The heated section of the drift is cut-out from the model area and treated as an inner closed boundary, as the radiative heat exchange within the Heater Drift is not explicitly modeled. It is assumed that the heat load produced in the drift is immediately transferred into the adjacent rock, a valid assumption considering the relatively fast process of thermal radiation. The exact location of the 50 wing heaters is also not modeled explicitly in space. Instead, the wing heaters are represented by two horizontal smeared-out heat sources on either side of the drift. In the vertical direction, the wing heater source is distributed over a thickness of $0.5 \mathrm{~m}$, extending from $\mathrm{z}=-0.5 \mathrm{~m}$ to $z=0.0 \mathrm{~m}$, thus fixing the center of the distributed heater source at the centerline of the wing heater boreholes at $-0.25 \mathrm{~m}$.

Prior to finalizing the mesh design, a thorough sensitivity study was performed to optimize the degree of mesh refinement close to the heater sources. The local grid has to be as fine as necessary to guarantee a proper representation of the physical processes, but coarse enough to ensure computational efficiency. Based on the sensitivity study, a radially symmetric mesh is designed 
around the Heater Drift using grid generator Module 1, with radial increments as small as $0.05 \mathrm{~m}$ at the drift wall $(\mathrm{R}=2.5 \mathrm{~m})$ increasing up to $0.80 \mathrm{~m}$ at a radial distance of $7.0 \mathrm{~m}$. Starting from this distance, the radial symmetric mesh transforms gradually into a rectilinear mesh. Module 2 is used to generate a locally refined mesh for the rock mass close to the wing heaters, with a similar design for both sides of the drift. Increments in the vertical direction start as small as $0.05 \mathrm{~m}$ at the heater-rock interface, and gradually increase with distance from the heater. Module 3 is then applied to superpose the local heater grids on a less-refined larger mesh for the entire vertical cross section, also generated using Module 2. The resulting grid design is symmetrical to the z-axis, except for an area adjacent to the Observation Drift. Here, another appropriately designed subgrid has been superimposed to adapt the geometry of the drift. The resulting 2-D mesh as shown in Figure 4.1-1 has 2242 grid blocks and 5057 connections between them.

Also included in Figure 4.2-2 is the location of the 5 hydrology holes 57 through 61 which form a fan in the xz-plane, starting from the Observation Drift. Figures 4.2-3 and 4.2-4 show two other $x z$-cross sections, located at $y=30.18 \mathrm{~m}$ and $y=44.8 \mathrm{~m}$. The figures depict the configuration of hydrology holes 74 through 78 and 185 through 186 . Note that the altitude of the Observation Drift varies in the different cross sections, as the drift gradually declines from the ESF main drift towards the thermal testing area.

Altogether, 24 2-D element planes have been merged in the $y$-direction (along the Heater Drift axis, perpendicular to the xz-cross section shown above) to generate the entire 3-D mesh. Table 4.2-1 gives a short summary of the arrangement of the planes. Starting from $y=0.0 \mathrm{~m}$ at the hot side of the bulkhead, planes 1 through 10 represent the heated section of the drift. The planes are arranged such that the location of hydrology holes (i.e., $y=10.06 \mathrm{~m}, y=30.18 \mathrm{~m}$, and $y=44.8 \mathrm{~m}$ ) matches with the center of Planes 4,6, and 8 , respectively. Each of these 10 planes has an identical 2-D discretization, except for the location of the Observation Drift, which varies in altitude from layer to layer. The next five planes 11 through 15 extend beyond the Heater Drift up to $y=137.5 \mathrm{~m}$. The first four planes in negative $y$-direction, -1 through -4 , extend along the bulkhead and the non-heated section of the Heater Drift. Plane -5 incorporates the width of the Connecting Drift (where certain grid blocks are cut-out from the original mesh to account for the open tunnel), and the remaining 3 planes extend from the Connecting Drift up to $y=-90.0 \mathrm{~m}$. Figure 4.2-5 depicts a vertical cross section along the centerline of the Heater Drift, focusing on the thermal test area and facing approximately south in the negative $x$-direction. Arrows at the top indicate planes where hydrology holes exist. (Note that the displayed grid in Figure 4.2-5 does not show the actual interfaces between grid blocks in the finite difference discretization, as do Figures 4.2-1 through 4.2-4. The post-processing plotting software automatically designs a mesh by connecting the center nodes of each finite difference grid. This post-processed mesh is depicted here.) 
Table 4.2-1: $\quad 3-D$ configuration in y-direction

\begin{tabular}{|c|c|c|c|}
\hline Plane No. & $\begin{array}{l}y \text {-center } \\
(\mathbf{m})\end{array}$ & $\begin{array}{l}\text { Thickness } \\
\text { (m) }\end{array}$ & Represented Geometries within Plane \\
\hline 1 & 0.25 & 0.5 & Heated section of Heater Drift; Observation Drift \\
\hline 2 & 1.25 & 1.5 & Heated section of Heater Drift; Observation Drift \\
\hline 3 & 3.5 & 3.0 & Heated section of Heater Drift; Observation Drift \\
\hline 4 & 10.06 & 10.12 & $\begin{array}{l}\text { hydrology holes } 57 \text { through } 61 \text {; heated section of Heater } \\
\text { Drift; Observation Drift }\end{array}$ \\
\hline 5 & 20.12 & 10.00 & Heated section of Heater Drift; Observation Drift \\
\hline 6 & 30.18 & 10.12 & $\begin{array}{l}\text { hydrology holes } 74 \text { through } 78 \text {; heated section of Heater } \\
\text { Drift; Observation Drift }\end{array}$ \\
\hline 7 & 39.42 & 8.36 & Heated section of Heater Drift; Observation Drift \\
\hline 8 & 44.8 & 2.4 & $\begin{array}{l}\text { hydrology holes } 85 \text { and } 86 \text {; heated section of Heater } \\
\text { Drift; Observation Drift }\end{array}$ \\
\hline 9 & 46.5 & 1.0 & Heated section of Heater Drift; Observation Drift \\
\hline 10 & 47.25 & 0.5 & Heated section of Heater Drift; Observation Drift \\
\hline 11 & 47.75 & 0.5 & Observation Drift \\
\hline 12 & 48.75 & 1.5 & Observation Drift \\
\hline 13 & 52.0 & 5.0 & Observation Drift \\
\hline 14 & 59.5 & 10.0 & Observation Drift \\
\hline 15 & 77.0 & 25.0 & Observation Drift \\
\hline 16 & 113.5 & 48.0 & Observation Drift \\
\hline-1 & -0.25 & 0.5 & Bulkhead in Heater Drift; Observation Drift \\
\hline-2 & -1.25 & 1.5 & Bulkhead in Heater Drift; Observation Drift \\
\hline-3 & -3.75 & 3.5 & "Cold" section of Heater Drift; Observation Drift \\
\hline-4 & -8.25 & 5.5 & "Cold" section of Heater Drift; Observation Drift \\
\hline-5 & -13.25 & 4.5 & Connecting Drift; Observation Drift \\
\hline-6 & -20.75 & 10.5 & \\
\hline-7 & -38.5 & 25.0 & \\
\hline-8 & -70.5 & 39.0 & \\
\hline
\end{tabular}

It should be mentioned that the geometry of the Heater Drift, the Connecting Drift, and the Access Observation Drift are represented by our grid design in great detail. However, the bulk- 
head, which insulates the heated section of the Heater Drift, is not explicitly modeled in this study. It is assumed that the bulkhead is a perfect insulator for heat transport in the drift, allowing no heat to escape from the Heater Drift to the "cold" side. Geometrical features of minor importance for the thermal-hydrological conditions in the test area, such as the plate loading niche or the DAS/Office Niche, are not represented in the model. Also note that all xz-planes outside of the heated section of the drift are modified in the grid design; i.e. very small grid blocks are merged together with increasing distance from the heaters. The entire 3-D model grid is composed of 48,249 grid blocks and 157,474 connections between them.

\subsection{Model Parameters}

All hydrological and thermal properties presented in this section are qualified if not otherwise stated. The matrix and fracture flow properties used in the DST model are carefully calibrated using inversion techniques to match measured data from Borehole SD-9. The inversion takes a property set for the initial guess derived in current calibration efforts performed for the UZ sitescale flow model (Bandurraga and Bodvarsson, 1997). Special constraint was placed on the inversion in that site-specific data of the thermal testing area are incorporated. The calibration is performed as follows:

- The calibration procedure uses the qualified inverse modeling code ITOUGH2 (Finsterle, 1993; Finsterle et al., 1996), applied to a one-dimensional vertical column extending from the ground surface down to the water table. Steady-state conditions and constant infiltration rates are assumed. Thie interaction between fractures and matrix is modeled with the ECM concept.

- The calibration is performed for two different infiltration rates, $3.6 \mathrm{~mm} / \mathrm{yr}$, which is the actual infiltration rate interpolated for the location of Borehole SD-9 from the most recent infiltration map for Yucca Mountain (Flint et al., in prep.), and $0.36 \mathrm{~mm} / \mathrm{yr}$ as a bounding case, since the percolation flux at the potential repository horizon remains one of the most uncertain data at Yucca Mountain.

- The rock properties are calibrated against measured saturation and water potential data from borehole SD-9. Calibrated parameters are permeability and van Genuchten - and $\mathrm{m}$, for both fractures and matrix. Input parameters for the specific calibration process for SD-9 are site average values and their standard deviation for the different layers. Input parameters for fracture and matrix permeability and the matrix van Genuchten and $m$ are based on laboratory and field measurements. Since no measurements exist for the fracture van Genuchten parameters, reasonable values have to be estimated. (See details in Sonnenthal et al., 1997).

- Some of the most sensitive parameters that will dictate the thermal-hydrological conditions of the Drift Scale Test are thermal conductivity, fracture gas-phase per- 
meability, and initial matrix liquid saturation within the tptpmn-unit where the DST area resides. Ambient (pre-heat) characterization data for these parameters are available. Therefore, these $a$-priori known data are treated as "fixed" values for the calibration, i.e. they are not changed in the calibration procedure. In particular, the fracture continuum permeability is set to $1.0 \times 10^{-13} \mathrm{~m}^{2}$ as estimated from pre-heat air permeability field tests (Tsang and Cook, 1997). The matrix saturation in the tptpmn is fixed at a value close to $92 \%$, based on the laboratory measurements of grab samples from the thermal test area (Tsang et al., 1996), and the mean of all tptpmn samples from the dry-drilled surface-based Borehole SD-9. $*^{1}$

Figures 4.3-1 and 4.3-2 show the results of the calibration for the entire vertical column, from the surface to the water table, for infiltration rates of $3.6 \mathrm{~mm} / \mathrm{yr}$ and $0.36 \mathrm{~mm} / \mathrm{yr}$, respectively. The calibrated saturation and water potential profiles are shown as solid lines, while the symbols mark USGS borehole data. The vertical extent of the DST model area is highlighted; it includes the Upper and Lower Lithophysal (tptpul and tptpll) and the Middle Non-Lithophysal (tptpmn) layer of the Topopah Spring unit. Both inversions yield the desired saturation value of $92 \%$ in the Middle Non-Lithophysal layer.

Table 4.3-1 lists the calibrated material properties of the DST model layers. Note that the fracture continuum permeability of the tptpmn is fixed at $1.0 \times 10^{-13} \mathrm{~m}^{2}$, and is not changed within the calibration process. Also note that the fracture van Genuchten $\alpha$ values are consistently very small for the high infiltration case, indicating that the air entry pressure in the fractures is quite high. This is a direct consequence of the ECM conceptualization of fracture-matrix interaction, namely thermodynamic equilibrium between the matrix and the fractures. For high infiltration, most of the percolation flux in the Topopah Spring unit must flow through the fracture continuum, as the flux in the matrix is limited by the low matrix permeability. Thus, the inversion procedure adjusts the fracture van Genuchten parameters such that at ambient, steadystate conditions, the fractures conduct a significant fraction of the percolation flux. The high fracture air entry pressure may be an indication that the steady-state condition assumed by ECM are unrealistic for higher infiltration rates. It is possible that much of the high infiltration is due to extreme storm events contributing pulse flow through localized structural features. In fact, recent studies have suggested that the interaction between fractures and matrix may be low

*1 At almost the completion of the simulations reported here, we became aware of new liquid saturation laboratory data (Wang and Suárez-Rivera, 1997). They reported the average liquid saturation on 26 rockcores from boreholes in the Drift Scale Test to be $93.15 \pm 5.93 \%$, and the average saturation for 12 cores in three dry drilled holes near the DST to be $83.85 \pm 3.67 \%$. It is not clear at this time whether the discrepancy in the liquid saturation values arises from drilling methods or from spatial heterogeneity; and whether a higher or a lower value of the liquid saturation is more representative of the initial conditions of the DST test block. Core samples from the DST area will continue to be analyzed and the present pretest model will be updated. On the other hand, if the percolation flux is fixed, a less than $10 \%$ variation of the initial liquid saturation does not significantly affect the thermal hydrological response of the DST. 
enough to allow for a non-equilibrium of capillary pressure throughout the entire Topopah Spring unit. If this is the case, the inversion procedure for liquid flow in the unsaturated zone should be modeled using a dual permeability model (DKM), with possibly reduced fracturematrix interaction (Doughty and Bodvarsson, 1997; Bandurraga and Bodvarsson, 1997; Ho, 1997), which will give rise to a different set of parameters. For this study we rely exclusively on the inversion parameters from the ECM conceptualization for material properties and initial conditions.

Table 4.3-1: $\quad$ Calibrated parameters for the DST model layers

\begin{tabular}{|c|c|c|}
\hline Fracture Permeability $\left(\mathrm{m}^{2}\right)$ & Infiltration $3.6 \mathrm{~mm} / \mathrm{yx}$ & Infiltration $0.36 \mathrm{~mm} / \mathrm{yr}$ \\
\hline tptpul & $0.20210^{-11}$ & $0.63510^{-12}$ \\
\hline tptpmn & $0.10010^{-12} *$ & $0.10010^{-12} *$ \\
\hline tptpll & $0.155410^{-11}$ & $0.18710^{-11}$ \\
\hline Matrix Permeability $\left(\dot{m}^{2}\right)$ & $\because \because \because$ & $\therefore \because$ \\
\hline tptpul & $0.20010^{-16}$ & $0.52510^{-17}$ \\
\hline tptpmn & $0.91410^{-17}$ & $0.12410^{16}$ \\
\hline tptpll & $0.23310^{-16}$ & $0.24710^{-15}$ \\
\hline Fracture van Genuchten $\alpha(1 / \mathrm{Pa})$ & $\therefore$ & 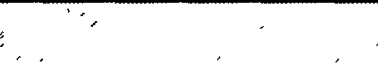 \\
\hline tptpul & $0.31410^{-4}$ & $0.15710^{-3}$ \\
\hline tptpmn & $0.21710^{4}$ & $0.97310^{4}$ \\
\hline tptpll & $0.23410^{4}$ & $0.16610^{-4}$ \\
\hline Matrix van Genuchten $\alpha(1 / P a)$ & $\because \therefore \cdots \quad \because \cdots \quad \therefore$ & $\because \ldots$ \\
\hline tptpul & $0.61110^{-5}$ & $0.10610^{-4}$ \\
\hline tptpmn & $0.17110^{-5}$ & $0.22510^{.5}$ \\
\hline tptpll & $0.33510^{-5}$ & $0.28210^{.5}$ \\
\hline Fracture van Genuchten in & $\therefore \quad \vdots \quad \cdots$ & $\because \therefore$ \\
\hline tptpul & 0.492 & 0.492 \\
\hline tptpmn & 0.483 & 0.492 \\
\hline tptpll & 0.492 & 0.492 \\
\hline Matrix van Genuchten m & $\because \because$ & $\because \because \cdots, \vdots \vdots$ \\
\hline tptpul & 0.252 & 0.243 \\
\hline tptpmn & 0.320 & 0.247 \\
\hline tptpll & 0.229 & 0.207 \\
\hline
\end{tabular}

* parameter "fixed" in calibration 
Because the data available for calibration are not sensitive with respect to the $m$, it could not be determined successfully by inverse modeling. In fact, the initial guess of $\mathrm{m}$ used for the inverse modeling exercise remained practically unchanged during calibration, which means that the choice of the initial guess essentially determines the calibration result. For our model, an initial guess of $m=0.492$ chosen, following the value of the UZ Site-scale model.

All the remaining, non-calibrated parameters used in the DST model are listed in Table 4.3-2. No distinction is made between the high- and low infiltration case. Most properties used are based on laboratory or field measurements. Fracture porosity and frequency is estimated by Sonnenthal et al. (1997), based on ESF fracture mapping.

Matrix porosity values represent the mean of all borehole measurements for the respective layers tptpul, tptpmn and tptpll (Flint et al., in prep.). Matrix van Genuchten parameters have been derived in moisture-retention experiments on core samples taken from UZ16. The $\alpha$ and $\mathrm{m}$ values are used as starting points for the calibration process described above, while the matrix residual saturation is directly taken from the measurements (Flint et al., in prep.). Fracture residual saturation is assumed to be 0.01 . It should be mentioned that the common van Genuchten relationships are applied for describing the unsaturated liquid flow only, while the relative permeability for gas is derived in this study from the Brooks-Corey formulation as follows:

$$
\mathrm{k}_{\mathrm{r}, \mathrm{g}}=\left(1-\mathrm{S}_{1, \mathrm{eff}}\right)^{2}\left(1-\mathrm{S}_{1, \mathrm{eff}}\left(\frac{2+\lambda}{\lambda}\right)\right)
$$

Often, the gas relative permeability is calculated as $\left(1-k_{r, 3}\right)$, where $k_{r, 3}$ is the liquid relative permeability. This, however, results in large gas relative permeability values even for very small gas saturations, since the van Genuchten formulation gives an extremely steep decline of the liquid relative permeability when liquid saturation decreases slightly from the fully saturated value.

Three thermal properties are required to model the thermal-hydrological situation in the rock: thermal conductivity (which may be temperature and saturation dependent), rock heat capacity, and rock density. In this study thermal conductivity is assumed to be a function of liquid saturation. With a high saturation ("wet") and a low saturation ("dry") thermal conductivity value, the resulting thermal conductivity is interpolated as follows:

$$
\mathrm{C}\left(\mathrm{S}_{1}\right)=\mathrm{C}_{\mathrm{dry}}+\left(\mathrm{C}_{\mathrm{wet}}-\mathrm{C}_{\mathrm{dry}}\right) \sqrt{\mathrm{S}_{1}}
$$

Site-specific data are used for thermal conductivity in the tptpmn. Measurements on core samples from the SHT give a saturated thermal conductivity of $2.03 \mathrm{~W} /\left(\mathrm{m}{ }^{\circ} \mathrm{K}\right)$ and a "dry" thermal conductivity of $1.67 \mathrm{~W} /\left(\mathrm{m}^{\circ} \mathrm{K}\right)$ (N. Brodsky, personal communication, non-Q). In-situ 
measurements by REKA probe in the DST area give a thermal conductivity of about $2 \mathrm{~W} /\left(\mathrm{m}^{\circ} \mathrm{K}\right)$ (R. Datta, personal communication, non-Q), which is consistent with the core sample measurements, since the ambient matrix saturation in the DST is quite high. For the other layers, recent estimates are used from core samples from North Ramp boreholes (Brodsky et al., 1997). Values for heat capacity are used as given in DOE/FUB (1993). Rock particle density is used instead of rock grain density; values are taken from Flint et al. (in prep.). Differences in particle and grain density at Yucca Mountain are generally smaller than $1 \%$, however, they could be more relevant in lithophysal zones where cavities exist. Also, thermal conductivity may be overestimated in lithophysal zones because the measurements are based on recovered cores, so that large non-interconnected pore space is not considered.

Reasonable numbers for the vapor diffusion parameters are $D_{\mathrm{va}}^{\circ}=2.14 \times 10^{-5} \mathrm{~m}^{2} / \mathrm{s}$ and $\theta=2.334$, after Pruess and Tsang (1994). A reasonable number for the tortuosity of the path followed during the gas diffusion process is $\tau=0.2$. These parameters are non- $Q$, as no measurements exist; however, the effect of binary vapor-air diffusion is very small compared other thermalhydrological processes. This would change only when enhanced vapor diffusion was considered, and the parameter group $\tau \phi S_{g}$, here on the order of 0.01 , was significantly increased by several orders of magnitude. In the present study for the DST, binary vapor-air diffusion is considered rather than enhanced vapor diffusion (see discussion in Section 3.2 above).

Table 4.3-2 Hydrogeological and thermal input values

\begin{tabular}{|c|c|c|c|}
\hline Parameter & tptpul & tptpmin & tṕtpll \\
\hline Matrix Porosity & 0.154 & 0.11 & 0.13 \\
\hline Matrix Residual Liquid Saturation & 0.06 & 0.18 & 0.08 \\
\hline Rock Particle Density in $\mathrm{kg} / \mathrm{m}^{3}$ & 2510.0 & 2530.0 & 2540.0 \\
\hline Fracture Porosity & 0.000171 & 0.000263 & 0.000329 \\
\hline Fracture Residual Liquid Saturation & 0.01 & 0.01 & 0.01 \\
\hline $\begin{array}{l}\text { Rock Thermal Conductivity in } \mathrm{W} /\left(\mathrm{m}^{\circ} \mathrm{K}\right) \\
\text { ("wet") }\end{array}$ & 1.7 & 2.0 & 2.29 \\
\hline $\begin{array}{l}\text { Rock Thermal Conductivity in } \mathrm{W} /\left(\mathrm{m}^{\circ} \mathrm{K}\right) \\
\text { ("dry") }\end{array}$ & 1.15 & 1.67 & 1.59 \\
\hline Rock Mass Heat Capacity in $J /\left(\mathrm{kg}^{\circ} \mathrm{K}\right)$ & 916.7 & 952.9 & 952.9 \\
\hline Vapor Diffusion Coefficient in $\mathrm{m}^{2} / \mathrm{s}$ & $2.14 \times 10^{-5}$ & $2.14 \times 10^{-5}$ & $2.14 \times 10^{-5}$ \\
\hline Factor for Temperature Dependence & 2.334 & 2.334 & 2.334 \\
\hline Tortuosity & $\tau=0.2$ & $\tau=0.2$ & $\tau=0.2$ \\
\hline
\end{tabular}


Further assumptions are:

- All thermal-hydrological properties are isotropic.

- Hydrogeologic properties (such as porosity, permeability etc.) are not affected by temperature changes or chemical reactions to heat; i.e. they are assumed to be constant in time. However, fracture apertures might in fact change as an effect of thermal rock mass expansion, giving rise to a change in fracture permeability.

- Rock properties are assumed for all the boreholes since we make the implicit assumption that wiring, grouting, and instrumentation in the test block does not affect the thermalhydrological behavior of the rock.

\subsection{Boundary and Initial Conditions}

The results obtained with the 1-D calibrated vertical column model are used to interpolate appropriate boundary conditions at the top and bottom of the 3-D DST model domain. However, the thickness and elevation of geological units at Borehole SD-9 are not exactly duplicated at the thermal testing area. Therefore, after finishing the SD-9 inversion, 1-D vertical column runs have to be performed with a slightly adjusted vertical layering, representing the situation at the thermal testing area. The simulation period for these initial runs is 10,000 years, atmospheric conditions are given at the top and full water saturation at the bottom, and the ECM concept is used to account for the combined effect of the fracture and matrix continuum.

The vertical profiles of initial saturation, pressure and temperature are then interpolated on the 3-D DST grid, depending on the z-coordinate of respective grid blocks. At the bottom of the DST domain, the interpolated values are used as Dirichlet-boundary conditions; i.e., the boundary elements have constant pressure, saturation and temperature throughout the simulation period. At the top boundary, a constant temperature and the respective percolation fluxes of $3.6 \mathrm{~mm} / \mathrm{yr}$ and $0.36 \mathrm{~mm} / \mathrm{yr}$ for the two scenarios are prescribed, thus allowing for minor pressure and saturation deviations from the interpolated values. These deviations might occur as a result of the mapping from the 1-D column to the 3-D DST grid which may introduce minor numerical inaccuracies. To avoid unwanted perturbations, initialization runs with the 3-D grid are performed for a time period of 10,000 years prior to turning on heat to ensure that a consistent initial state is achieved.

All lateral outer boundaries of the model area are modeled as no-flow boundaries for heat, liquid, and gas. Except for the heated section of the Heater Drift and the bulkhead, the drifts are modeled by constant pressure, temperature, and saturation conditions, assuming that they are ventilated and the heating of the rock does not affect the parameters in the open drift. No attempt is made to model the dry-out of the rock adjacent to tunnel walls due to ventilation. Therefore, the relative humidity in the drifts is fixed so that the open void is in equilibrium with the adjacent rock at initial state. Some of the drift walls will be insulated with a very low 
thermal conductivity material. In this model, the non-heated section of the Heater Drift is assumed to be completely insulated, while the Connection and Observation Drift is assumed to be insulated on the near-heater walls only. The insulation is explicitly modeled, it is $15.2 \mathrm{~cm}$ thick, has a $0.0447 \mathrm{Watt} /\left(\mathrm{m}^{2} \mathrm{~K}\right)$ thermal conductivity, a density of $32 \mathrm{~kg} / \mathrm{m}^{3}$, and a heat capacity of $835 \mathrm{~J} /(\mathrm{kg} \mathrm{K}$ ) (values chosen are similar to the SHT-design calculations, Birkholzer and Tsang, 1996). The surfaces are assumed to be open for moisture to escape from the test block in the form of both liquid water and vapor.

The radiative heat exchange within the Heater Drift is not explicitly modeled in this study. The heat load generated inside the drift is placed directly onto the rock elements adjacent to the drift wall. Since it is not yet clear if the radiation in the drift is effective enough to completely equilibrate the temperature along the drift wall, two extrerne cases of drift wall boundary conditions are studied to bound the effect of thermal radiation: In the first case, a uniform areal heat load is introduced at the rock surfaces along the drift wall, which will eventually give rise to cooler temperatures at the two ends of the Heater Drift. In the second case, a uniform temperature is assumed at the rock surfaces along the entire length of the Heater Drift. The first case represents a less effective radiative heat exchange within the drift, and the second case represents totally effective black body radiation within the drift. The real system behavior is expected to be bounded somewhere between the two cases. The wing heaters are modeled as two horizontal smeared-out heat sources on either side of the drift. Assuming that the inner and outer wing heater sections are each 4.75 in length and that the heat input is uniformly distributed along the 47.5-m-long heated portion of the drift, the areal horizontal load amounts to a maximum of $126.9 \mathrm{KW} / \mathrm{m}^{2}$ of the inner wing heater and $190.1 \mathrm{KW} / \mathrm{m}^{2}$ for the outer wing heater. It is assumed that no thermal radiation takes place between the wing heater boreholes and the Heater Drift; i.e., the temperature in the wing heaters is not necessarily in equilibrium with the drift temperature.

Figures 4.4-1 and 4.4-2 present the initial thermal-hydrological situation in the 3-D DST model domain for the $3.6 \mathrm{~mm} / \mathrm{yr}$ and the $0.36 \mathrm{~mm} / \mathrm{yr}$ scenario, showing matrix saturation, fracture saturation, and temperature measured along a vertical sampling line. The vertical sampling line chosen is located at $\mathrm{x}=0.0 \mathrm{~m}$ and $\mathrm{y}=30.18 \mathrm{~m}$, and thus intersects the Heater Drift. Note a minor increase in liquid saturation above the Heater Drift, and a minor decrease below, as the percolation flux must bypass the tunnel. The fracture continuum saturations are consistently higher in the high infiltration case compared to the low infiltration case. For high infiltration rates, most of the vertical flux takes place in the fracture continuum, as the matrix is not conductive enough to support the infiltrated liquid. In fact, for the tptpmn layer the ratio of vertical flux occurring in the fractures to the entire vertical flux in the rock amounts to about $80 \%$ for the high infiltration case, but only about $1 \%$ for the low infiltration case. The temperature profile reflects the geothermal gradient. 


\section{$5 \quad$ Three-dimensional Thermal-Hydrological Simulation Results}

Three-dimensional simulations have been performed for both the $3.6 \mathrm{~mm} / \mathrm{yr}$ infiltration scenario and the $0.36 \mathrm{~mm} / \mathrm{yr}$ infiltration scenario, for a particular heating rate and heating schedule. Results from additional studies to probe the impact of different heating rates and schedules on the DST will be discussed in Section 6. In this section, for the particular heating rate, two conceptualizations of heat transfer from the canisters to the rock formation will be studied. In the first case, a uniform heat load is introduced along the drift wall, representing little effects of radiative heat exchange within the drift. In the second case, a uniform temperature is assumed at the rock surfaces along the drift wall, representing totally effective black body radiation in the drift. The resulting three-dimensional temperature and moisture distributions in the drift scale test block are presented and discussed in detail for each of the scenarios.

The evolution of the thermal hydrological conditions in the DST will be reflected in the monitoring data from sensors placed throughout the test block. In particular, the predicted readings of temperature, gas pressure and relative humidity in the 12 hydrology holes shall be presented and carefully analyzed below in Section 7. In addition to the passive monitoring data, interference air injection tests in each of the 48 isolated zones of the hydrology holes are planned; thus, the effect of moisture redistribution on air permeability tests shall also be discussed in Section 7 . These predictions will help planning the time schedule and the geometrical configuration of the air permeability tests, as they will indicate at what specific times tests should be performed, and in which zones of the various boreholes air should be injected in order to capture the spatial and temporal variation of liquid saturation in the rock mass.

The particular heating schedule considered here is as follows: After turning on heat, both the indrift heaters and the wing heaters will run with full capacity (100\%) for 1 year. After 1 year, the power output of in-drift and wing heaters drops to $50 \%$ capacity for another 3 years. After a total heating period of 4 years, all heaters are turned off, and the rock mass is allowed to cool down. The simulation runs cover 4 years of this cooling period; however, since the cooling and rewetting of the heater area is a very slow process, the thermal-hydrological situation is far from returning to preheat conditions at the end of the simulation period. Passive cooling is assumed in the simulations, i.e., the Heater Drift behind the bulkhead is not supposed to be ventilated or actively cooled.

A 2-D sensitivity analysis has been performed prior to the three-dimensional simulations to study the effects of different heating scenarios. The basis for the sensitivity runs is to search for those rates and schedules that will keep the drift wall of the Heater Drift below $200{ }^{\circ} \mathrm{C}$ throughout the duration of the heating phase. Results of this sensitivity study are presented below in 
Pretest Analysis of the Thermal-Hydrological Conditions of the ESF Drift Scale Test

Section 6. One of the many heating schedules analyzed in the 2-D simulations was eventually chosen as base-case for the three-dimensional runs. This heating schedule, described above, meets the $200{ }^{\circ} \mathrm{C}$ constraint for both the $3.6 \mathrm{~mm} / \mathrm{yr}$ and the $0.36 \mathrm{~mm} / \mathrm{yr}$ scenario. Furthermore, choosing full capacity of heating from the beginning of the test insures that within the drift wall temperature constraint, maximum heat input can be provided to the rock mass so that a larger volume of rock is heated up for a longer duration of time. The heating schedule chosen is a fairly simple scheme, and no effort was made to fine-tune or optimize the setup assuming more complex heating schedules, such as ramping down the heater power instead of just dropping from $100 \%$ to $50 \%$, or running the in-drift and wing heaters at different percentages of their maximum capacity. We show below that the drift wall temperature is sensitive to different infiltration and heat exchange scenarios; therefore, further optimization of the heating scheme seems unnecessary for these pretest calculations. During the DST, when the model will be calibrated to field measurements, the heating schedules for the remaining test period can and will be optimized using updated simulation runs.

\subsection{Simulation Results for an Infiltration Rate of $3.6 \mathrm{~mm} / \mathrm{yr}$}

The first part of this section presents the thermal-hydrological conditions for an infiltration rate of $3.6 \mathrm{~mm} / \mathrm{yr}$ and a uniform heat load applied along the walls of the Heater Drift. This gives rise to a non-uniform temperature distribution along the walls. Simulation runs using a uniform temperature boundary condition along the Heater Drift wall will be briefly discussed at the end of this section. It will be shown, however, that the choice of the heat exchange model within the Heater Drift has little effect on the thermal-hydrological response in the bulk of the rock mass.

Figure 5.1-1 through 5.1-3 show the temperature evolution in the Heater Drift at three different distances from the bulkhead, namely $y=10.06 \mathrm{~m}, \mathrm{y}=30.18 \mathrm{~m}$ and $\mathrm{y}=44.8 \mathrm{~m}$, respectively. These three distances coincide with the location of the three arrays of hydrology holes, and represent layers 4, 6 and 8 of the 3-D model grid (see Table 4.2-1). All temperature curves are similar, and essentially reflect the heating schedule: The temperatures rise very fast in the beginning, show a minor heat-pipe effect near $100^{\circ} \mathrm{C}$, and reach a first peak after 1 year. At this time, the heater power is reduced to $50 \%$, and the temperature at the drift wall almost instantly drops about 20 to $30^{\circ} \mathrm{C}$. Eventually, the temperature starts rising again, but much more slowly than before due to the reduced thermal load. After 4 years, the heaters are turned off, and initially the temperature in the drift decreases rapidly. At later stages, however, the cooling process slows down significantly, and the in-drift temperatures after 4 years of cooling are still as high as $70{ }^{\circ} \mathrm{C}$. Generally, the temperature history is characterized by three stages: a rapid temperature rise in the first year, a more steady-state high-temperature "plateau" thereafter, and a cooling period in the end. The temperature response to changes of the heat power is much dampened and retarded with increasing distance from the drift wall; e.g. the temperature readings in all 
hydrology holes show a much smoother behavior than the one observed at the drift walls (see Section 7).

For all three cross sections depicted, the highest wall temperatures are consistently measured at the springline of the drift. This is due to the combined thermal load of the in-drift heat canisters and the wing heaters located on both sides of the Heater Drift. The lowest temperatures are measured at the crown; they are about $25^{\circ} \mathrm{C}$ lower than the springline temperatures, and about $15^{\circ} \mathrm{C}$ lower than the bottom temperatures. At the crown, the heating of the rock mass is clearly influenced by gravity-driven liquid flux. Note that the differences between crown, bottom and springline are almost negligible for those time periods when the temperatures are below the nominal boiling point. This indicates that the different behavior of bottom and crown is mainly an effect of heat-induced vapor-liquid counterflow, which exceeds the ambient percolation flux by several orders of magnitude.

A comparison of Figures 5.1-1, 5.1-2 and 5.1-3 indicates significant temperature differences along the Heater Drift, with high temperatures in the middle of the heated section and cooler regions at both ends. The maximum temperature of $196{ }^{\circ} \mathrm{C}$ is seen at the springline in the $\mathrm{y}=30.18 \mathrm{~m}$ cross section. This is about $50^{\circ} \mathrm{C}$ higher than the temperature seen at $\mathrm{y}=44.8 \mathrm{~m}$, which is close to the western terminus of the drift.

Contour plots of the predicted thermal-hydrological behavior in the thermal testing area are given in Figures 5.1-4 through 5.1-21. Temperature and moisture distributions are presented at three different times, namely after 1 year, just before the heater power is reduced from $100 \%$ to $50 \%$, after 4 years, just before the heater is turned off, and after 8 years, which includes 4 years of cooling. Results are shown for two vertical cross sections, a xz-cross section orthogonal to the Heater Drift, facing approximately west in positive y-direction, and a yz-cross section parallel to the Heater Drift, facing approximately south in a positive $\mathrm{x}$-direction. The $\mathrm{xz}$-cross section matches plane 6 of the 3-D model grid at $y=30.18 \mathrm{~m}$, i.e., it represents the plane of hydrology holes $74,75,76,77$, and 78 . The yz-cross section intersects the Heater Drift at $\mathrm{x}=0.0 \mathrm{~m}$.

Figures 5.1-4 and 5.1-5 show the temperature response 1 year after the heater is turned on. The maximum temperatures of about $175^{\circ} \mathrm{C}$ are observed close to the drift springline and at the tip of the wing heaters. (Remember that the outer part of the wing heater operates at a larger heater power than the inner part.) A significant portion of the rock has already heated up; e.g., the $100{ }^{\circ} \mathrm{C}$ isotherm extends vertically up to $6 \mathrm{~m}$ in both directions, the $50{ }^{\circ} \mathrm{C}$ isotherm extends vertically up to $12 \mathrm{~m}$ in both directions. As can be seen from Figure 5.1-4, hydrology holes 76, 77 and 78 are significantly affected by the thermal load, showing temperatures of about $100{ }^{\circ} \mathrm{C}$ and more at some locations along the borehole. The yz-cross section depicted in Figure 5.2-5 indicates that the temperature variation parallel to the Heater Drift is fairly small at this early 
stage of heating; only the very ends of the heated section show lower temperatures. This shows that the heat fluxes are mainly orthogonal to the Heater Drift centerline, and implies that a 2-D vertical model considering thermal-hydrological conditions in the xz-plane might be a good representation of the 3-D behavior at this time.

Figures 5.1-6 and 5.1-7 show the matrix liquid saturation at 1 year, which is significantly different from the initial moisture distribution presented in Figure 4.4-1 above. An extended dryout zone has developed around the Heater Drift and the wing heaters. Moisture is carried away from the heated area in the form of vapor, mainly in the fractures because of the low matrix conductivity, and driven by the gas pressure gradient. In cooler regions, the vapor condenses at the fracture walls, giving rise to an increase in liquid saturation in both fractures and matrix. Subsequently, the liquid, driven by capillary forces, migrates away from the condensation zone; part of it towards the boiling region, and smaller amounts outward, away from the heaters. The resulting moisture distribution is clearly non-symmetrical in the vertical direction, with the majority of the saturation build-up below the heater, which indicates the presence of relatively fast gravity-driven liquid flux in the fractures. Above the heater, gravity adds to the strong capillary gradient between condensation zone and boiling area, and helps to move liquid back to the boiling region. Below the heater, gravity moves liquid away from the boiling region.

At this stage of heating, the thermal-hydrological response of the heat is limited to the tptpmn layer. The overlying tptpul layer and the underlying tptpll layer are essentially unaffected and remain at their initial saturation values of about 0.74 and 0.81 , respectively. However, the saturation build-up in the tptpmn has already reached the interfaces to the adjacent geological units, and further vertical movement of the condensation zone appears to be somewhat retarded at the layer boundaries. This can be an effect of different material properties in different layers; it may also be related to the lower initial saturation in the adjacent layers, which offers a larger open matrix pore volume for the condensate. At 1 year, hydrology holes 75, 76, 77 and 78 are partially located in areas of increased matrix saturation; hydrology hole 77 is also intersecting the dry-out region below the wing heater.

Figures 5.1-8 and 5.1-9 present the liquid saturation in the fractures at 1 year. The pre-heat initial fracture saturation is about $17 \%$ in the tptpmn and about $11 \%$ in the other model layers. This saturation value is relatively high, indicating that even before turning on heat, most of the percolation flux takes place in the fracture continuum. After 1 year of heating, the fracture saturations in the tptpmn build up considerably to maximum values around $45 \%$, which allows for significantly higher liquid fluxes in the fractures. In the condensation zone below the heater, liquid fluxes increase to about $3 \mathrm{~m} / \mathrm{yr}$ in vertical downward direction, forced by gravity and capillary suction. Above and at the sides of the wing heaters, flux values are as high as $10 \mathrm{~m} / \mathrm{yr}$, driven by strong capillary forces between the condensation zone and the boiling zone. However, the increase of fracture saturation is limited by the fact that most of the condensing liquid is 
immediately drawn into the matrix by capillary suction. As a consequence of the ECM formulation, where local equilibrium between matrix and fracture is assumed at all times, the characteristics of the fracture saturation contours in Figures 5.2-8 and 5.2-9 and the matrix saturation contours in Figure 5.2-6 and 5.2-7 are very similar.

Figures 5.1-10 to 5.1-15 show a similar sequence of temperature and saturation distribution at 4 years, immediately before the heater is turned off. Since the heaters have been operating at $50 \%$ power for 3 years, the maximum temperatures close to the heat sources have not increased significantly from the 1 year values. However, the volume of heated rock has substantially increased. All hydrology holes in the depicted xz-plane are expected to show significant increases in the temperature readings. The moisture distribution contours reveal a similar development. Both the dry-out zone around the heaters and the condensation zone have extended significantly compared to the situation after 1 year. Matrix and fracture saturation build-up is observed not only in the tptpmn, but also in the underlying tptpul layer, and, to a lesser degree, in the overlying tptpul. The affected rock volume extends as far as $50 \mathrm{~m}$ below the Heater Drift centerline. The maximum saturation values in both fractures and matrix are slightly lower than the maximum values observed at 1 year, partially due to the reduced heater power, partially due to the much larger rock volume affected by the thermal load. This results in reduced liquid flow, with flux values of about $1 \mathrm{~m} / \mathrm{yr}$ in the condensation zone vertically downward, and fluxes of up to $3 \mathrm{~m} / \mathrm{yr}$ from the condensation zone towards the boiling zone. All hydrology holes are expected to reveal significant observations from passive and active monitoring, as all of them are at least partially intersecting the dry-out or the condensation zone.

Figures 5.1-16 to 5.1-21 present the thermal-hydrological situation at 8 years since the start of the test, which is 4 years after the heater is turned off. During this cooling period, the rock mass around the heater has cooled substantially; however, the maximum temperature at this time is still as high as $70^{\circ} \mathrm{C}$. In the absence of vaporization and condensation processes, the condensation zone outside of the dry-out area has partially vanished; the matrix and fracture saturations close to the dry-out region have dropped to values slightly smaller than the initial saturations, because liquid is driven from the condensation zone toward the heater to rewet the dry-out region. However, rewetting is a very slow process. As the saturation values around the dry-out zone are close to or even below the initial values, liquid fluxes have significantly decreased compared to the heating periods, with maximum values of about $15 \mathrm{~mm} / \mathrm{yr}$. Note that the $82.5 \%$ matrix saturation contour line in the tptpll (and the $12.5 \%$ fracture saturation contour line) has moved vertically downward from its location at 4 years. This indicates that only part of the condensate that had accumulated below the drift during heating is returning towards the dry-out region during cooling; another part is apparently migrating downward, away from the heater area, driven by gravity and capillary forces. 
The temporal evolution of the thermal-hydrological properties in the DST block requires study in more detail. Figures 5.1-22 through 5.1-25 show temperature, gas pressure, matrix and fracture liquid saturation along a horizontal sampling line in the hydrology hole plane at $y=30.18 \mathrm{~m}$. The sampling line extends from the center of the drift at $\mathrm{x}=0.0 \mathrm{~m}, \mathrm{z}=0.0 \mathrm{~m}$ along the wing heater to the Observation Drift. Results are presented at 6 months, 1 year, 2 years, 3 years, and 4 years during the heating period, and at 1 year, 2 years, 3 years, and 4 years during the cooling period.

The temperature distributions in Figure 5.1-22 show a distinct heat-pipe region throughout the heating period. This region of liquid and vapor counter-flow is evidenced by the plateau in the temperature curve near $100^{\circ} \mathrm{C}$. It is also evident that the temperature distribution along the first $10 \mathrm{~m}$ from the drift wall is fairly uniform, indicating that the operating power of the in-drift heater and the wing heater has appropriately balanced. The temperatures in this area vary only as much as $25^{\circ} \mathrm{C}$ during the time interval from 1 year to 4 years. This implies that the chosen heating schedule gives fairly steady-state conditions for a sufficiently long time period. Further away from the heater, the temperatures rise significantly with time, and the heated rock volume increases substantially. When the heater is turned off after 4 years, the temperatures decrease rapidly in the first year, but much more slowly thereafter. Without the vaporization and subsequent condensation processes which arise in response to heating, heat-pipe effects are absent during this cooling period.

Areas of gas pressure build-up (Figure 5.1-23) correspond to the high-temperature boiling regions shown above (Figure 5.1-22). The maximum pressures are observed during the first year of heating, while the heaters are operating at $100 \%$ power. As soon as the heater power is reduced to $50 \%$, the gas pressures drop significantly, and remain at a constant value throughout the heating period. During cooling, gas pressures return to ambient conditions almost immediately after turning off heat.

The matrix and fracture saturation profiles shown in Figures 5.2-24 and 5.2-25, respectively, demonstrate the steep gradients of moisture content at the interface between dry-out and condensation zones. Note that the horizontal sampling line runs from the Heater Drift along the wing heaters. The dry-out zone reflects the horizontal extent of the wing heater array; beyond this array, the saturation increases immediately. The single saturation peak observed at initial heating stages about $2 \mathrm{~m}$ away from the drift wall is due to the horizontal offset between the drift wall and the wing heaters. The highest saturations are found at 1 year; thereafter, the saturation peak values decrease slowly with time, while the saturation front moves radially outward. The cooling of the rock results in a fast decrease of the peak saturation values to approximately the initial state before turning on the heat, as part of the liquid is driven towards the dry-out zone. However, after this fast response to turning off the heat, the rewetting process becomes very 
slow. It will take much longer than 4 years for the dry-out zone to return to the initially high saturation values in the tptpmn.

Figures 5.1-26 through 5.1-33 give a similar sequence of thermal-hydrological conditions for a vertical sampling line at $\mathrm{x}=0.0 \mathrm{~m}$ and $\mathrm{y}=30.18 \mathrm{~m}$, extending from the center of the drift both upwards and downwards. The temperature profiles in Figure 5.1-26 and 5.1-27 show similar characteristics as observed before: a boiling region of several meters' extent, a very distinct heatpipe region, and a large region with temperatures below boiling, but well above the ambient state. The different thermal conductivity values assigned for the three geological units seem to have negligible impact on the temperature profile, as no gradient changes become apparent at layer interfaces. Although the vertical distribution appears almost symmetrical to the drift centerline, a closer examination reveals some differences between the temperatures below and above the symmetry axis. The vertical extent of the heat-pipe plateau above the heater is slightly larger than below. Above the heater, pressure driven vapor and liquid counter-flow is enhanced by buoyancy effects, forcing additional liquid flux downwards (towards the boiling region) and vapor upwards. Below the heater, the gravity component drives liquid away from the boiling region. For the same reason, the maximum temperatures at the drift crown are lower than at the bottom of the Heater Drift. Minor asymmetry can be also seen in the gas pressure profiles depicted in Figures 5.1-28 and 5.1-29, with slightly higher pressures above the Heater Drift than below.

The saturation profiles in Figure 5.1-30 through 5.1-33 clearly demonstrate the presence of vertical gravity-driven liquid flux, as the saturation build-up below the heater is more prominent and much more extended than above. This is true for both the heating and the cooling phases. Initial moisture distribution profiles are also included in the figures for reference. As already observed before, the highest saturations are found after 1 year of heating. At 4 years, the peak saturation values have decreased; however, noticeable saturation build-up can now be observed in a much larger area, particularly below the heaters. The dry-out region close to the heat sources increases gradually with time. When heat is turned off, the saturation profiles start to equilibrate, as liquid from high-saturation zones is either driven back to the heater areas due to capillary forces or away from the heaters due to gravity. However, after 4 years of cooling, the saturation values are still far from reaching pre-heat conditions. The dry-out areas remain essentially dry, while saturation values far away from the heat sources are still higher than at initial state, in particular below the Heater Drift in the tptpll.

The temporal evolution of the total dry-out rock volume during heating and cooling is depicted in Figure 5.1-34. This volume is evaluated by adding up the volumes of grid blocks having matrix saturation values below a certain threshold value, which is somewhat arbitrarily chosen to be $50 \%$. According to this calculation, the dry-out volume will rise to a maximum value of more than 10,000 cubic meters after 4 years of heating. Assuming a matrix porosity of 0.11 and an 
Pretest Analysis of the Thermal-Hydrological Conditions of the ESF Drift Scale Test

average saturation change in the boiling area from about $92 \%$ to about $18 \%$, more than 800 cubic meters of liquid will be mobilized in the heater test.

Also included in Figure 5.1-34 is the resulting dry-out curve for the other case studied, which assumes a uniform temperature boundary in the Heater Drift rather than the uniform areal heat load boundary discussed earlier. Both cases yield very similar results, which implies that the overall thermal-hydrological conditions are rather unaffected by the mode of heat exchange within the Heater Drift. However, within and close to the drift, the different boundary conditions give rise to substantial temperature differences. Figure 5.1-35 presents the temperature evolution at the Heater Drift wall for the uniform temperature runs. A comparison with Figures 5.1-1 through 5.1-3 reveals similar characteristics in the temperature evolution, but different absolute temperature values. The maximum temperature reached at the drift wall in Figure 5.1-35 is $160^{\circ} \mathrm{C}$ after 4 years of heating. This is about $30^{\circ} \mathrm{C}$ lower than the maximum temperature value observed in Figure 5.1-2, measured at the springline of the $y=30.18 \mathrm{~m}$ cross section. However, it is about $30{ }^{\circ} \mathrm{C}$ higher than the crown drift wall temperature measured in Figure 5.1-3, which shows the temperature evolution at $y=44.8 \mathrm{~m}$. Generally, the uniform temperature case tends to give lower local rock temperatures in the middle section of the Heater Drift and higher local rock temperature at the ends, when compared to the uniform areal heat load case. The real system behavior is expected to be bounded somewhere between the two cases.

Figures 5.1-36 through 5.1-39 show that the impact of the drift wall boundary condition is of very local nature. The figures present temperature and matrix liquid saturation profiles along the same horizontal and vertical sampling lines as chosen before. Heavier lines give the uniform temperature results; thinner lines show the uniform heat load results. As the sampling lines are chosen at $y=30.18 \mathrm{~m}$, close to the center of the Heater Drift, the uniform temperature case yields less thermal load and lower rock wall temperatures than the other case. However, the differences between the two cases decrease with increasing distance from the drift wall. In fact, with respect to the sensor readings in the hydrology holes, these differences will be marginal and can safely be neglected. Input parameter uncertainties will affect the simulation results much more than the choice of the boundary condition.

\subsection{Simulation Results for an Infiltration Rate of $0.36 \mathrm{~mm} / \mathrm{yr}$}

In this section, additional model calculations are presented assuming an infiltration rate of $0.36 \mathrm{~mm} / \mathrm{yr}$, which is $10 \%$ of the current estimate of $3.6 \mathrm{~mm} / \mathrm{yr}$ at Borehole SD-9. The surface infiltration rate is one of the most uncertain parameters at Yucca Mountain; yet it is closely related to the vertical flux through the mountain, one of the most crucial properties for the performance of the potential nuclear waste repository. The assumed percolation flux will also affect the thermal-hydrological conditions at the DST. A smaller flux rate will result in higher temperatures, since less water is seeping downward towards the heated rock volume. Another 
aspect related to the infiltration rate is even more important: The inversion procedure presented in Section 4.3 is strongly influenced by the assumed flux scenario; i.e., a different set of material properties and initial conditions has been derived for the two infiltration rates considered (see Table 4.3-1). The most prominent difference between the two scenarios is that in the $0.36 \mathrm{~mm} / \mathrm{yr}$ case, most of the fractures are fairly dry and not very conductive at ambient state, while in the $3.6 \mathrm{~mm} / \mathrm{yr}$ case, the fracture saturations are sufficiently high at ambient state to allow for most of the flux to be flowing in the fractures.

The results of the $0.36 \mathrm{~mm} / \mathrm{yr}$ infiltration scenario are presented using a similar sequence of figures and graphs to that of Section 5.1, allowing for a direct comparison. The general characteristics of the thermal-hydrological conditions are fairly similar for the two scenarios; the differences are more quantitative than qualitative. As the main processes involved in the heating and cooling of the rock mass have been previously analyzed and discussed in detail, we shall concentrate here on elaborating the particular impact of the smaller infiltration and the changed rock properties in comparison to the $3.6 \mathrm{~mm} / \mathrm{yr}$ results.

The main part of this section presents the thermal-hydrological conditions for the case where the thermal load from the in-drift heaters is uniformly distributed at the drift walls. Figures 5.2-1 through 5.2-3 depict the temperature evolution in the Heater Drift at three different distances from the bulkhead, namely $y=10.06 \mathrm{~m}, \mathrm{y}=30.18 \mathrm{~m}$ and $\mathrm{y}=44.8 \mathrm{~m}$, respectively. Similar to the $3.6 \mathrm{~mm} / \mathrm{yr}$ infiltration scenario, the temperature history is characterized by three stages: a rapid temperature rise in the first year, a steady-state high-temperature "plateau" thereafter, and a cooling period in the end. However, the observed temperatures are consistently about 10 to $15^{\circ} \mathrm{C}$ higher for the low infiltration scenario, due to less effective liquid reflux from the surrounding rock back to the boiling zone. The maximum wall temperature of $208{ }^{\circ} \mathrm{C}$ is measured at the springline in the $y=30.18 \mathrm{~m}$ cross section.

Contour plots of the predicted thermal-hydrological behavior in the thermal testing area are given in Figures 5.2-4 through 5.2-21, which are to be compared with Figures 5.1-4 through 5.1-21 for the high infiltration scenario. Figures 5.2-4, 5.2-5, 5.2-10 and 5.2-11 show the temperature response at 1 year and at 4 years, respectively. The volumetric extent of the heated rock portion appears to be similar for the two infiltration scenarios, which can be seen, for example, by comparing the $50{ }^{\circ} \mathrm{C}$ isotherm. However, the maximum temperatures reached at certain times are clearly different; the low infiltration scenario yields considerably higher temperatures close to the heaters.

Figures 5.2-6 through 5.2-9 and 5.2-12 through 5.2-15 depict matrix and fracture saturation contours at 1 year and at 4 years, respectively. As a result of the inversion procedure, the initial moisture distribution of the low infiltration scenario is quite different from the high infiltration case presented before, particularly with respect to the fracture saturations. However, the matrix 
Pretest Analysis of the Thermal-Hydrological Conditions of the ESF Drift Scale Test

liquid saturation in the tptpmn is almost identical for the two scenarios, as the calibration had been conditioned to a $92 \%$ saturation value.

The impact of the thermal load is immediately obvious in that a distinct dry-out zone has developed around the heaters, followed by a condensation zone featuring a substantial saturation build-up in both the matrix and the fractures. Comparison of the two infiltration scenarios shows that the dry-out is larger when the infiltration rate is low. Consequently, as more vapor is produced in a given time period, the saturation build-up in the condensation zone is more pronounced than in the $3.6 \mathrm{~mm} / \mathrm{yr}$ infiltration scenario; in fact, the matrix saturation values rise up to almost full saturation. Part of the reason for this significant increase is the nature of the characteristic functions of fractures and matrix. For the low infiltration rate, the inversion yields much lower air entry pressures in the fractures than the respective values for the matrix. Consequently, the initial fracture saturation is very low; i.e., the fractures are not very conductive at ambient state. An effective mechanism for redistributing the condensate can only be provided when the fracture saturations build up sufficiently to allow for liquid mobilization in the fractures. Indeed, as can be seen in the contour plots, the maximum fracture saturations are above $40 \%$ at 1 year and above $30 \%$ at 4 years. These values are directly related to significant increases of the respective matrix saturation, as the ECM formulation assumes thermodynamic equilibrium between the two components. The resulting moisture distributions are clearly nonsymmetrical in vertical direction, which indicates that the fractures indeed conduct substantial amounts of liquid away from the boiling area. The maximum fracture fluxes are about $4 \mathrm{~m} / \mathrm{yr}$ at 1 year and about $1.2 \mathrm{~m} / \mathrm{yr}$ at 4 years in the vertical downward direction, while fluxes from the condensation to the boiling zones are as high as $8 \mathrm{~m} / \mathrm{yr}$ at 1 year and $3 \mathrm{~m} / \mathrm{yr}$ at 4 years. These values are similar to the fluxes measured in the high infiltration scenario. However, in the downward direction away from the heat source, the liquid does not migrate as far as in the high infiltration scenario, as the vertical extent of the saturation build-up is clearly smaller in case of low infiltration. Again, this is mainly related to the characteristic curves: As the saturation values slowly decrease with travel distance, the fractures become less and less conductive until further migration is essentially stopped. This effect is less dominant in the high infiltration scenario, where fractures are conductive even at ambient state.

Figures 5.2-16 to 5.2-21 present the thermal-hydrological situation at 8 years, which is 4 years after the heater is turned off. The rock mass around the heater has cooled substantially during this period; it eventually arrives at a maximum temperature of $75^{\circ} \mathrm{C}$, which is slightly higher than in the high infiltration scenario. The matrix saturation contours reveal a more prominent difference between the two infiltration scenarios considered. In the low infiltration scenario, the matrix saturation in the condensation zone is (after 4 years of cooling) still significantly higher than at ambient state, while in the high infiltration scenario, the saturation build-up in the condensation zone area has already vanished at this time. This again is due to the different characteristic curves assumed: In the former scenario, the fractures drain rapidly and become 
almost non-conductive in the absence of vaporization and condensation processes. The water volume accumulated in the matrix during heating gets essentially "trapped," as both fractures and matrix have very small effective permeabilities. In the high infiltration scenario, the fractures remain conductive to some degree and allow for a faster moisture redistribution. This effect is also obvious when comparing the sizes of the dry-out rock volume after 4 years of cooling; it is noticeably larger for the $0.36 \mathrm{~mm} / \mathrm{yr}$ infiltration rate, indicating that the rewetting rate is limited.

Figures 5.2-22 through 5.2-25 show temperature, gas pressure, matrix and fracture liquid saturation along a horizontal sampling line in the hydrology hole plane at $y=30.18 \mathrm{~m}$. Figures 5.2-26 through 5.2-33 give a similar sequence of thermal-hydrological properties for a vertical sampling line at $x=0.0 \mathrm{~m}$ and $\mathrm{y}=30.18 \mathrm{~m}$, extending from the center of the drift both upwards and downwards. Results are presented at 6 months, 1 year, 2 years, 3 years and 4 years during the heating period, and at 1 year, 2 years, 3 years and 4 years during the cooling period. The sampling lines and time periods chosen are identical to the ones presented in Section 5.1 (see Figure 5.1-22 through 5.1-33). A one-by-one comparison of the graphs clearly shows that while the general characteristics of the thermal-hydrological conditions are similar for the two scenarios, there are some quantitative and qualitative differences. In addition and complementary to the above discussion of contour plots, a close look at Figures 5.2-22 through 5.2-33 reveals the following points:

- The near-heater temperatures are about 10 to $15^{\circ} \mathrm{C}$ higher in the low infiltration scenario. A distinct heat-pipe can be observed; however, it is less prominent than in the high infiltration scenario, as the $100^{\circ} \mathrm{C}$ "plateau" is not as wide. Temperatures outside of the boiling zone are almost identical for the two scenarios (Figures 5.2-22, 5.2-26, 5.2-27 compared to Figures 5.1-22, 5.1-26, 5.1-27).

- The gas pressure build-up in the boiling zone is less pronounced in the low infiltration scenario. This is probably a result of the lower fracture liquid saturation, giving rise to higher gas relative permeability values (Figures 5.2-23, 5.2-28, 5.2-29 compared to Figures 5.1-23, 5.1-28, 5.1-29).

- During heating, the matrix saturations are close to $100 \%$ in the condensation zone. In the high infiltration scenario, this saturation build-up is less prominent, but more extended in space. During cooling, the matrix saturations in the condensation zone remain on a level significantly higher than at ambient state. In the high infiltration scenario, they tend to equilibrate much faster (Figures 5.2-24, 5.2-30, 5.2-31 compared to Figures 5.1-24, 5.1-30, 5.1-31).

- During heating, the fracture saturations in the condensation zone increase to similar values for both scenarios. These values are sufficiently high to allow for relatively fast liquid flow in the fractures. However, in case of low infiltration the fracture saturation 
Pretest Analysis of the Thermal-Hydrological Conditions of the ESF Drift Scale Test

starts at (and returns to) a much smaller ambient level, namely about 5\%. At this saturation, the fractures are essentially non-conductive (Figures 5.2-25, 5.2-32, 5.2-33 compared to Figures 5.1-25, 5.1-32, 5.1-33).

The temporal evolution of the total dry-out rock volume during heating and cooling is depicted in Figure 5.2-34. In the low infiltration scenario, the dry-out volume will rise to a maximum value of more than 13,000 cubic meters after 4 years of heating. This is about $30 \%$ more than in the other scenario. After 4 years of cooling, the dry-out rock volume has decreased to about 10,000 cubic meters; i.e., more than 3,000 cubic meters of rock have been rewetted. This process is less effective than in the high infiltration scenario, where the dry-out rock volume decreases from about 11,000 cubic meters to about 6,000 cubic meters during 4 years of cooling.

Also included in Figure 5.2-34 is the resulting dry-out curve for the other $0.36 \mathrm{~mm}$ infiltration case studied, which assumes a uniform temperature boundary in the Heater Drift rather than a uniform areal heat load boundary as before. However, as has already been observed in Section 5.1, the thermal-hydrological conditions in the bulk of the rock mass are rather unaffected by the Heater Drift wall boundary condition. At some distance from the Heater Drift, the differences between the two cases become marginal and can be neglected (Figures 5.2-36 through 5.2-39). Only within and close to the Heater Drift, the different boundary conditions give rise to substantial temperature differences (Figure 5.2-35).

\subsection{Summary}

The expected thermal-hydrological conditions in the DST test block are briefly summarized in this section. Table 5.3-1 gives the maximum Heater Drift wall temperatures at different stages during the heating and cooling of the rock mass. Also given is the volumetric extent of the dryout rock mass, calculated by adding up all grid block volumes which experience a significant reduction in moisture content. The scenarios considered include a $3.6 \mathrm{~mm} / \mathrm{yr}$ infiltration case and a $0.36 \mathrm{~mm} / \mathrm{yr}$ infiltration case, both of which have been studied using two different drift wall boundary conditions in order to capture uncertainties from the effect of heat radiation inside the Heater Drift. All scenarios assume 1-year heating at 100\% power, followed by 3 years heating with $50 \%$ power before heat is finally turned off and a passive cooling period begins. The simulation runs cover 4 years of this cooling period. Some important findings are listed below:

- The chosen heater schedule meets the criteria that (1) the drift wall temperatures do not significantly exceed $200{ }^{\circ} \mathrm{C}$, (2) the temperatures in the near-heater rock volume remain relatively unchanged for several years, so that experiments can be performed in a quasi-steady environment, and (3) a substantial rock volume is being affected by the thermal load, as is manifested in rising temperatures, drying of rock mass due to vaporization, saturation build-up due to condensation of vapor, and enhanced liquid 
flow from the condensation zone, both towards the boiling area and vertically downwards away from the heater test block.

- For $3.6 \mathrm{~mm} / \mathrm{yr}$ infiltration, the maximum temperatures are expected to be about 10 to $15^{\circ} \mathrm{C}$ lower than in the low infiltration case. Also, after 4 years of heating, the driedout rock volume is about $30 \%$ smaller, which indicates the importance of an accurate estimate of hydrologic properties for evaluating the thermal-hydrological situation in the DST block. Rewetting of the dry-out rock volume is a very slow process in both infiltration scenarios; however, in the low infiltration case, it is even slower than in the high infiltration case, as the rock becomes less conductive when temperatures and saturations slowly return to near-ambient conditions during the cooling phase.

- The assumed mode of thermal radiation within the Heater Drift does have a noticeable effect on the calculated temperatures in and close to the drift. However, the results from the two bounding cases studied become more similar with increasing distance from the drift, and the remaining differences can be neglected for most practical purposes, in particularly for the estimation of temperature, pressure, and relative humidity readings in the hydrology holes. The predictions for the sensor readings in the hydrology holes are presented and carefully analyzed below in Section 7 of this report.

Table 5.3-1: Maximum drift wall temperature and dry-out rock volume for different scenarios ( $\mathrm{C}=$ crown $; \mathrm{B}=$ bottom; $\mathrm{S}$ = springline $)$

\begin{tabular}{|c|c|c|c|c|c|c|c|c|c|c|c|c|}
\hline Scenario & \multicolumn{3}{|c|}{$\begin{array}{l}\text { Temp. at } 2 \text { yrs } \\
(C)\end{array}$} & \multicolumn{3}{|c|}{$\begin{array}{l}\text { Temp, at 4yrs } \\
\text { (C) }\end{array}$} & \multicolumn{3}{|c|}{$\begin{array}{l}\text { Temp. at } 8 \text { yrs } \\
\text { (C) }\end{array}$} & \multicolumn{3}{|c|}{$\begin{array}{l}\text { dry-out rock volume } \\
\left(\mathrm{m}^{3} \times 1000\right)\end{array}$} \\
\hline $3.6-3-\mathrm{D}$ & 144 & 153 & 169 & 172 & 179 & 196 & 71 & 71 & 71 & 6.6 & 10.6 & 5.9 \\
\hline $3.6-3-D^{*}$ & \multicolumn{3}{|c|}{140} & \multicolumn{3}{|c|}{160} & \multicolumn{3}{|c|}{63} & 6.4 & 10.3 & 5.6 \\
\hline $0.36-3-\mathrm{D}$ & 154 & 168 & 183 & 182 & 191 & 208 & 73 & 73 & 74 & 8.8 & 12.9 & 9.7 \\
\hline $0.36-3-D^{*}$ & \multicolumn{3}{|c|}{152} & \multicolumn{3}{|c|}{171} & \multicolumn{3}{|c|}{65} & 8.8 & 12.9 & 9.5 \\
\hline
\end{tabular}

* simulation performed with uniform temperature boundary condition at Heater Drift wall 


\section{Sensitivity Studies}

In this section, we evaluate the sensitivity of the therrnal-hydrological response in the DST to (1) different heating scenarios, and (2) alternative concepts used for modeling the fracture-matrix interaction, namely the effective continuum model (ECM) and the dual permeability formulation (DKM). In order to reduce the numerical effort, we restrict the study to two dimensions, with the modeling domain chosen to be a xz-cross section perpendicular to the Heater Drift center line. The numerical simulations are again performed with the simulator TOUGH2. The 2-D grid is identical to the $x z$-cross section shown in Figure 4.2-3, resembling the particular geometry of the 3-D model plane located at $y=30.18 \mathrm{~m}$, thus representing the vertical plane of hydrology holes 74 to 78 . Unless we specify otherwise, the conceptual model, input data, and boundary and initial conditions are identical to the scenario considered in the first part of Section 5.1 ; i.e., a $3.6 \mathrm{~mm} / \mathrm{yr}$ infiltration rate is assumed, and a uniform heat load is applied along the walls of the Heater Drift. In addition to the analysis presented here, we also examined the effects of using a different gas relative permeability formulation, using a different fracture $m$ parameter, and neglecting vapor pressure lowering, all of which proved to be of less importance.

Results from a two-dimensional model cannot exactly represent the actual three-dimensional behavior of the rock mass. However, it will be shown that the 2-D thermal-hydrological response only slightly overestimates the three-dimensional system behavior when comparing the 2-D results to those $\mathrm{xz}$-cross sections of the 3-D grid which intersect the Heater Drift in the center part, e.g. xz-planes 4, 5, or 6 (see Table 4.2-1). Two-dimensional simulations in a sensitivity study have considerable merit, as they not only help to understand the relative importance of parameters and processes in a qualitative manner, but also allow for a much better performance with respect to computer time and data handling than a fully three-dimensional study.

\subsection{Heating Schedule}

Several considerations guide the choice of a desirable heating schedule for the DST. The basic consideration is based on one of the thermal goals of the repository design, namely that the drift wall temperature should not exceed $200{ }^{\circ} \mathrm{C}$. This constraint limits the maximum heat input into the test. On the other hand, the objective of the DST to monitor the coupled thermal, mechanical, chemical, and hydrological processes in the compressed time frame of a field test (years rather than hundreds of years in a real repository) involves the necessity of injecting in a maximum load of heat into the rock mass in a short time. Another consideration is that certain experiments, particularly the hydrochemical tests, need to be conducted in a quasi-steady environment. Thus the near-heater temperatures should remain relatively unchanged for several 
years after they have experienced a fast increase at early stages. All these considerations lead to a heater operating schedule that involves full power output in the beginning to enforce a fast response in the DST, followed by a longer period of reduced power output during which the temperatures are maintained at the desired level, before the heaters are finally turned off after a long-enough heating period to affect a significant rock volume.

In addition to the base-case heater scheme presented in Section 5, the following alternative heater schedules have been studied:

(1) $80 \%$ power output of in-drift and wing heaters for 4 years;

(2) $80 \%$ power output of in-drift heaters for 4 years, wing heaters start 1 year later and operate at $80 \%$ for the remaining 3 years;

(3) $80 \%$ power output of all heaters for 18 months, then reduced power output of in-drift heaters to $50 \%$, while wing heaters keep operating at $80 \%$; and

(4) $80 \%$ power output of all heaters for 18 months, then reduced power output of all heaters to $50 \%$.

All these heater schemes allow an easy operation in that they are fairly simple and do not involve complicated modes of turning on and off the in-drift and wing heaters, respectively. The results of this 2-D modeling exercise are summarized in Table 6.1-1, giving the predicted temperatures at the drift wall and the dry-out rock volume after 2 and 4 years of heating, for heater schedules (1) through (4) as well as the for base-case schedule. For reference, the 3-D model results obtained in Section 5.1 are listed as well, extracted from the 3-D grid for the $x z$-cross section at $y=30.18 \mathrm{~m}$. Typically, the 2-D wall temperatures exceed the $3-D$ results of this particular cross section by only $5{ }^{\circ} \mathrm{C}$. Also, the predicted dry-out volume is quite similar for the 2-D and 3-D models; the resulting volumes are almost identical at 2 years and differ only as much as $10 \%$ at 4 years. For comparison, the 3-D dry-out volume has been calculated by adding up only those grid block elements located in the particular cross section at $y=30.18 \mathrm{~m}$, and by dividing the resulting volume by the thickness of the plane.

The first heating scenario with $80 \%$ power output for the entire heating period results in high drift wall temperatures of about $300{ }^{\circ} \mathrm{C}$ at 4 years, which by far exceeds the $200^{\circ} \mathrm{C}$ criterion. A similar problem is encountered when operating the heaters according to scenarios (2) and (3). Only Scenario (4) and the base-case scenario, which was chosen for the 3-D runs in Section 5 above, yield reasonable temperatures at the Heater Drift walls, and both of them feature very similar values of dry-out rock volume at 2 and at 4 years, respectively. A closer examination of the temporal evolution of temperature and dry rock volume for these two cases reveals that the main differences occur during the first 18 months of heating, as Scenario (4) shows a considerably slower response to the heat input (Figures 6.1-1 and 6.1-2). Thereafter, the differences decrease rapidly, and after another 3 months both the temperature and the volume curve are 
Pretest Analysis of the Thermal-Hydrological Conditions of the ESF Drift Scale Test

almost identical. This is not a surprise considering that the total heat input into the DST during the 4 years of heating differs only as much as $2 \%$ between the two cases.

Table 6.1-1: Maximum drift wall temperature and dry-out rock volume for different heating schemes $(\mathrm{C}=$ crown $\mathrm{B}=$ bottom $\mathrm{S}=$ springline; $\mathrm{BC}=\mathrm{Base}$ Case $)$

\begin{tabular}{|c|c|c|c|c|c|c|c|c|c|c|c|}
\hline \multicolumn{2}{|c|}{$\begin{array}{c}\text { Scenario } \\
\text { No } \mid \begin{array}{c}\text { Time } \\
\text { Period }\end{array}\end{array}$} & \multicolumn{2}{|c|}{$\begin{array}{l}\text { Heater Power } \\
(\%) \\
\text { in-drift| wing }\end{array}$} & \multicolumn{3}{|c|}{ 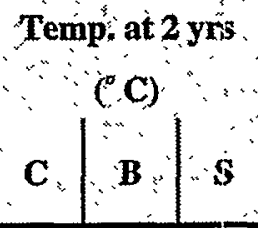 } & \multicolumn{3}{|c|}{ 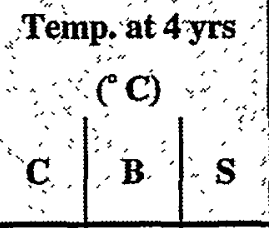 } & \multicolumn{2}{|c|}{$\begin{array}{l}\text { dry-out rock yolume } \\
\left(\mathrm{m}^{3} / \mathrm{m} \times 1000\right) \\
2 \text { yrs }{ }_{4} \text { yrs }\end{array}$} \\
\hline 1 & 4 years & 80 & 80 & 176 & 191 & 213 & 254 & 266 & 293 & 188.4 & 407.9 \\
\hline 2 & $\begin{array}{l}1 \text { year } \\
3 \text { years }\end{array}$ & $\begin{array}{l}80 \\
80\end{array}$ & $\begin{array}{c}0 \\
80\end{array}$ & 145 & 160 & 178 & 233 & 245 & 272 & 102.3 & 347.9 \\
\hline 3 & $\begin{array}{l}11 / 2 \text { years } \\
21 / 2 \text { years }\end{array}$ & $\begin{array}{l}80 \\
50 \\
\end{array}$ & $\begin{array}{l}80 \\
80\end{array}$ & 144 & 157 & 179 & 198 & 209 & 237 & 179.0 & 381.2 \\
\hline 4 & $\begin{array}{l}11 / 2 \text { years } \\
21 / 2 \text { years }\end{array}$ & $\begin{array}{l}80 \\
50\end{array}$ & $\begin{array}{l}80 \\
50\end{array}$ & 141 & 154 & 170 & 176 & 184 & 201 & 163.0 & 288.0 \\
\hline$B C$ & $\begin{array}{l}1 \text { year } \\
3 \text { years }\end{array}$ & $\begin{array}{c}100 \\
50\end{array}$ & $\begin{array}{c}100 \\
50\end{array}$ & 145 & 158 & 172 & 175 & 184 & 200 & 169.3 & 290.9 \\
\hline $\mathrm{BC}$ & $\begin{array}{l}1 \text { year }{ }^{* 2} \\
3 \text { years }\end{array}$ & $\begin{array}{c}100 \\
50\end{array}$ & $\begin{array}{l}100 \\
50\end{array}$ & 144 & 153 & 169 & 172 & 179 & 196 & 171.0 & 272.7 \\
\hline
\end{tabular}

\subsection{Dual Permeability}

In this section, a dual permeability formulation is applied for modeling the thermal-hydrological behavior of the rock mass, as opposed to the ECM model previously used. A dual permeability model is able to capture the transient response in the matrix to perturbations of temperature, pressure, or saturation in the fractures. In other words, fracture and matrix continua do not need to be in thermodynamic equilibrium at all times, as assumed with the ECM. The matrix is represented by one continuum, i.e., a dual permeability formulation rather than a "MINC" (Multiple Interacting Continua, after Pruess and Narasimhan, 1985) formulation is applied. This means that the fracture-matrix interaction is proportional to the primary variable difference between the 
two continua. Several studies have shown that this approach, often referred to as "quasi-steady," may slightly underestimate the exchange rates between fractures and matrix, mainly because it cannot accurately account for the early time behavior in matrix blocks with steep gradients at the block surfaces.

The material properties used for the DKM runs are identical to the properties previously used in the ECM modeling exercises. Dual permeability models require some additional information regarding the geometry of the fractured rock (i.e., the interface area between fractures and matrix, and the size and shape of matrix blocks). Both parameters are derived from fracture frequencies estimated by Sonnenthal et al. (1997) for the different layers of the Topopah Spring geological unit, namely 0.69 fractures per meter for the tptpul, 1.88 fractures per meter for the tptpmn, and 1.81 fractures per meter for the tptpll. The geometrical model for estimating the fracture-matrix interface area and the matrix block shape is quite simple; one set of fractures is assumed with parallel equidistant fractures. In this study, the entire fracture-matrix interface area is supposed to be available for heat and mass exchange between fractures and matrix. Recently proposed interface reduction models, such as scaling the interface area by either a constant factor smaller than 1, by liquid saturation, or by relative permeability, are not used here (Doughty and Bodvarsson, 1997; Bandurraga and Bodvarsson, 1997; Ho, 1997). Application of such interface scaling would reduce the potential for mass exchange between fractures and matrix, and thereby enhance the differences between DKM and ECM model results.

Using material properties and boundary conditions similar to the ECM simulations, the DKM model is run for 10,000 years prior to the turning on of heat to achieve a consistent initial state. This initial state is slightly different from the ECM initial condition, in particular at layer interfaces, where liquid has to be transferred between fractures and matrix as the flux partitioning between the two components changes with changing layer material properties. In the DKM runs, a pressure disequilibrium between fractures and matrix emerges at these interfaces and forces liquid flux from the fractures to the matrix and vice versa, while in the ECM, a pressure equilibrium is assumed at all times as the mass exchange is not explicitly modeled.

Figures 6.2-1 through 6.2-5 present dual permeability model results in comparison to the ECM results. The temporal evolution and spatial variation of temperatures is fairly insensitive to the modeling conceptualization, as is apparent from Figures 6.2-1 and 6.2-3. The vertical temperature profile shows a slightly less pronounced heat-pipe plateau for the DKM runs; also it seems that the temperatures outside the boiling region are more strongly affected by convective heat flux: Above the heater, the DKM temperatures are lower than those calculated with ECM, below the heater, they are higher, indicating the DKM results in more cold water flowing towards the condensation zone from above, and more heated water flowing away from the condensation zone below the heaters. 
More prominent differences between DKM and ECM are evident in the vertical saturation profiles shown in Figures 6.2-4 and 6.2-5. While the vertical extent of the dry-out rock volume above and below the Heater Drift is almost identical, and while the build-up of saturation in the condensation zone immediately adjacent to the dry-out zone is similar for the two cases, the saturation profiles show a clearly different behavior further away from the heated area. In the DKM, the saturation perturbation in the fractures migrates much further than in the matrix. This is particularly evident in the vertical downward direction, indicating that there is a large region of enhanced gravity-driven flux. In fact, the perturbation of saturation in the fracture continuum extends all the way to the bottom of the model area. As this jeopardizes the validity of the initially chosen constant-pressure boundary condition, a "free drainage" boundary condition was applied instead (McCord, 1991). In contrast, the ECIM model gives a much less extended region of fracture saturation build-up above and below the heater. The reason for this behavior is in the different dynamics of the thermal-hydrological response in fractures and matrix, which cannot be captured with the equilibrium assumption associated with ECM. As vapor is driven away from the heaters, it will eventually condense at the fracture walls, and liquid saturation in the fractures will increase. This gives rise to significantly enhanced liquid flux in the fractures, away from the condensation zone. At the same time, part of the liquid imbibes into the matrix, as a capillary pressure gradient between the fractures and the matrix develops. However, as matrix imbibition is relatively slow, some fraction of the condensate can migrate very far in the fractures before being affected by that process. The ECM concept cannot capture this retarded response in the matrix; it assumes a pressure equilibrium between fractures and matrix at all times, which essentially means that the imbibition rate is strong enough to guarantee a zero response time. Therefore, the ECM results underestimate the potential for grávity-driven liquid flux far away from the near-heat environment.

Another interesting aspect can be seen in Figure 6.2-2, which presents the evolution of the dryout rock volume estimated from the two models. Almost identical during the heating period, the curves show significant differences during cooling. For the DKM, the rewetting is much slower; in fact, the dry-out rock volume even increases for another year after the heaters are turned off before eventually starting to show some effect of moisture reflux into the dry-out zone. Our interpretation is that these differences are less a result of the DKM having a better capability of modeling the dynamics of this cooling process, and more a result of the fact that during heating, the DKM yields higher liquid flux away from the condensation zone in the vertical downward direction, leaving less liquid available to be drawn back toward the heat source when the heaters are turned off.

Our results indicate the importance of the model conceptualization. However, both ECM and DKM give similar results for the near-heater environment, in particular the rock volume bracketed by the hydrology holes. Therefore, the predicted readings of temperature, gas pressure, and saturation in the hydrology holes are not expected to be affected by the model formula- 
tion used, except for the saturation build-up observed during the cooling period, as the rewetting rate appears to be overestimated with ECM. The real system behavior may be bounded somewhere between the two extreme cases of ECM and dual permeability. The former conceptual model underestimates matrix response times because of the equilibrium assumption; the latter overestimates them by calculating the fracture-matrix interaction with a steady-state exchange approach. The latter could be improved by analysis using MNC. Again, in this study we have not applied recently proposed models for reducing the fracture-matrix interface area (Doughty and Bodvarsson, 1997; Bandurraga and Bodvarsson, 1997; Ho, 1997) which would enhance the differences between DKM and ECM model results. 
Pretest Analysis of the Thermal-Hydrological Conditions of the ESF Drift Scale Test

\section{Prediction of Sensor Reading in Hydrology Holes}

The model results from the three-dimensional thermal-hydrological simulations presented in Section 5 above are used here to predict readings of temperature, gas pressure, and relative humidity in the 12 hydrology holes during the heating and cooling phases of the test. In addition to the passive monitoring, single-hole and interference air injection tests will be performed in isolated sections of the hydrology holes. Therefore, the effect of moisture redistribution on air permeability tests is also discussed in this section. However, no explicit simulation of air injection tests has been performed in this study, since the test configuration with the specific packer and sensor location in each hydrology hole has yet to be finalized. In fact, the model predictions will provide guidance as to which zones should be used for air injection, where along the boreholes packers and sensors should be placed, and at what specific time intervals injection tests should be performed. However, the reader should keep in mind that the simulation runs are done without taking local heterogeneities into account. It is thus to be expected that the actual measurements will deviate from the predictions. The heterogeneity information will be forthcoming, as pre-heat air permeability tests will be conducted for the hydrology holes.

The predicted sensor readings in all 12 hydrology holes are shown in Appendix A1 for the $3.6 \mathrm{~mm} / \mathrm{yr}$ infiltration scenario, and in Appendix A2 for the $0.36 \mathrm{~mm} / \mathrm{yr}$ infiltration scenario. In both cases, the heat transfer from canisters to the drift,wall is represented by the uniform heat load boundary conditions, assuming little radiative heat exchange within the drift. The heaters are operating at full power for 1 year, followed by 3 years heating with $50 \%$ power before heat is finally turned off and a passive cooling period begins. The thermal-hydrological conditions seen at certain locations in the boreholes are interpolated from the nearest grid points of the 3-D model, since the borehole geometry, packer and sensor locations are not explicitly represented in the grid design. In doing so, the interpolated thermal-hydrological state represents a very local situation in the borehole, while in reality the sensor readings will always represent a longer section along the borehole, namely the length of the packed-off zones. Thus, our predictions of sensor readings can only be an estimate of the real system response.

The first sections of Appendices A1 and A2 show the temperature evolution during 4 years of heating and 4 years of cooling at 36 representative sensor locations in the hydrology holes. In each hole, three hypothetical sensors are placed at distances of $9.5 \mathrm{~m}, 19.5 \mathrm{~m}$ and $29.5 \mathrm{~m}$ from the collar in the Observation Drift, measured in the horizontal direction and referred to in the figures as borehole number plus subscript 2,4 and 6 , respectively. For example, the notation 596 refers to a sensor in borehole 59 placed at a horizontal distance of $29.5 \mathrm{~m}$ from the collar. Predictions have been made for a total number of 8 hypothetical observation points in each hole, but only three of these are shown in the figures, therefore the indices 2,4 , and 6 . The chosen 
locations correspond to local $\mathrm{x}$-coordinates of $-20.0 \mathrm{~m},-10.0 \mathrm{~m}$, and $0.0 \mathrm{~m}$, as the north wall of the Observation Drift and the centerline of the Heater Drift are separated by a horizontal distance of $29.5 \mathrm{~m}$. All hydrology holes have a different incline, however, ranging from +24.0 to -29.4 degrees; hence, the $\mathrm{z}$-coordinates of all sensors are different. The temperature evolution plots are given in Figures A1-1 through A1-12 and A2-1 through A2-12.

The second section of Appendices A1 and A2 gives temperature, matrix saturation, and gas pressure profiles along all 12 hydrology holes for particular time steps, namely at 6 months, 1 year, 2 years, 3 years, and 4 years during heating, and at 1 year, 2 years, 3 years, and 4 years during cooling (Figures A1-13 through A1-72 and A2-13 through A2-72). The matrix saturation profiles also show the initial-state situation. Gas pressure profiles are only presented for the heating phase, since the pressure readings will return to pre-heat conditions very soon after turning off heat.

Both sections in the Appendices are arranged such that first the array with hydrology holes 57 through 61 is shown, located closest to the bulkhead at $y=10.06 \mathrm{~m}$; then the array with hydrology holes 74 through 78 , located at $y=30.18 \mathrm{~m}$, and finally the array with hydrology holes 185 and 186, which is close to the western terminus of the Heater Drift at $y=44.8 \mathrm{~m}$. For the following discussion we refer the reader to the geometry of the hydrology holes as outlined in Section 3.1 and shown in Figures 3.1-1, 3.1-2 and 4.2-2 through 4.2-4, respectively.

\subsection{Passive Monitoring}

The thermal-hydrological processes induced by the heater power output comprise the heating and drying of the rock mass surrounding the heat source, the carrying away of moisture in the form of vapor from the heated area, and the subsequent condensation of the vapor in the cooler regions of the rock mass farther away from the heat source. With time, the entire spatial pattern of drying, vaporization, and condensation slowly migrates away from the heaters. After the power output of the heaters is turned off, cooling of the rock mass and rewetting of the dried-out zone occurs. The different hydrology holes are designed such that during the testing period they will encounter some or all of the above-mentioned processes. Careful analysis reveals that the 12 boreholes can be classified into three categories, each of which feature a characteristic thermalhydrological behavior along a significant section of the borehole:

- The first category includes boreholes in very close proximity to the heater sources, namely hydrology holes 60 and 77 . The thermal-hydrological state can be characterized as "hot and dry." Both boreholes 60 and 77 almost intersect the tip of the wing heater arrays, and both are only about $1 \mathrm{~m}$ away from the Heater Drift at the closest point. Typically, sensors emplaced in these boreholes will measure a fast temperature build-up soon after heating starts. The prediction indicates that at 1 year, the tempera- 
tures along a significant portion of the borehole have already exceeded the nominal boiling point, and the matrix saturations have started to decrease significantly (i.e., the boreholes intersect the dry-out zone that develops around the heaters). The maximum temperatures will be seen in hydrology hole 77 , as high as $145^{\circ} \mathrm{C}$ for $3.6 \mathrm{~mm} / \mathrm{yr}$ infiltration and $155^{\circ} \mathrm{C}$ for $0.36 \mathrm{~mm} / \mathrm{yr}$ infiltration. A significant gas pressure build-up will be observed as soon as the temperatures approach the nominal boiling point. After the heat is turned off, the matrix saturations remain very low during the entire monitoring period, since the rewetting process is very slow.

- Boreholes 59, 61, 76, 78 and 186 fall into the second category that might be characterized as "hot and wet." Soon after heating begins, the matrix saturations increase due to the condensation of vapor. The temperatures rise quite fast to about $100{ }^{\circ} \mathrm{C}$ typically after 1 year of heating, but thereafter remain at this temperature state for a long time period. In fact, for $3.6 \mathrm{~mm} / \mathrm{yr}$ infiltration, the temperatures stay constant around $100^{\circ} \mathrm{C}$ throughout the entire remaining heating period. At the same time, the matrix saturations may slowly decrease, but essentially remain in a "wet" state, as the temperatures apparently do not significantly exceed the nominal boiling point. Only hydrology holes 76 and 78 will see a substantial reduction of the matrix saturation, but only in the final period of heating after 4 years. It seems that at this time the thermal-hydrological situation along boreholes 76 and 78 is changing from a "hot and wet" to "hot and dry" condition. The results for $0.36 \mathrm{~mm} / \mathrm{yr}$ infiltration show a similar, but more distinct behavior in that the initial saturation build-up in the matrix is more pronounced, and that the above-described transition from one thermal-hydrological state to the other takes place slightly earlier. In order to fully capture this transition, the heater test should be operated with a heating period of no less than 4 years, ideally even longer than that. Gas pressures will noticeably build up throughout the heating period; however, the pressure response will be slower and less pronounced than for the "hot and dry" boreholes.

- The last category comprises the boreholes furthest away from the heaters, namely hydrology holes $57,58,74,75$ and 185 . The temperature along these boreholes will stay below the nominal boiling point at all times. The matrix saturations increase due to condensation of vapor and stay above the initial saturation during the entire heating period. After heat is turned off and the rock mass starts cooling down, the high saturation values slowly return to pre-heat conditions, as water is driven by strong capillary forces to the dry-out zones. Note that all boreholes in this category are located above the Heater Drift and intersect the interface between the tptpmn and the tptpul unit, as evident from the drop in the saturation profiles. The pressure sensors are not expected to register readings much different from the ambient value during passive monitoring; only boreholes 58 and 75 may see a slight gas pressure build-up at 4 years of heating, 
indicating that the temperatures get closer to $100{ }^{\circ} \mathrm{C}$. This third category might be summarized as "warm and wet."

The measuring systems to be installed in the hydrology holes will monitor temperature, pressure, and relative humidity. Matrix saturation is not directly measured with the humicaps. Nevertheless, it was decided to present saturation rather than relative humidity in the figures in Appendices A1 and A2, because the former parameter reveals more about the thermal-hydrological state than the latter. The relative humidity can be calculated from local capillary pressure and temperature estimates using Kelvin's equation, given above in Section 3.2. As saturation is related to capillary pressure, the relative humidity can in fact monitor moisture distribution changes in the DST. However, for saturation values not significantly lower than the ambient saturation, relative humidity will always be close to $100 \%$. This means that the relative humidity readings will enable detection of "hot and dry" regions close to the heaters, but are not sensitive to smaller saturation changes within the "wet" environment due to vapor condensation or gravity-driven liquid flux in the fractures. In fact, a significant and detectable reduction of relative humidity is expected only in hydrology holes 60 and 77, and possibly in hydrology holes 76 and 78 after 4 years of heating.

\subsection{Active Testing}

The field air injection tests performed at different times during heating and cooling in the SHT block have shown that they are capable of capturing the spatial variation and temporal evolution of the liquid saturation in the rock mass as a result of vaporization, condensation, drying and rewetting (Birkholzer and Tsang, 1996; Freifeld and Tsang, 1997a, 1997b). The main impact on air permeability is the change of fracture saturation due to drying or vaporization processes, which will change the gas-phase relative permeability in the fractures. In a typical air injection test, a constant mass flux is injected in a packed-off section of one hydrology hole, and the pressure response is measured in the injection zone as well as at different monitoring sensors in other hydrology holes. After a steady-state response is reached, the injection is halted and recovery is monitored. Since the gas-phase relative permeability in the rock adjacent to the injection zone changes during different phases of heating and cooling, the measured pressure response from tests performed at specific time periods will be different.

It has been shown in Section 5 above that significant moisture redistribution processes take place in the DST block, giving rise to spatial and temporal changes in fracture liquid saturation. It is clear from these results that the pressure response to air injection performed in the hydrology holes will evolve with time. Below, we present a discussion on the expected results from singlehole air permeability tests which will be conducted in the different hydrology holes; i.e., we estimate the possible changes in pressure response to injection measured in the packed-off injection zone. (Interference air injection tests will also be conducted; however, the cross-hole pres- 
sure response is far to complex to be analyzed or predicted in this design study.) The following results can be expected from single-hole air permeability tests:

- The hydrology holes categorized as "hot and wet" or "warm and wet" are expected to show an increased single-hole pressure response to air injection, as the gas-phase permeability in the surrounding rock decreases with time after heat is turned on. All these boreholes are partially located in the condensation zone, where matrix and fracture saturations build up due to condensation of vapor. Supposing that the packedoff injection zone is appropriately placed along the boreholes, injection tests will be able to detect this build-up. Once the saturation has increased, the hydrology holes further away from the heater, namely $57,58,74,75$, and 185 , remain at this "wet" state throughout the heating and some part of the cooling period; i.e., they will probably show a similarly high pressure response throughout most of the testing. Other hydrology holes closer to the wing heaters or the Heater Drift, namely 59, 61, 76, 78, and 186 , are expected to show a similar build-up of injection pressure throughout the first few years of heating, but a reversed situation at the end of the heating period, as the local liquid saturation slowly decreases to or even below the pre-heat values.

- Sensors placed in hydrology holes categorized as "hot and dry" will reveal a significant decrease of liquid saturation along the near-heater borehole sections soon after heating starts. As pointed out before, this decrease can be detected with the relative humidity readings. However, it is very unlikely that these saturation changes will be detectable in air injection tests, as the fractures start with low saturation values at ambient state, and the minor saturation decrease due to the dry-out will not noticeably change the gas relative permeability.

- The simulation results presented in Section 5 reveal an extended zone of increased saturation below the heated areas, indicating that relatively fast gravity-driven flux is expected to occur in the fractures. According to the ECM simulation runs, this zone may extend as much as $50 \mathrm{~m}$ in the vertical downward direction after 4 years of heating; according to the DKM runs, it may be even larger. However, with the present configuration of hydrology holes, there is no direct way of detecting potentially enhanced liquid flux in the fractures far below the heater area. hydrology holes 61, 78 and 186 , which bracket the heater area from the lower end, are only covering part of the condensation zone, with $\mathrm{z}$-coordinates of about $-12.5 \mathrm{~m}$ at the bottom of the boreholes. This limitation in test configuration is particularly unfortunate since the two fracture-matrix interaction models applied in this study, ECM and DKM, show considerable differences with respect to gravity-driven liquid flux, but there will be no potential for directly detecting the real system behavior and thereby evaluating the validity of these concepts. 
We should note that the actual air permeability values measured in the field are strongly affected by local heterogeneities along the boreholes, in particularly by the different degrees of fracturing encountered. The impact of the thermal-hydrological evolution on air permeability will have to be analyzed taking local heterogeneity into account. Since a complete set of baseline interference air permeability tests will be conducted in the 12 hydrology holes prior to turning on heat in the DST, a detailed set of spatially varying fracture continuum permeabilities will be available and need to be incorporated into the conceptual model. 


\section{Summary}

We have presented the results of the modeling of both the heating and cooling phases of the Drift Scale Test (DST). The impact on the thermal-hydrological conditions in the rock mass from different input parameters such as heating rates and schedules, different percolation fluxes at the test horizon, and alternative conceptualization of the matrix-fracture interaction such as the effective continuum model and the dual permeability formulation were discussed. In particular, the simulations give the expected readings on the humidity, temperature and pressure sensors due to their response to the changing thermal-hydrological conditions in the (DST). Furthermore, with regard to the active air permeability tests to be conducted in the hydrology holes during the DST, we discussed when, where, and how the pressure response will occur. These simulated results provide guidance to the location of the high-temperature packers and sensors yet to be installed in the hydrology holes.

The results presented indicate that the optimum heating scheme would be to apply almost full heater power at the beginning of the test to enforce a fast response in the DST, followed by a long period of reduced power output during which the temperatures are maintained at the desired level. The results also confirmed that the DST should be a long-term test, that a heating period of at least 4 years is desired, in order (1) to have the benefit of collecting more complete data on the wetting and drying phenomenon monitored by the sensors in the hydrology holes, (2) to be able to maintain quasi-steady thermal-hydrological conditions for a sufficiently long time period which is a favorable environment for certain experiments planned in the DST.

The conclusions of this report are mainly based on qualified data and qualified software. The simulations presented were performed with a numerical model employing what we considered to be the "best" input parameters and "most reasonable" conceptualization. The properties were based on (1) the UZ site-scale model calibration of a surface-to-water-table column at well SD-9, and (2) laboratory and field measurements at the DST area. A complex 3-D grid design was developed to resemble the DST configuration as closely as possible. Where uncertainty due to parameter and conceptualization was anticipated, special care was taken to discuss their impact on the simulated results. Therefore, the presented model provides insight into how the DST is expected to perform and how to conduct the DST. It will serve as a baseline model upon which as-built data, further characterization data, and actual monitoring data may be used for refining and calibrating. 


\section{Acknowledgments}

We thank Stefan Finsterle, Christine Doughty, Don Mangold, Vivi Fissekidou and Dan Hawkes for their review of the manuscript and comments for improvement. Assistance from Nima Afshar in data handling and graphics is gratefully acknowledged. This work was supported by the Director, Office of Civilian Radioactive Waste Management, U.S. Department of Energy, through Memorandum Purchase Order EA9013MC5X between TRW Environmental Safety Systems Inc. and the Ernest Orlando Lawrence Berkeley National Laboratory. The support is provided to Berkeley Lab through the U. S. Department of Energy Contract No. DE-AC0376 SF00098.

\section{References}

Bandurraga, T.M. and G.S. Bodvarsson, 1997. Calibrating matrix and fracture properties using inverse modeling, Chapter 6 of The site-scale unsaturated zone model of Yucca Mountain, Nevada, for the Viability Assessment, G.S. Bodvarsson, T.M. Bandurraga, and Y.-S. Wu, eds., Yucca Mountain Project Milestone Report SP24UFM4, DTN: LB9706001233129.001, Lawrence Berkeley National Laboratory Report, Berkeley, CA.

Birkholzer, J.T. and Y.W. Tsang, December 1996. Forecast of thermal-hydrological conditions and air injection test results of the single heater test at Yucca Mountain, Yucca Mountain Project Milestone Report SP918M4, Lawrence Berkeley National Laboratory Report LBNL-39789, UC-814, ACCN: MOY.970521.04, Lawrence Berkeley National Laboratory, Berkeley, CA.

Bodvarsson, G.S., T.M. Bandurraga, and Y.-S. Wu, eds., 1997. The site-scale unsaturated zone model of Yucca Mountain, Nevada, for the Viability Assessment, Yucca Mountain Project Milestone Report SP24UFM4, DTN: LB9706001233129.001, Lawrence Berkeley National Laboratory Report, Berkeley, CA.

Brodsky, N.S., M. Riggins, J. Connolly, and P. Ricci, 1997. Thermal conductivity and heat capacity measurements for boreholes UE25 NRG-4, UE25 NRG-5, USW NRG-6, and USW NRG-7/7a, SAND 95-1955, DTN: SNL01A05059301.005/NA, Sandia National Laboratories, Albuquerque, NM.

Department of Energy (DOE), 1993. Reference Information Base (RIB), Yucca Mountain Site Characterization Project, YMP/93-02m/Rev. 3, ACCN: MO9212RIB00028.003.

Department of Energy (DOE), 1995. In situ thermal testing program strategy, DOE/YMSCO-003, Las Vegas, NV, U.S. Department of Energy, Yucca Mountain Site Characterization Office. 
Pretest Analysis of the Thermal-Hydrological Conditions of the ESF Drift Scale Test

Doughty, C. and G.S. Bodvarsson, 1997. Investigation of conceptual and numerical approaches for evaluating moisture flow and chemical transport, Chapter 5 of The site-scale unsaturated zone model of Yucca Mountain, Nevada, for the Viability Assessment, G.S. Bodvarsson, T.M. Bandurraga, and Y.-S. Wu, eds., Yucca Mountain Project Milestone Report SP24UFM4, DTN: LB9706001233129.001, Lawrence Berkeley National Laboratory Report, Berkeley, CA.

Edlefsen, N.E. and A.B.C. Anderson, 1943. Thermodynamics of soil moisture, ACCN: NNA.19900312.0151, Hilgardia, vol. 15, no. 2, pp. 31-298.

Finsterle, S., 1993. ITOUGH2 user's guide, version 2.2, Lawrence Berkeley National Laboratory Report LBNL-34581, UC-600, ACCN: MOL.19941026.0075, Lawrence Berkeley National Laboratory, Berkeley, CA.

Finsterle, S., K. Pruess, and P. Fraser, 1996. ITOUGH2 software qualification, Lawrence Berkeley National Laboratory Report LBNL-39489, UC-800, ACCN: MOY-970206-04, Lawrence Berkeley National Laboratory, Berkeley, CA.

Flint, A.L., J.A. Hevesi, and L.E. Flint, (in preparation). Conceptual and numerical model of infiltration for the Yucca Mountain area, Nevada, U.S. Geological Survey Water-Resources Investigation Report, ACCN: MOL.19970409.0087, DTN: GS960908312211.003, U.S. Geological Survey, Denver, CO.

Flint, L.E., (in preparation). Matrix properties of hydrogeologic units at Yucca Mountain, Nevada, U.S. Geological Survey Open-File Report, ACCN: MOL.19970324.0046, DTN: GS950308312231.002 (Q), U.S. Geological Survey, Denver, CO.

Freifeld, B. and Y. Tsang, January 1997a. Letter report on first quarter results of measurements in hydrology holes in single heater test area in the ESF, Yucca Mountain Project Milestone Report SP9263M4, ACCN: MOY-970513-01, DTN: LB970100123142.001, Lawrence Berkeley National Laboratory, Berkeley, CA.

Freifeld, B. and Y. Tsang, May 1997b. Letter report on second quarter results of measurements in hydrology holes in single heater test area in the ESF, Yucca Mountain Project Milestone Report SP9216M4, DTN: LB970500123142.001, Lawrence Berkeley National Laboratory, Berkeley, CA.

Hinds, J., T.M. Bandurraga, M.A. Feighner, and Y.S. Wu, 1997. Geology of the unsaturated zone and the UZ model, Chapter 3 of The site-scale unsaturated zone model of Yucca Mountain, Nevada, for the Viability Assessment, G.S. Bodvarsson, T.M. Bandurraga, and Y.-S. Wu, eds., Yucca Mountain Project Milestone Report SP24UFM4, DTN: LB9706001233129.001, Lawrence Berkeley National Laboratory Report, Berkeley, CA.

Ho, C.L. and S.W. Webb, 1996. A review of porous media enhanced vapor-phases diffusion mechanisms, models and data-does enhanced vapor-phase diffusion exist?, Technical Report, SAND96-1198, Sandia National Laboratories, Albuquerque, NM. 
Ho, C.K., 1997. Models of fracture-matrix interactions during multiphase heat and mass flow in unsaturated fractured porous media, in the Sixth Symposium on Multiphase Transport in Porous Media, 1997 ASME International Mechanical Engineering Congress and Exposition, Dallas, TX.

Jury, W.A. and J. Letey, Jr., 1979. Water movement in soil: Reconciliation of theory and experiment, Soil Sci. Soc. Am. J., vol. 43, no. 5, pp. 823-827.

McCord, J.T., 1991. Application of second-type boundaries in unsaturated flow modeling, Water Resources Research, vol. 27, pp. 3257-3260.

Pruess, K. and T.N. Narasimhan, 1985. A practical method for modeling fluid and heat flow in fractured porous media, ACCN: NNA.19890522.0235, Soc. Pet. Eng. J., vol. 25, no. 1, pp. 14-26.

Pruess, K., 1987. TOUGH user's guide, Nuclear Regulatory Commission, Report NUREG/CR-4645, Lawrence Berkeley Laboratory Report LBL-20700, ACCN: NNA.19890315.0010, Lawrence Berkeley National Laboratory, Berkeley, CA.

Pruess, K., May 1991. TOUGH2 - A general purpose numerical simulator for multiphase fluid and heat flow, Lawrence Berkeley Laboratory Report LBL-29400, UC-251, ACCN: NNA.1940202.0088, Lawrence Berkeley National Laboratory, Berkeley, CA.

Pruess, K. and Y. W. Tsang, 1994. Thermal modeling for a potential high-level nuclear waste repository at Yucca Mountain, Nevada, Lawrence Berkeley Laboratory Report LBL-35381, UC-600, HQO.19940506.0005, ACCN: NNA.19940427.0248, Lawrence Berkeley National Laboratory, Berkeley, CA.

Pruess, K., A. Simmons, Y.S. Wu, and G.J. Moridis, 1996. TOUGH2 software qualification, Lawrence Berkeley Laboratory Report LBL-38383, UC-814, ACCN: MOL19960610.0010-0020, Lawrence Berkeley National Laboratory, Berkeley, CA.

Sonnenthal, E., R. Ahlers, and G.S. Bodvarsson, 1997. Fracture and fault properties for the UZ site-scale flow model, Chapter 7 of The site-scale unsaturated zone model of Yucca Mountain, Nevada, for the Viability Assessment, G.S. Bodvarsson, T.M. Bandurraga, and Y.-S. Wu, eds., Yucca Mountain Project Milestone Report SP24UFM4, DTN: LB9706001233129.001, Lawrence Berkeley National Laboratory Report, Berkeley, CA.

Tsang, Y.W., J. Wang, B. Freifeld, P. Cook, R. Suarez-Rivera, and T. Tokunaga, 1996. Letter report on hydrological characterization of the single heater test area in the ESF, Yucca Mountain Project Milestone Report OS327322D1, DTN: LB960500834244.001, ACCN: MOY-970512-07-B, Lawrence Berkeley National Laboratory, Berkeley, CA.

Tsang, Y.W. and P. Cook, 1997. Ambient characterization of the ESF drift scale test area by field air permeability measurements, Yucca Mountain Site Project Milestone Report SP9512M4, DTN: LB970600123142.001, Lawrence Berkeley National Laboratory, Berkeley, CA. 
Pretest Analysis of the Thermal-Hydrological Conditions of the ESF Drift Scale Test

Vargaftik, N.B., 1975. Tables of the Thermophysical Properties of Liquids and Gases in Normal and Dissociated States, John Wiley \& Sons, Inc., ACCN: NNA.19940428.0016, 2nd Edition.

Walker, W.R., J.D. Sabey, and D.R. Hampton, 1981. Studies of heat transfer and water migration in soils, Final Report, Department of Agricultural and Chemical Engineering, Colorado University, Fort Collins, $\mathrm{CO}$.

Wang, J. and R. Suárez-Rivera, 1997. Laboratory test results of hydrological properties from dry drilled and wet drilled cores in the drift scale test area and in the single heater test area of the thermal test facility, Yucca Mountain Project Milestone Report SP5130M4, DTN: LB970500123142.003, Lawrence Berkeley National Laboratory, Berkeley, CA.

Wu, Y.-S., C.F. Ahlers, P. Fraser, A. Simmons, and K. Pruess, October 1996. Software qualification of selected TOUGH2 modules, Lawrence Berkeley Laboratory Report LBL-39490, UC-800, ACCN: MOL.19970219.0100-0105, Lawrence Berkeley National Laboratory, Berkeley, CA. 
June 1997

\section{Figures}




\section{Plan View}

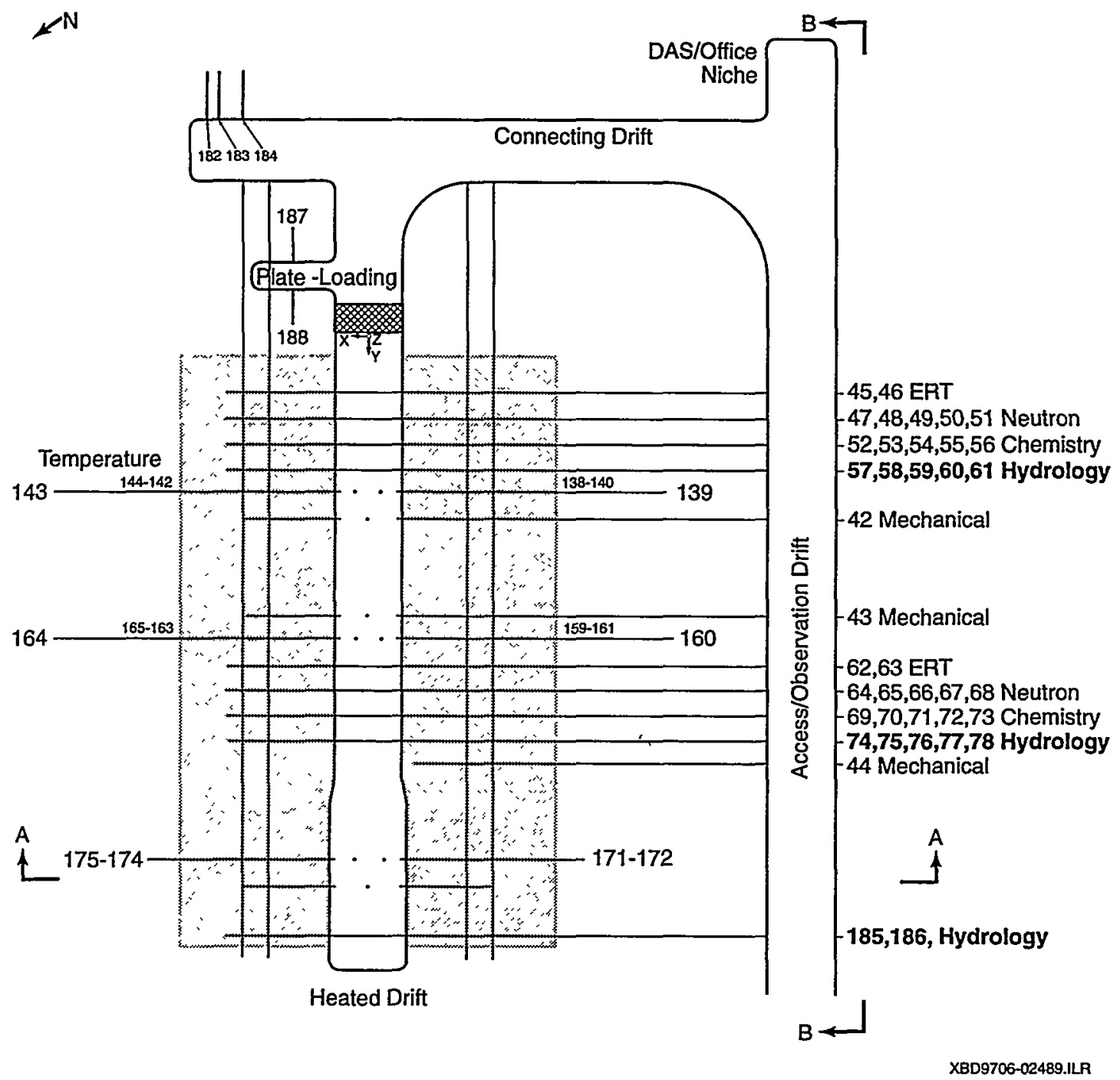

Figure 3.1-1 Plan view of the Drift Scale Test area. The shaded area represents the wing heaters. 

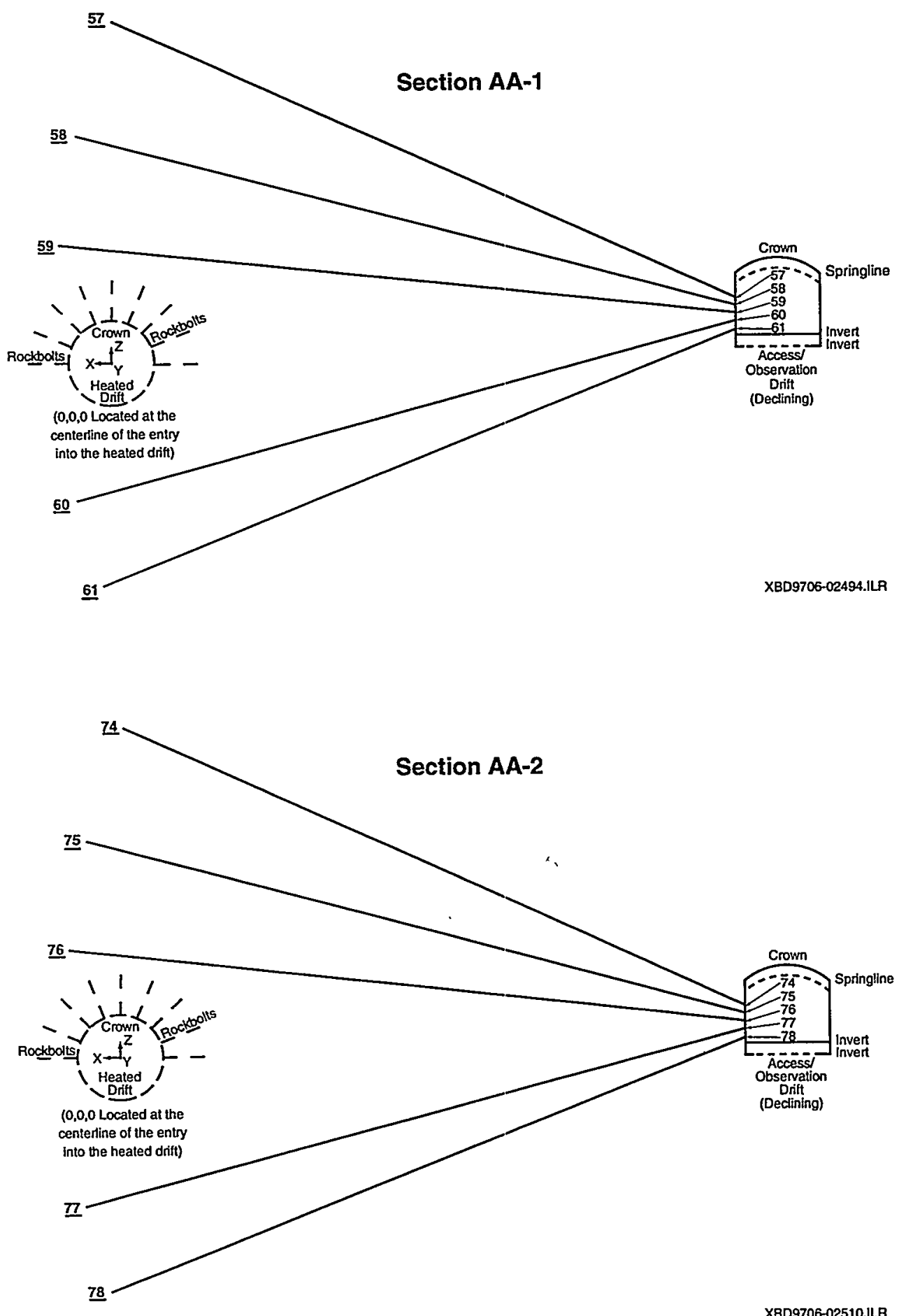

Figure 3.1-2 Vertical profile of the Drift Scale Test area along Section A-A, showing the configuration of hydrology holes 57 through 61 and 74 through 78. 


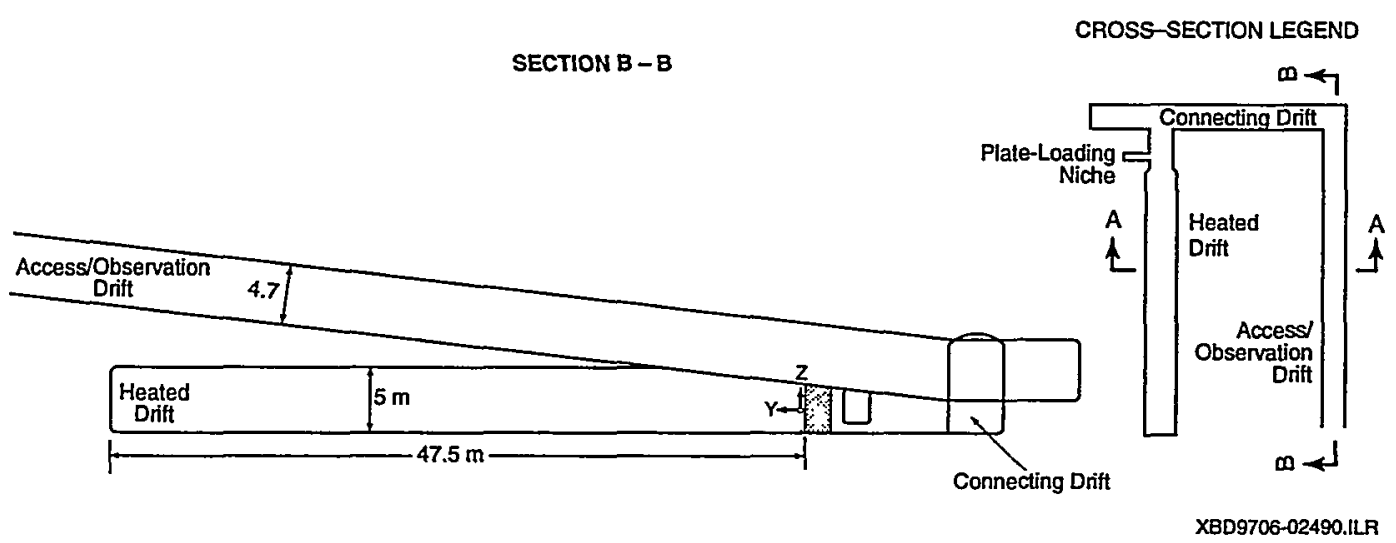

Figure 3.1-3 Vertical profile of Drift Scale Test area along Section B-B. 


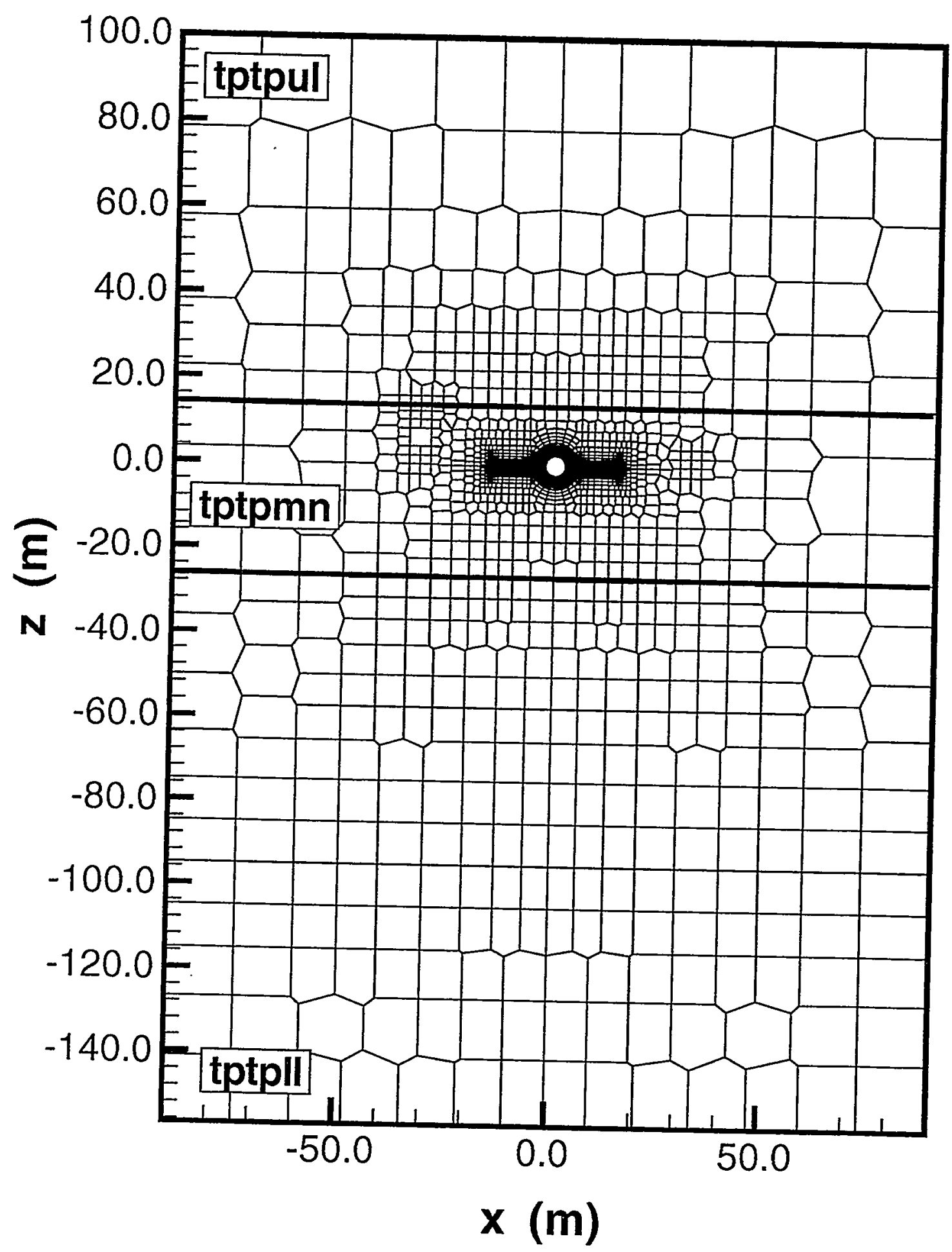

Figure 4.2-1 Discretization of the DST model in a typical xz-cross section. 


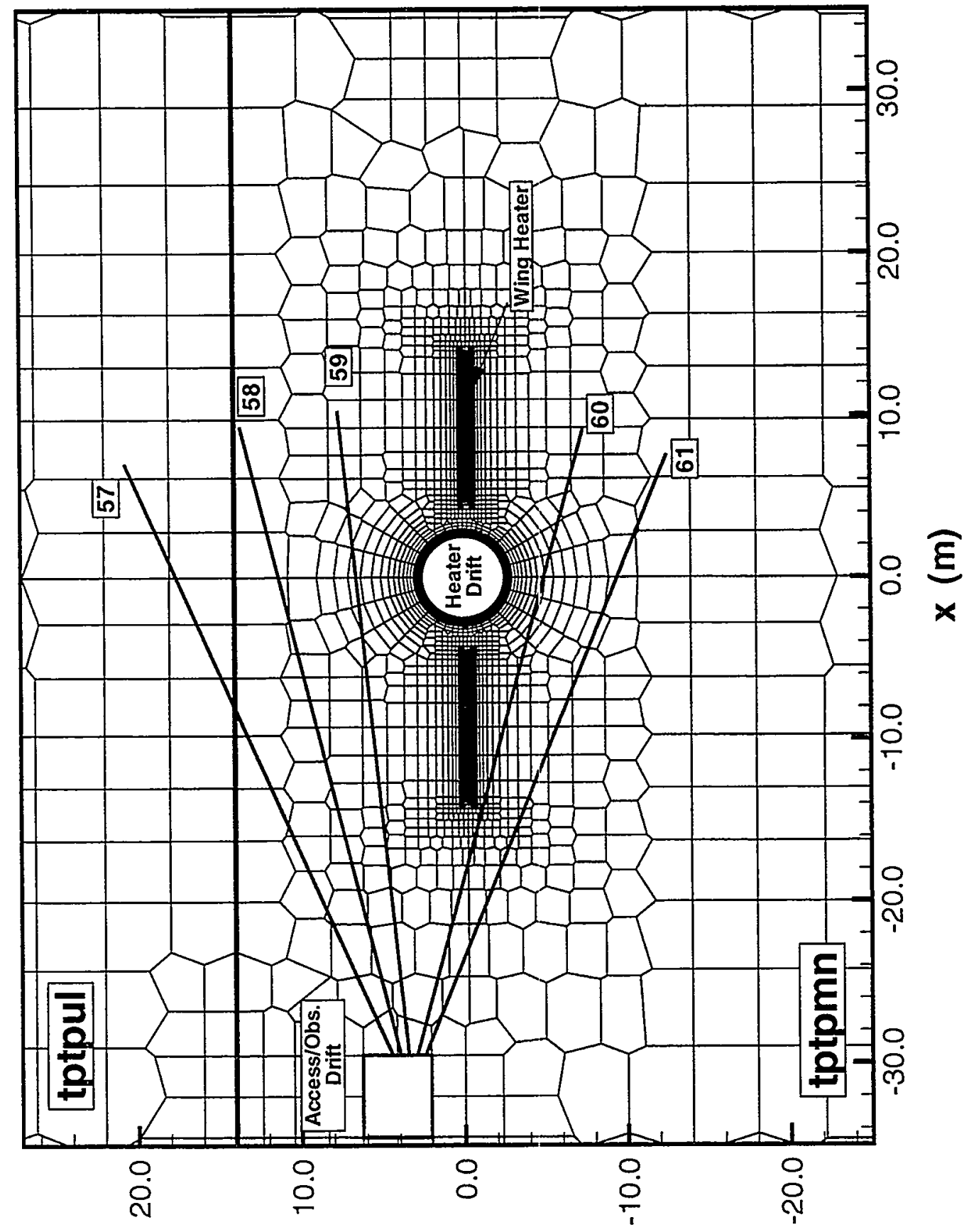

Figure 4.2-2 Discretization of the DST model in xz-cross section at $y=10.06 \mathrm{~m}$, focusing on the near-drift area. Also presented is the location of hydrology holes 57 through 61. 


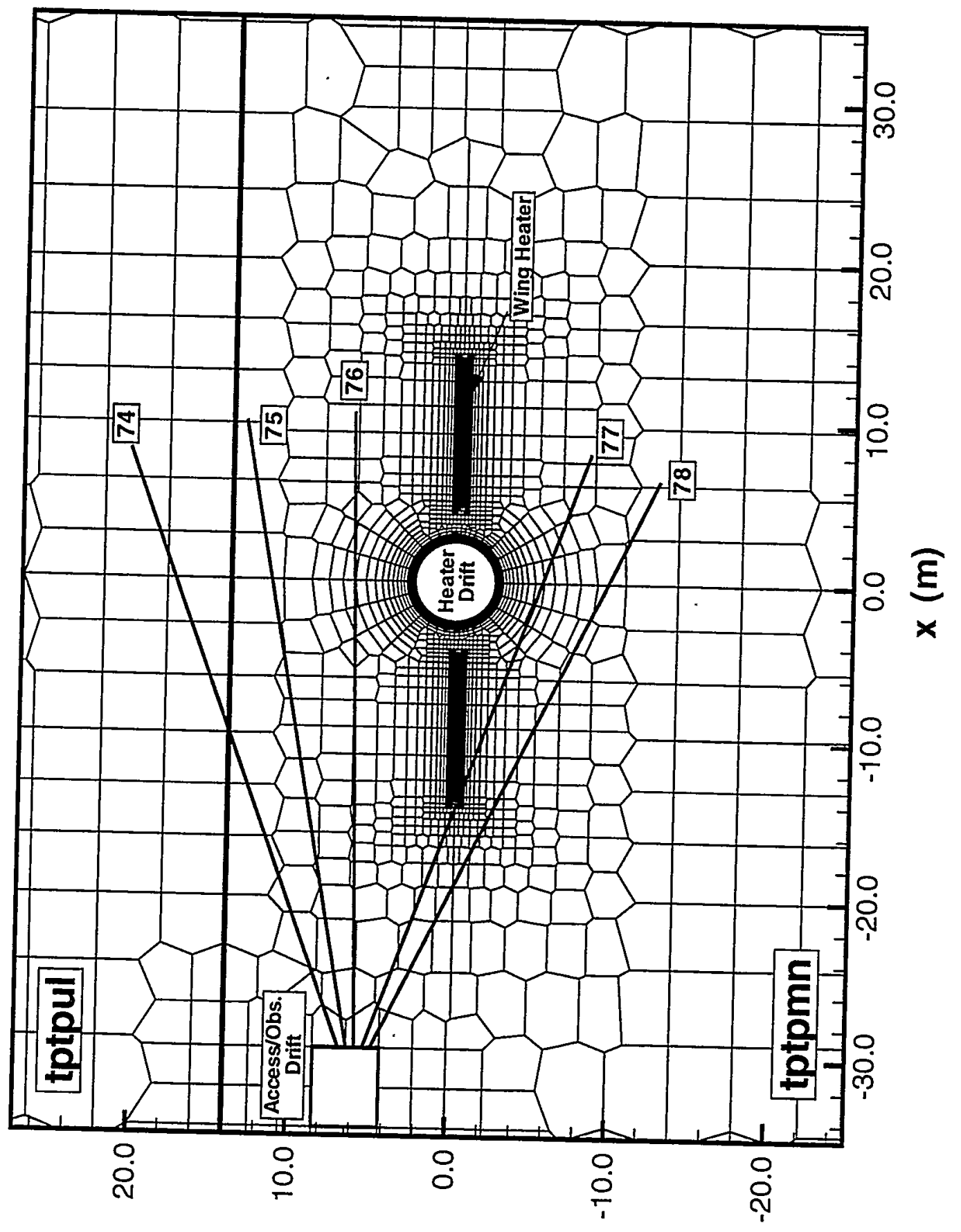

Figure 4.2-3 Discretization of the DST model shown in xz-cross section at $y=30.18 \mathrm{~m}$, focusing on the near-drift area. Also presented is the location of hydrology holes 74 through 77. 


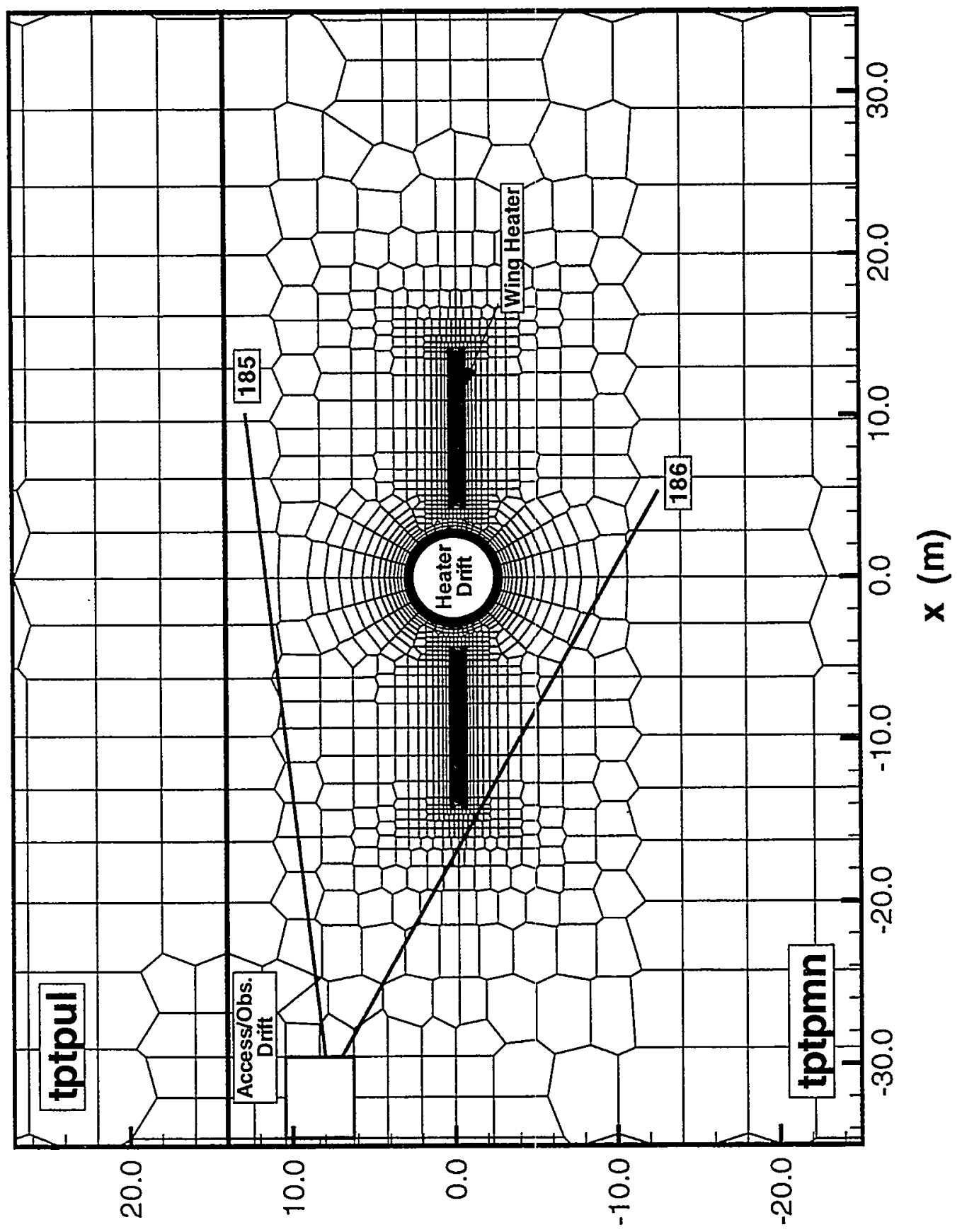

Figure 4.2-4 Discretization of the DST model shown in xz-cross section at $y=44.8 \mathrm{~m}$, focusing on the near-drift area. Also presented is the location of hydrology holes 185 and 186 


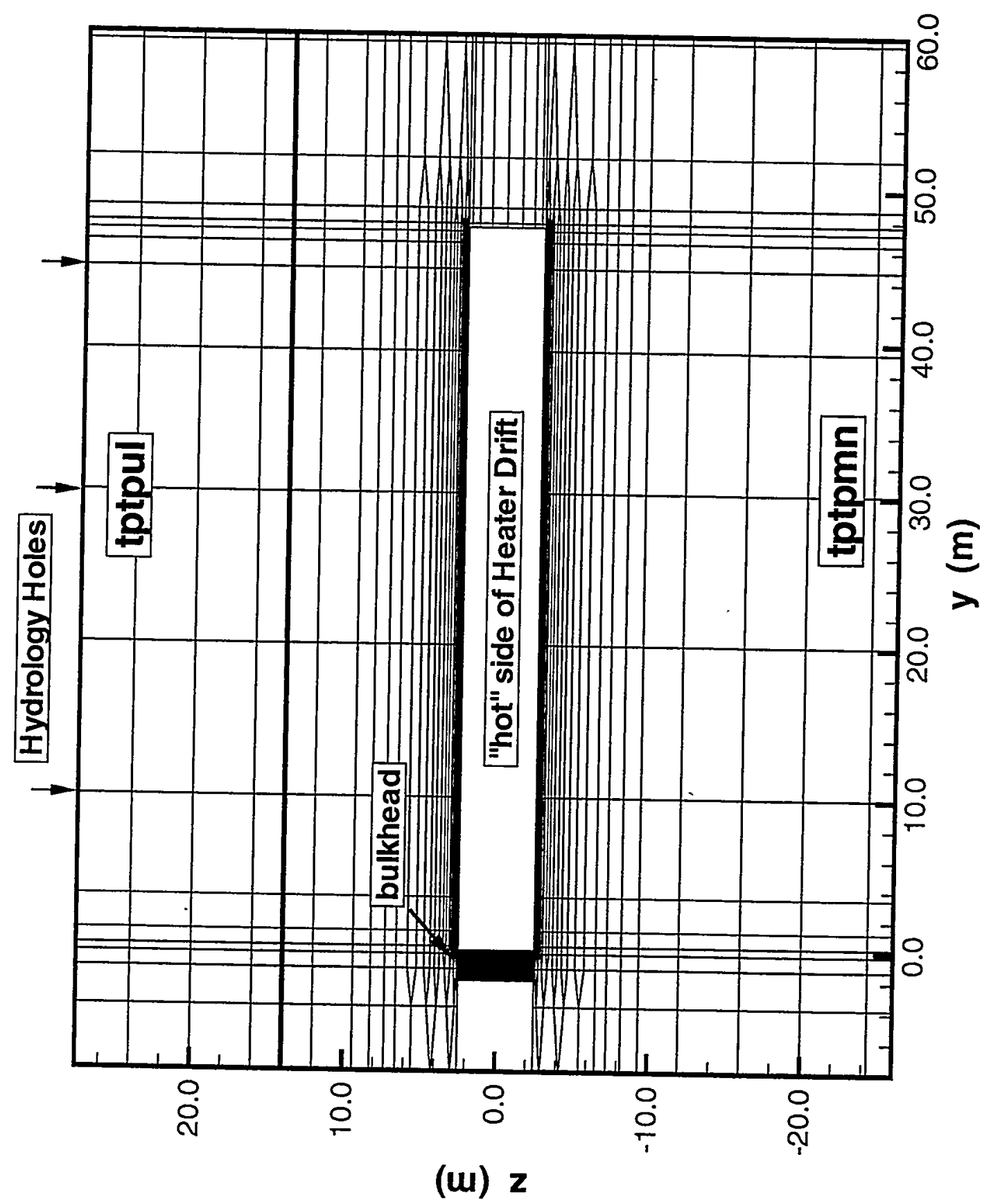

Figure 4.2-5 Discretization of the DST model shown in yz-cross section at $x=0.0 \mathrm{~m}$, focusing on the near-drift area. Also shown is the location of the three spatial clusters of hydrology holes. 

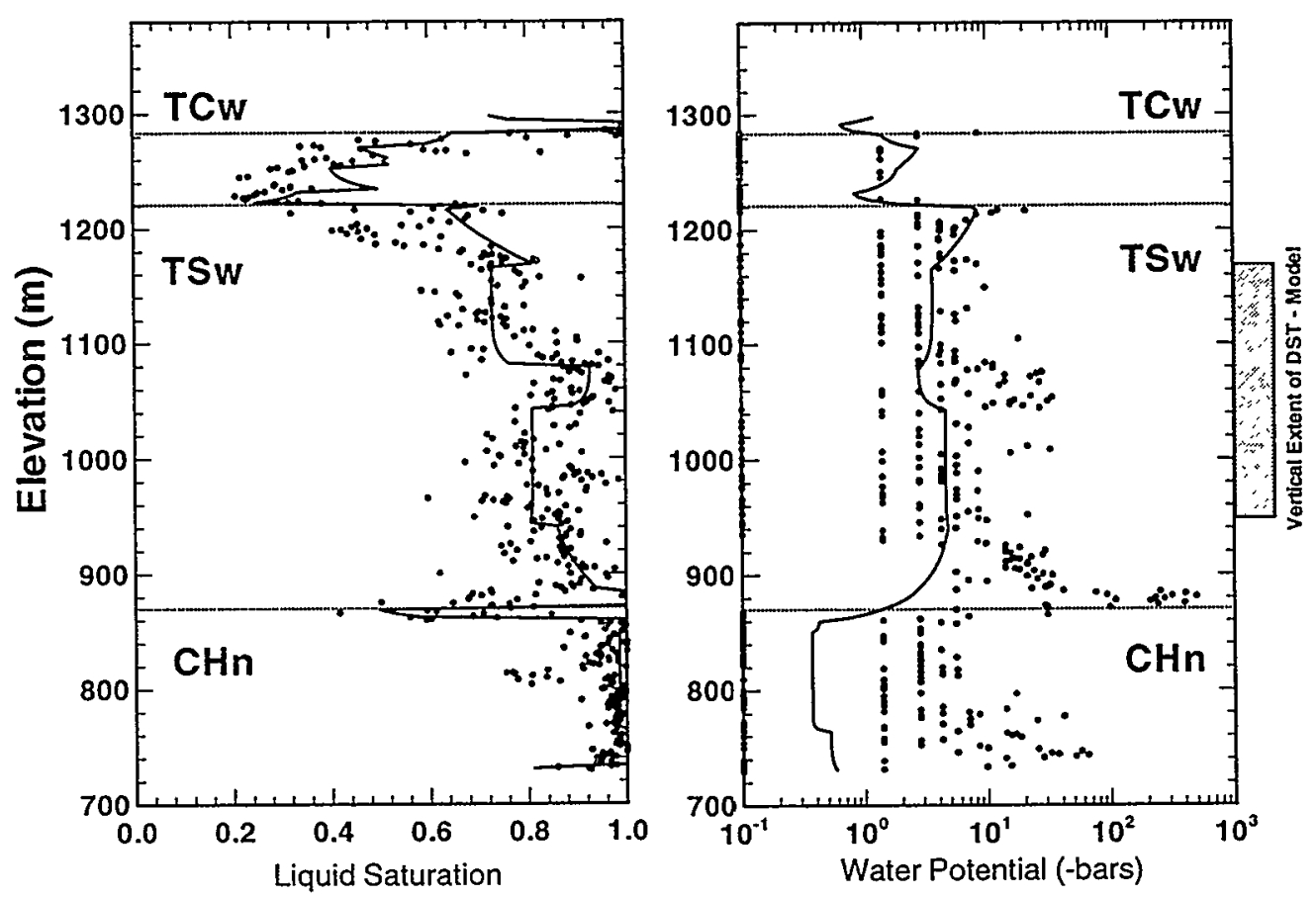

Figure 4.3-I Calibrated saturation and water potential profiles from SD-9 inversion for $3.6 \mathrm{~mm} / \mathrm{yr}$ infiltration case. Symbols indicate observed data.
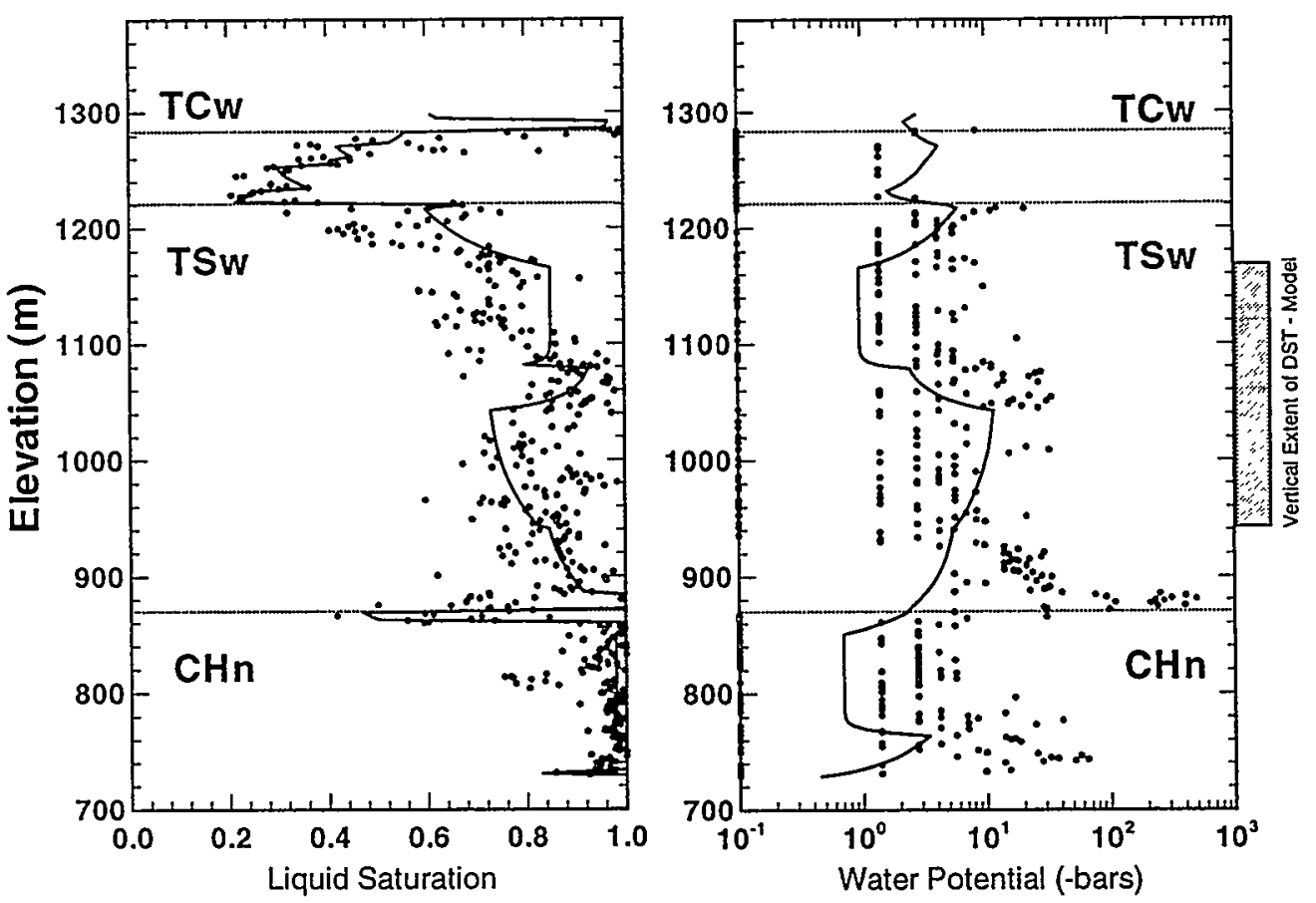

Figure 4.3-2 Calibrated saturation and water potential profiles from SD-9 inversion for $0.36 \mathrm{~mm} / \mathrm{yr}$ infiltration case. Symbols indicate observed data. 


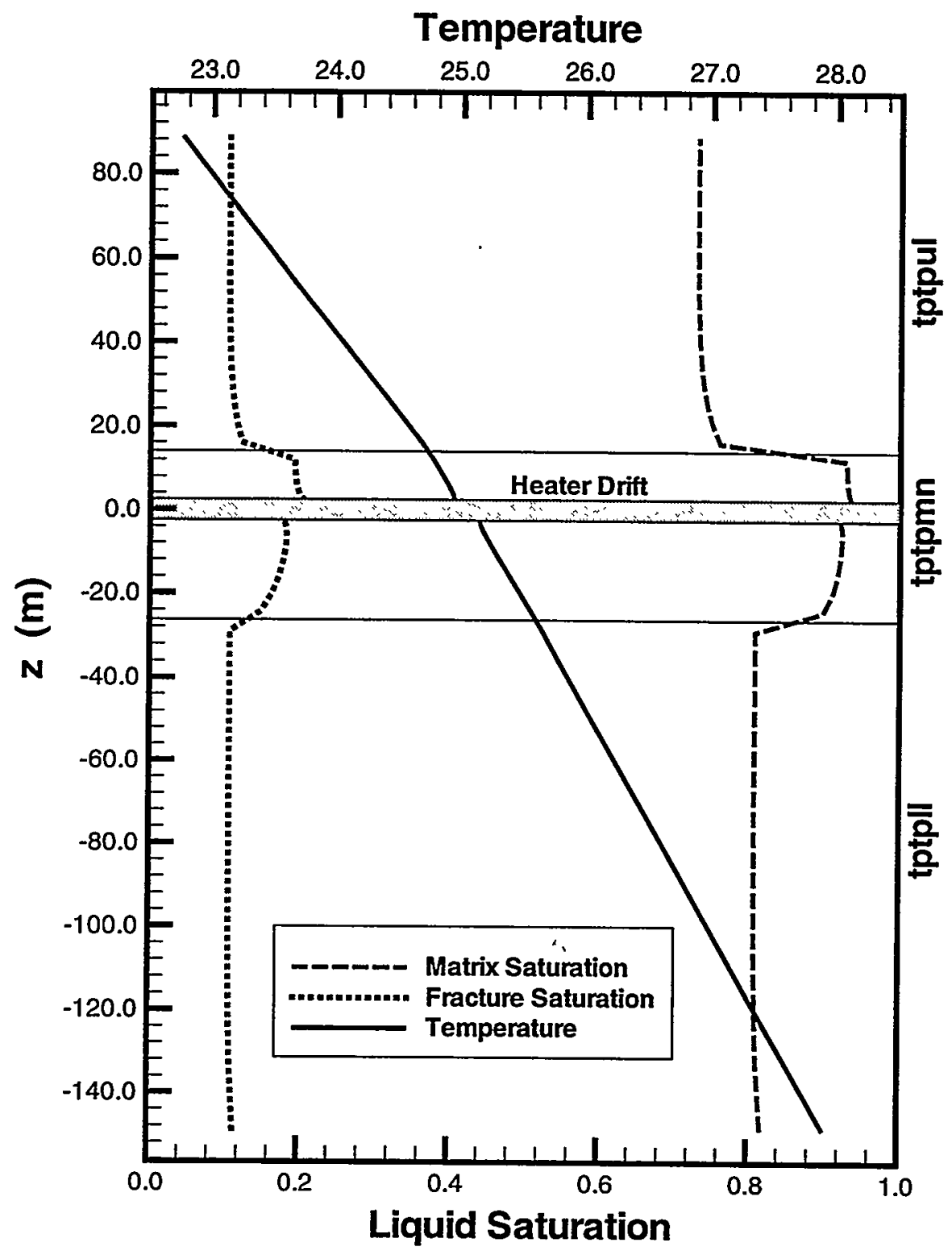

Figure 4.4-1 Initial saturation and temperature profile in DST model area measured along $z$-axis at $x=0.0 \mathrm{~m}$ and $y=30.18 \mathrm{~m}$ for $3.6 \mathrm{~mm} / \mathrm{yr}$ infiltration case. 


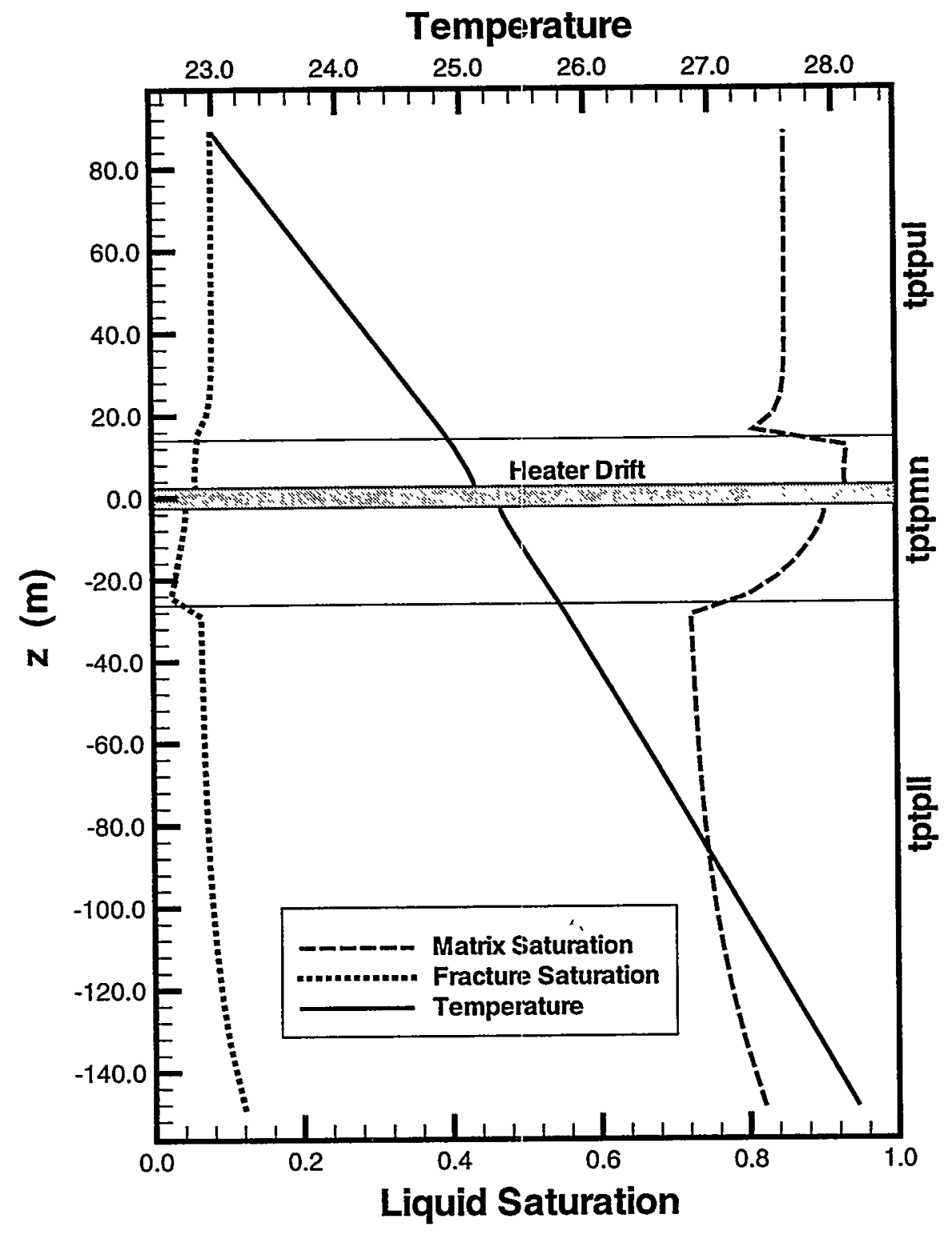

Figure 4.4-2 Initial saturation and temperature profile in DST model area measured along $z$-axis at $x=0.0 \mathrm{~m}$ and $y=30.18 \mathrm{~m}$ for $0.36 \mathrm{~mm} / y \mathrm{r}$ infiltration case. 


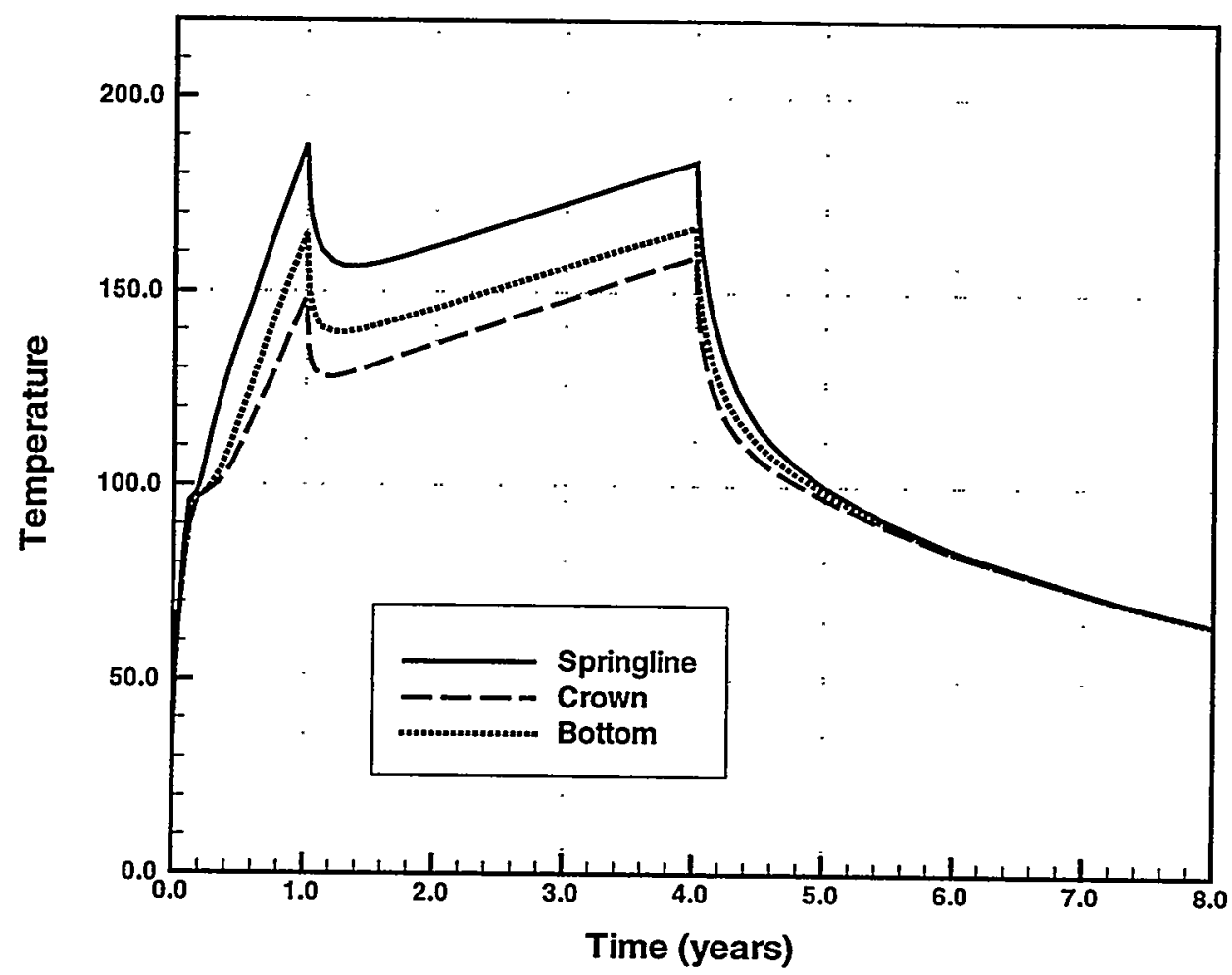

Figure 5.1-1 Temperature evolution at the heater drift wall at $y=10.06 \mathrm{~m}$ from the bulkhead for $3.6 \mathrm{~mm} / \mathrm{yr}$ infiltration case (1 year heating at 100\%, 3 years heating at $50 \%$ ).

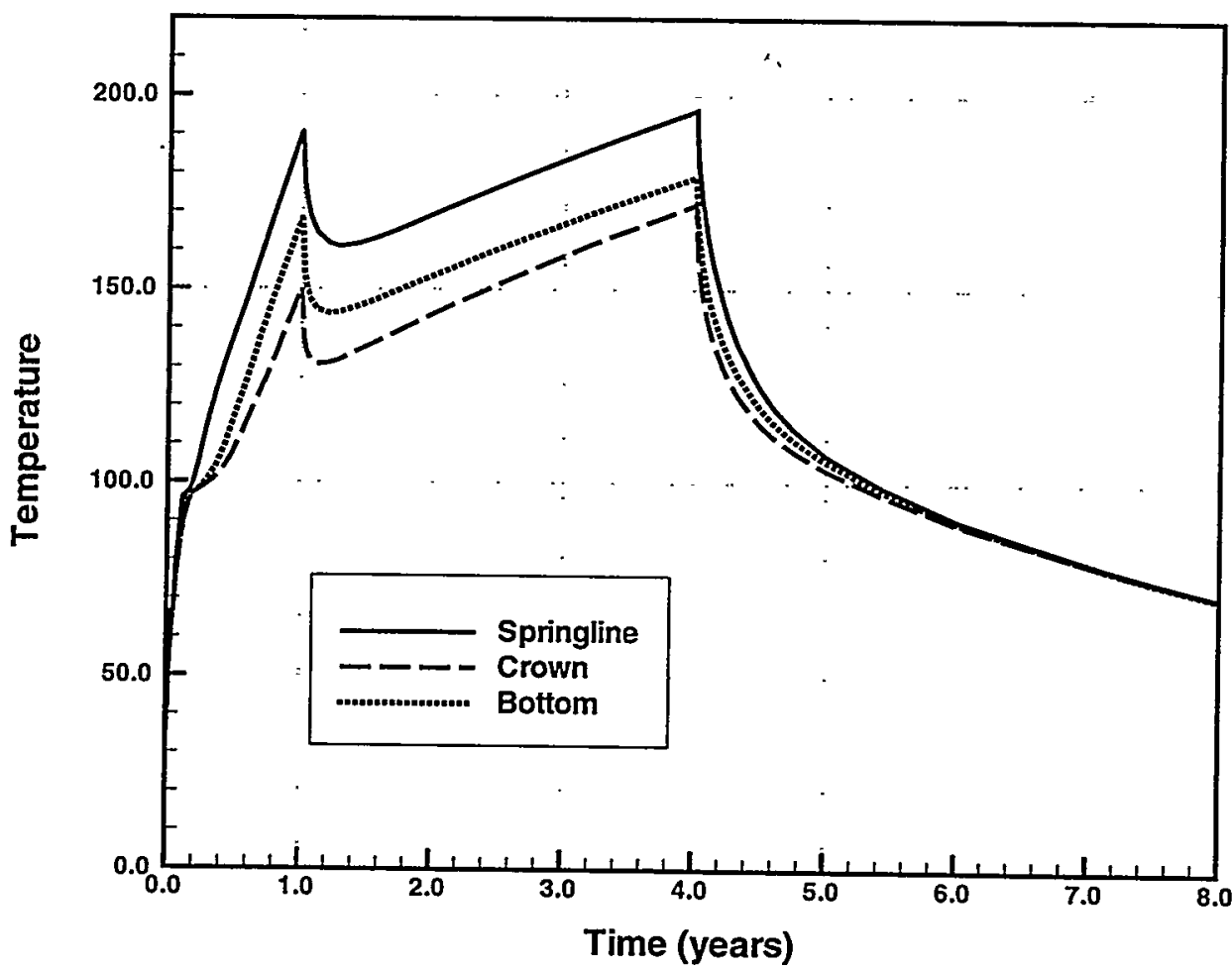

Figure 5.1-2 Temperature evolution at the heater drift wall at $y=30.18 \mathrm{~m}$ from the bulkhead for $3.6 \mathrm{~mm} / \mathrm{yr}$ infiltration case (I year heating at 100\%, 3 years heating at $50 \%$ ). 


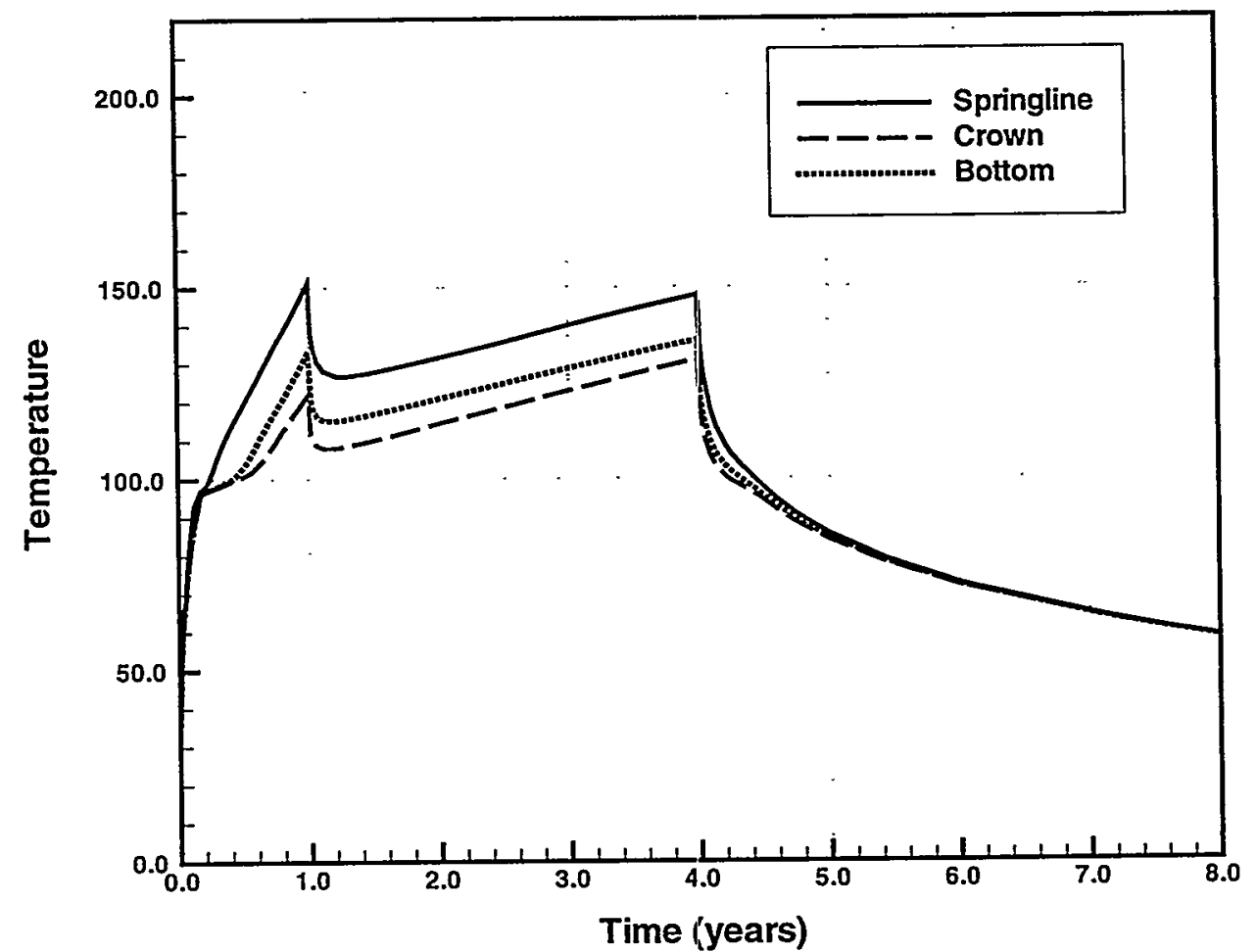

Figure 5.1-3 Temperature evolution at the heater drift wall at $y=44.8 \mathrm{~m}$ from the bulkhead for $3.6 \mathrm{~mm} / \mathrm{yr}$ infiltration case (1 year heating at 100\%, 3 years heating at 50\%). 


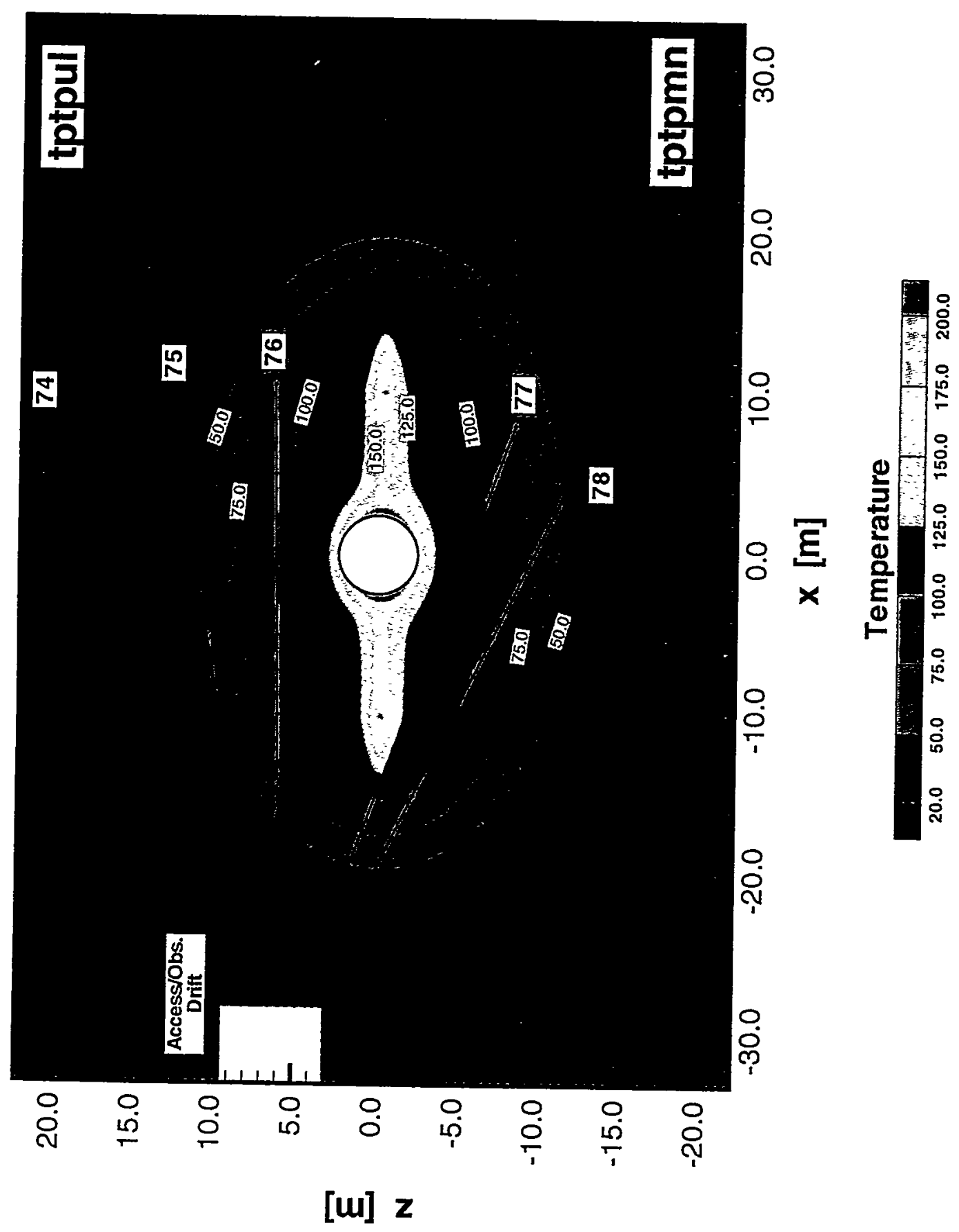

Figure 5.1-4 Temperature response after 1 year of heating in $x z$-cross section at $y=30.18 \mathrm{~m}$ for $3.6 \mathrm{~mm} / \mathrm{yr}$ infiltration case ( 1 year heating at 100\%, 3 years heating at 50\%). Also presented is the location of hydrology holes 74 through 77. 


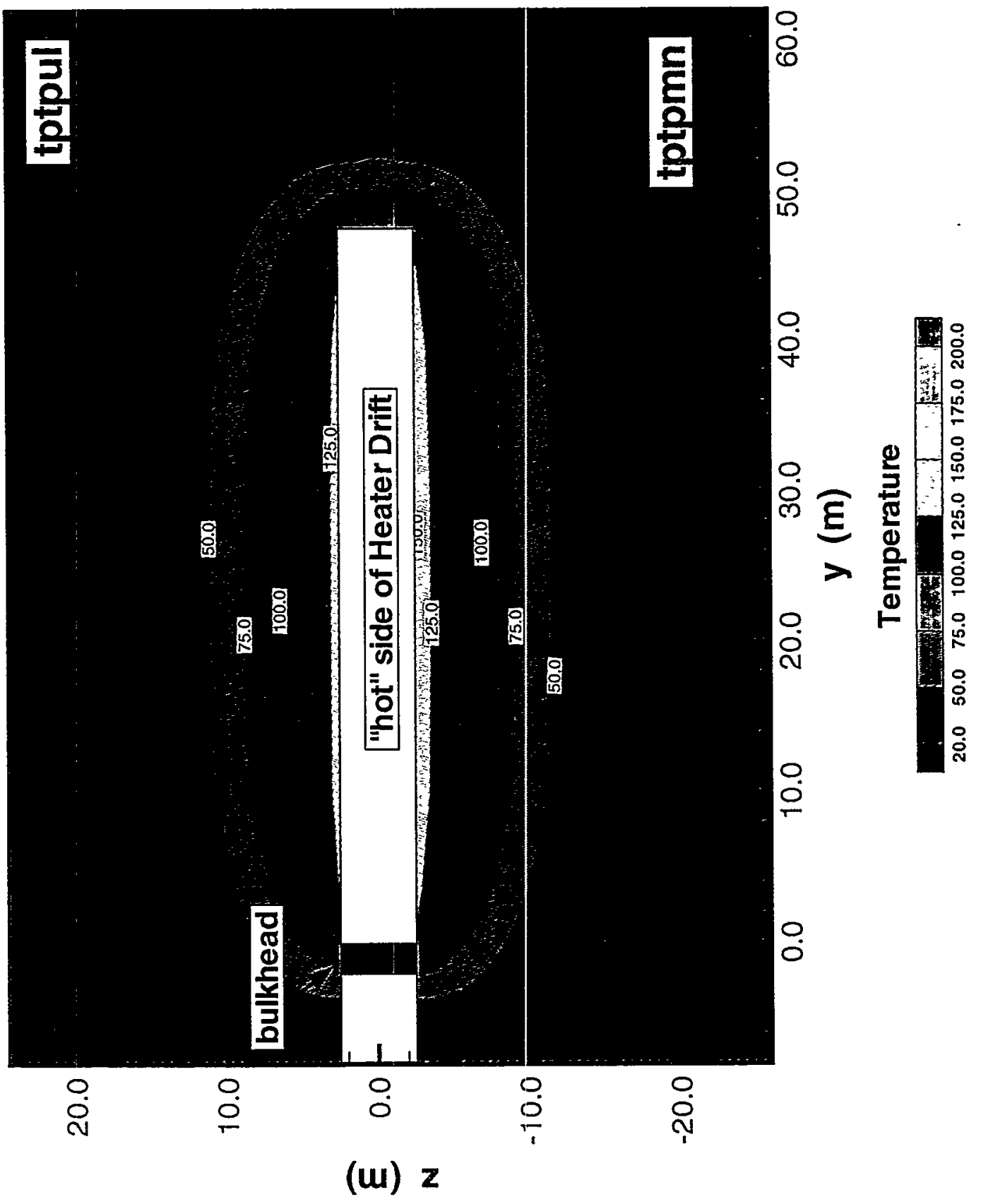

Figure 5.1-5 Temperature response after 1 year of heating in yz-cross section at $x=0.0 \mathrm{~m}$ for $3.6 \mathrm{~mm} / \mathrm{yr}$ infiltration case (1 year heating at 100\%, 3 years heating at 50\%). 


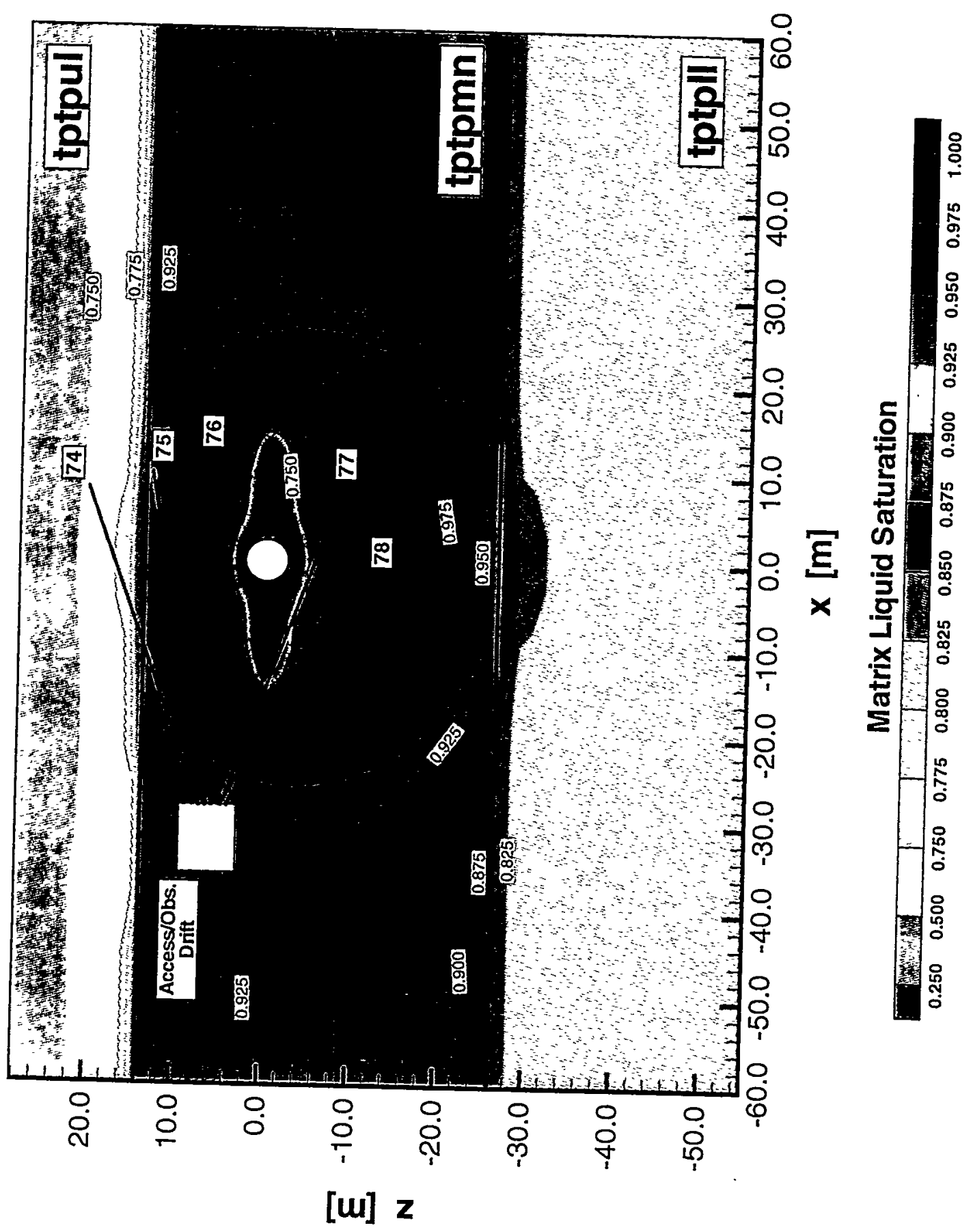

Figure 5.1-6 Matrix liquid saturation after 1 year of heating in $x z$-cross section at $y=30.18 \mathrm{~m}$ for $3.6 \mathrm{~mm} / \mathrm{yr}$ infiltration case (1 year heating at 100\%, 3 years heating at $50 \%$ ). Also presented is the location of hydrology holes 74 through 77. 


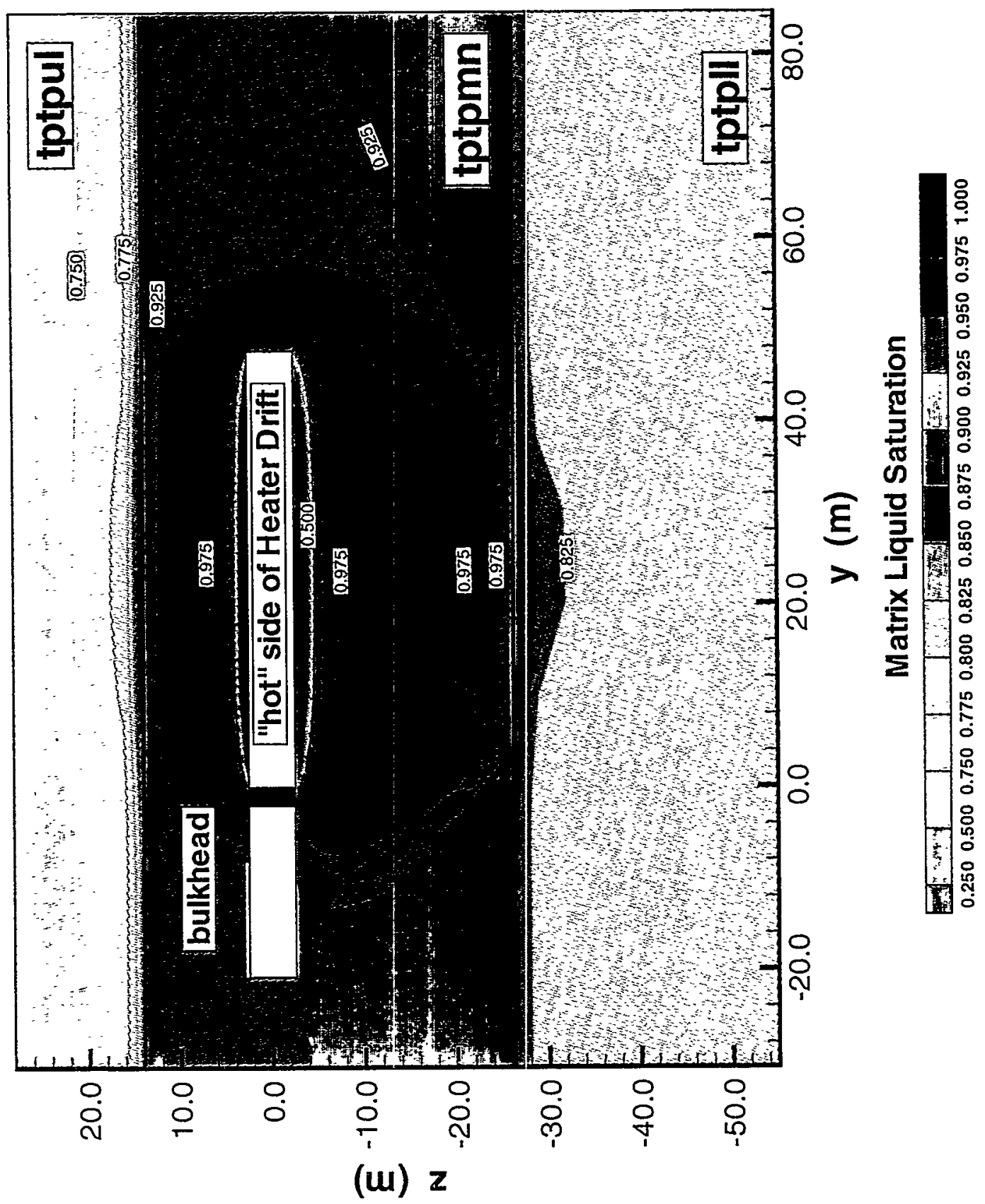

Figure 5.1-7 Matrix liquid saturation after 1 year of heating in yz-cross section at $x=0.0 \mathrm{~m}$ for $3.6 \mathrm{~mm} / \mathrm{yr}$ infiltration case (1 year heating at 100\%, 3 years heating at 50\%). 


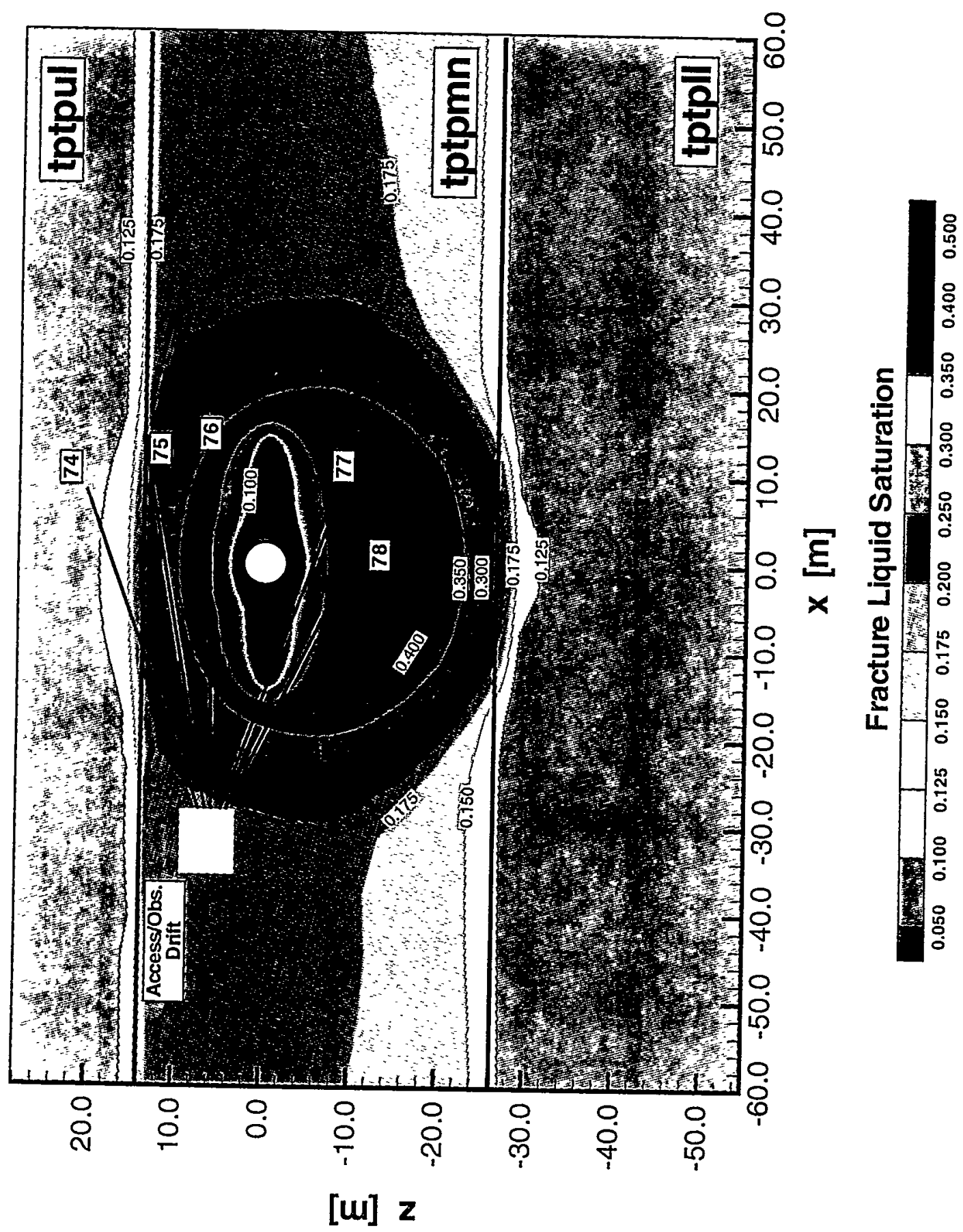

Figure 5.1.8 Fracture liquid saturation after 1 year of heating in $x z$-cross section at $y=30.18 \mathrm{~m}$ for $3.6 \mathrm{~mm} / \mathrm{yr}$ infiltration case (1 year heating at 100\%, 3 years heating at $50 \%$ ). Also presented is the location of hydrology holes 74 through 77. 


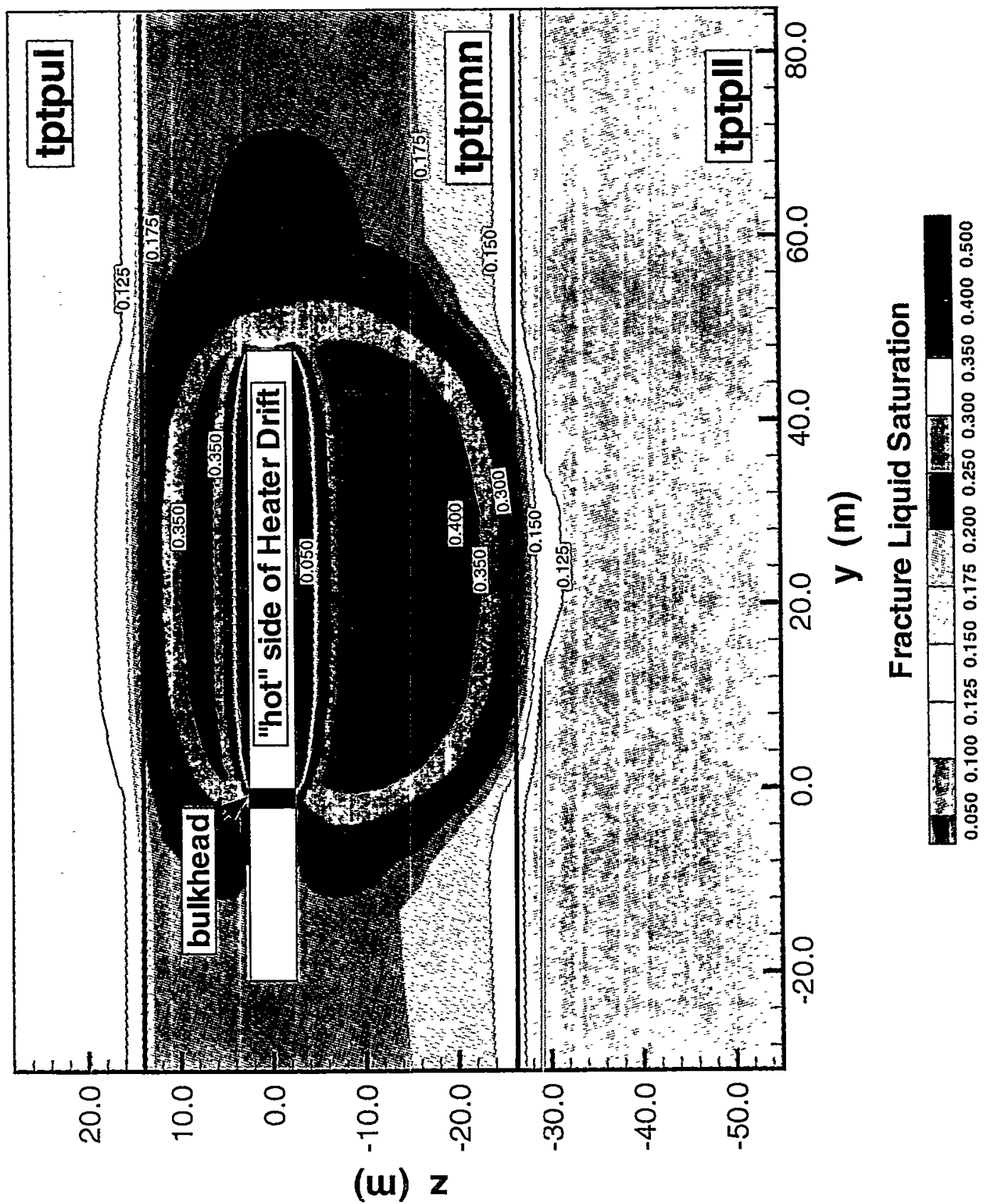

Figure 5.1-9 Fracture liquid saturation after 1 year of heating in $y z$-cross section at $x=0.0 \mathrm{~m}$ for $3.6 \mathrm{~mm} / \mathrm{yr}$ infiltration case (1 year heating at 100\%, 3 years heating at $50 \%$ ). 


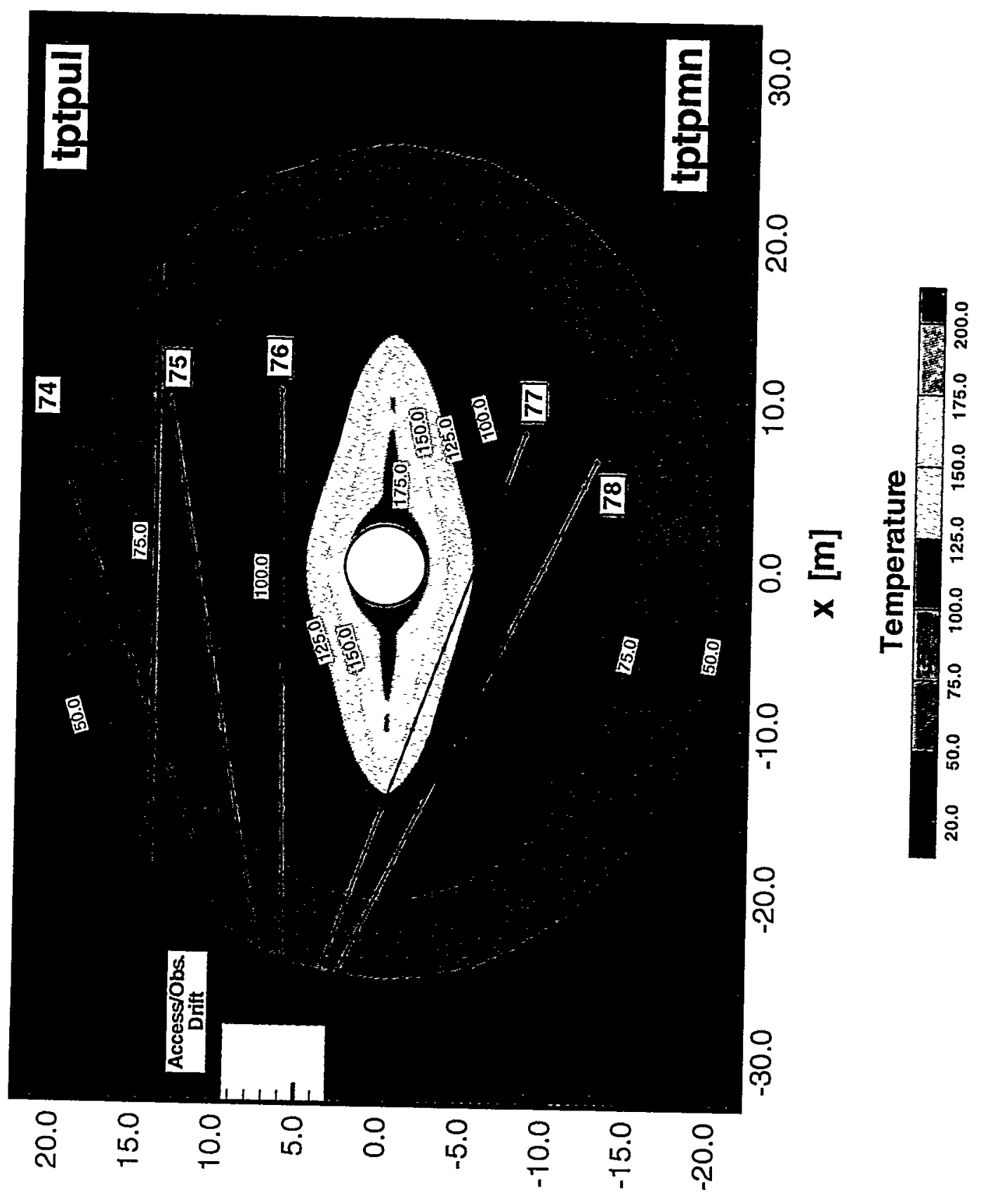

[w] z

Figure 5.1-10 Temperature response after 4 years of heating in $x z$-cross section at $y=30.18 \mathrm{~m}$ for $3.6 \mathrm{~mm} / \mathrm{yr}$ infiltration case (1 year heating at 100\%, 3 years heating at $50 \%$ ). Also presented is the location of hydrology holes 74 through 77. 


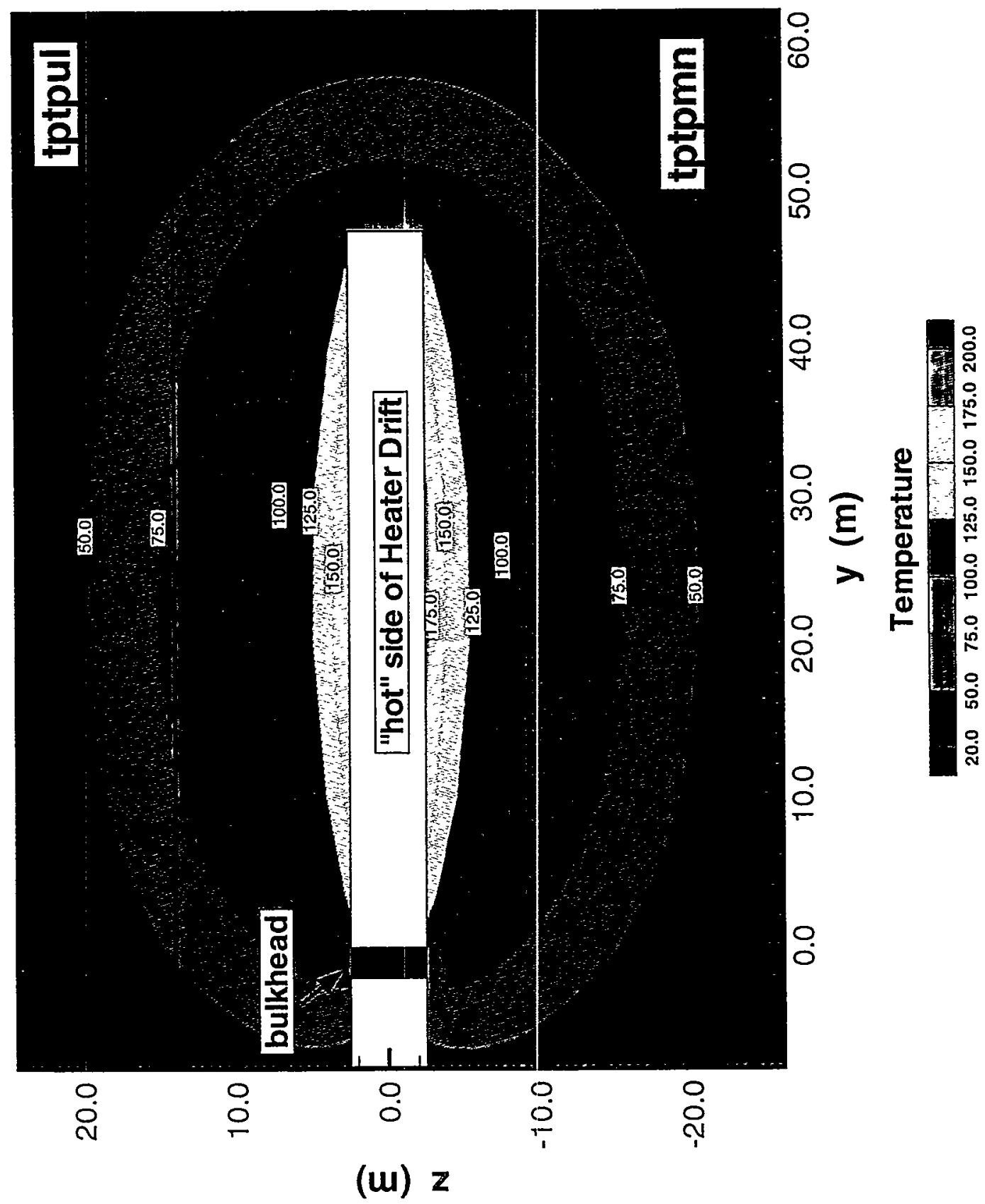

Figure 5.1-11 Temperature response after 4 years of heating in yz-cross section at $x=0.0 \mathrm{~m}$ for $3.6 \mathrm{~mm} / \mathrm{yr}$ infiltration case (1 year heating at 100\%, 3 years heating at 50\%). 


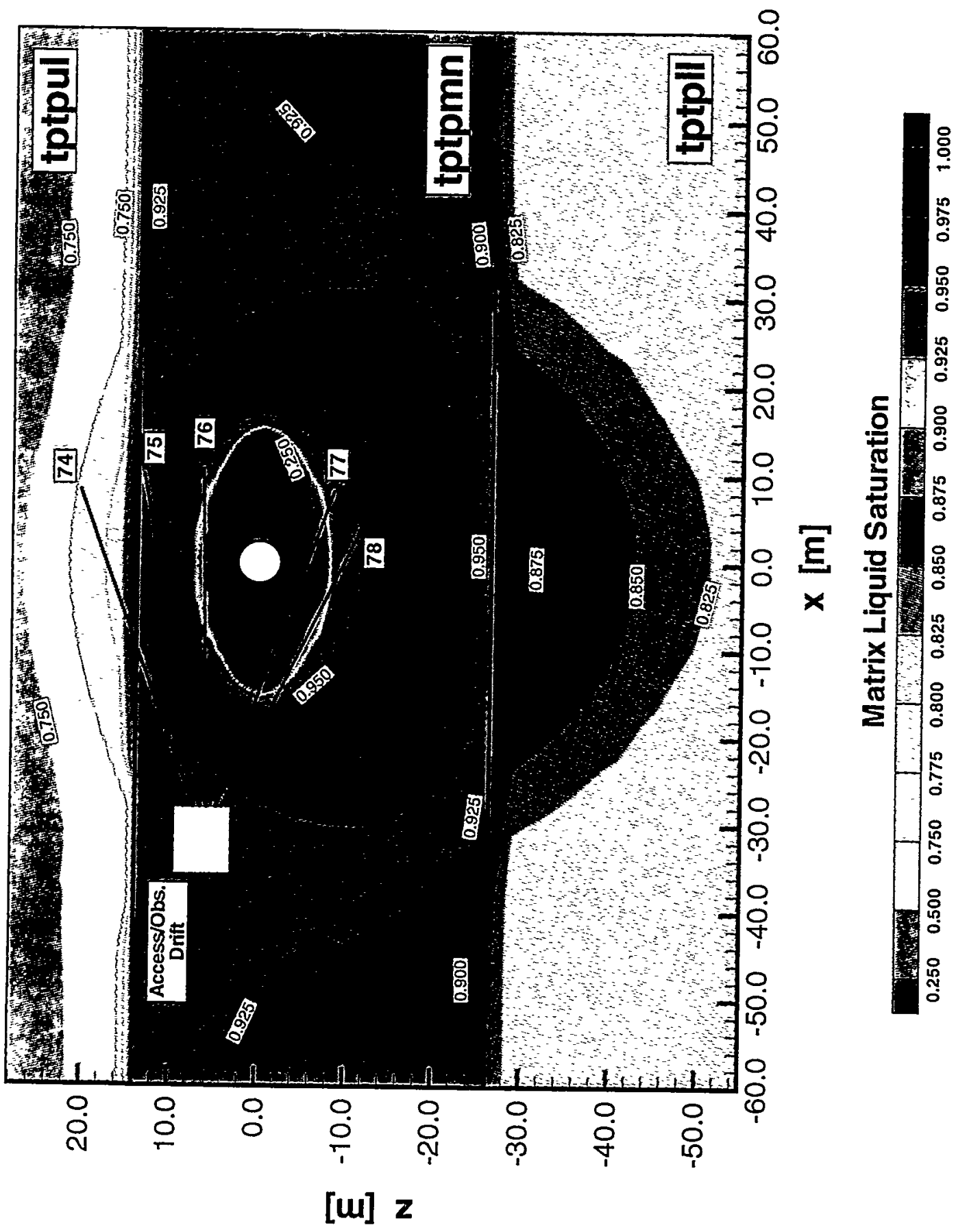

Figure 5.1-12 Matrix liquid saturation after 4 years of heating in $x z$-cross section at $y=30.18 \mathrm{~m}$ for $3.6 \mathrm{~mm} / \mathrm{yr}$ infiltration case (1 year heating at 100\%, 3 years heating at 50\%). Also presented is the location of hydrology holes 74 through 77. 


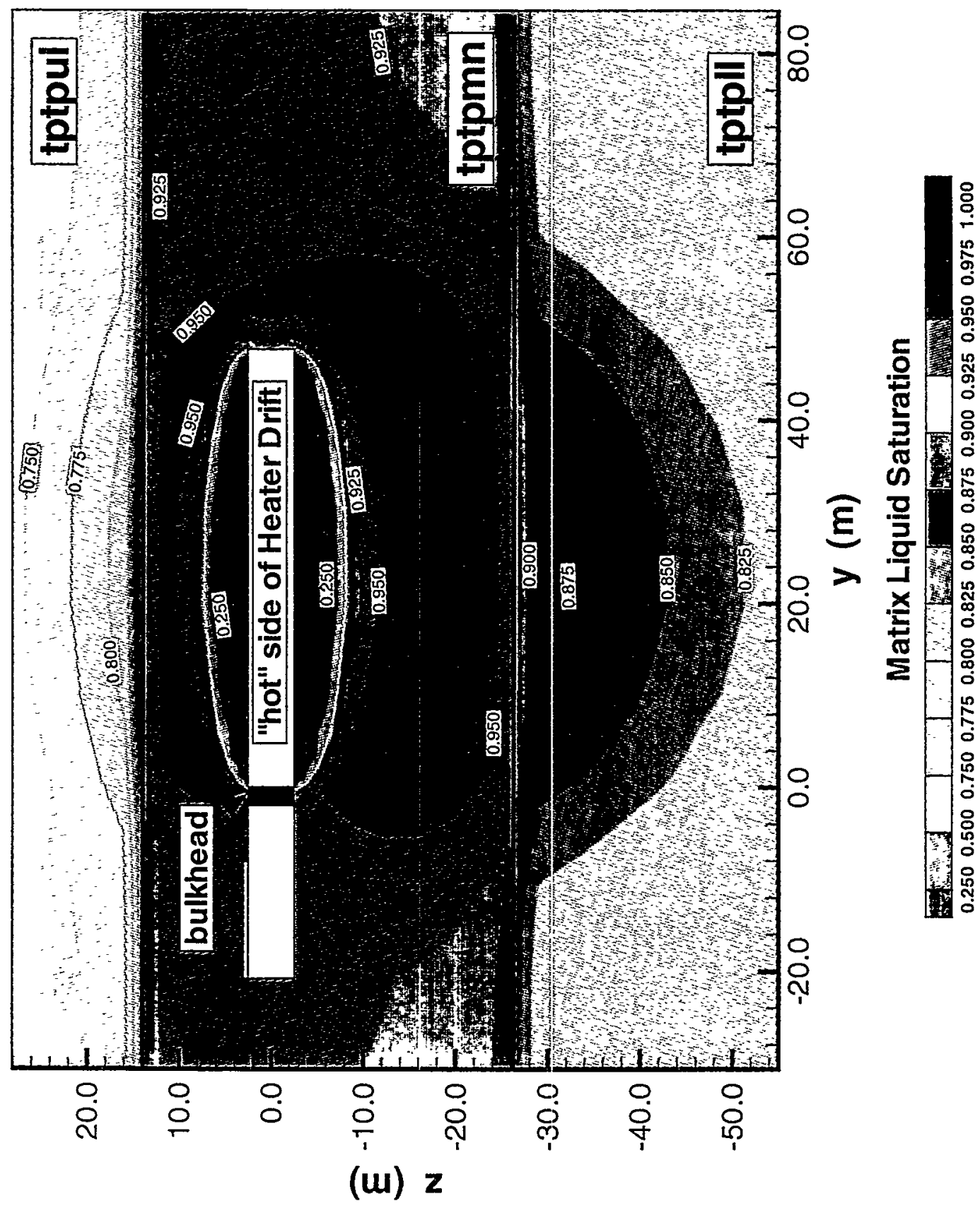

Figure 5.1-13 Matrix liquid saturation after 4 years of heating in yz-cross section at $x=0.0 \mathrm{~m}$ for $3.6 \mathrm{~mm} / \mathrm{yr}$ infiltration case (1 year heating at 100\%, 3 years heating at 50\%). 


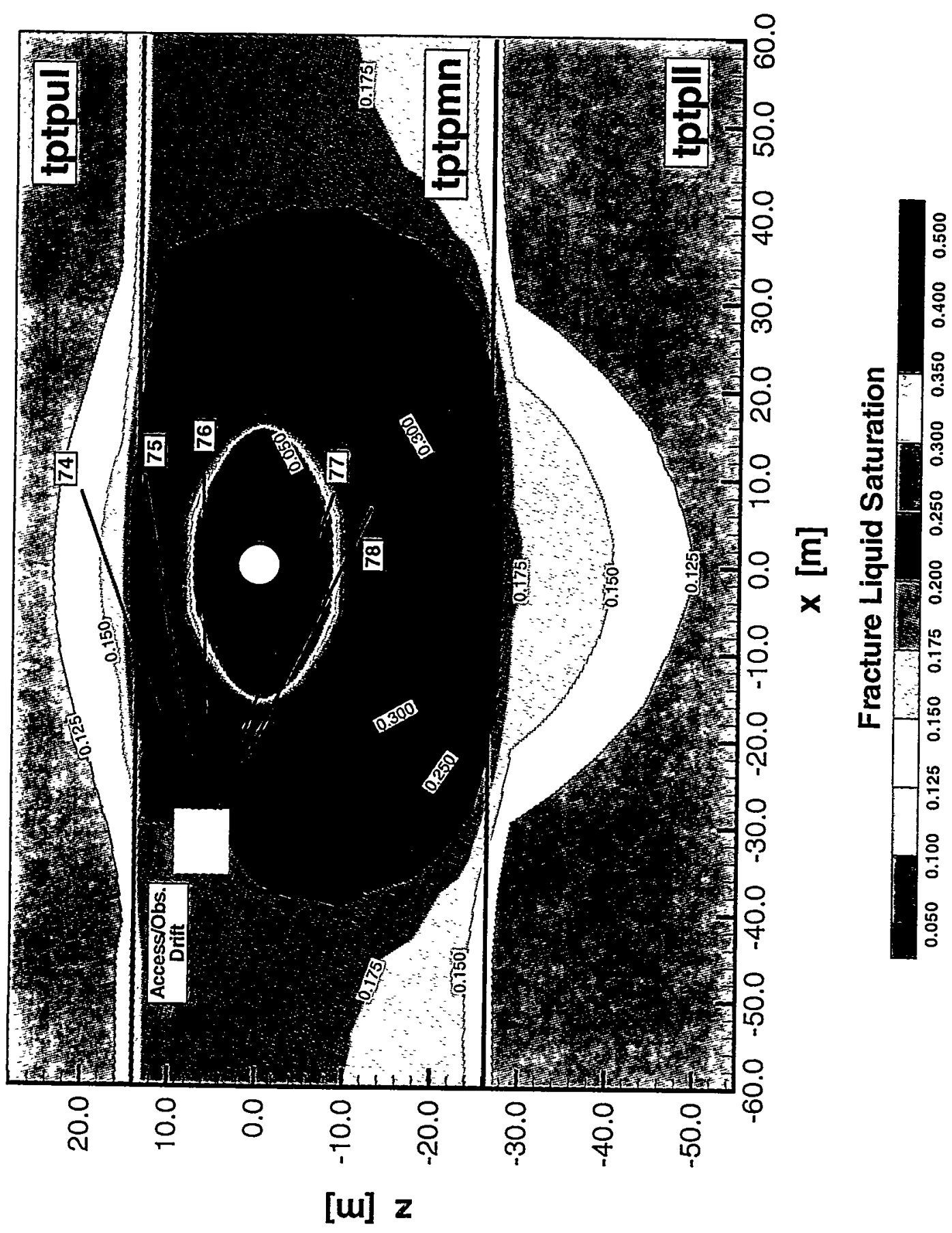

Figure 5.1-14 Fracture liquid saturation after 4 years of heating in $x z$-cross section at. $y=30.18 \mathrm{~m}$ for $3.6 \mathrm{~mm} / \mathrm{yr}$ infiltration case ( 1 year heating at 100\%, 3 years heating at $50 \%$ ). Also presented is the location of hydrology holes 74 through 77 


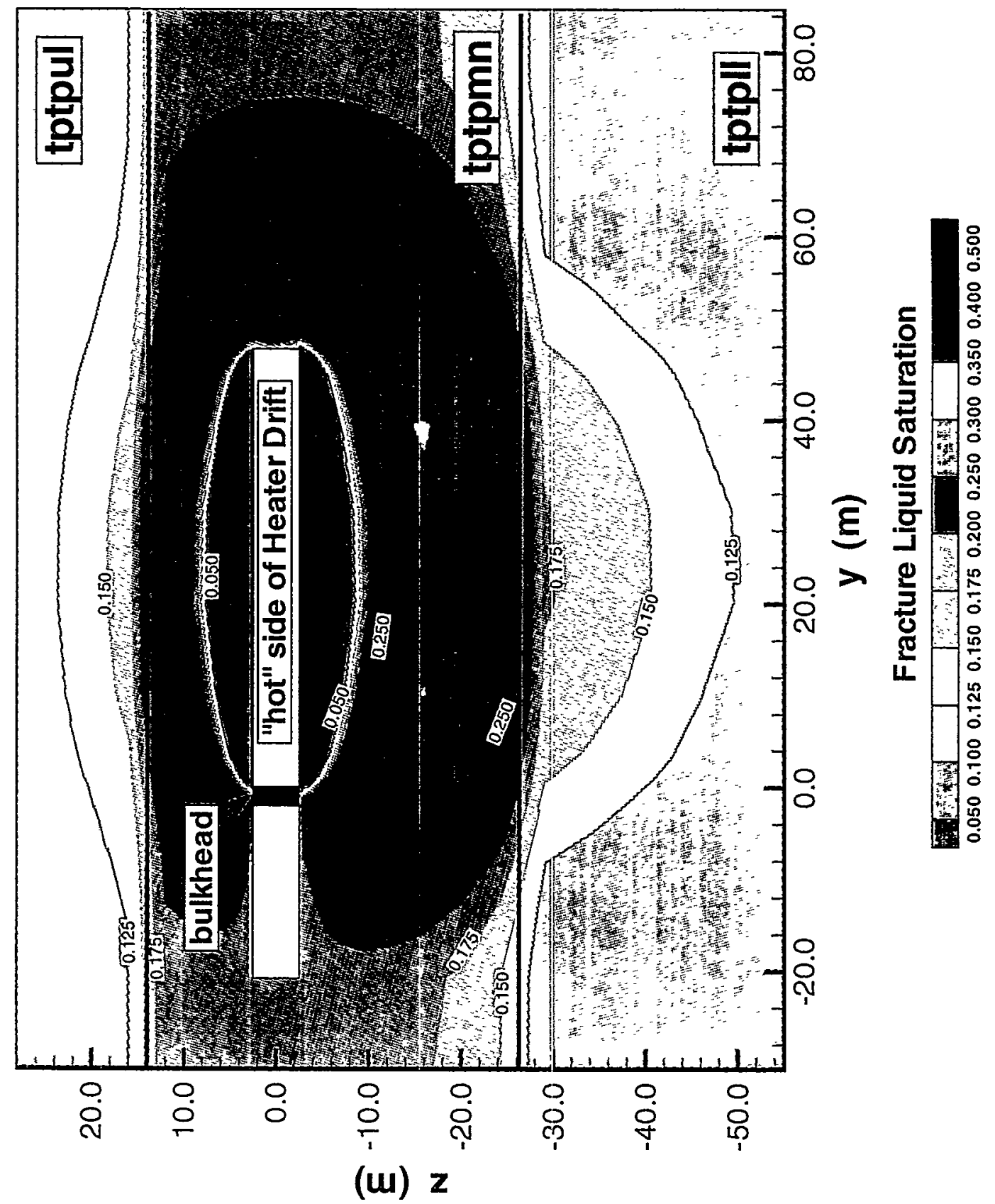

Figure 5.1-15 Fracture liquid saturation after 4 years of heating in yz-cross section at $x=0.0 \mathrm{~m}$ for $3.6 \mathrm{~mm} / \mathrm{yr}$ infiltration case (1 year heating at 100\%, 3 years heating at $50 \%$ ). 


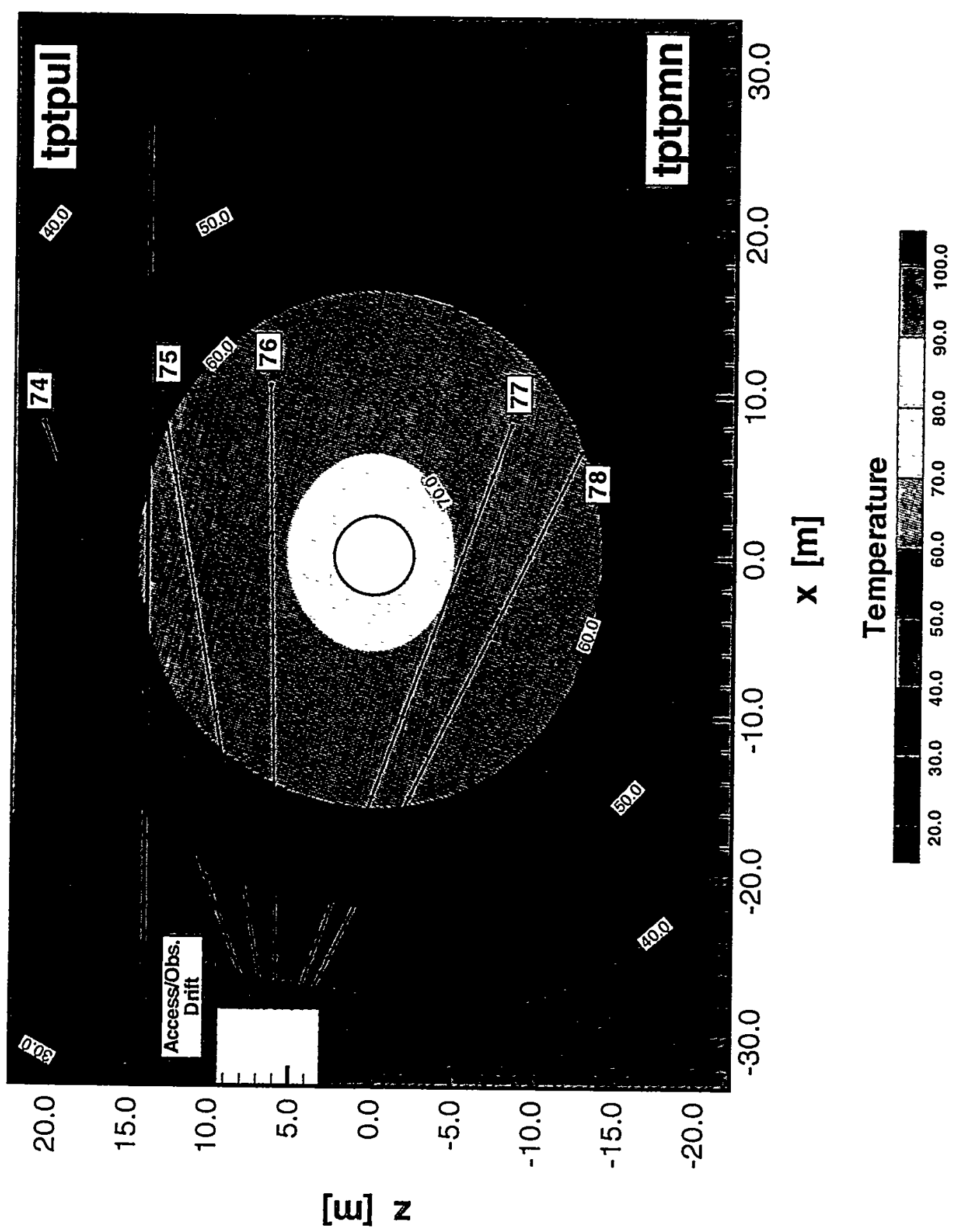

Figure 5.1-16 Temperature response after 4 years of cooling in $x z$-cross section at $y=30.18 \mathrm{~m}$ for $3.6 \mathrm{~mm} / \mathrm{yr}$ infiltration case ( 1 year heating at 100\%, 3 years heating at $50 \%$ ). Also presented is the location of hydrology holes 74 through 77. 


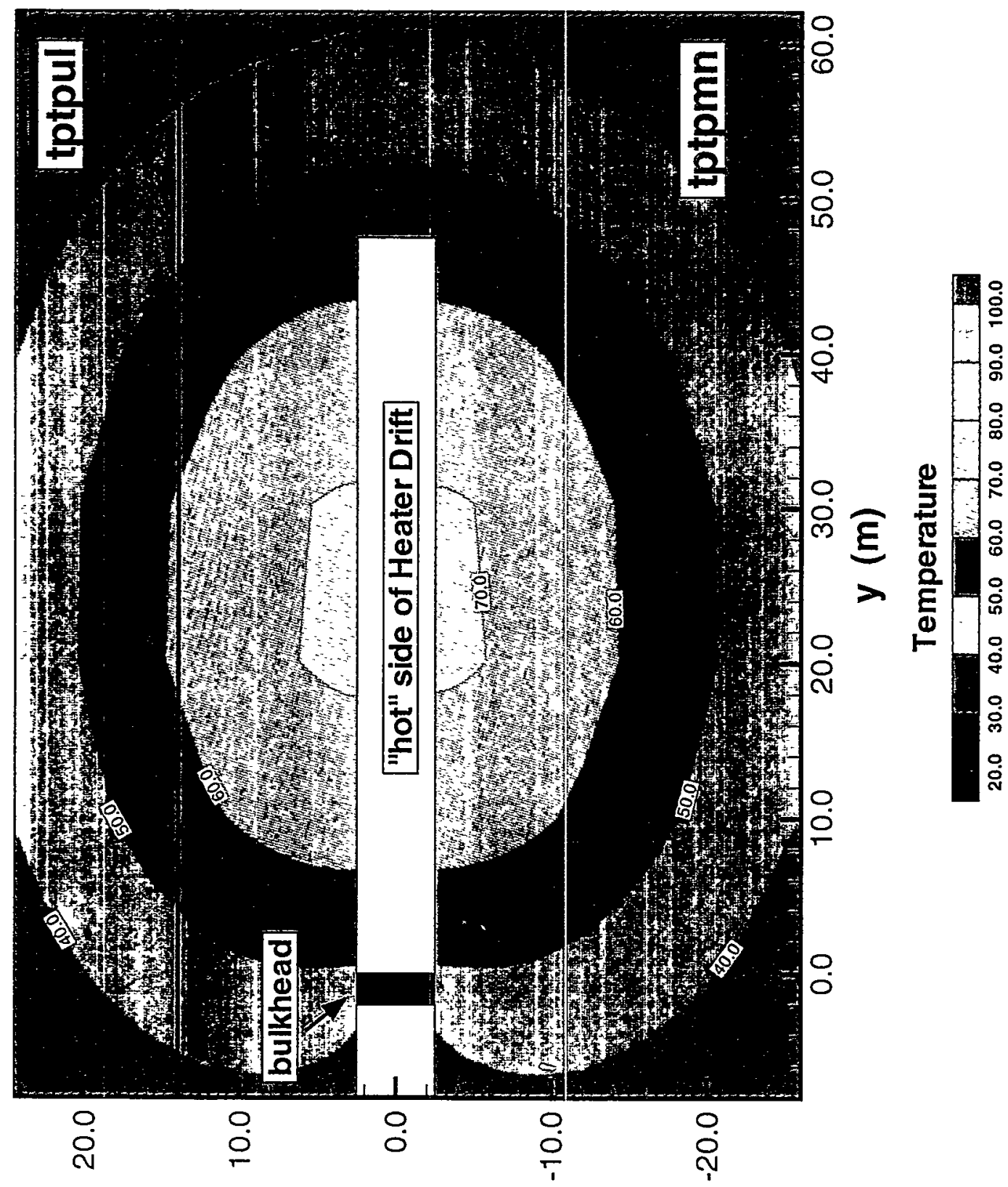

(u) $\mathbf{z}$

Figure 5.1-17 Temperature response after 4 years of cooling in yz-cross section at $x=0.0 \mathrm{~m}$ for $3.6 \mathrm{~mm} / \mathrm{yr}$ infiltration case (1 year heating at 100\%, 3 years heating at 50\%). 


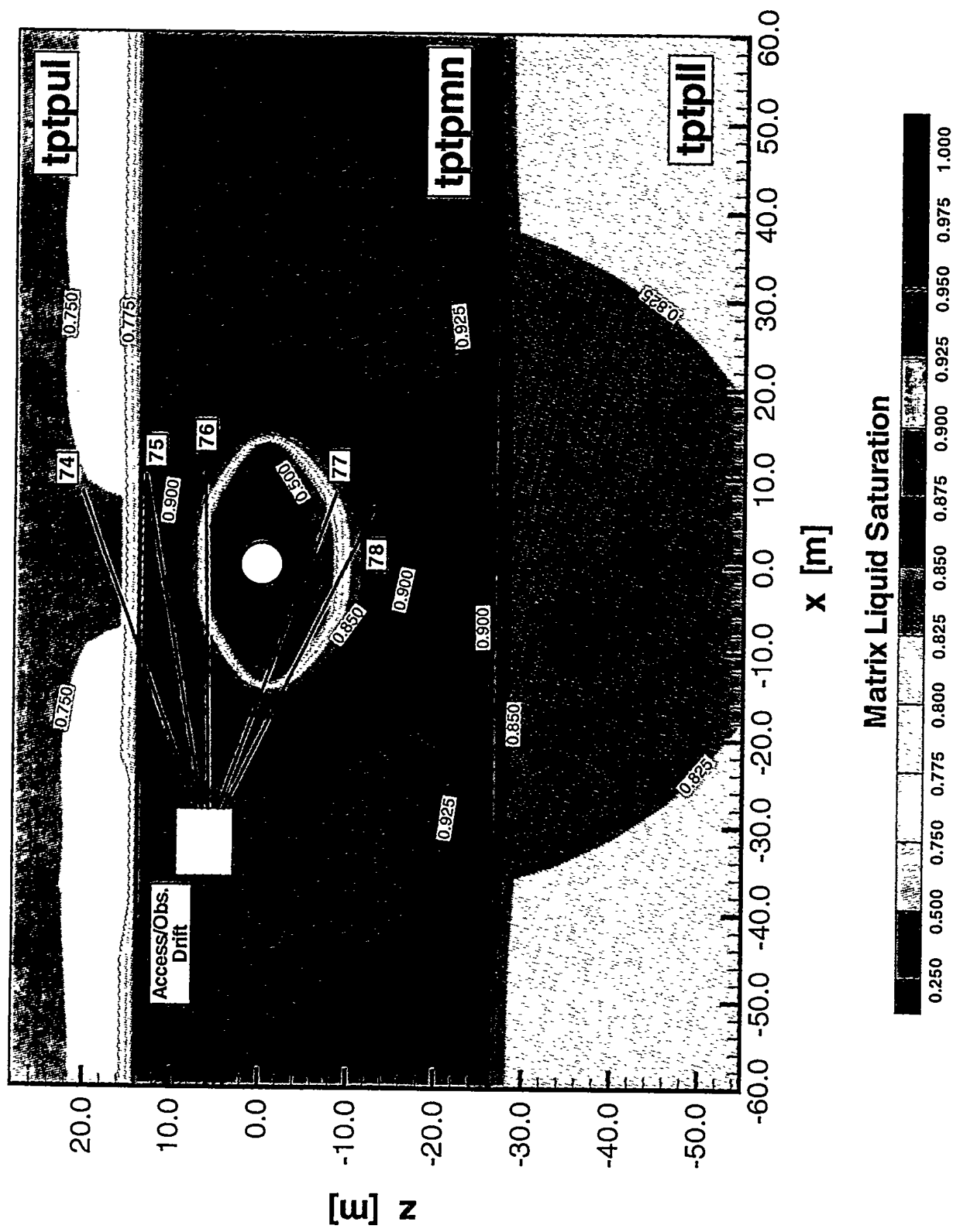

Figure 5.1-18 Matrix liquid saturation after 4 years of cooling in $x z$-cross section at $y=30.18 \mathrm{~m}$ for $3.6 \mathrm{~mm} / \mathrm{yr}$ infiltration case (1 year heating at 100\%, 3 years heating at 50\%). Also presented is the location of hydrology holes 74 through 77. 


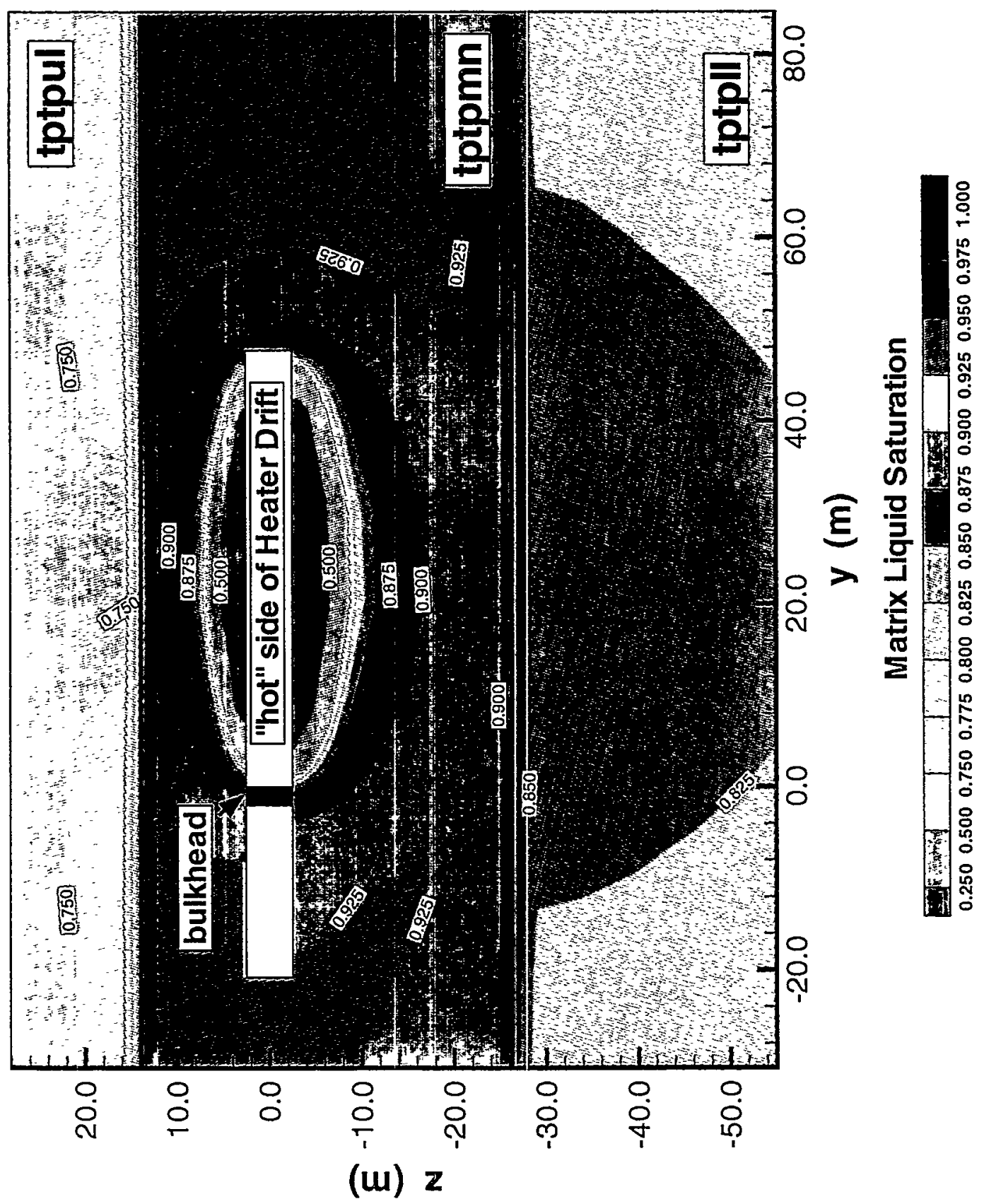

Figure 5.1-19 Matrix liquid saturation after 4 years of cooling in yz-cross section at $x=0.0 \mathrm{~m}$ for $3.6 \mathrm{~mm} / \mathrm{yr}$ infiltration case (1 year heating at 100\%, 3 years heating at $50 \%$ ). 


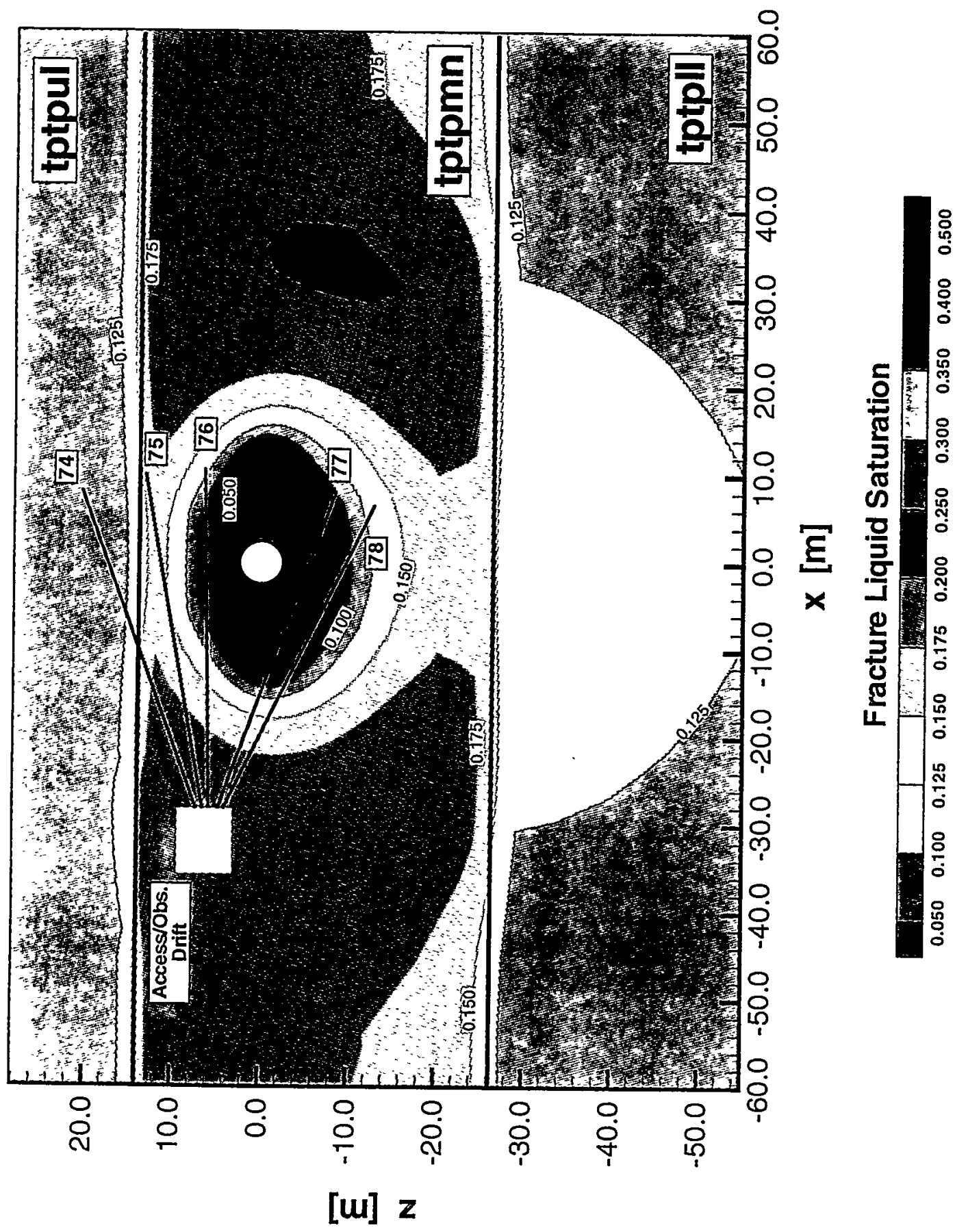

Figure 5.1-20 Fracture liquid saturation after 4 years of cooling in $x z$-cross section at $y=30.18 \mathrm{~m}$ for $3.6 \mathrm{~mm} / \mathrm{yr}$ infiltration case (1 year heating at 100\%, 3 years heating at $50 \%$ ). Also presented is the location of hydrology holes 74 through 77. 


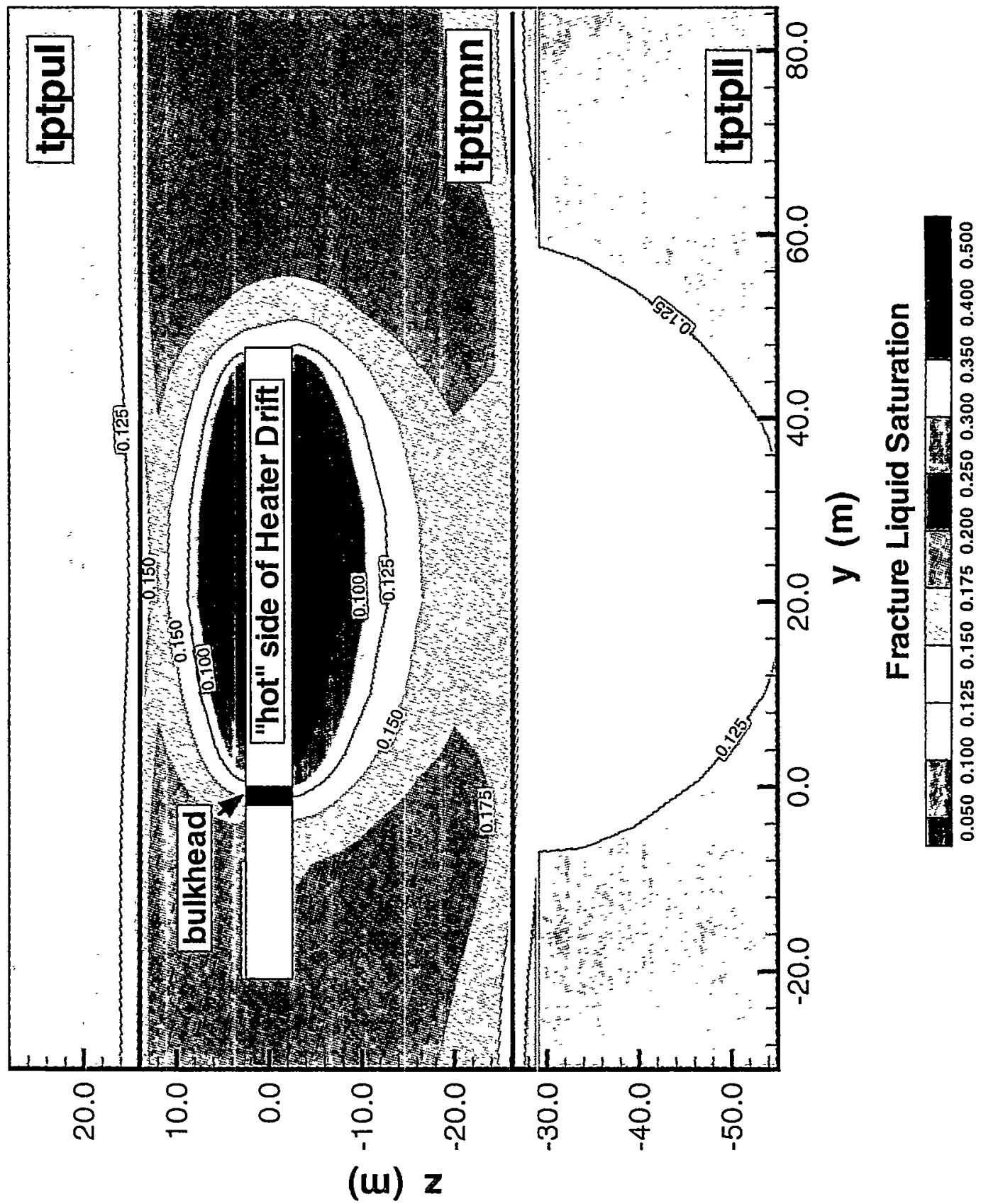

Figure 5.1-21 Fracture liquid saturation after 4 years of cooling in yz-cross section at $x=0.0 \mathrm{~m}$ for $3.6 \mathrm{~mm} / \mathrm{yr}$ infiltration case (1 year heating at 100\%, 3 years heating at $50 \%$ ). 


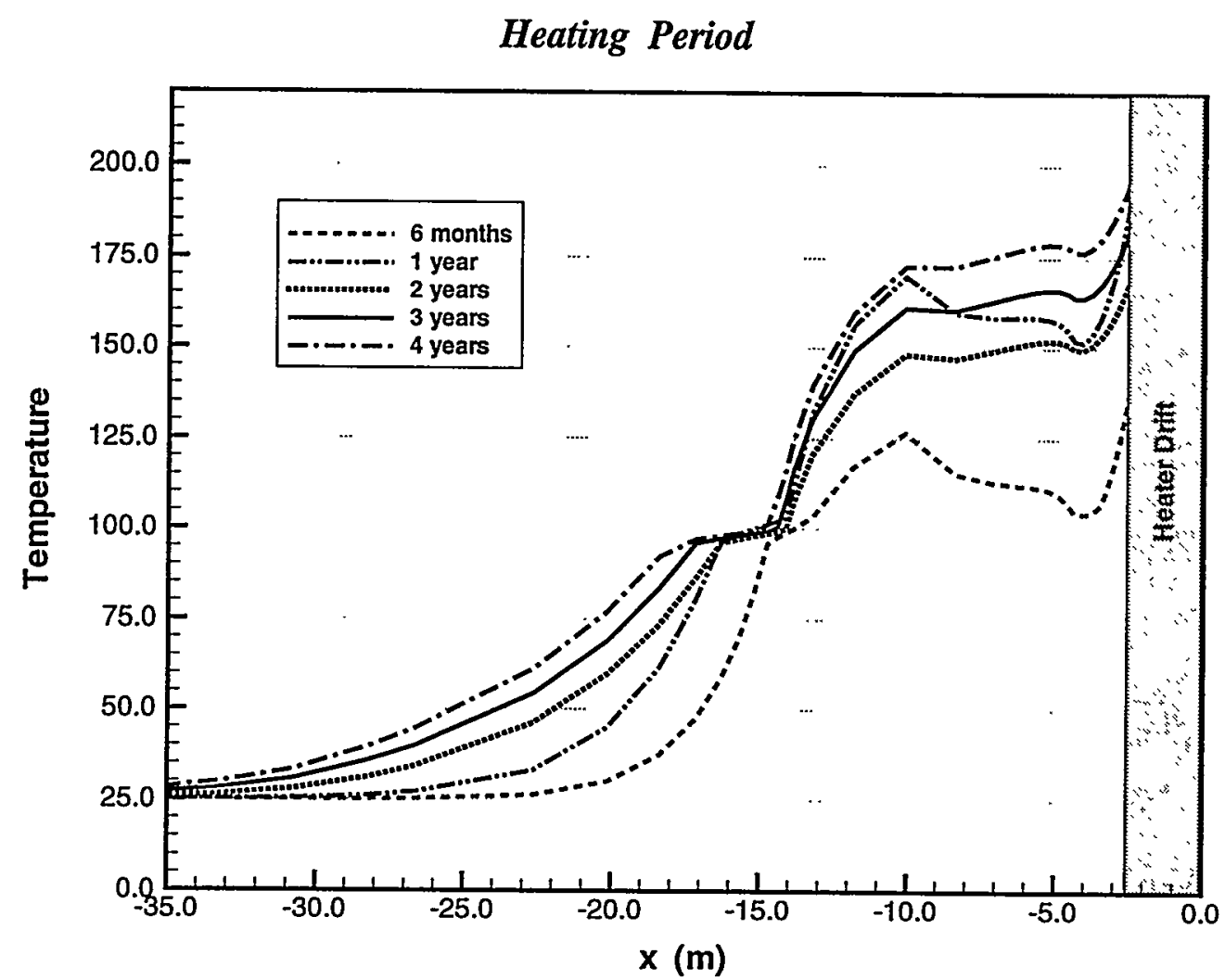

\section{Cooling Period}

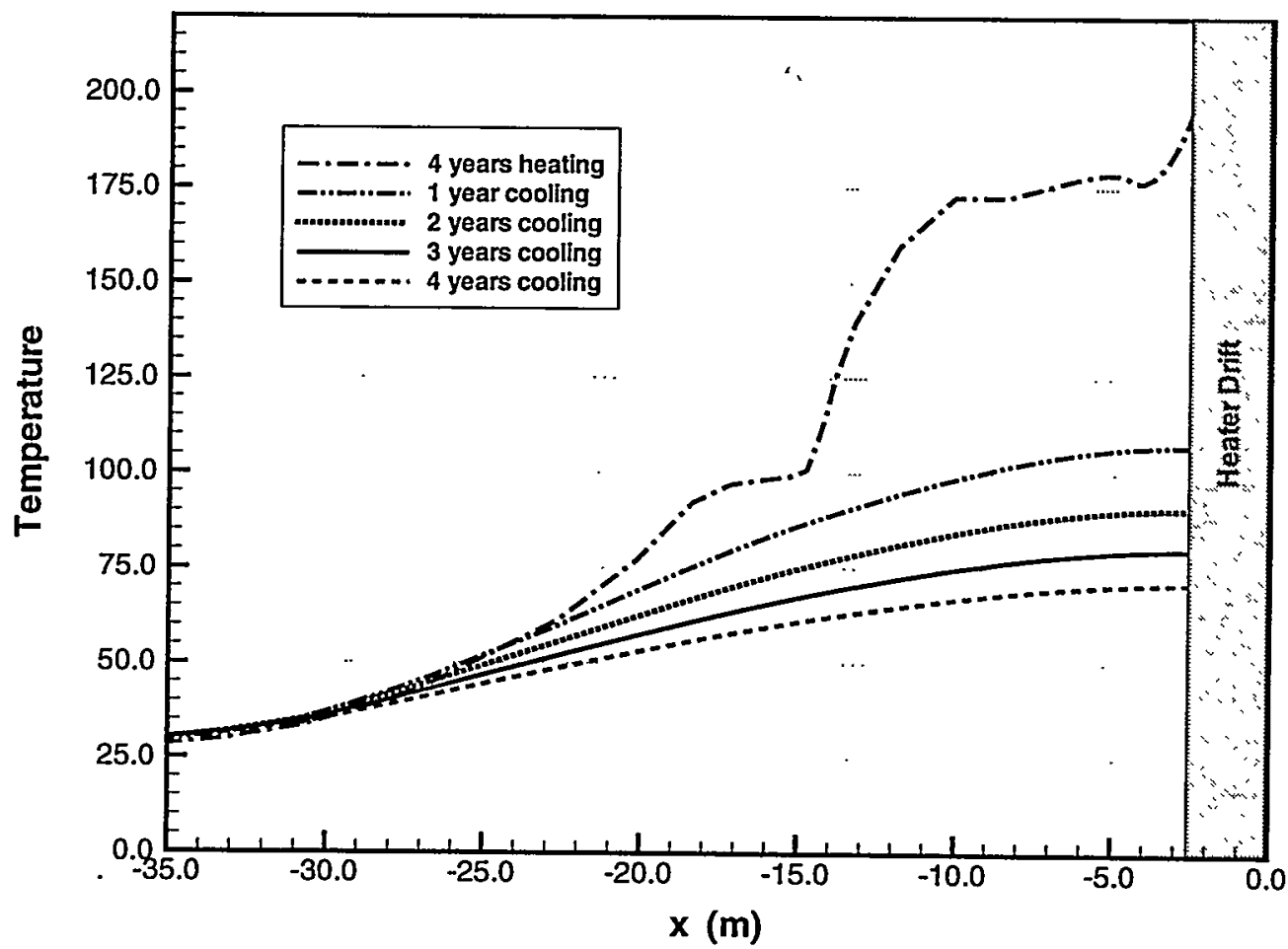

Figure 5.1-22 Temperature profiles along $x$-axis at $y=30.18 \mathrm{~m}$ and $z=0.0 \mathrm{~m}$ for $3.6 \mathrm{~mm} / \mathrm{yr}$ infiltration case (1 year heating at 100\%, 3 years heating at $50 \%$ ). 
Heating Period

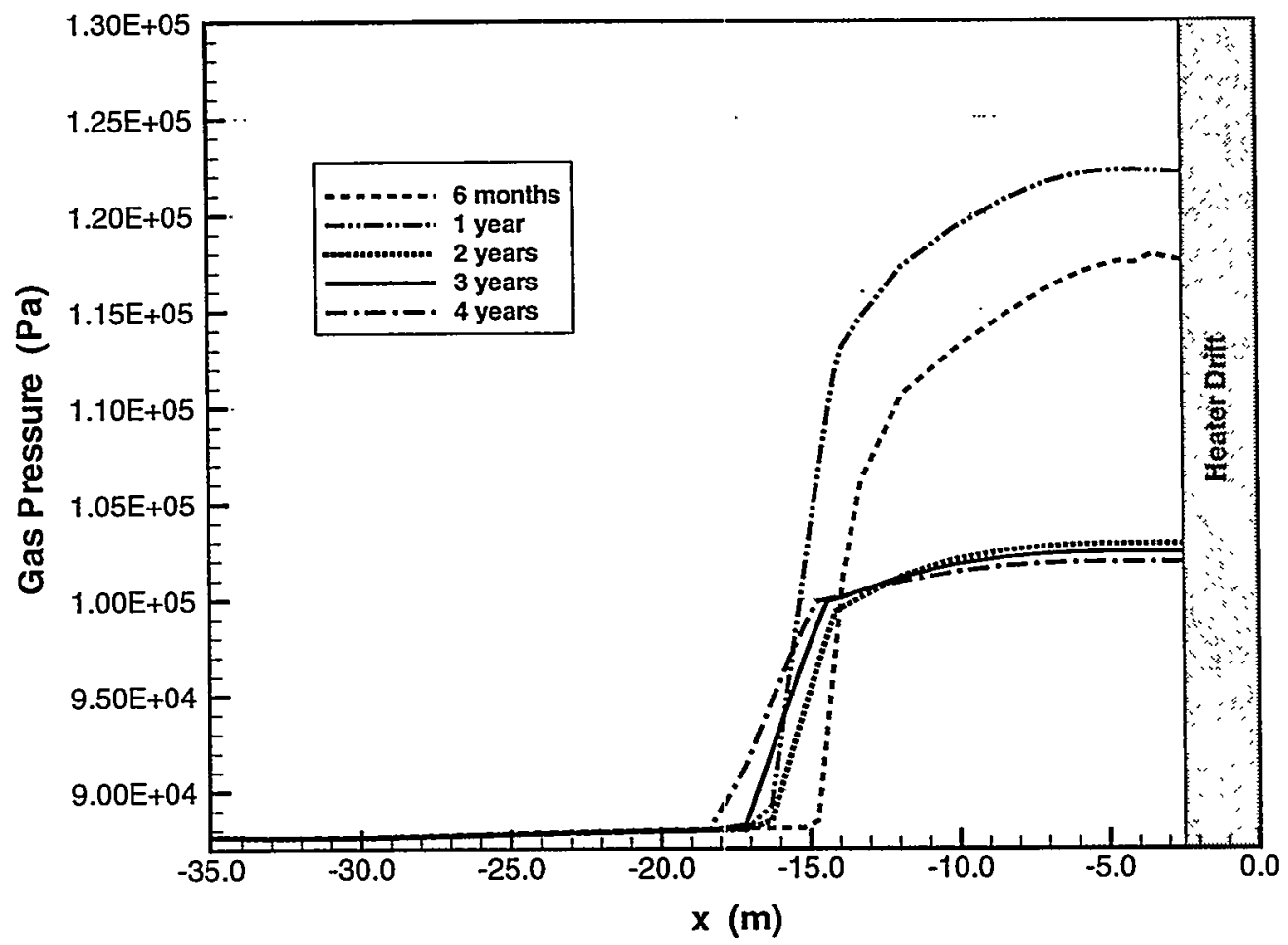

Cooling Period

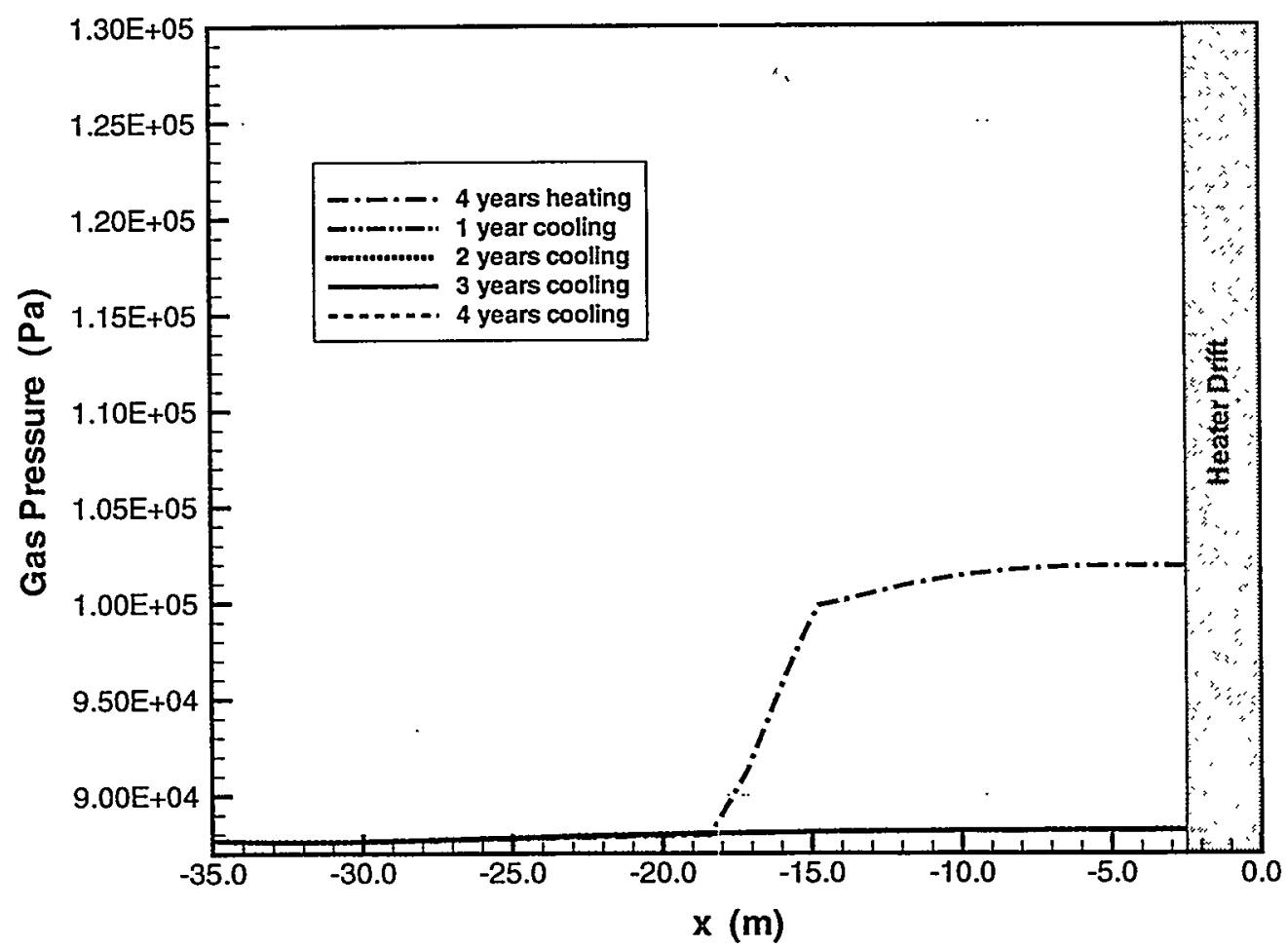

Figure 5.1-23 Gas pressure profiles along $x$-axis at $y=30.18 \mathrm{~m}$ and $z=0.0 \mathrm{~m}$ for $3.6 \mathrm{~mm} / \mathrm{yr}$ infiltration case ( 1 year heating at 100\%, 3 years heating at $50 \%$ ). 

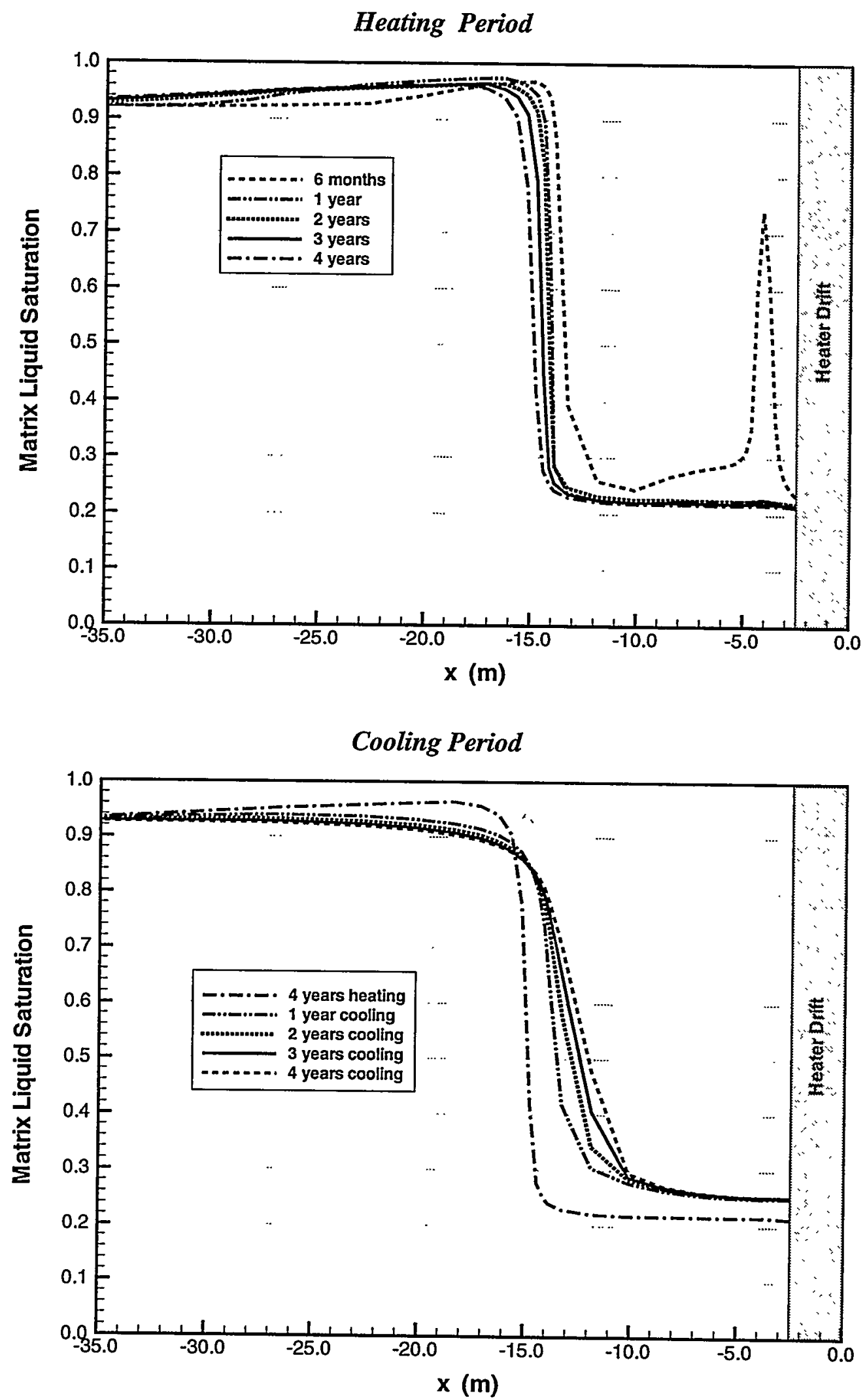

Figure 5.1-24 Matrix liquid saturation profiles along $x$-axis at $y=30.18 \mathrm{~m}$ and $z=0.0 \mathrm{~m}$ for $3.6 \mathrm{~mm} / \mathrm{yr}$ infiltration case (1 year heating at 100\%, 3 years heating at $50 \%$ ). 


\section{Heating Period}

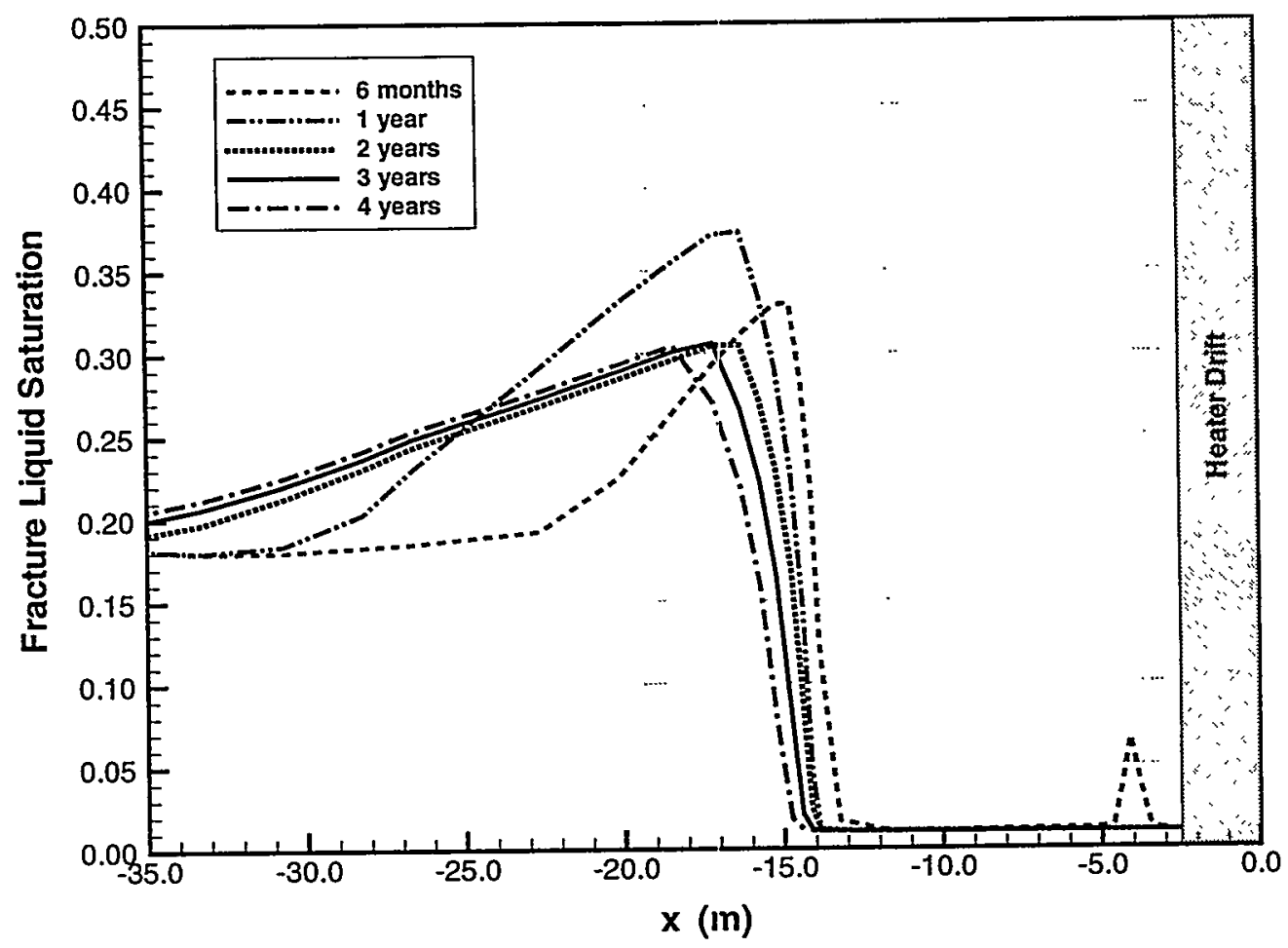

\section{Cooling Period}

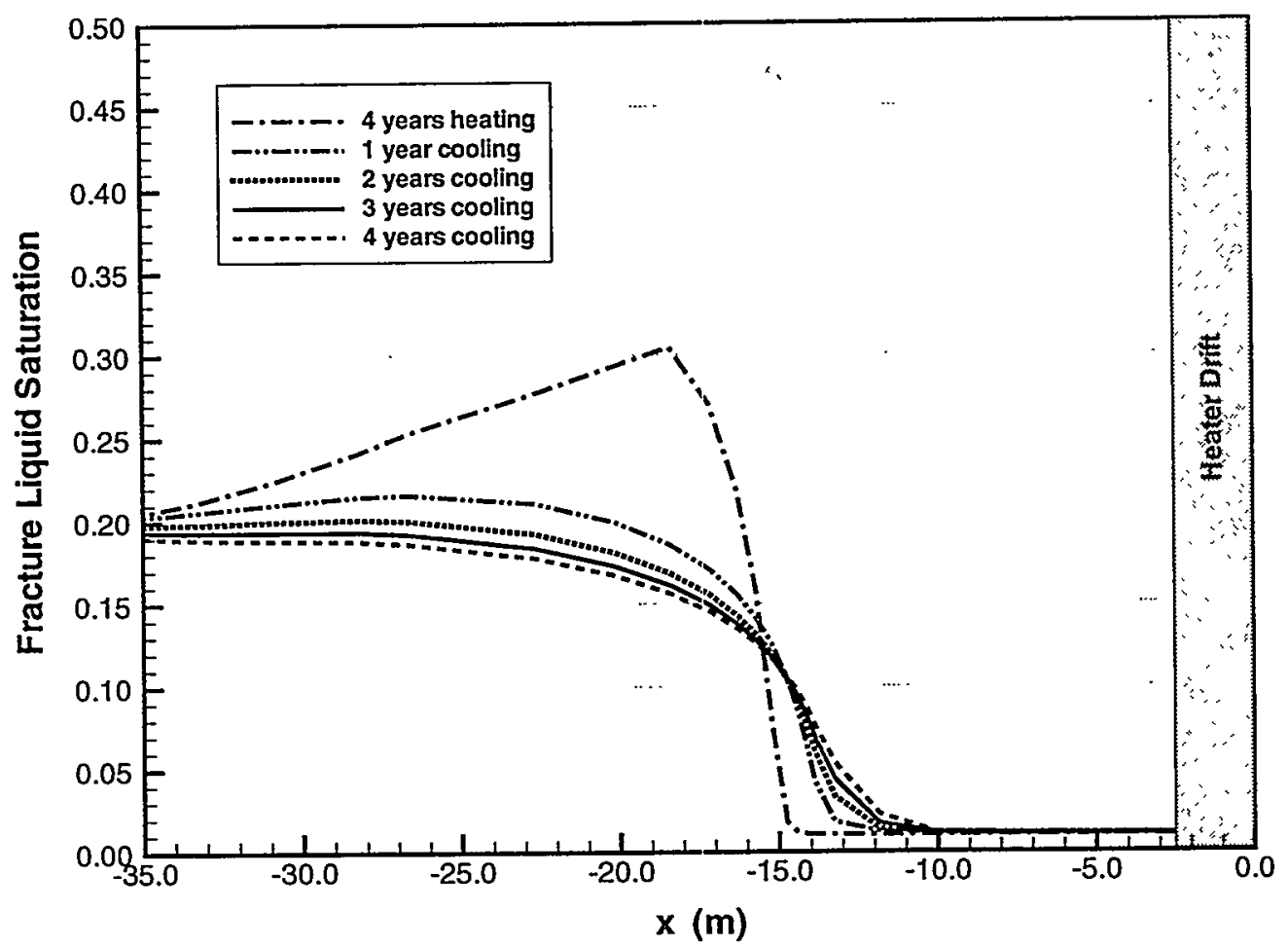

Figure 5.1-25 Fracture liquid saturation profiles along $x$-axis at $y=30.18 \mathrm{~m}$ and $z=0.0 \mathrm{~m}$ for $3.6 \mathrm{~mm} / \mathrm{yr}$ infiltration case (1 year heating at 100\%, 3 years heating at $50 \%$ ). 


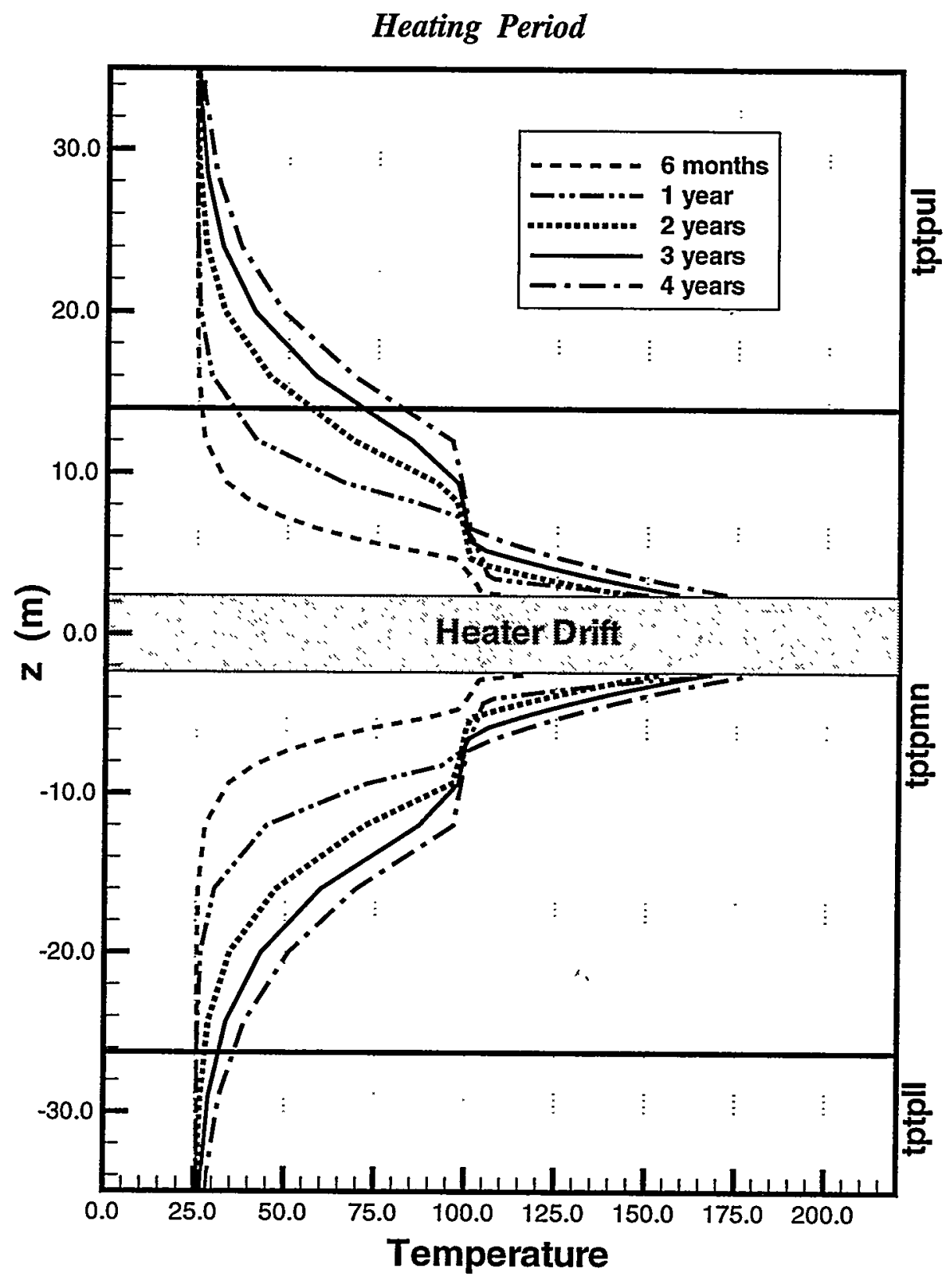

Figure 5.1-26 Temperature profiles along $z$-axis at $x=0.0 \mathrm{~m}$ and $y=30.18 \mathrm{~m}$ for $3.6 \mathrm{~mm} / \mathrm{yr}$ infiltration case during heating ( 1 year heating at 100\%, 3 years heating at 50\%). 
Pretest Analysis of the Thermal-Hydrological Conditions of the ESF Drift Scale Test

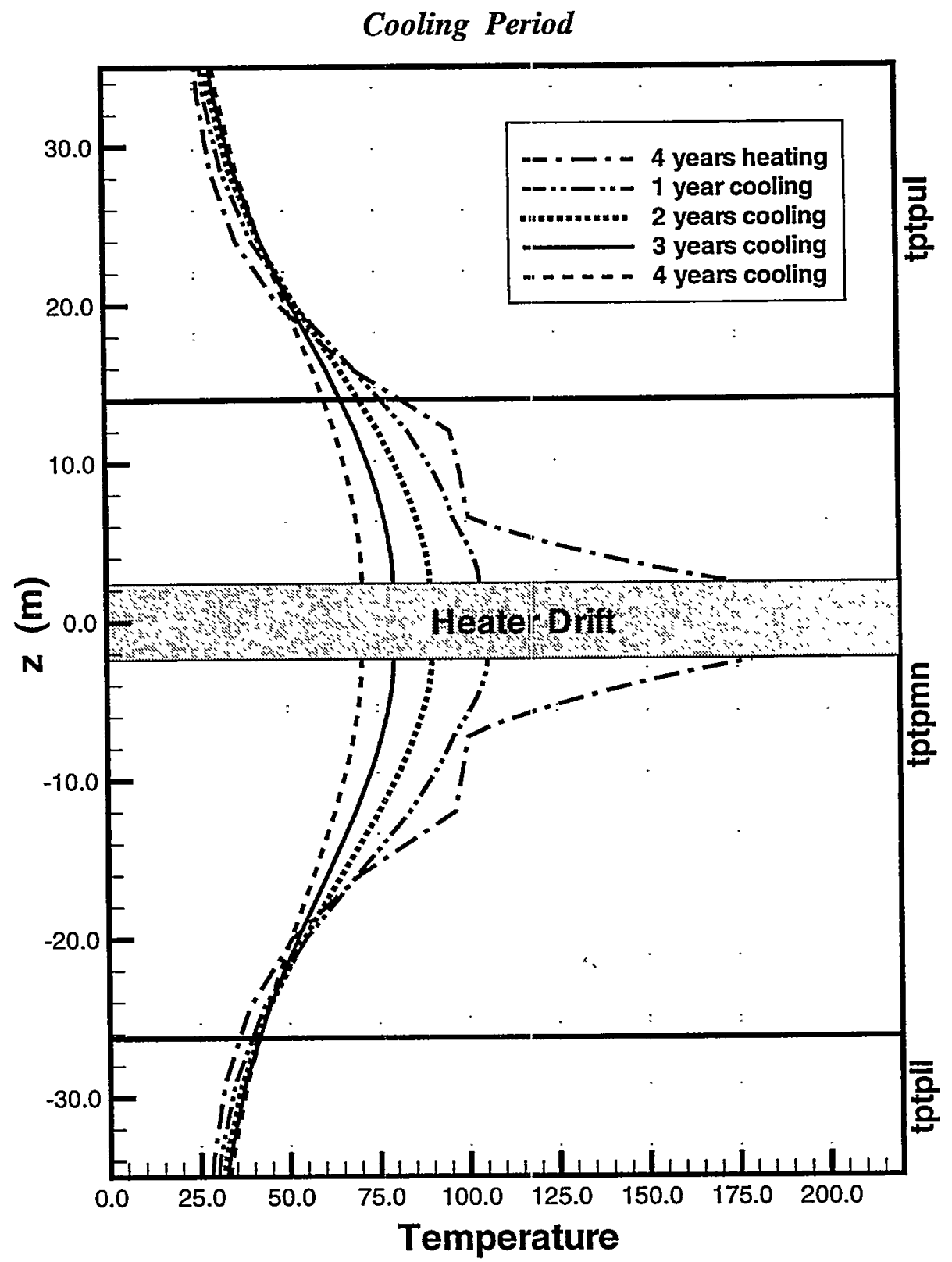

Figure 5.1-27 Temperature profiles along z-axis at $x=0.0 \mathrm{~m}$ and $y=30.18 \mathrm{~m}$ for $3.6 \mathrm{~mm} / \mathrm{yr}$ infiltration case during cooling ( 1 year heating at $100 \%, 3$ years heating at $50 \%$ ). 


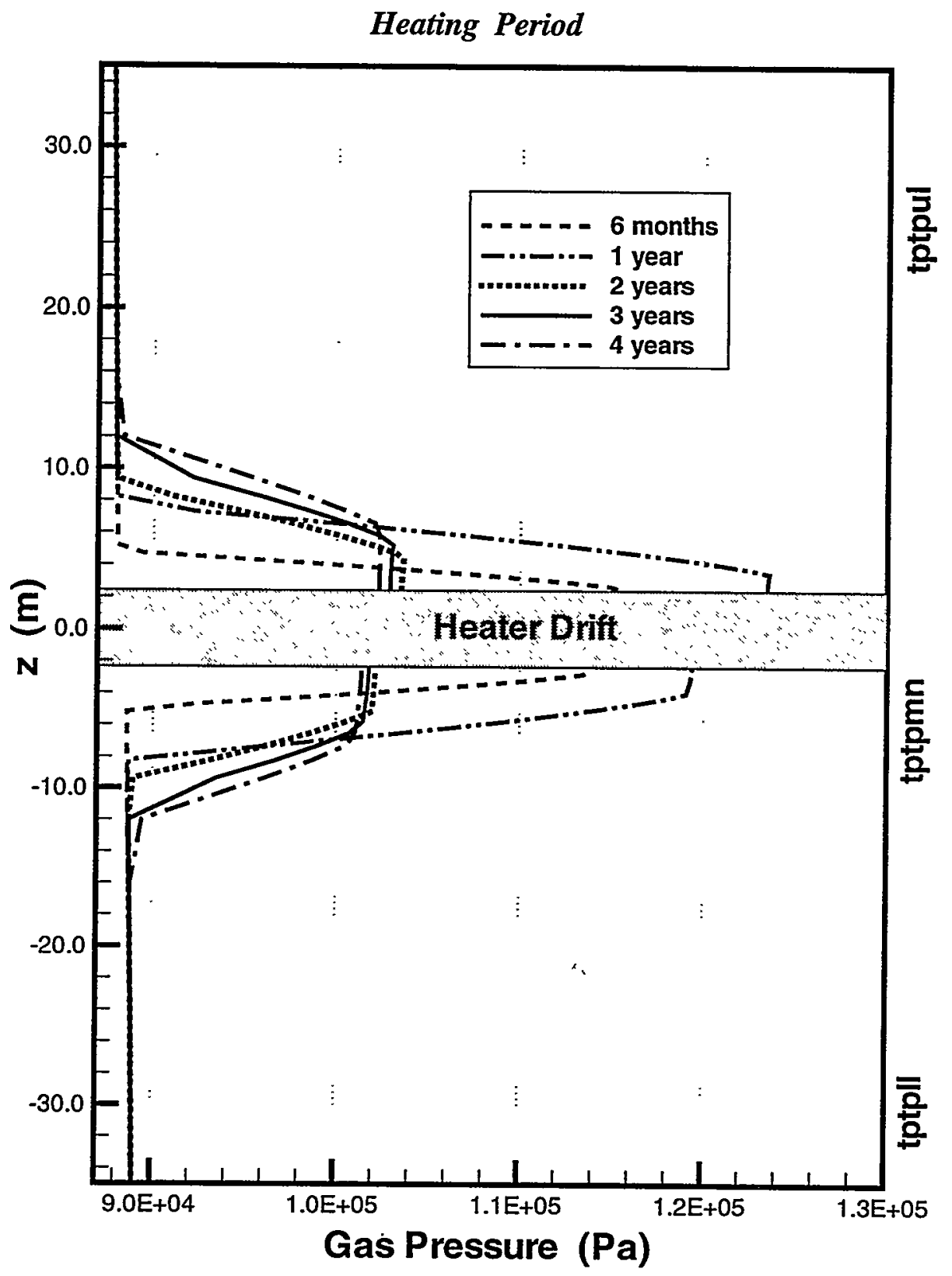

Figure 5.1-28 Gas pressure profiles along $z$-axis at $x=0.0 \mathrm{~m}$ and $y=30.18 \mathrm{~m}$ for $3.6 \mathrm{~mm} / \mathrm{yr}$ infiltration case during heating (1 year heating at 100\%, 3 years heating at 50\%). 


\section{Cooling Period}

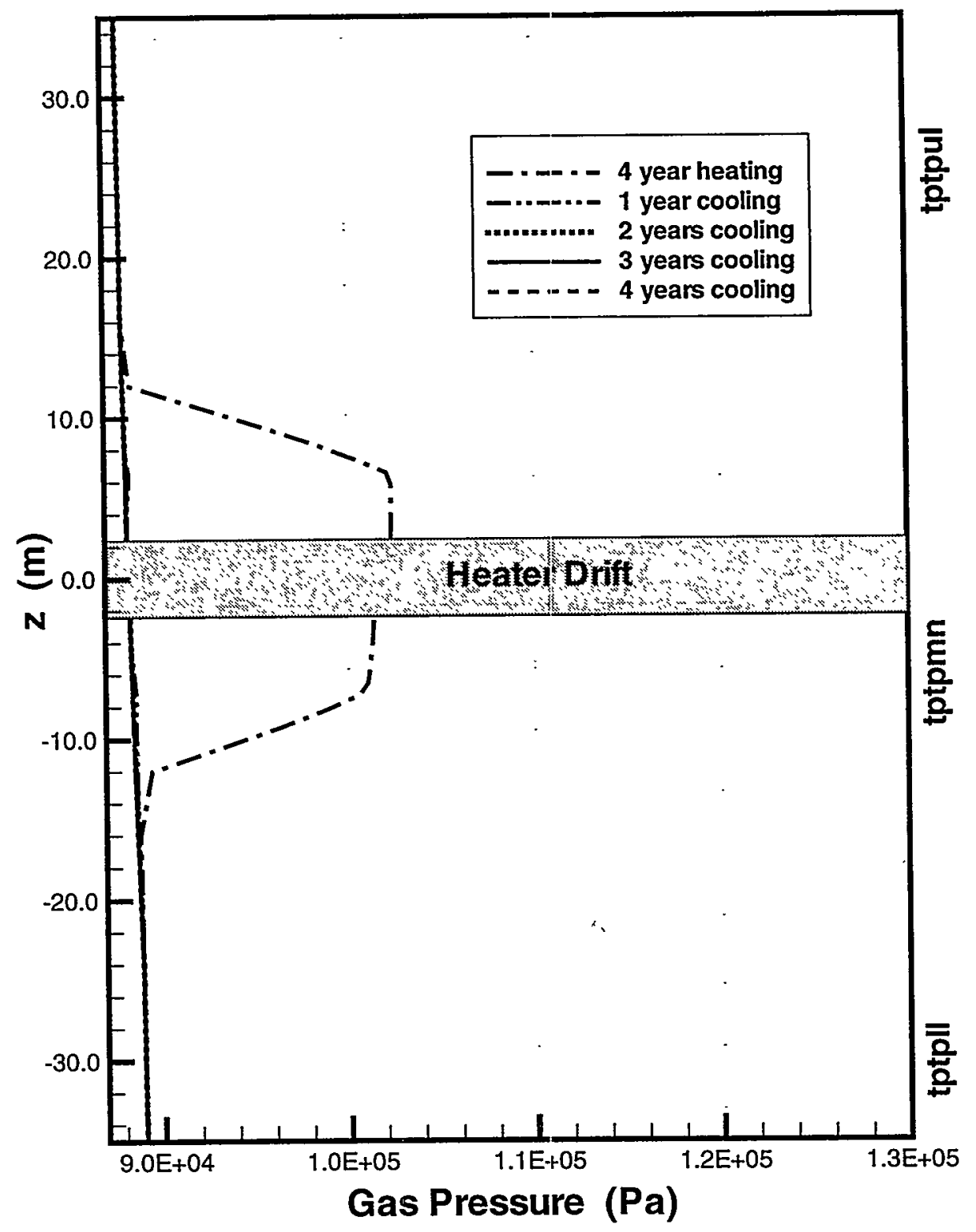

Figure 5.1-29 Gas pressure profiles along $z$-axis at $x=0.0 \mathrm{~m}$ and $y=30.18 \mathrm{~m}$ for $3.6 \mathrm{~mm} / \mathrm{yr}$ infiltration case during cooling (1 year heating at 100\%, 3 years heating at 50\%). 


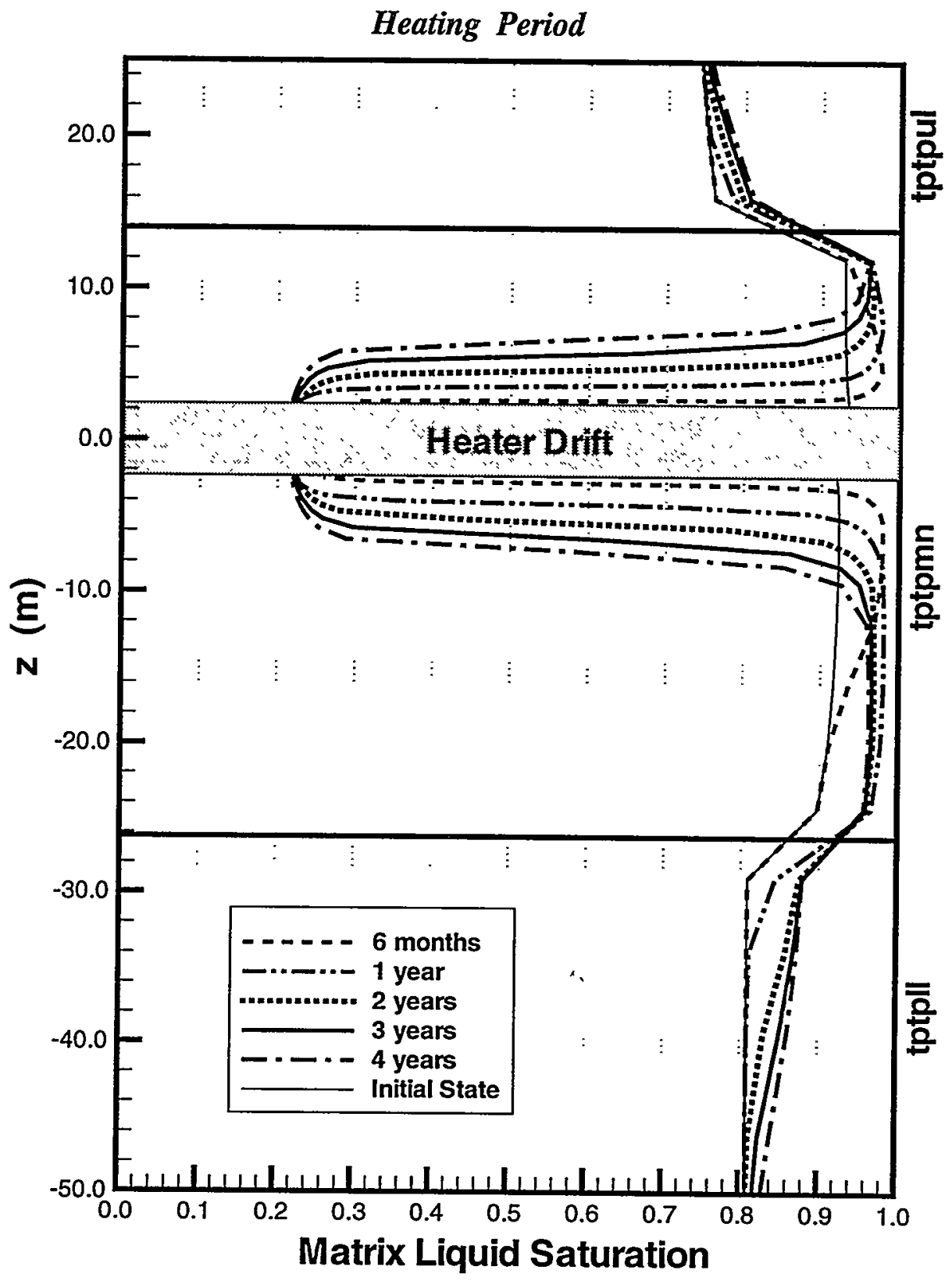

Figure 5.1-30 Matrix liquid saturation profiles along $z$-axis at $x=0.0 \mathrm{~m}$ and $y=30.18 \mathrm{~m}$ for $3.6 \mathrm{~mm} / \mathrm{yr}$ infiltration case during heating (I year heating at 100\%, 3 years heating at $50 \%$ ). 


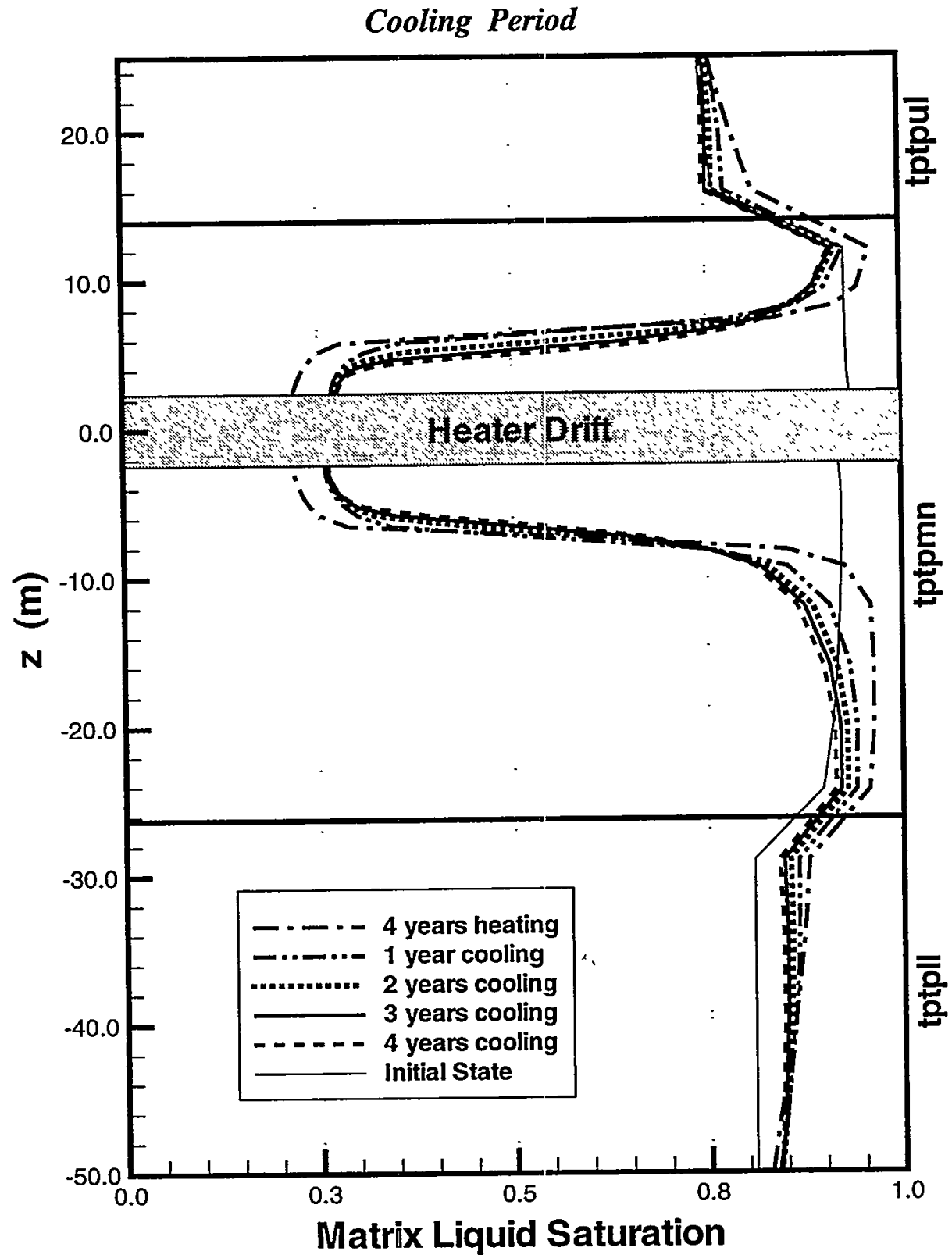

Figure 5.I-31 Matrix liquid saturation profiles along $z$-axis at $x=0.0 \mathrm{~m}$ and $y=30.18 \mathrm{~m}$ for $3.6 \mathrm{~mm} / \mathrm{yr}$ infiltration case during cooling (I year heating at 100\%, 3 years heating at 50\%). 


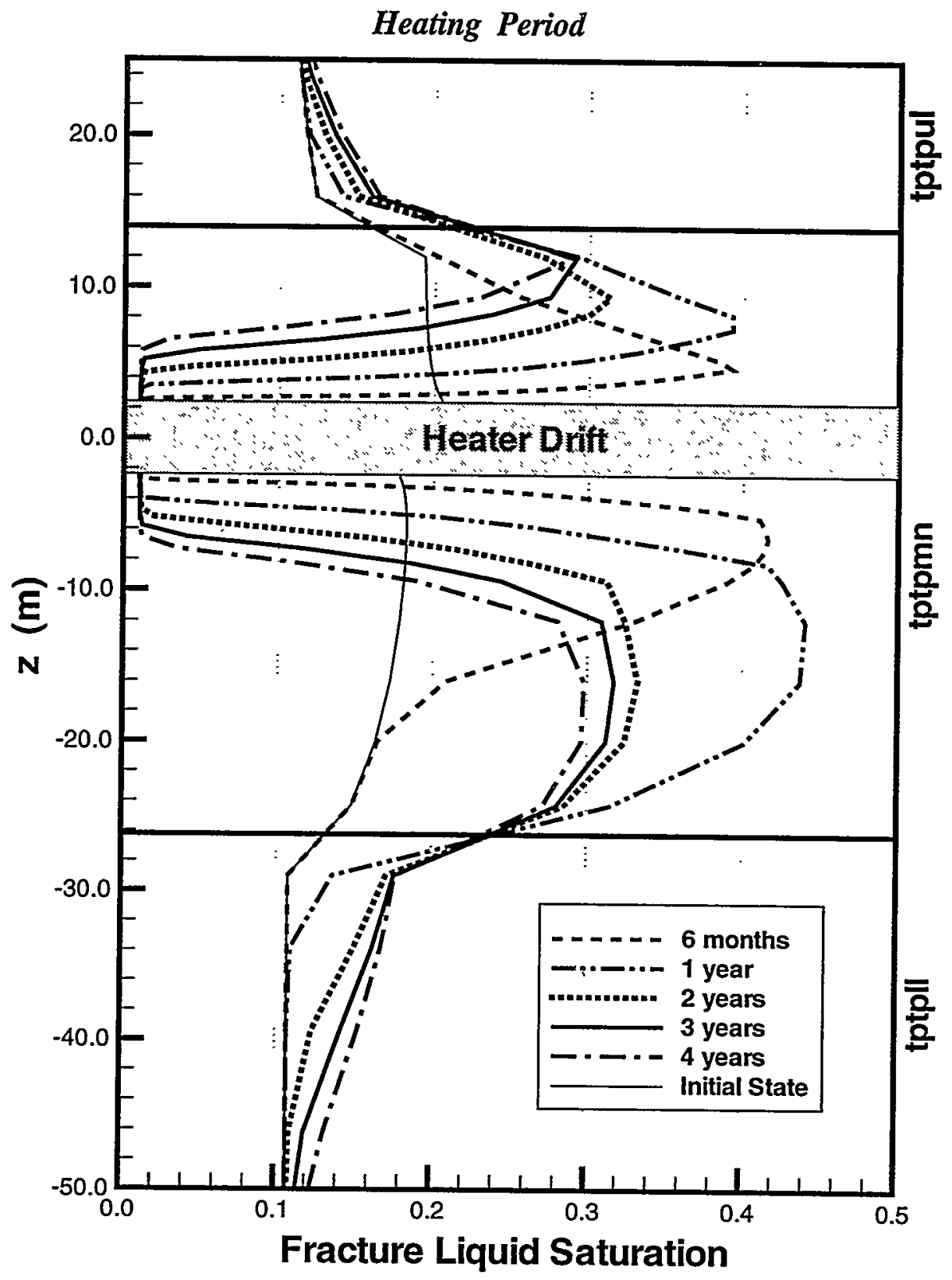

Figure 5.1-32 Fracture liquid saturation profiles along $z$-axis at $x=0.0 \mathrm{~m}$ and $y=30.18 \mathrm{~m}$ for $3.6 \mathrm{~mm} / \mathrm{yr}$ infiltration case during heating (1 year heating at 100\%, 3 years heating at $50 \%$ ). 


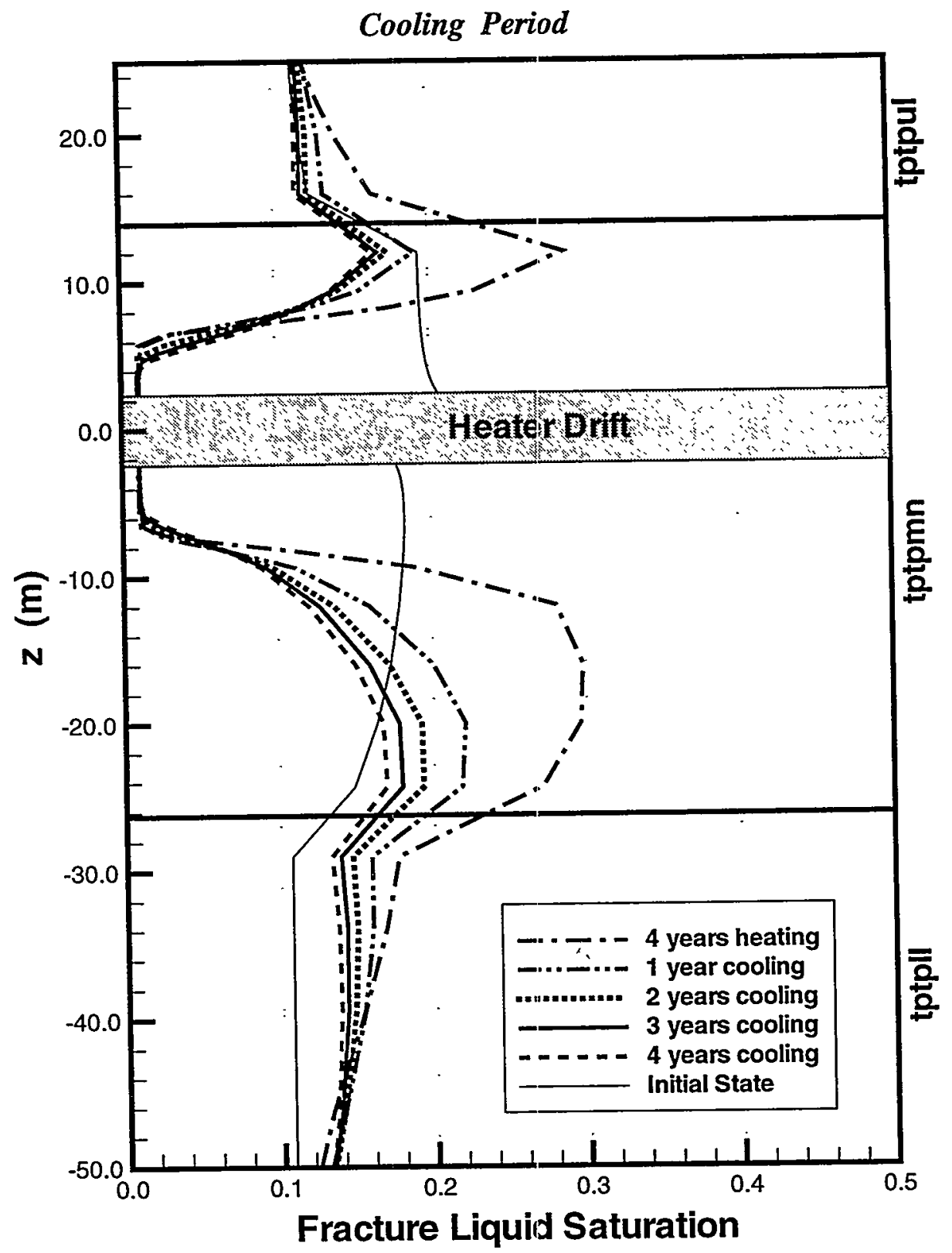

Figure 5.1-33 Fracture liquid saturation profiles along $z$-axis at $x=0.0 \mathrm{~m}$ and $y=30.18 \mathrm{~m}$ for $3.6 \mathrm{~mm} / \mathrm{yr}$ infiltration case during cooling (I year heating at 100\%, 3 years heating at 50\%). 


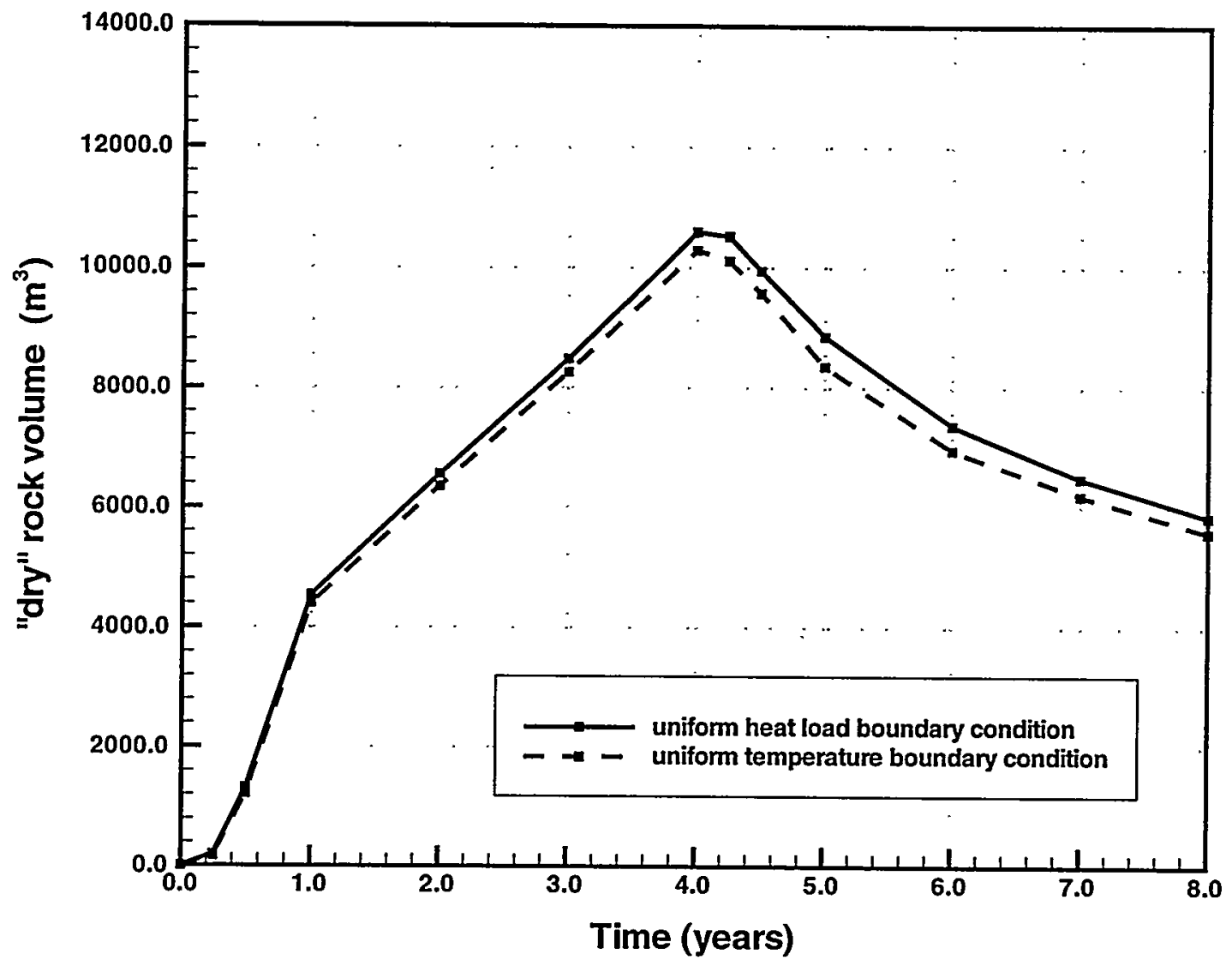

Figure 5.1-34 Evolution of dry-out rock volume for $3.6 \mathrm{~mm} / \mathrm{yr}$ infiltration case. Both the uniform temperature and the uniform heat load case are shown (1 year heating at 100\%, 3 years heating at $50 \%$ ). 


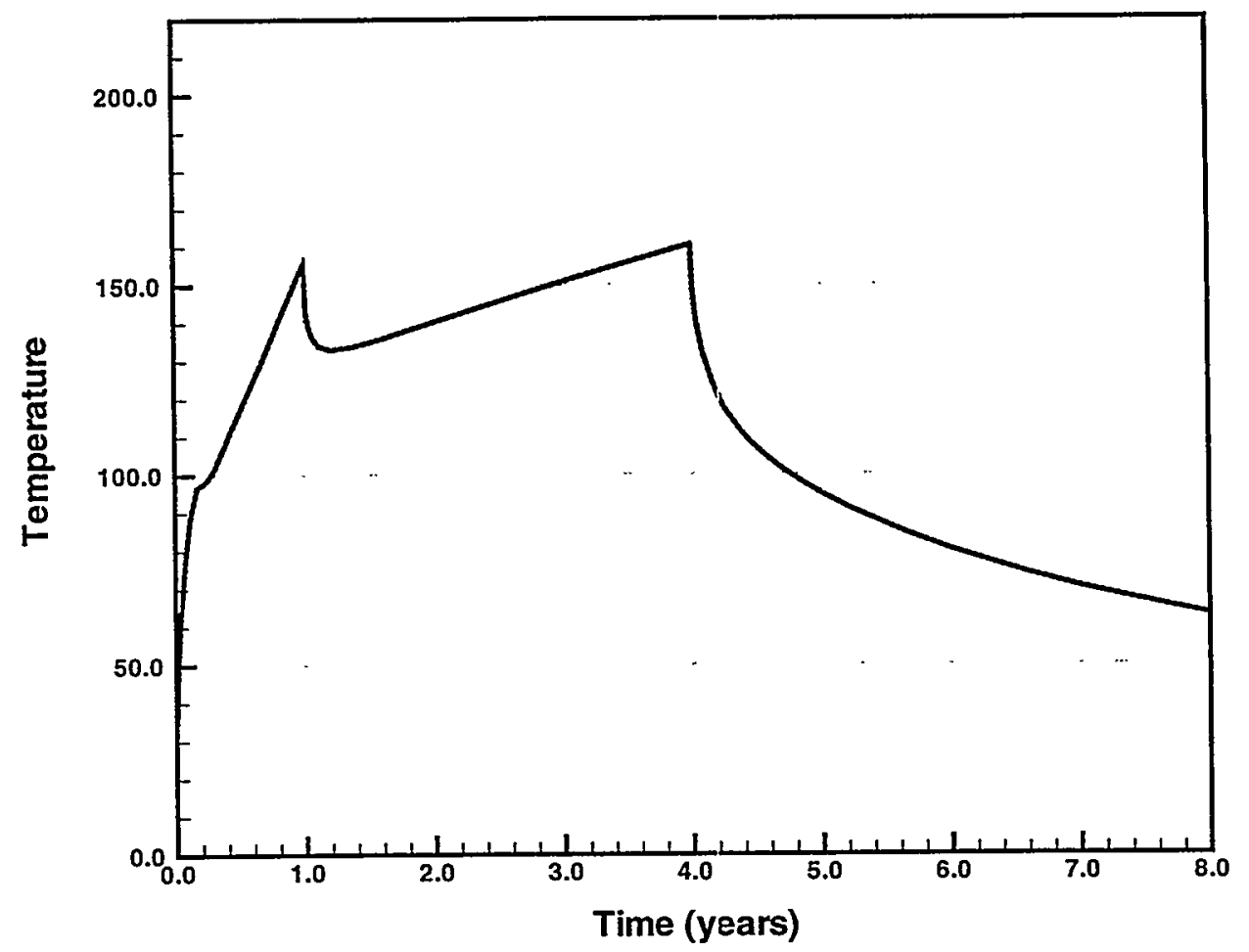

Figure 5.1-35 Temperature evolution at the heater drift wall for uniform temperature boundary condition in the heater drift ( 1 year heating at 100\%, 3 years heating at 50\%). 


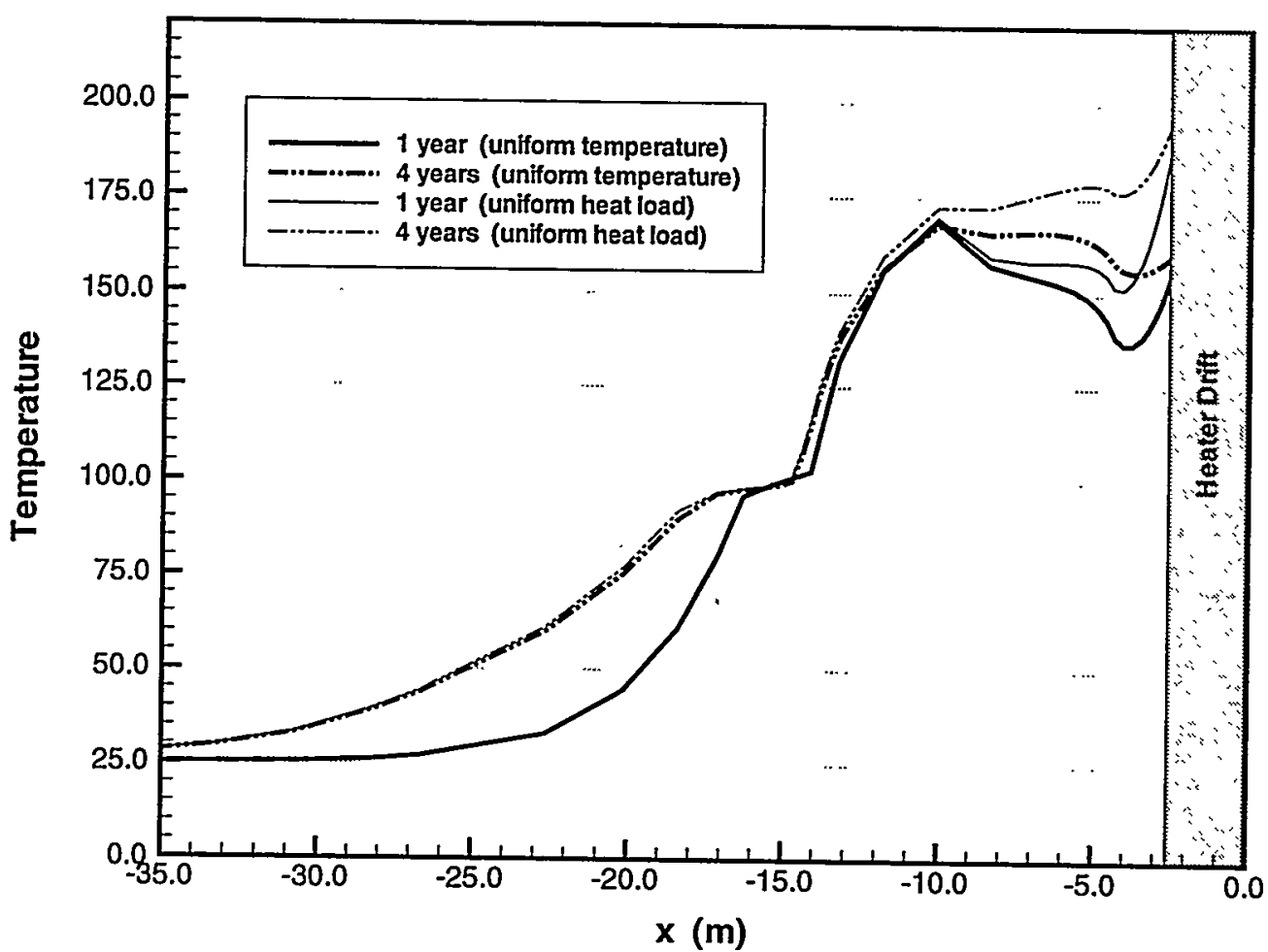

Figure 5.1-36 Temperature profiles along $x$-axis at $y=30.18 \mathrm{~m}$ and $z=0.0 \mathrm{~m}$ for $3.6 \mathrm{~mm} / \mathrm{yr}$ infiltration case. Both the uniform temperature and the uniform heat load case are shown (1 year heating at 100\%, 3 years heating at 50\%).

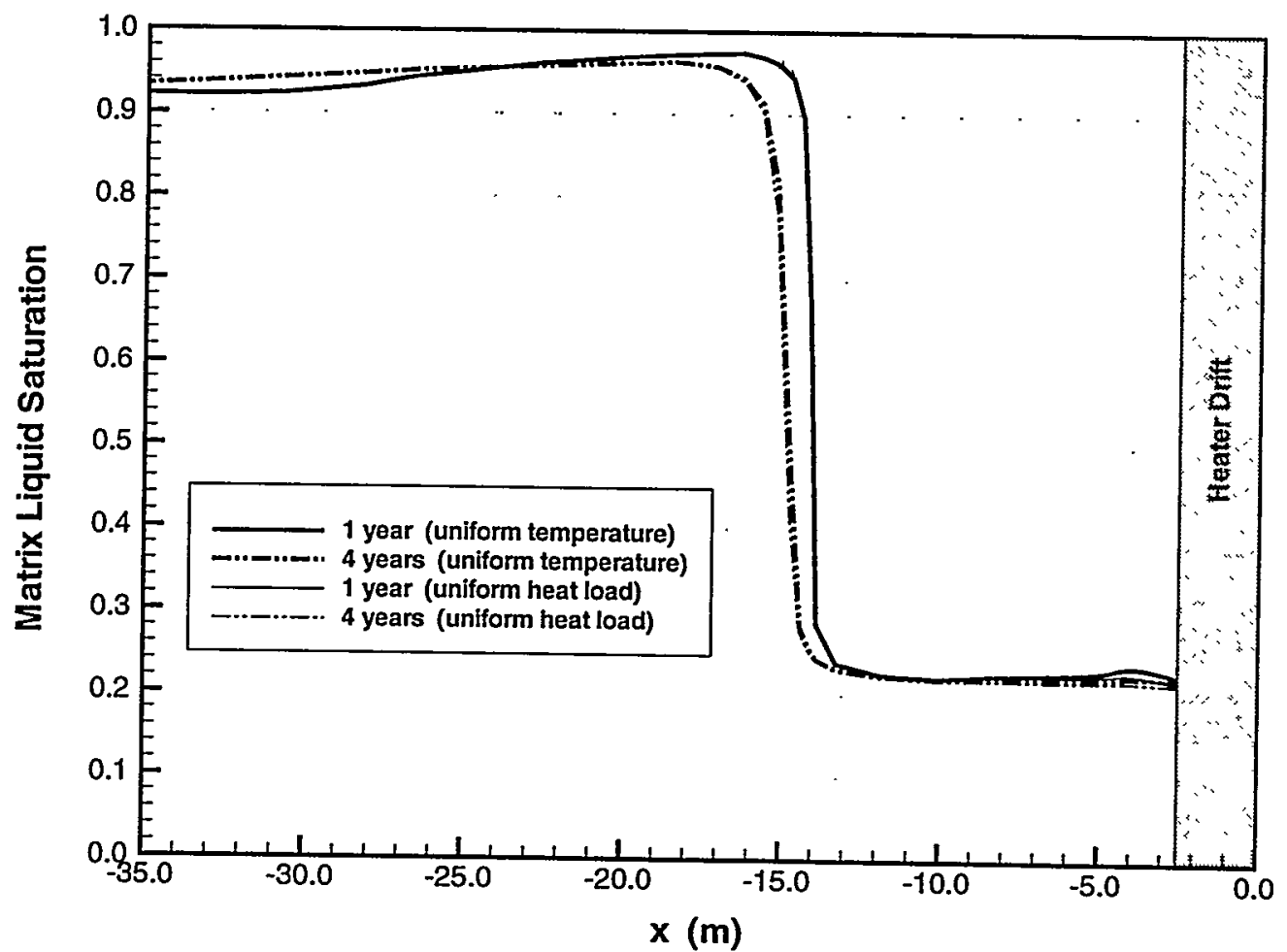

Figure 5.1-37 Matrix liquid saturation profiles along $x$-axis at $y=30.18 \mathrm{~m}$ and $z=0.0 \mathrm{~m}$ for $3.6 \mathrm{~mm} / \mathrm{yr}$ infiltration case. Both the uniform temperature and the uniform heat load case are shown (1 year heating at 100\%, 3 years heating at 50\%). 
Pretest Analysis of the Thermal-Hydrological Conditions of the ESF Drift Scale Test

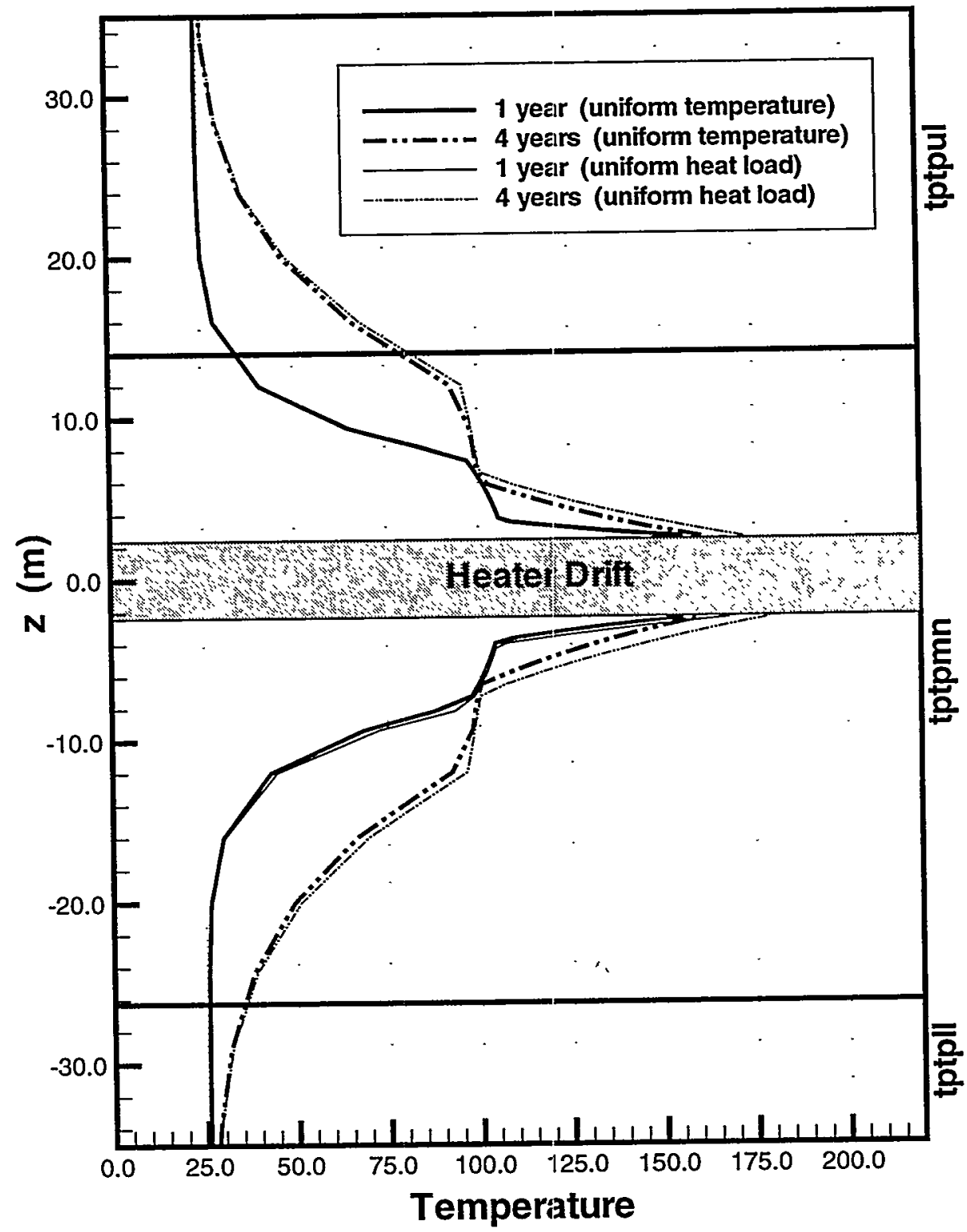

Figure 5.1-38 Temperature profiles along $z$-axis at $x=0.0 \mathrm{~m}$ and $y=30.18 \mathrm{~m}$ for $3.6 \mathrm{~mm} / y \mathrm{r}$ infiltration case. Both the uniform temperature and the uniform heat load case are shown (1 year heating at 100\%, 3 years heating at 50\%). 


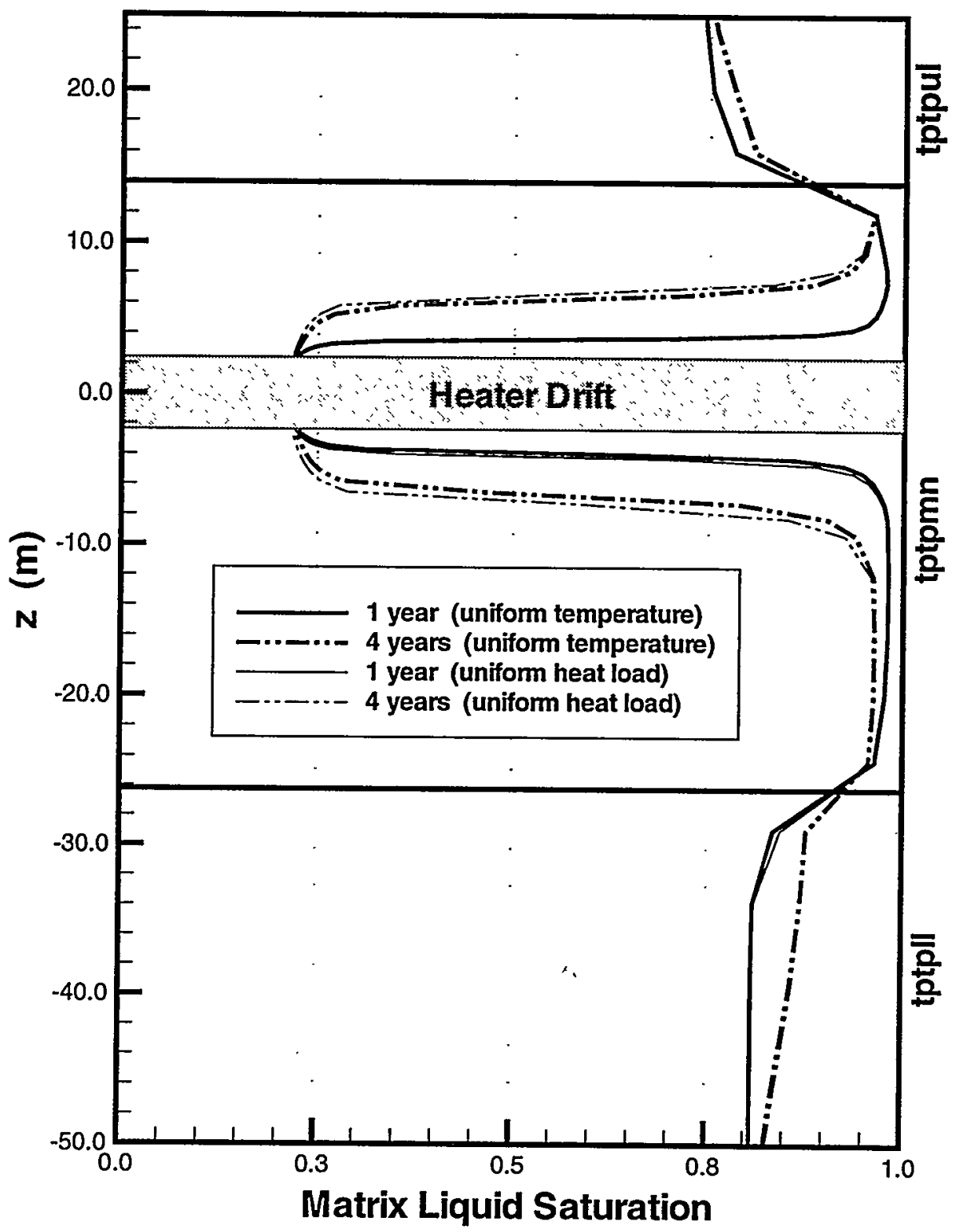

Figure 5.1-39 Matrix liquid saturation profiles along z-axis at $x=0.0 \mathrm{~m}$ and $y=30.18 \mathrm{~m}$ for $3.6 \mathrm{~mm} / \mathrm{yr}$ infiltration case. Both the uniform temperature and the uniform heat load case are shown (1 year heating at 100\%, 3 years heating at 50\%). 


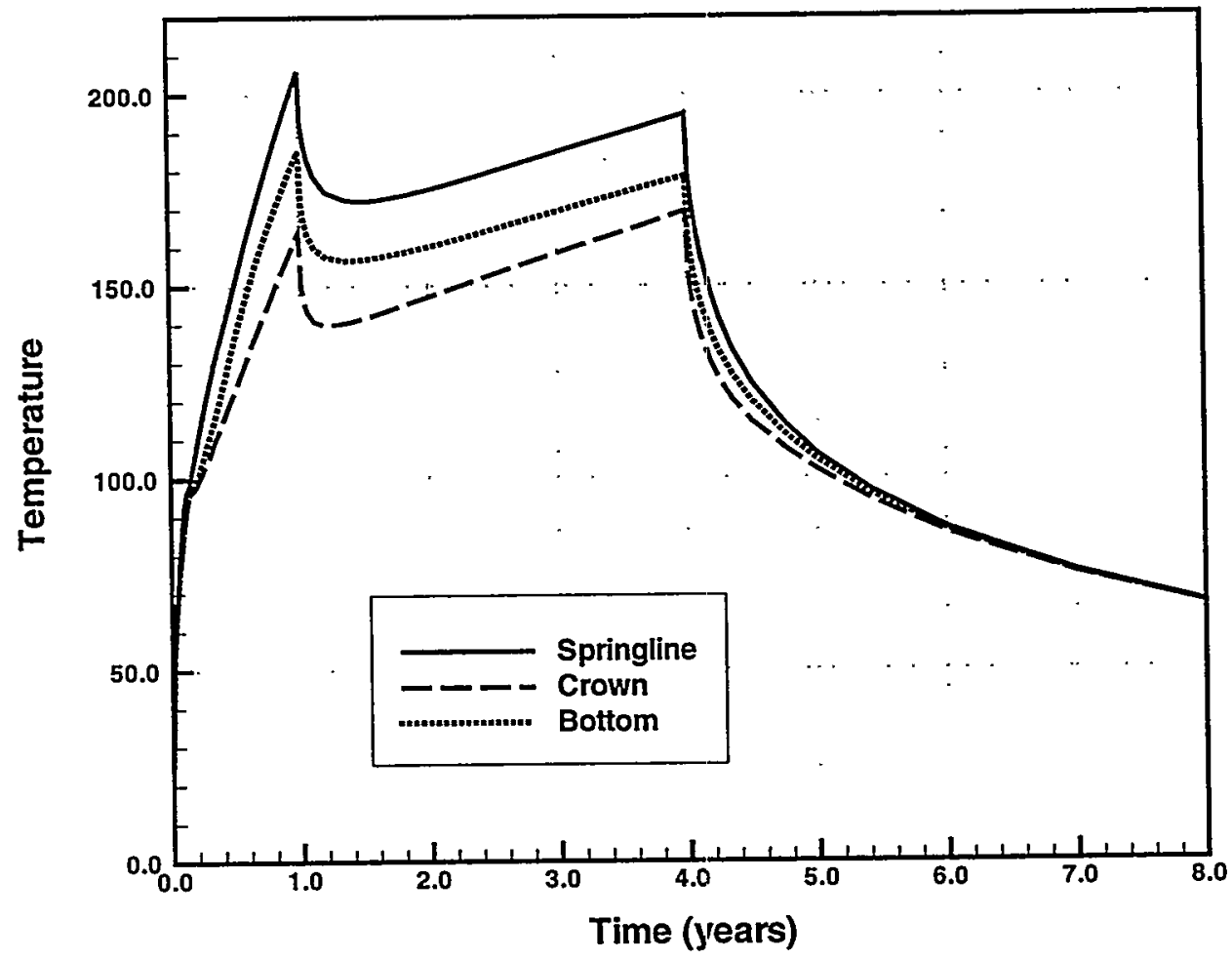

Figure 5.2-1 Temperature evolution at the heater drift wall at $y=10.06 \mathrm{~m}$ from the bulkhead for $0.36 \mathrm{~mm} / \mathrm{yr}$ infiltration case (1 year heating at 100\%, 3 years heating at 50\%).

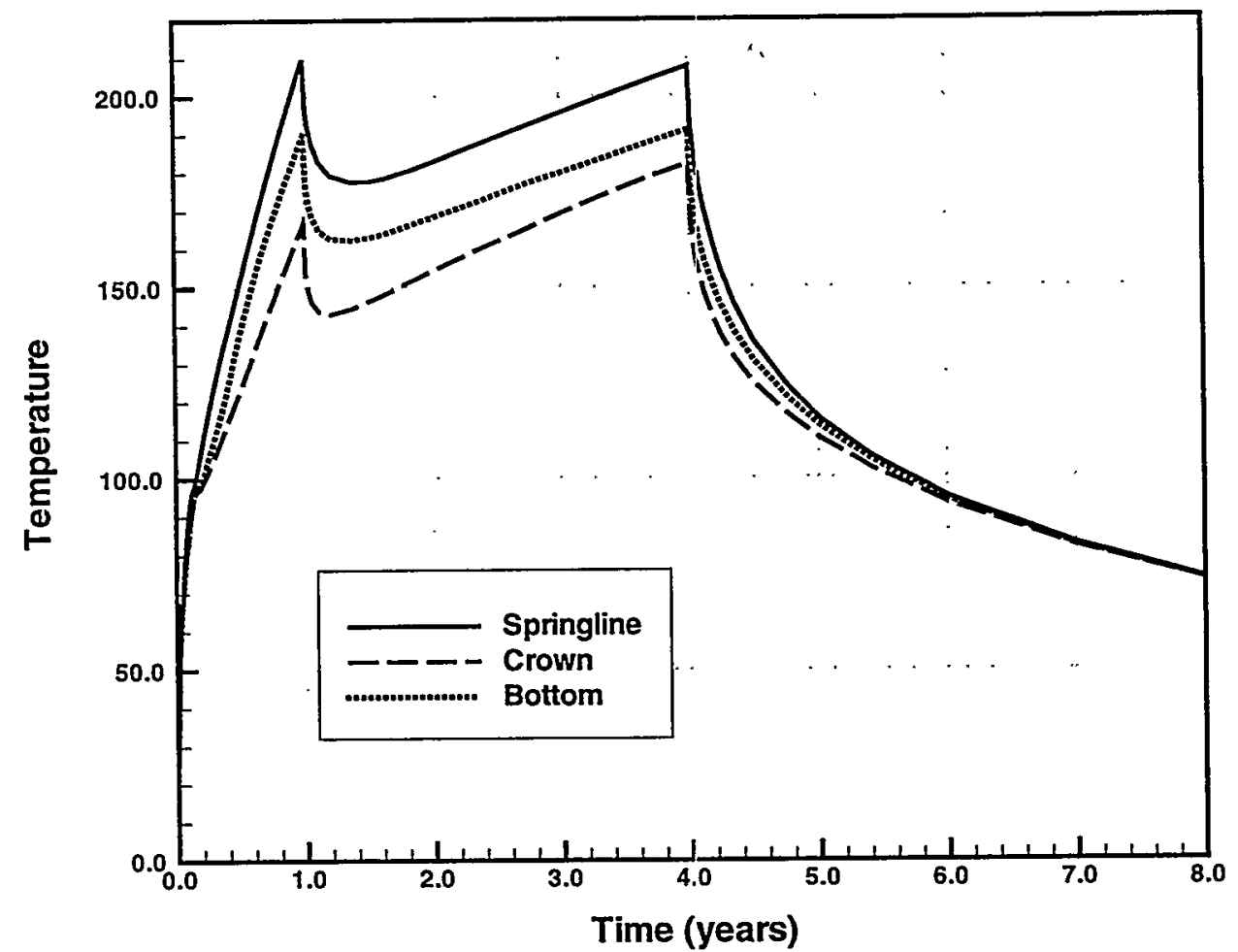

Figure 5.2-2 Temperature evolution at the heater drift wall at $y=30.18 \mathrm{~m}$ from the bulkhead for $0.36 \mathrm{~mm} / \mathrm{yr}$ infiltration case (1 year heating at 100\%, 3 years heating at $50 \%$ ). 


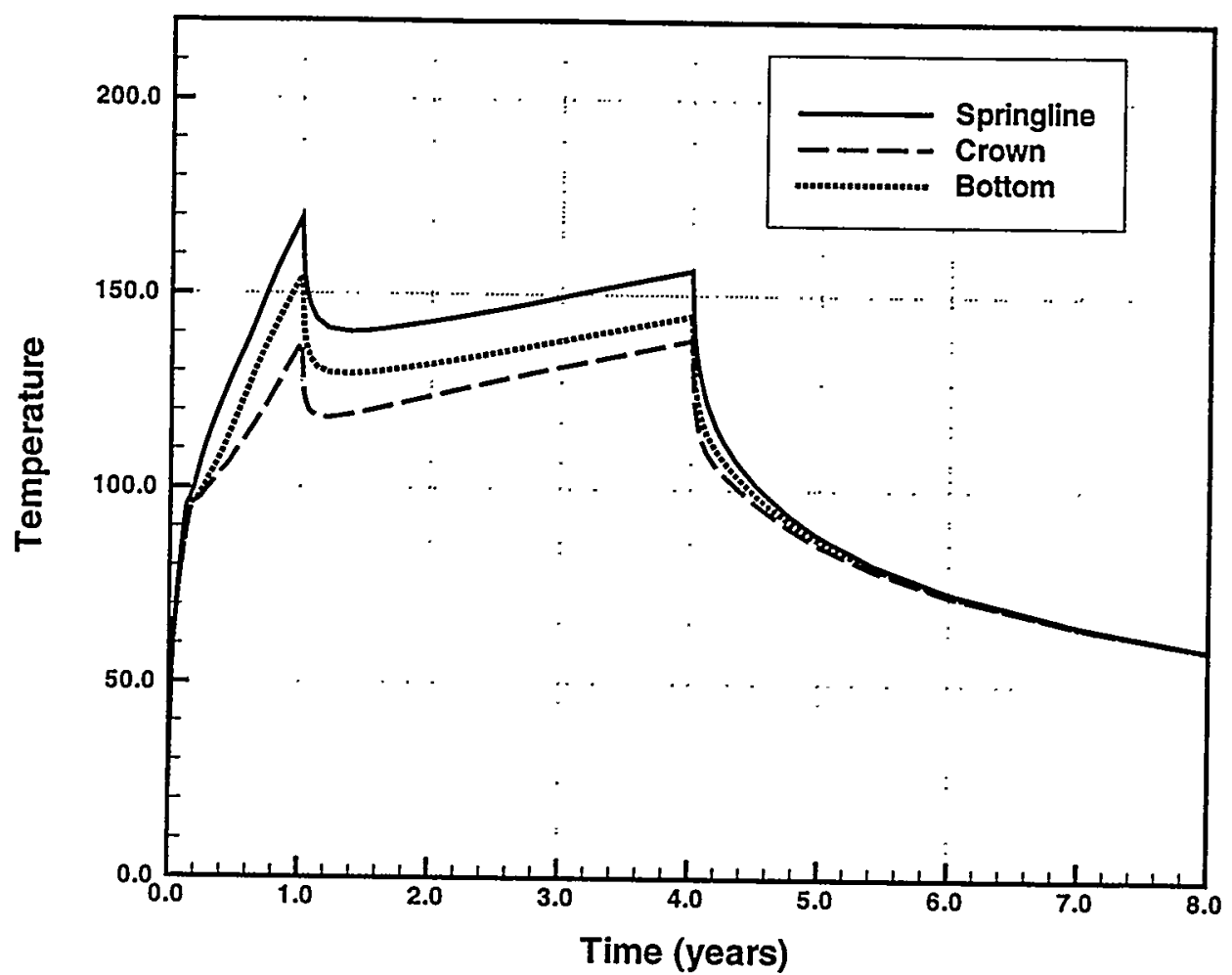

Figure 5.2-3 Temperature evolution at the heater drift wall at $y=44.8 \mathrm{~m}$ from the bulkhead for $0.36 \mathrm{~mm} / \mathrm{yr}$ infiltration case (1 year heating at 100\%, 3 years heating at 50\%). 


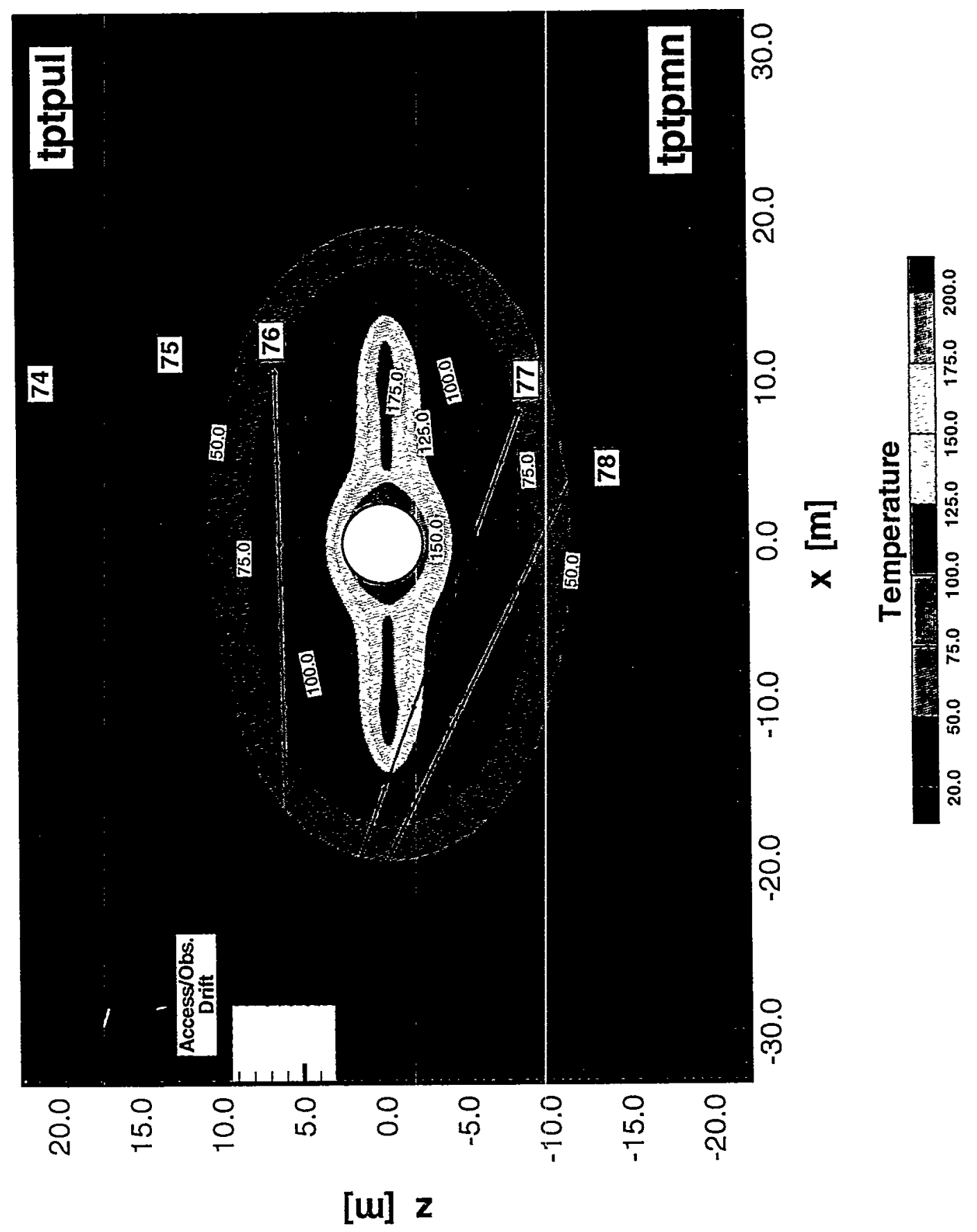

Figure 5.2-4 Temperature response after 1 year of heating in $x z$-cross section at $y=30.18 \mathrm{~m}$ for $0.36 \mathrm{~mm} / \mathrm{yr}$ infiltration case (1 year heating at $100 \%, 3$ years heating at $50 \%$ ). 


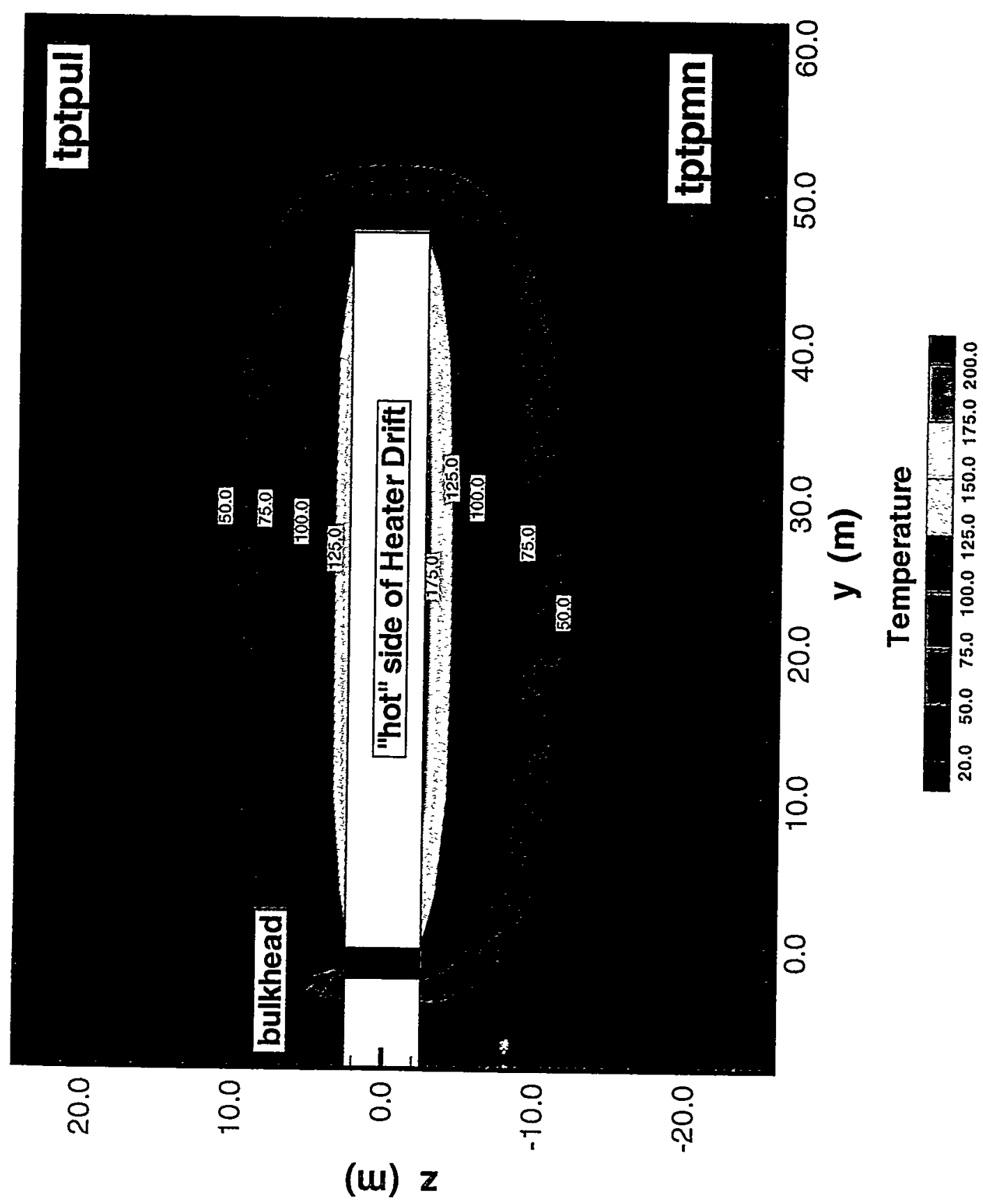

Figure 5.2-5 Temperature response after 1 year of heating in yz-cross section at $x=0.0 \mathrm{~m}$ for $0.36 \mathrm{~mm} / \mathrm{yr}$ infiltration case (1 year heating at 100\%, 3 years heating at $50 \%$ ). 


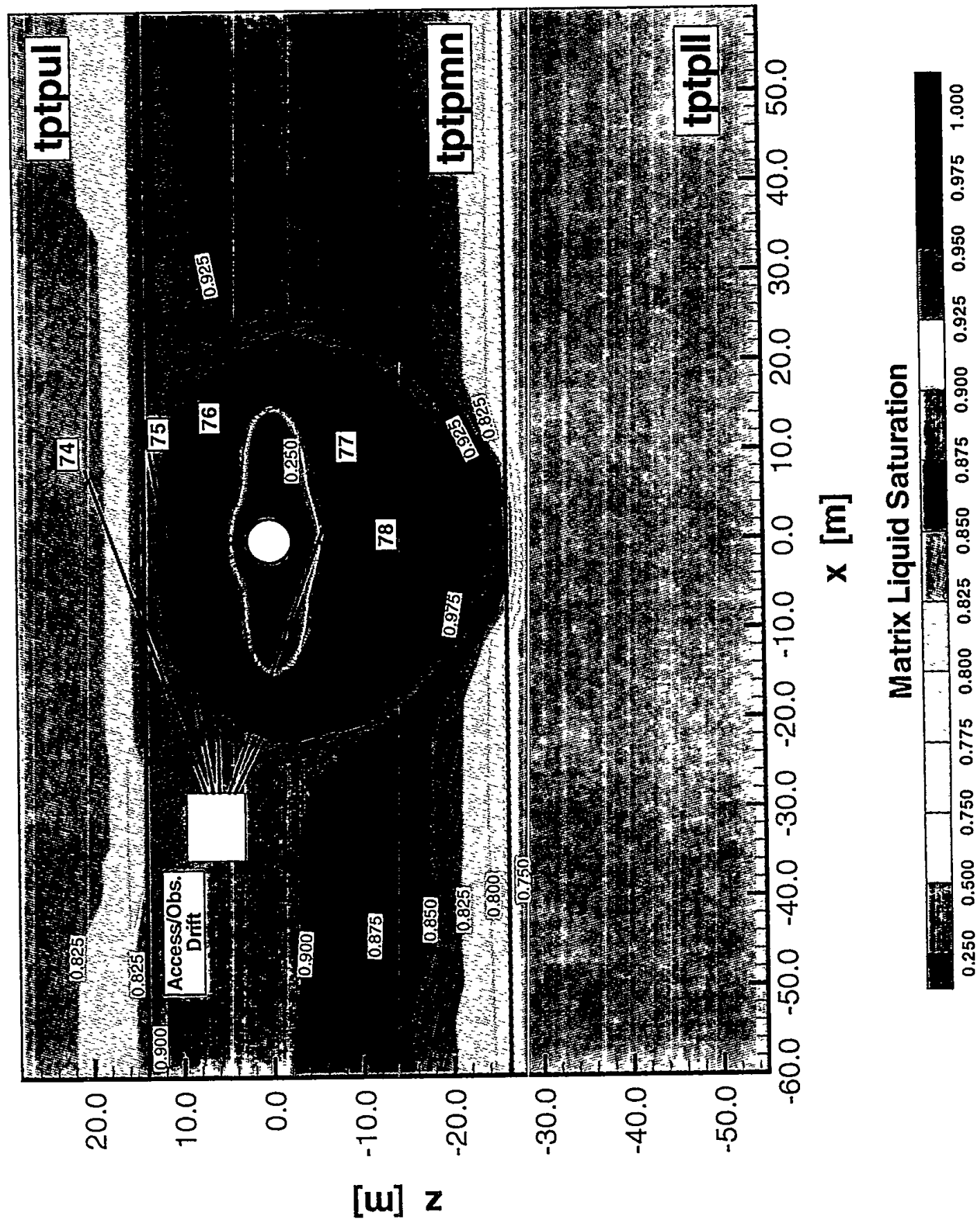

Figure 5.2-6 Matrix liquid saturation after 1 year of heating in $x z$-cross section at $y=30.18 \mathrm{~m}$ for $0.36 \mathrm{~mm} / \mathrm{yr}$ infiltration case ( 1 year heating at 100\%, 3 years heating at 50\%). Also presented is the location of hydrology holes 74 through 77 


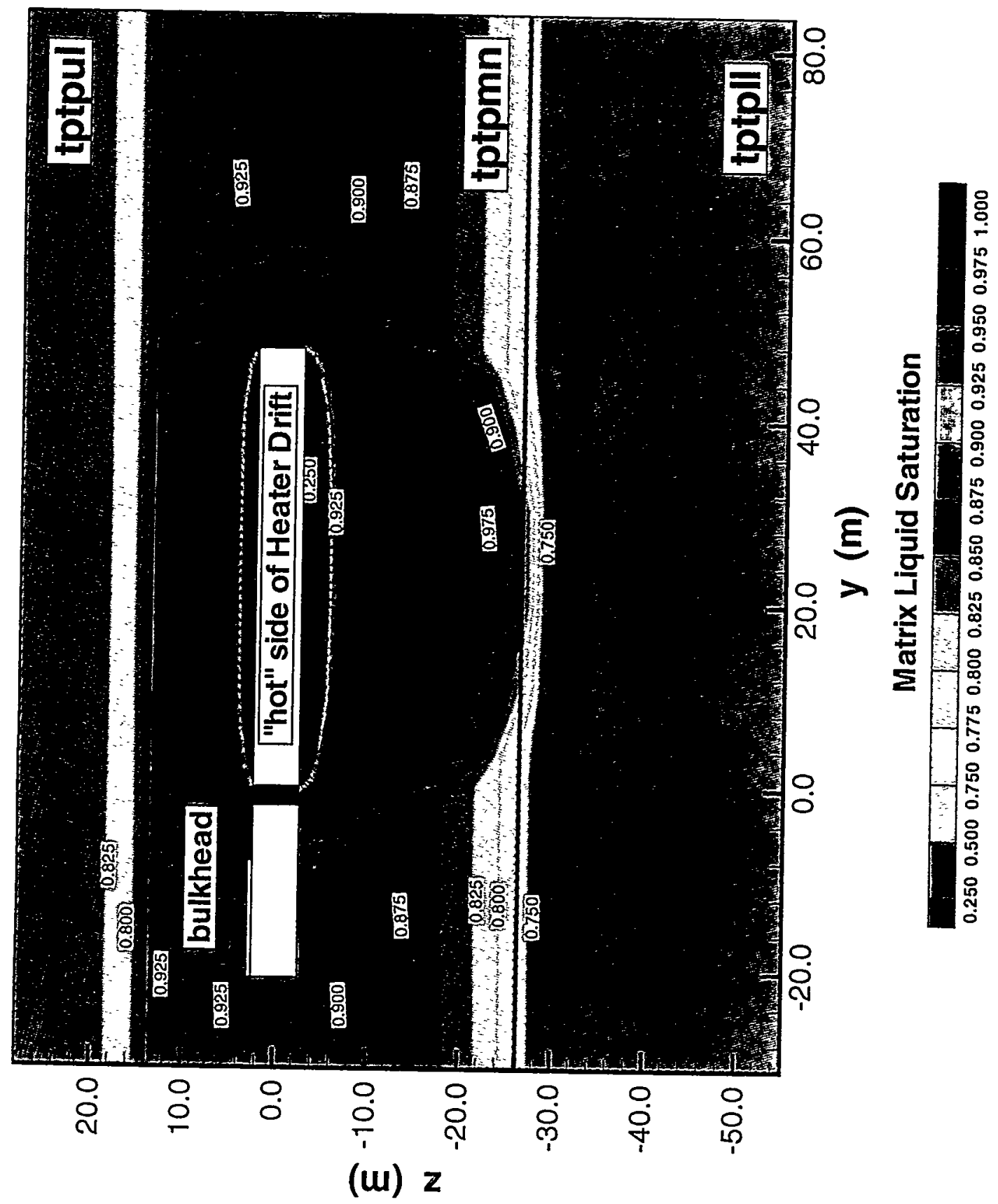

Figure 5.2-7 Matrix liquid saturation after 1 year of heating in yz-cross section at $x=0.0 \mathrm{~m}$ for $0.36 \mathrm{~mm} / \mathrm{yr}$ infiltration case (1 year heating at 100\%, 3 years heating at 50\%). 


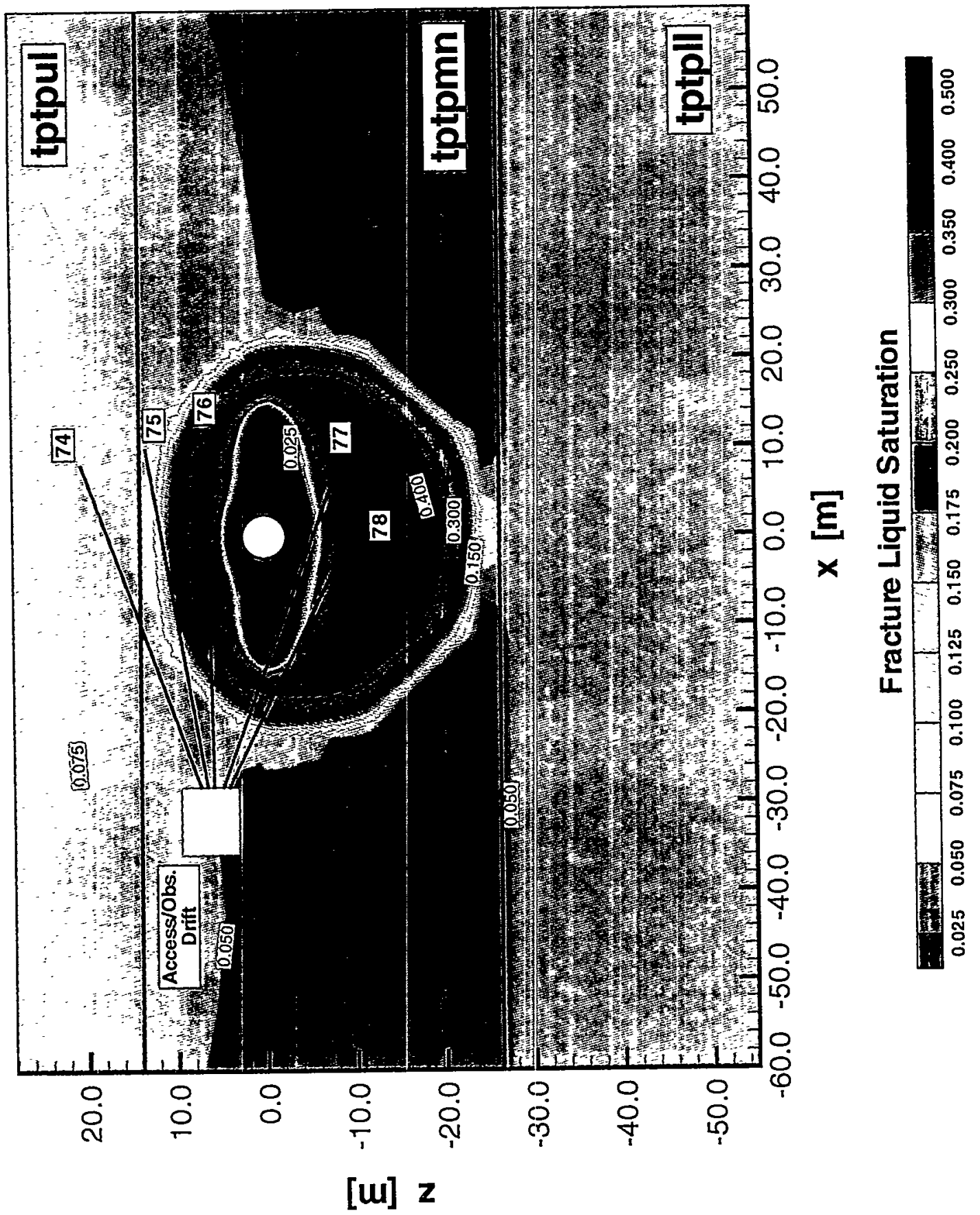

Figure 5.2-8 Fracture liquid saturation after 1 year of heating in $x z$-cross section at $y=30.18 \mathrm{~m}$ for $0.36 \mathrm{~mm} / \mathrm{yr}$ infiltration case (1 year heating at 100\%, 3 years heating at $50 \%$ ). Also presented is the location of hydrology holes 74 through 77. 


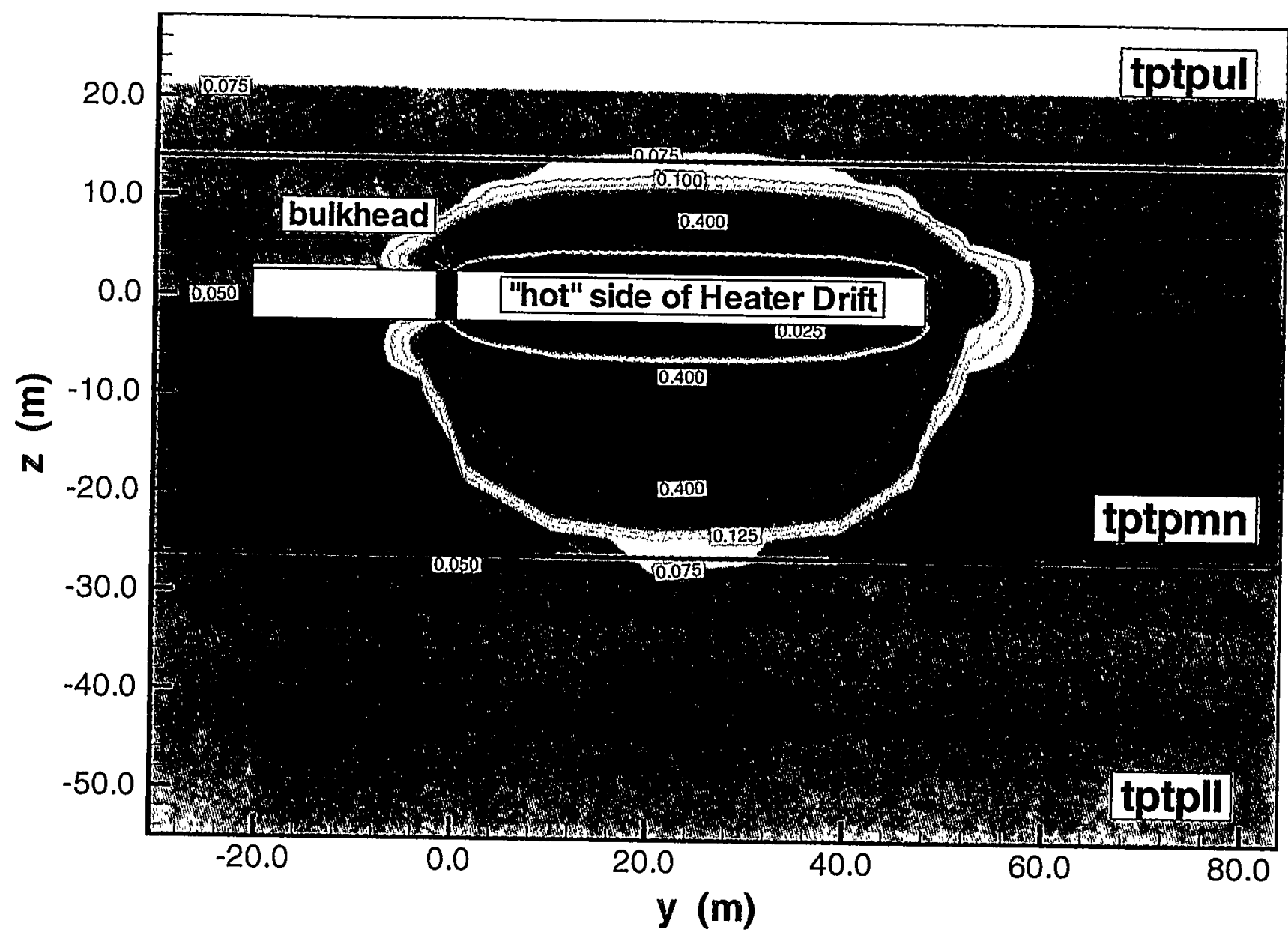

Fracture Liquid Saturation

$\begin{array}{llllllllllllllll}0.025 & 0.050 & 0.075 & 0.100 & 0.125 & 0.150 & 0.175 & 0.200 & 0.250 & 0.300 & 0.350 & 0.400 & 0.500\end{array}$ 


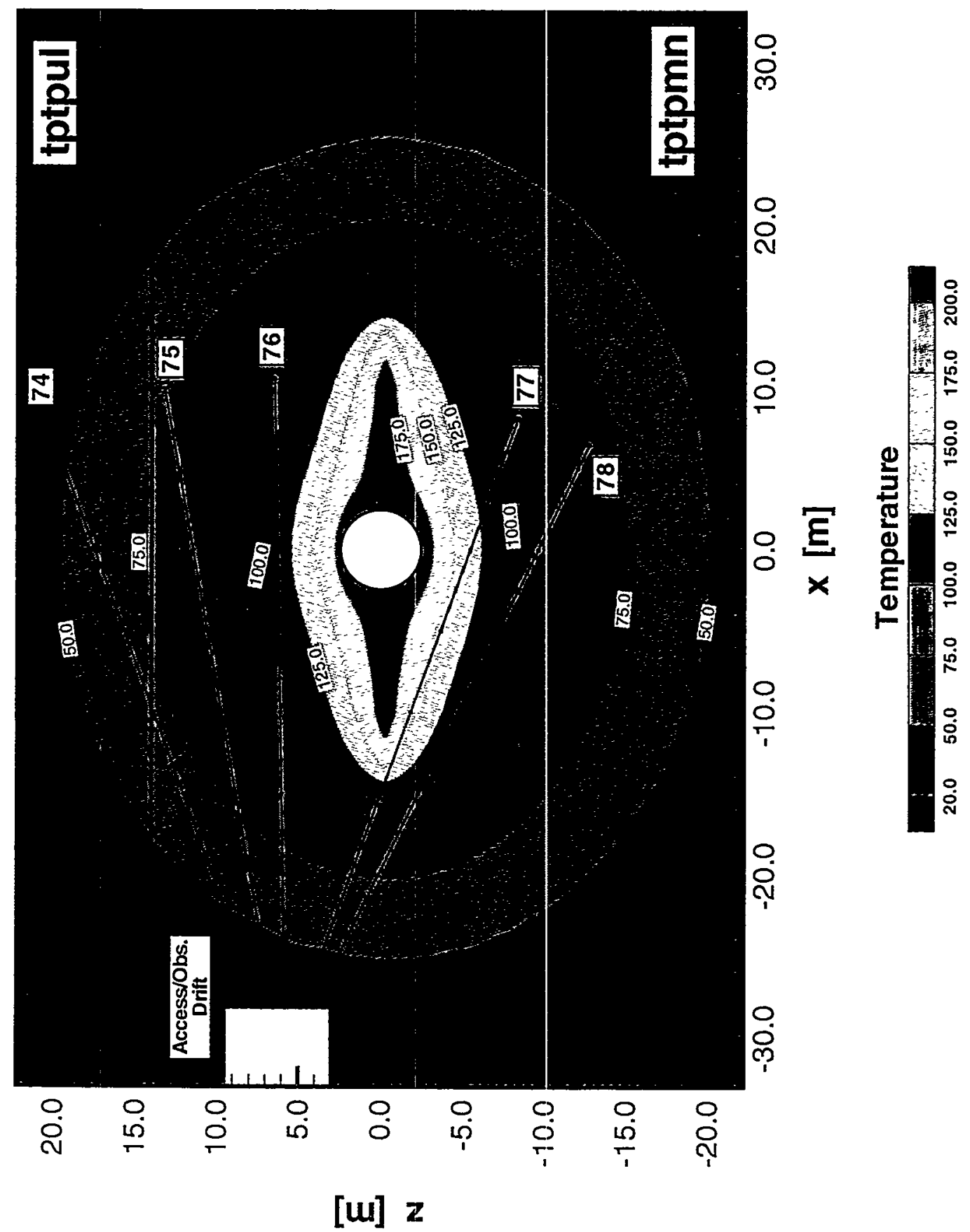

Figure 5.2-10 Temperature response after 4 years of heating in $x z$-cross section at $y=30.18 \mathrm{~m}$ for $0.36 \mathrm{~mm} / \mathrm{yr}$ infiltration case ( 1 year heating at 100\%, 3 years heating at $50 \%$ ).

Also presented is the location of hydrology holes 74 through 77. 


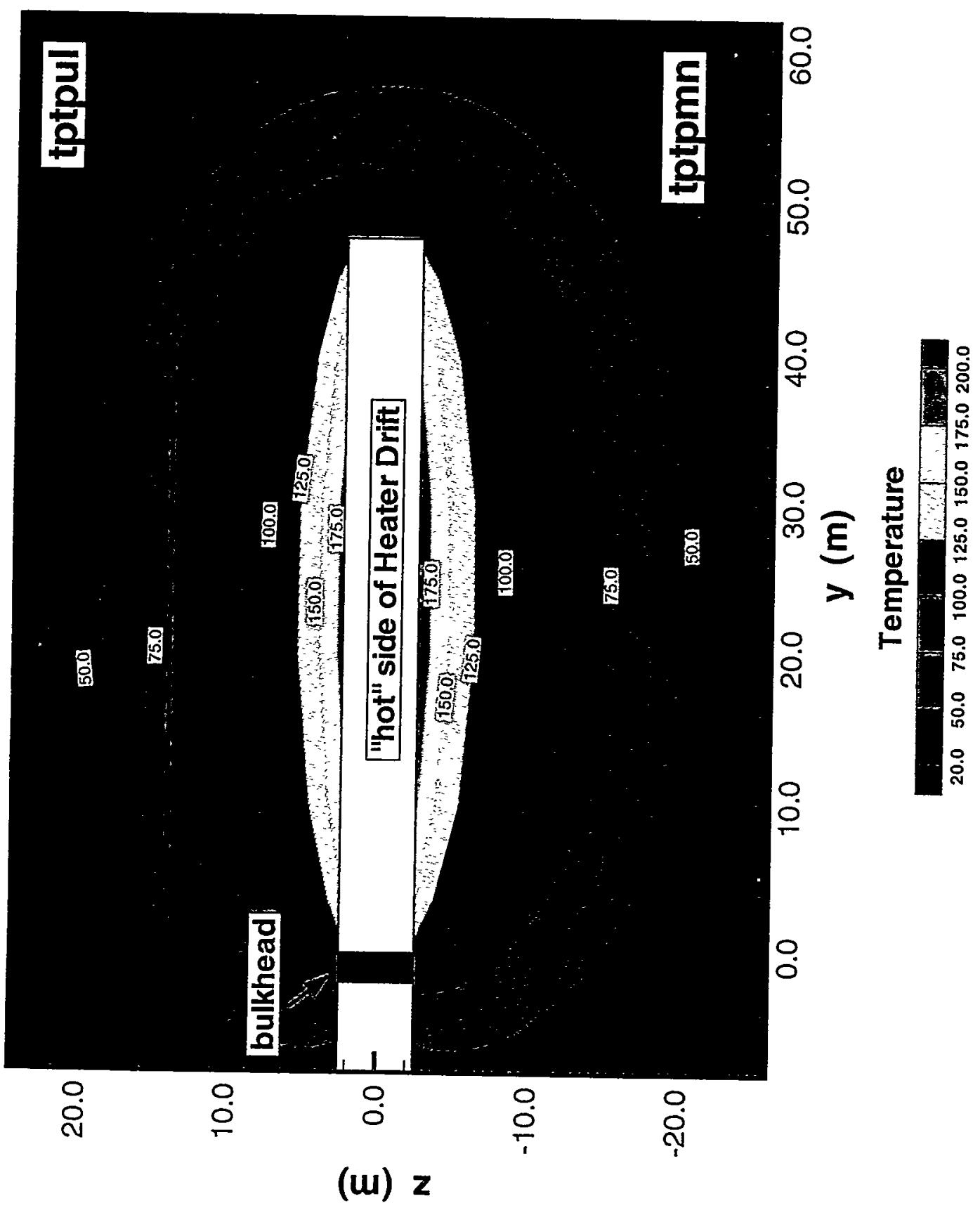

Figure 5.2-11 Temperature response after 4 years of heating in yz-cross section at $x=0.0 \mathrm{~m}$ for $0.36 \mathrm{~mm} / \mathrm{yr}$ infiltration case (1 year heating at 100\%, 3 years heating at 50\%). 


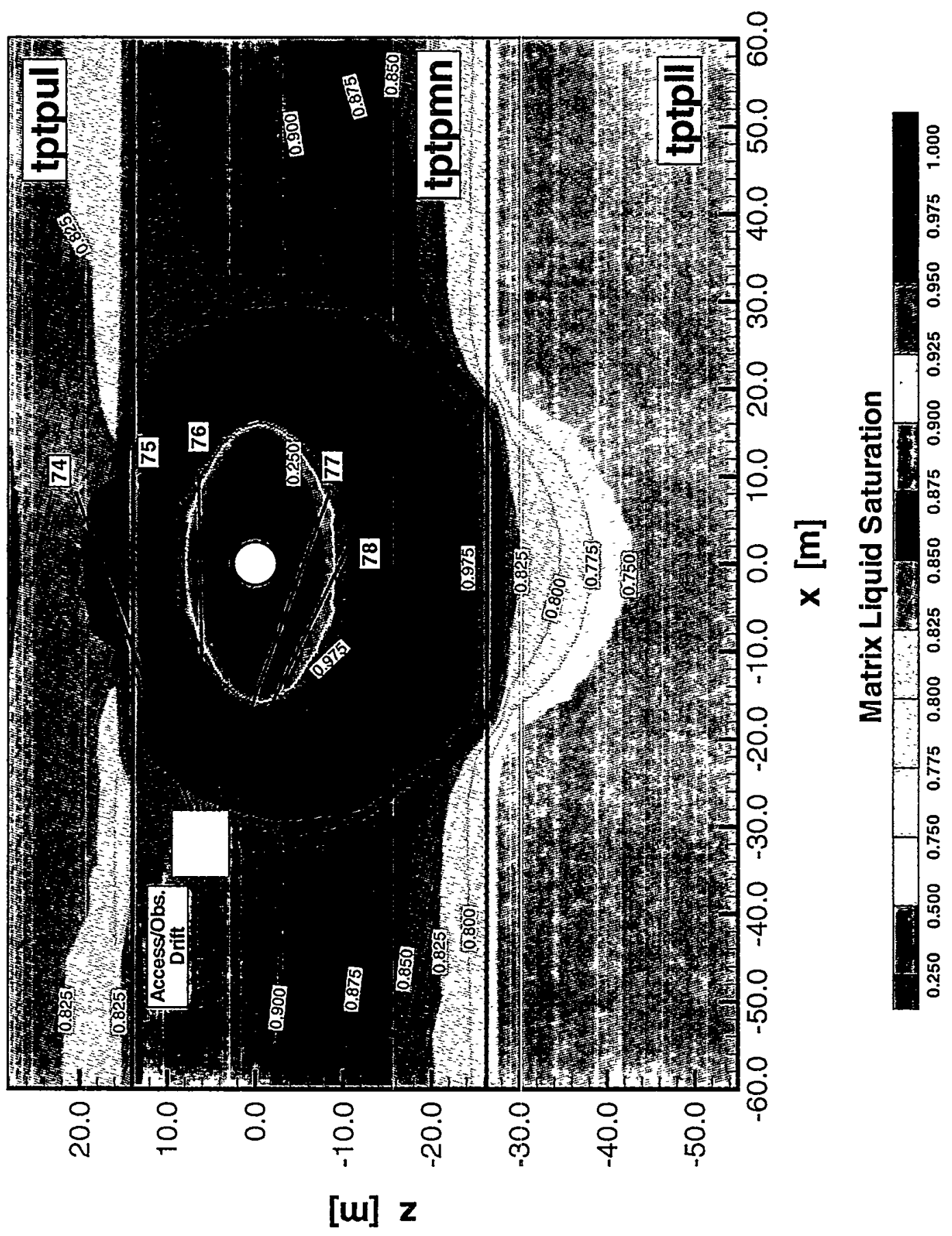

Figure 5.2-12 Matrix liquid saturation after 4 years of heating in $x z$-cross section at $y=30.18 \mathrm{~m}$ for $0.36 \mathrm{~mm} / \mathrm{yr}$ infiltration case ( 1 year heating at 100\%, 3 years heating at $50 \%$ ). Also presented is the location of hydrology holes 74 through 77. 


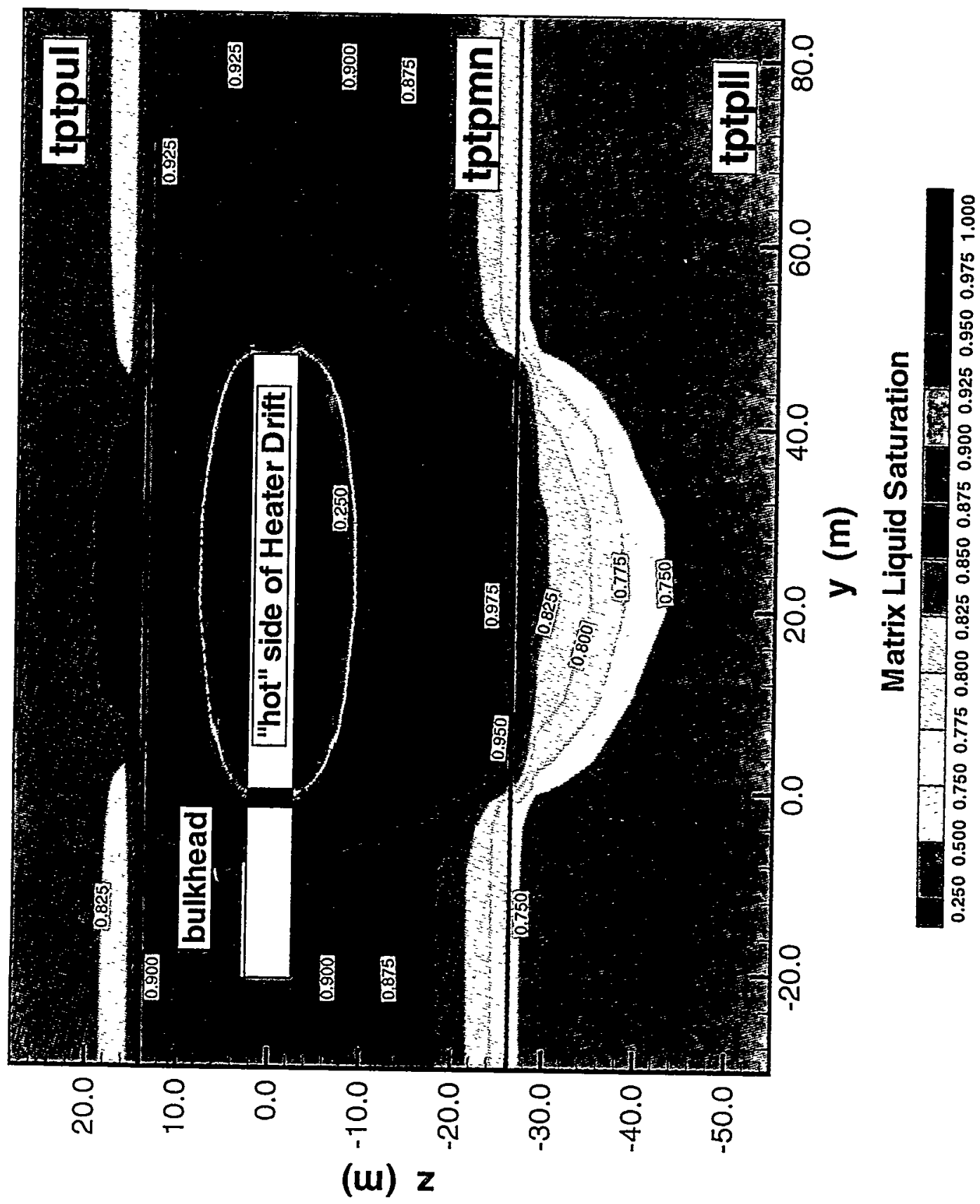

Figure 5.2-13 Matrix liquid saturation after 4 years of heating in yz-cross section at $x=0.0 \mathrm{~m}$ for $0.36 \mathrm{~mm} / \mathrm{yr}$ infiltration case (1 year heating at 100\%, 3 years heating at $50 \%$ ). 


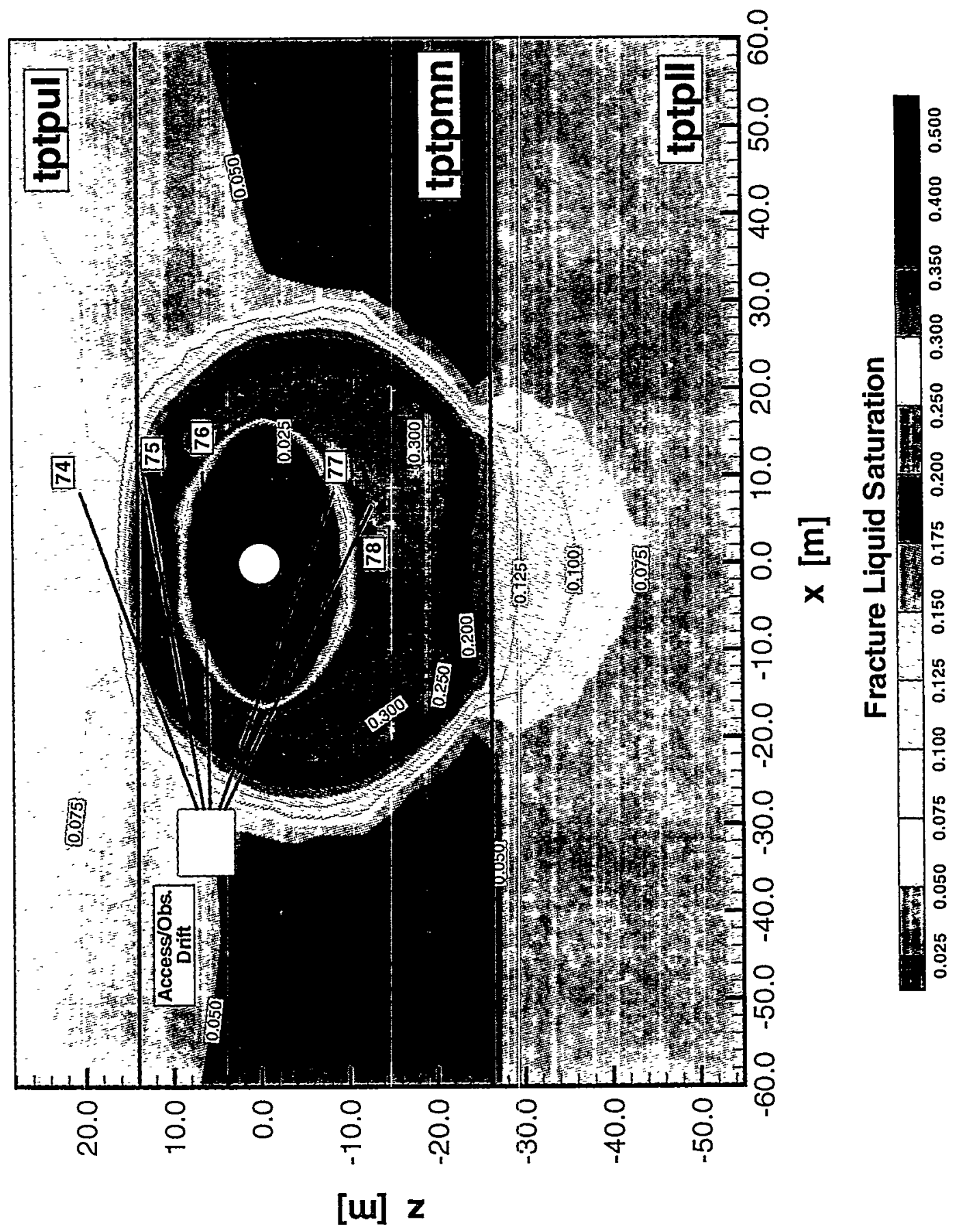

Figure 5.2-14 Fracture liquid saturation after 4 years of heating in $x z$-cross section at $y=30.18 \mathrm{~m}$ for $0.36 \mathrm{~mm} / \mathrm{yr}$ infiltration case (1 year heating at 100\%, 3 years heating at $50 \%$ ). Also presented is the location of hydrology holes 74 through 77. 


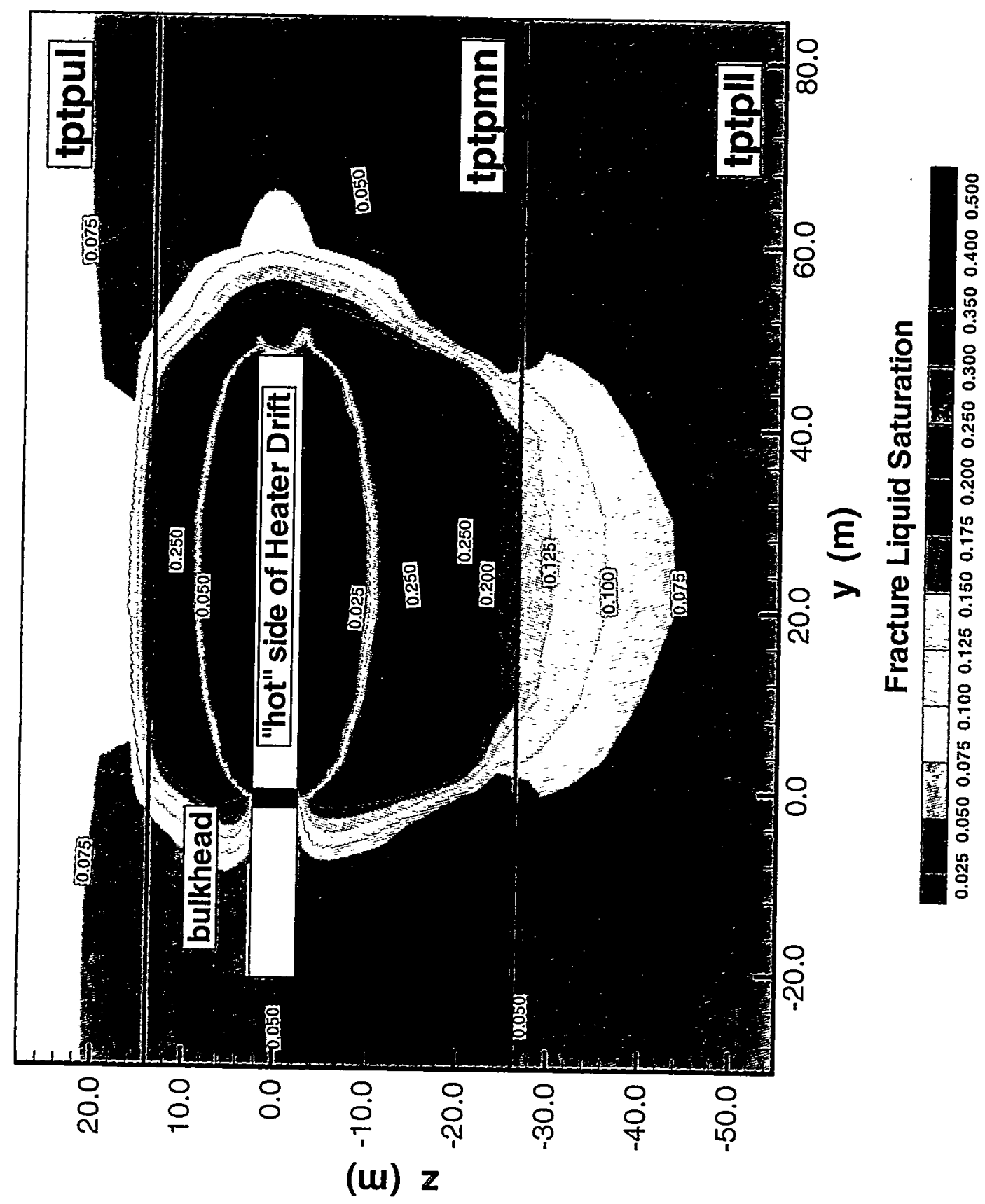

Figure 5.2-15 Fracture liquid saturation after 4 years of heating in yz-cross section at $x=0.0 \mathrm{~m}$ for $0.36 \mathrm{~mm} / \mathrm{yr}$ infiltration case (1 year heating at 100\%, 3 years heating at 50\%). 


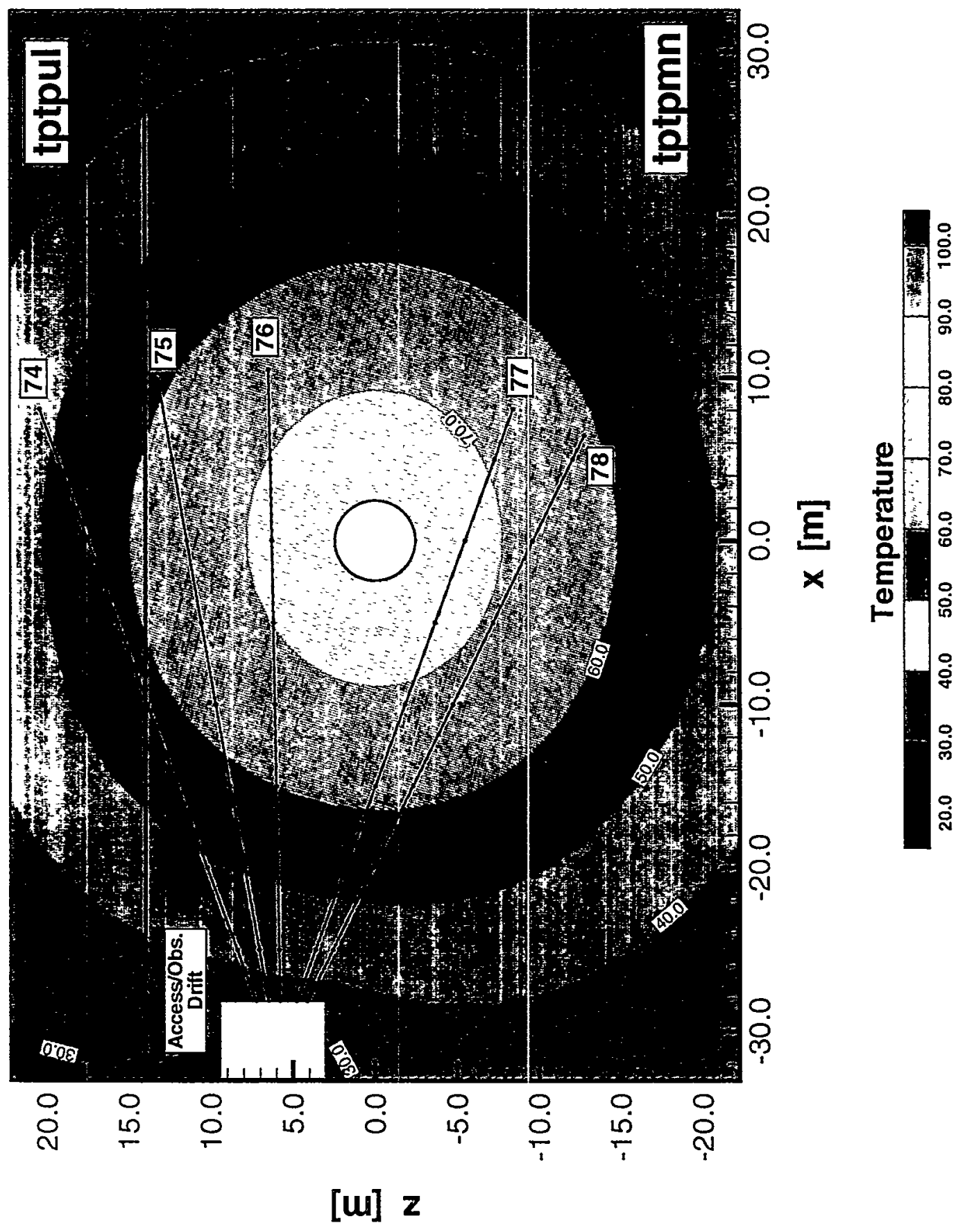

Figure 5.2-16 Temperature response after 4 years of cooling in $x z$-cross section at $y=30.18 \mathrm{~m}$ for $0.36 \mathrm{~mm} / \mathrm{yr}$ infiltration case (1 year heating at 100\%, 3 years heating at $50 \%$ ). Also presented is the location of hydrology holes 74 through 77. 


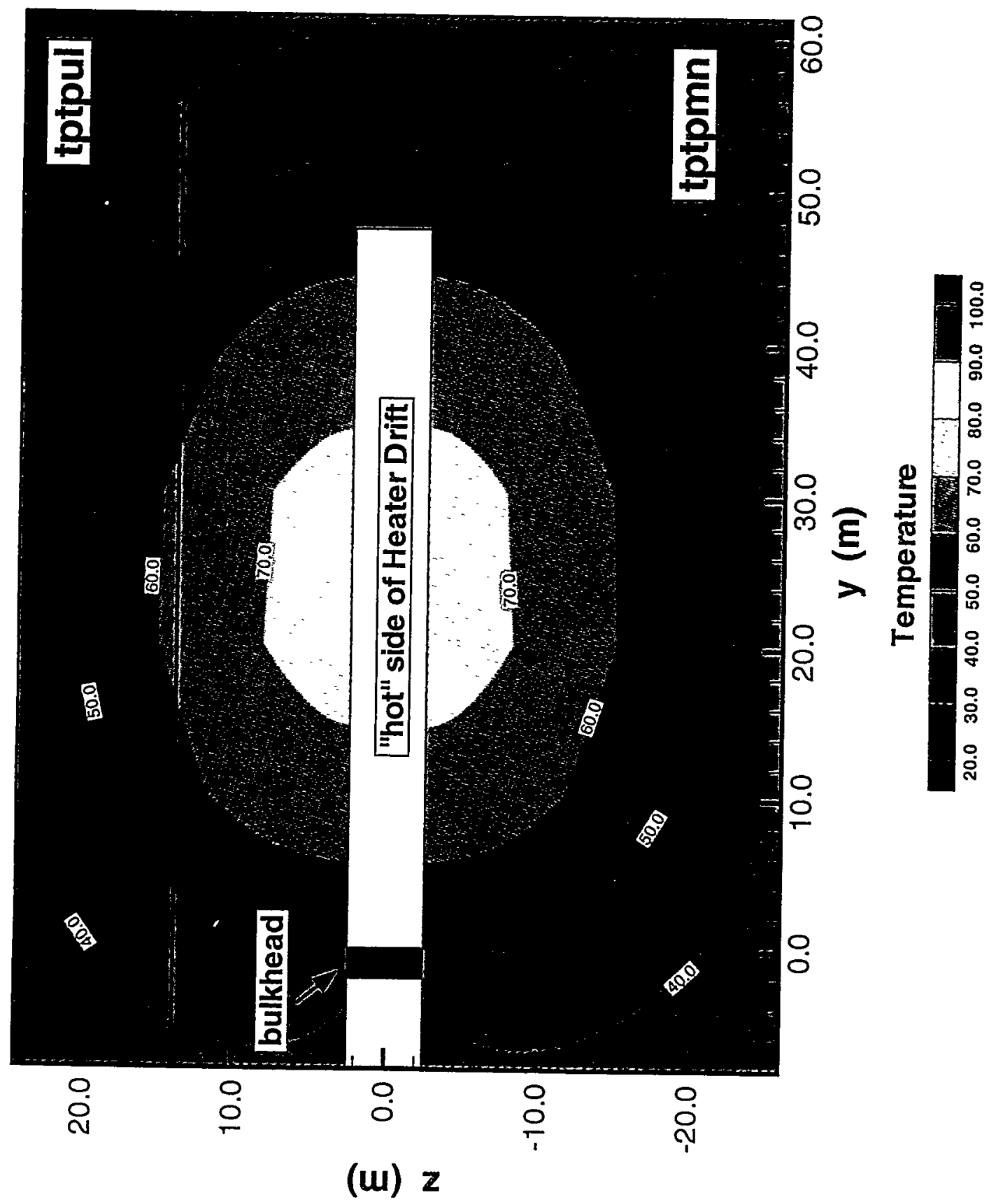

Figure 5.2-17 Temperature response after 4 years of cooling in yz-cross section at $x=0.0 \mathrm{~m}$ for $0.36 \mathrm{~mm} / \mathrm{yr}$ infiltration case (1 year heating at 100\%, 3 years heating at 50\%). 


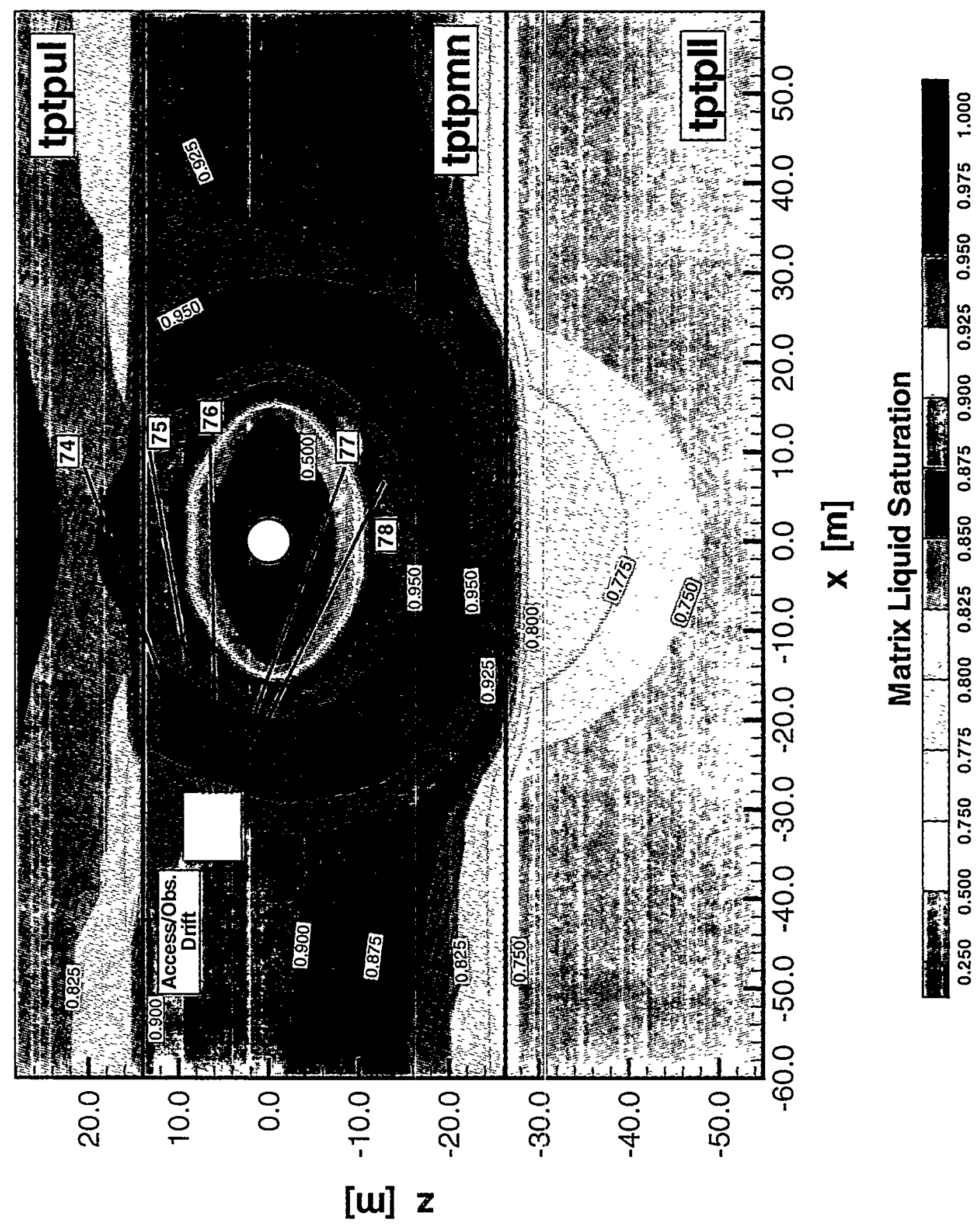

Figure 5.2-18 Matrix liquid saturation after 4 years of cooling in $x z$-cross section at $y=30.18 \mathrm{~m}$ for $0.36 \mathrm{~mm} / y \mathrm{r}$ infiltration case (1 year heating at 100\%, 3 years heating at 50\%). Also presented is the location of hydrology holes 74 through 77 


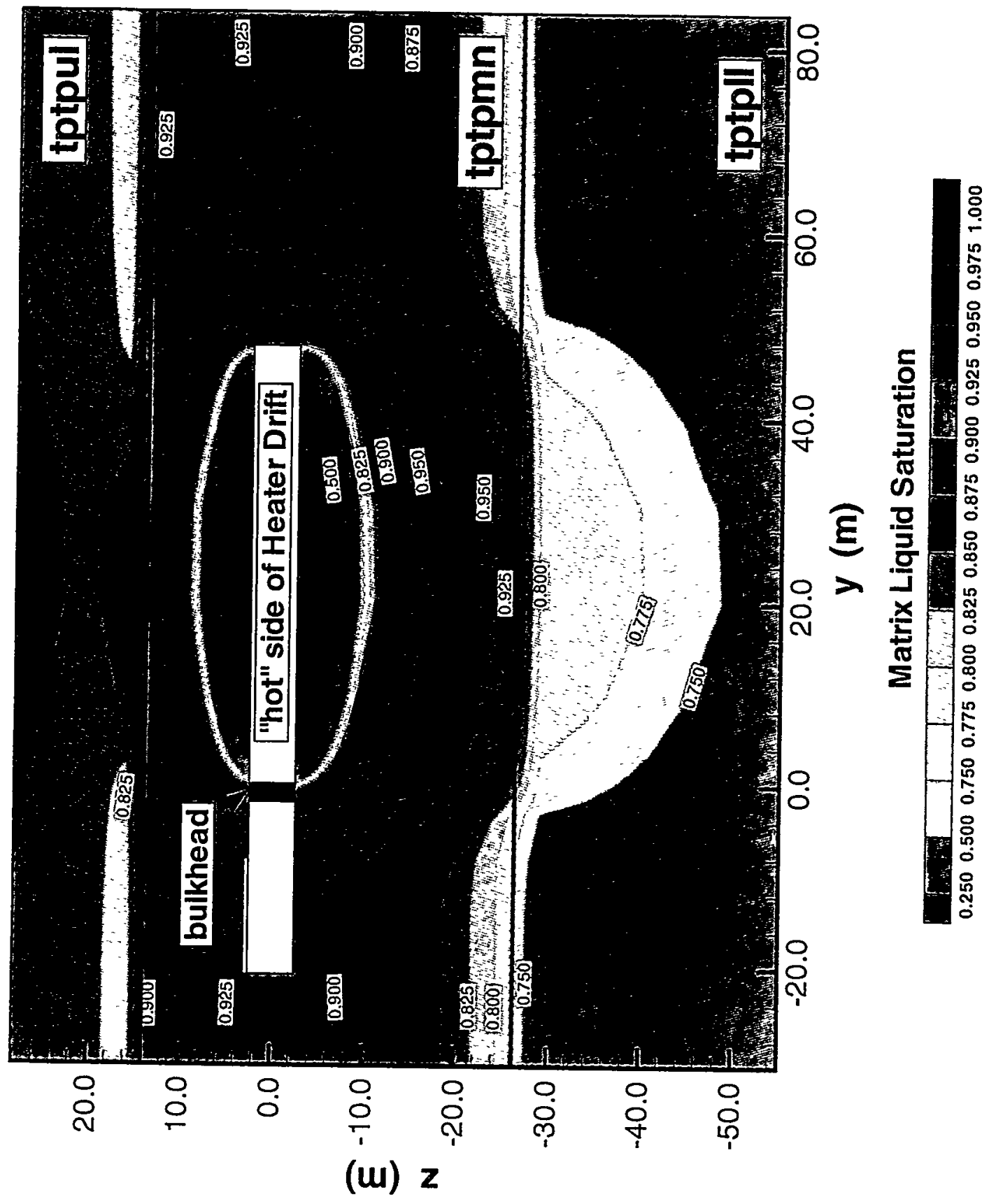

Figure 5.2-19 Matrix liquid saturation after 4 years of cooling in $y z$-cross section at $x=0.0 \mathrm{~m}$ for $0.36 \mathrm{~mm} / \mathrm{yr}$ infiltration case (1 year heating at 100\%, 3 years heating at 50\%). 


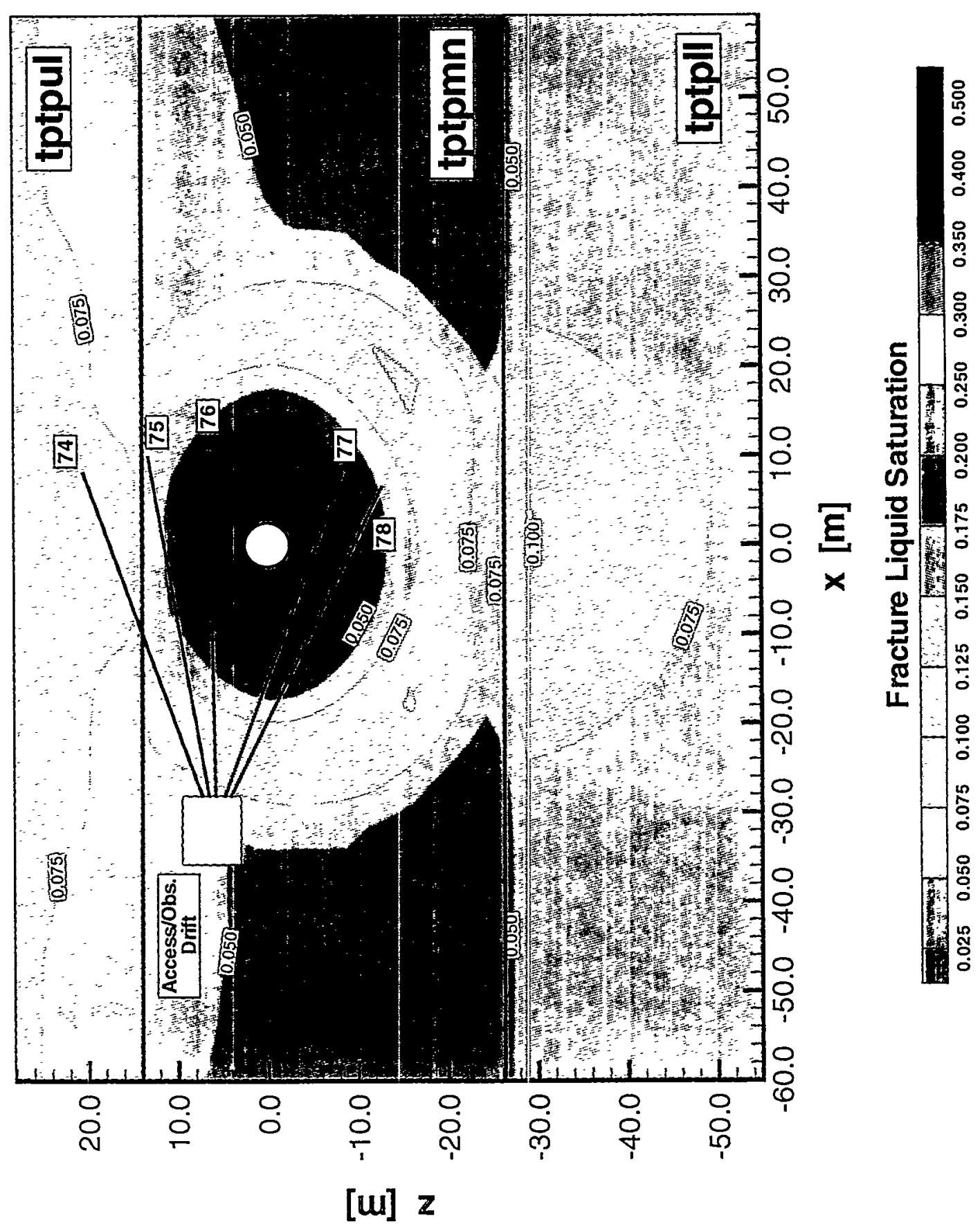

Figure 5.2-20 Fracture liquid saturation after 4 years of cooling in $x z$ - cross section at $y=30.18 \mathrm{~m}$ for $0.36 \mathrm{~mm} / \mathrm{yr}$ infiltration case (1 year heating at 100\%, 3 years heating at $50 \%$ ). Also presented is the location of hydrology holes 74 through 77. 


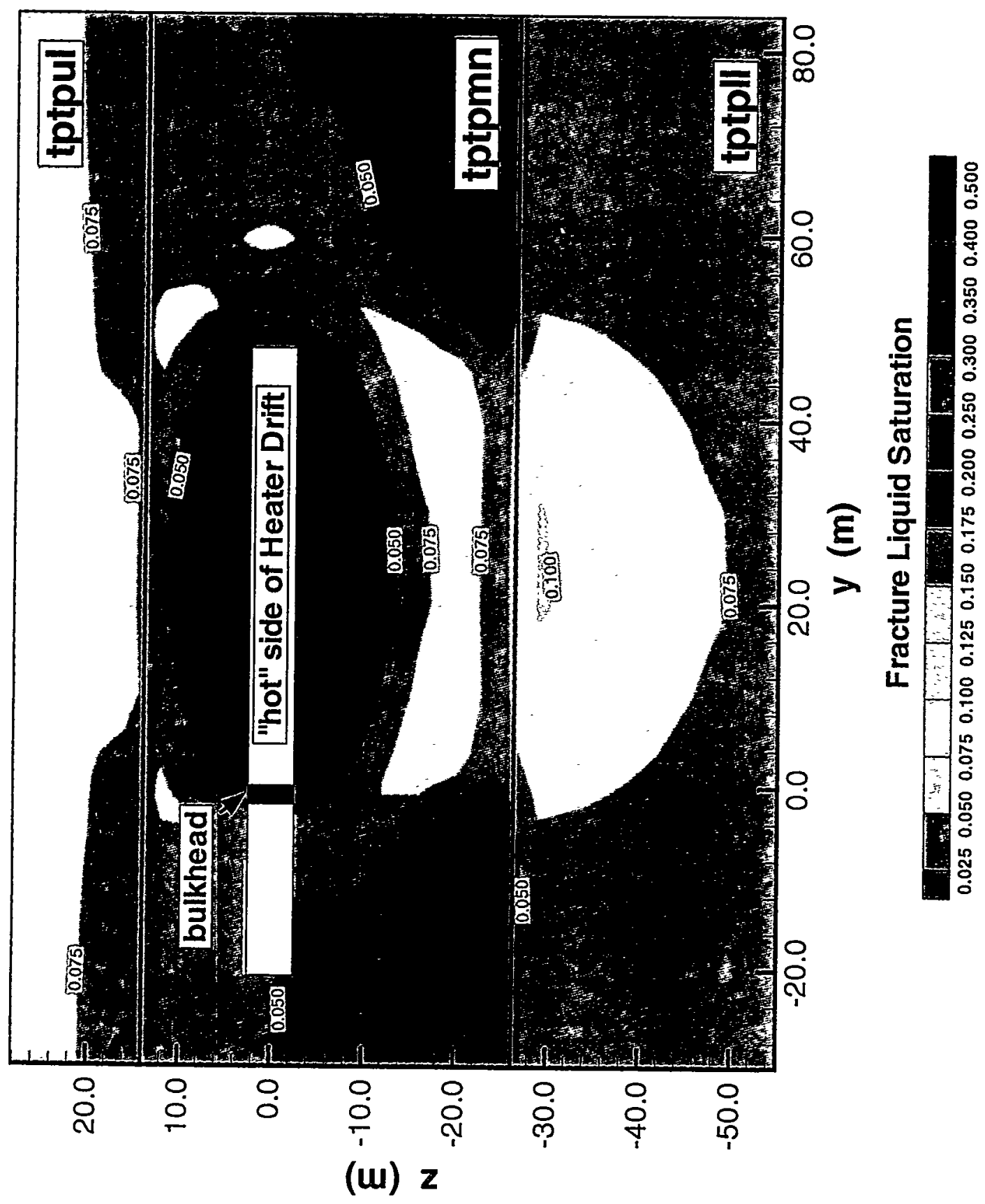

Figure 5.2-21 Fracture liquid saturation after 4 years of cooling in $y z$-cross section at $x=0.0 \mathrm{~m}$ for $0.36 \mathrm{~mm} / \mathrm{yr}$ infiltration case (1 year heating at 100\%, 3 years heating at $50 \%$ ). 


\section{Heating Period}

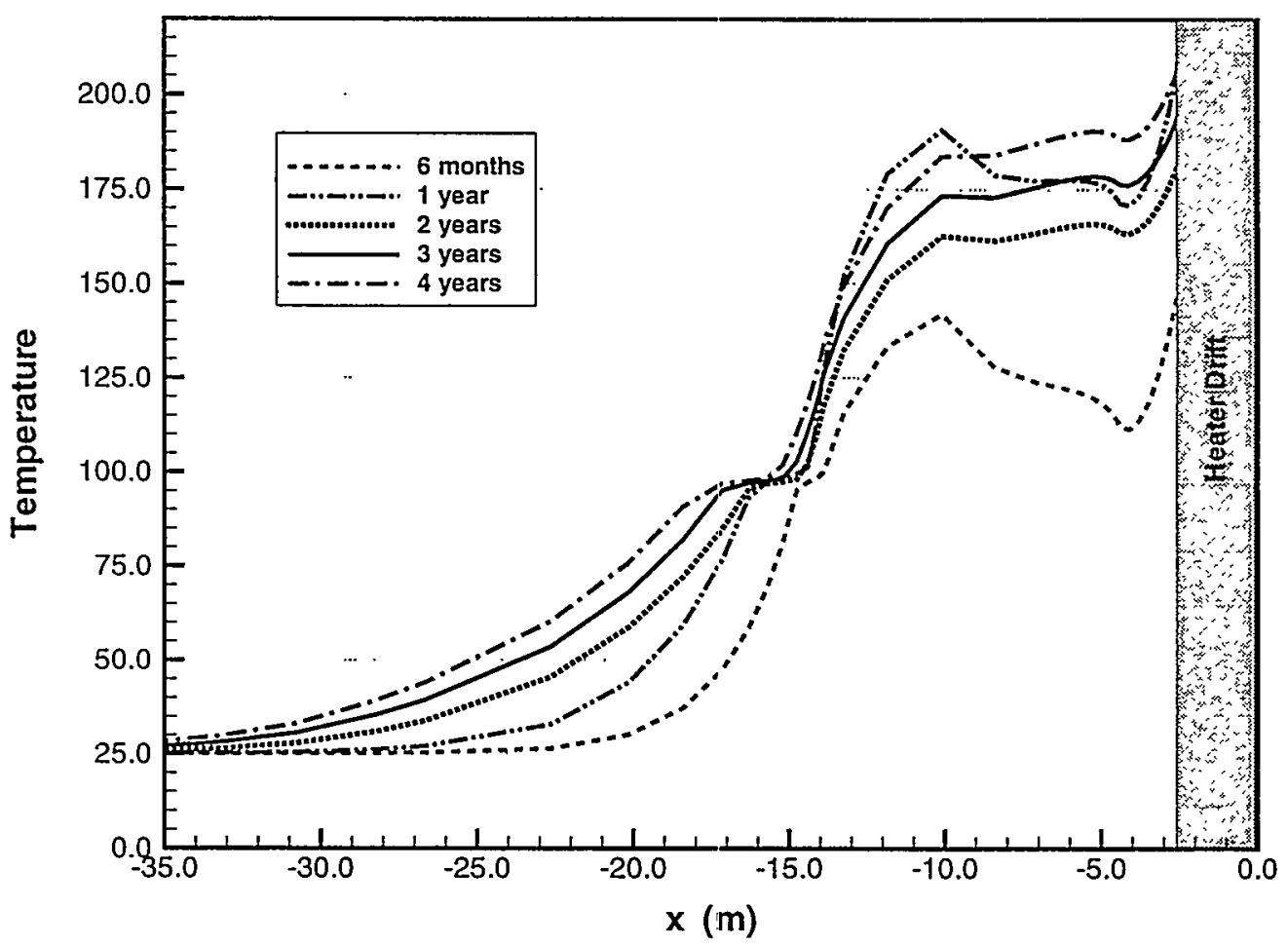

Cooling Period

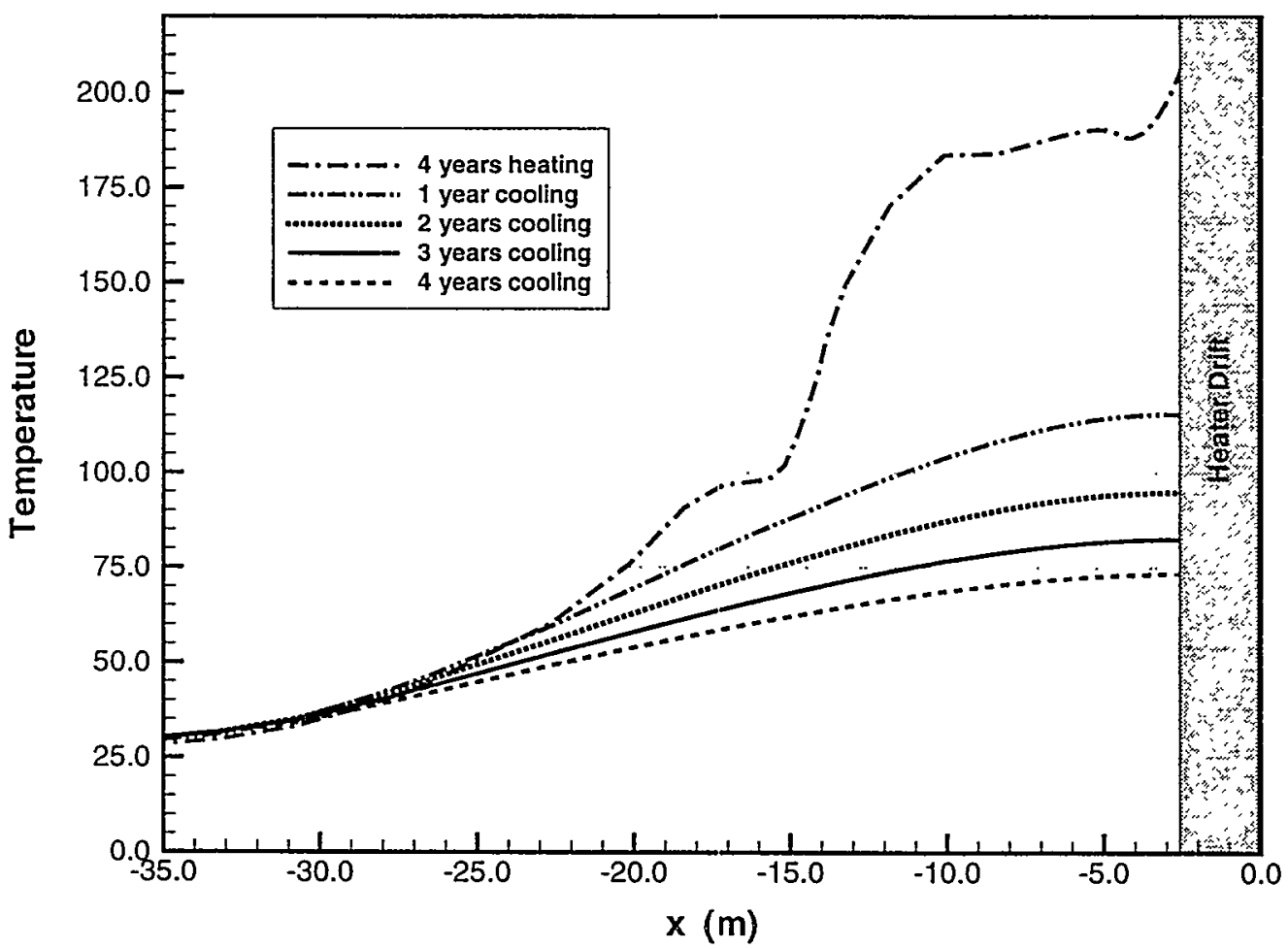

Figure 5.2-22 Temperature profiles along $x$-axis at $y=30.18 \mathrm{~m}$ and $z=0.0 \mathrm{~m}$ for $0.36 \mathrm{~mm} / \mathrm{yr}$ infiltration case ( 1 year heating at $100 \%, 3$ years heating at $50 \%$ ). 


\section{Heating Period}

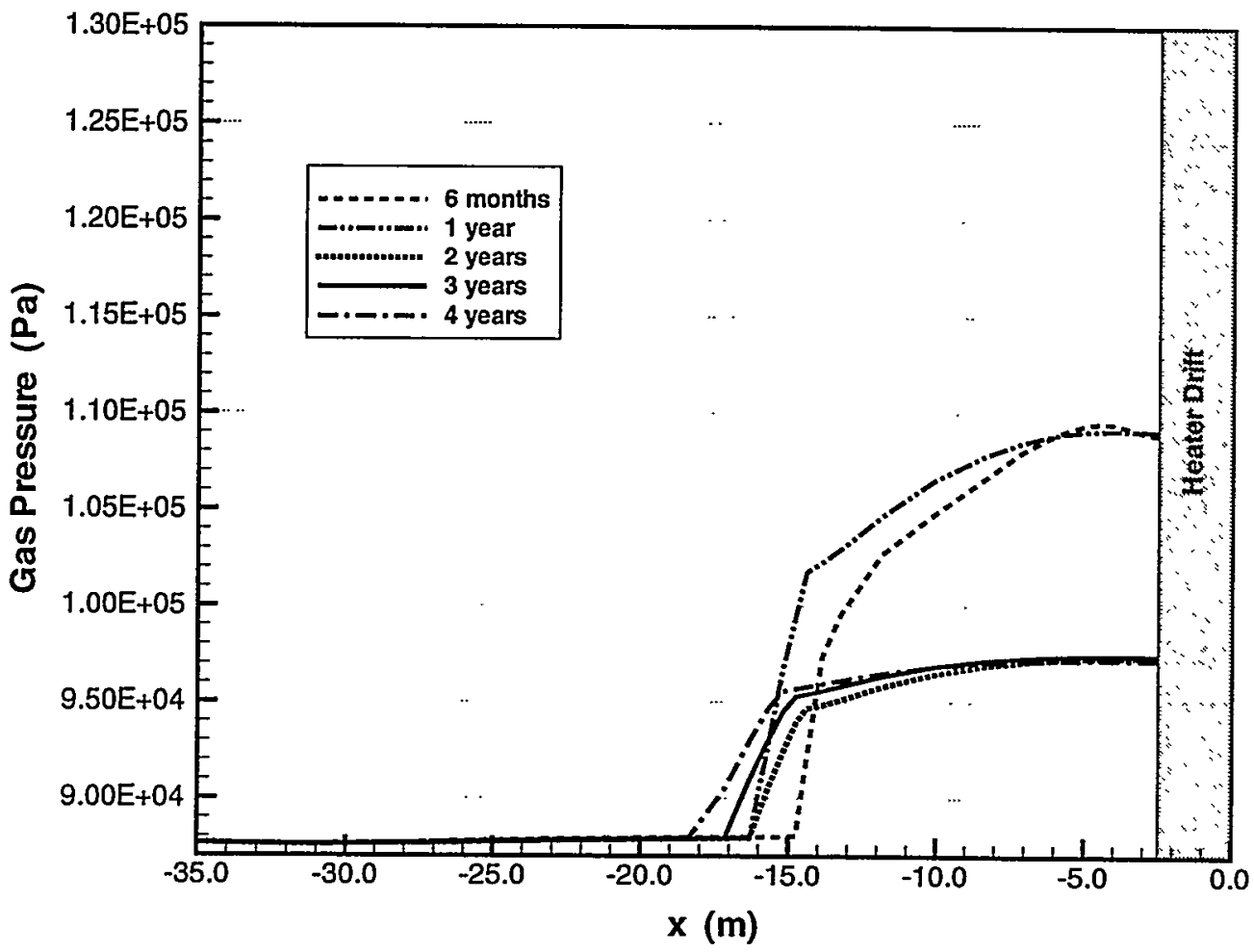

Cooling Period

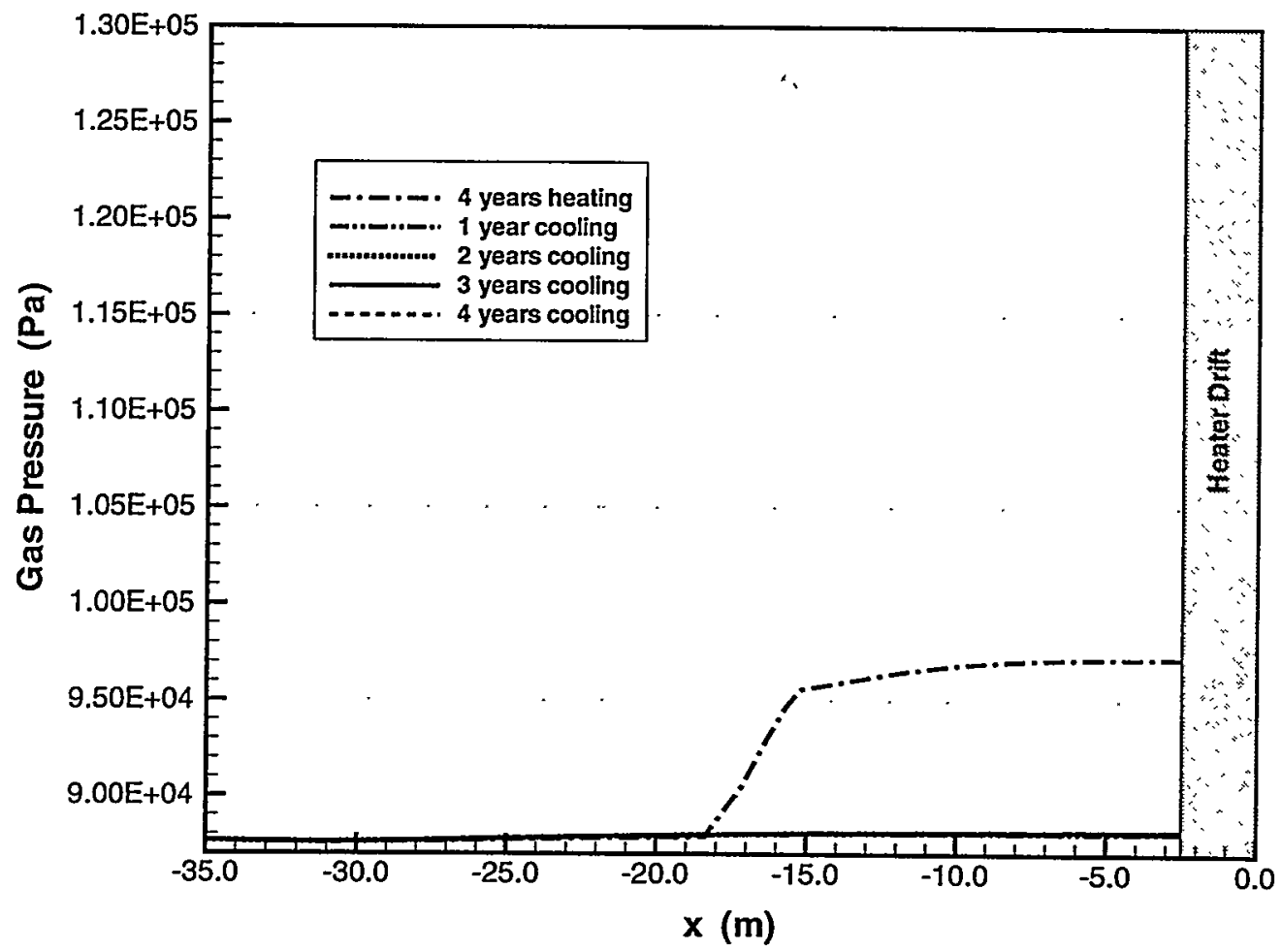

Figure 5.2-23 Gas pressure profiles along $x$-axis at $y=30.18 \mathrm{~m}$ and $z=0.0 \mathrm{~m}$ for $0.36 \mathrm{~mm} / y$ r infiltration case (1 year heating at 100\%, 3 years heating at $50 \%$ ). 


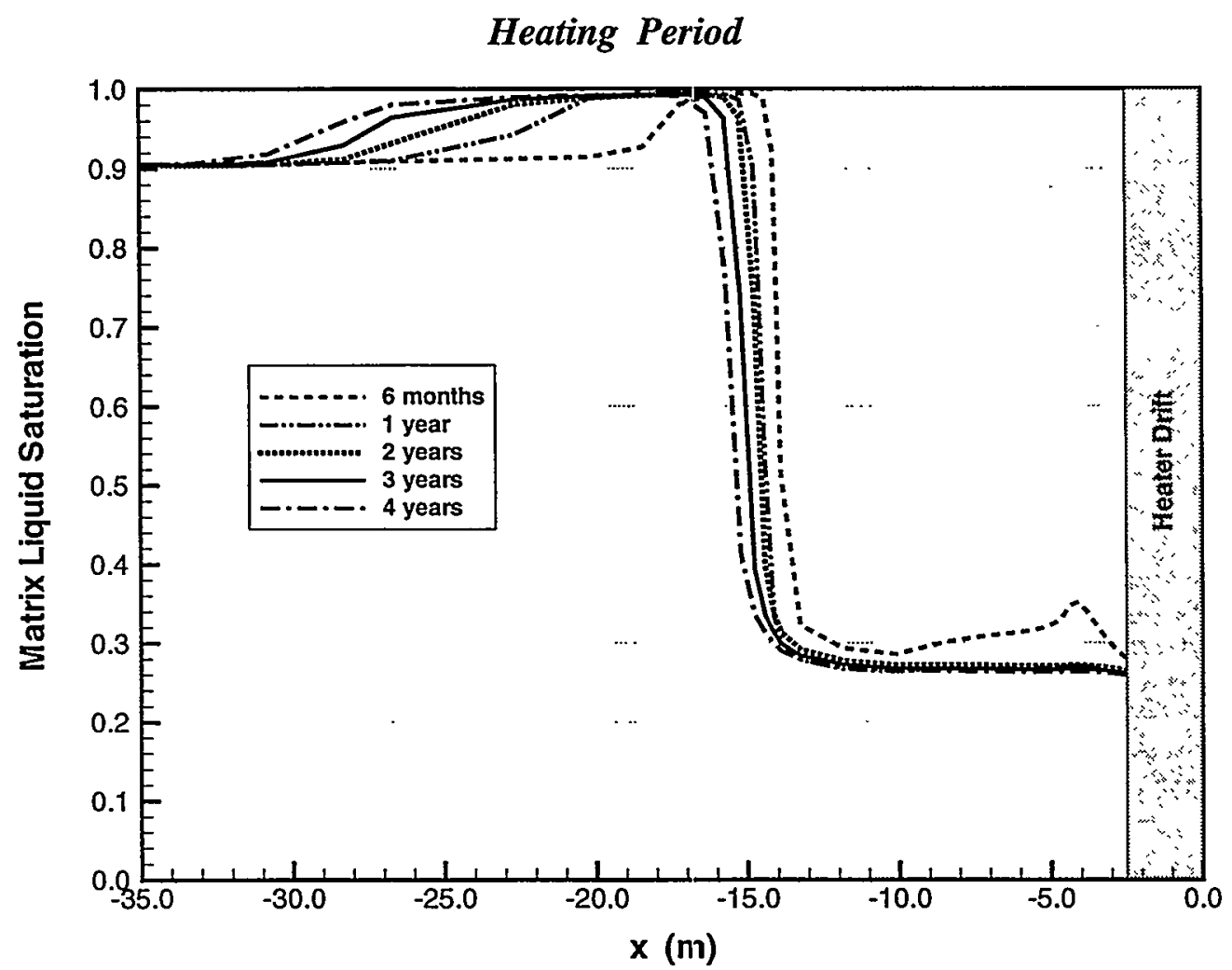

Cooling Period

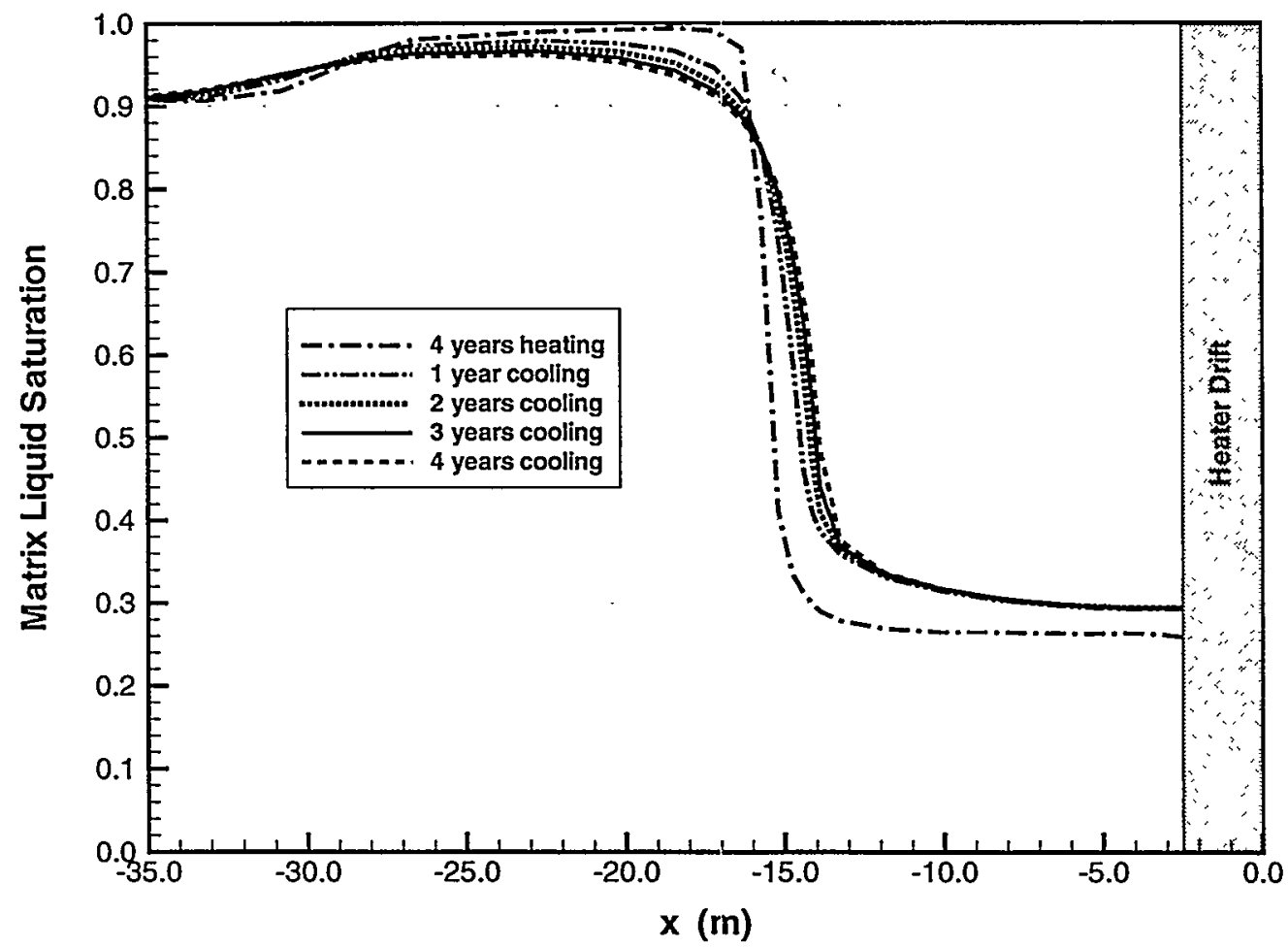

Figure 5.2-24 Matrix liquid saturation profiles along $x$-axis at $y=30.18 \mathrm{~m}$ and $z=0.0 \mathrm{~m}$ for $0.36 \mathrm{~mm} / \mathrm{yr}$ infiltration case (1 year heating at $100 \%, 3$ years heating at $50 \%$ ). 


\section{Heating Period}

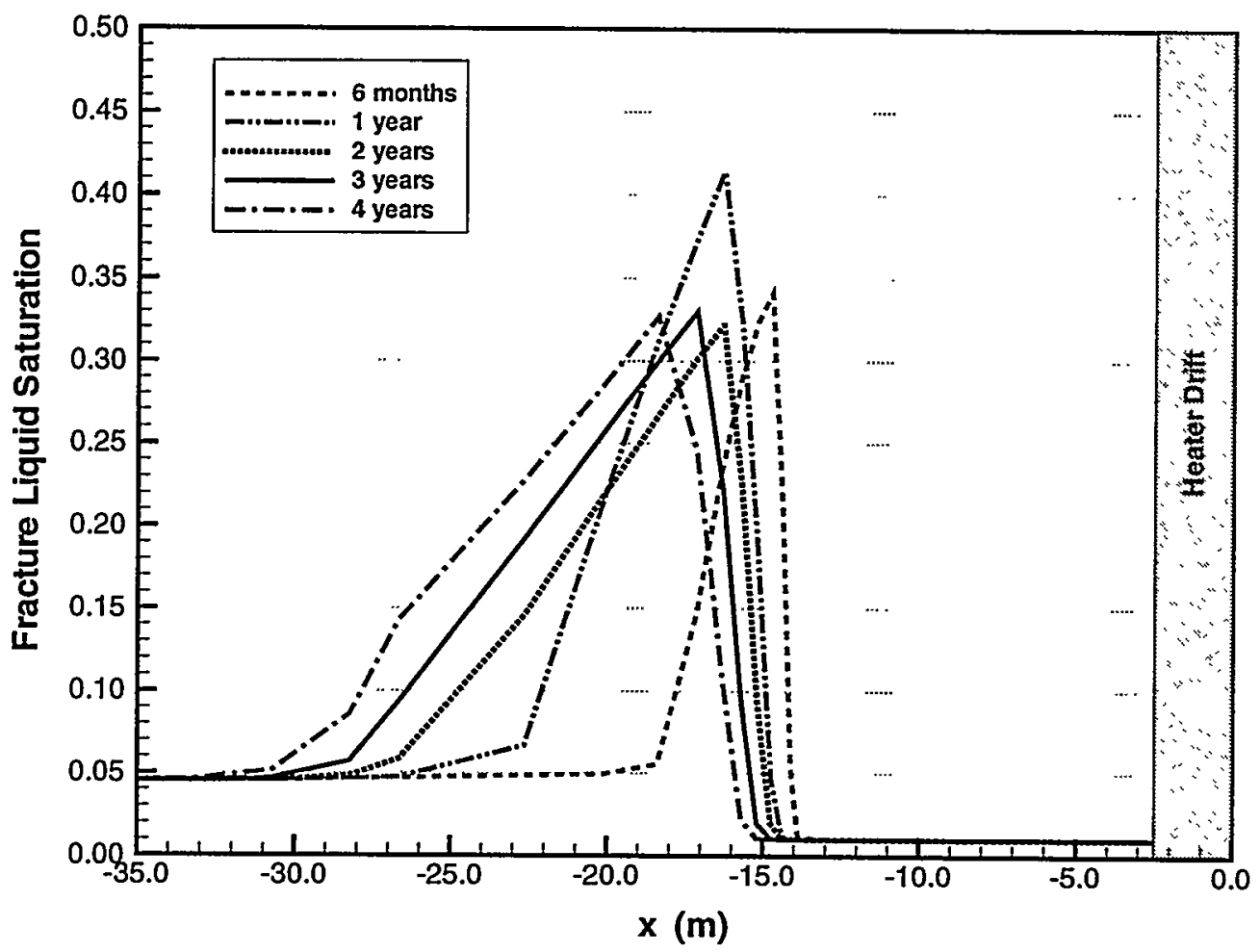

Cooling Period

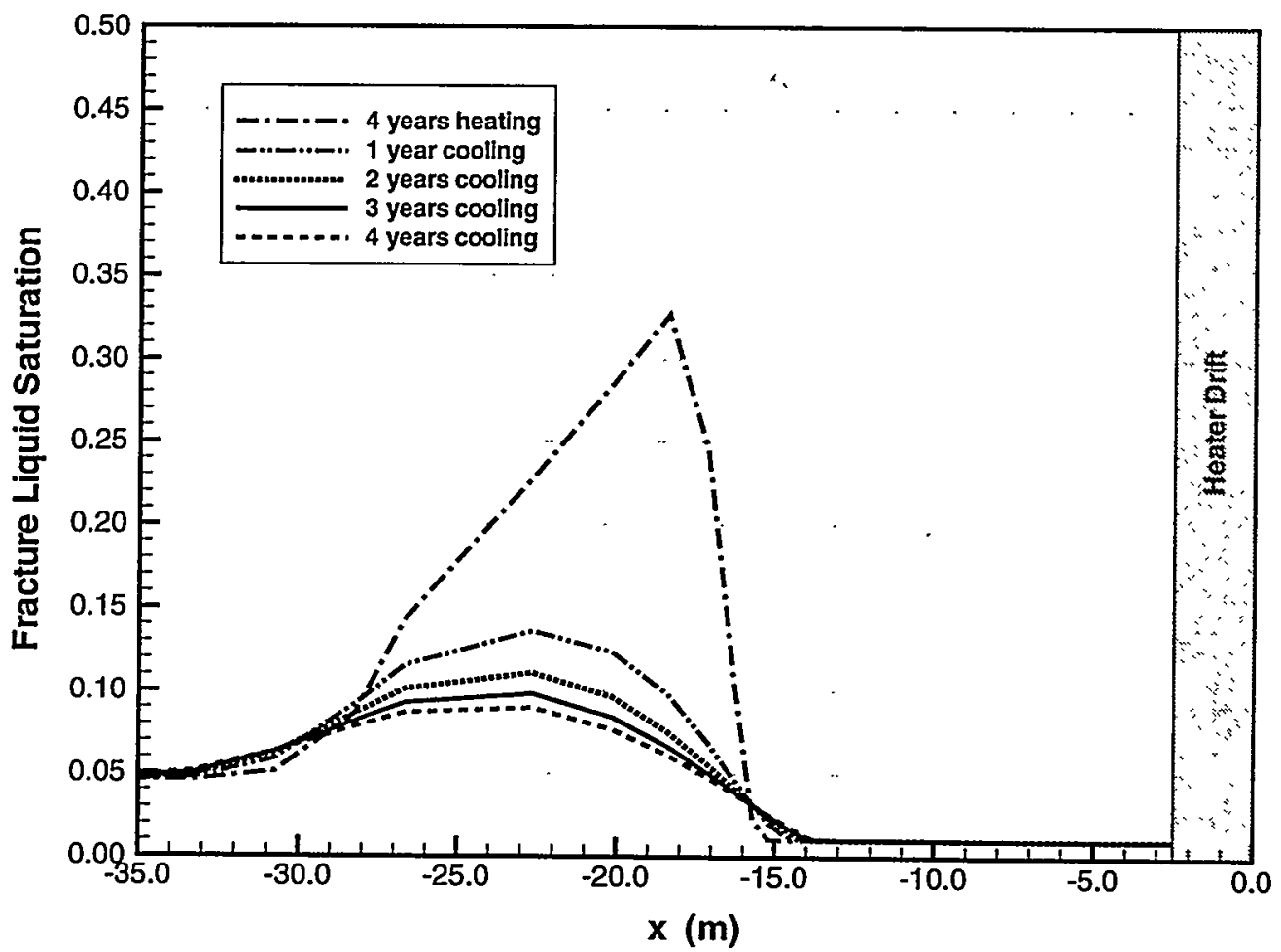

Figure 5.2-25 Fracture liquid saturation profiles along $x$-axis at $y=30.18 \mathrm{~m}$ and $z=0.0 \mathrm{~m}$ for $0.36 \mathrm{~mm} / \mathrm{yr}$ infiltration case (1 year heating at 100\%, 3 years heating at $50 \%$ ). 
Heating Period

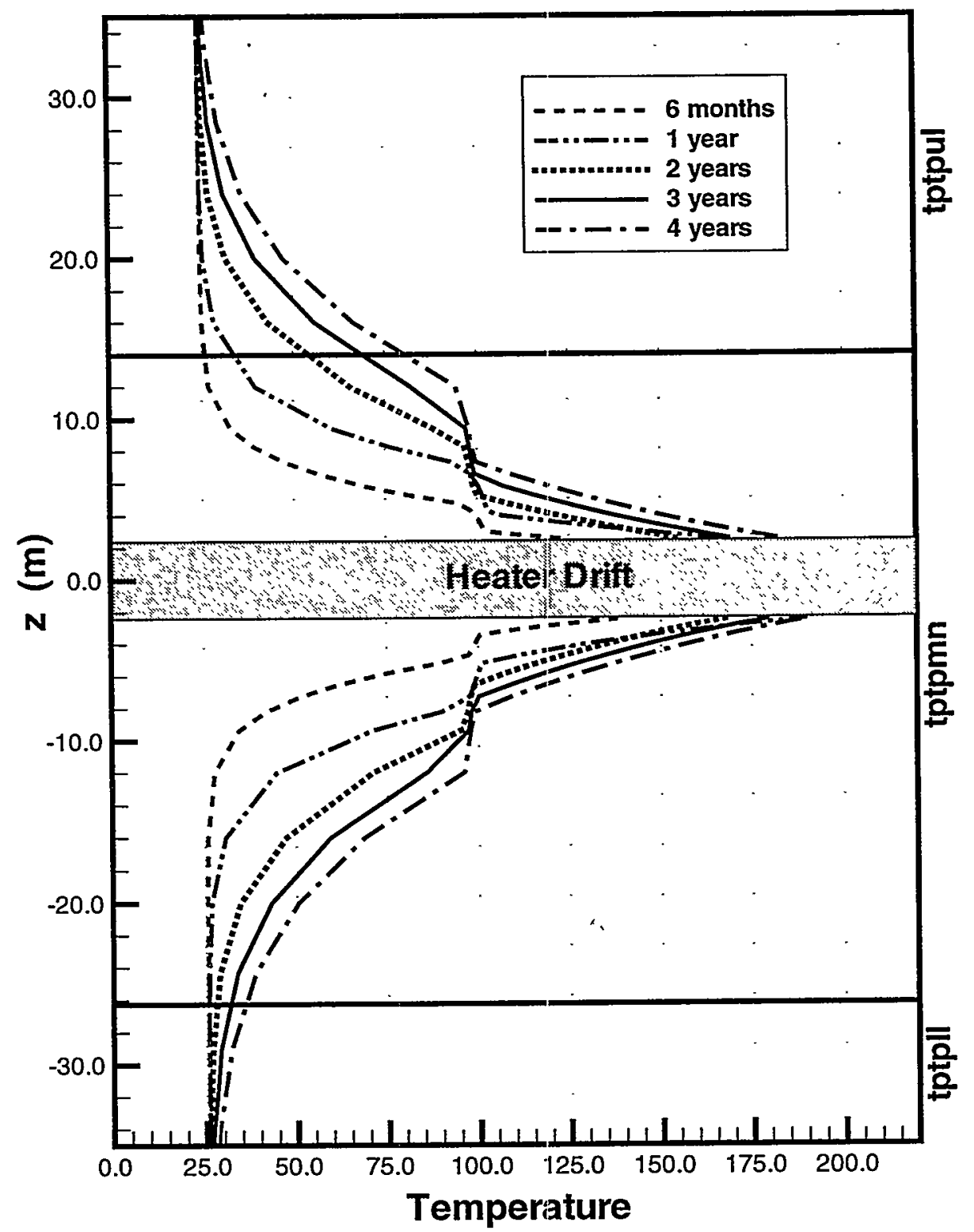

Figure 5.2-26 Temperature profiles along $z$-axis at $x=0.0 \mathrm{~m}$ and $y=30.18 \mathrm{~m}$ for $0.36 \mathrm{~mm} / \mathrm{yr}$ infiltration case during heating ( 1 year heating at 100\%, 3 years heating at $50 \%$ ). 
Cooling Period

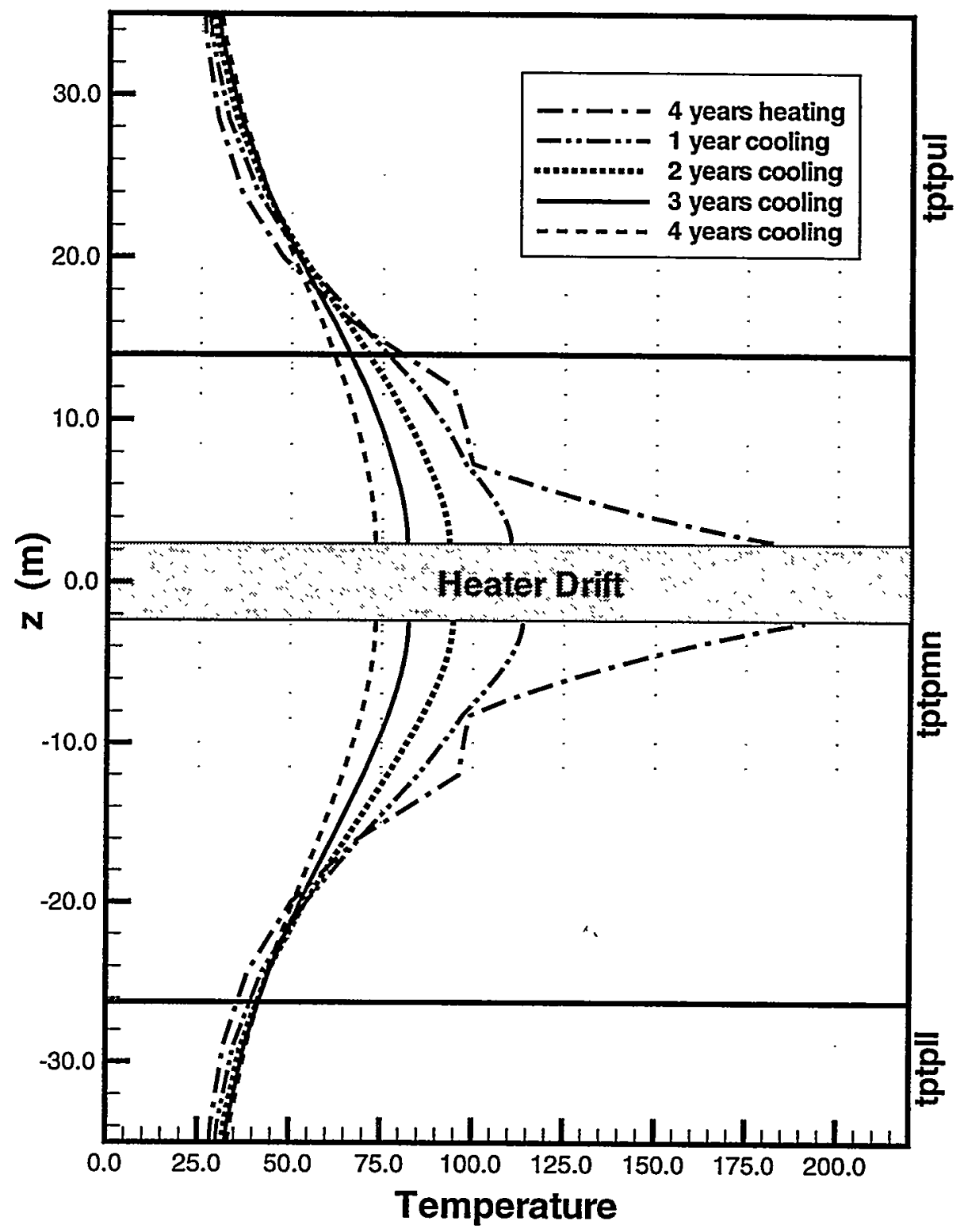

Figure 5.2-27 Temperature profiles along $z$-axis at $x=0.0 \mathrm{~m}$ and $y=30.18 \mathrm{~m}$ for $0.36 \mathrm{~mm} / \mathrm{yr}$ infiltration case during cooling (1 year heating at 100\%, 3 years heating at $50 \%$ ). 


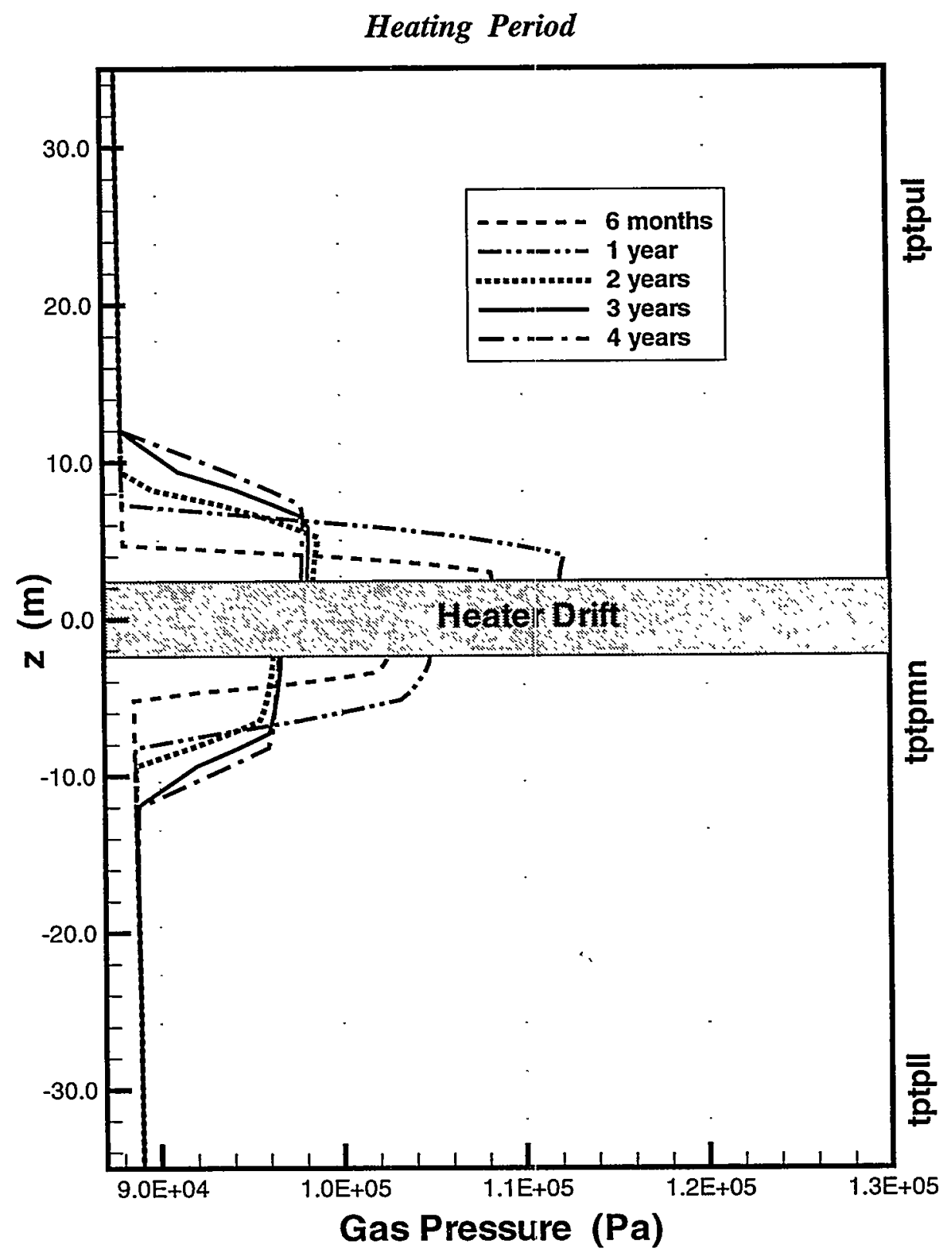

Figure 5.2-28 Gas pressure profiles along $z$-axis at $x=0.0 \mathrm{~m}$ and $y=30.18 \mathrm{~m}$ for $0.36 \mathrm{~mm} / \mathrm{yr}$ infiltration case during heating ( 1 year heating at $100 \%, 3$ years heating at $50 \%$ ). 


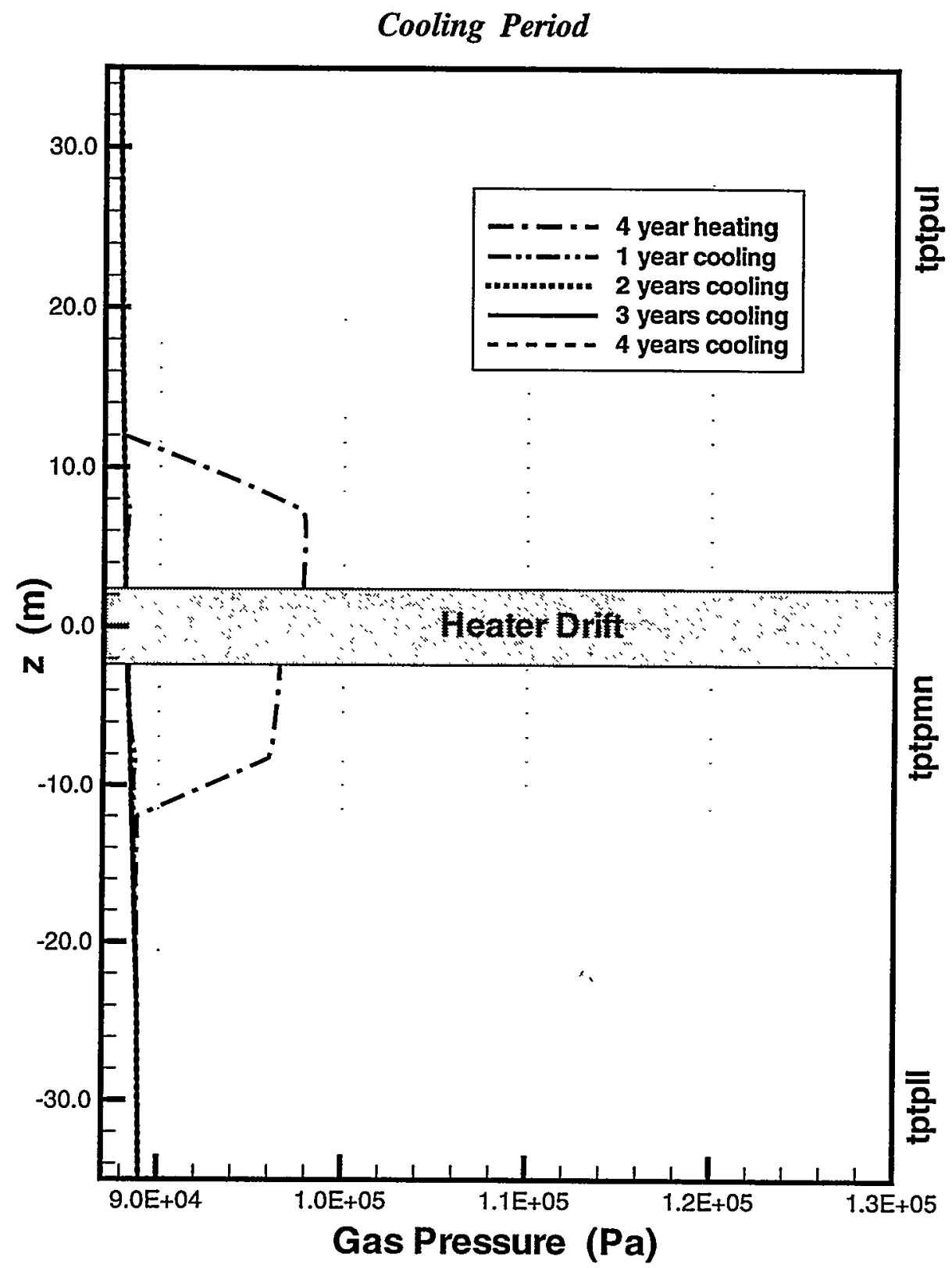

Figure 5.2-29 Gas pressure profiles along $z$-axis at $x=0.0 \mathrm{~m}$ and $y=30.18 \mathrm{~m}$ for $0.36 \mathrm{~mm} / \mathrm{yr}$ infiltration case during cooling ( 1 year heating at 100\%, 3 years heating at 50\%). 


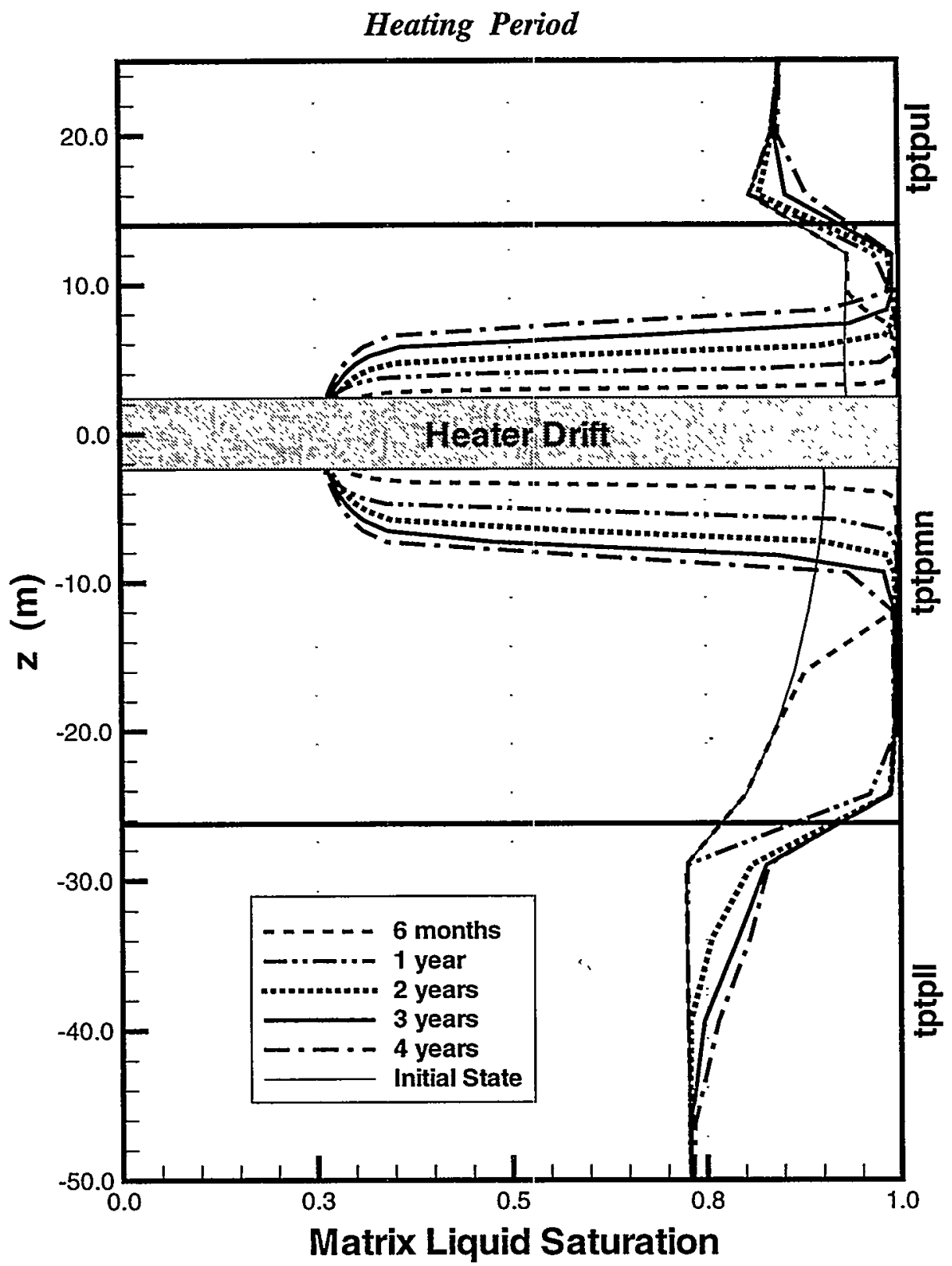

Figure 5.2-30 Matrix liquid saturation profiles along $z$-axis at $x=0.0 \mathrm{~m}$ and $y=30.18 \mathrm{~m}$ for $0.36 \mathrm{~mm} / \mathrm{yr}$ infiltration case during heating (1 year heating at 100\%, 3 years heating at $50 \%$ ). 


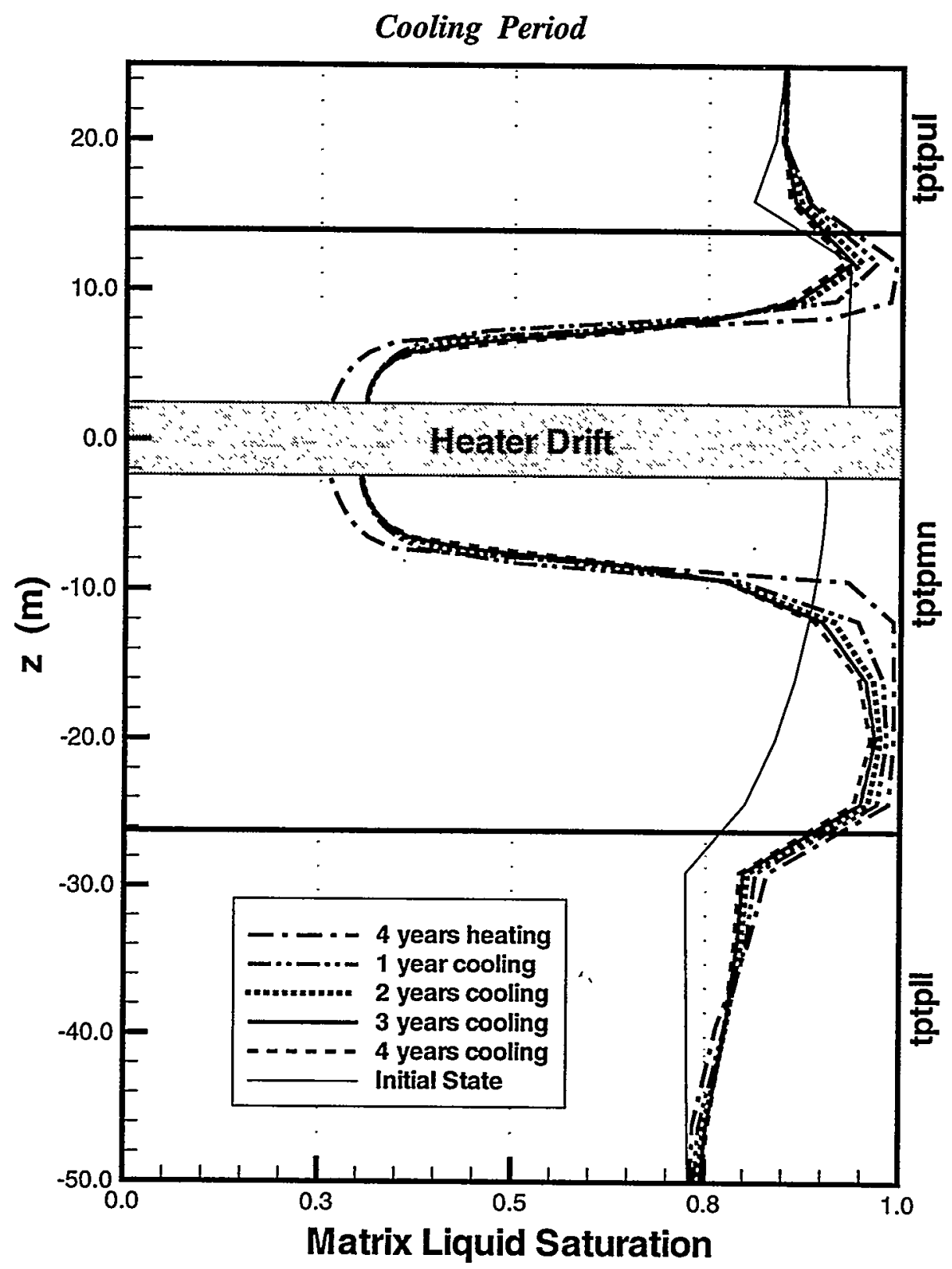

Figure 5.2-31 Matrix liquid saturation profiles along $z$-axis at $x=0.0 \mathrm{~m}$ and $y=30.18 \mathrm{~m}$ for $0.36 \mathrm{~mm} / \mathrm{yr}$ infiltration case during cooling (1 year heating at 100\%, 3 years heating at $50 \%$ ). 


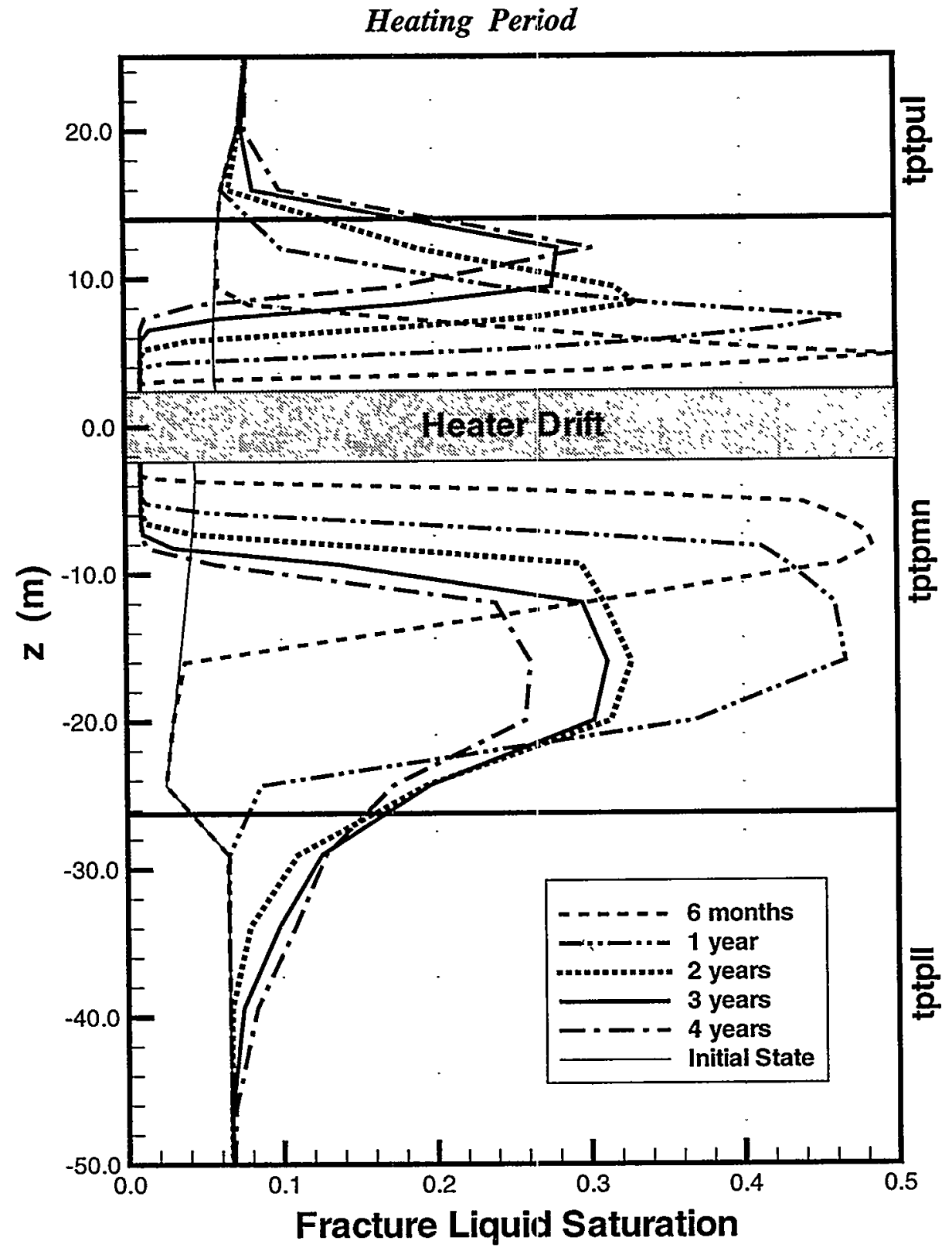

Figure 5.2-32 Fracture liquid saturation profiles along $z$-axis at $x=0.0 \mathrm{~m}$ and $y=30.18 \mathrm{~m}$ for $0.36 \mathrm{~mm} / \mathrm{yr}$ infiltration case during heating (1 year heating at 100\%, 3 years heating at $50 \%$ ). 


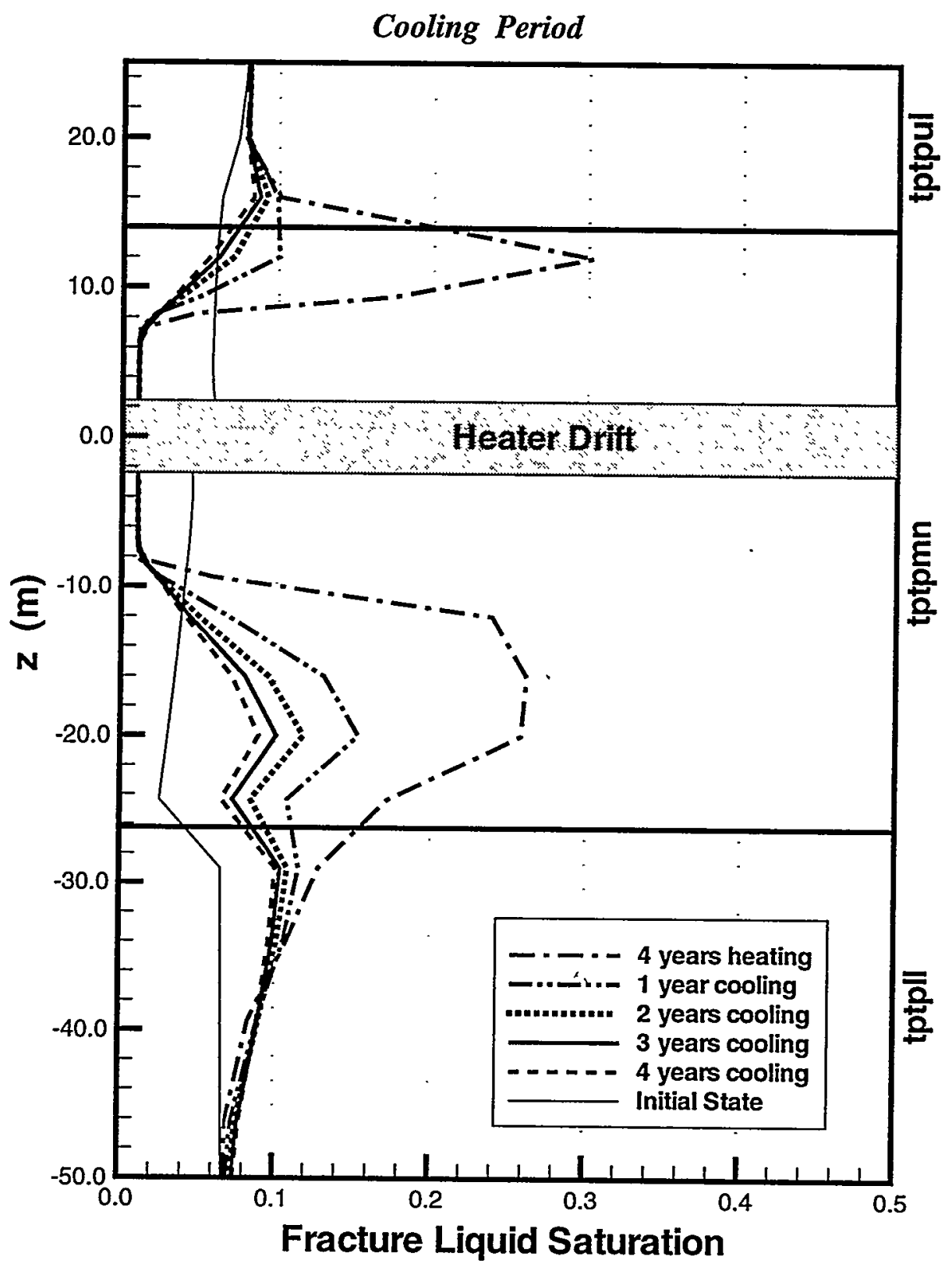

Figure 5.2-33 Fracture liquid saturation profiles along $z$-axis at $x=0.0 \mathrm{~m}$ and $y=30.18 \mathrm{~m}$ for $0.36 \mathrm{~mm} / \mathrm{yr}$ infiltration case during cooling (1 year heating at 100\%, 3 years heating at $50 \%$ ). 


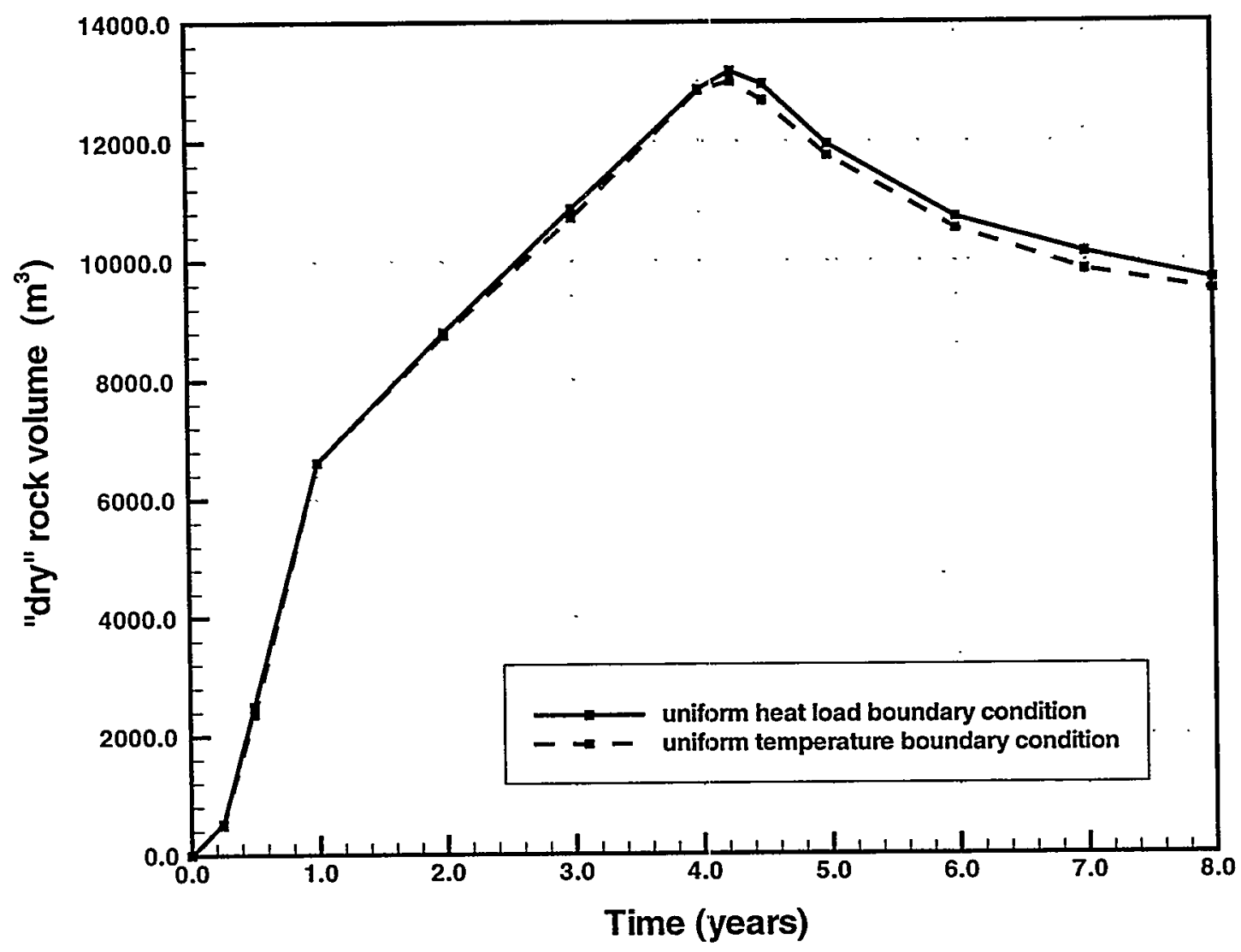

Figure 5.2-34 Evolution of dry-out rock volume for $0.36 \mathrm{~mm} / \mathrm{yr}$ infiltration case. Both the uniform temperature and the uniform heat load case are shown

(1 year heating at 100\%, 3 years heating at $50 \%$ ). 


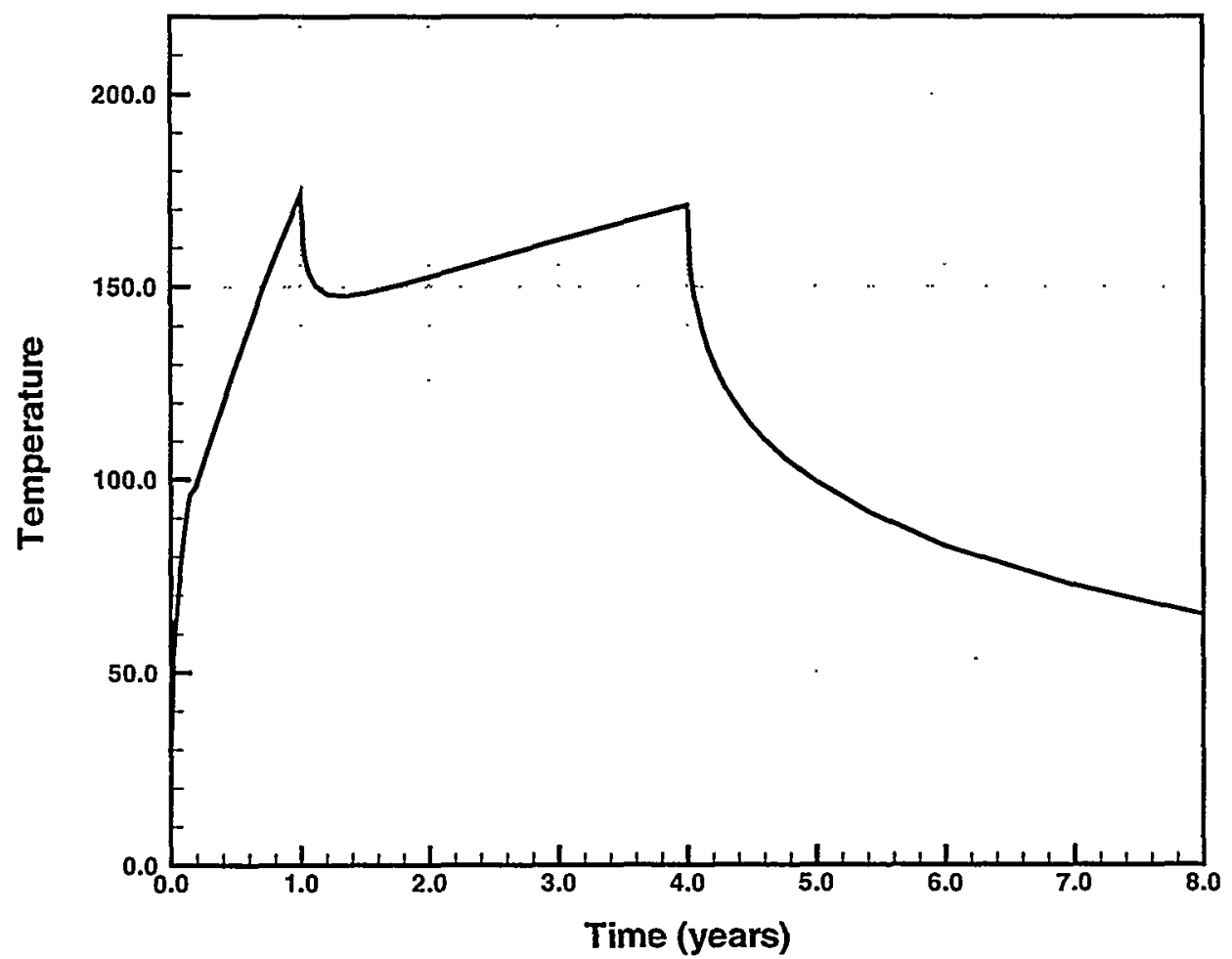

Figure 5.2-35 Temperature evolution at the heater drift wall for uniform temperature boundary condition in the heater drift (1 year heating at 100\%, 3 years heating at 50\%). 


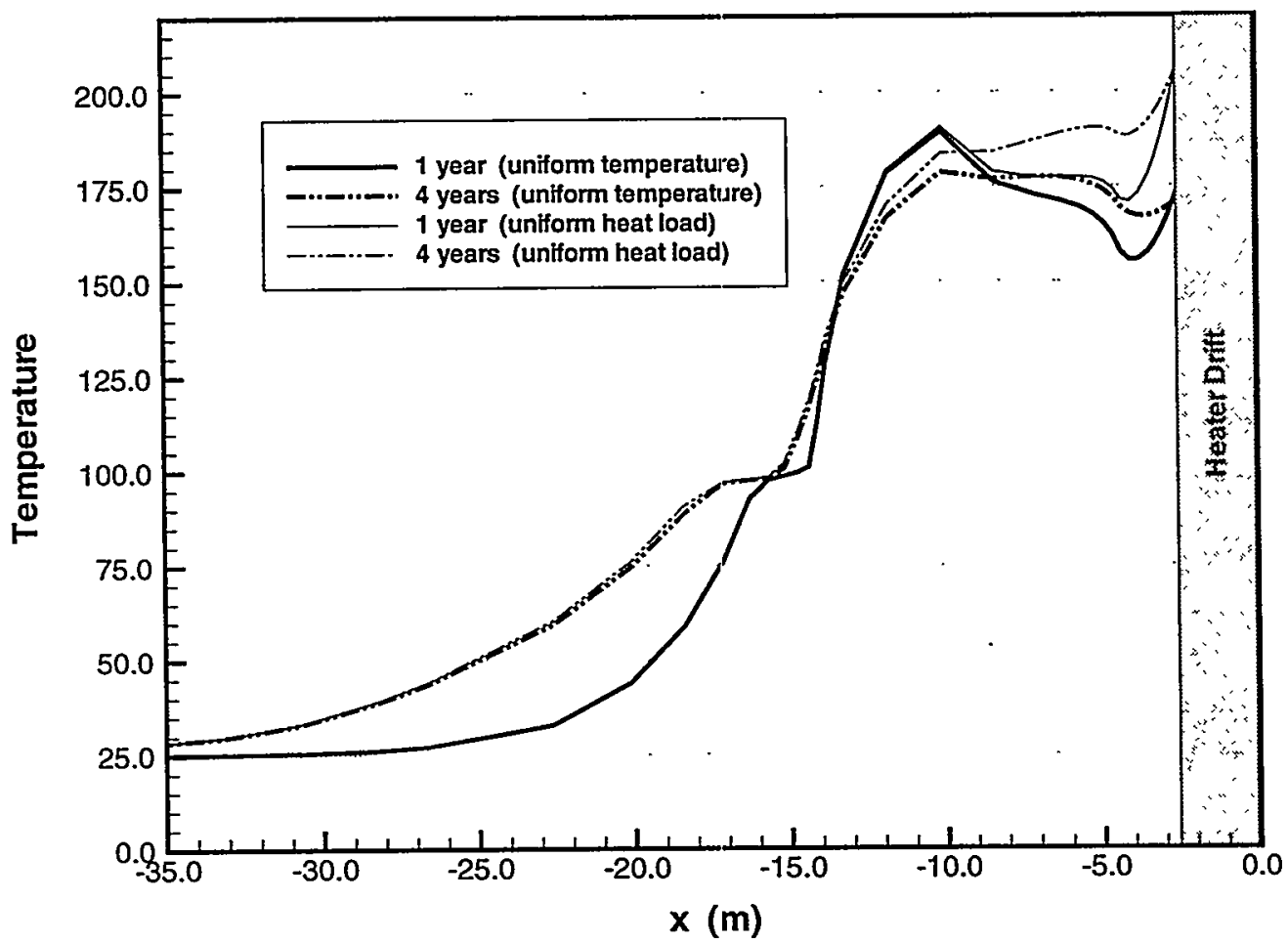

Figure 5.2-36 Temperature profiles along $x$-axis at $y=30.18 \mathrm{~m}$ and $z=0.0 \mathrm{~m}$ for $0.36 \mathrm{~mm} / \mathrm{yr}$ infiltration case. Both the uniform temperature and the uniform heat load case are shown

(I year heating at 100\%, 3 years heating at $50 \%$ ).

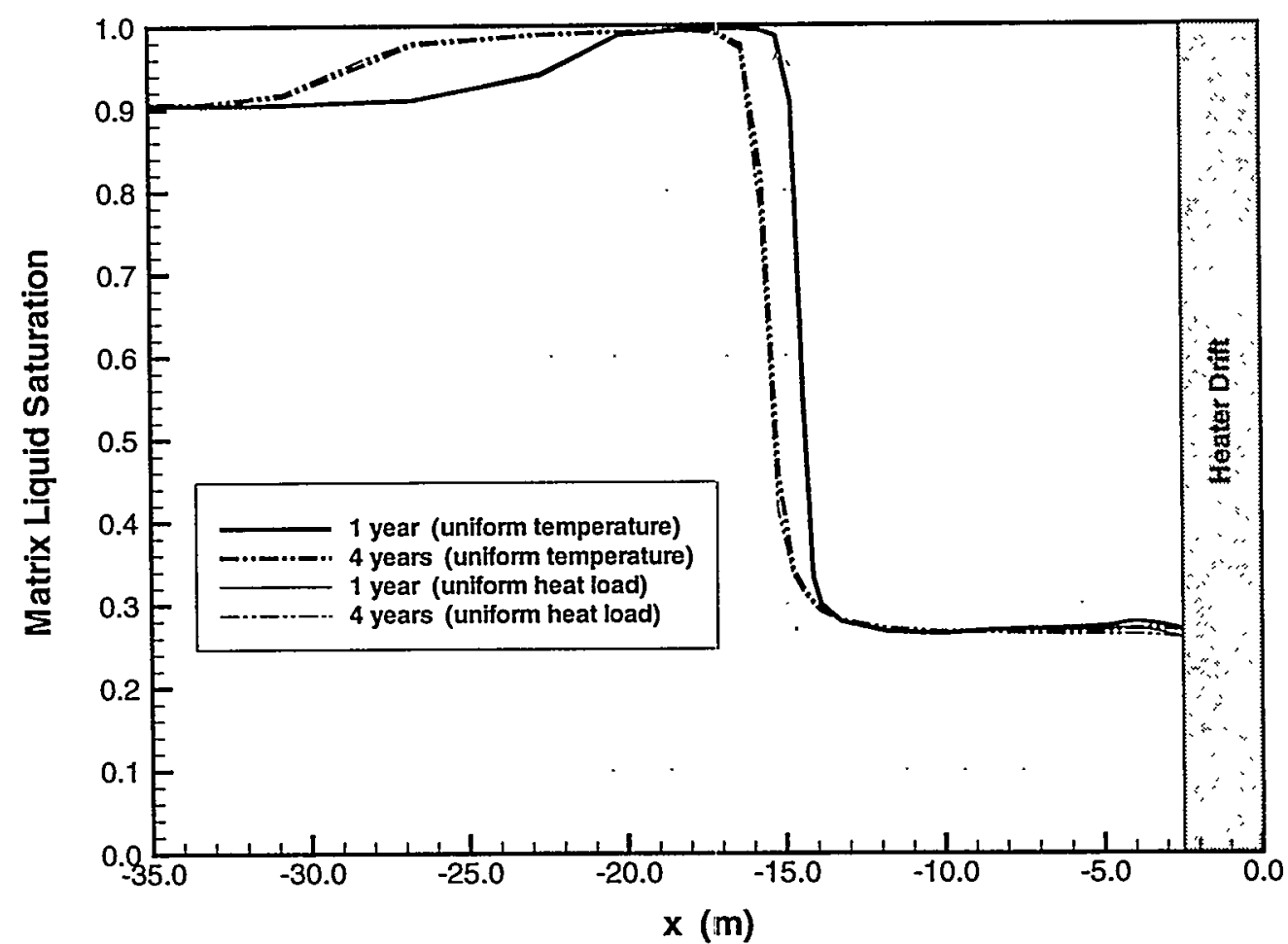

Figure 5.2-37 Matrix liquid saturation profiles along $x$-axis at $y=30.18 \mathrm{~m}$ and $z=0.0 \mathrm{~m}$ for $0.36 \mathrm{~mm} / \mathrm{yr}$ infiltration case. Both the uniform temperature and the uniform heat load case are shown (1 year heating at 100\%, 3 years heating at 50\%). 


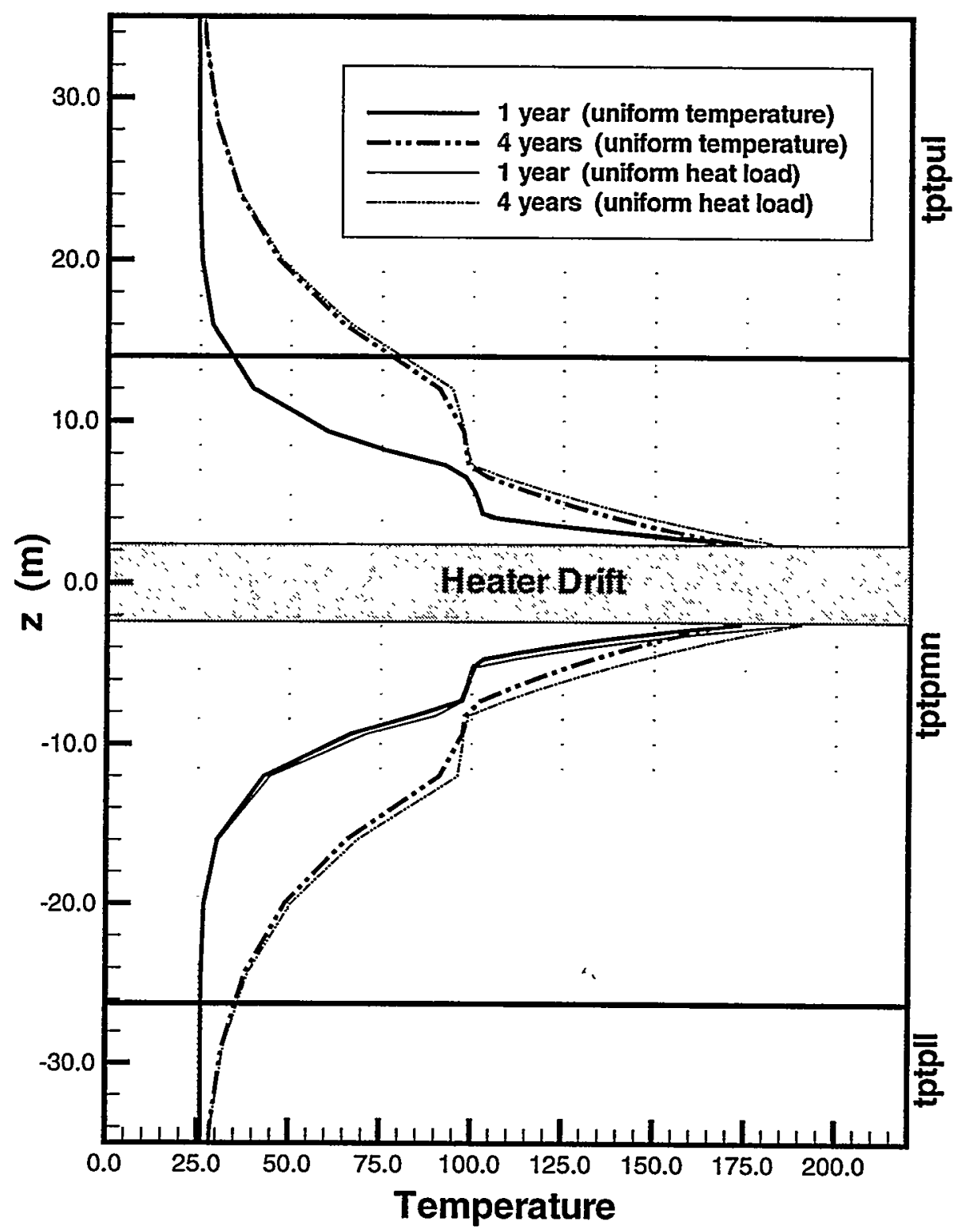

Figure 5.2-38 Temperature profiles along $z$-axis at $x=0.0 \mathrm{~m}$ and $y=30.18 \mathrm{~m}$ for $0.36 \mathrm{~mm} / \mathrm{yr}$ infiltration case. Both the uniform temperature and the uniform heat load case are shown (1 year heating at 100\%, 3 years heating at $50 \%$ ). 


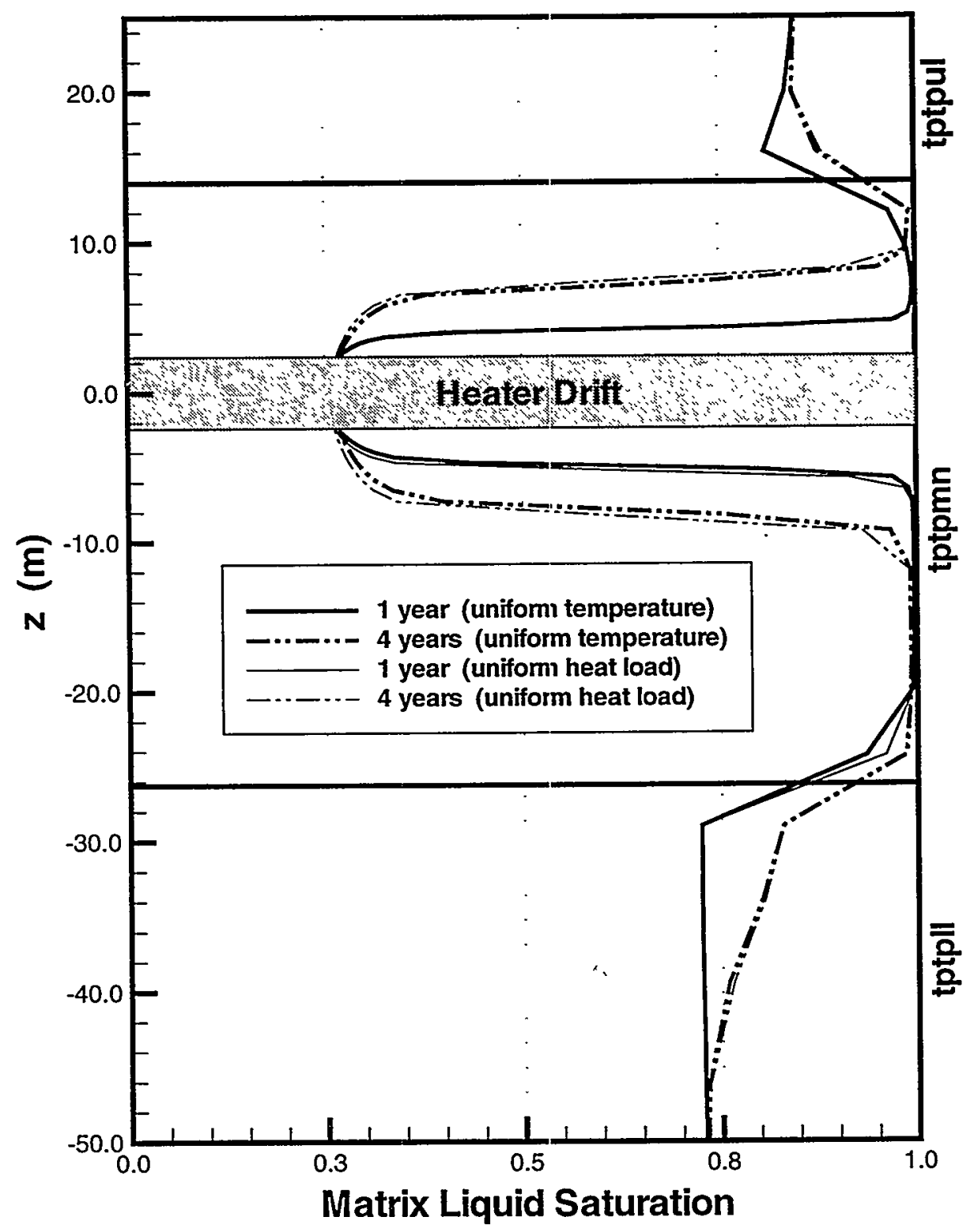

Figure 5.2-39 Matrix liquid saturation profiles along $z$-axis at $x=0.0 \mathrm{~m}$ and $y=30.18 \mathrm{~m}$ for $0.36 \mathrm{~mm} / \mathrm{yr}$ infiltration case. Both the uniform temperature and the uniform heat load case are shown (I year heating at 100\%, 3 years heating at 50\%). 


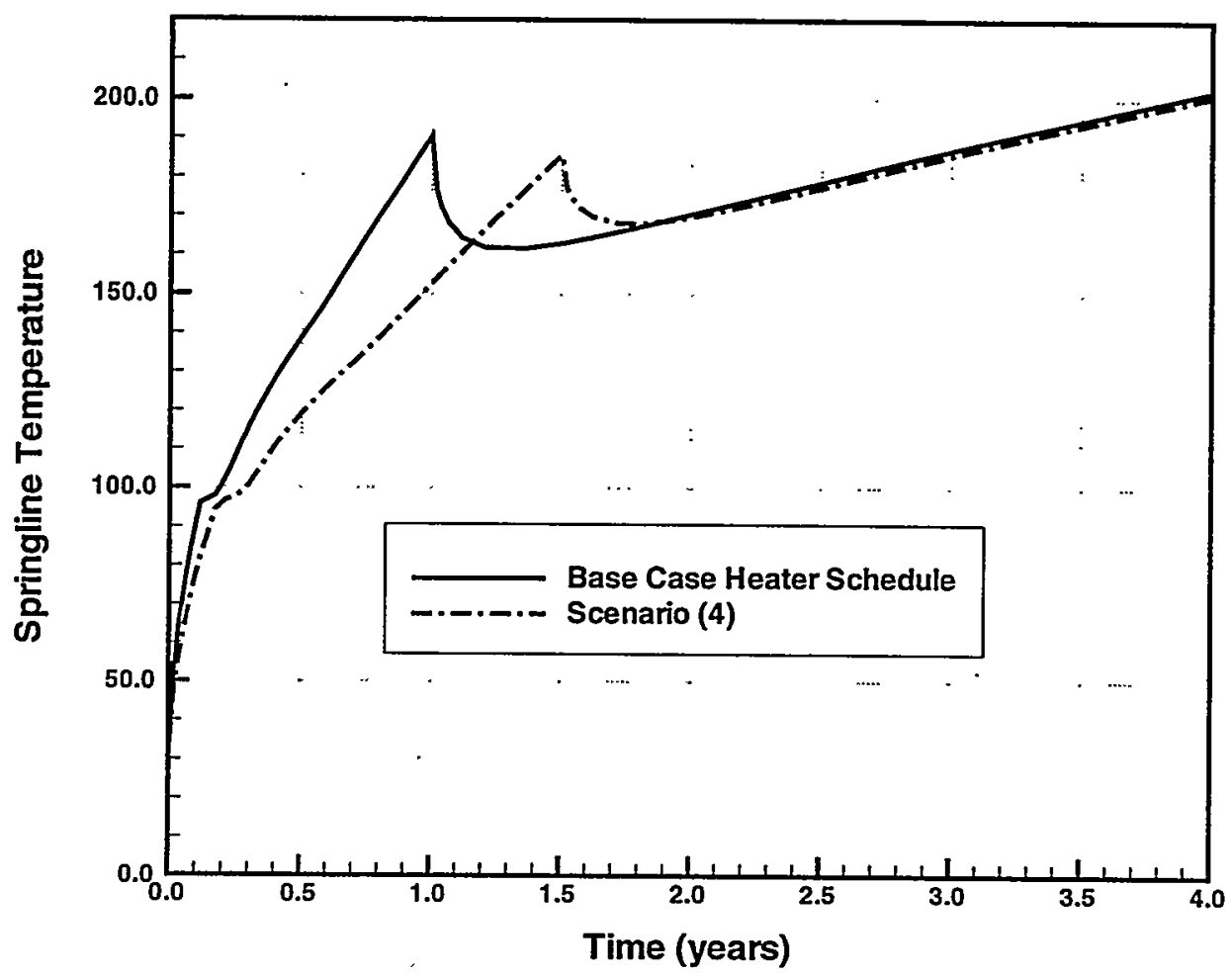

Figure 6.1-1 Temperature evolution at the heater drift wall for different heating scenarios.

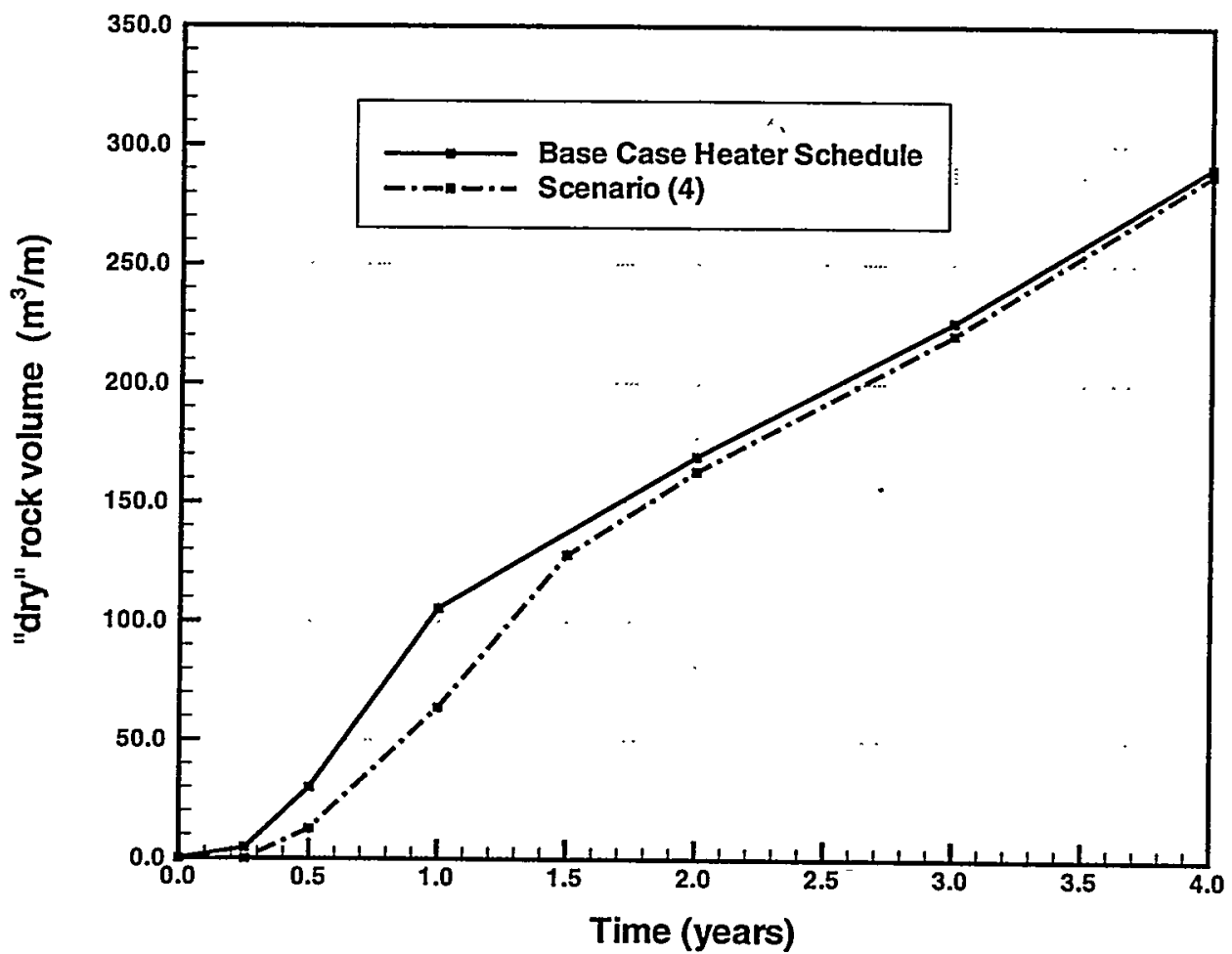

Figure 6.1-2 Evolution of dry-out rock volume for different heating scenarios. 


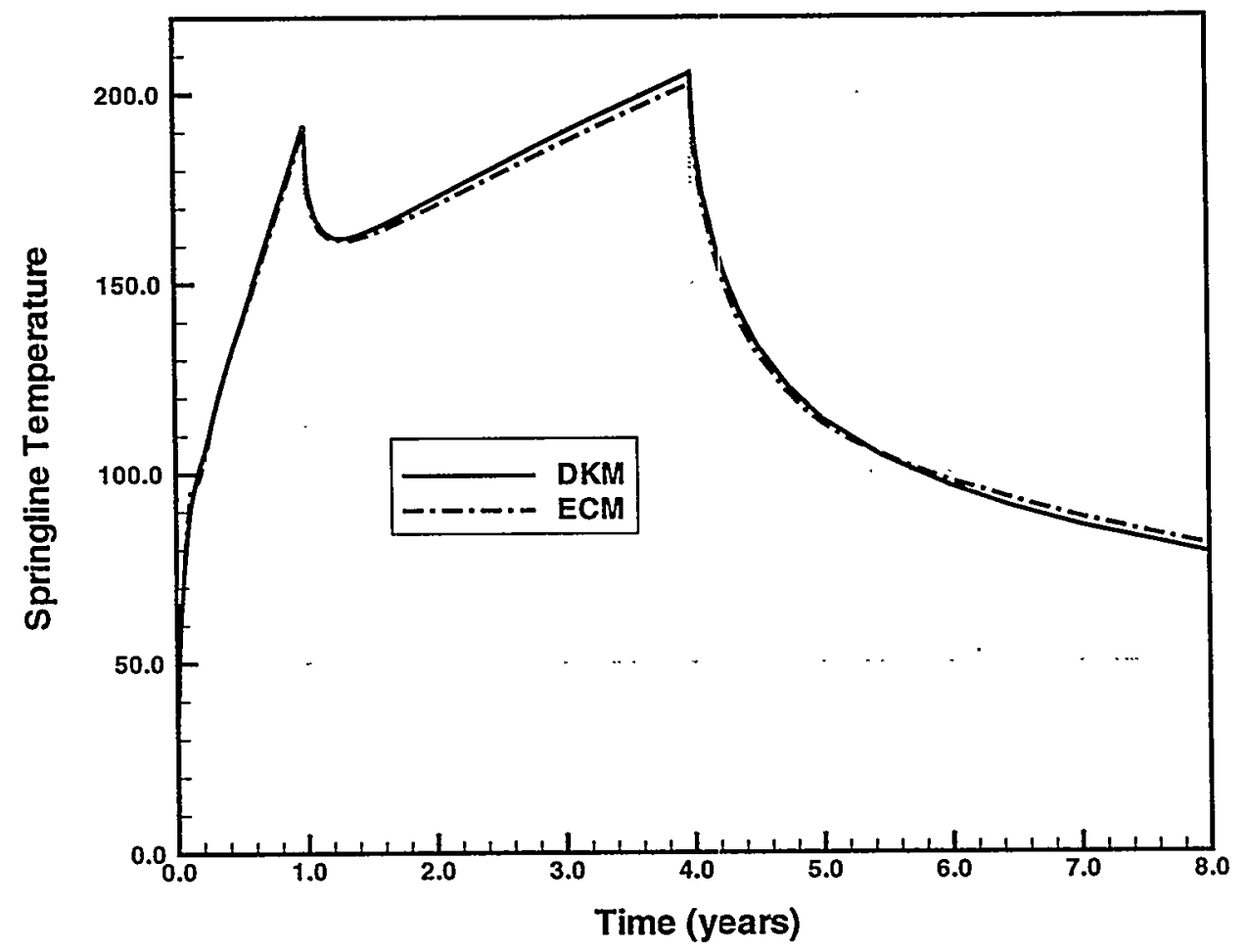

Figure 6.2-1 Temperature evolution at the heater drift wall for DKM versus ECM (1 year heating at 100\%, 3 years heating at $50 \%$ ).

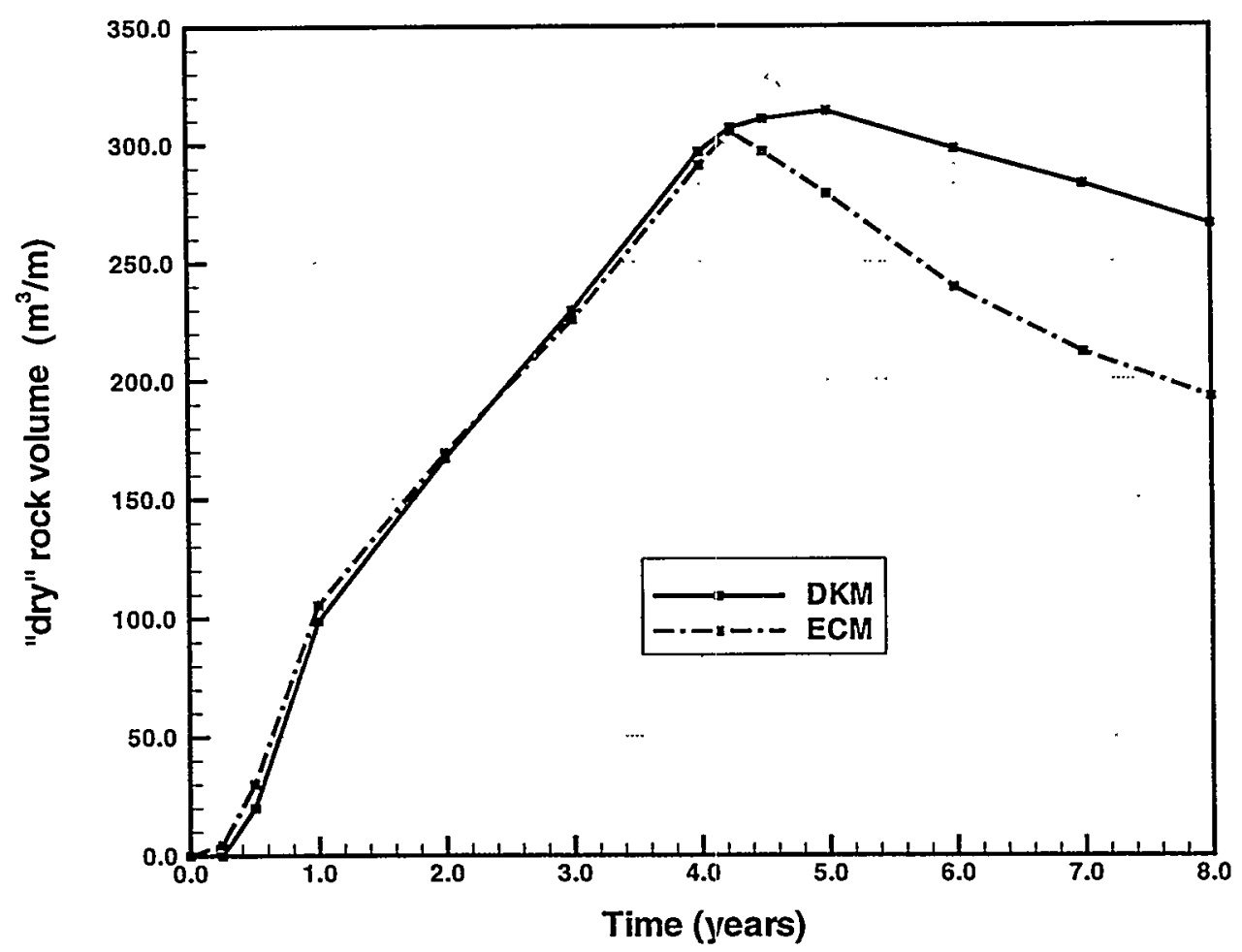

Figure 6.2-2 Evolution of dry-out rock volume for DKM versus ECM (1 year heating at 100\%, 3 years heating at 50\%). 


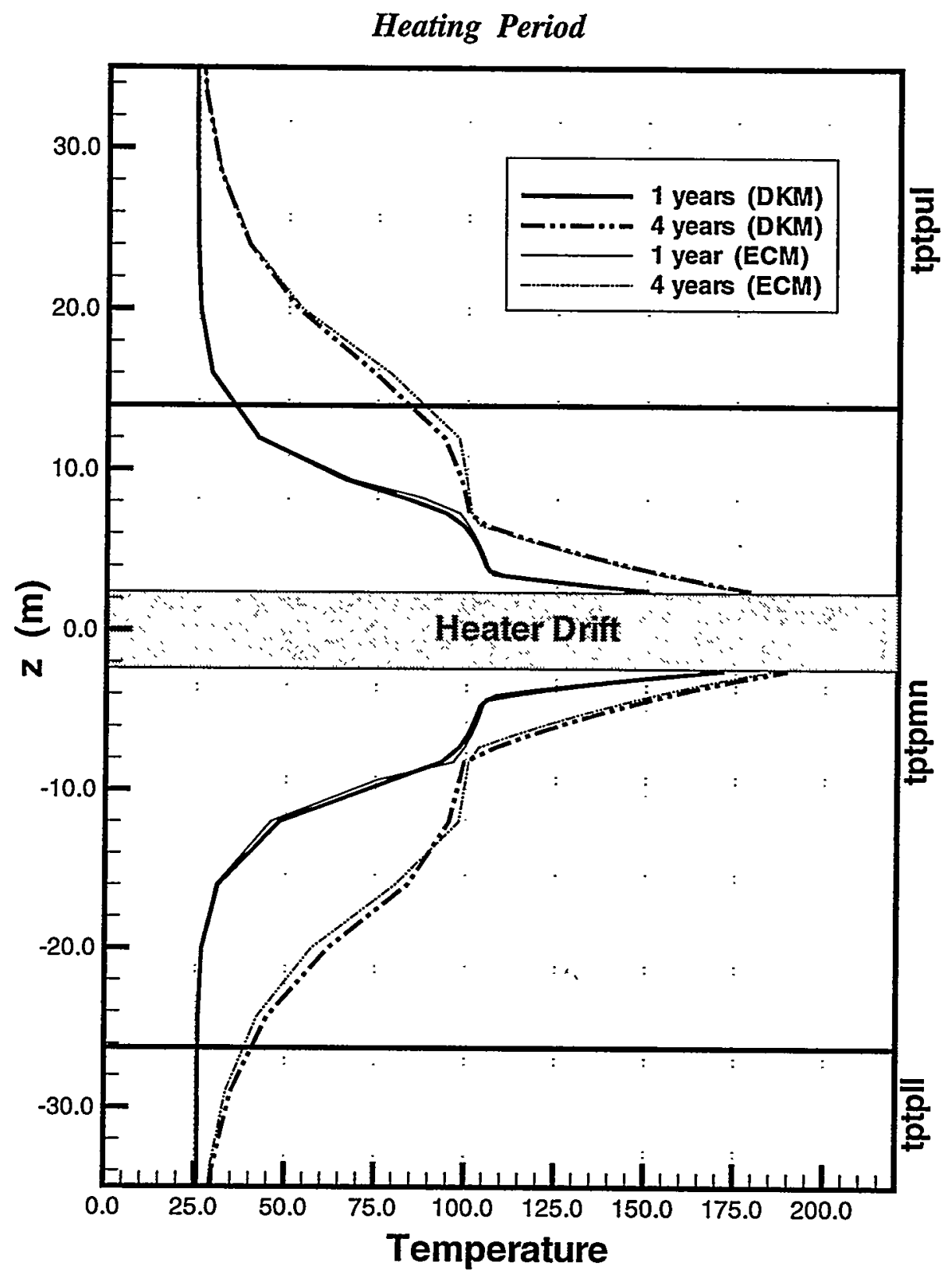

Figure 6.2-3 Temperature profiles along $z$-axis at $x=0.0 \mathrm{~m}$ simulated using $D K M$ and ECM for $3.6 \mathrm{~mm} / \mathrm{yr}$ infiltration case during heating

(1 year heating at 100\%, 3 years heating at 50\%). 


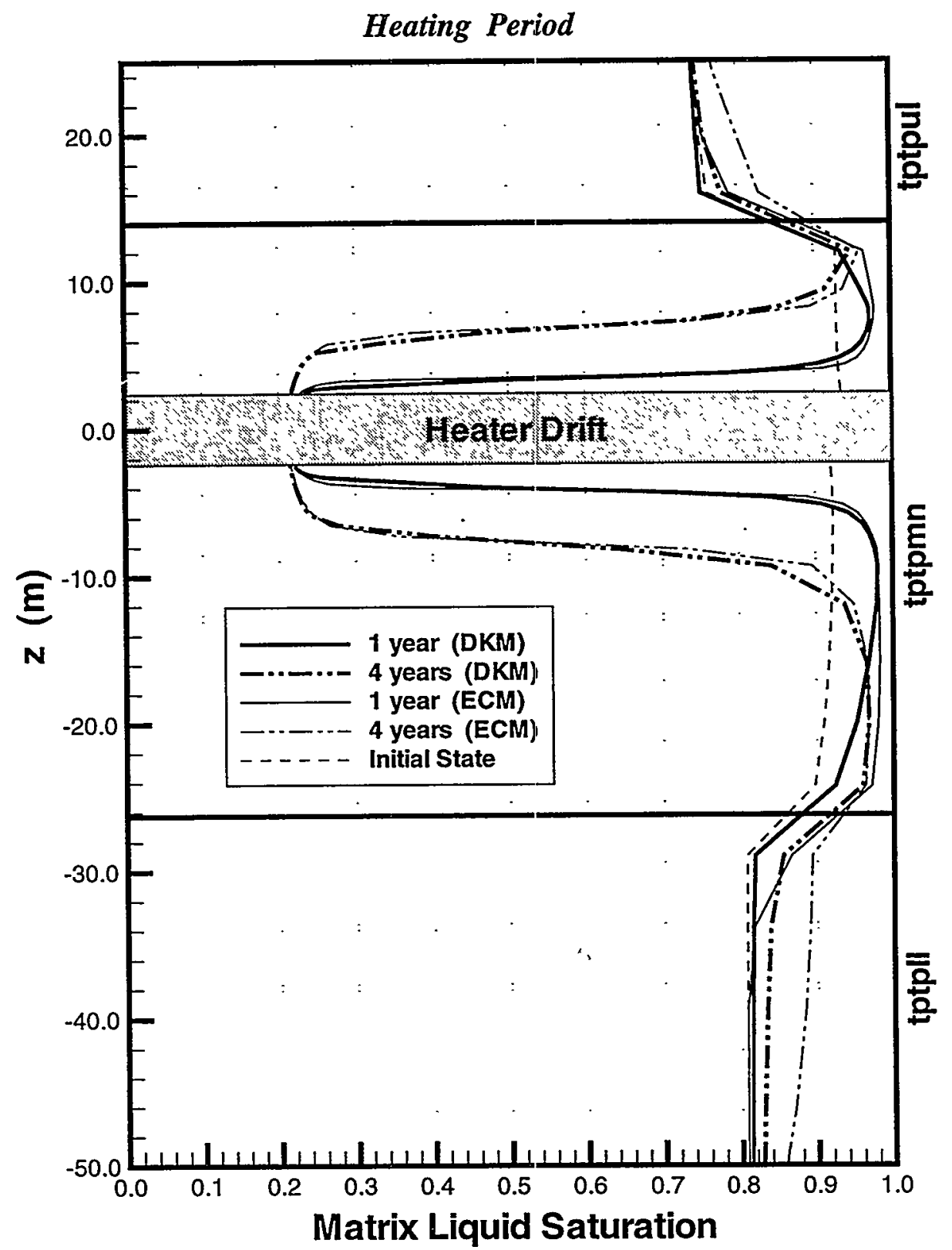

Figure 6.2-4 Matrix liquid saturation profiles along $z$-axis at $x=0.0 \mathrm{~m}$ simulated using $D K M$ and ECM for $3.6 \mathrm{~mm} / y \mathrm{r}$ infiltration case during heating

(1 year heating at 100\%, 3 years heating at 50\%). 


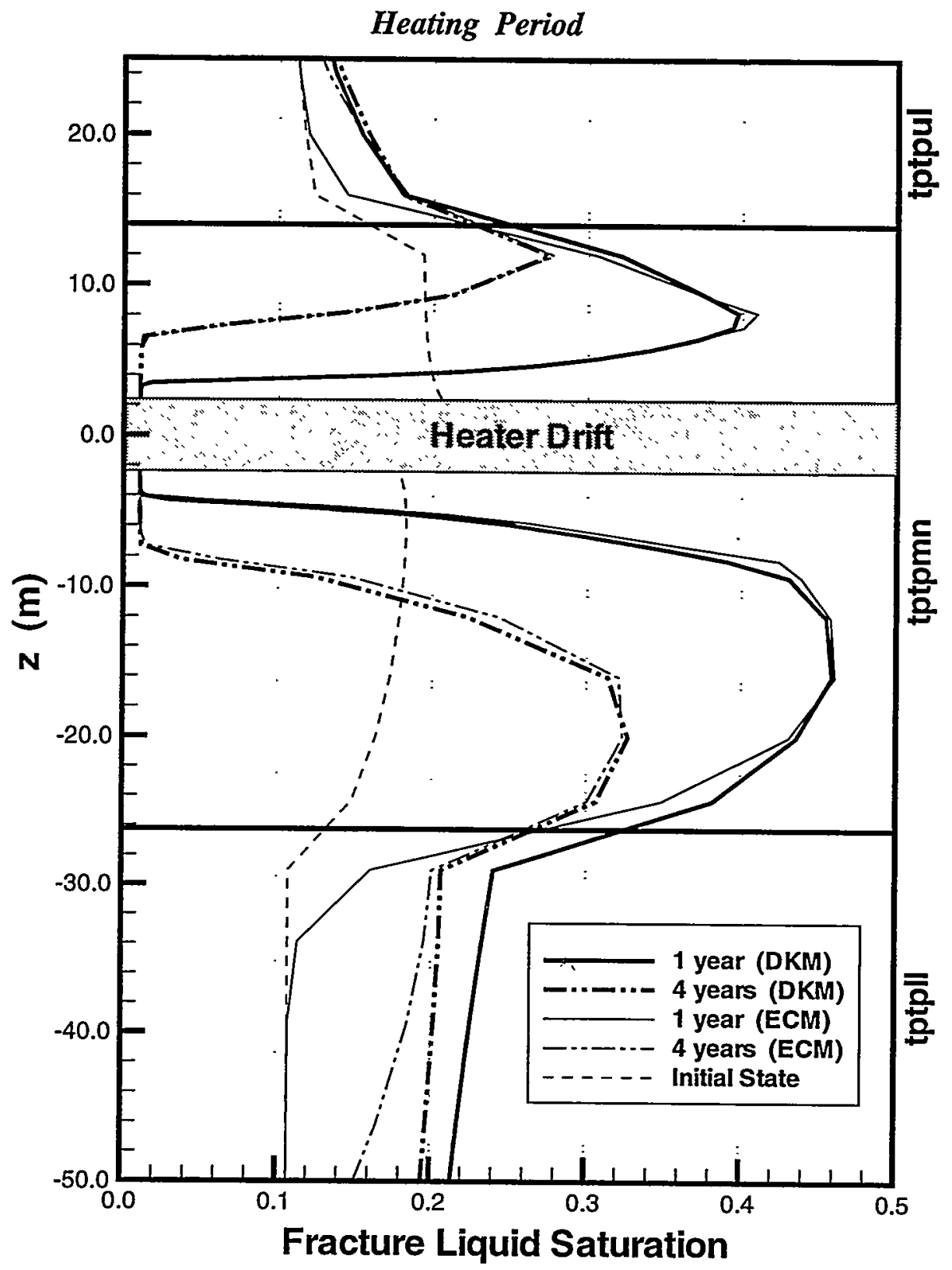

Figure 6.2-5 Fracture liquid saturation profiles along $z$-axis at $x=0.0 \mathrm{~m}$ simulated using DKM and ECM for $3.6 \mathrm{~mm} / \mathrm{yr}$ infiltration case during heating

(1 year heating at 100\%, 3 years heating at $50 \%$ ). 


\section{Appendix A1:}

Thermal-hydrological Response in Hydrology Holes

$3.6 \mathrm{~mm} / \mathrm{yr}$ infiltration

1 year heating at 100\%, 3 years heating at 50\% 
Pretest Analysis of the Thermal-Hydrological Conditions of the ESF Drift Scale Test

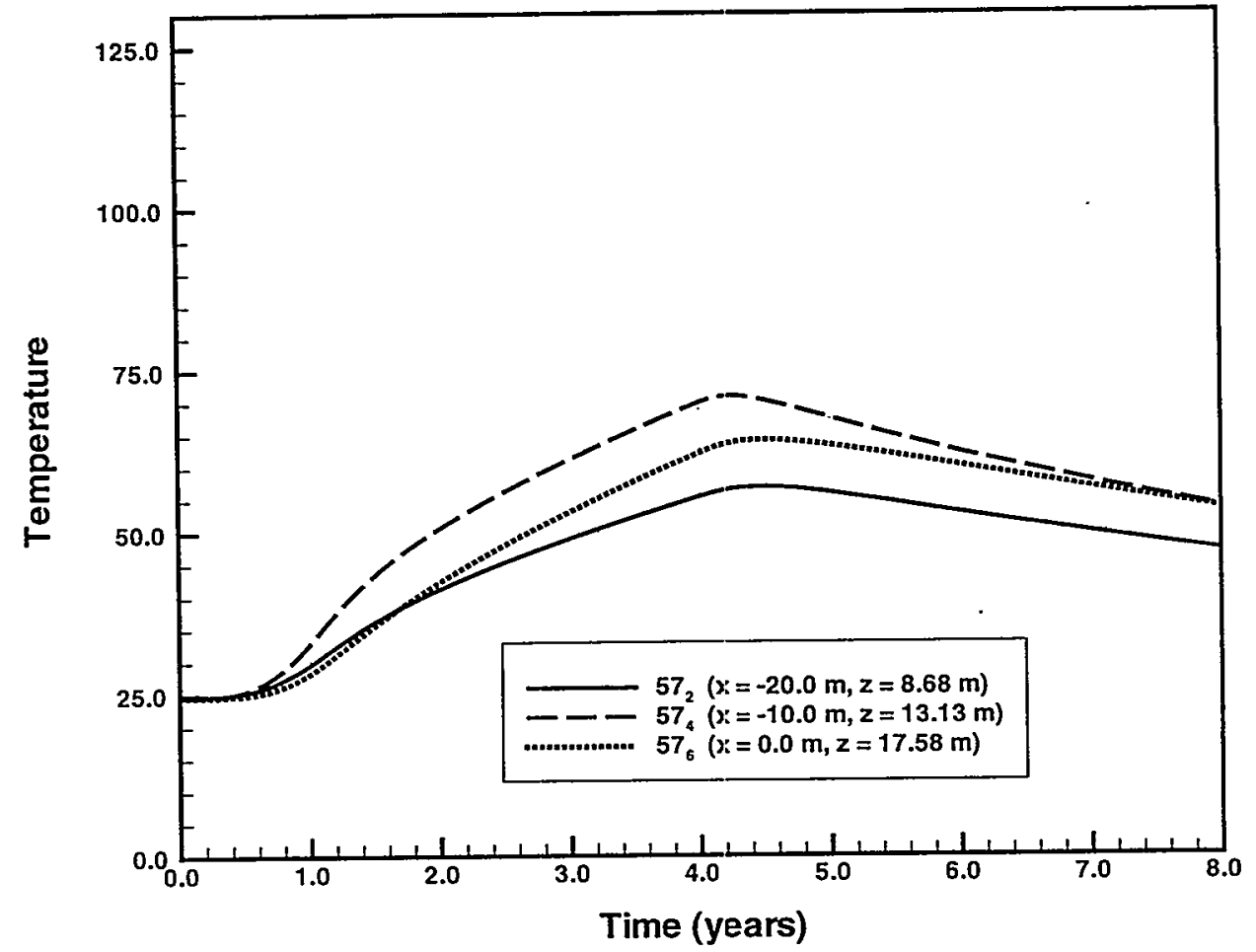

Figure Al-1 Temperature evolution at different sensor locations in borehole 57 for $3.6 \mathrm{~mm} / \mathrm{yr}$ infiltration case (1 year heating at 100\%, 3 years heating at 50\%).

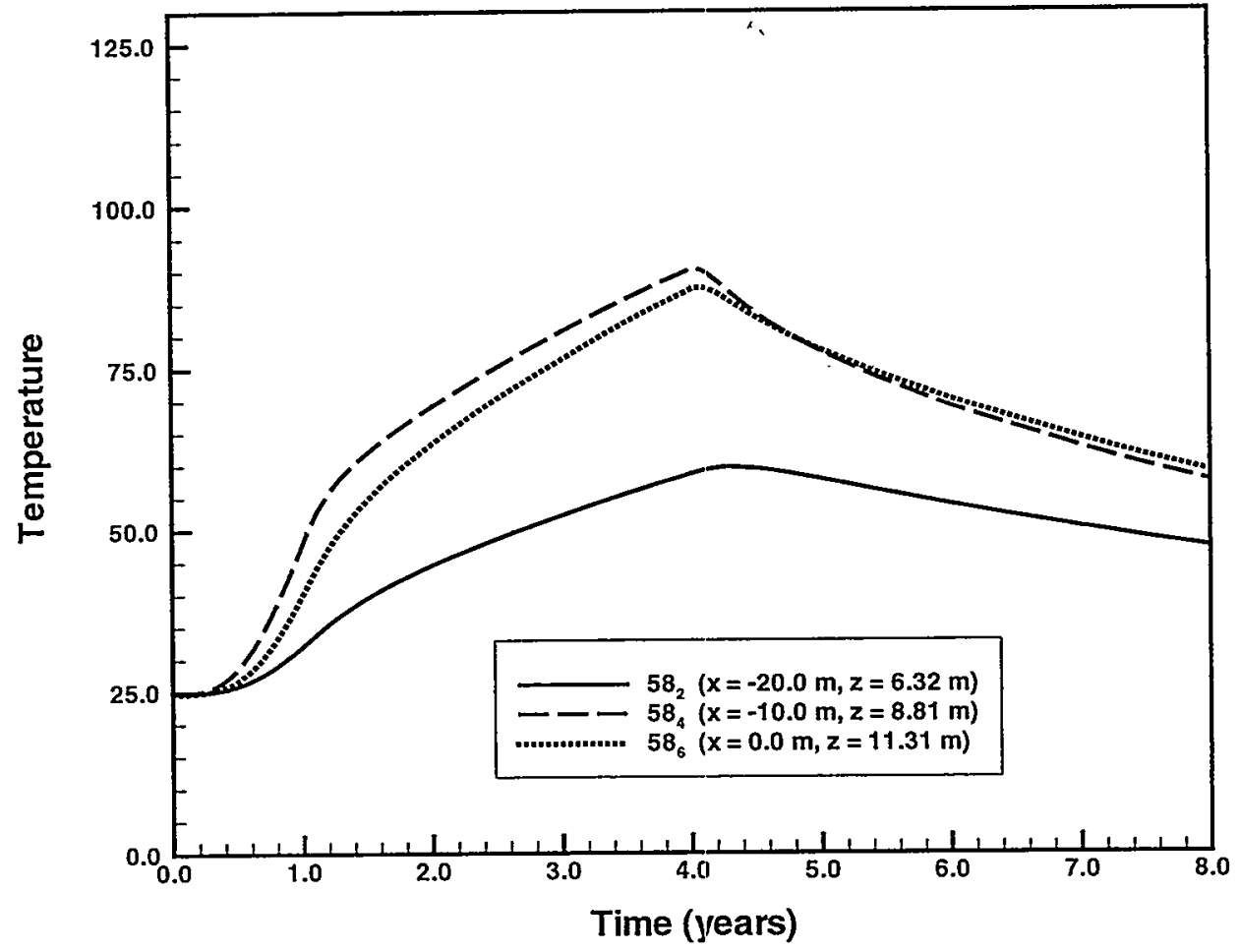

Figure Al-2 Temperature evolution at different sensor locations in borehole 58 for $3.6 \mathrm{~mm} / \mathrm{yr}$ infiltration case (1 year heating at 100\%, 3 years heating at 50\%). 


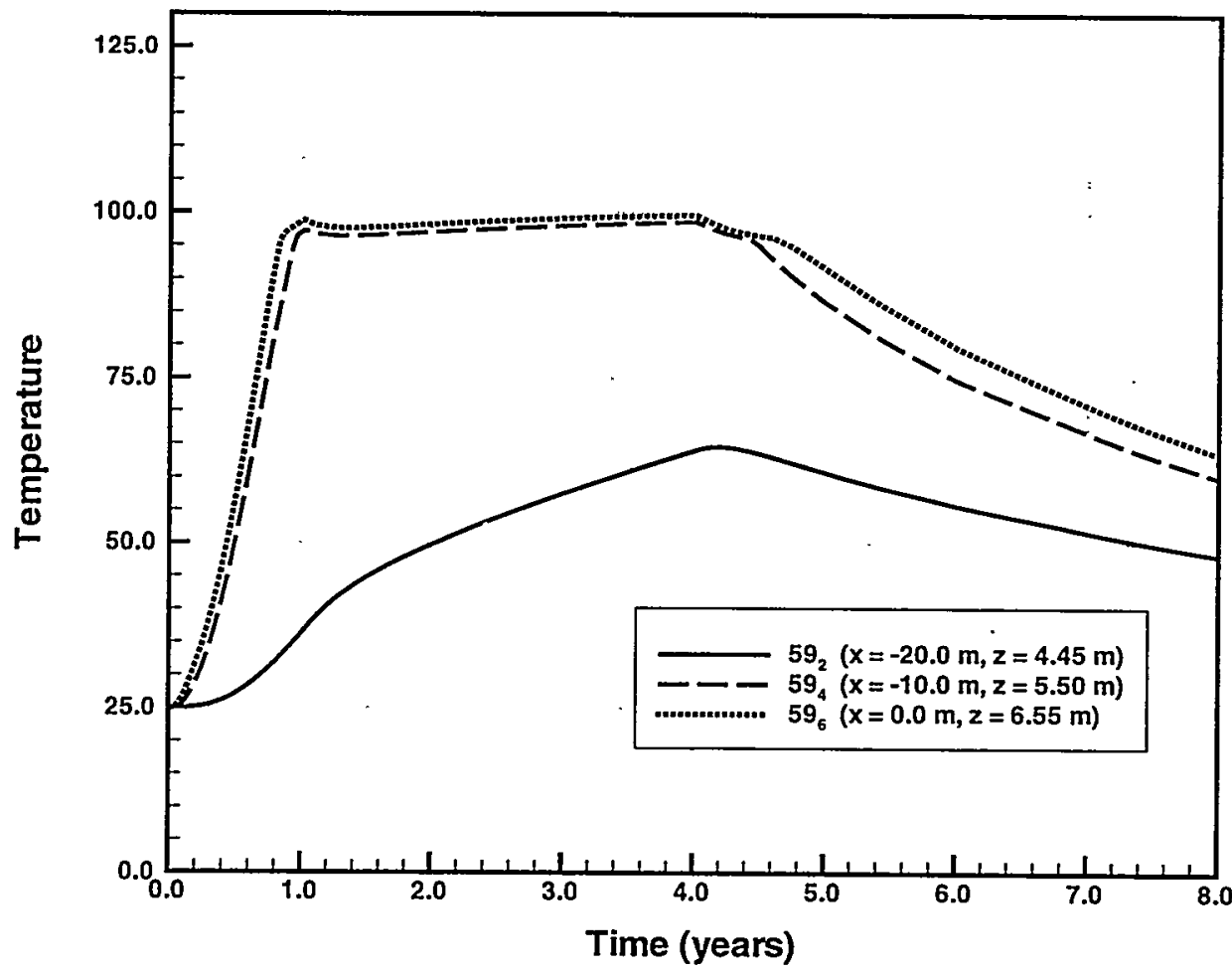

Figure A1-3 Temperature evolution at different sensor locations in borehole 59 for $3.6 \mathrm{~mm} / \mathrm{yr}$ infiltration case ( 1 year heating at 100\%, 3 years heating at 50\%).

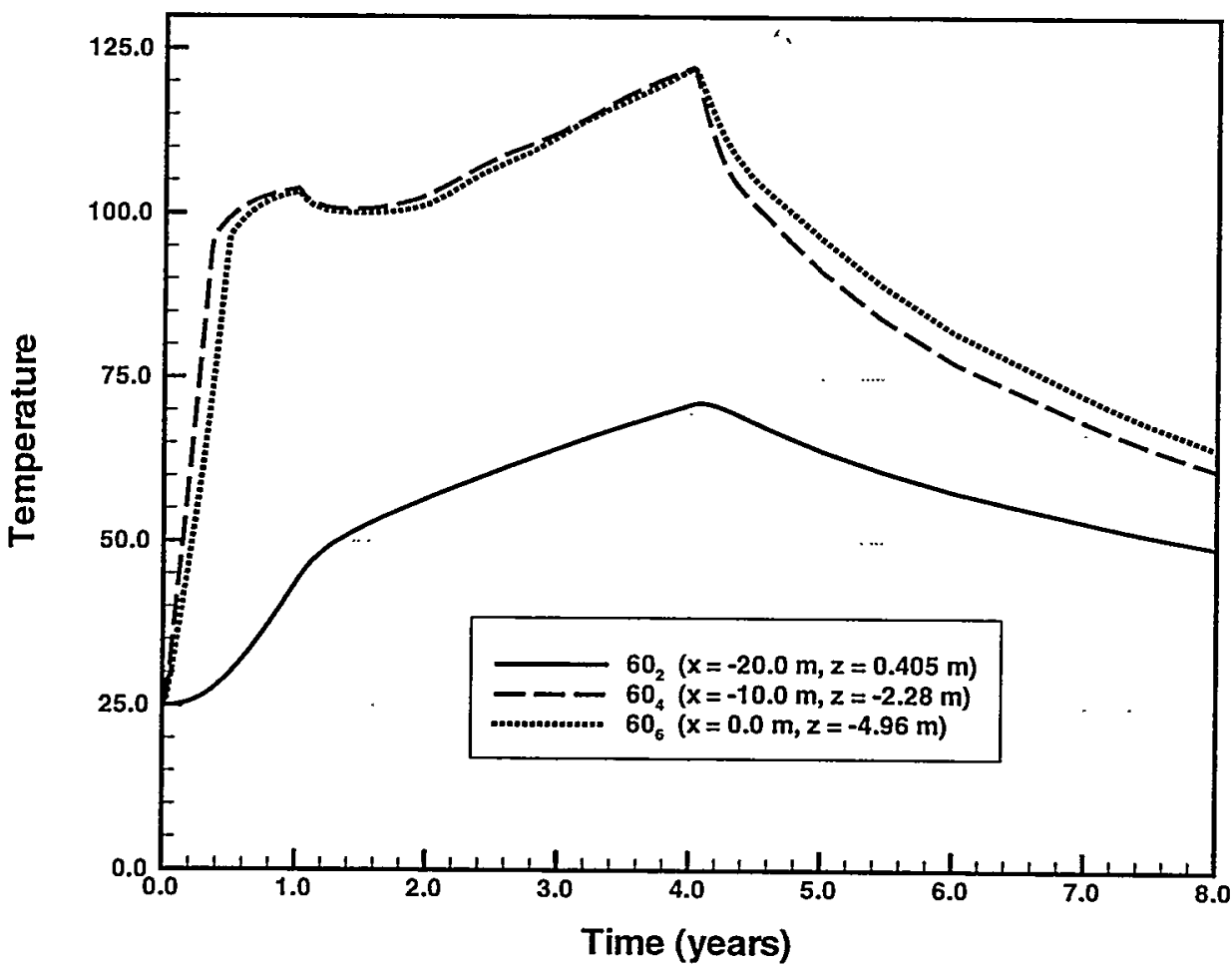

Figure AI-4 Temperature evolution at different sensor locations in borehole 60 for $3.6 \mathrm{~mm} / \mathrm{yr}$ infiltration case (1 year heating at 100\%, 3 years heating at 50\%). 


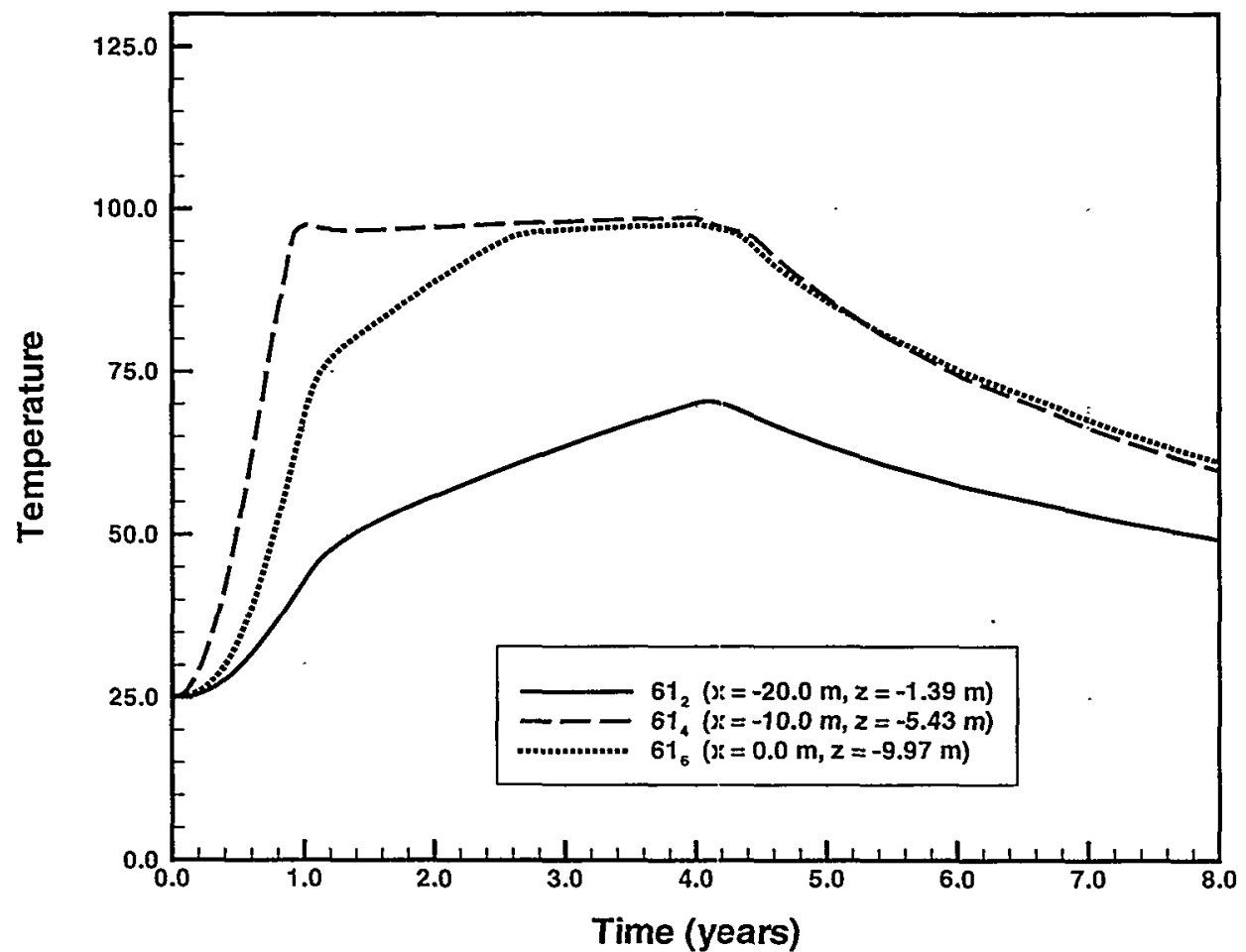

Figure A1-5 Temperature evolution at different sensor locations in borehole 61 for $3.6 \mathrm{~mm} / \mathrm{yr}$ infiltration case ( 1 year heating at 100\%, 3 years heating at 50\%). 


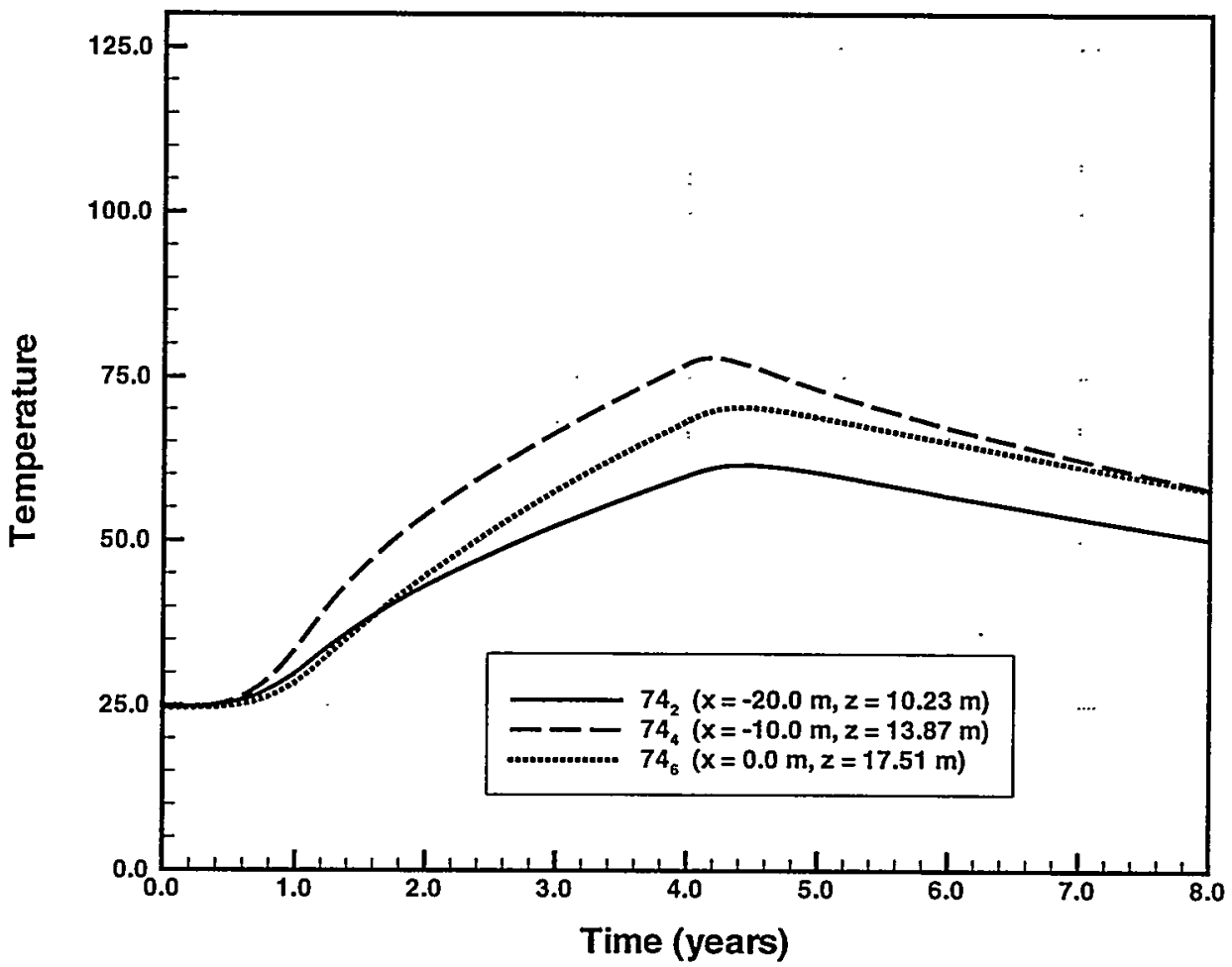

Figure A1-6 Temperature evolution at different sensor locations in borehole 74 for $3.6 \mathrm{~mm} / \mathrm{yr}$ infiltration case ( 1 year heating at 100\%, 3 years heating at 50\%).

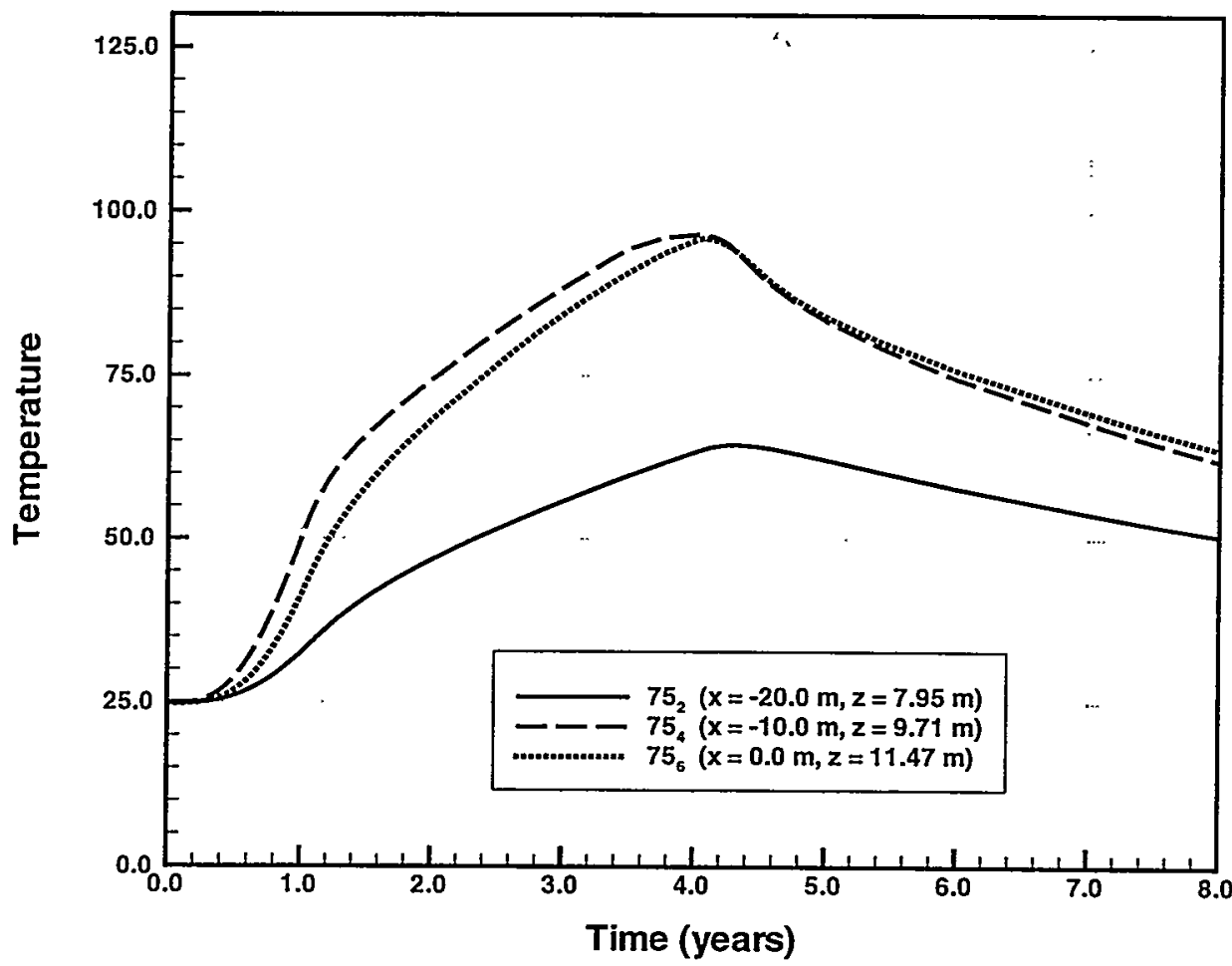

Figure Al-7 Temperature evolution at different sensor locations in borehole 75 for $3.6 \mathrm{~mm} / \mathrm{yr}$ infiltration case ( 1 year heating at 100\%, 3 years heating at $50 \%$ ). 
Pretest Analysis of the Thermal-Hydrological Conditions of the ESF Drift Scale Test

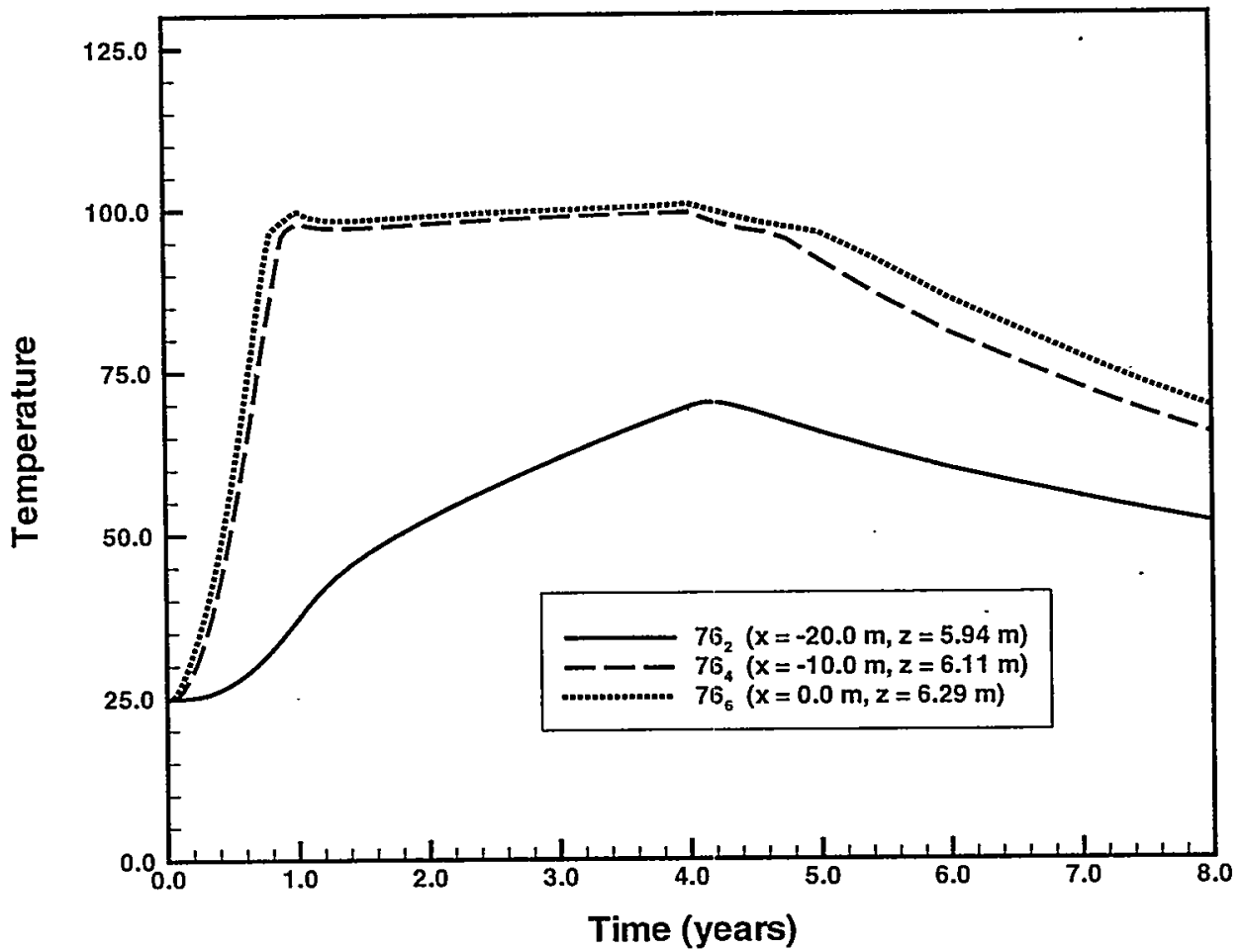

Figure A1-8 Temperature evolution at different sensor locations in borehole 76 for $3.6 \mathrm{~mm} / \mathrm{yr}$ infiltration case ( 1 year heating at $100 \%, 3$ years heating at $50 \%$ ).

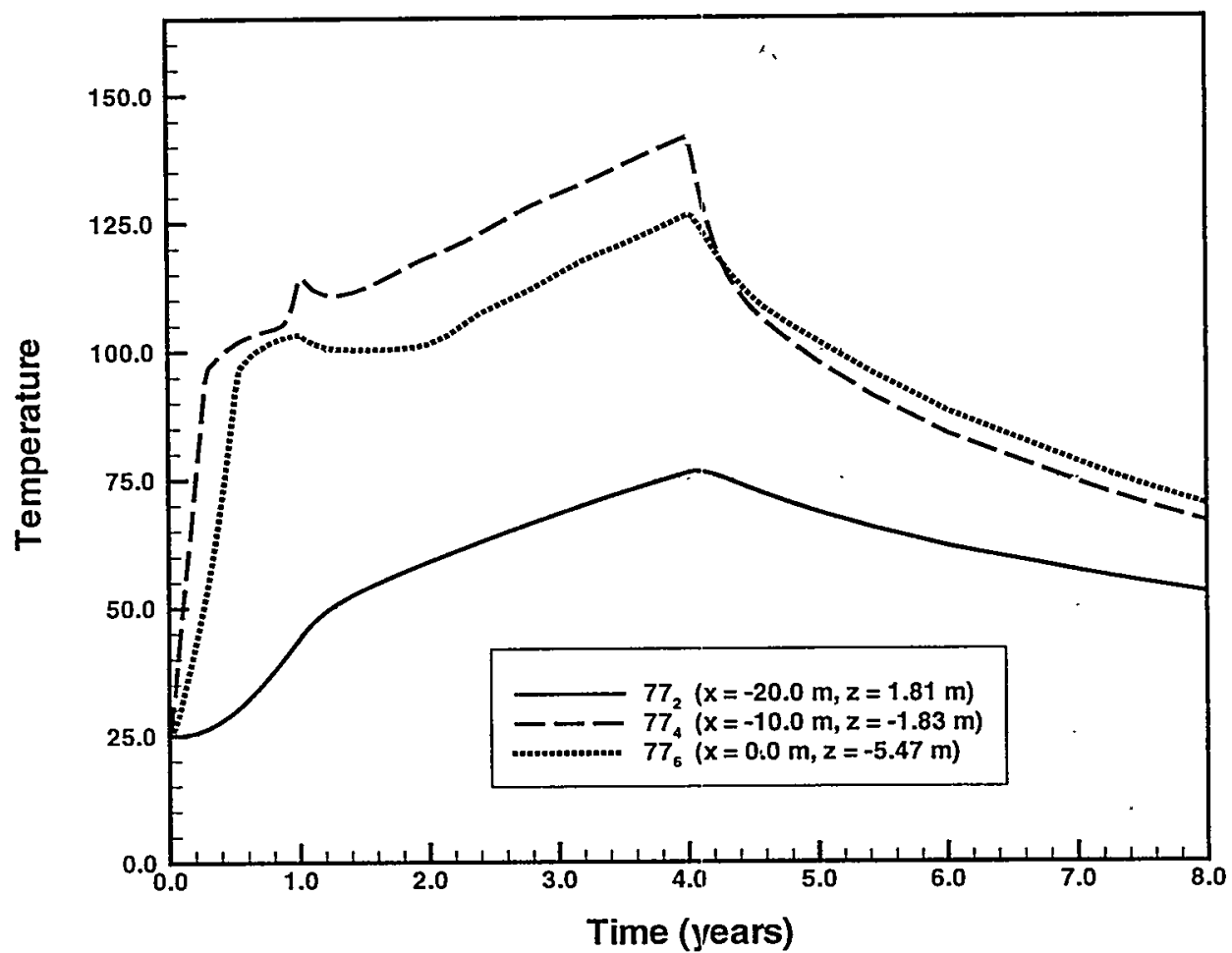

Figure A1-9 Temperature evolution at different sensor locations in borehole 77 for $3.6 \mathrm{~mm} / \mathrm{yr}$ infiltration case (1 year heating at 100\%, 3 years heating at 50\%). 


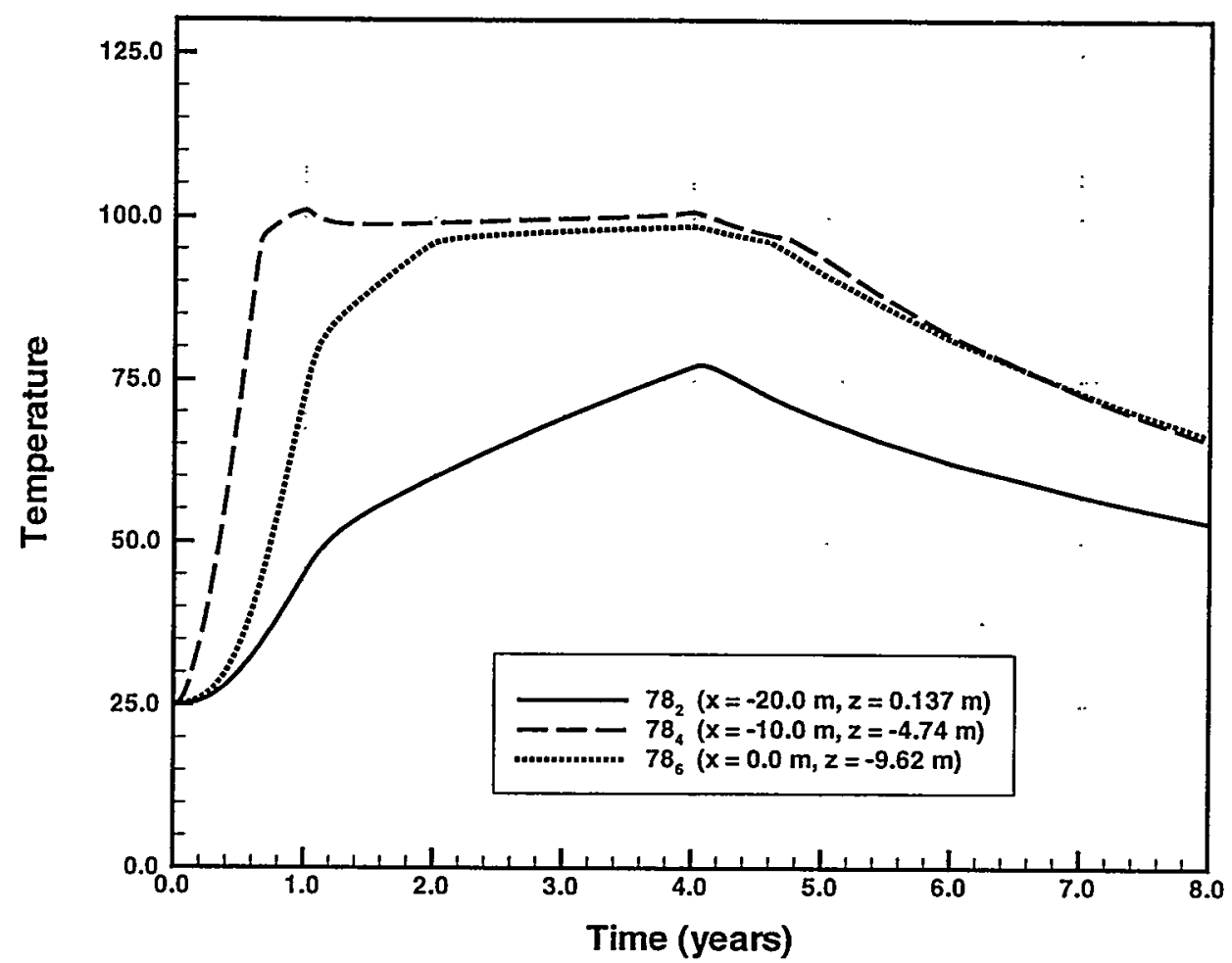

Figure A1-10 Temperature evolution at different sensor locations in borehole 78 for $3.6 \mathrm{~mm} / \mathrm{yr}$ infiltration case (1 year heating at 100\%, 3 years heating at 50\%). 


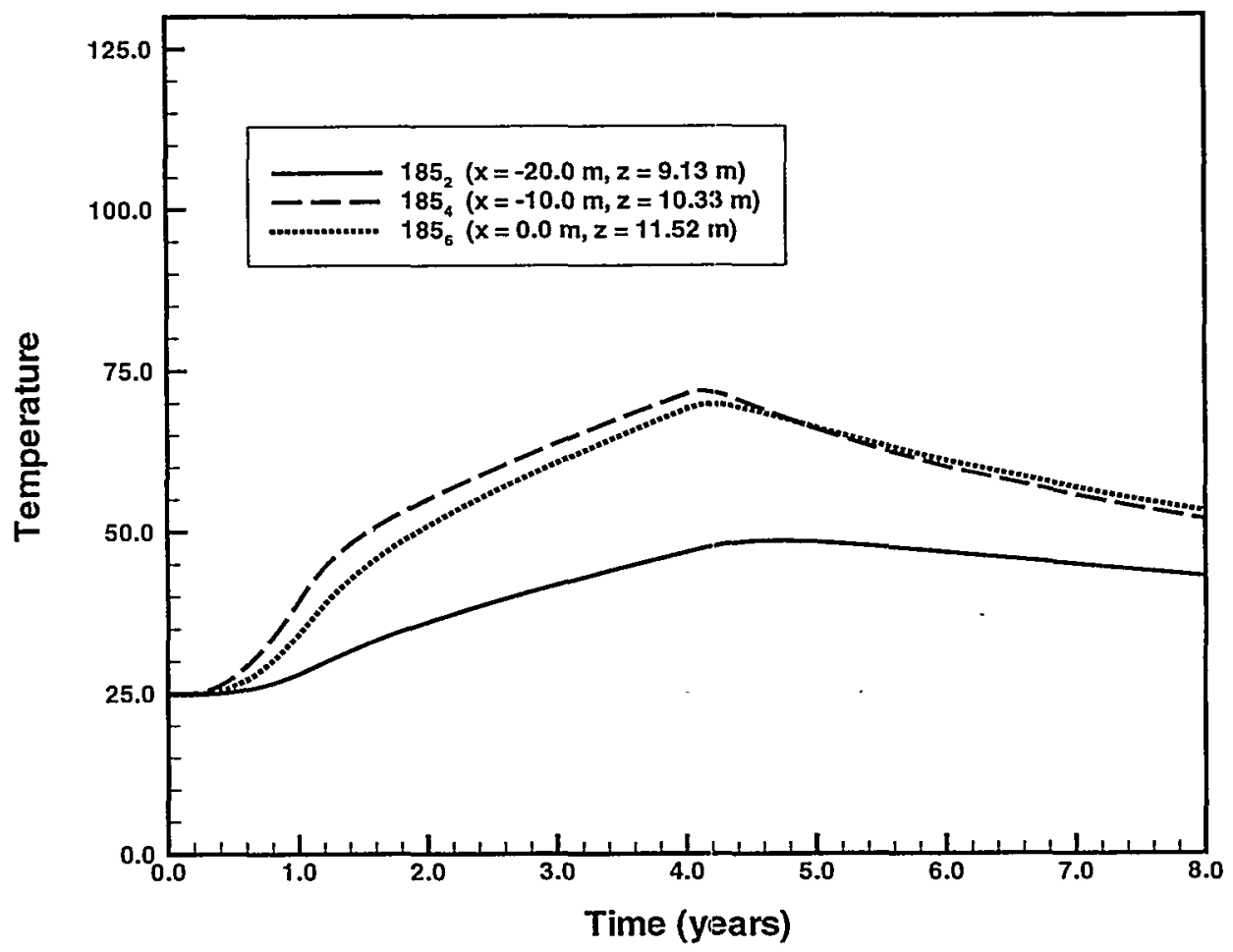

Figure A1-11 Temperature evolution at different sensor locations in borehole 185 for $3.6 \mathrm{~mm} / \mathrm{y}$ r infiltration case (1 year heating at 100\%, 3 years heating at $50 \%$ ).

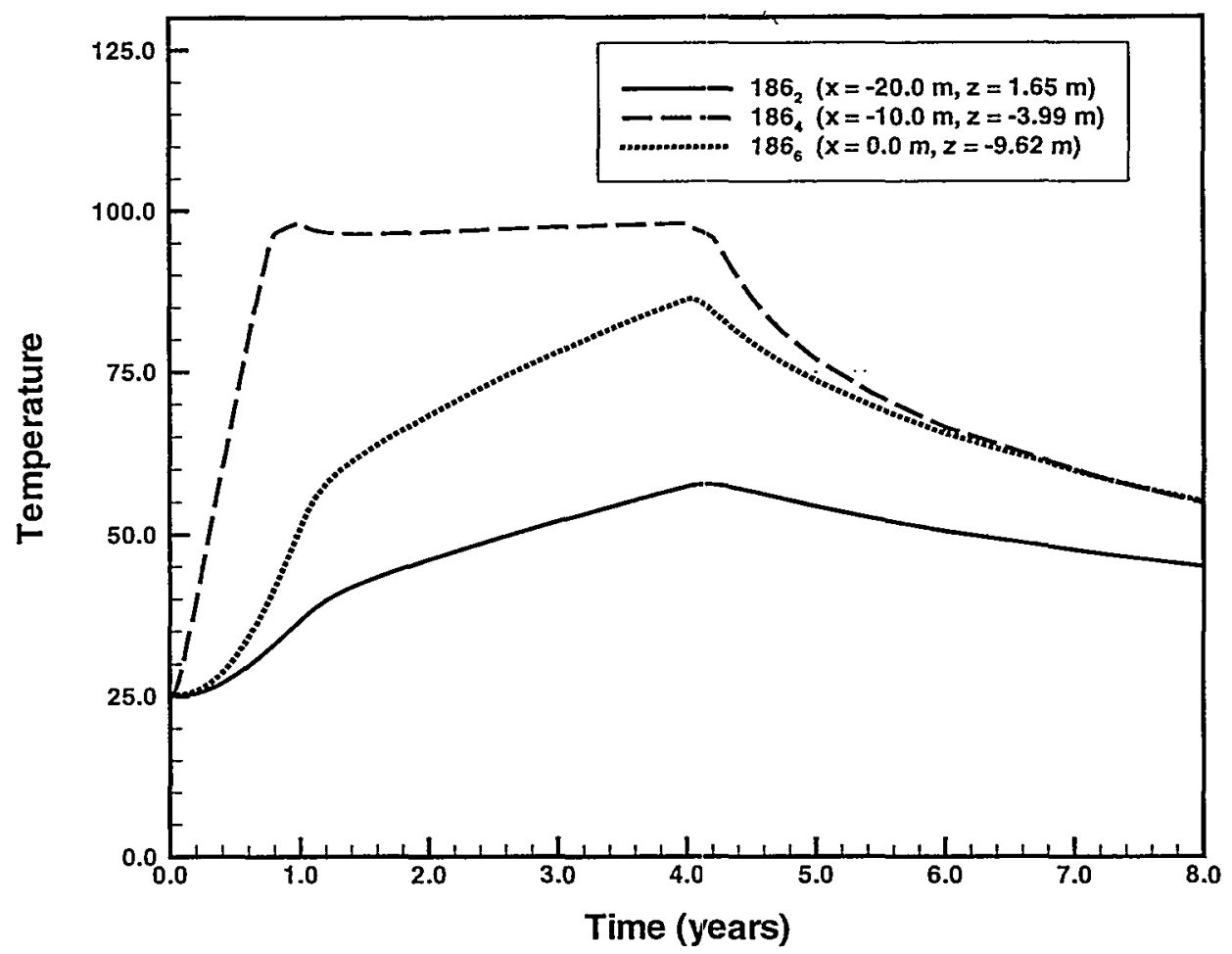

Figure A1-12 Temperature evolution at different sensor locations in borehole 186 for $3.6 \mathrm{~mm} / \mathrm{yr}$ infiltration case (1 year heating at 100\%, 3 years heating at $50 \%$ ). 


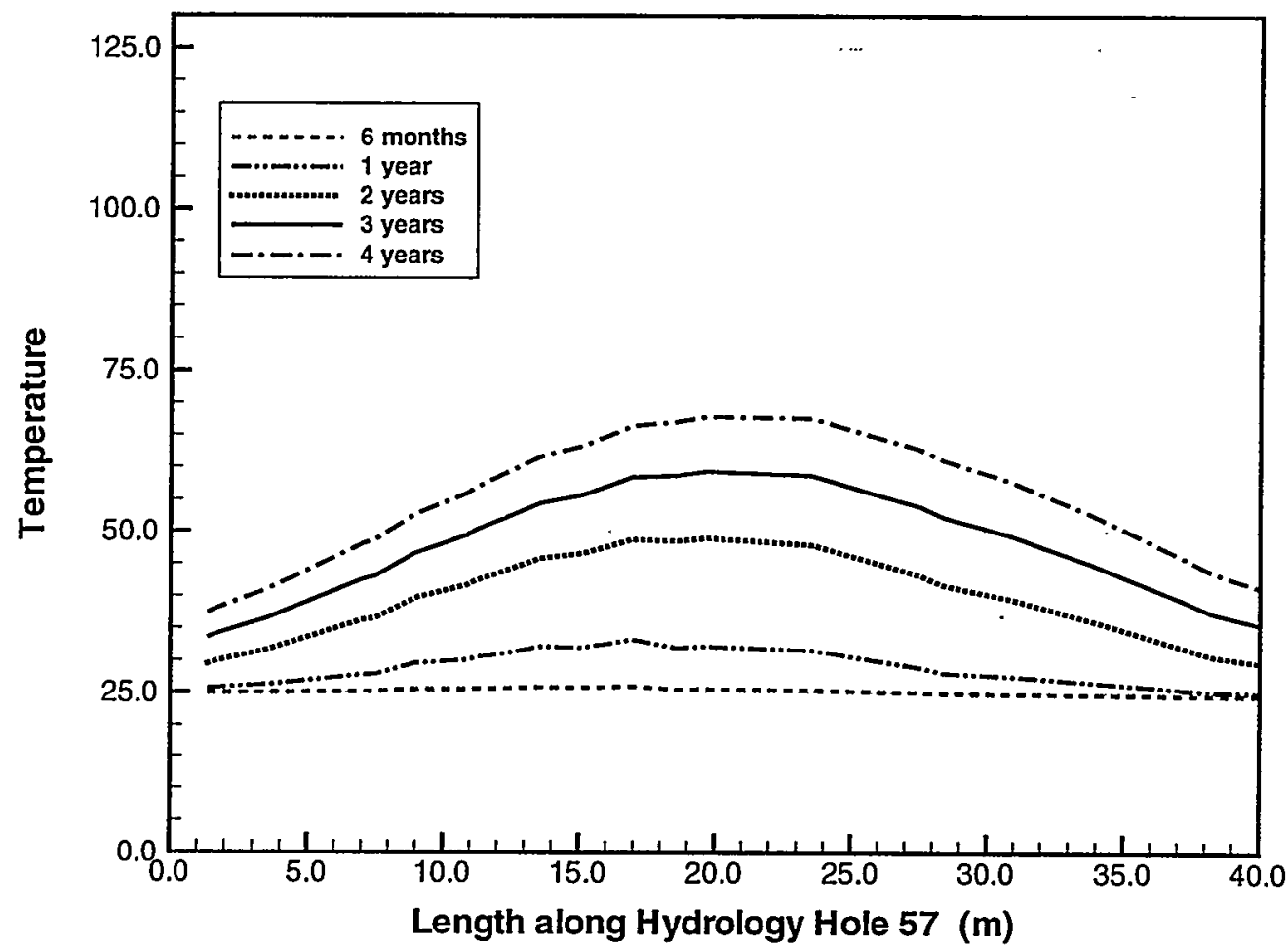

Figure A1-13 Temperature profile along borehole 57 at different times during heating period for $3.6 \mathrm{~mm} / \mathrm{yr}$ infiltration case (I year heating at 100\%, 3 years heating at $50 \%$ ).

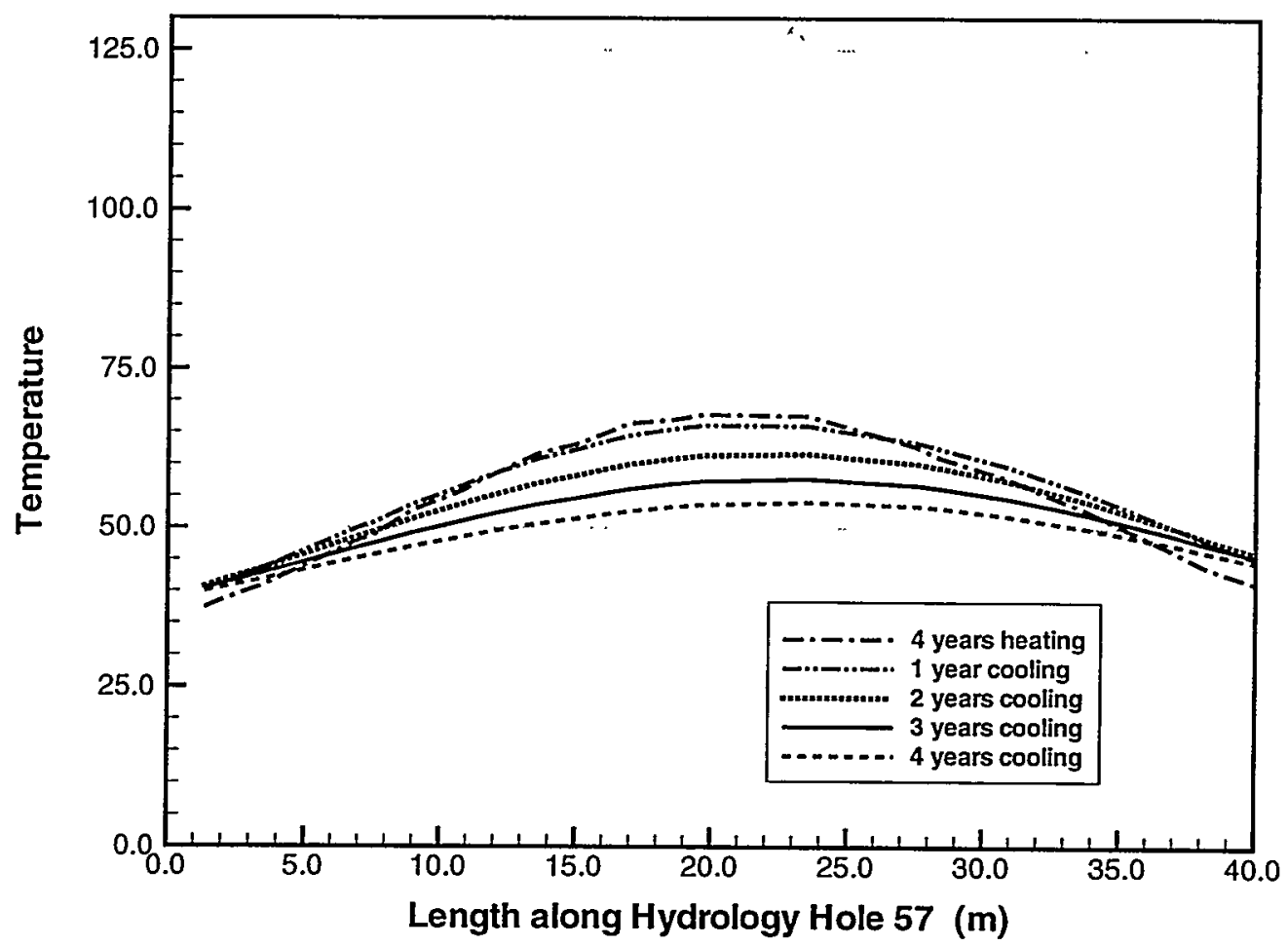

Figure A1-14 Temperature profile along borehole 57 at different times during cooling period for $3.6 \mathrm{~mm} / \mathrm{yr}$ infiltration case (1 year heating at 100\%, 3 years heating at 50\%). 


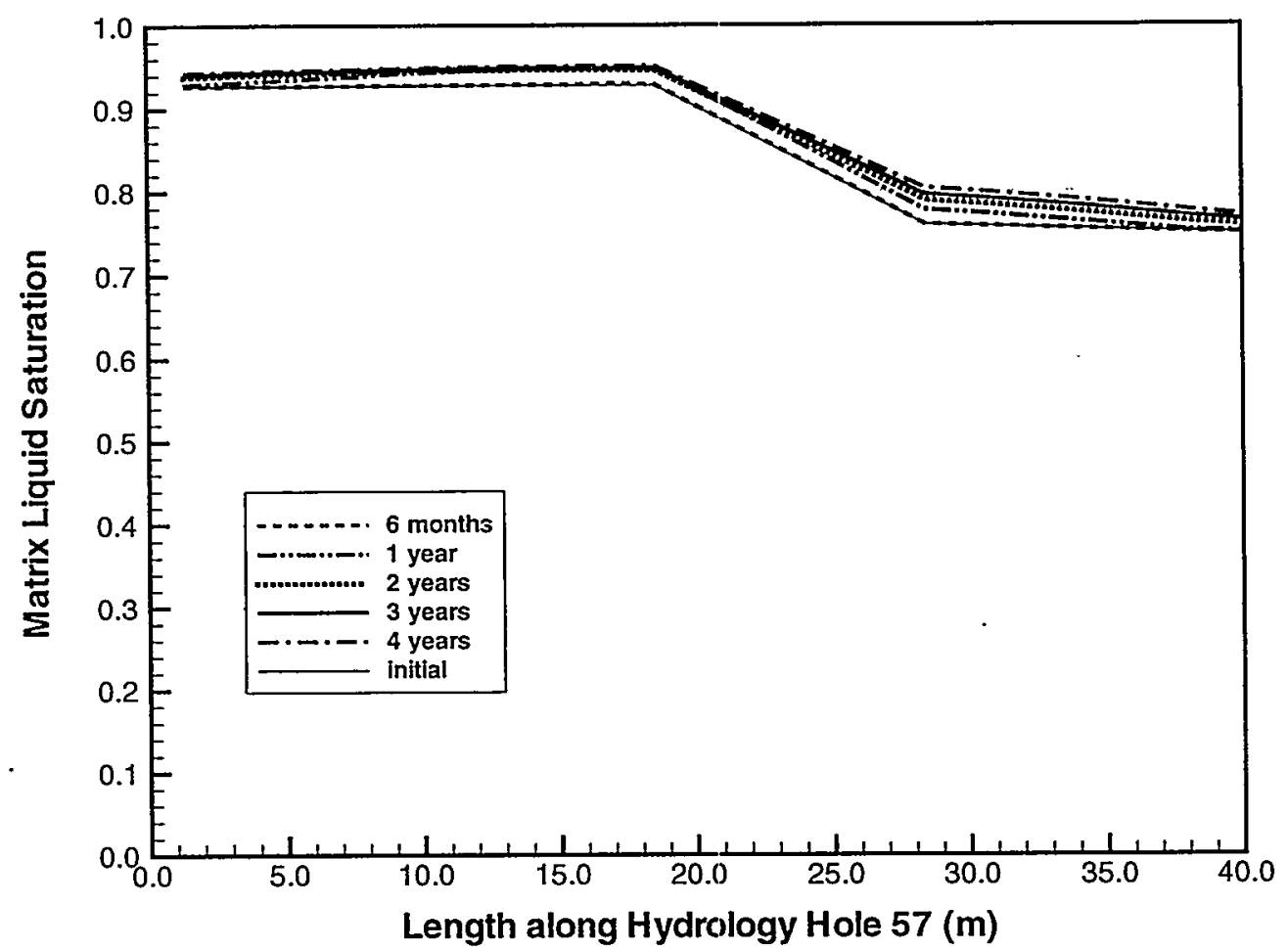

Figure A1-15 Matrix saturation profile along borehole 57 at different times during heating period for $3.6 \mathrm{~mm} / \mathrm{yr}$ infiltration case (1 year heating at 100\%, 3 years heating at 50\%).

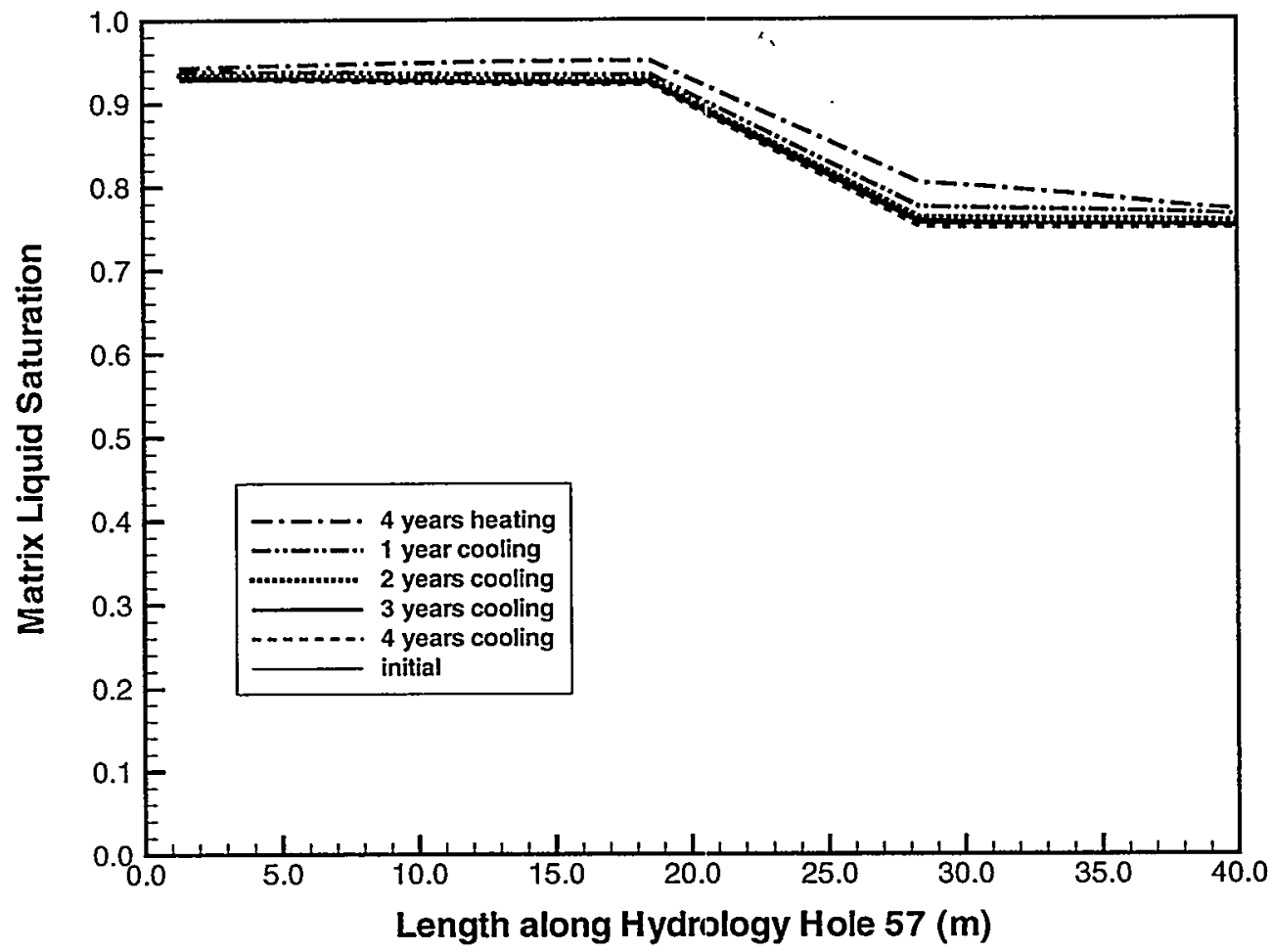

Figure A1-16 Matrix saturation profile along borehole 57 at different times during cooling period for $3.6 \mathrm{~mm} / \mathrm{yr}$ infiltration case (1 year heating at 100\%, 3 years heating at 50\%). 


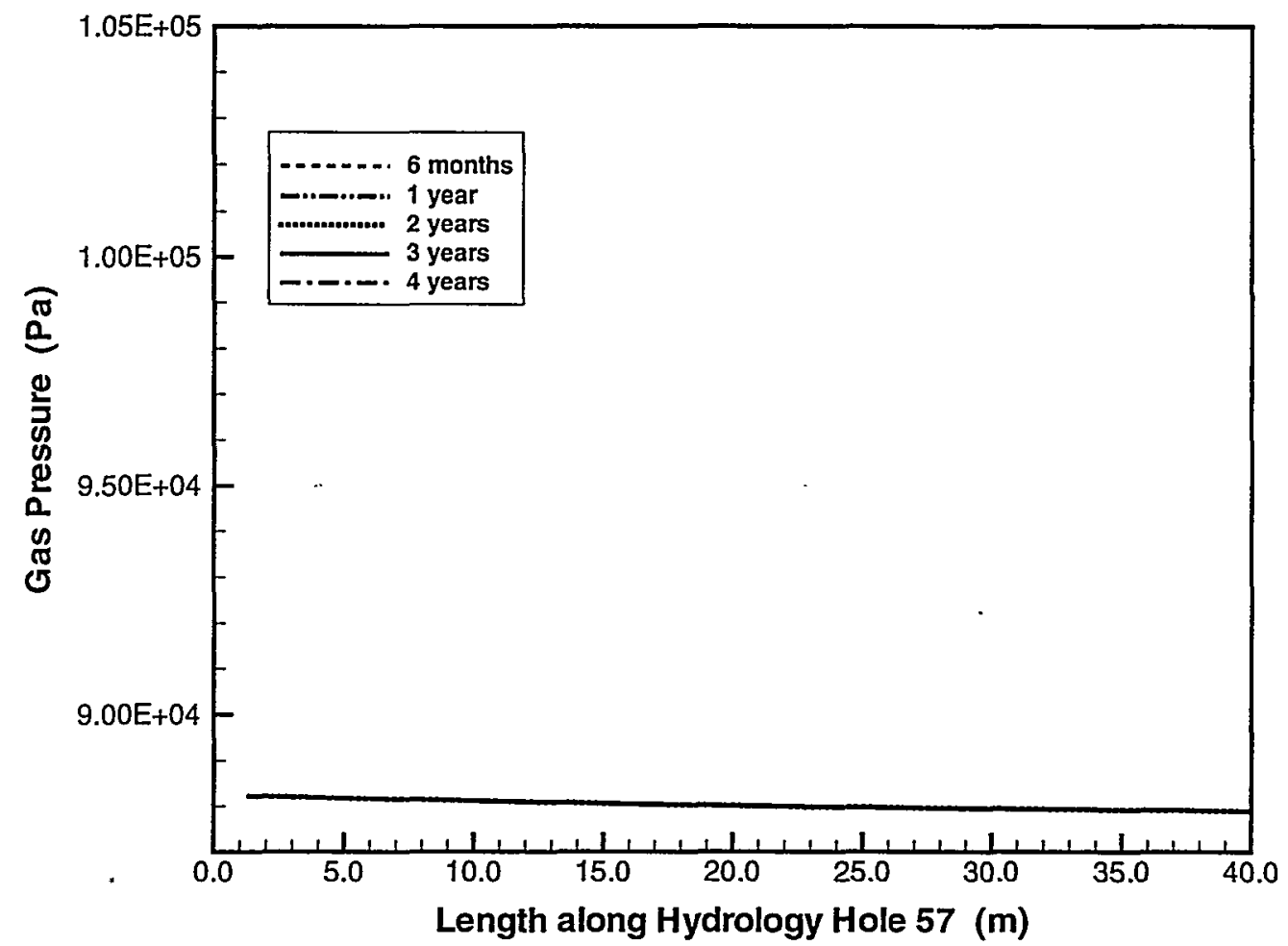

Figure A1-17 Gas pressure profile along borehole 57 at different times during heating period for $3.6 \mathrm{~mm} / \mathrm{yr}$ infiltration case ( 1 year heating at 100\%, 3 years heating at $50 \%$ ). 


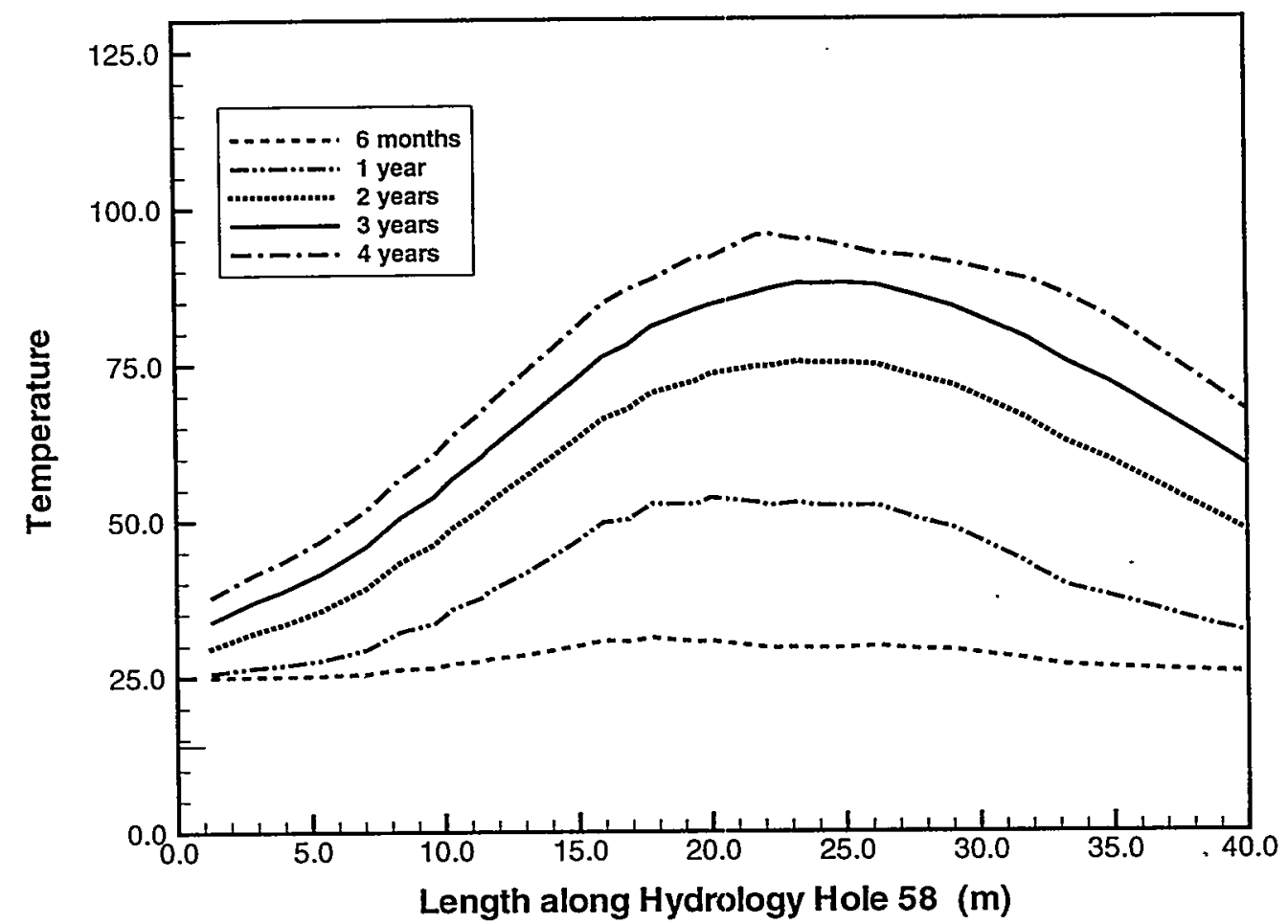

Figure Al-18 Temperature profile along borehole 58 at different times during heating period for $3.6 \mathrm{~mm} / \mathrm{yr}$ infiltration case ( 1 year heating at 100\%, 3 years heating at $50 \%$ ).

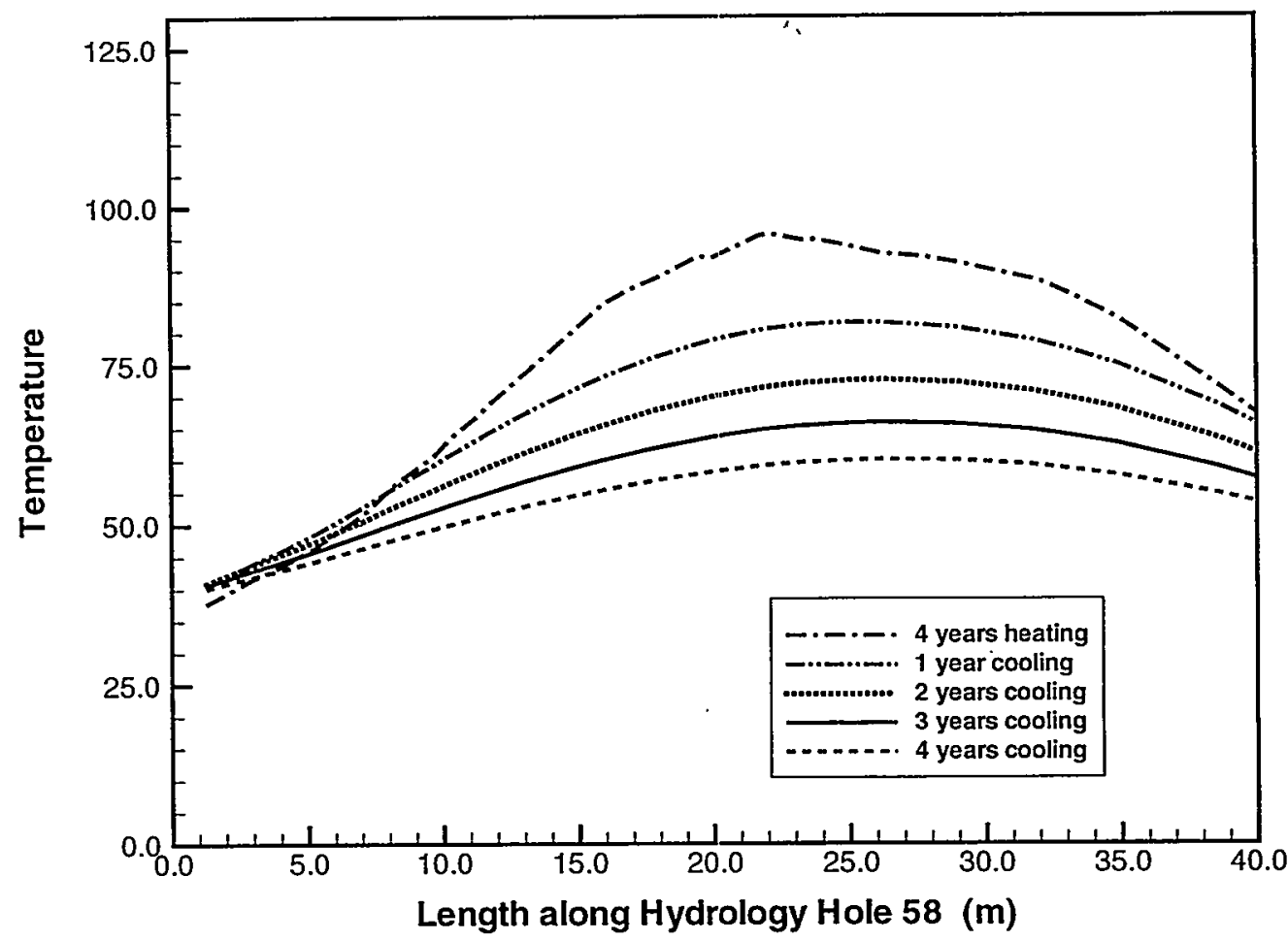

Figure A1-19 Temperature profile along borehole 58 at different times during cooling period for $3.6 \mathrm{~mm} / \mathrm{yr}$ infiltration case (1 year heating at 100\%, 3 years heating at 50\%). 


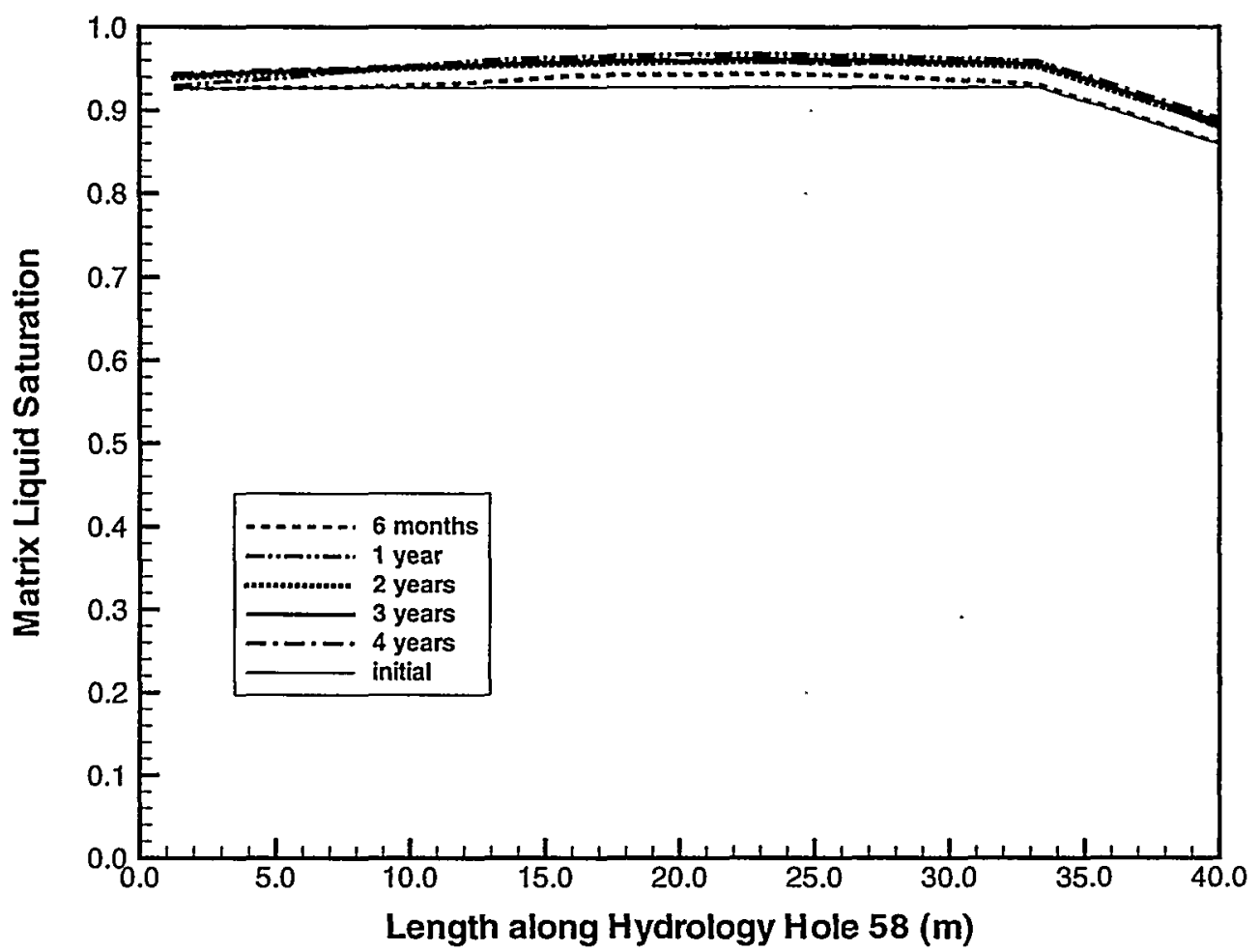

Figure A1-20 Matrix saturation profile along borehole 58 at different times during heating period for $3.6 \mathrm{~mm} / \mathrm{yr}$ infiltration case (I year heating at 100\%, 3 years heating at 50\%).

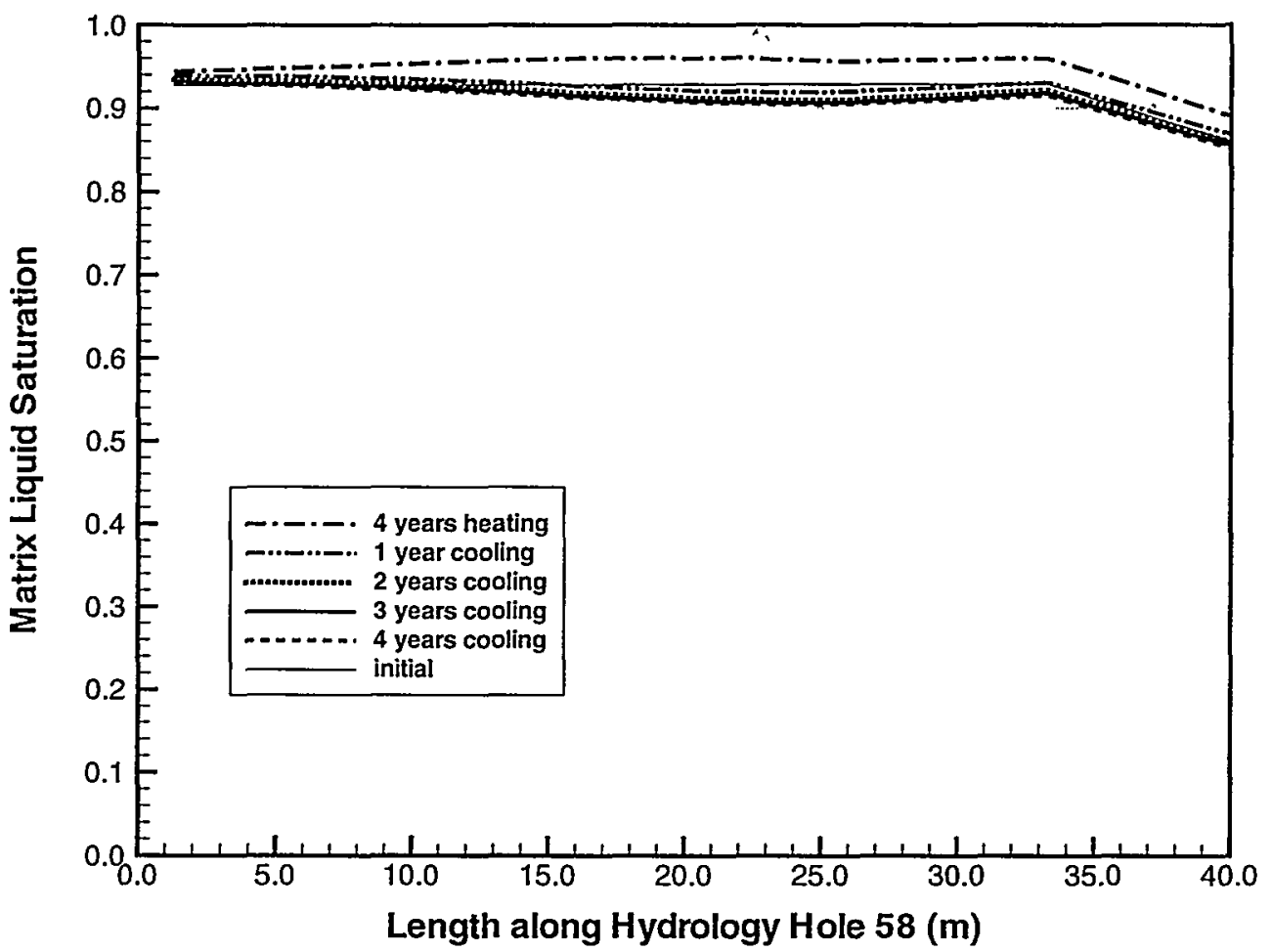

Figure A1-21 Matrix saturation profile along borehole 58 at different times during cooling period for $3.6 \mathrm{~mm} / \mathrm{yr}$ infiltration case (I year heating at 100\%, 3 years heating at $50 \%$ ). 
Pretest Analysis of the Thermal-Hydrological Conditions of the ESF Drift Scale Test

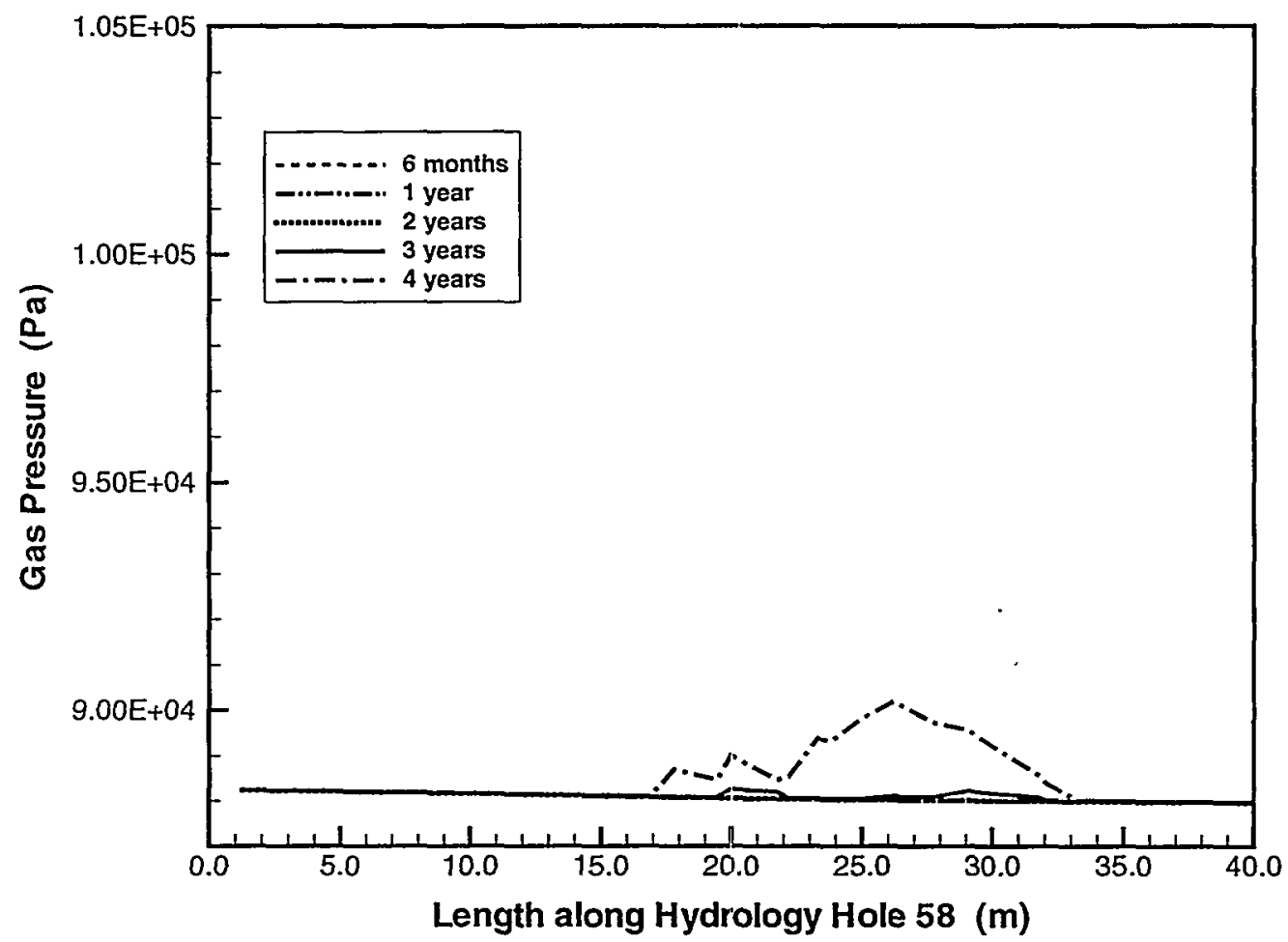

Figure A1-22 Gas pressure profile along borehole 58 at different times during heating period for $3.6 \mathrm{~mm} / \mathrm{yr}$ infiltration case (1 year heating at 100\%, 3 years heating at $50 \%$ ). 


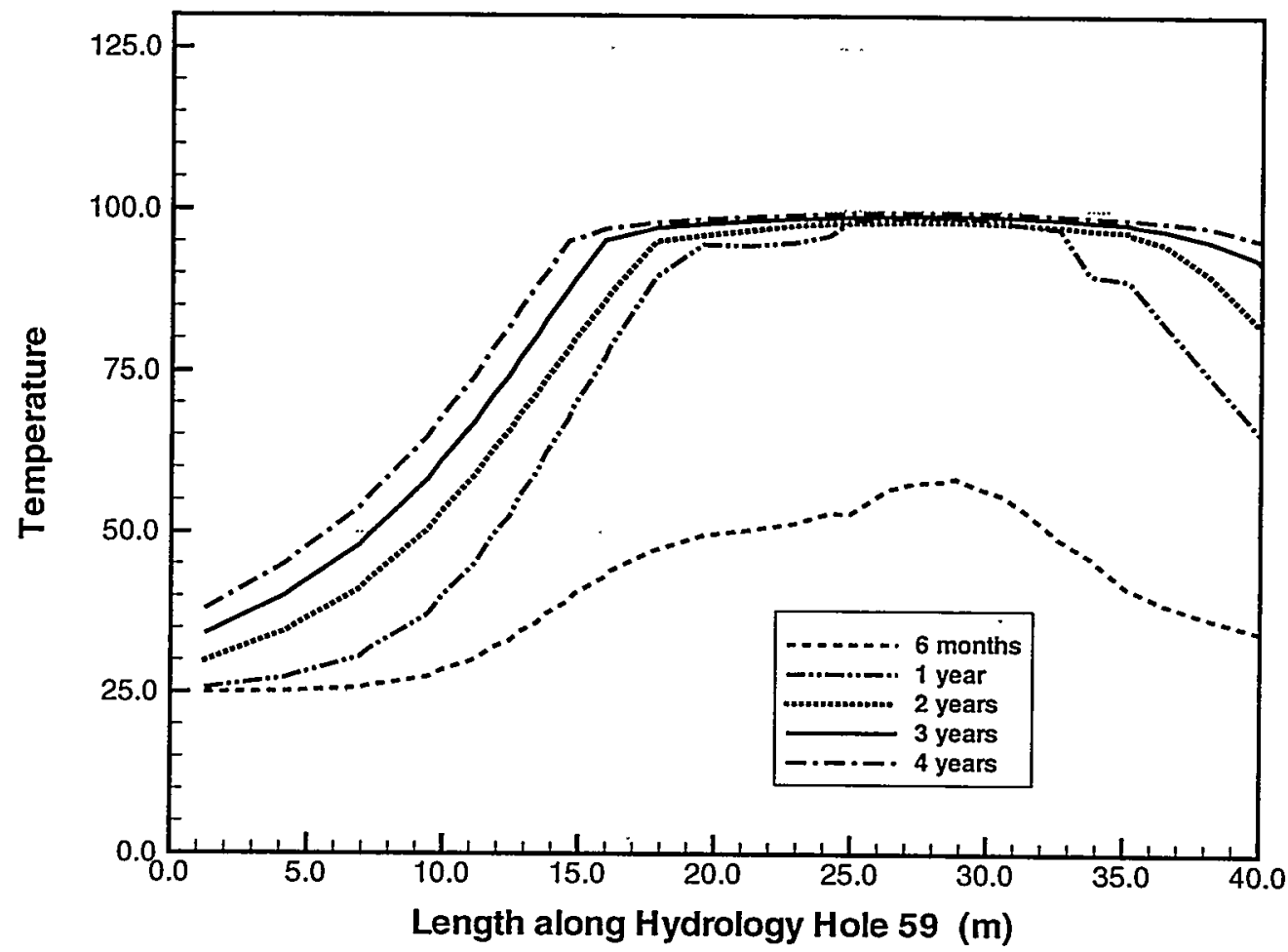

Figure A1-23 Temperature profile along borehole 59 at different times during heating period for $3.6 \mathrm{~mm} / \mathrm{yr}$ infiltration case (1 year heating at 100\%, 3 years heating at $50 \%$ ).

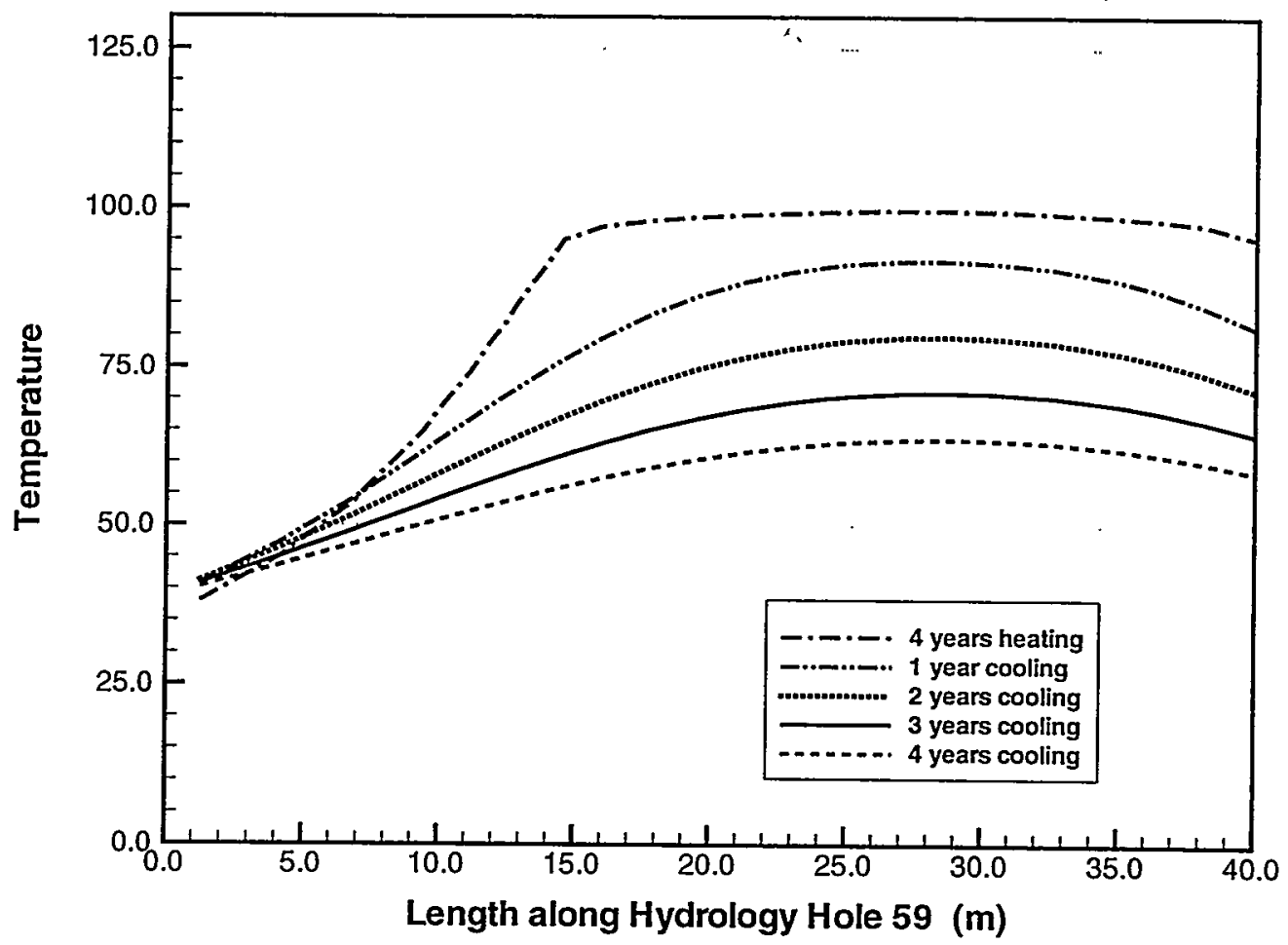

Figure A1-24 Temperature profile along borehole 59 at different times during cooling period for $3.6 \mathrm{~mm} / y$ r infiltration case (1 year heating at 100\%, 3 years heating at $50 \%$ ). 


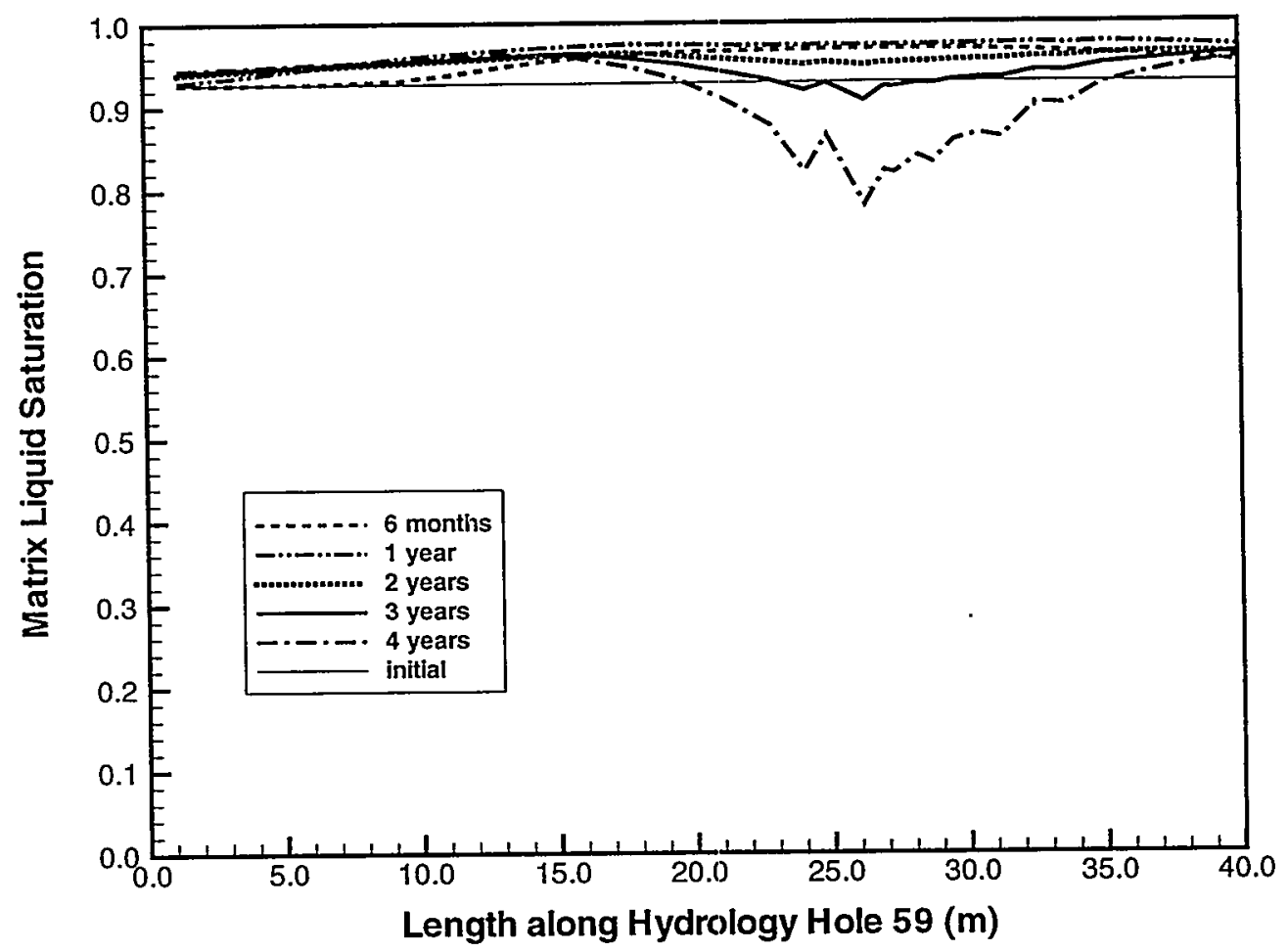

Figure AI-25 Matrix saturation profile along borehole 59 at different times during heating period for $3.6 \mathrm{~mm} / \mathrm{yr}$ infiltration case (1 year heating at $100 \%, 3$ years heating at $50 \%$ ).

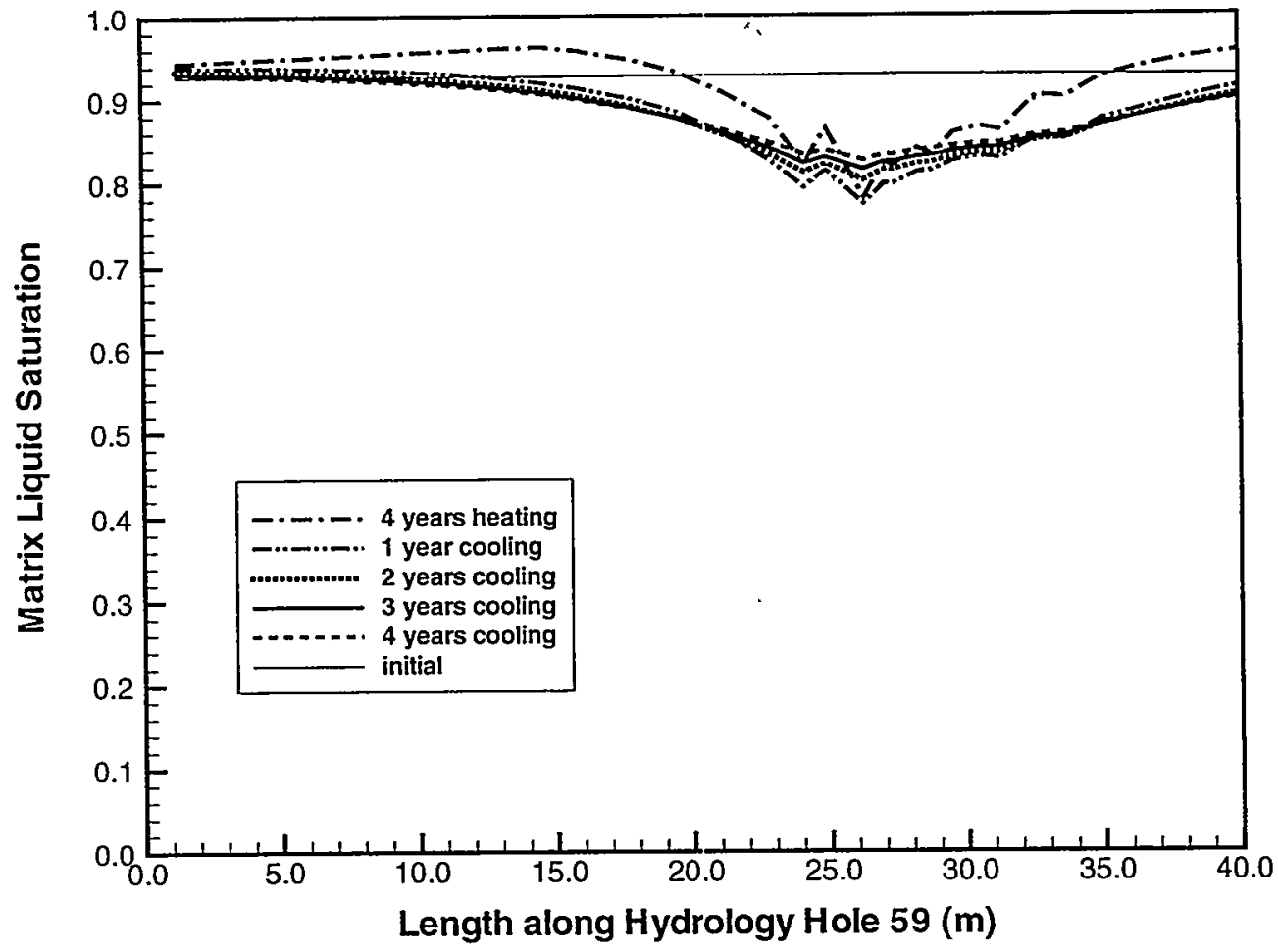

Figure A1-26 Matrix saturation profile along borehole 59 at different times during cooling period for $3.6 \mathrm{~mm} / \mathrm{yr}$ infiltration case ( 1 year heating at $100 \%, 3$ years heating at $50 \%$ ). 


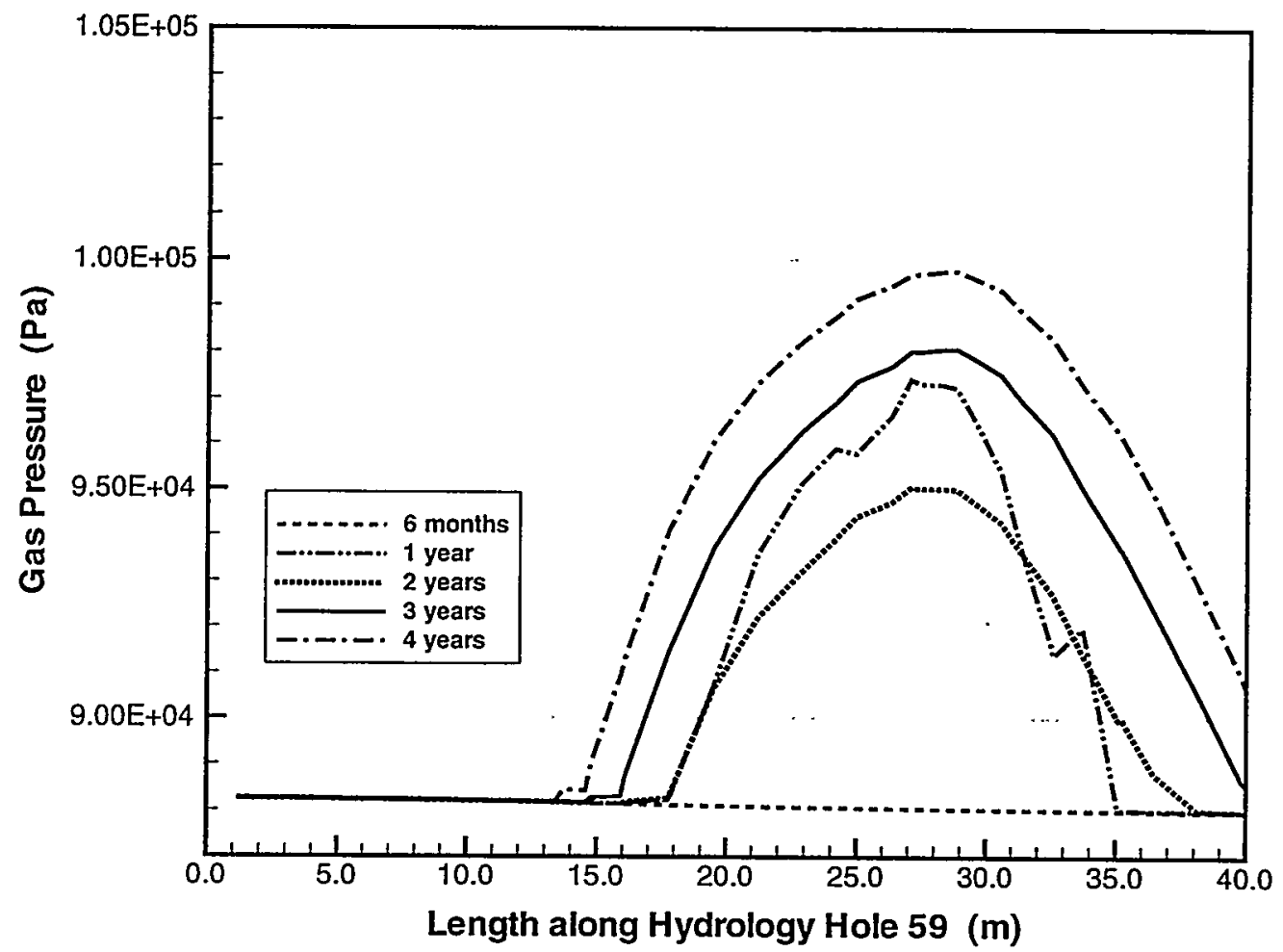

Figure A1-27 Gas pressure profile along borehole 59 at different times during heating period for $3.6 \mathrm{~mm} / \mathrm{yr}$ infiltration case ( 1 year heating at 100\%, 3 years heating at 50\%). 


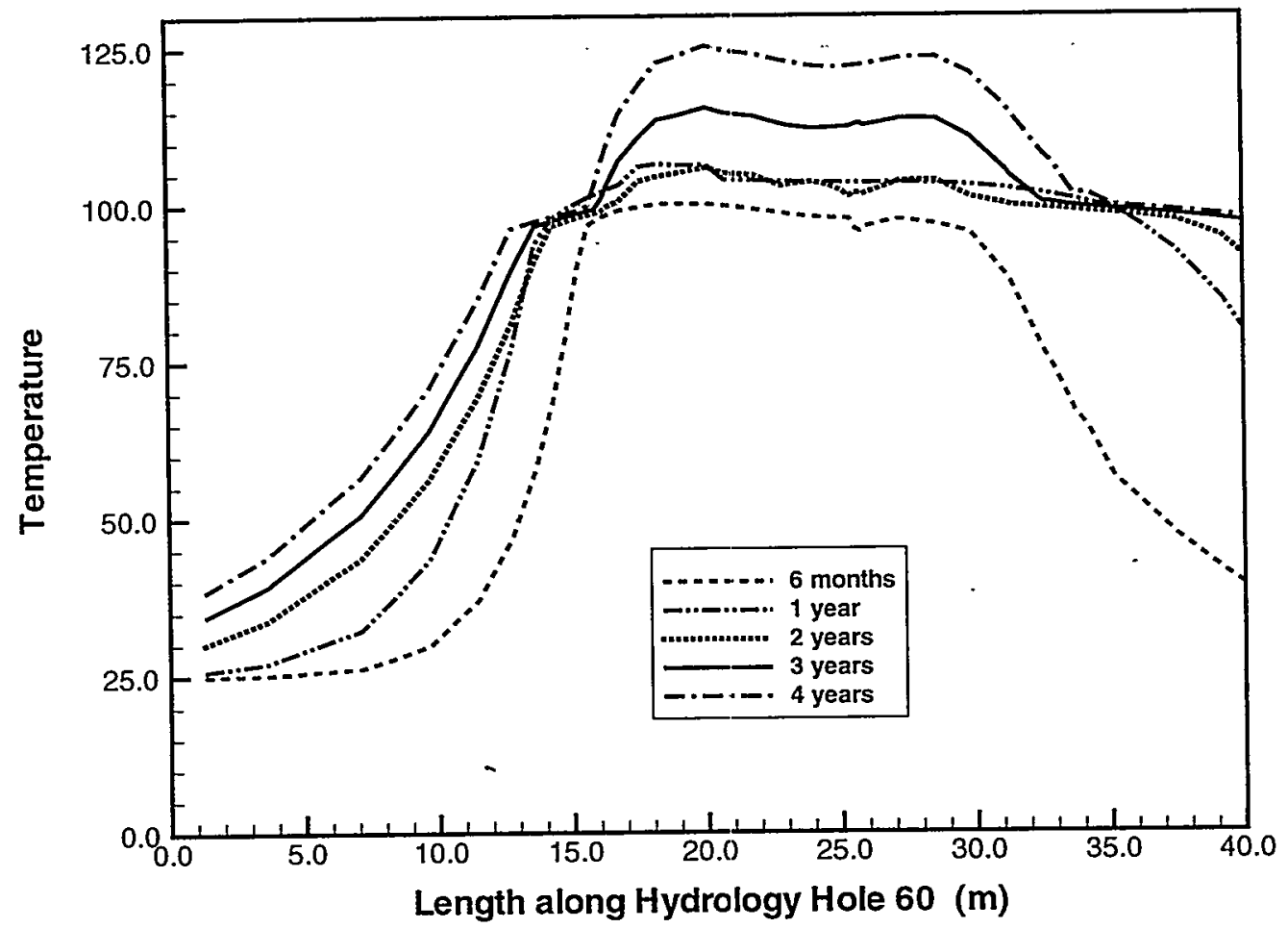

Figure Al-28 Temperature profile along borehole 60 at different times during heating period for $3.6 \mathrm{~mm} / \mathrm{yr}$ infiltration case ( 1 year heating at $100 \%, 3$ years heating at $50 \%$ ).

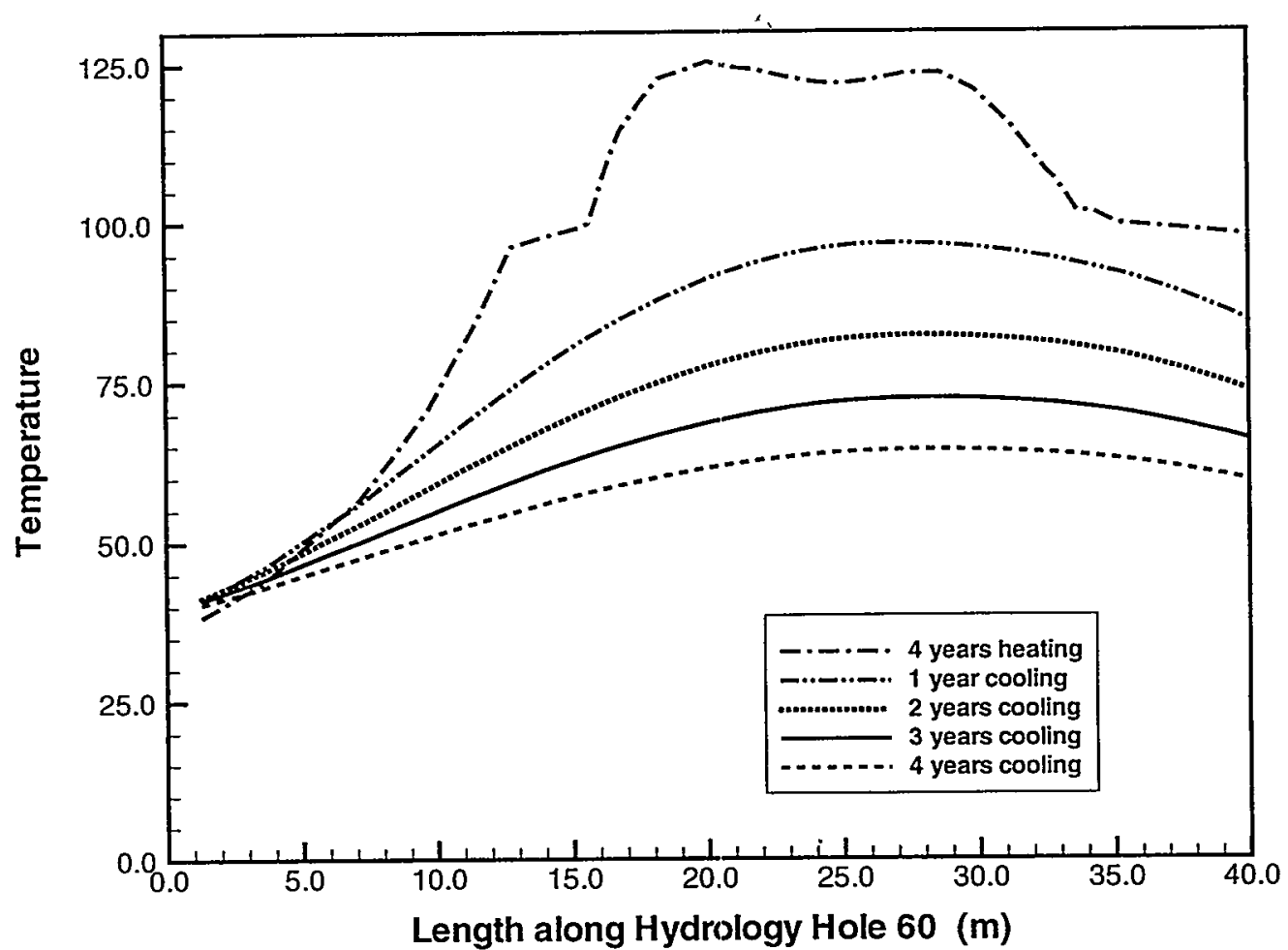

Figure A1-29 Temperature profile along borehole 60 at different times during cooling period for $3.6 \mathrm{~mm} / \mathrm{yr}$ infiltration case (1 year heating at 100\%, 3 years heating at $50 \%$ ). 


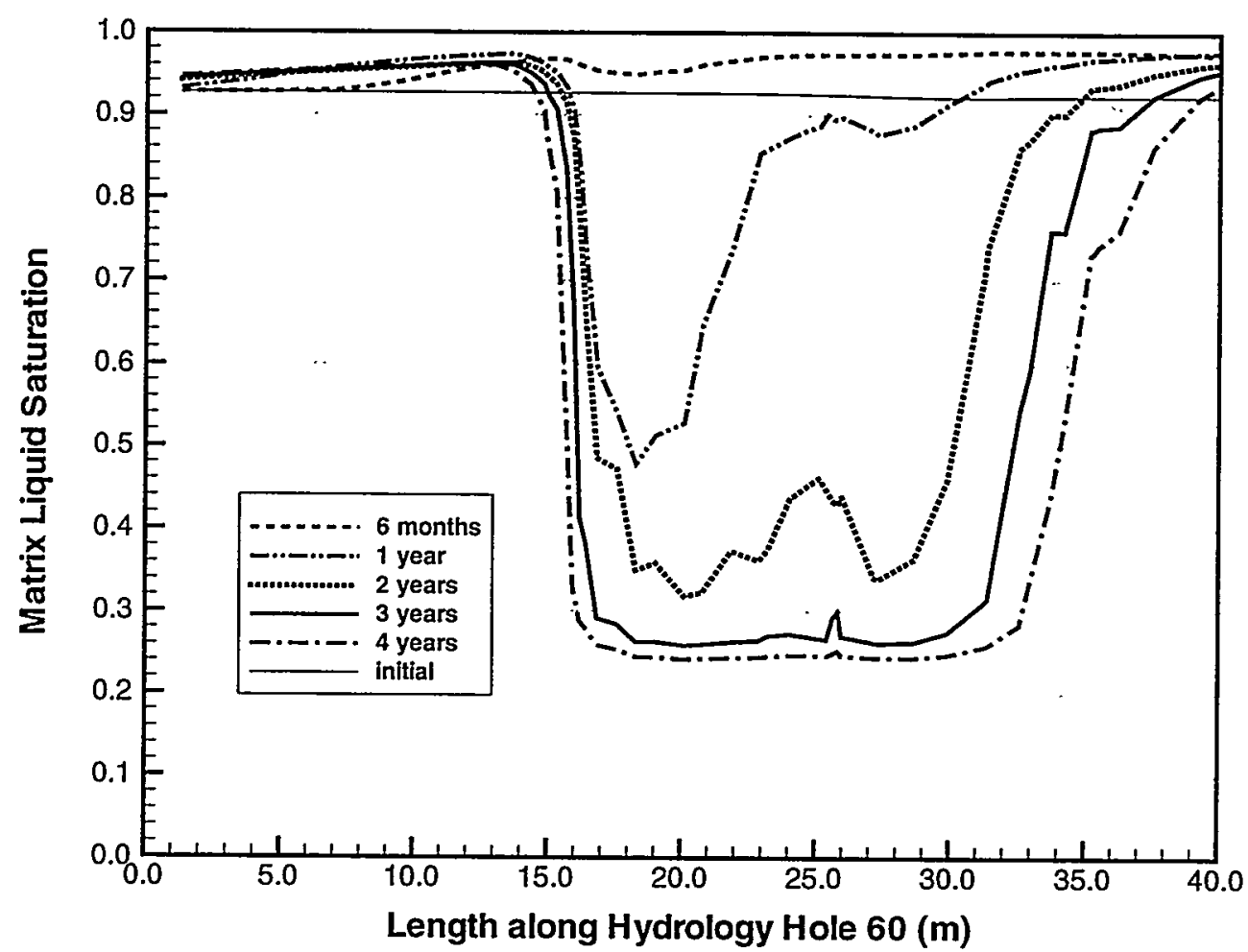

Figure AI-30 Matrix saturation profile along borehole 60 at different times during heating period for $3.6 \mathrm{~mm} / \mathrm{yr}$ infiltration case (I year heating at 100\%, 3 years heating at 50\%).

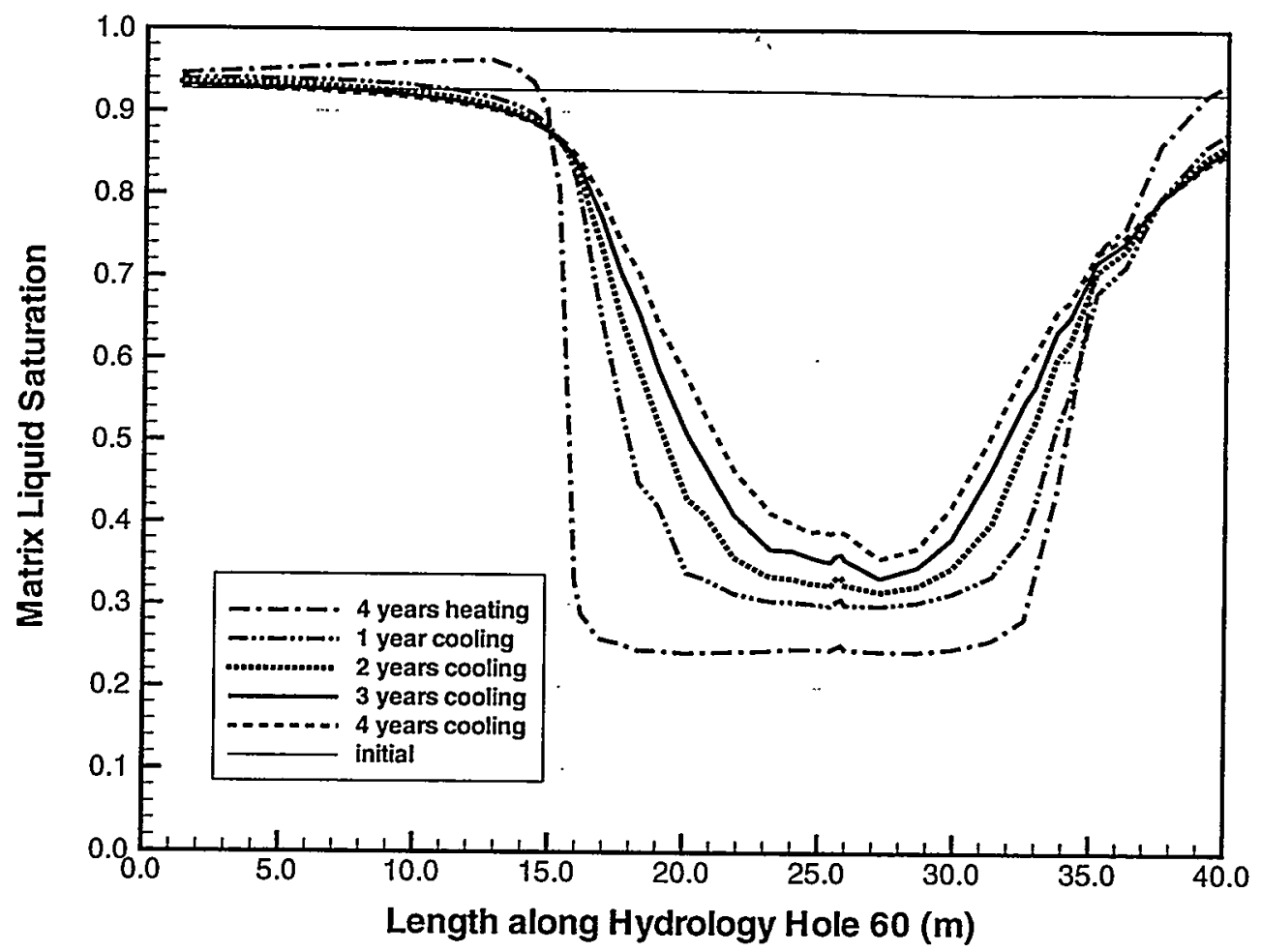

Figure A1-31 Matrix saturation profile along borehole 60 at different times during cooling period for $3.6 \mathrm{~mm} / \mathrm{yr}$ infiltration case (I year heating at 100\%, 3 years heating at $50 \%$ ). 
Pretest Analysis of the Thermal-Hydrological Conditions of the ESF Drift Scale Test

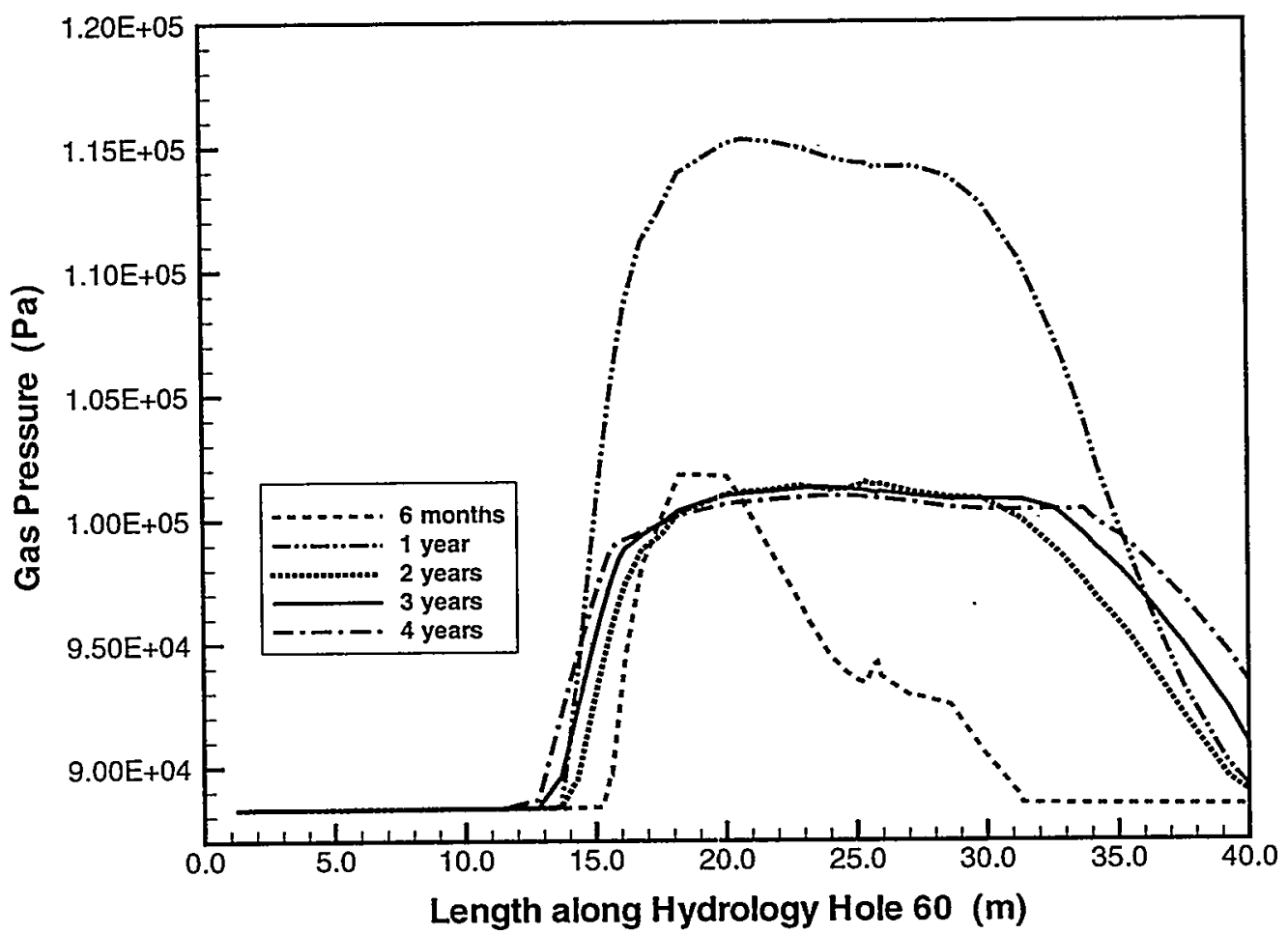

Figure A1-32 Gas pressure profile along borehole 60 at different times during heating period for $3.6 \mathrm{~mm} / \mathrm{yr}$ infiltration case (1 year heating at 100\%, 3 years heating at $50 \%$ ). 


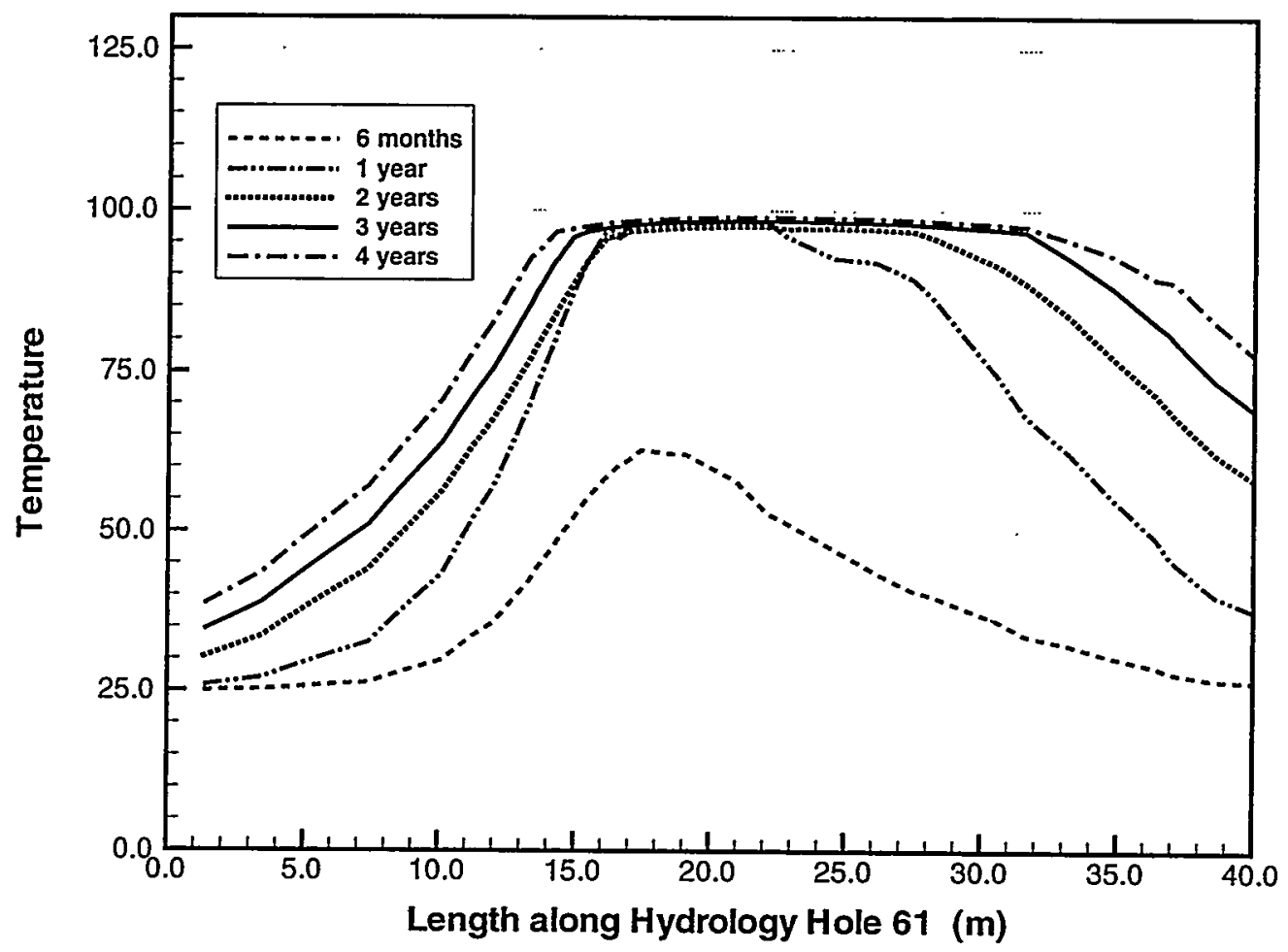

Figure A1-33 Temperature profile along borehole 61 at different times during heating period for $3.6 \mathrm{~mm} / \mathrm{yr}$ infiltration case (1 year heating at 100\%, 3 years heating at 50\%).

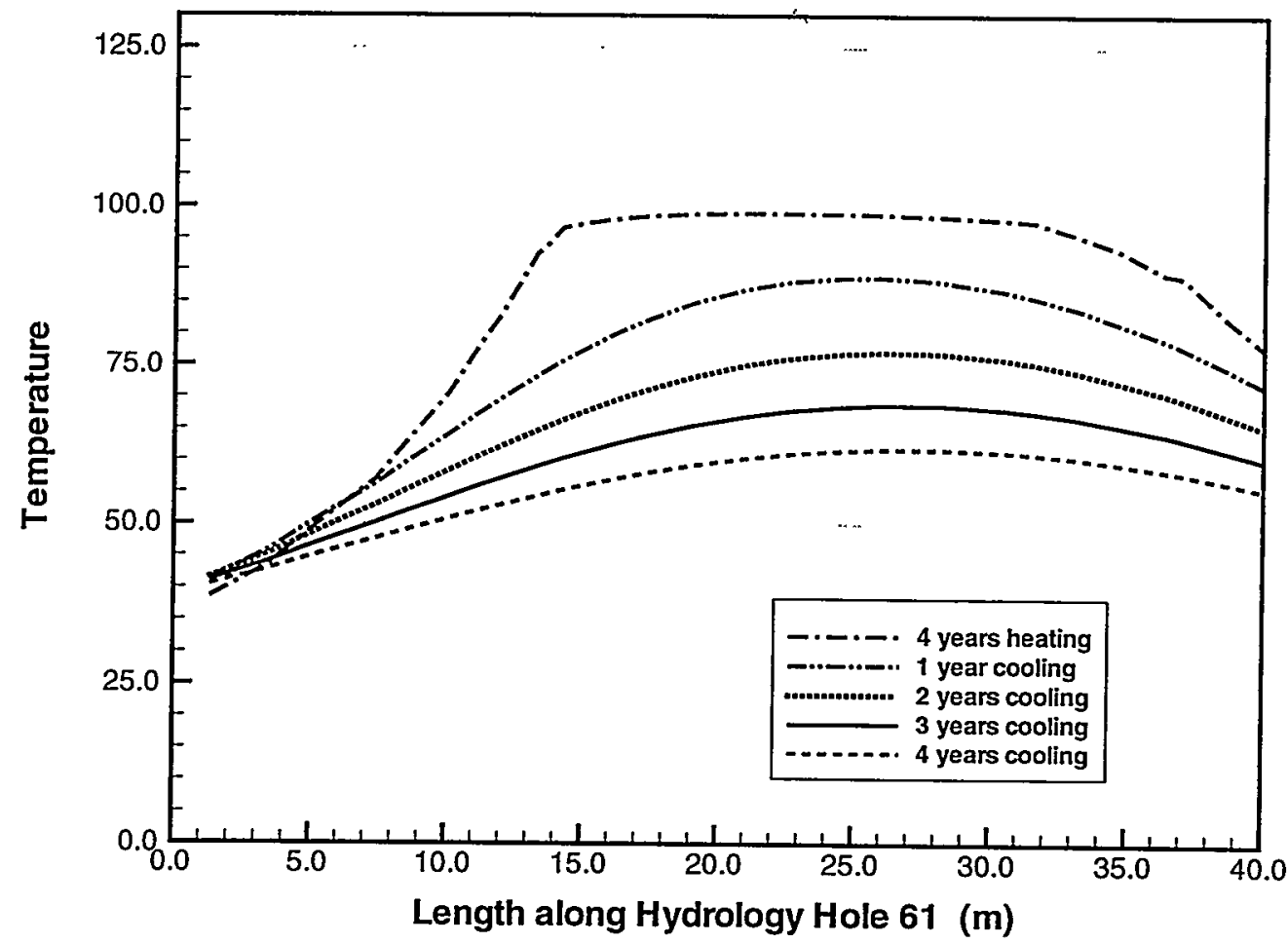

Figure A1-34 Temperature profile along borehole 61 at different times during cooling period for $3.6 \mathrm{~mm} / \mathrm{yr}$ infiltration case ( 1 year heating at 100\%, 3 years heating at $50 \%$ ). 
Pretest Analysis of the Thermal-Hydrological Conditions of the ESF Drift Scale Test

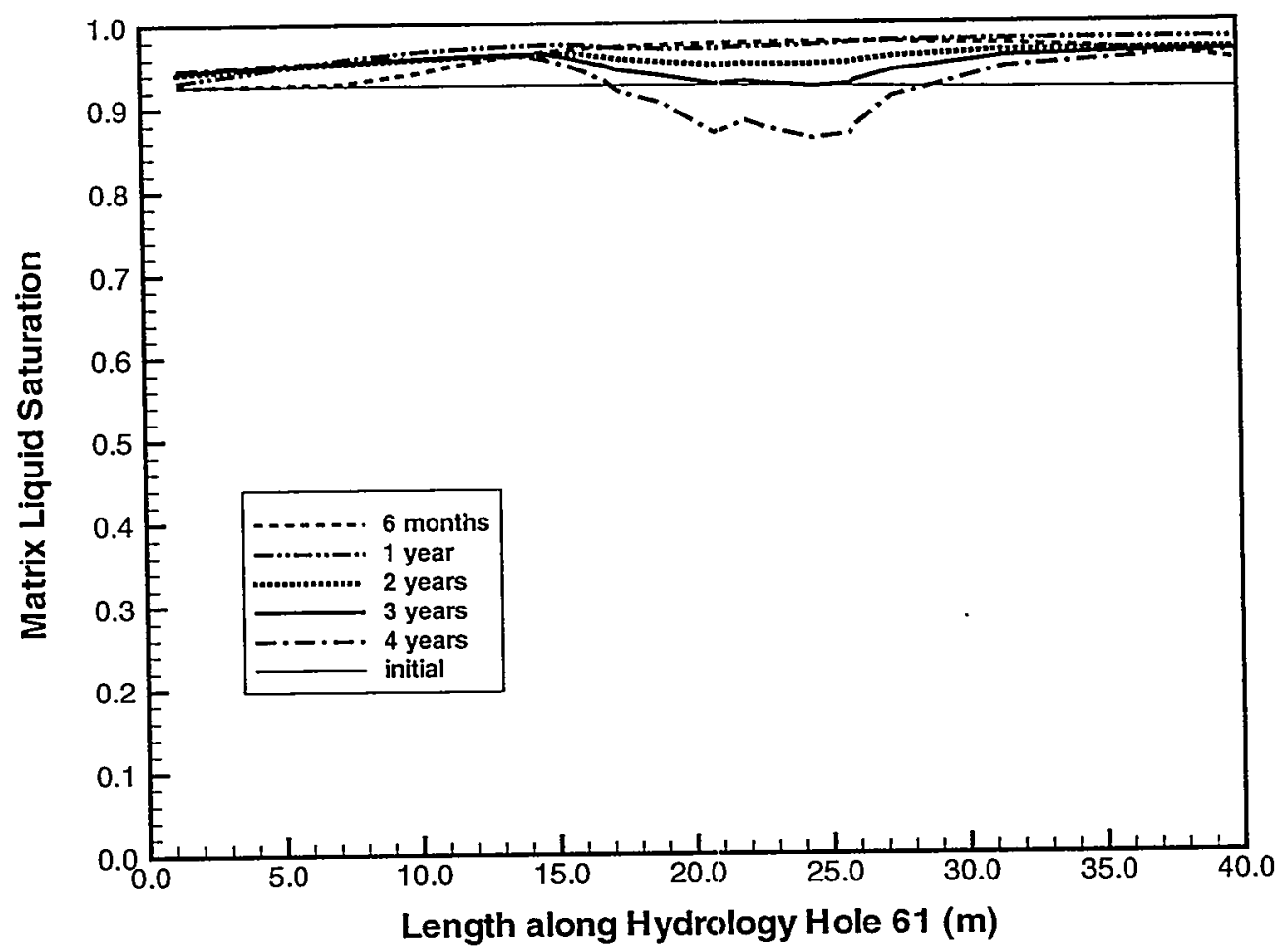

Figure Al-35 Matrix saturation profile along borehole 61 at different times during heating period for $3.6 \mathrm{~mm} / \mathrm{yr}$ infiltration case (1 year heating at 100\%, 3 years heating at 50\%).

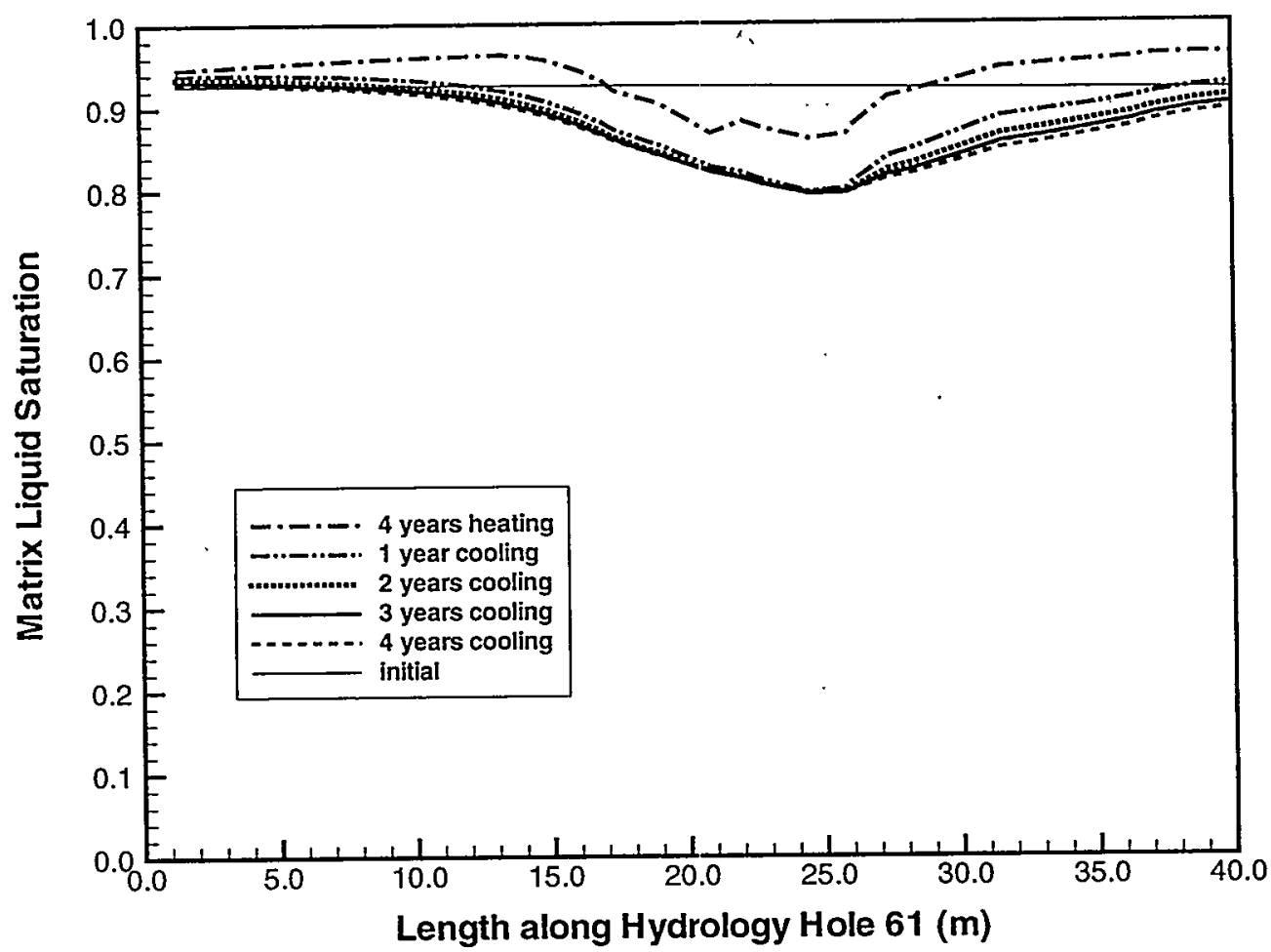

Figure A1-36 Matrix saturation profile along borehole 61 at different times during cooling period for $3.6 \mathrm{~mm} / \mathrm{yr}$ infiltration case (1 year heating at 100\%, 3 years heating at 50\%). 


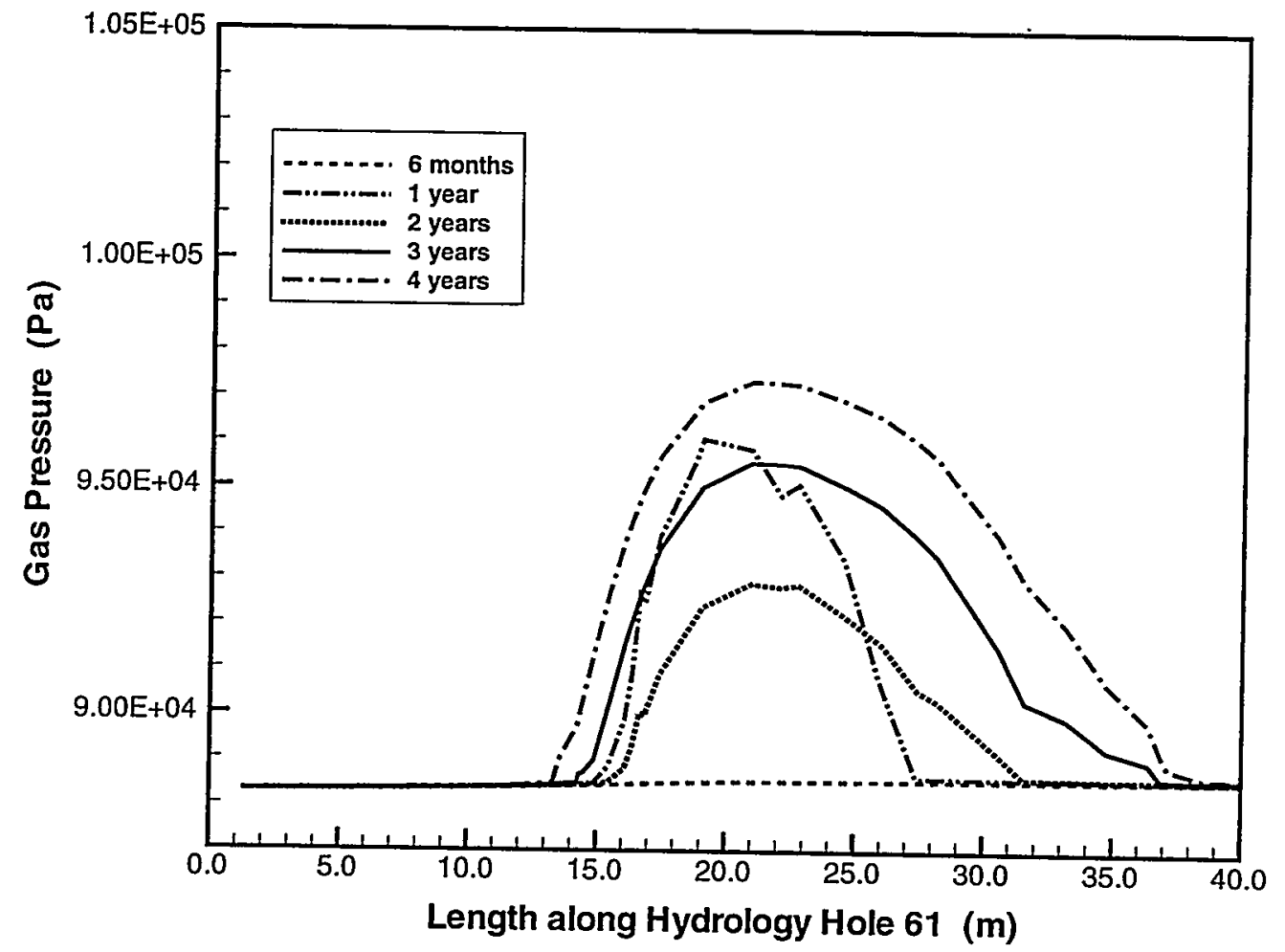

Figure A1-37 Gas pressure profile along borehole 61 at different times during heating period for $3.6 \mathrm{~mm} / \mathrm{yr}$ infiltration case (1 year heating at 100\%, 3 years heating at $50 \%$ ). 


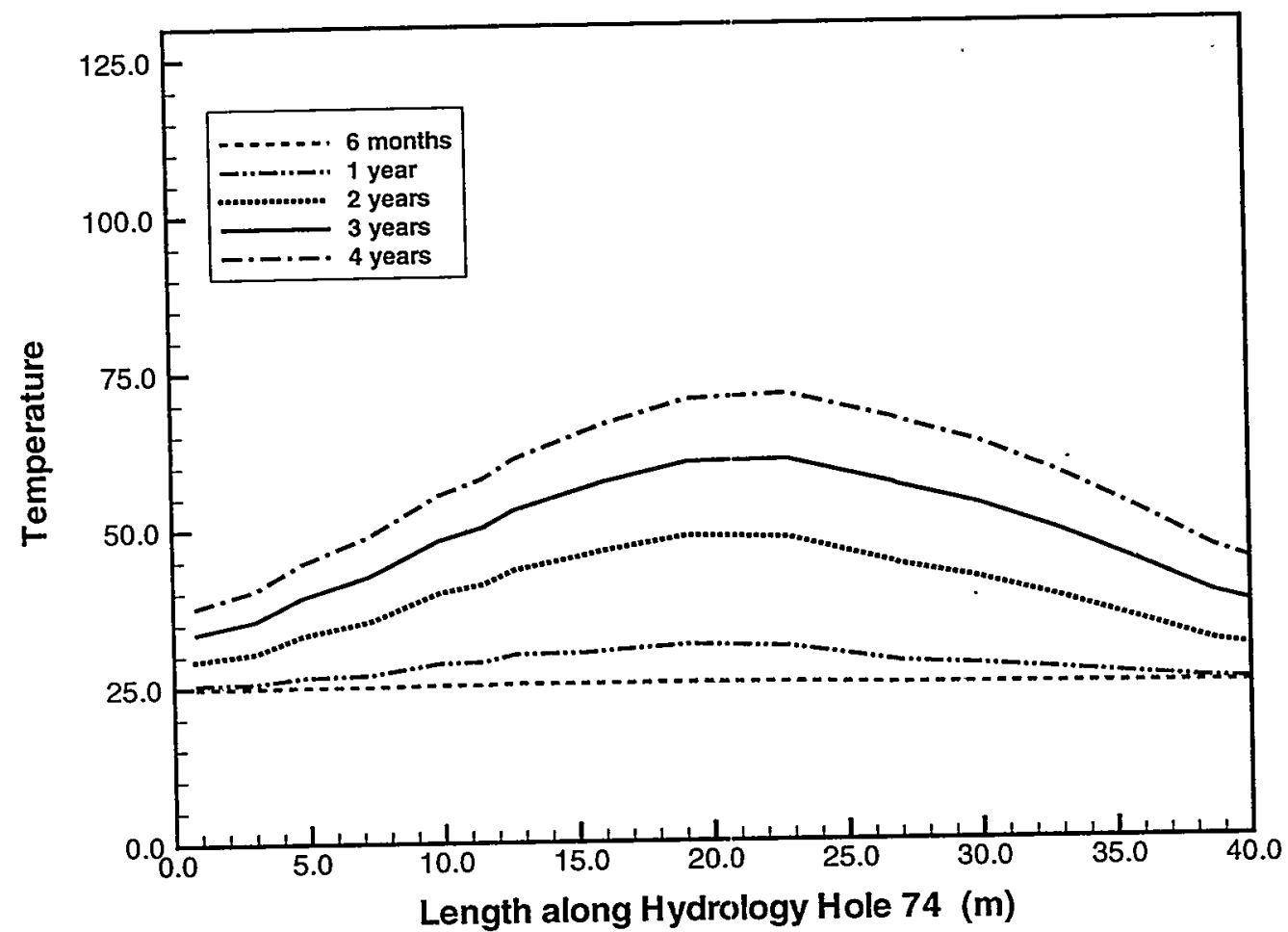

Figure AI-38 Temperature profile along borehole 74 at different times during heating period for $3.6 \mathrm{~mm} / \mathrm{yr}$ infiltration case (1 year heating at $100 \%$, 3 years heating at $50 \%$ ).

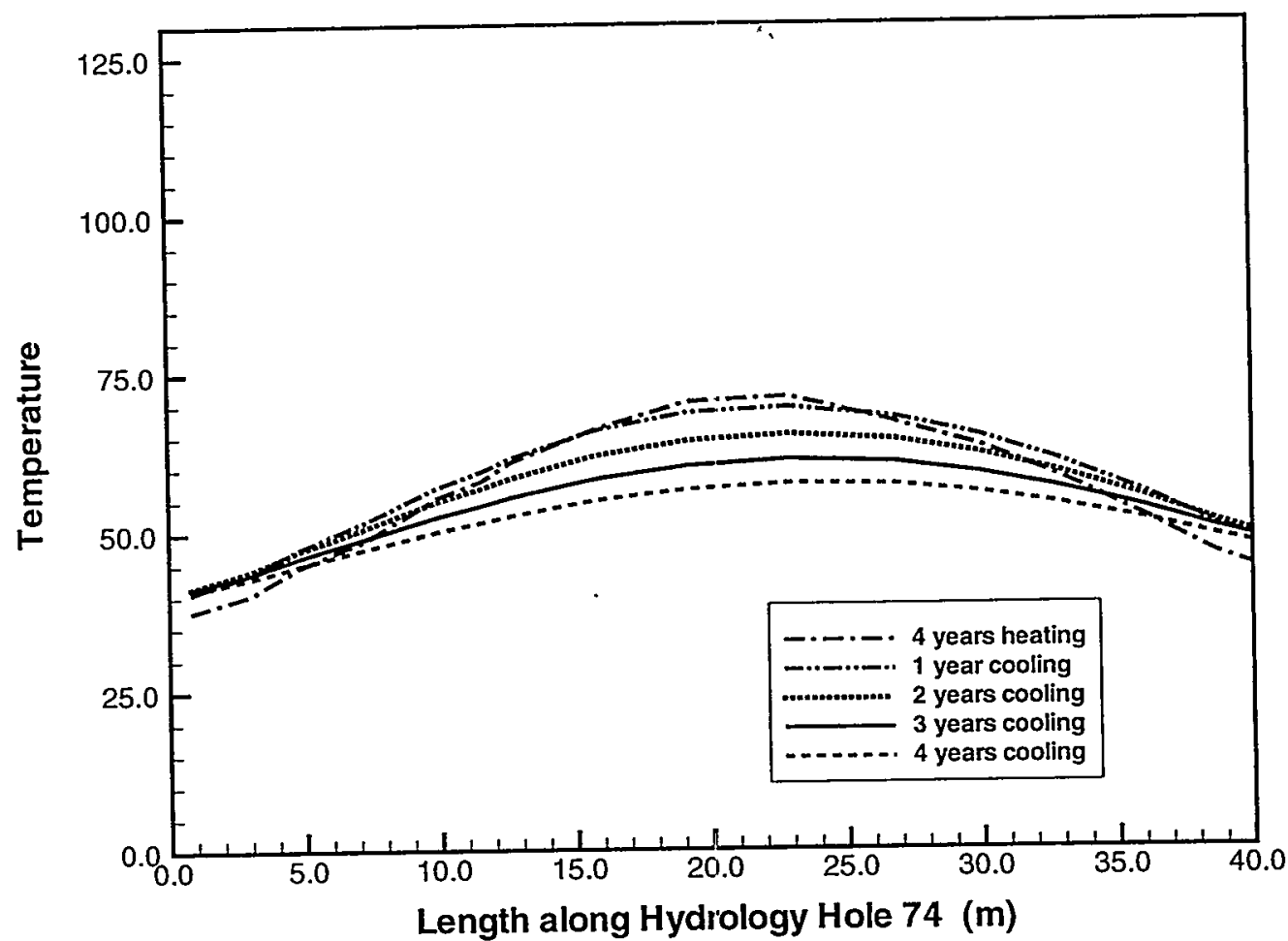

Figure Al-39 Temperature profile along borehole 74 at different times during cooling period for $3.6 \mathrm{~mm} / \mathrm{yr}$ infiltration case (1 year heating at 100\%, 3 years heating at $50 \%$ ). 


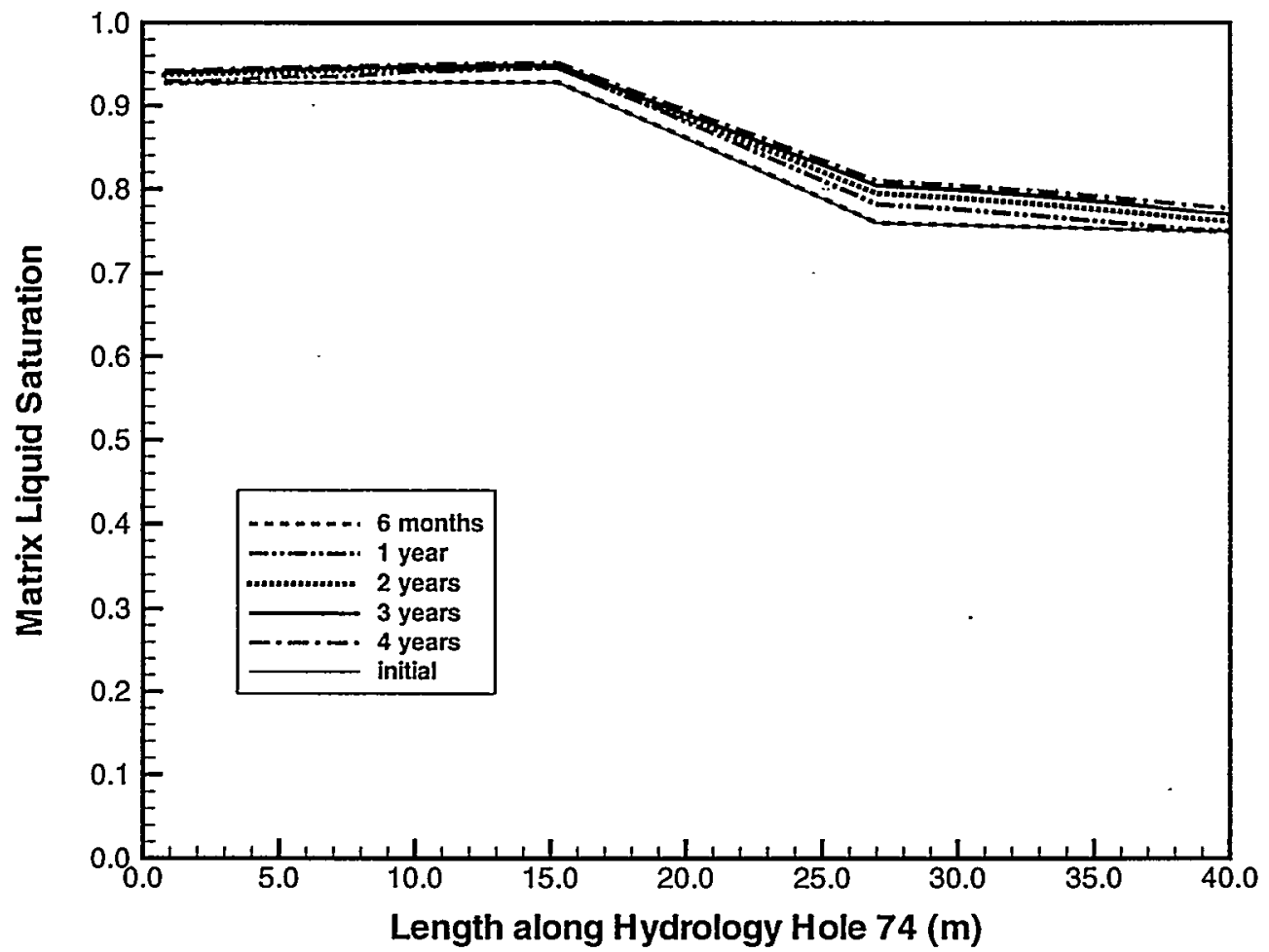

Figure A1-40 Matrix saturation profile along borehole 74 at different times during heating period for $3.6 \mathrm{~mm} / \mathrm{yr}$ infiltration case (I year heating at 100\%, 3 years heating at 50\%).

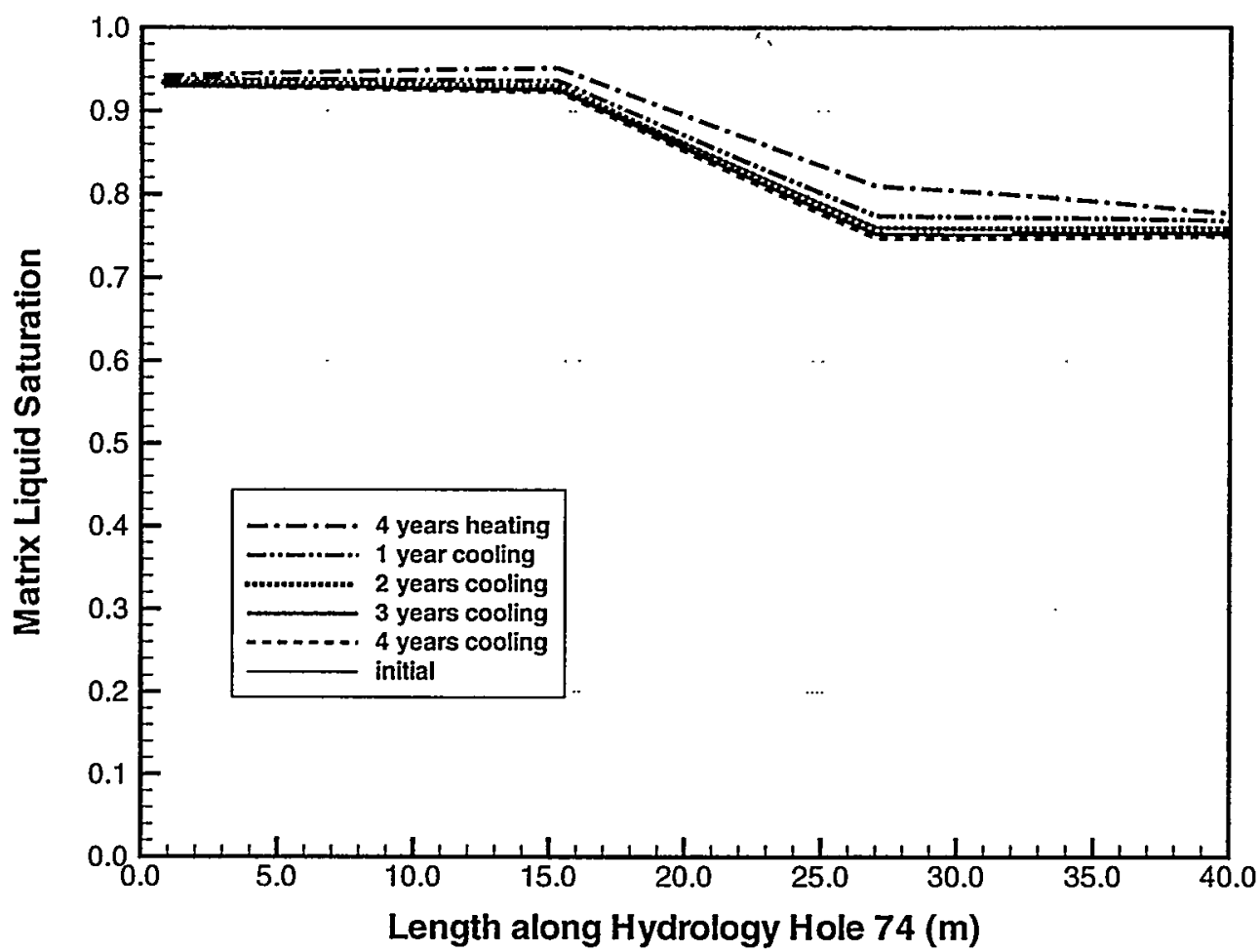

Figure AI-4I Matrix saturation profile along borehole 74 at different times during cooling period for $3.6 \mathrm{~mm} / \mathrm{yr}$ infiltration case (1 year heating at 100\%, 3 years heating at 50\%). 
Pretest Analysis of the Thermal-Hydrological Conditions of the ESF Drift Scale Test

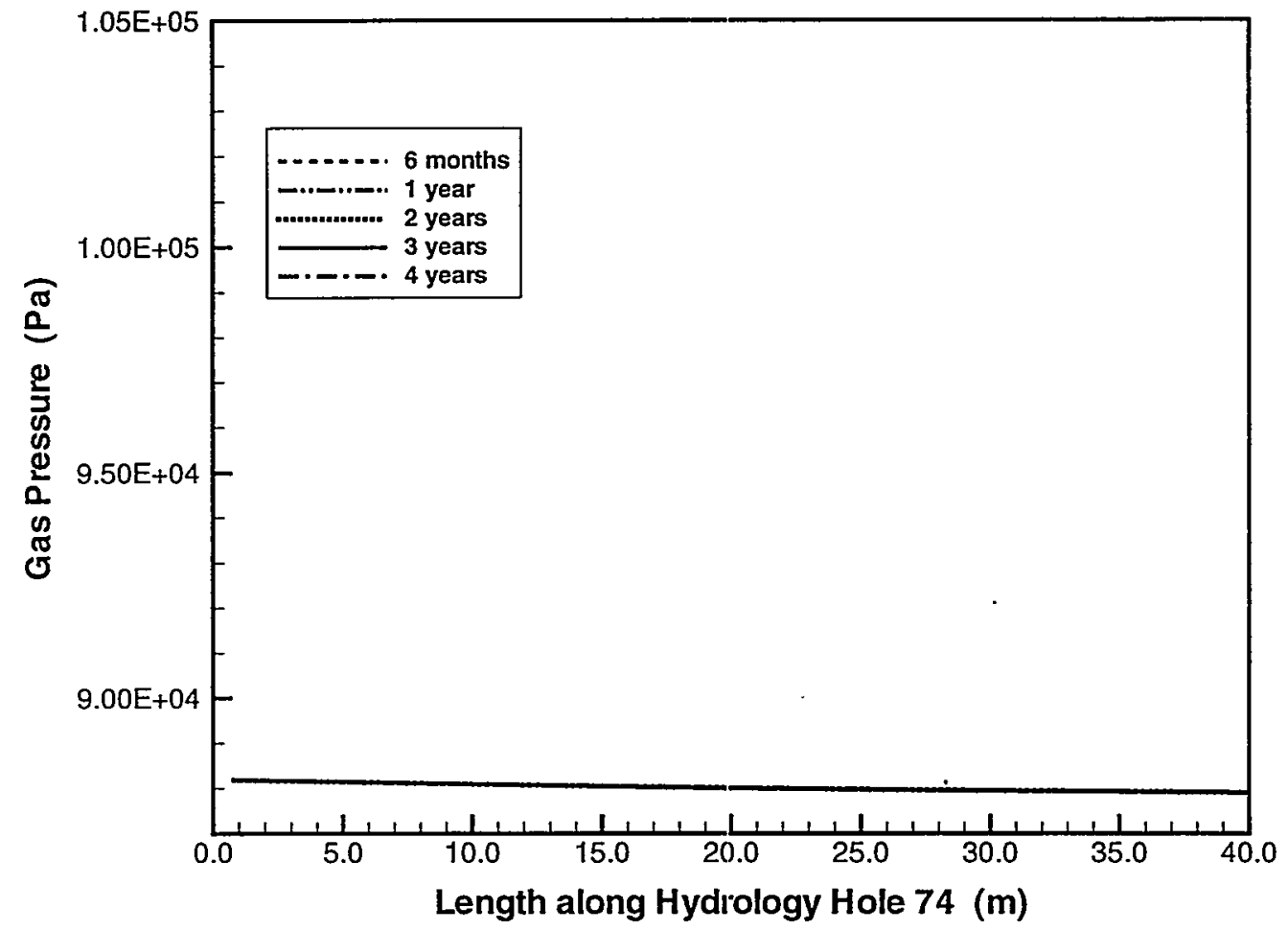

Figure A1-42 Gas pressure profile along borehole 74 at different times during heating period for $3.6 \mathrm{~mm} / \mathrm{yr}$ infiltration case (1 year heating at 100\%, 3 years heating at $50 \%$ ). 


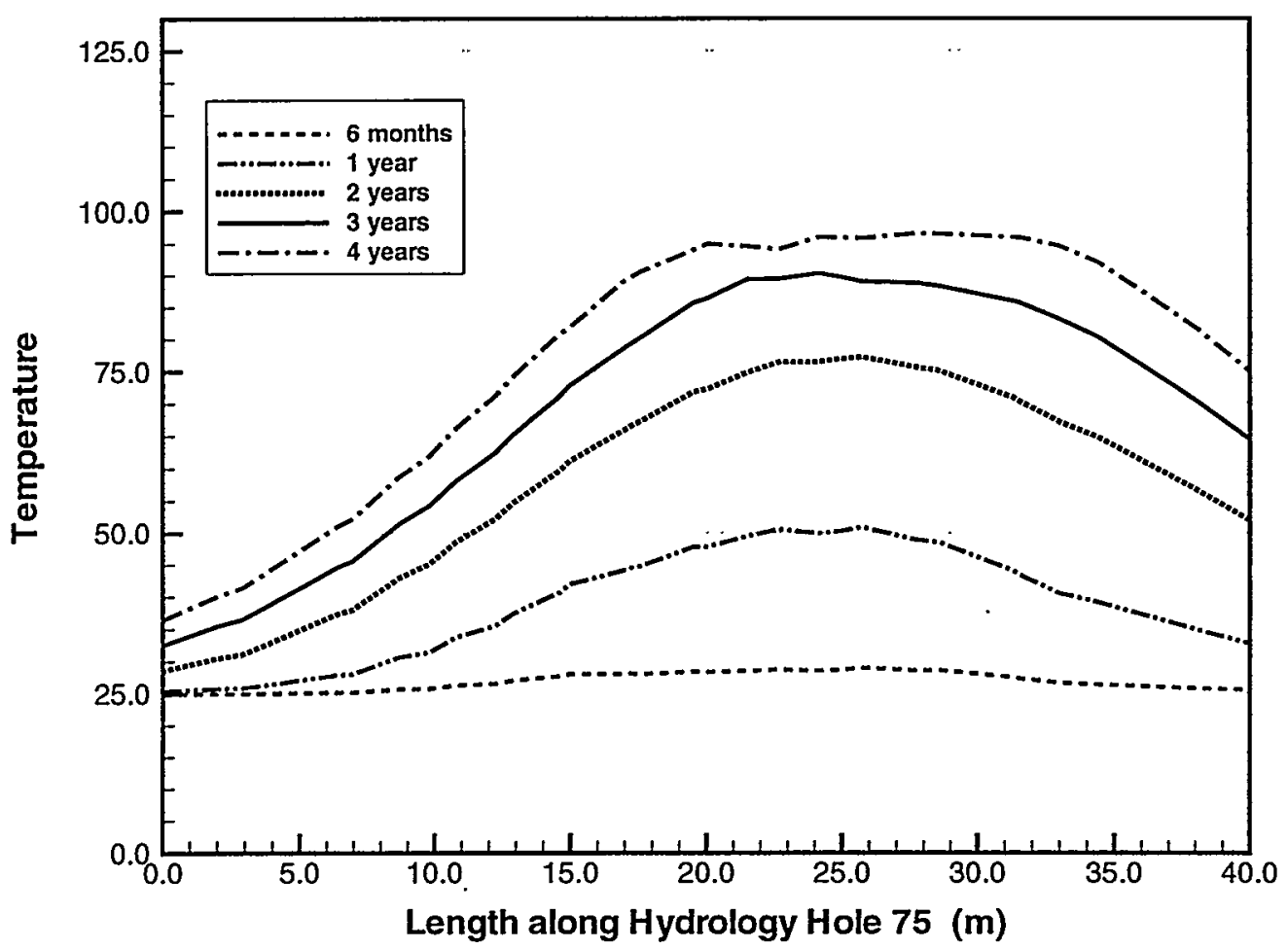

Figure A1-43 Temperature profile along borehole 75 at different times during heating period for $3.6 \mathrm{~mm} / \mathrm{yr}$ infiltration case (1 year heating at 100\%, 3 years heating at $50 \%$ ).

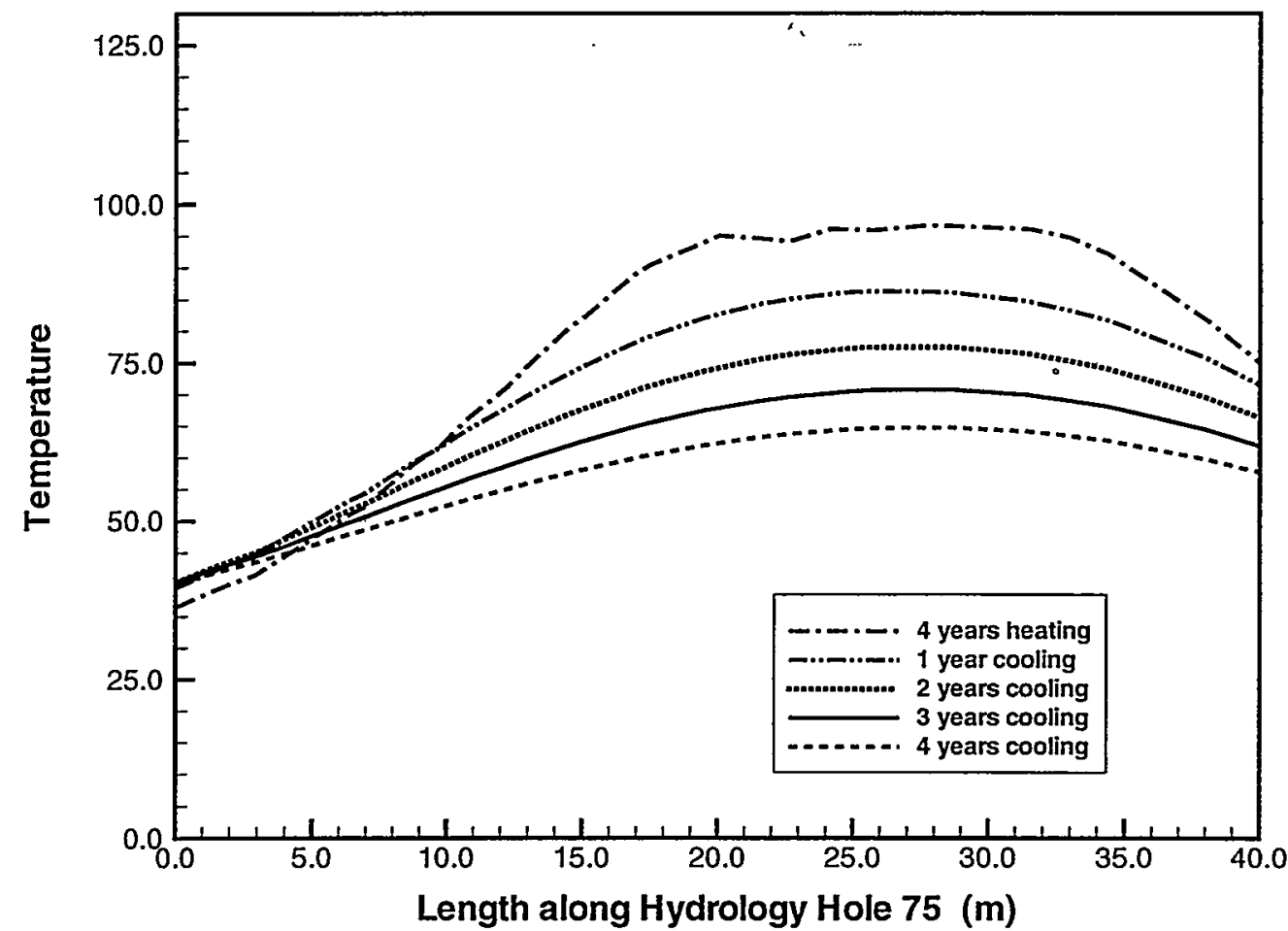

Figure A1-44 Temperature profile along borehole 75 at different times during cooling period for $3.6 \mathrm{~mm} / \mathrm{yr}$ infiltration case ( $I$ year heating at 100\%, 3 years heating at $50 \%$ ). 
Pretest Analysis of the Thermal-Hydrological Conditions of the ESF Drift Scale Test

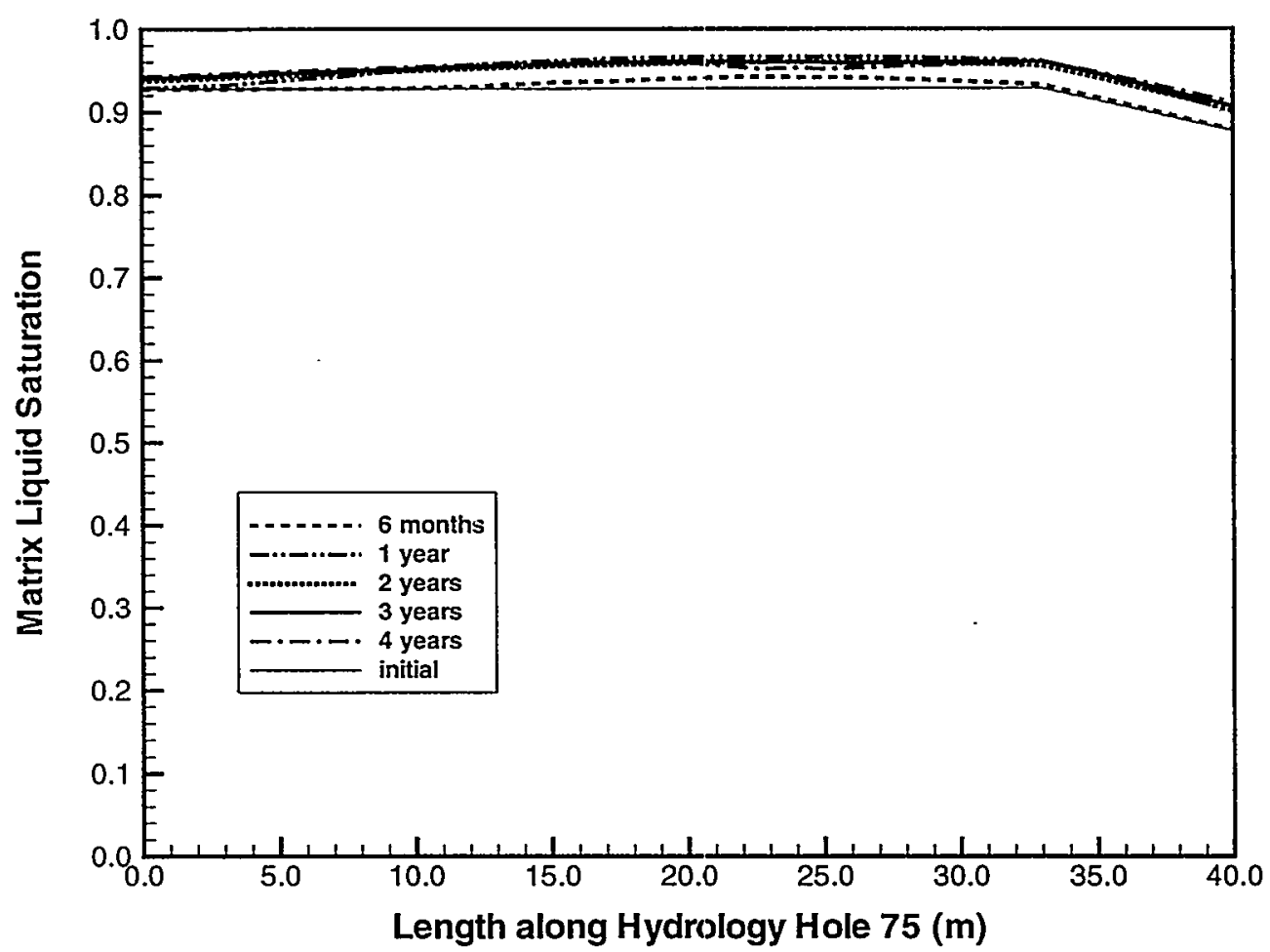

Figure A1-45 Matrix saturation profile along borehole 75 at different times during heating period for $3.6 \mathrm{~mm} / \mathrm{yr}$ infiltration case ( 1 year heating at 100\%, 3 years heating at 50\%).

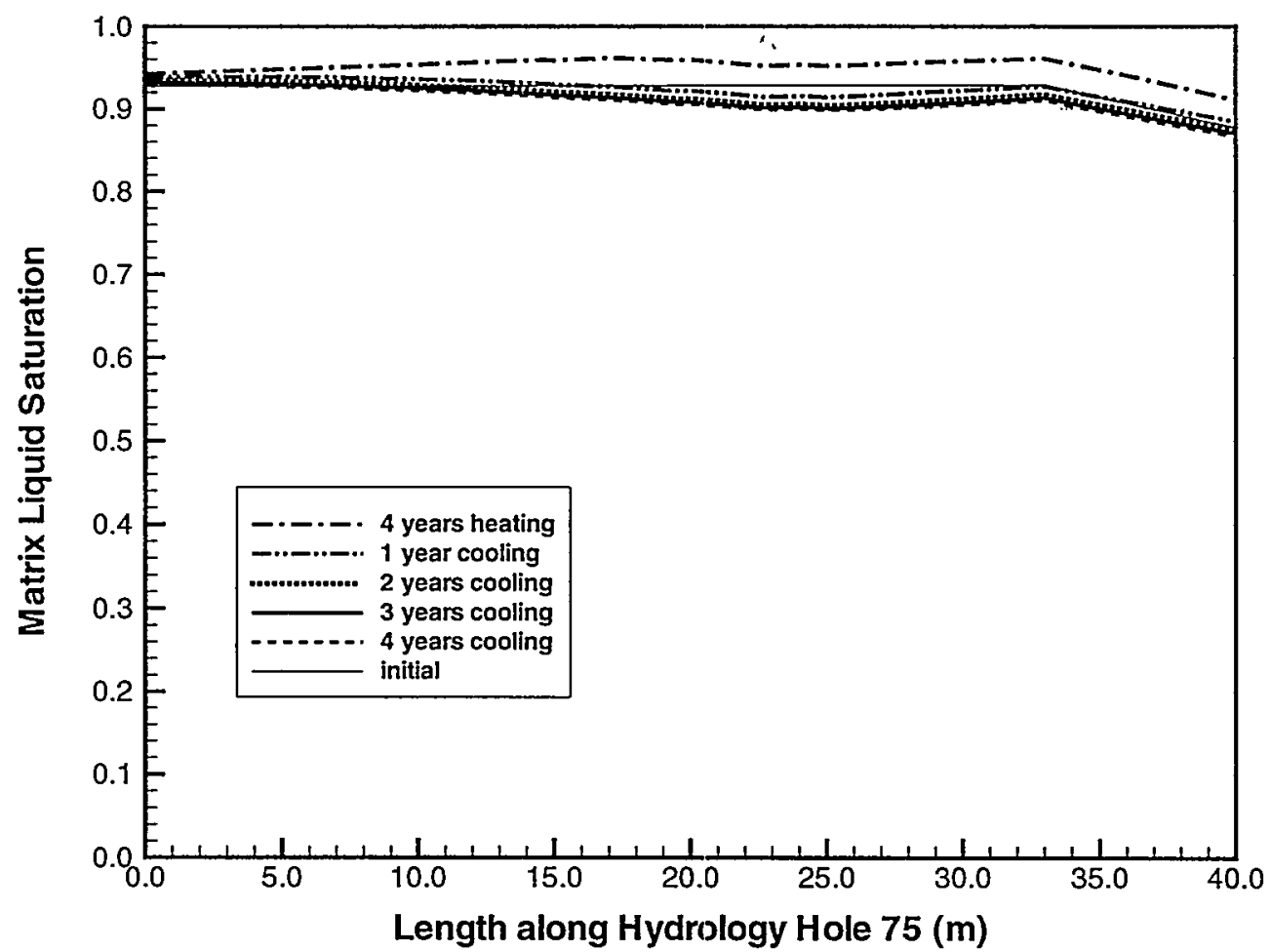

Figure A1-46 Matrix saturation profile along borehole 75 at different times during cooling period for $3.6 \mathrm{~mm} / \mathrm{yr}$ infiltration case (1 year heating at 100\%, 3 years heating at $50 \%$ ). 


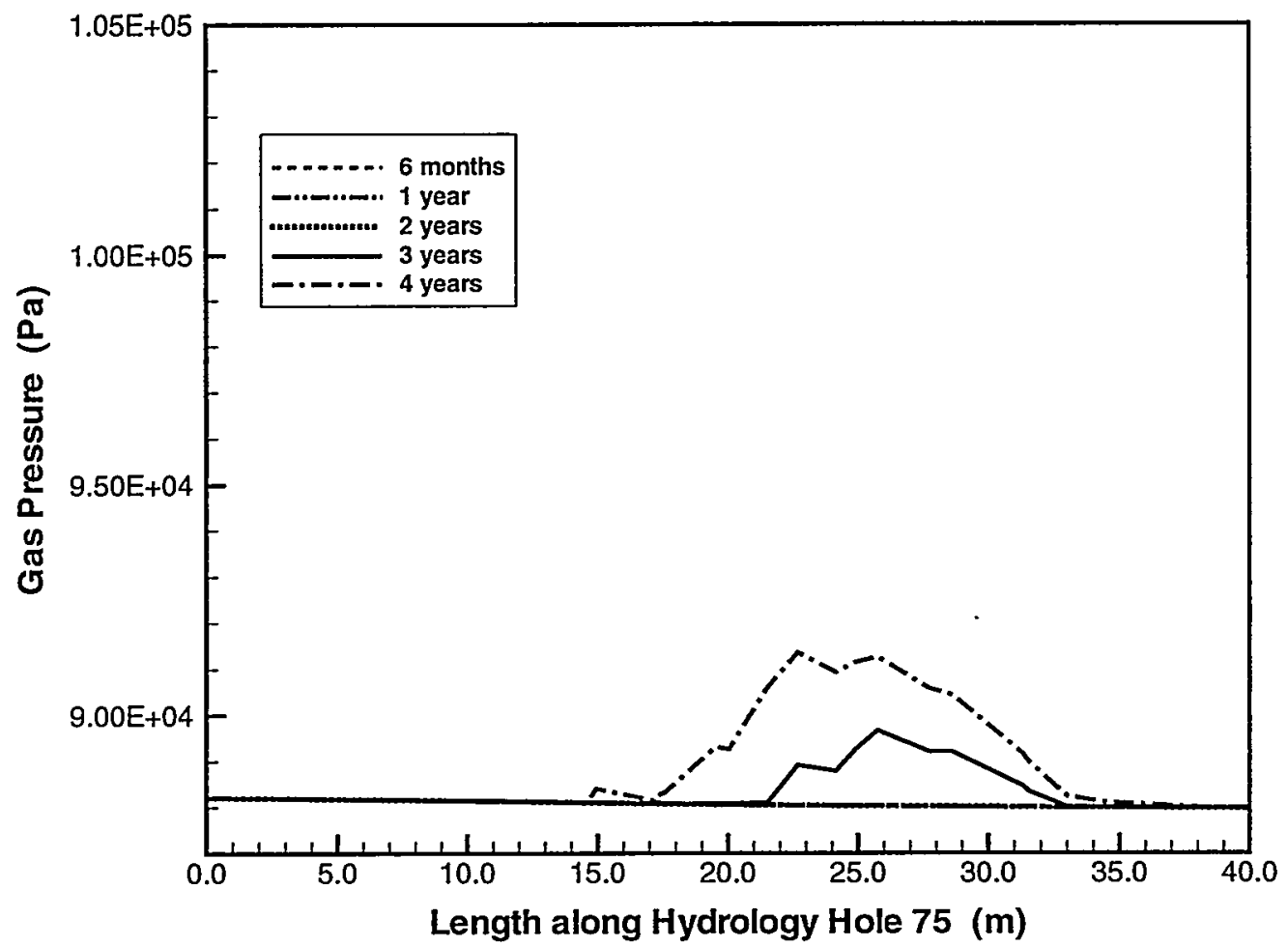

Figure A1-47 Gas pressure profile along borehole 75 at different times during heating period for $3.6 \mathrm{~mm} / \mathrm{yr}$ infiltration case (I year heating at 100\%, 3 years heating at 50\%). 


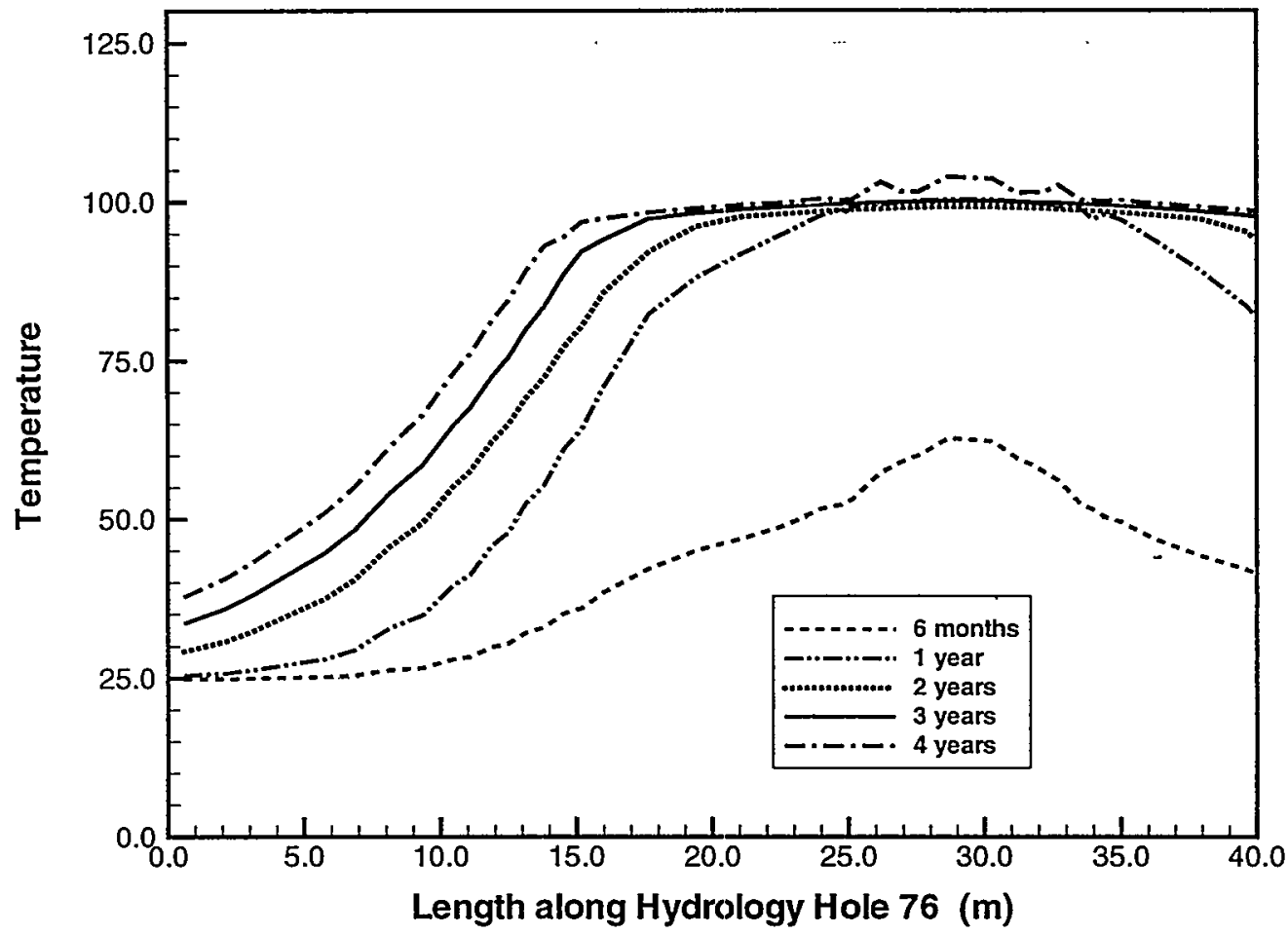

Figure A1-48 Temperature profile along borehole 76 at different times during heating period for $3.6 \mathrm{~mm} / \mathrm{yr}$ infiltration case (1 year heating at 100\%, 3 years heating at $50 \%$ ).

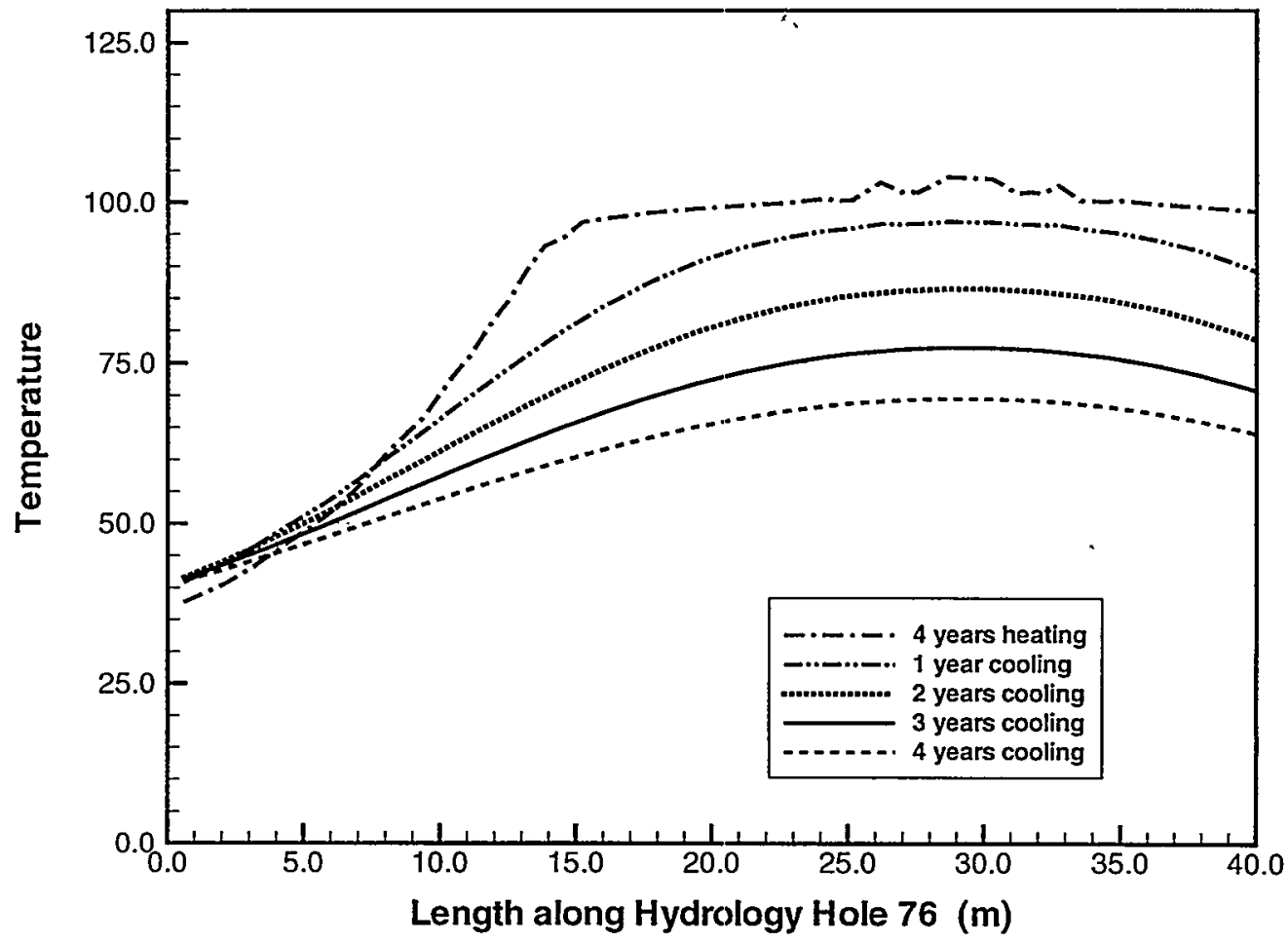

Figure A1-49 Temperature profile along borehole 76 at different times during cooling period for $3.6 \mathrm{~mm} / \mathrm{yr}$ infiltration case ( 1 year heating at 100\%, 3 years heating at 50\%). 


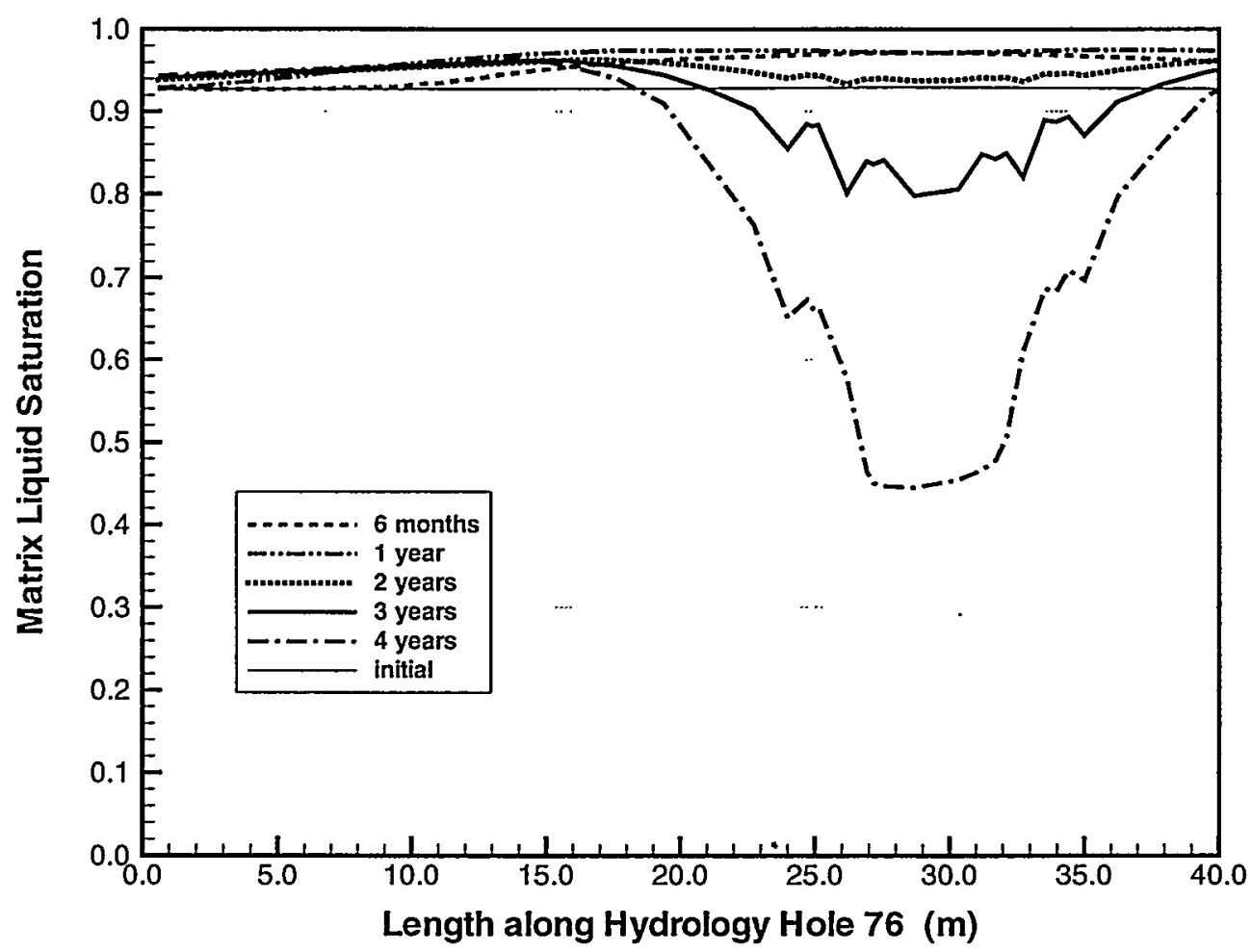

Figure AI-50 Matrix saturation profile along borehole 76 at different times during heating period for $3.6 \mathrm{~mm} / \mathrm{yr}$ infiltration case ( 1 year heating at 100\%, 3 years heating at 50\%).

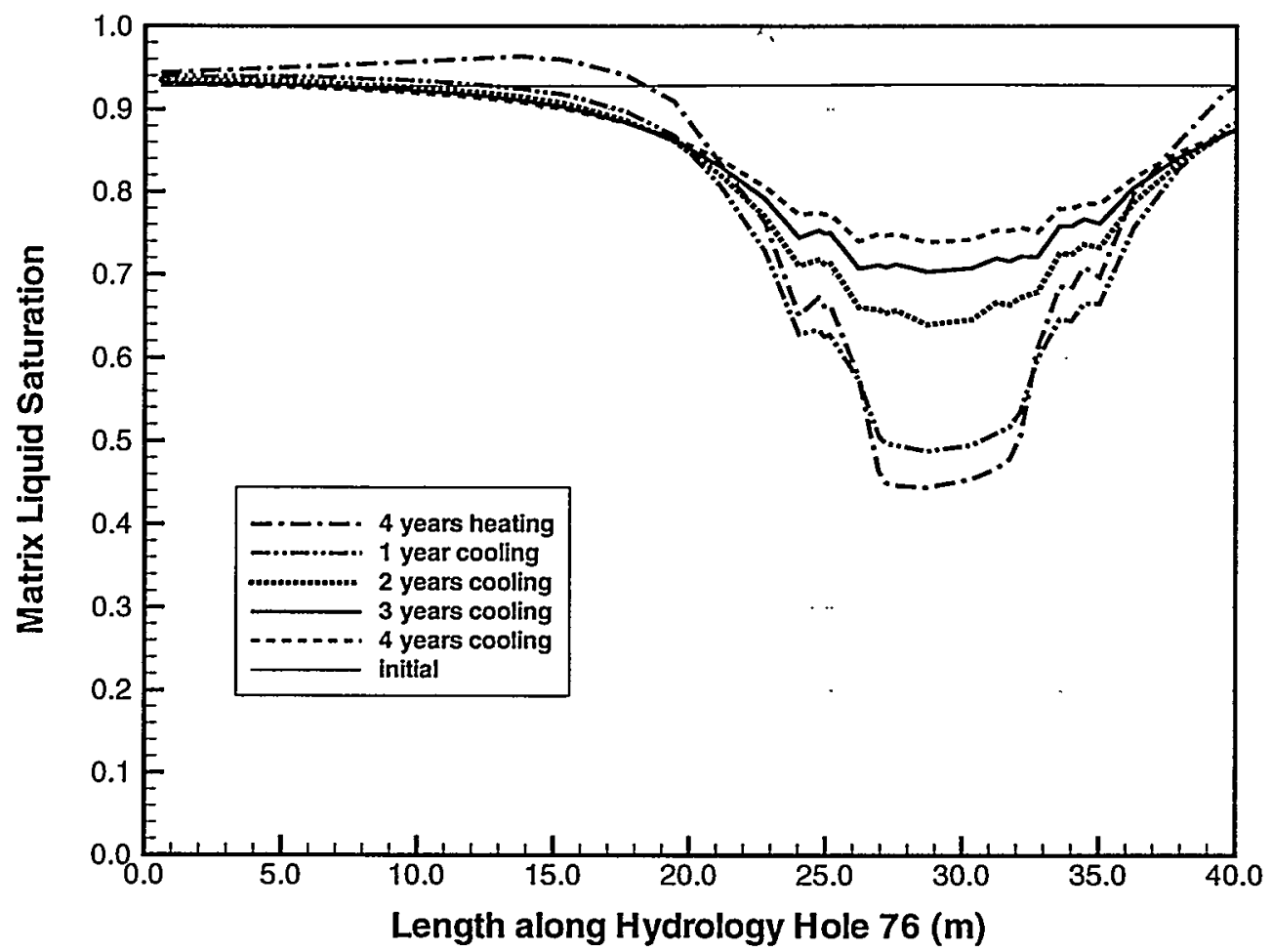

Figure A1-51 Matrix saturation profile along borehole 76 at different times during cooling period for $3.6 \mathrm{~mm} / \mathrm{yr}$ infiltration case ( 1 year heating at 100\%, 3 years heating at $50 \%$ ). 
Pretest Analysis of the Thermal-Hydrological Conditions of the ESF Drift Scale Test

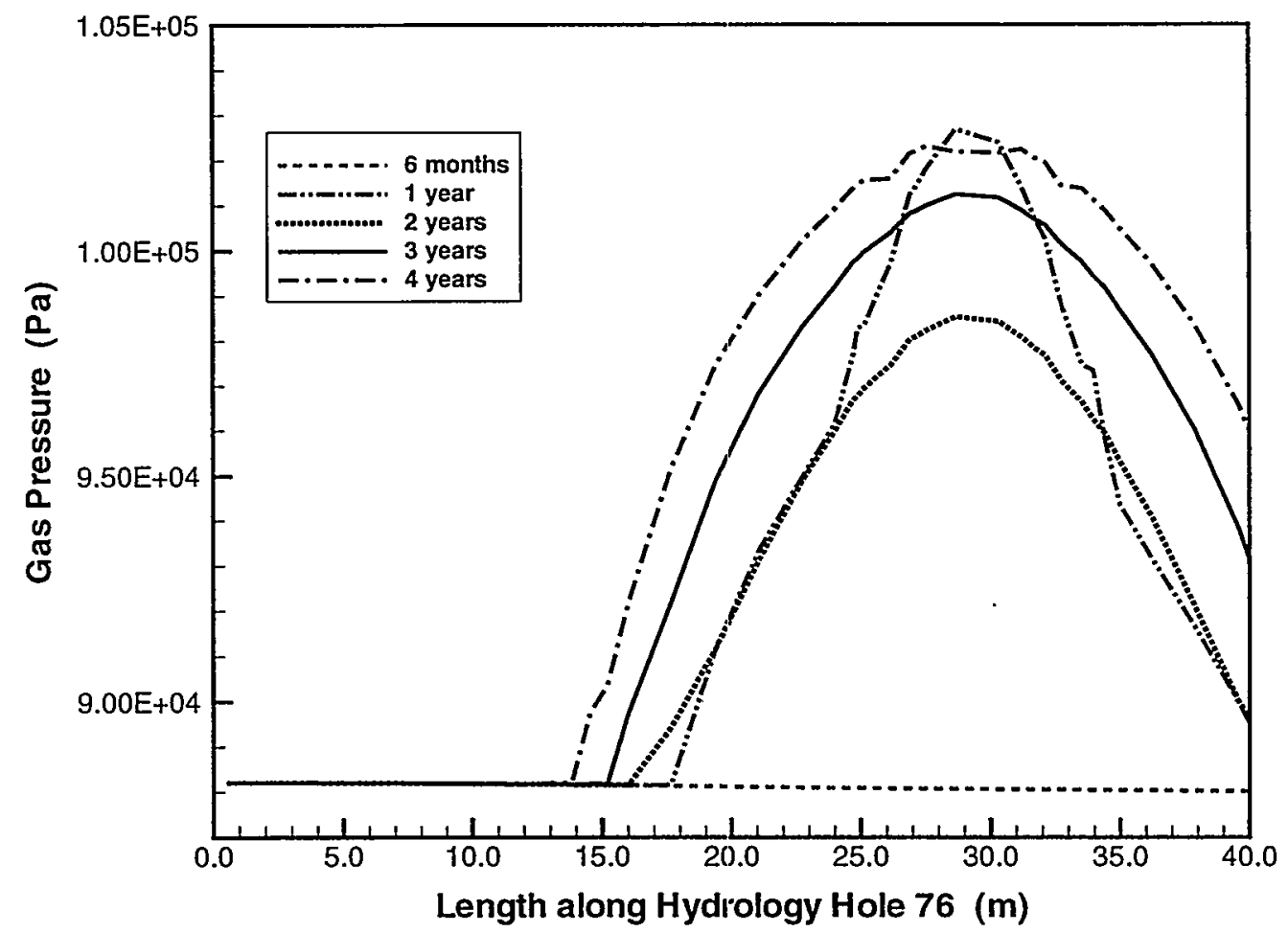

Figure Al-52 Gas pressure profile along borehole 76 at different times during heating period for $3.6 \mathrm{~mm} / \mathrm{yr}$ infiltration case (1 year heating at 100\%, 3 years heating at 50\%). 


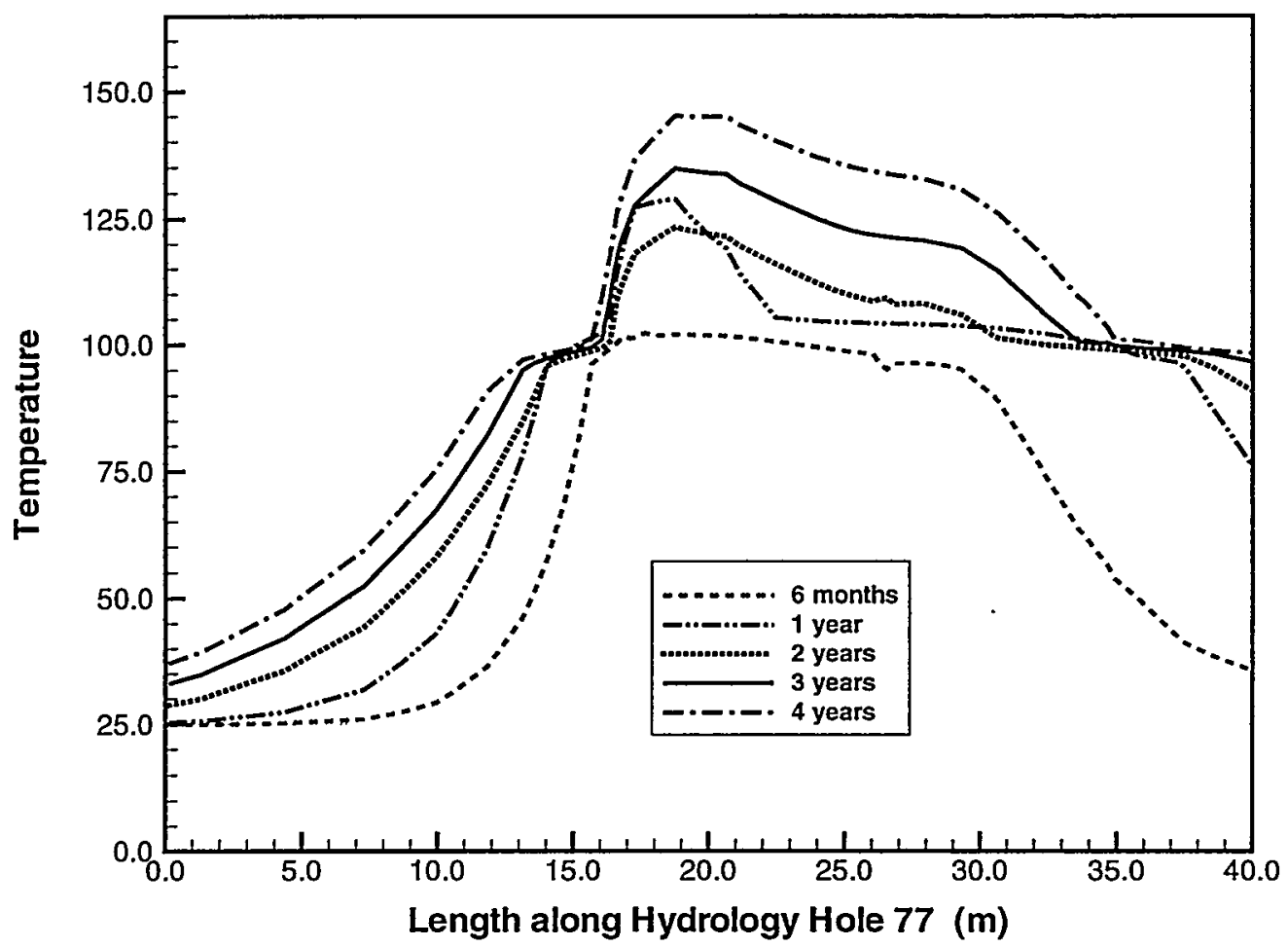

Figure A1-53 Temperature profile along borehole 77 at different times during heating period for $3.6 \mathrm{~mm} / \mathrm{yr}$ infiltration case (1 year heating at 100\%, 3 years heating at 50\%).

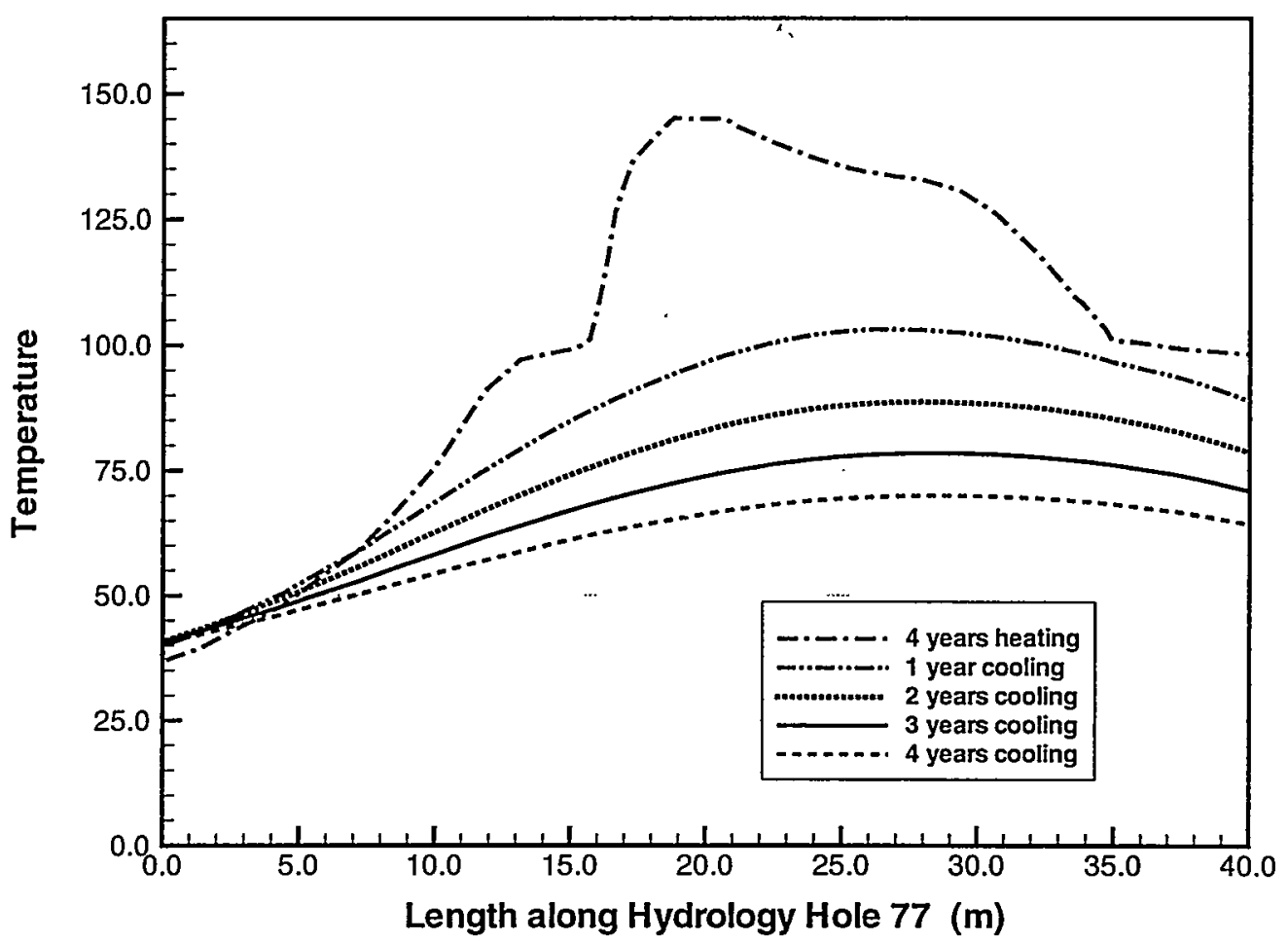

Figure A1-54 Temperature profile along borehole 77 at different times during cooling period for $3.6 \mathrm{~mm} / \mathrm{yr}$ infiltration case ( 1 year heating at $100 \%, 3$ years heating at $50 \%$ ). 


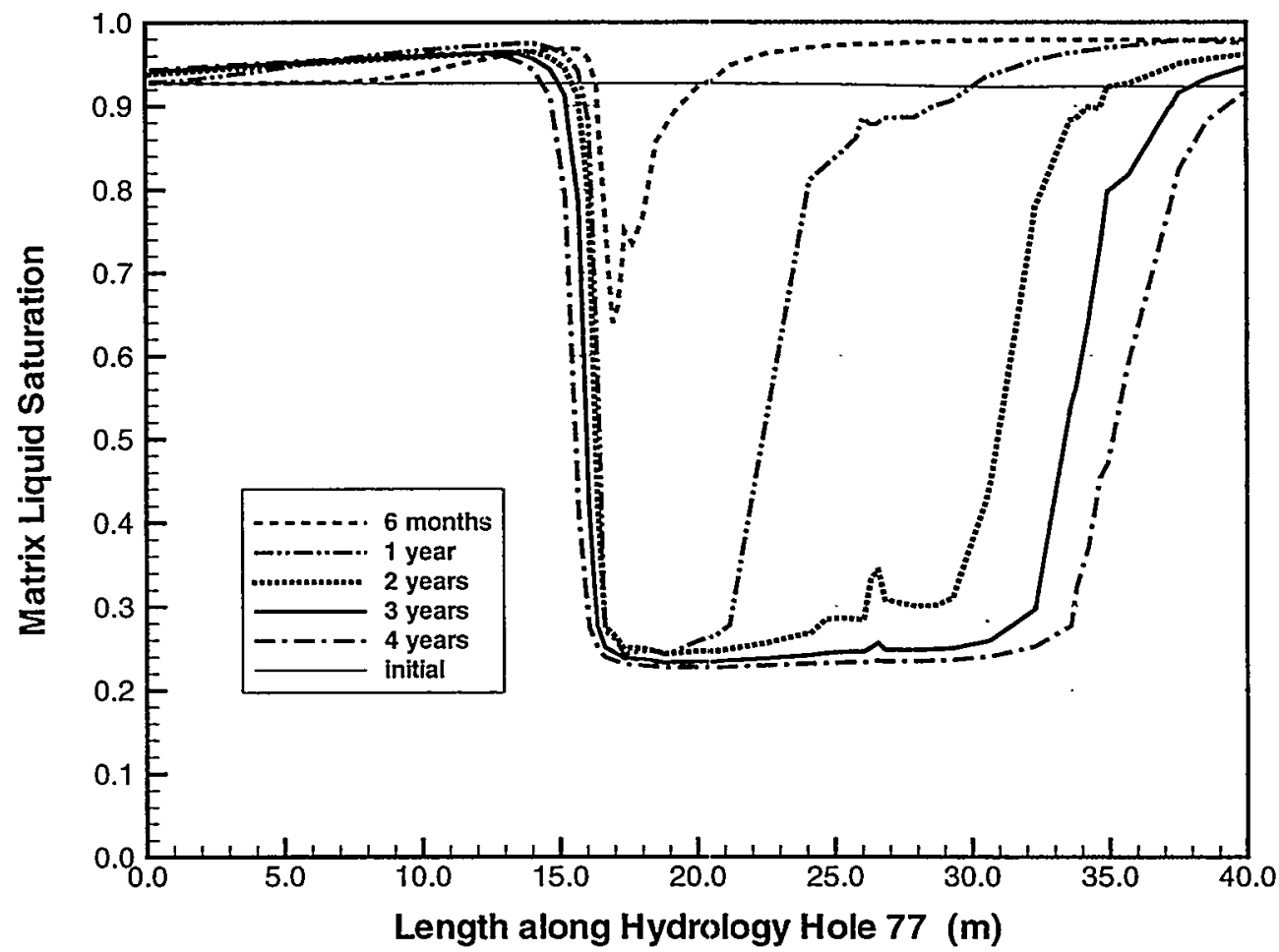

Figure A1-55 Matrix saturation profile along borehole 77 at different times during heating period for $3.6 \mathrm{~mm} / \mathrm{yr}$ infiltration case (I year heating at 100\%, 3 years heating at $50 \%$ ).

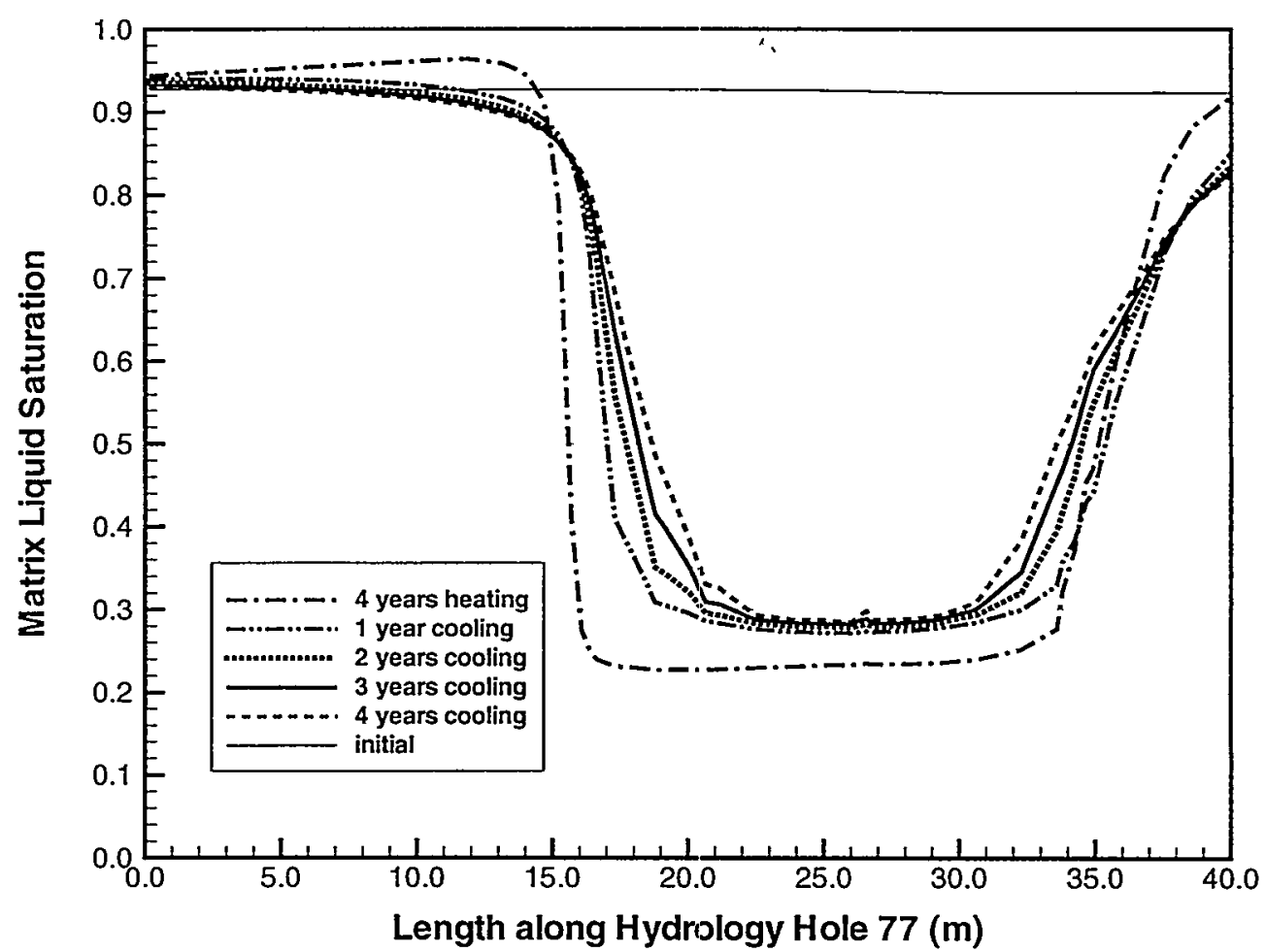

Figure A1-56 Matrix saturation profile along borehole 77 at different times during cooling period for $3.6 \mathrm{~mm} / \mathrm{yr}$ infiltration case (I year heating at 100\%, 3 years heating at $50 \%$ ). 


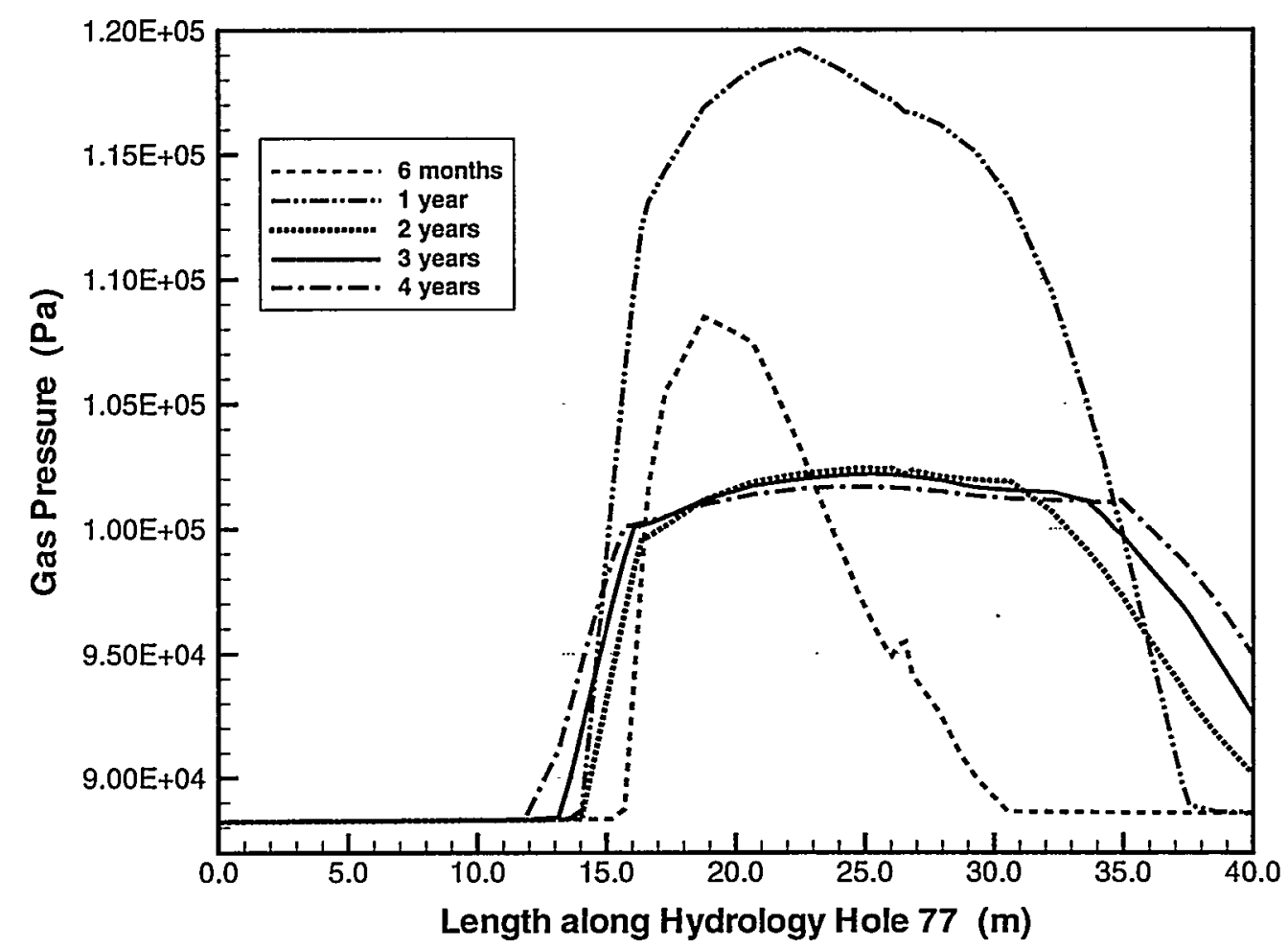

Figure A1-57 Gas pressure profile along borehole 77 at different times during heating period for $3.6 \mathrm{~mm} / \mathrm{yr}$ infiltration case (1 year heating at 100\%, 3 years heating at 50\%). 


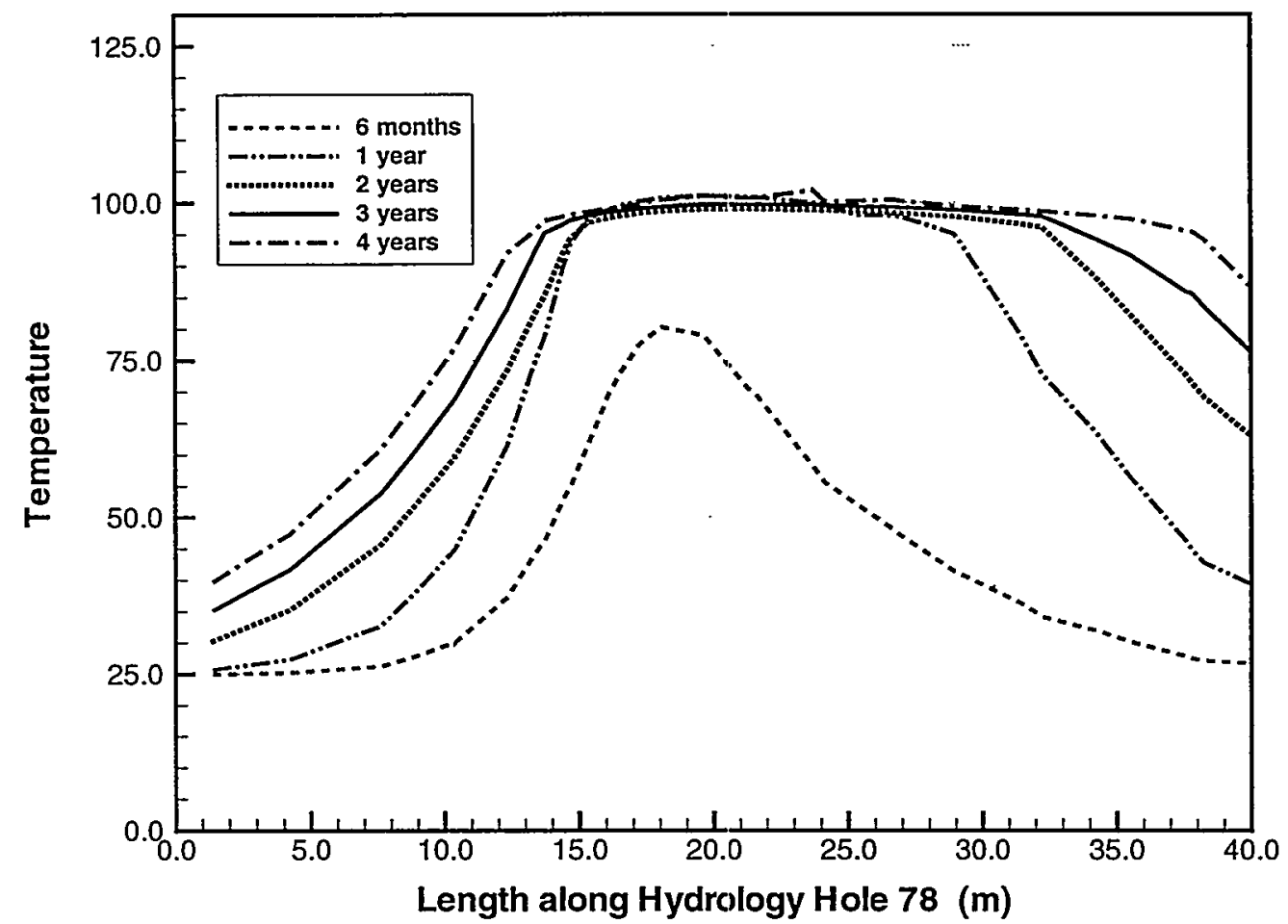

Figure A1-58 Temperature profile along borehole 78 at different times during heating period for $3.6 \mathrm{~mm} / \mathrm{yr}$ infiltration case (1 year heating at 100\%, 3 years heating at 50\%)

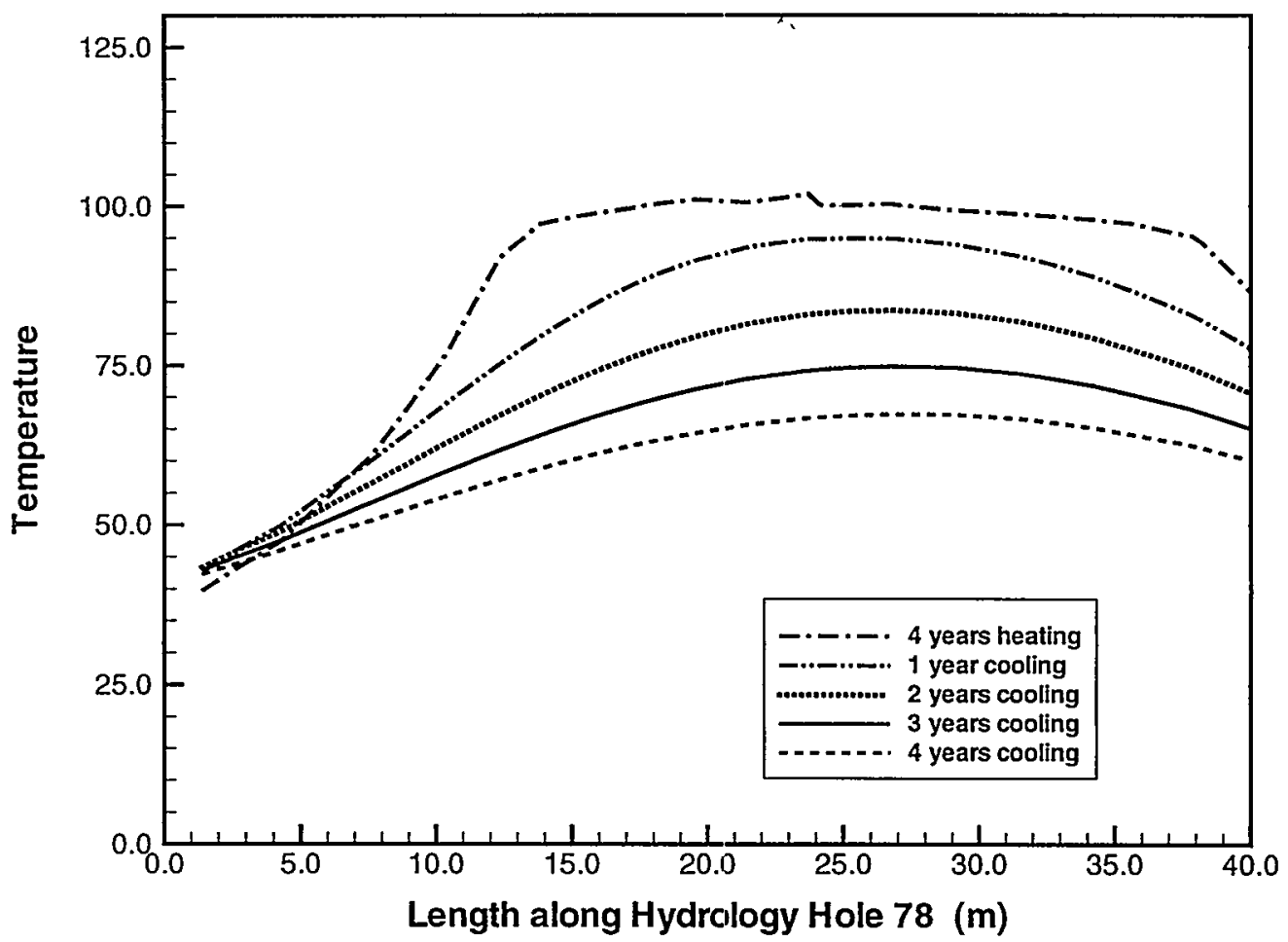

Figure A1-59 Temperature profile along borehole 78 at different times during cooling period for $3.6 \mathrm{~mm} / \mathrm{yr}$ infiltration case (1 year heating at 100\%, 3 years heating at $50 \%$ ). 


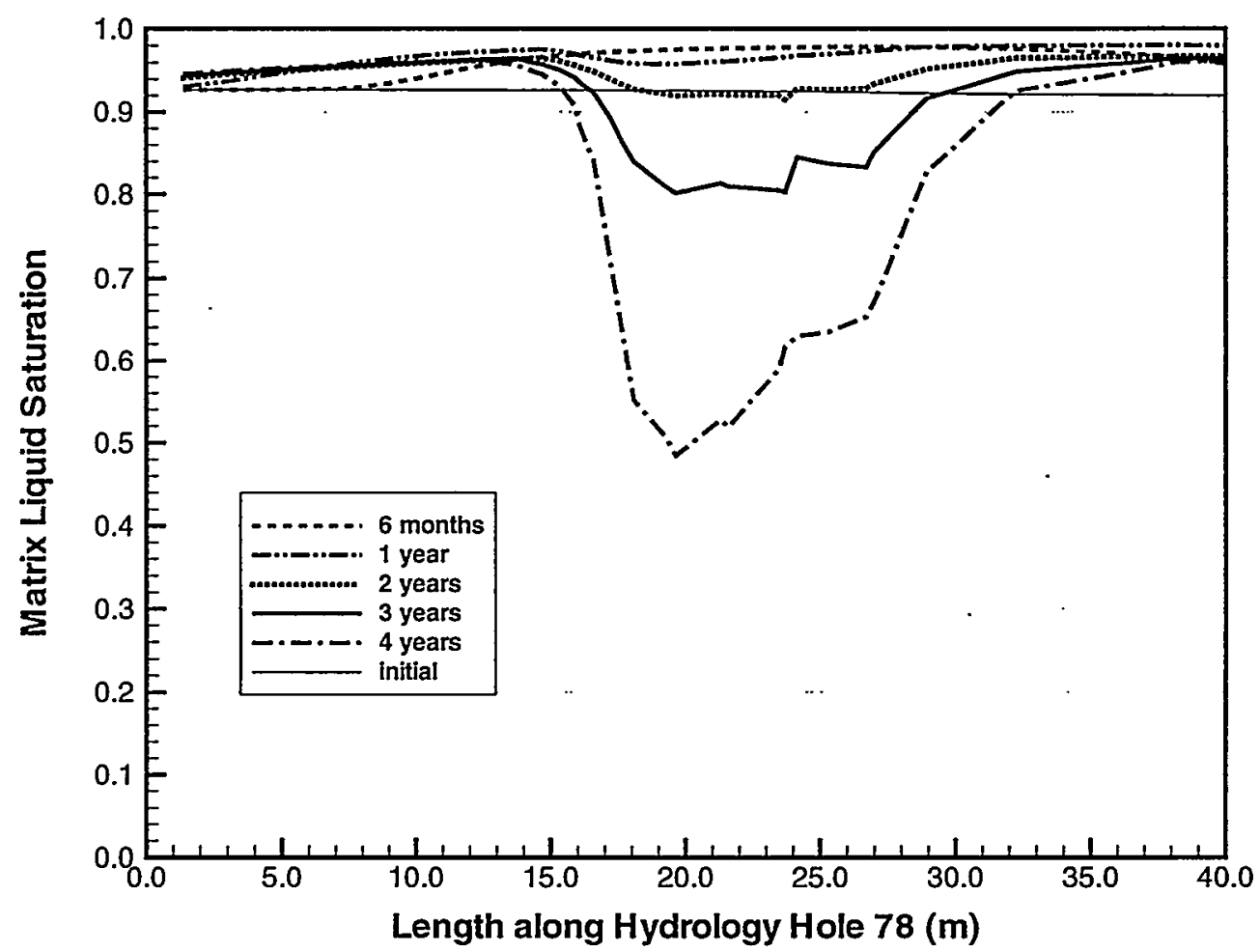

Figure A1-60 Matrix saturation profile along borehole 78 at different times during heating period for $3.6 \mathrm{~mm} / \mathrm{yr}$ infiltration case (1 year heating at 100\%, 3 years heating at $50 \%$ ).

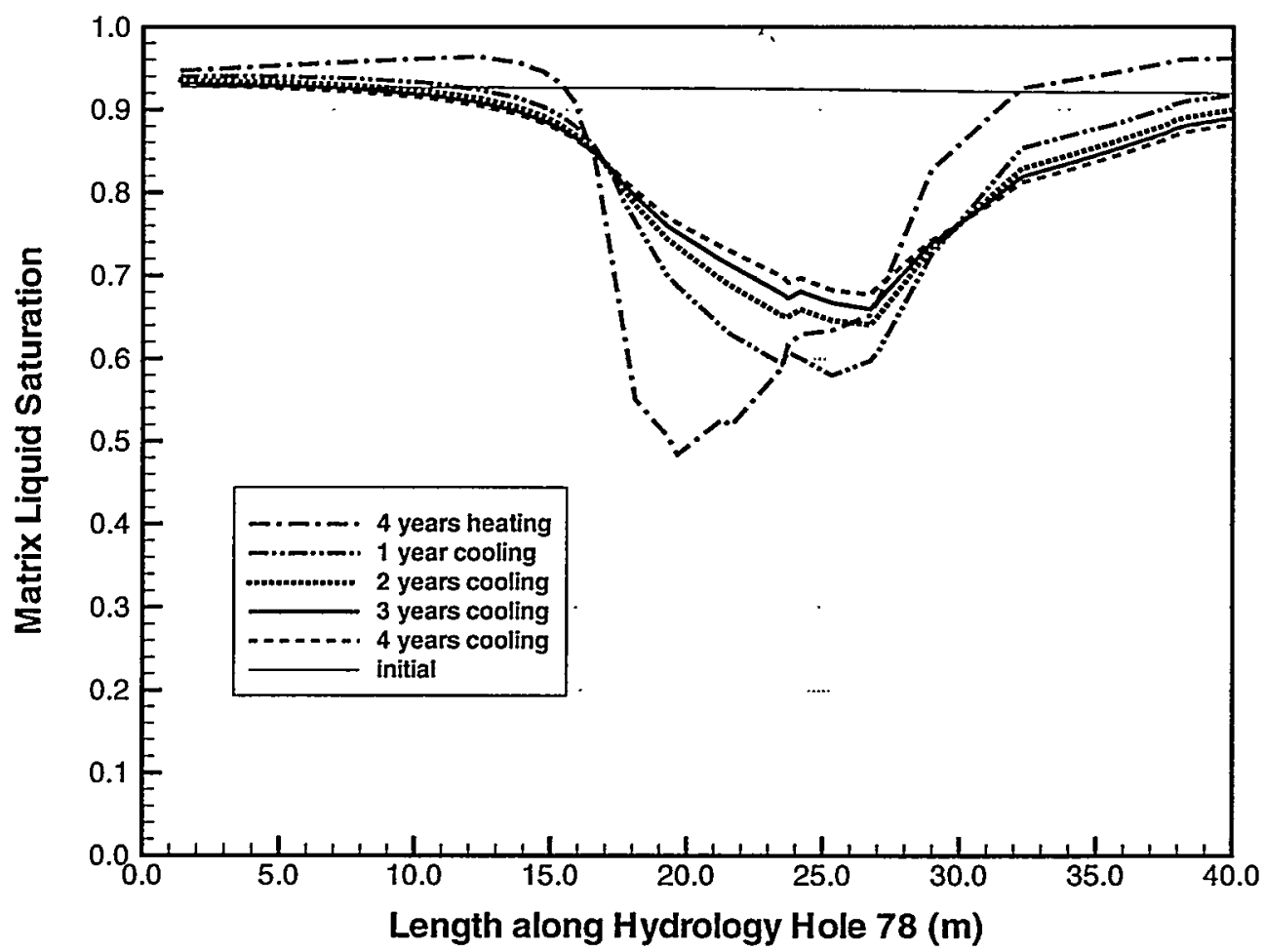

Figure A1-61 Matrix saturation profile along borehole 78 at different times during cooling period for $3.6 \mathrm{~mm} / \mathrm{yr}$ infiltration case (1 year heating at $100 \%, 3$ years heating at $50 \%$ ). 
Pretest Analysis of the Thermal-Hydrological Conditions of the ESF Drift Scale Test

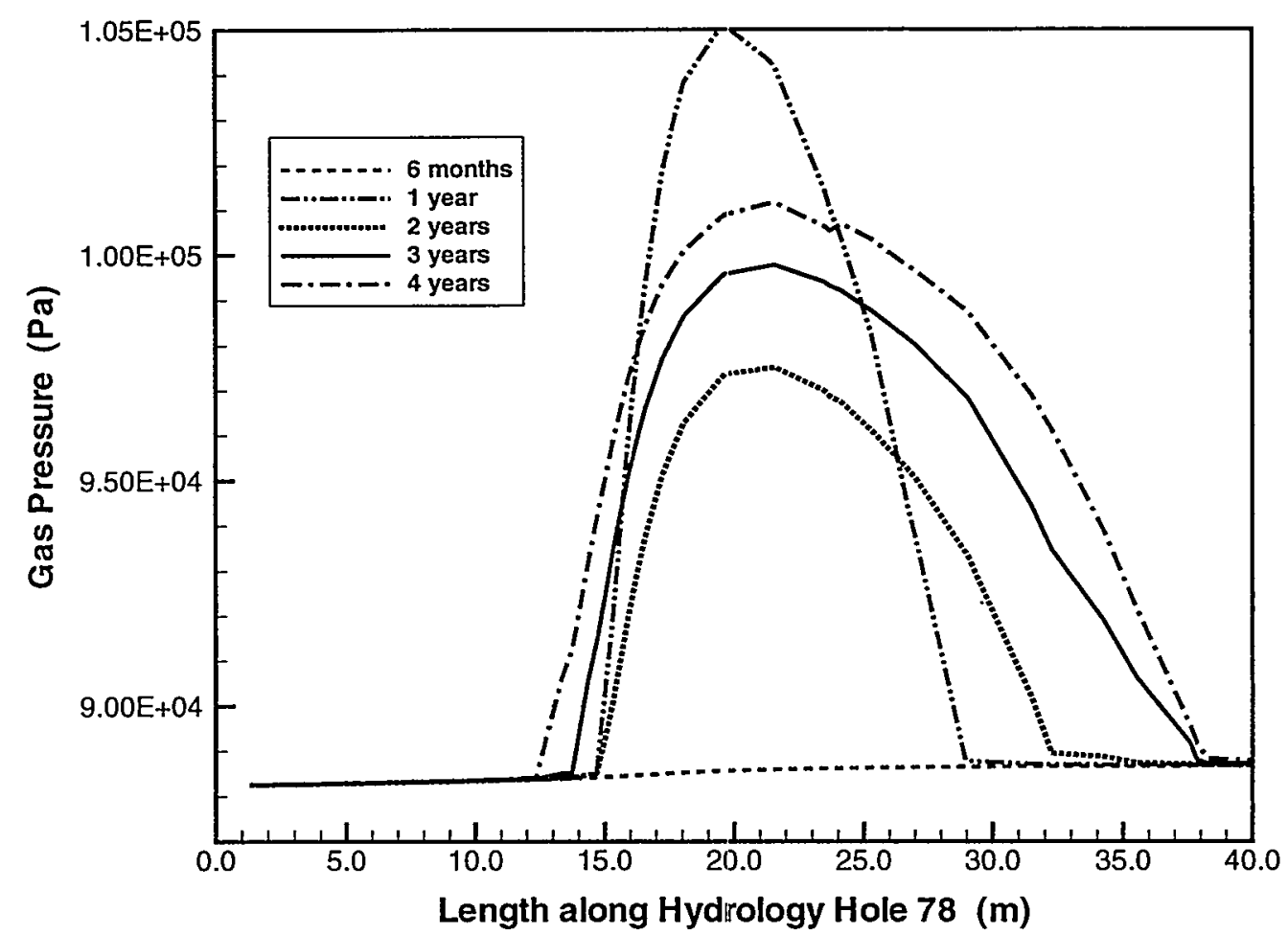

Figure A1-62 Gas pressure profile along borehole 78 at different times during heating period for $3.6 \mathrm{~mm} / \mathrm{yr}$ infiltration case (I year heating at 100\%, 3 years heating at 50\%). 


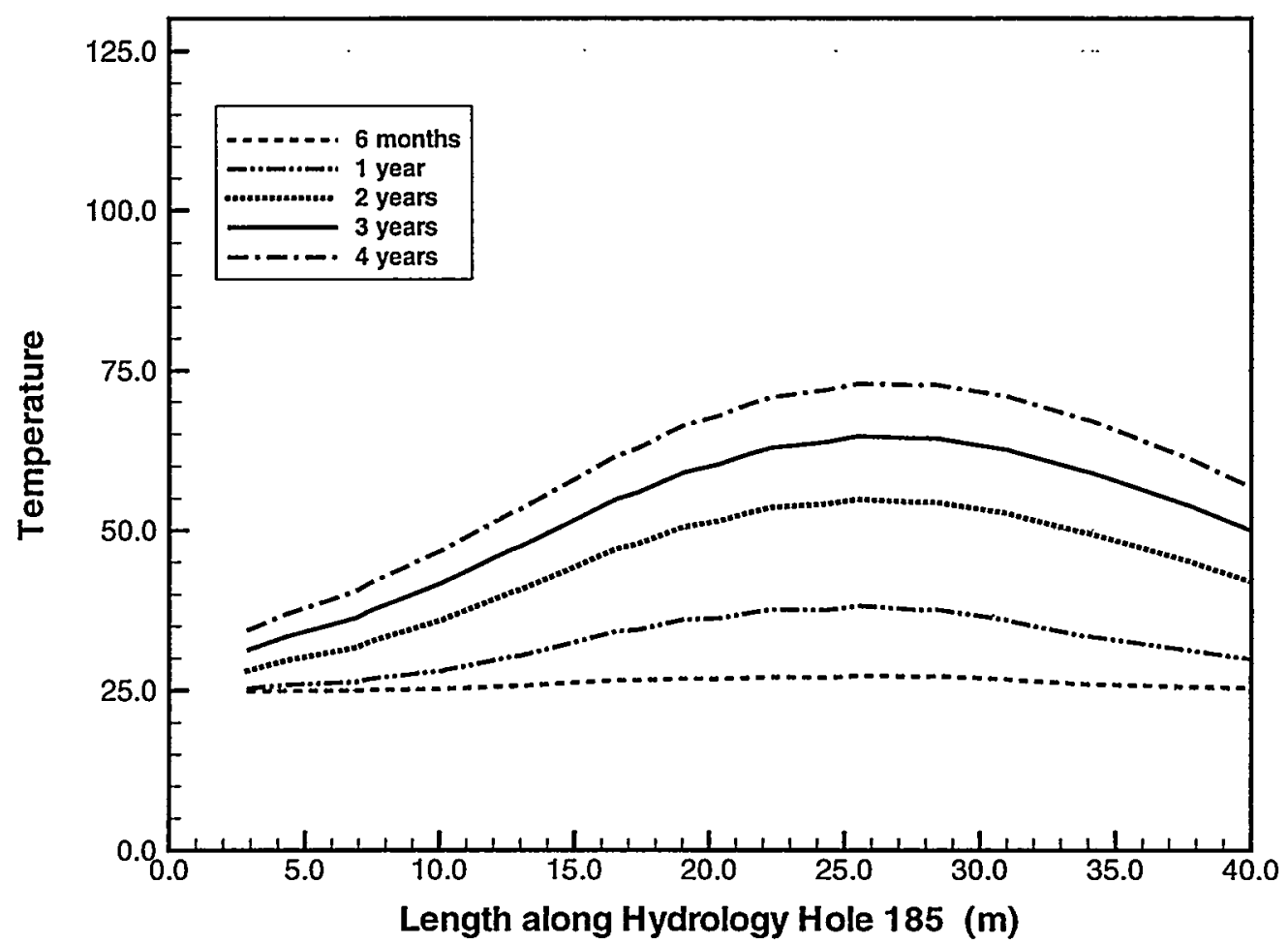

Figure A1-63 Temperature profile along borehole 185 at different times during heating period for $3.6 \mathrm{~mm} / \mathrm{yr}$ infiltration case ( 1 year heating at 100\%, 3 years heating at $50 \%$ ).

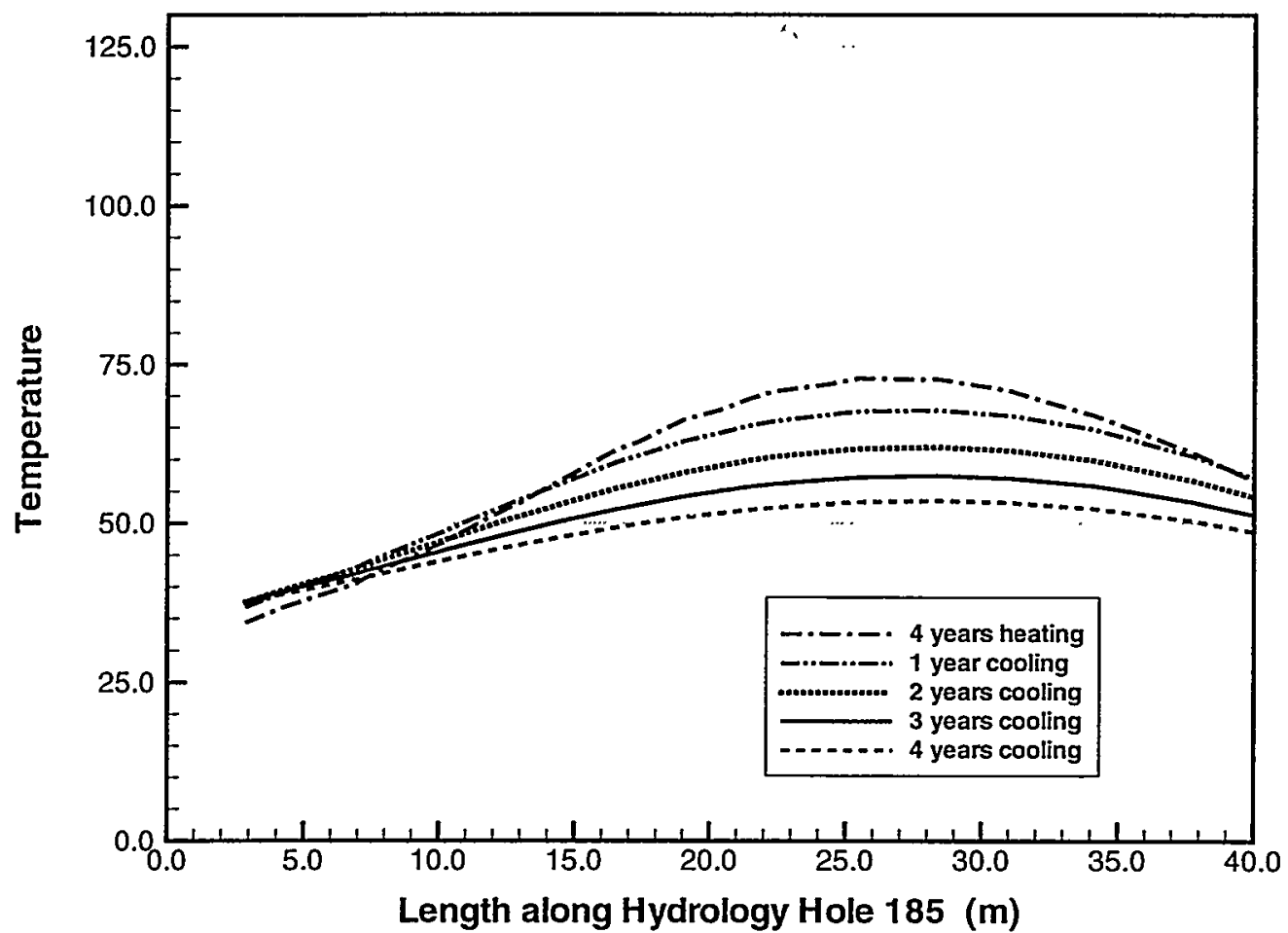

Figure A1-64 Temperature profile along borehole 185 at different times during cooling period for $3.6 \mathrm{~mm} / \mathrm{yr}$ infiltration case ( 1 year heating at 100\%, 3 years heating at $50 \%$ ). 
Pretest Analysis of the Thermal-Hydrological Conditions of the ESF Drift Scale Test

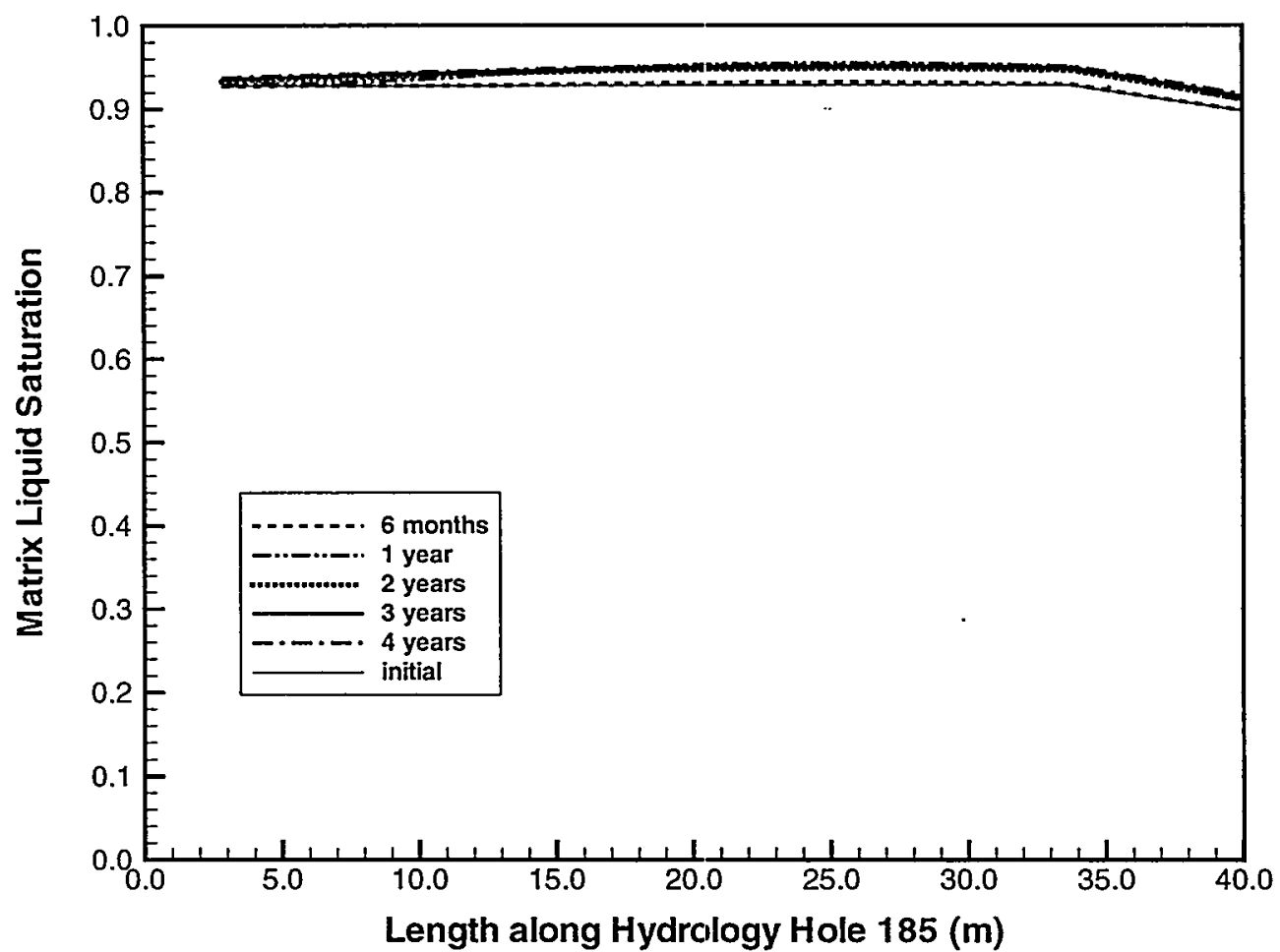

Figure A1-65 Matrix saturation profile along borehole 185 at different times during heating period for $3.6 \mathrm{~mm} / y$ r infiltration case (1 year heating at 100\%, 3 years heating at 50\%).

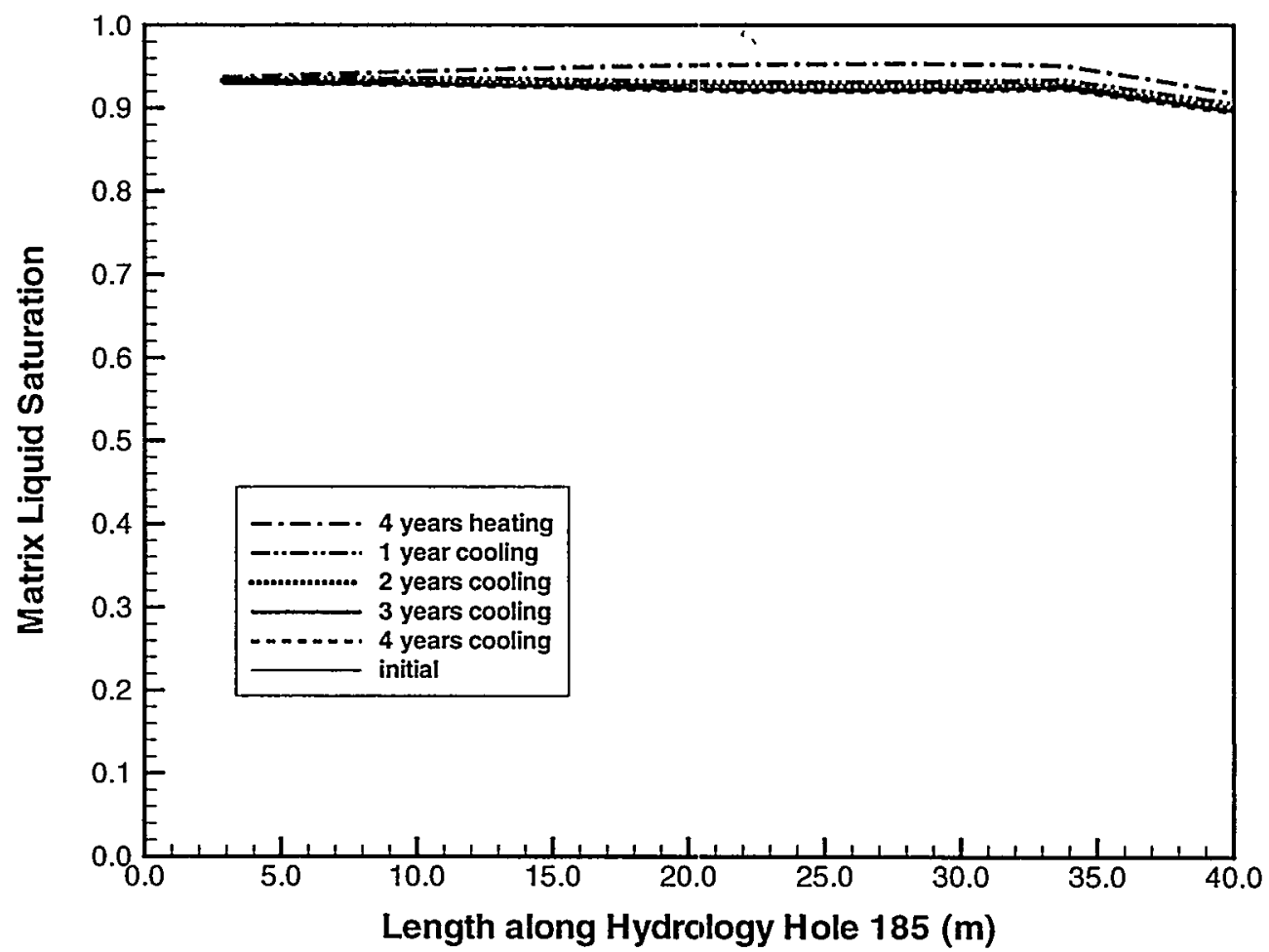

Figure AI-66 Matrix saturation profile along borehole 185 at different times during cooling period for $3.6 \mathrm{~mm} / \mathrm{yr}$ infiltration case (1 year heating at 100\%, 3 years heating at 50\%). 


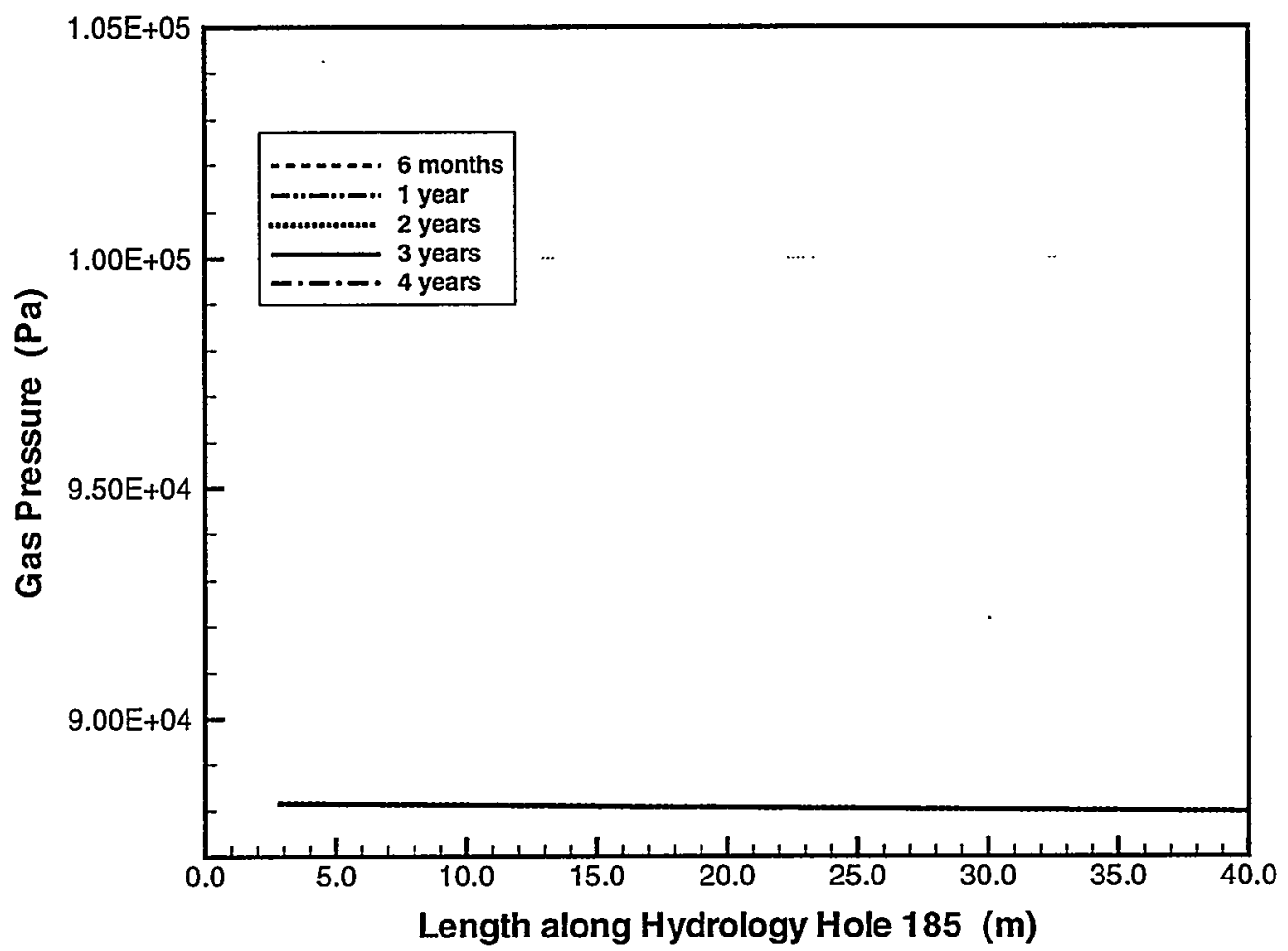

Figure A1-67 Gas pressure profile along borehole 185 at different times during heating period for $3.6 \mathrm{~mm} / y$ r infiltration case (1 year heating at 100\%, 3 heating years heating at 50\%). 


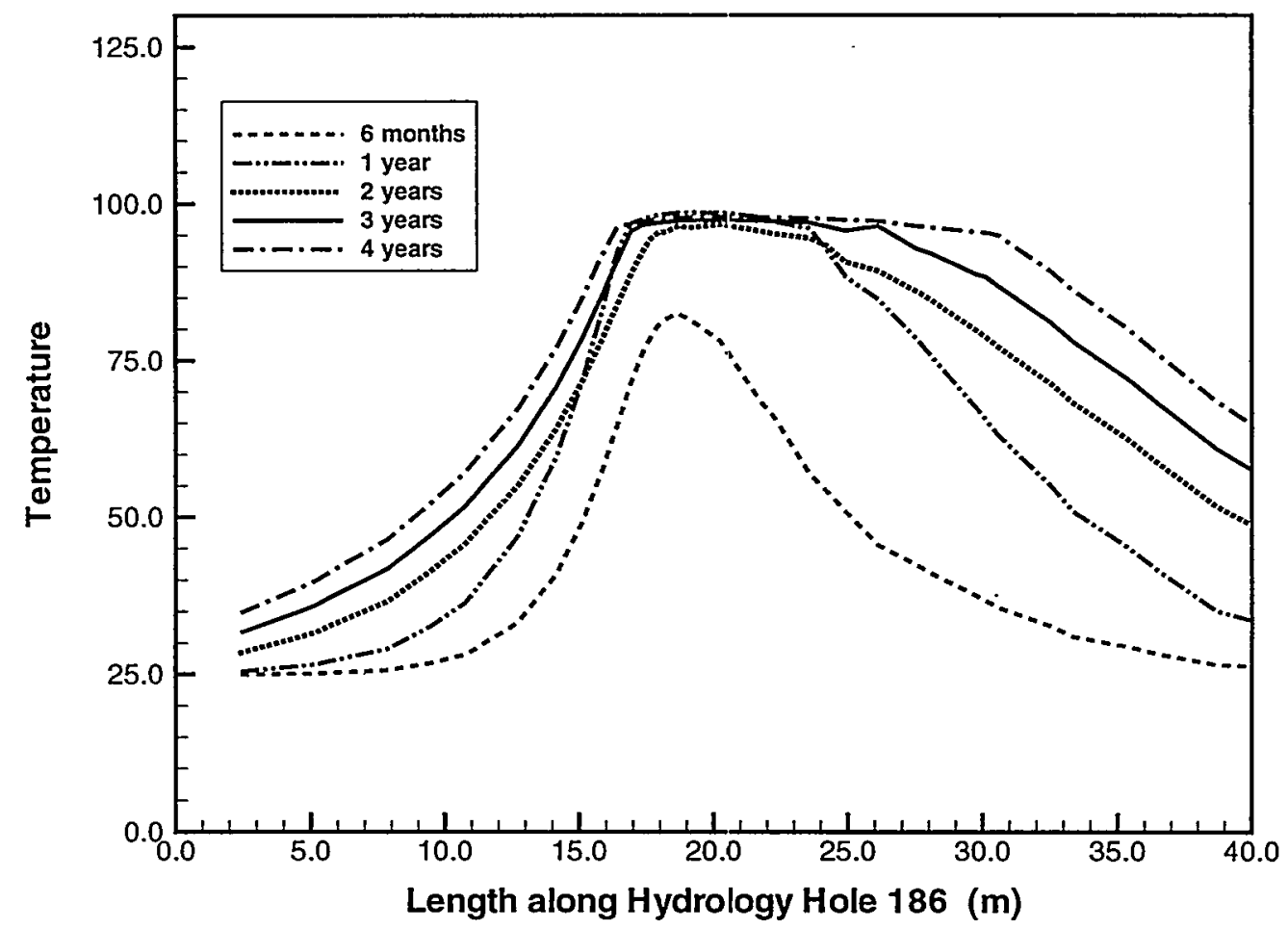

Figure A1-68 Temperature profile along borehole 186 at different times during heating period for $3.6 \mathrm{~mm} / \mathrm{yr}$ infiltration case (I year heating at 100\%, 3 years heating at $50 \%$ ).

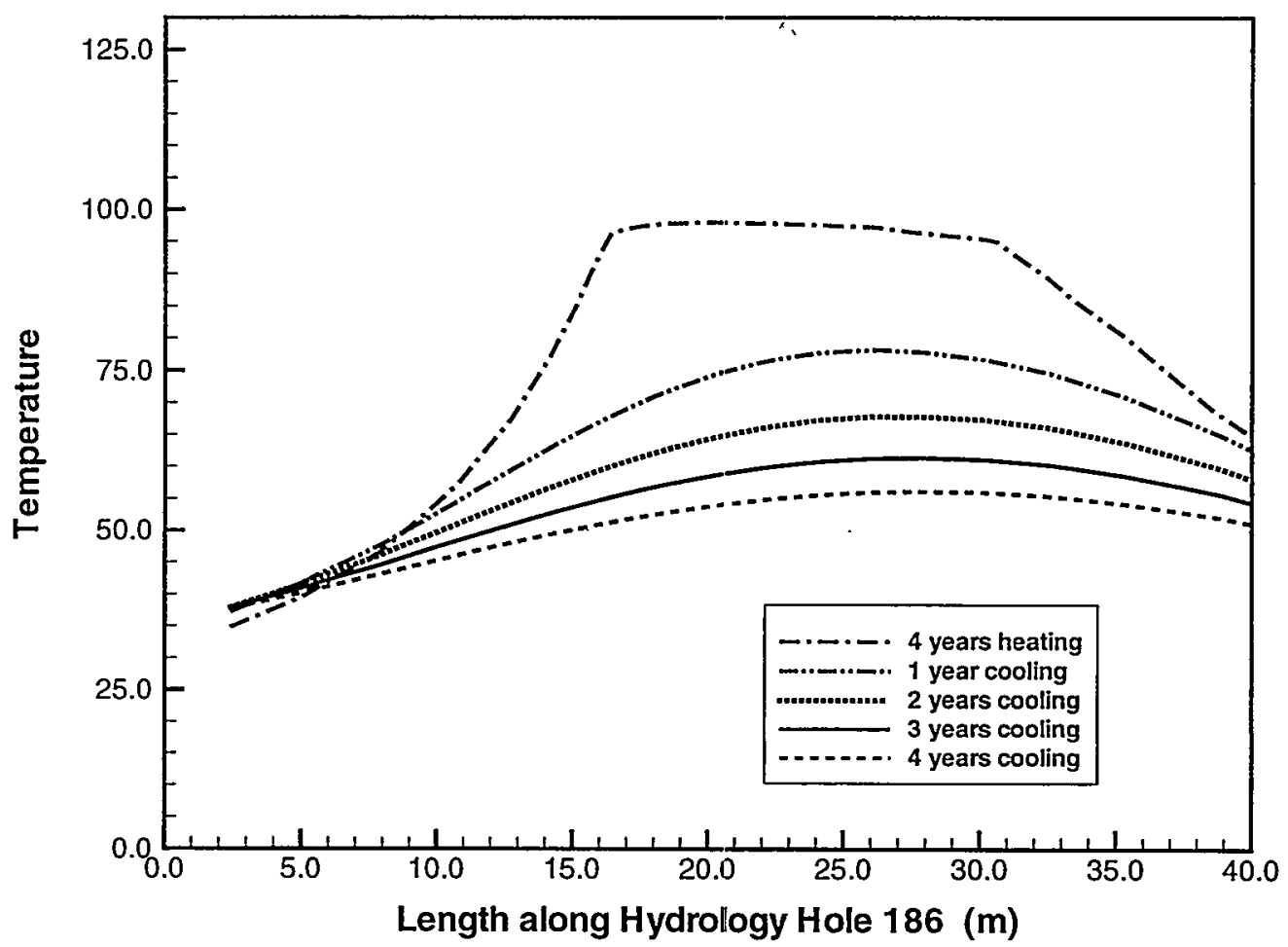

Figure A1-69 Temperature profile along borehole 186 at different times during cooling period for $3.6 \mathrm{~mm} / \mathrm{yr}$ infiltration case ( 1 year heating at 100\%, 3 years heating at 50\%). 


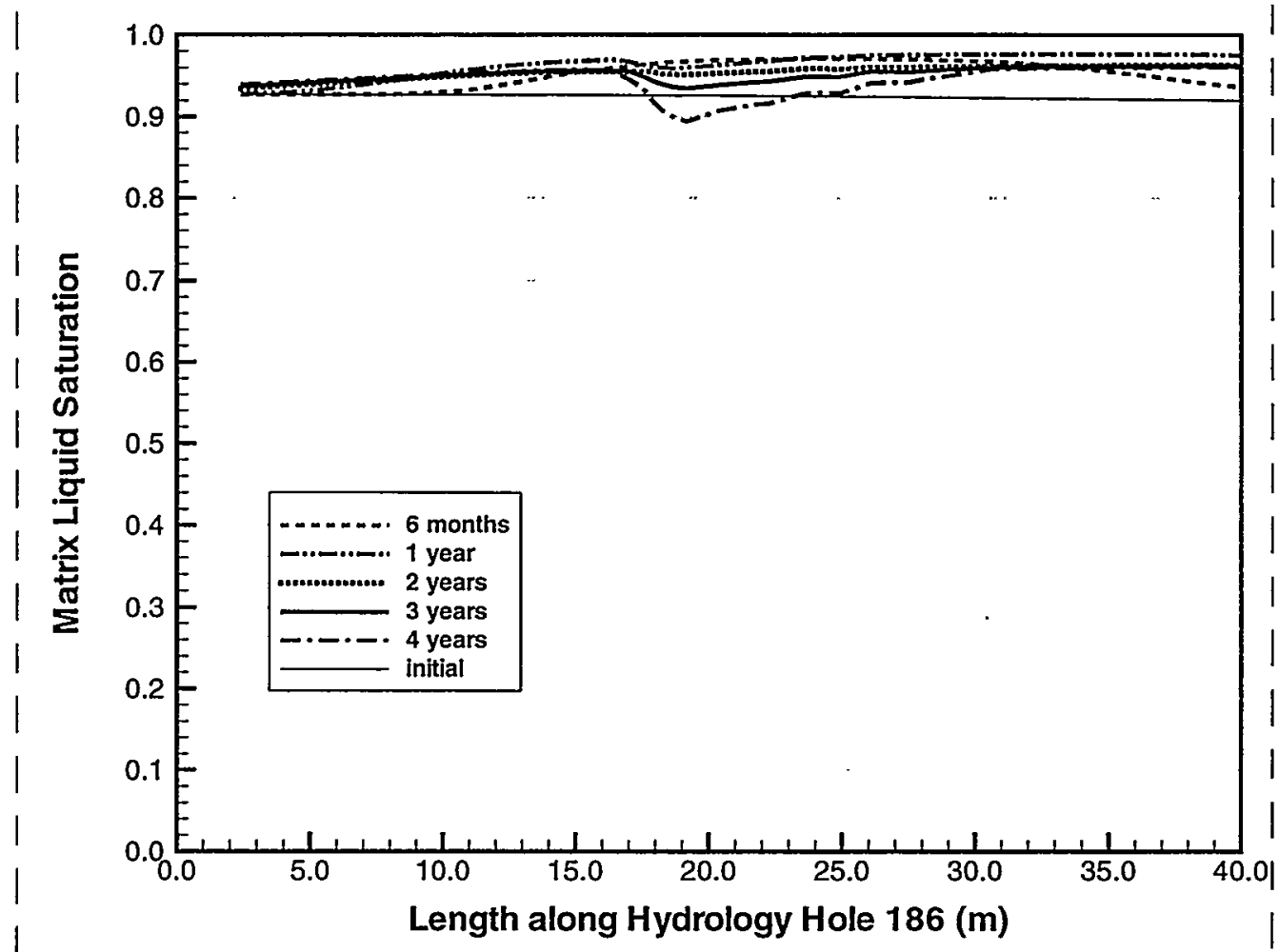

Figure A1-70 Matrix saturation profile along borehole 186 at different times during heating period for $3.6 \mathrm{~mm} / \mathrm{yr}$ infiltration case (1 year heating at 100\%, 3 years heating at 50\%).

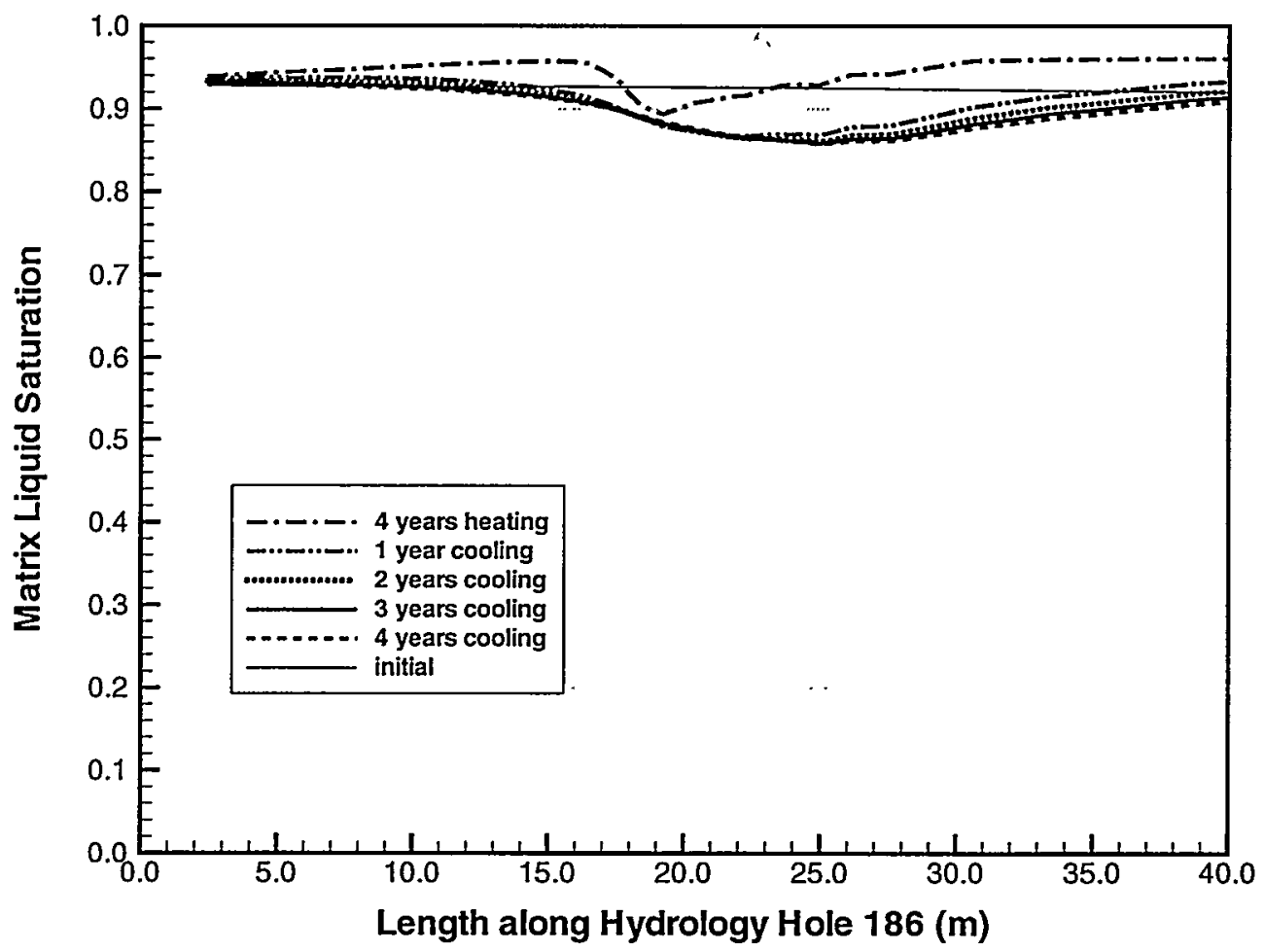

Figure A1-71 Matrix saturation profile along borehole 186 at different times during cooling period for $3.6 \mathrm{~mm} / \mathrm{yr}$ infiltration case (1 year heating at 100\%, 3 years heating at 50\%). 
Pretest Analysis of the Thermal-Hydrological Conditions of the ESF Drift Scale Test

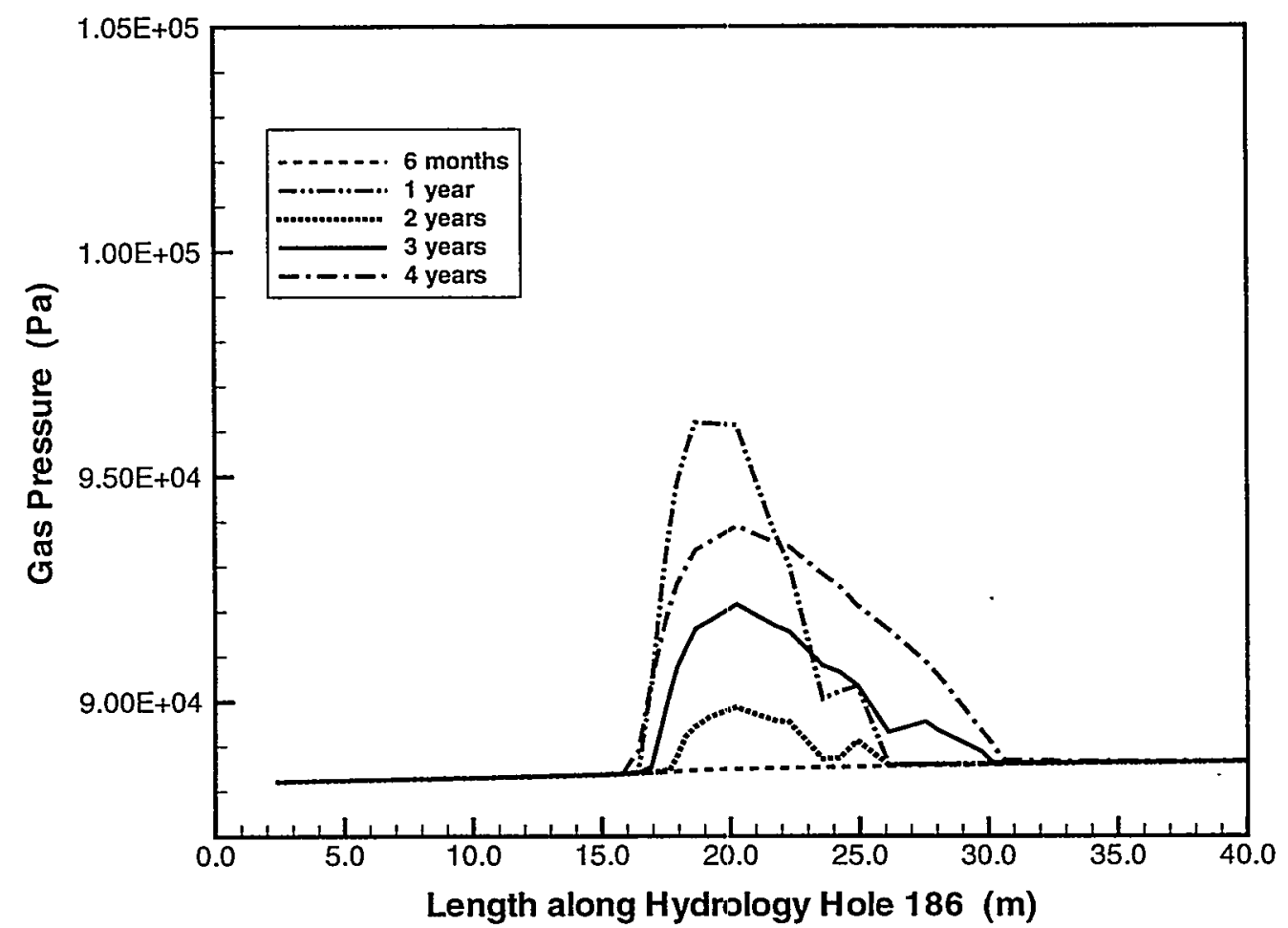

Figure A1-72 Gas pressure profile along borehole 186 at different times during heating period for $3.6 \mathrm{~mm} / \mathrm{yr}$ infiltration case (1 year heating at 100\%, 3 years heating at $50 \%$ ). 


\section{Appendix A2:}

Thermal-hydrological Response in Hydrology Holes

$$
0.36 \mathrm{~mm} / \mathrm{yr} \text { infiltration }
$$

1 year heating at 100\%, 3 years heating at 50\% 
Pretest Analysis of the Thermal-Hydrological Conditions of the ESF Drift Scale Test

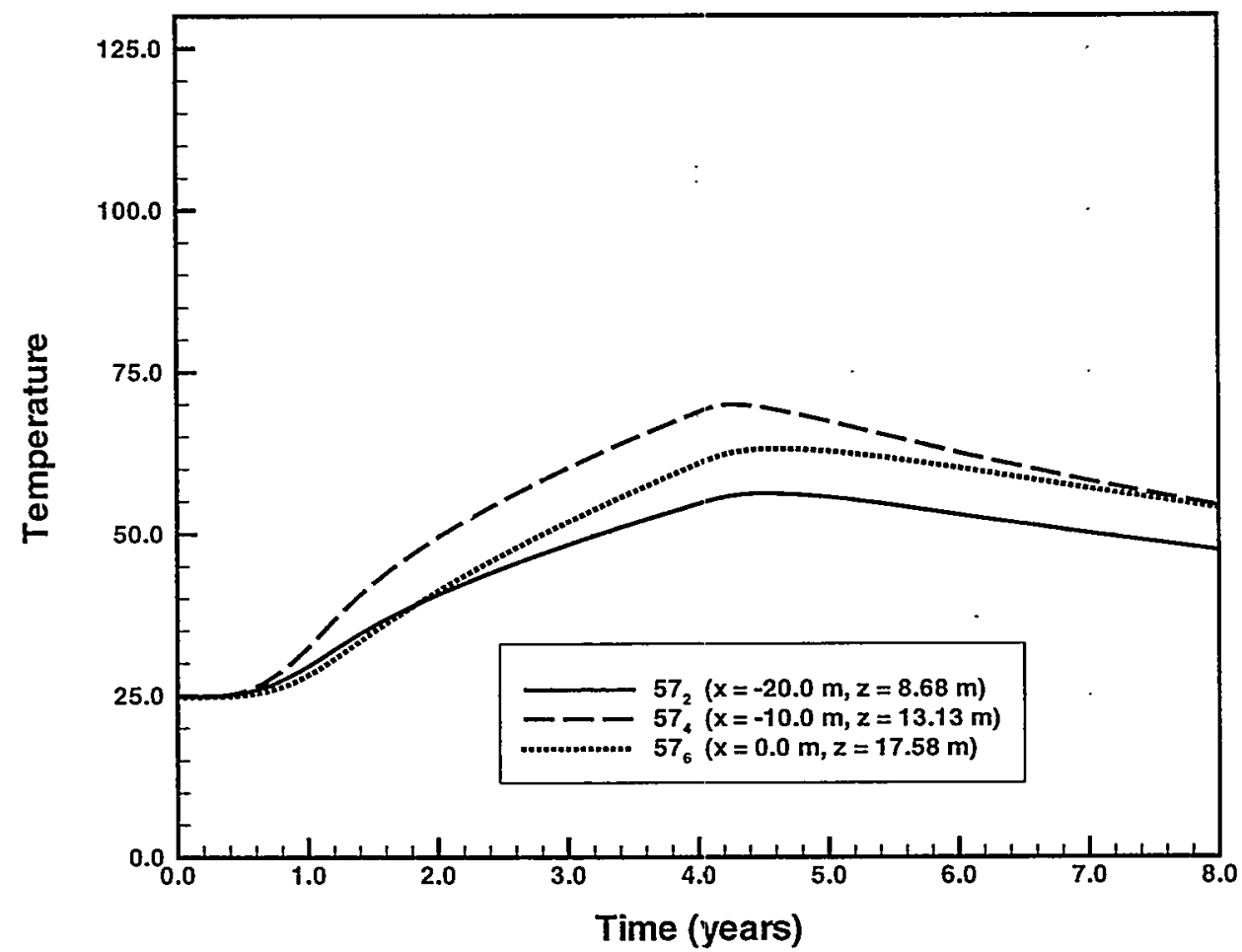

Figure A2-1 Temperature evolution at different sensor locations in borehole 57 for $0.36 \mathrm{~mm} / \mathrm{yr}$ infiltration case ( 1 year heating at 100\%, 3 years heating at 50\%).

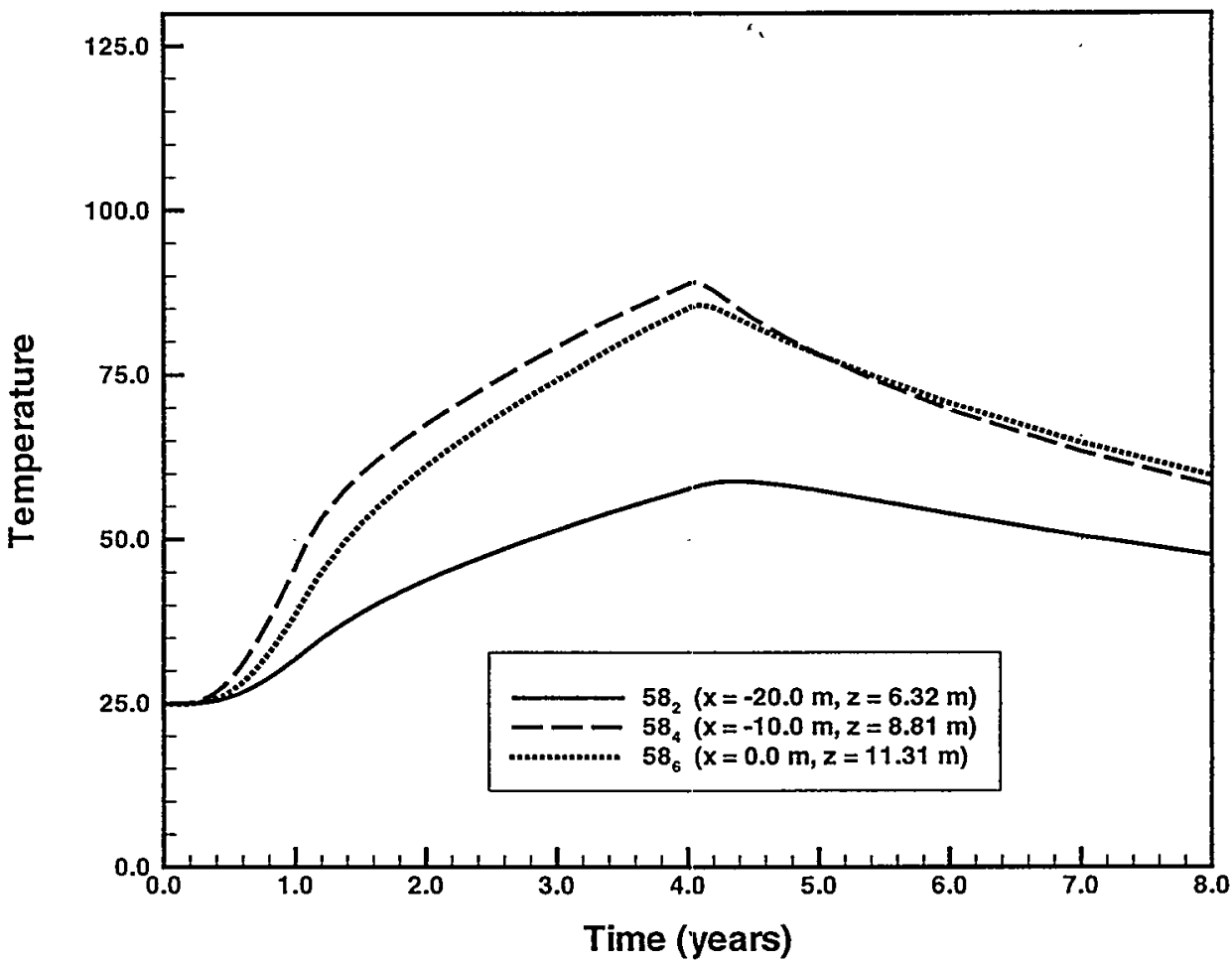

Figure A2-2 Temperature evolution at different sensor locations in borehole 58 for $0.36 \mathrm{~mm} / \mathrm{yr}$ infiltration case ( 1 year heating at 100\%, 3 years heating at 50\%). 


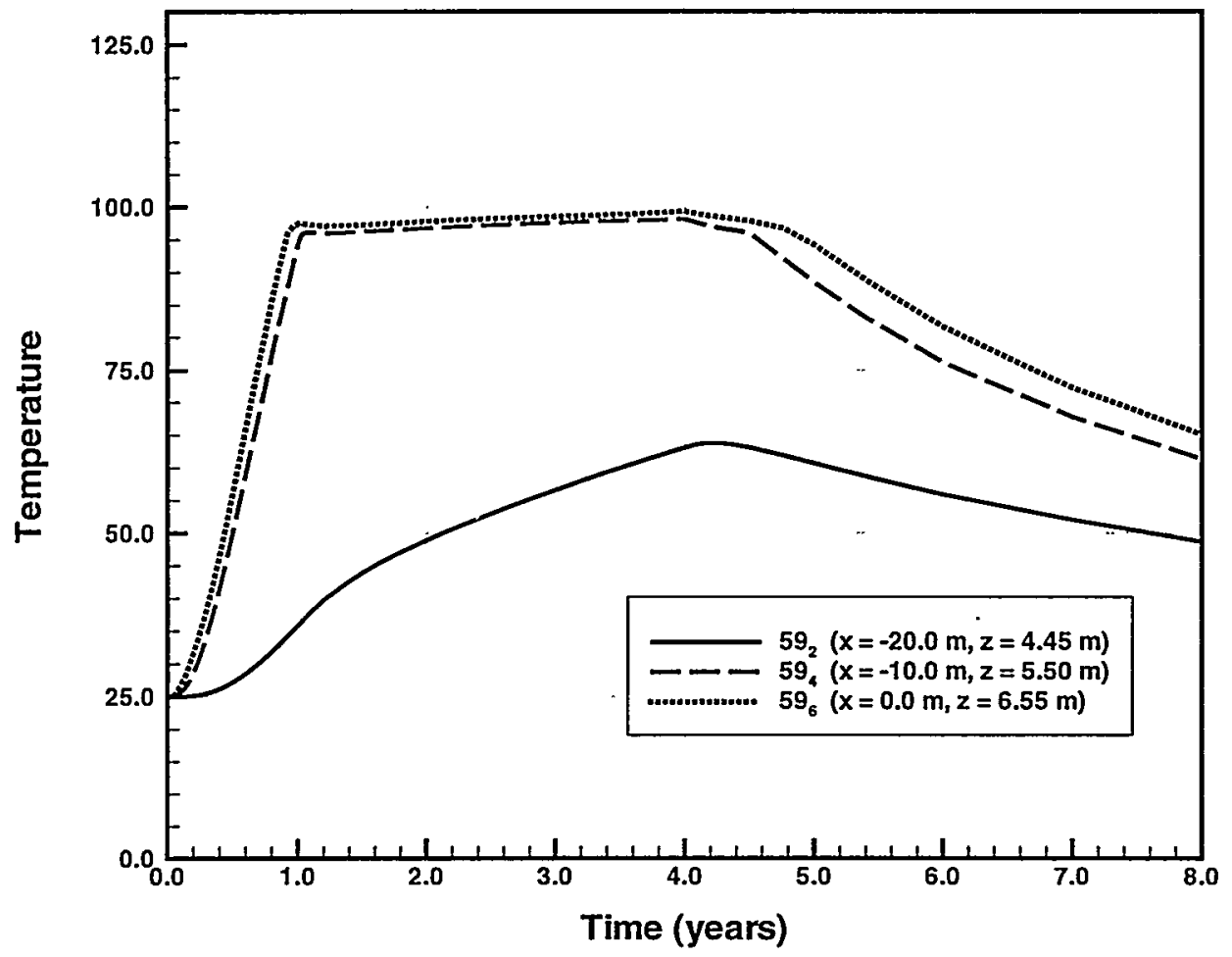

Figure A2-3 Temperature evolution at different sensor locations in borehole 59 for $0.36 \mathrm{~mm} / \mathrm{yr}$ infiltration case ( 1 year heating at 100\%, 3 years heating at 50\%).

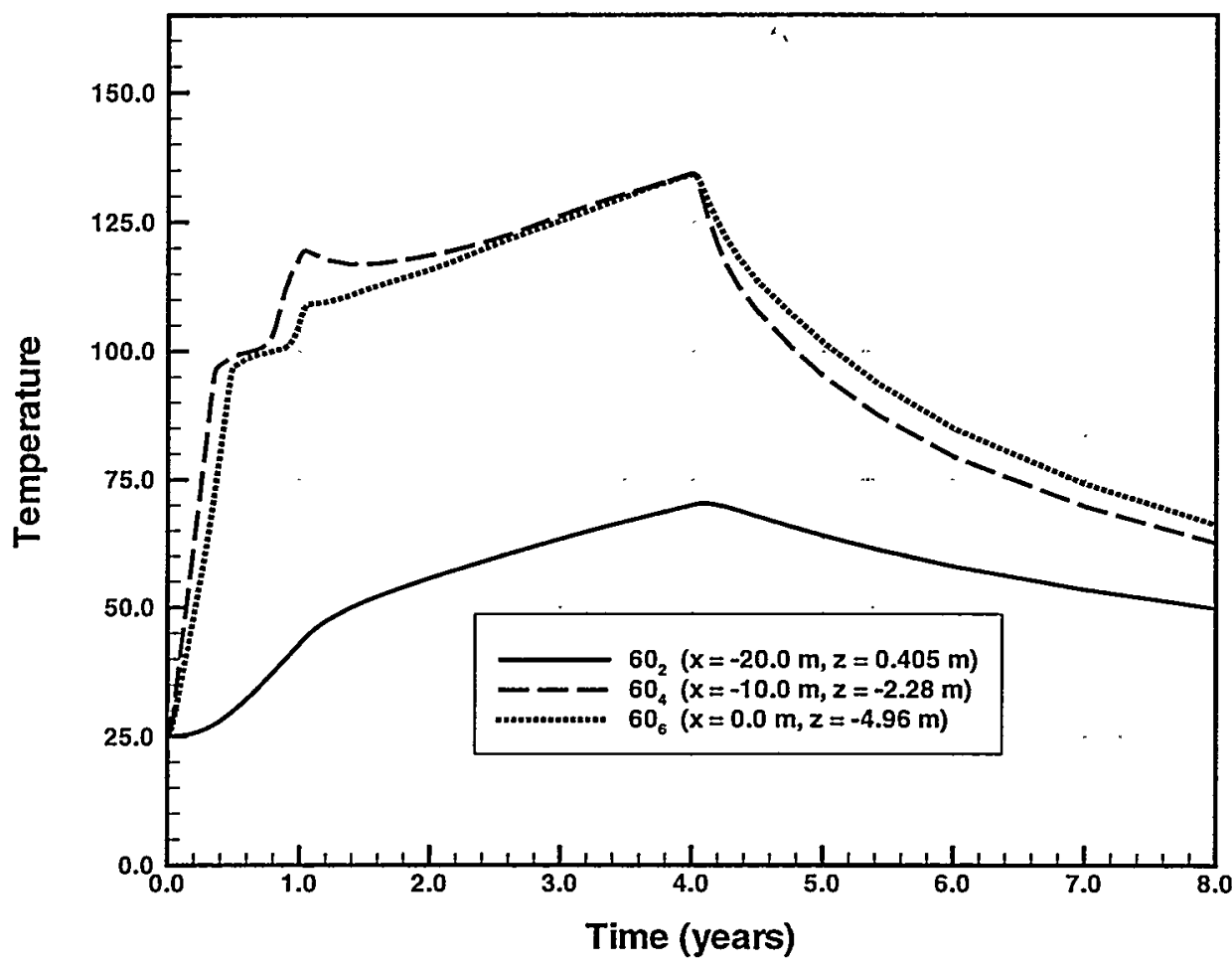

Figure A2-4 Temperature evolution at different sensor locations in borehole 60 for $0.36 \mathrm{~mm} / \mathrm{yr}$ infiltration case (1 year heating at 100\%, 3 years heating at 50\%). 
Pretest Analysis of the Thermal-Hydrological Conditions of the ESF Drift Scale Test

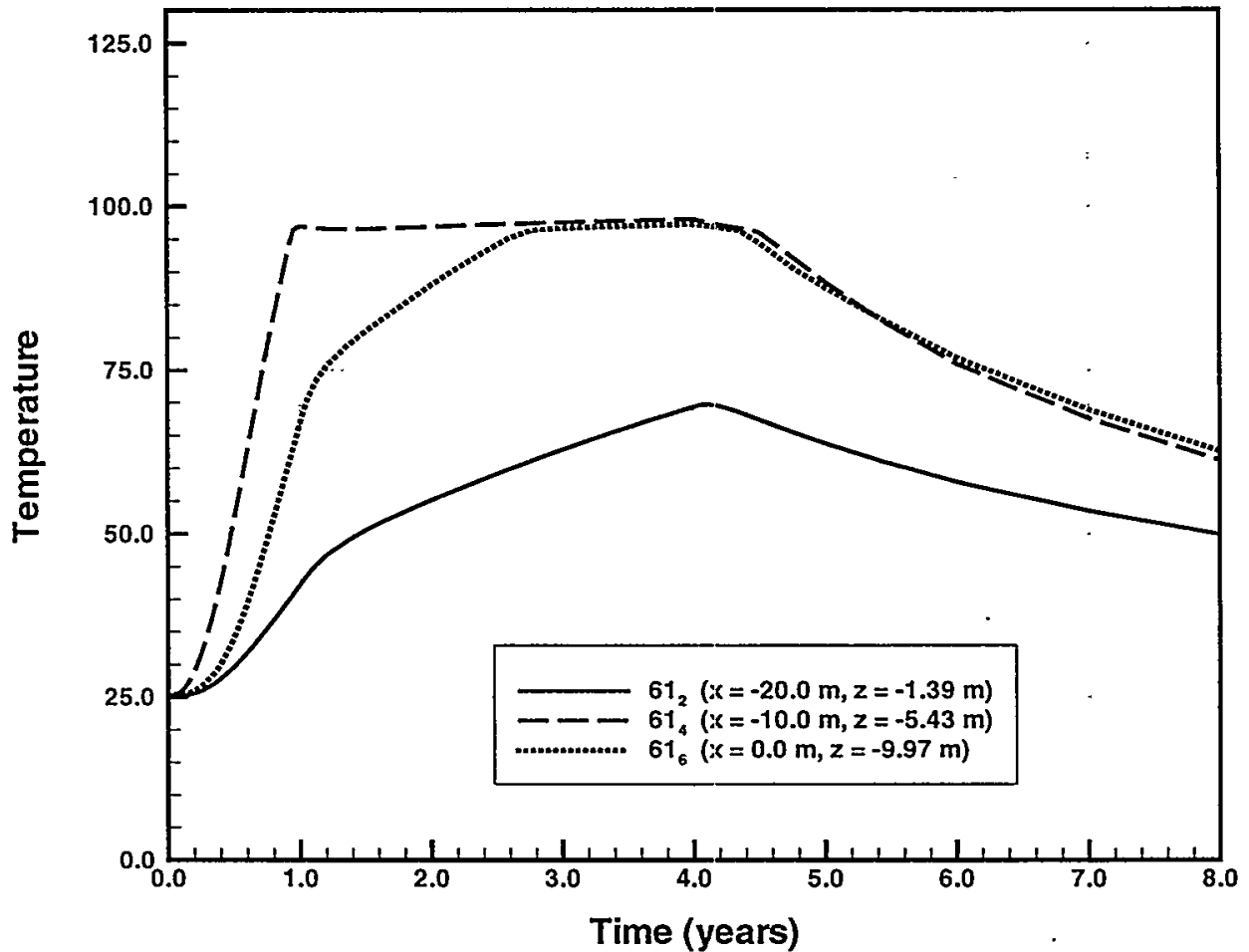

Figure A2-5 Temperature evolution at different sensor locations in borehole 61 for $0.36 \mathrm{~mm} / \mathrm{yr}$ infiltration case ( 1 year heating at 100\%, 3 years heating at 50\%). 


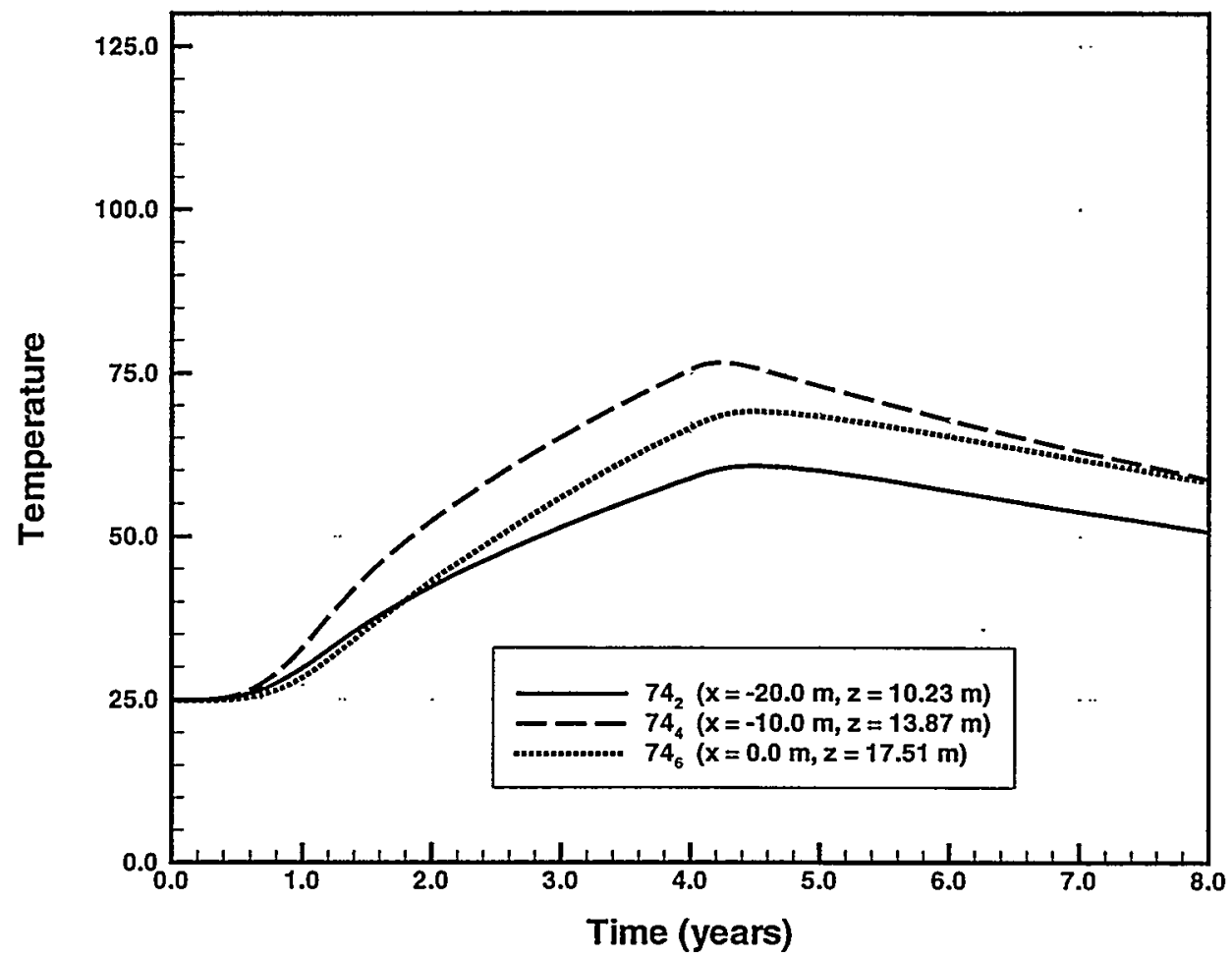

Figure A2-6 Temperature evolution at different sensor locations in borehole 74 for $0.36 \mathrm{~mm} / \mathrm{yr}$ infiltration case ( 1 year heating at $100 \%, 3$ years heating at $50 \%$ ).

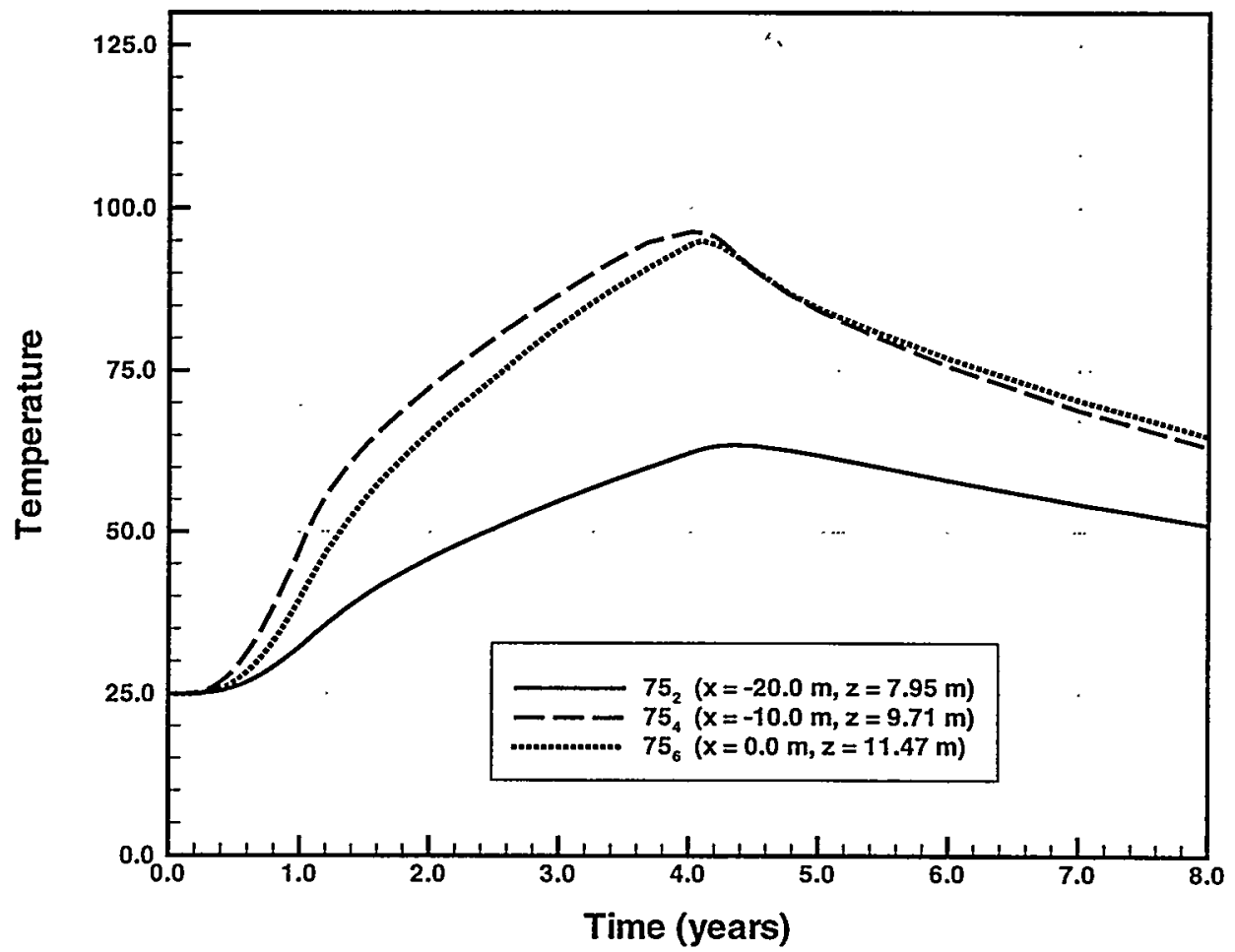

Figure A2-7 Temperature evolution at different sensor locations in borehole 75 for $0.36 \mathrm{~mm} / \mathrm{yr}$ infiltration case (I year heating at 100\%, 3 years heating at 50\%). 


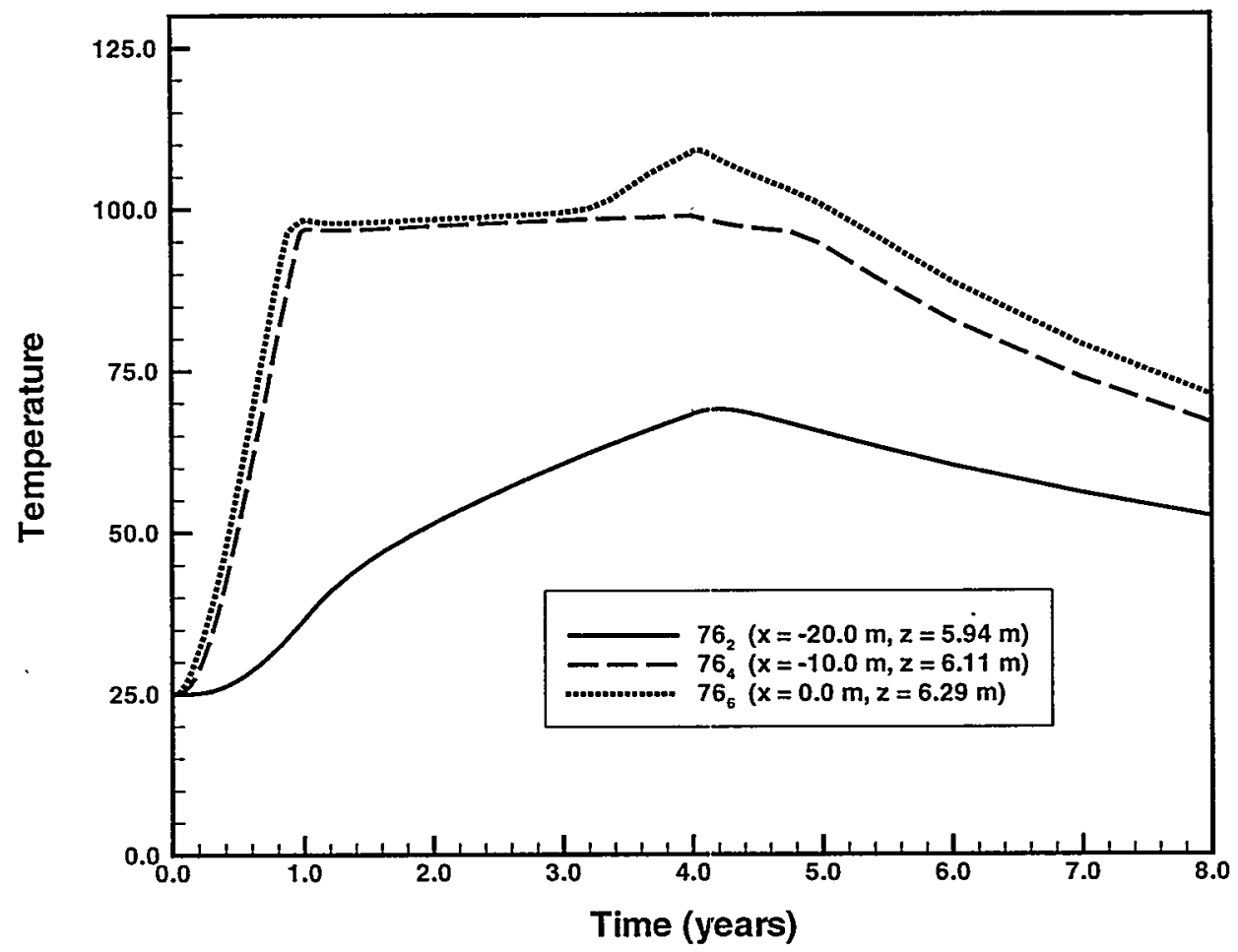

Figure A2-8 Temperature evolution at different sensor locations in borehole 76 for $0.36 \mathrm{~mm} / \mathrm{yr}$ infiltration case (1 year heating at 100\%, 3 years heating at 50\%).

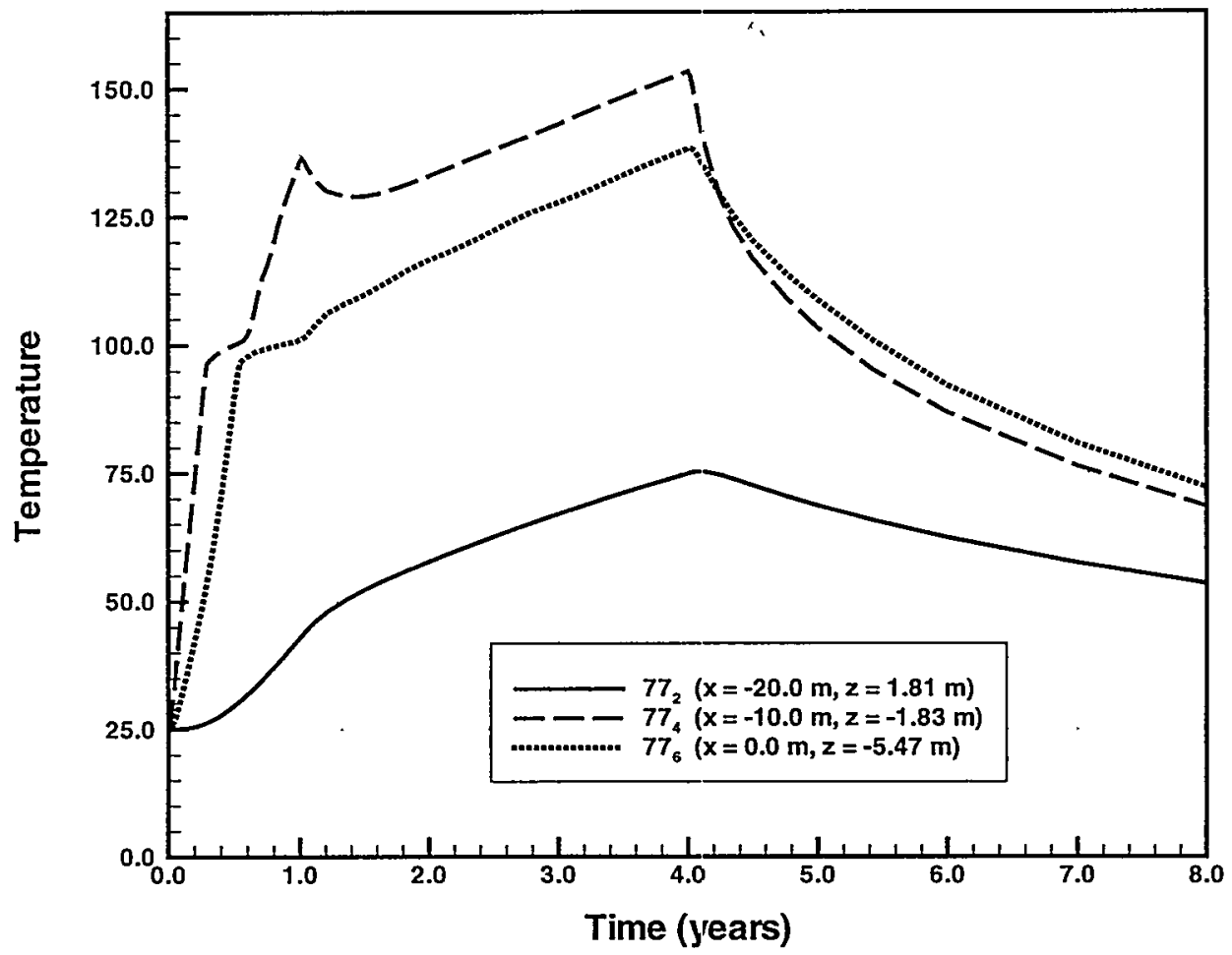

Figure A2-9 Temperature evolution at different sensor locations in borehole 77 for $0.36 \mathrm{~mm} / \mathrm{yr}$ infiltration case ( 1 year heating at 100\%, 3 years heating at $50 \%$ ). 
June 1997

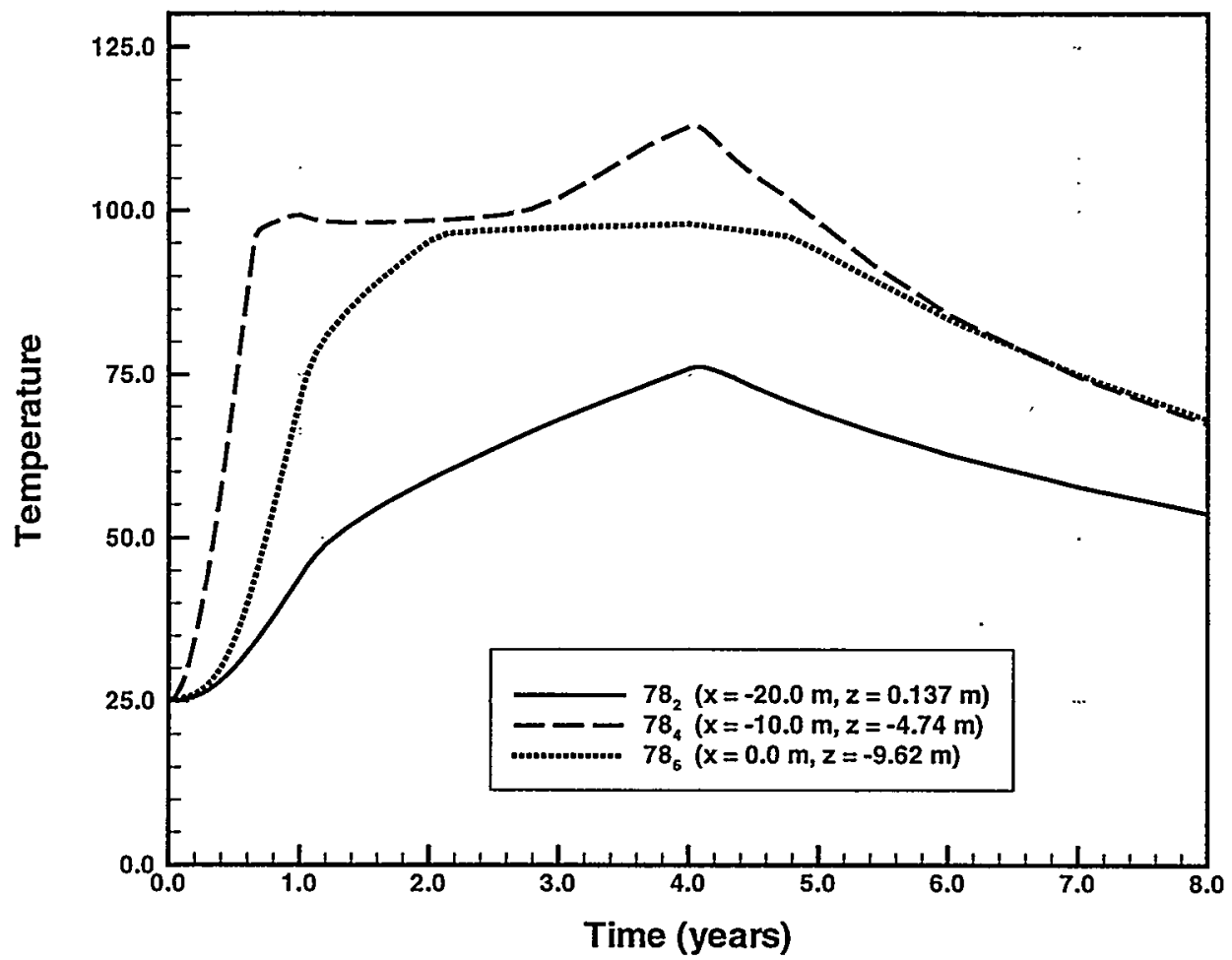

Figure A2-10 Temperature evolution at different sensor locations in borehole 78 for $0.36 \mathrm{~mm} / y \mathrm{r}$ infiltration case (1 year heating at 100\%, 3 years heating at 50\%). 
Pretest Analysis of the Thermal-Hydrological Conditions of the ESF Drift Scale Test

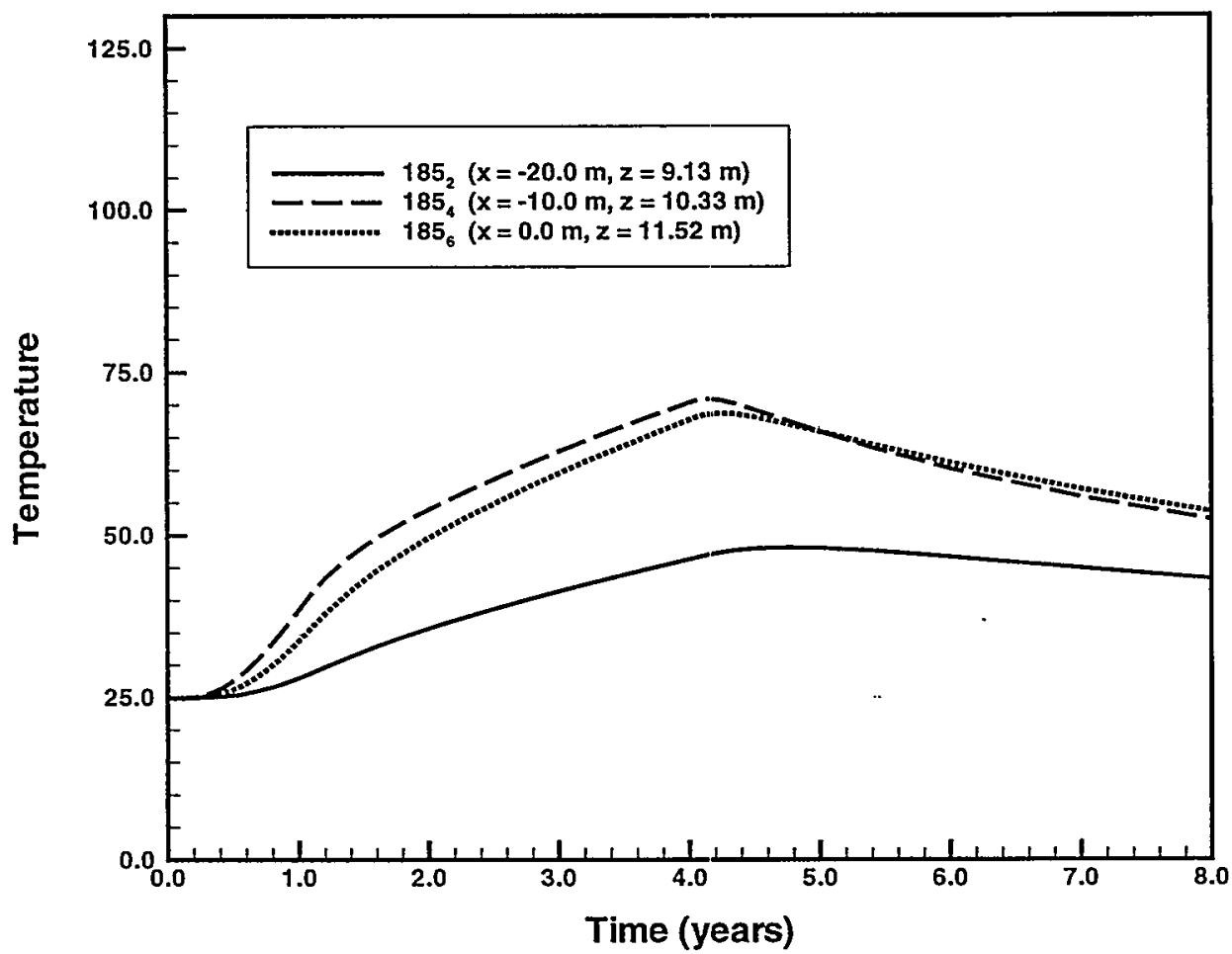

Figure A2-11 Temperature evolution at different sensor locations in borehole 185 for $0.36 \mathrm{~mm} / \mathrm{yr}$ infiltration case (1 year heating at 100\%, 3 years heating at $50 \%$ ).

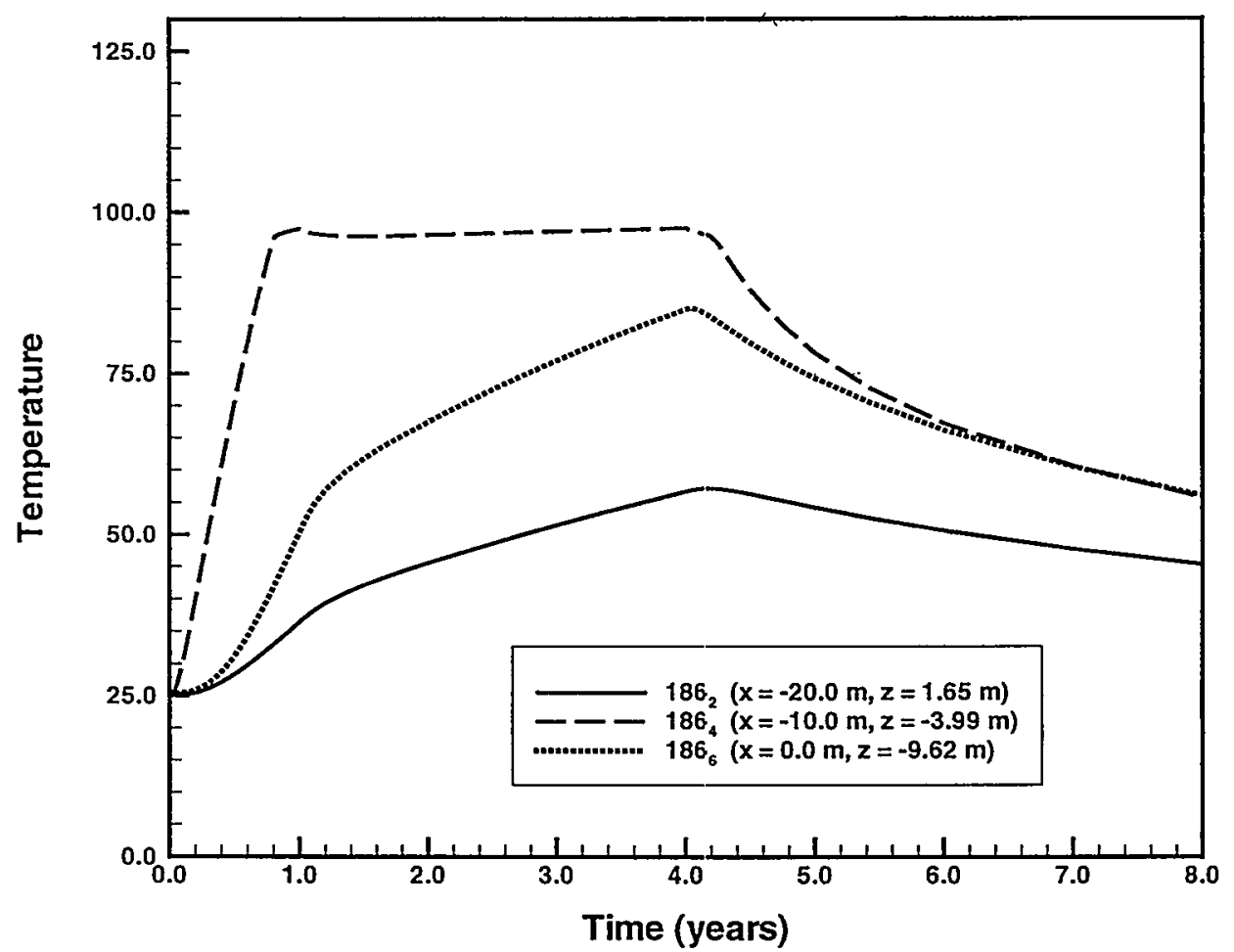

Figure A2-12 Temperature evolution at different sensor locations in borehole 186 for $0.36 \mathrm{~mm} / \mathrm{yr}$ infiltration case ( 1 year heating at 100\%, 3 years heating at 50\%). 


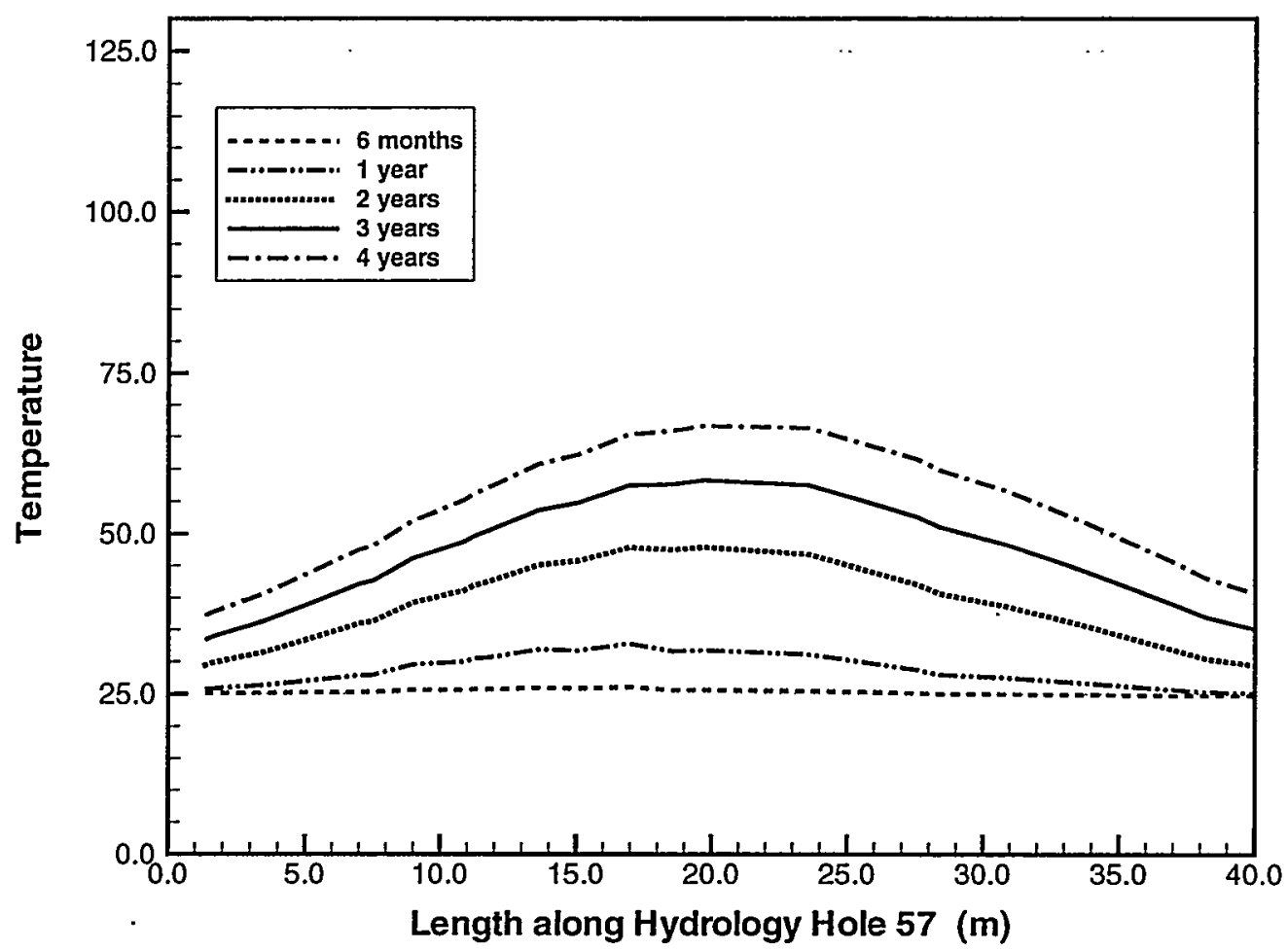

Figure A2-13 Temperature profile along borehole 57 at different times during heating period for $0.36 \mathrm{~mm} / \mathrm{yr}$ infiltration case (1 year heating at $100 \%, 3$ years heating at $50 \%$ ).

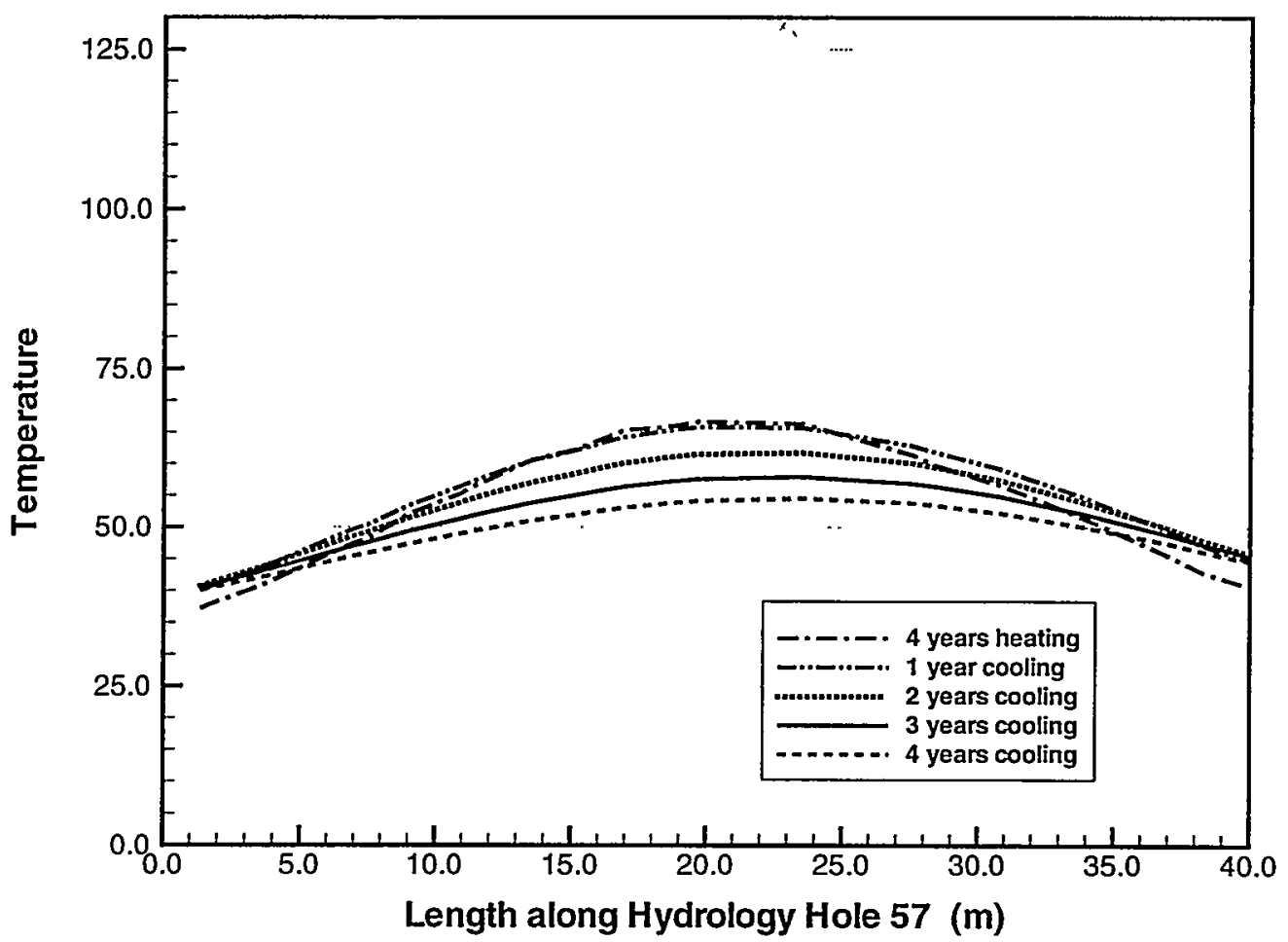

Figure A2-14 Temperature profile along borehole 57 at different times during cooling period for $0.36 \mathrm{~mm} / \mathrm{yr}$ infiltration case (1 year heating at $100 \%, 3$ years heating at $50 \%$ ). 


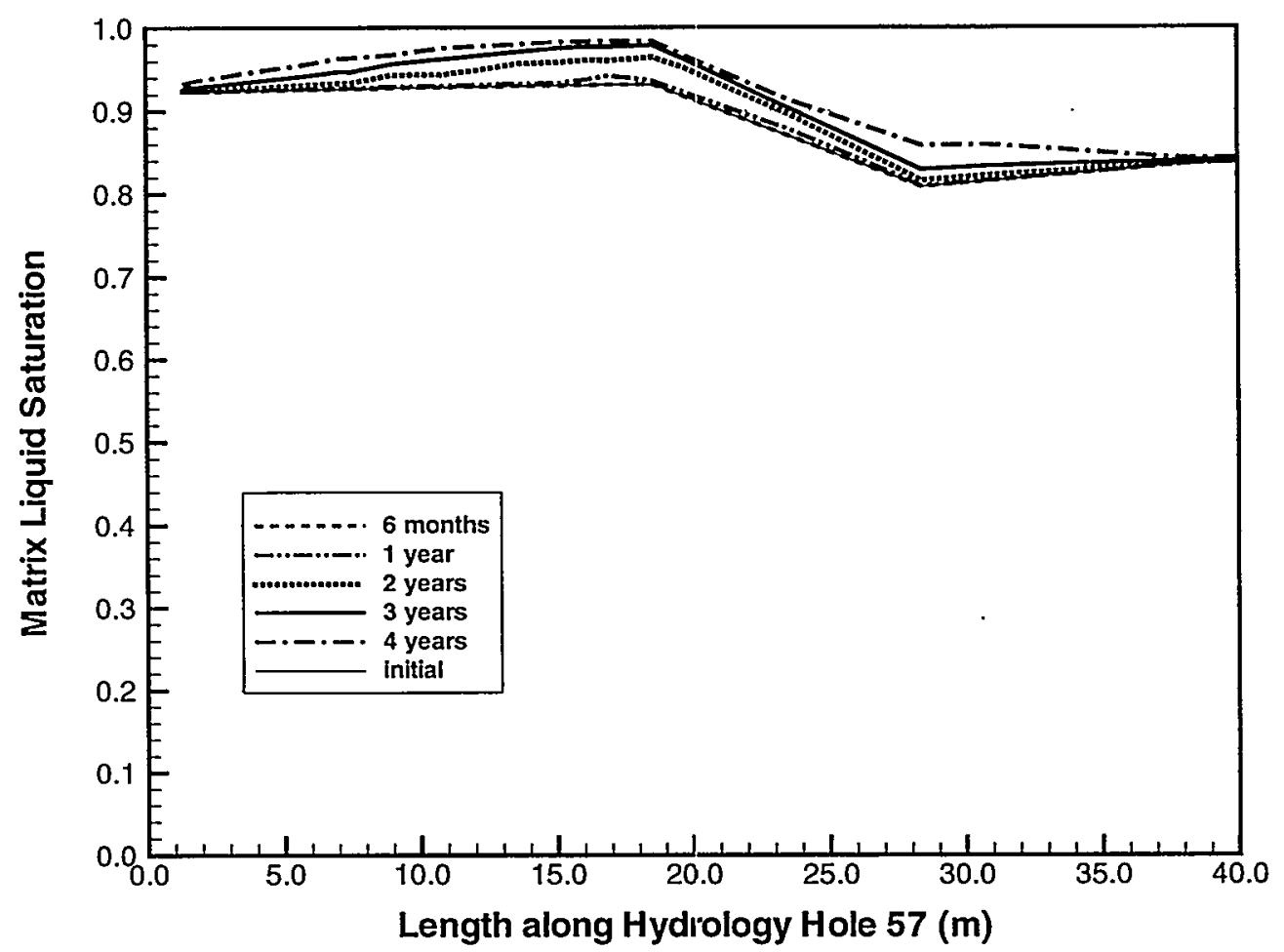

Figure A2-15 Matrix saturation profile along borehole 57 at different times during heating period for $0.36 \mathrm{~mm} / \mathrm{yr}$ infiltration case (1 year heating at 100\%, 3 years heating at 50\%).

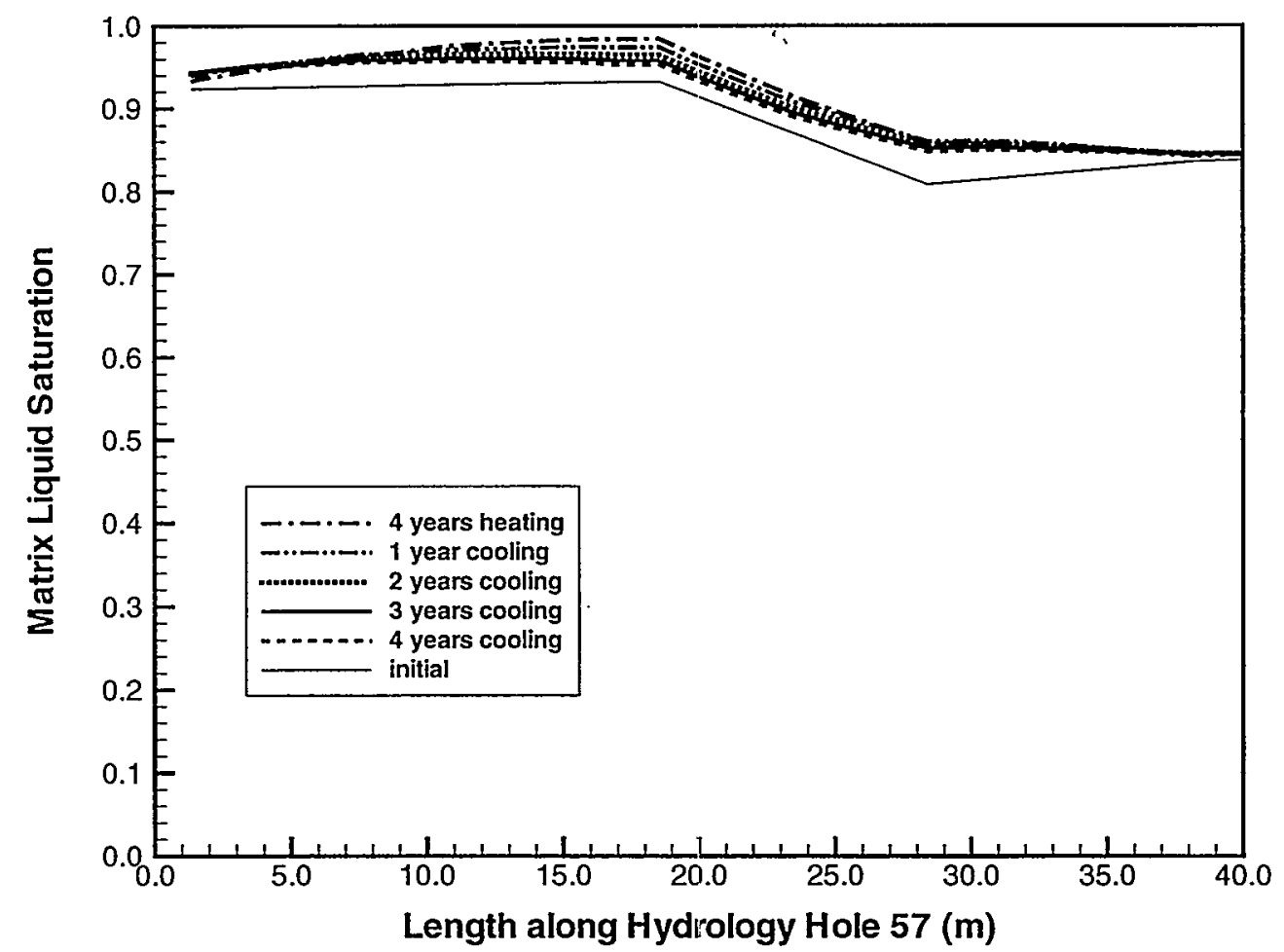

Figure A2-16 Matrix saturation profile along borehole 57 at different times during cooling period for $0.36 \mathrm{~mm} / \mathrm{yr}$ infiltration case (1 year heating at 100\%, 3 years heating at 50\%). 


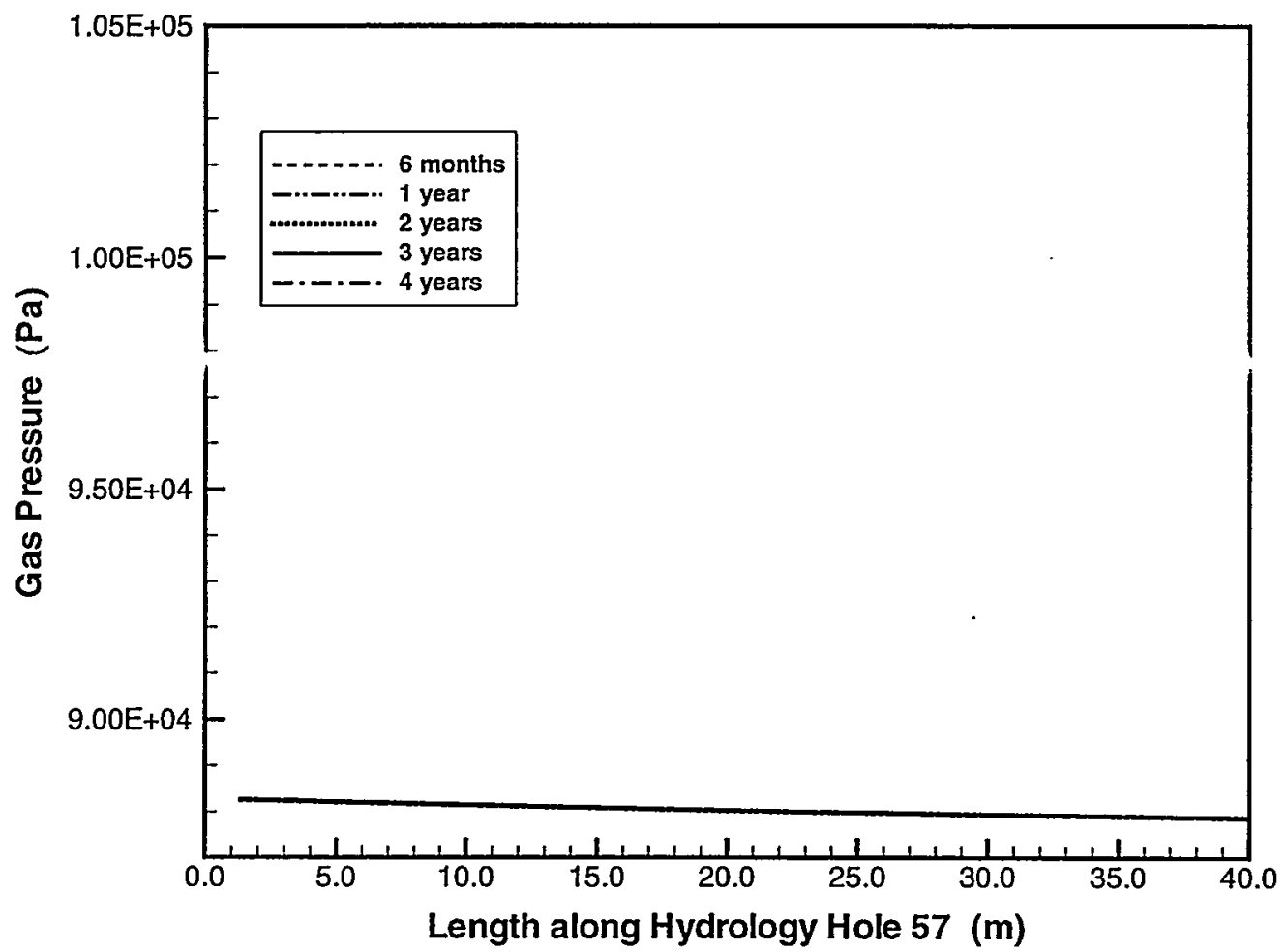

Figure A2-17 Gas pressure profile along borehole 57 at different times during heating period for $0.36 \mathrm{~mm} / \mathrm{yr}$ infiltration case (1 year heating at 100\%, 3 years heating at $50 \%$ ). 


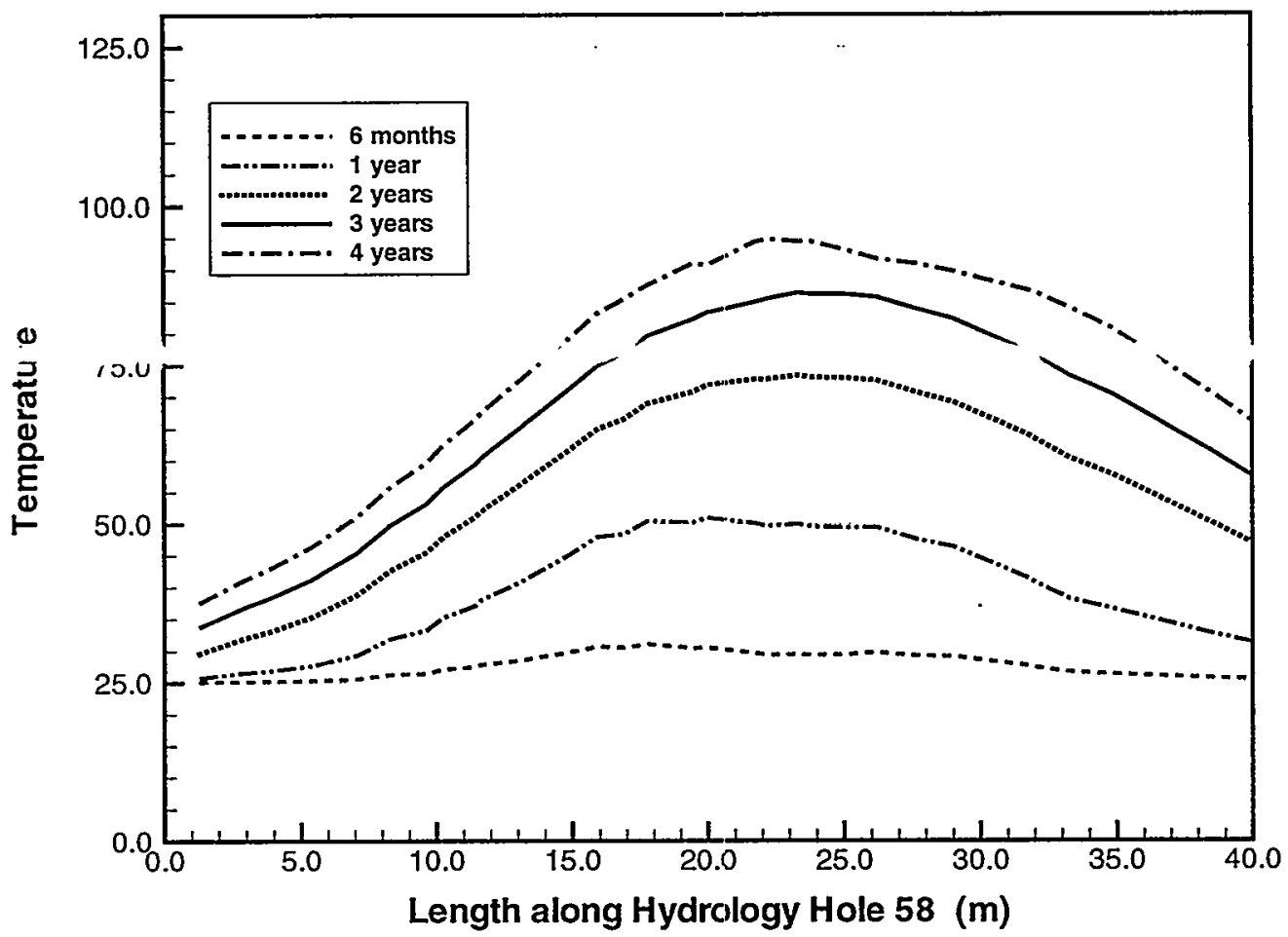

Figure A2-18 Temperature profile along borehole 58 at different times during heating period for $0.36 \mathrm{~mm} / \mathrm{yr}$ infiltration case (I year heating at 100\%, 3 years heating at $50 \%$ ).

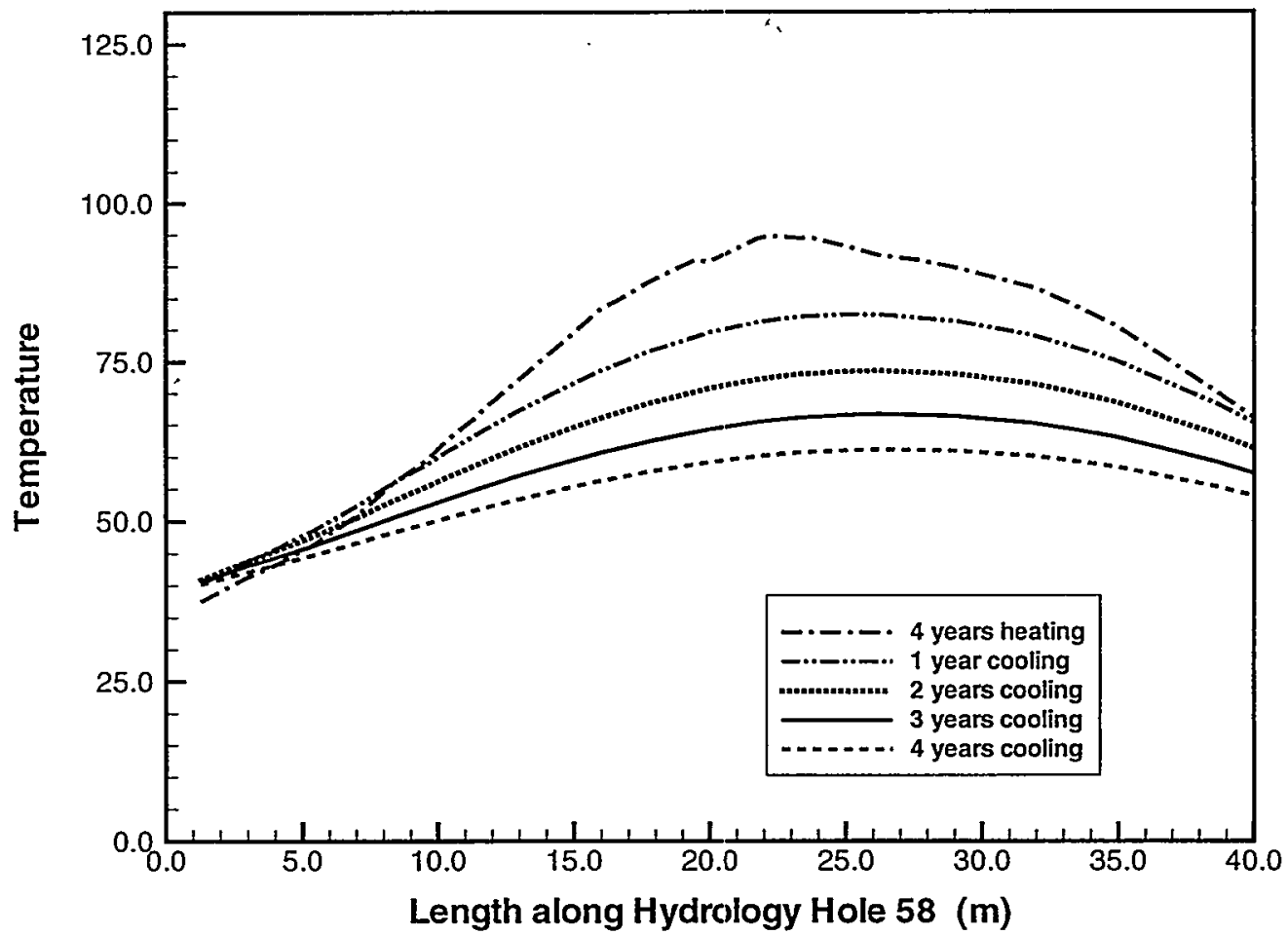

Figure A2-19 Temperature profile along borehole 58 at different times during cooling period for $0.36 \mathrm{~mm} / \mathrm{yr}$ infiltration case (1 year heating at 100\%, 3 years heating at $50 \%$ ). 


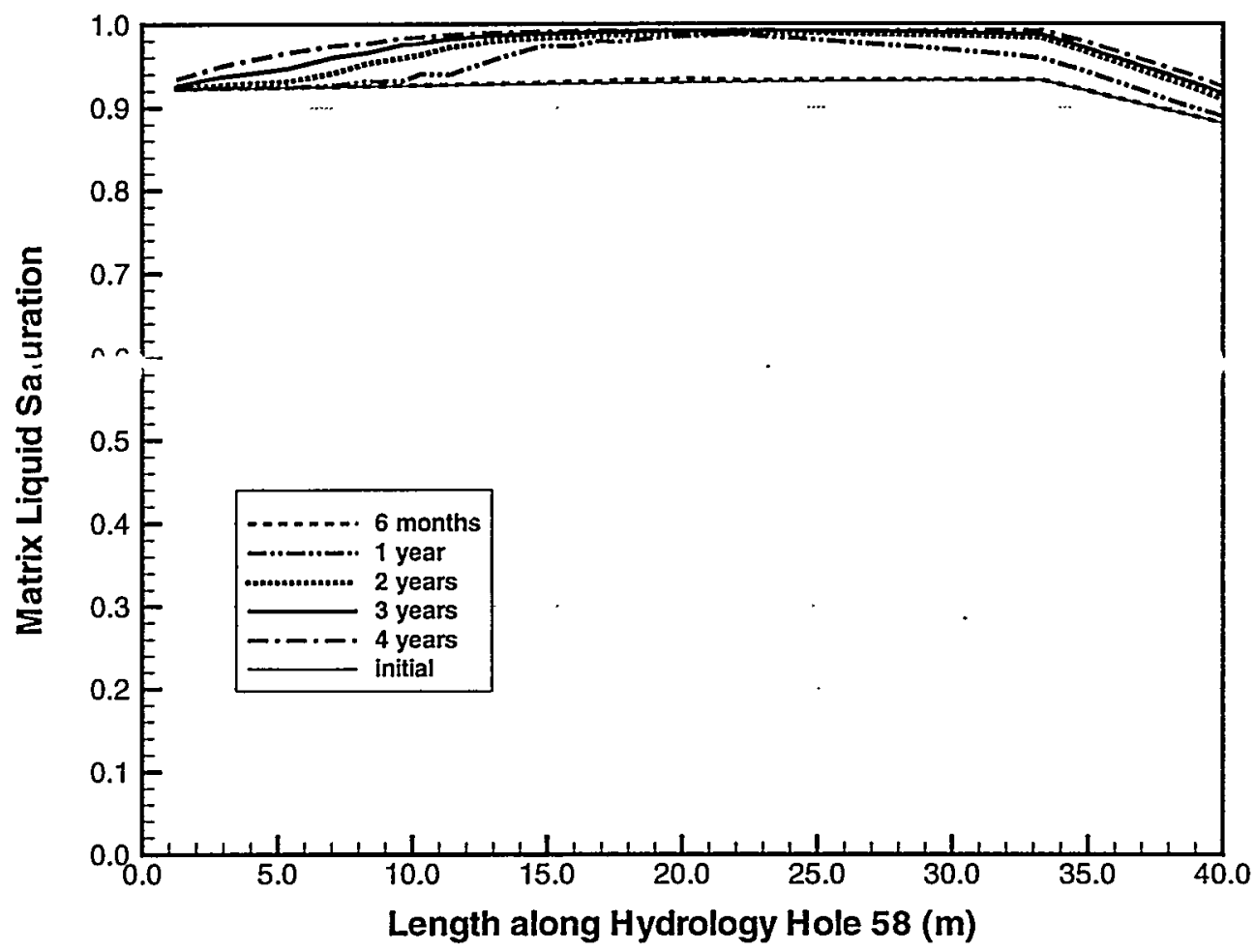

Figure A2-20 Matrix saturation profile along borehole 58 at different times during heating period for $0.36 \mathrm{~mm} / \mathrm{yr}$ infiltration case (1 year heating at 100\%, 3 years heating at $50 \%$ ).

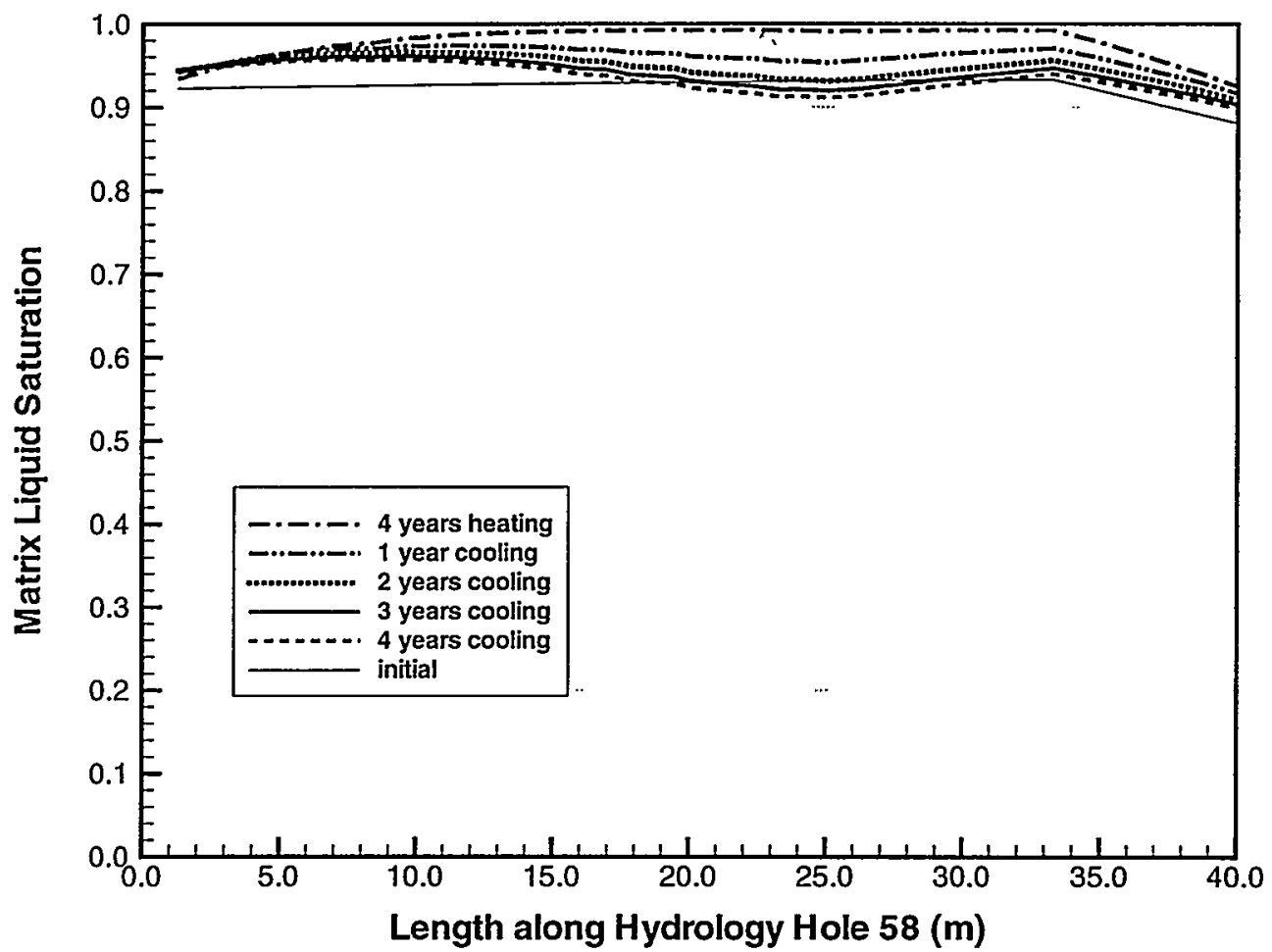

Figure A2-21 Matrix saturation profile along borehole 58 at different times during cooling period for $0.36 \mathrm{~mm} / \mathrm{yr}$ infiltration case (1 year heating at 100\%, 3 years heating at 50\%). 
Pretest Analysis of the Thermal-Hydrological Conditions of the ESF Drift Scale Test

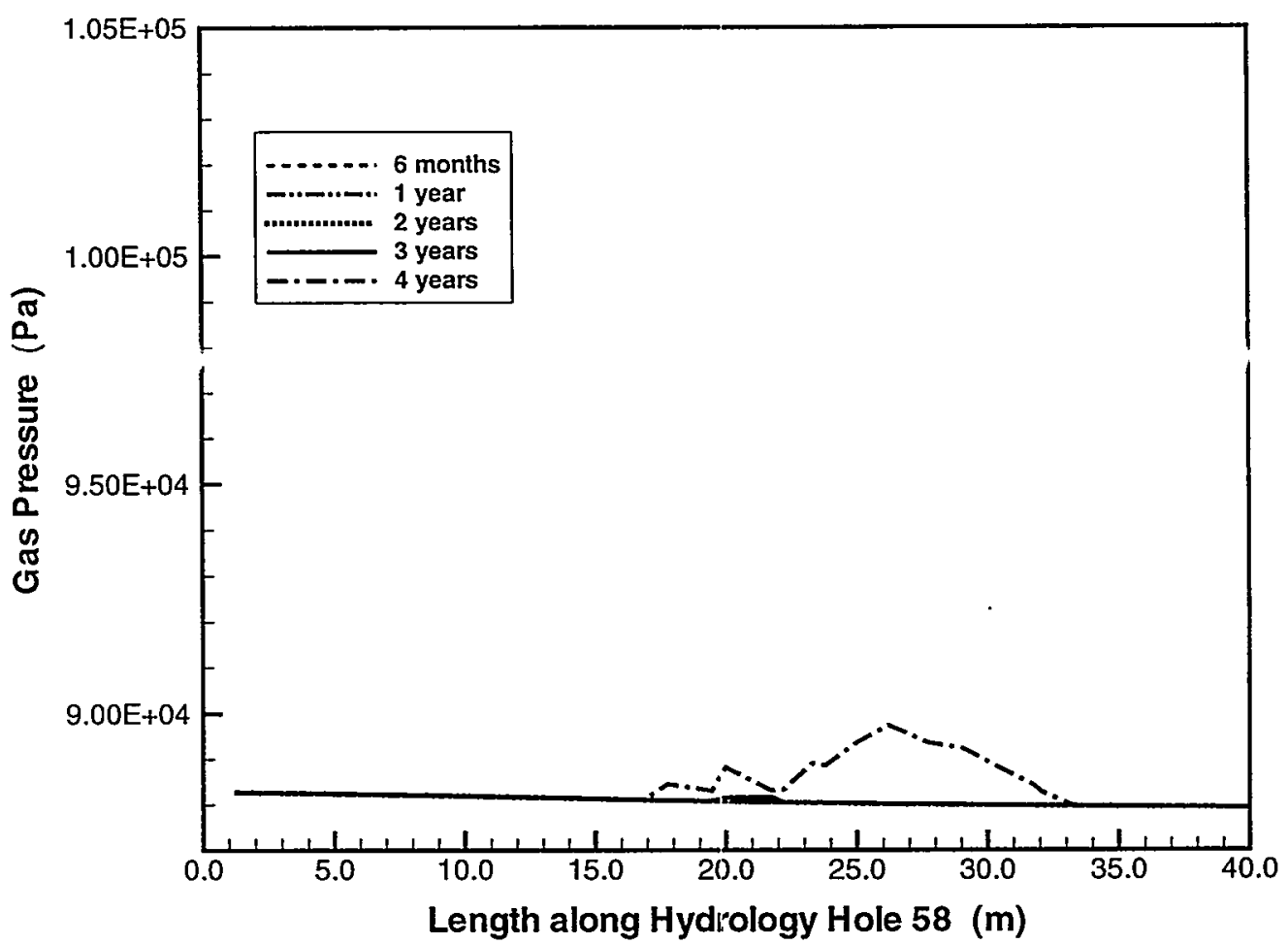

Figure A2-22 Gas pressure profile along borehole 58 at different times during heating period for $0.36 \mathrm{~mm} / \mathrm{yr}$ infiltration case (1 year heating at 100\%, 3 years heating at $50 \%$ ). 


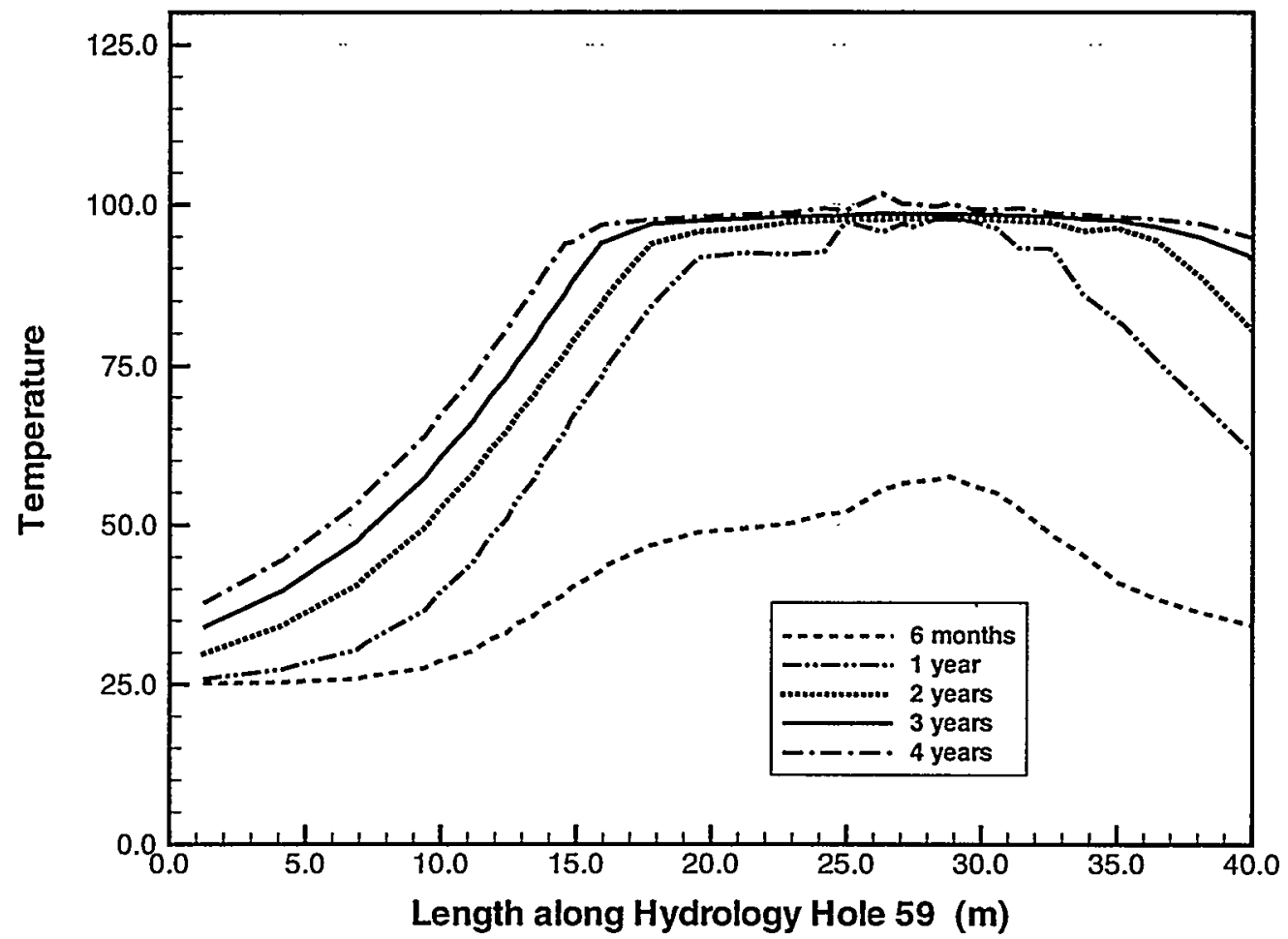

Figure A2-23 Temperature profile along borehole 59 at different times during heating period for $0.36 \mathrm{~mm} / \mathrm{yr}$ infiltration case (I year heating at 100\%, 3 years heating at $50 \%$ ).

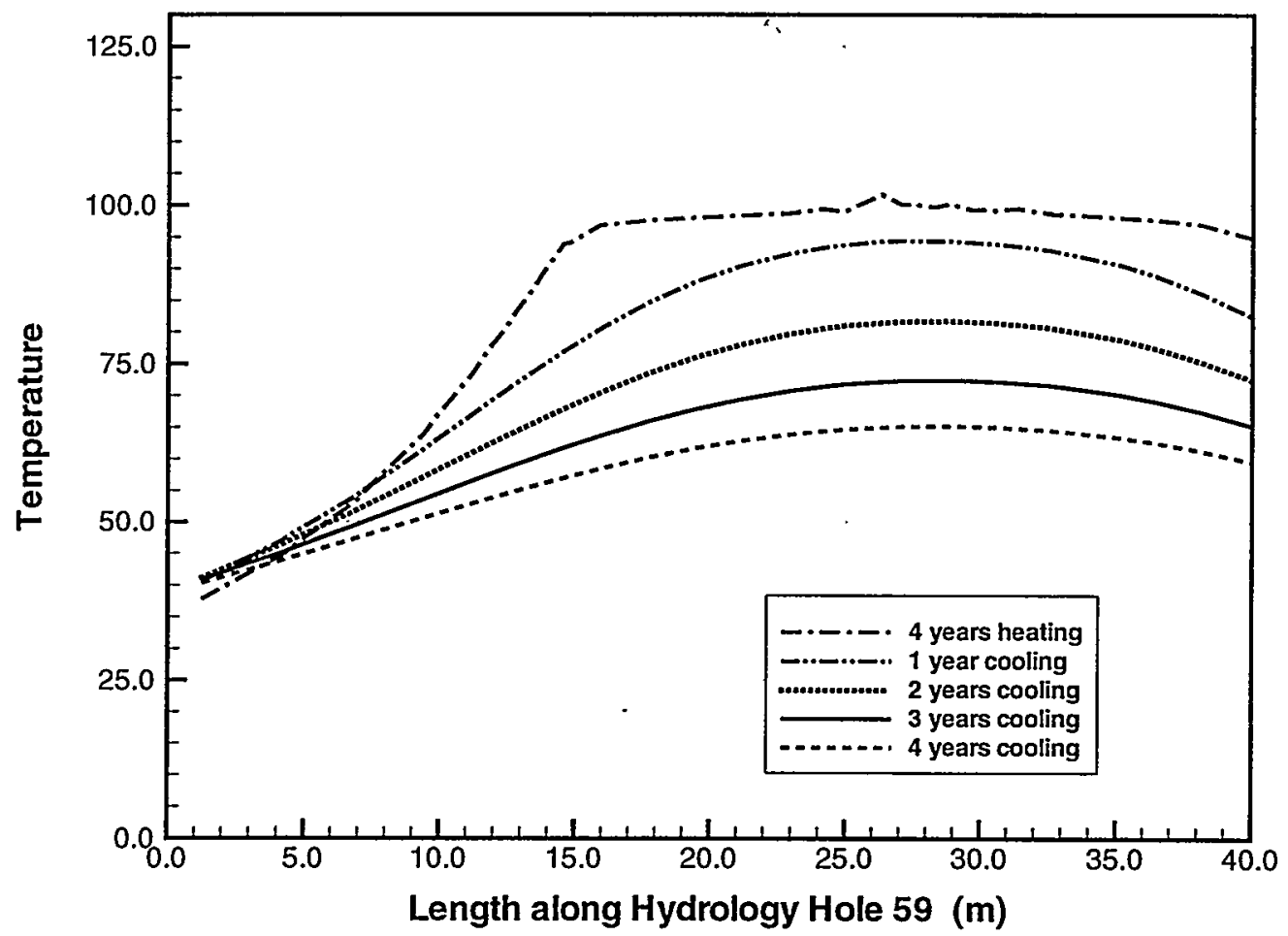

Figure A2-24 Temperature profile along borehole 59 at different times during cooling period for $0.36 \mathrm{~mm} / \mathrm{yr}$ infiltration case (1 year heating at 100\%, 3 years heating at 50\%). 


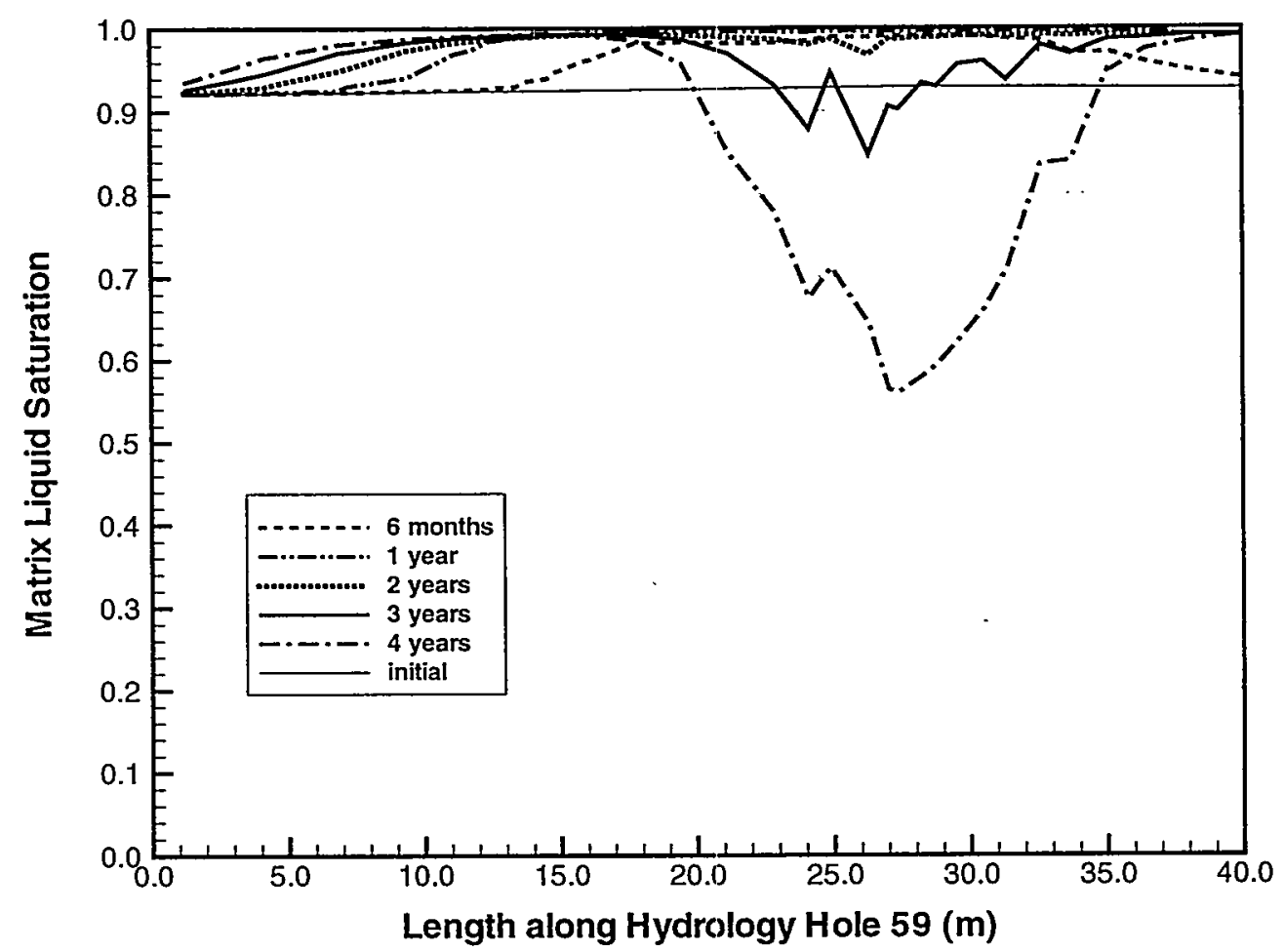

Figure A2-25 Matrix saturation profile along borehole 59 at different times during heating period for $0.36 \mathrm{~mm} / \mathrm{yr}$ infiltration case (1 year heating at 100\%, 3 years heating at 50\%).

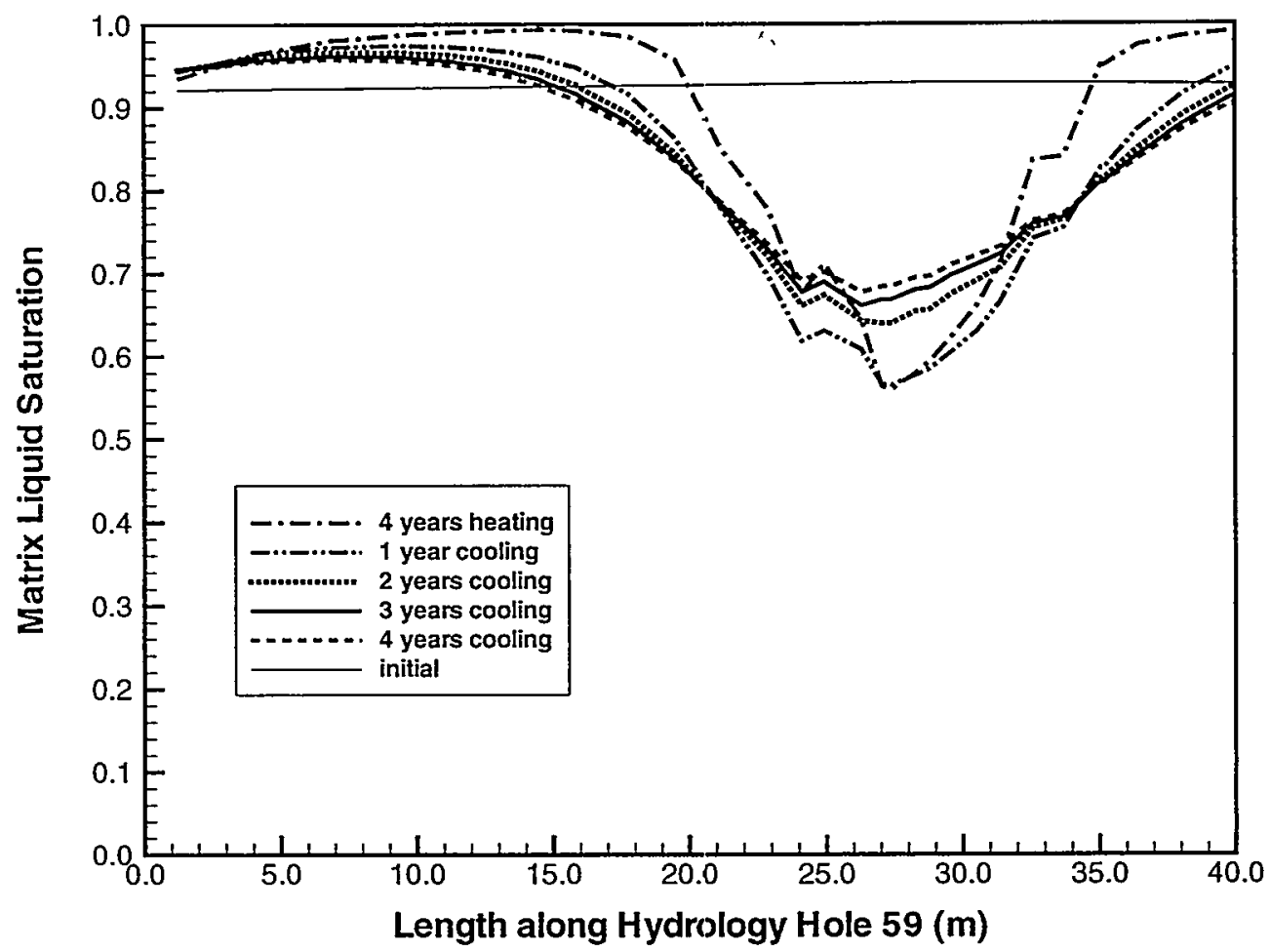

Figure A2-26 Matrix saturation profile along borehole 59 at different times during cooling period for $0.36 \mathrm{~mm} / \mathrm{yr}$ infiltration case (1 year heating at 100\%, 3 years heating at 50\%). 


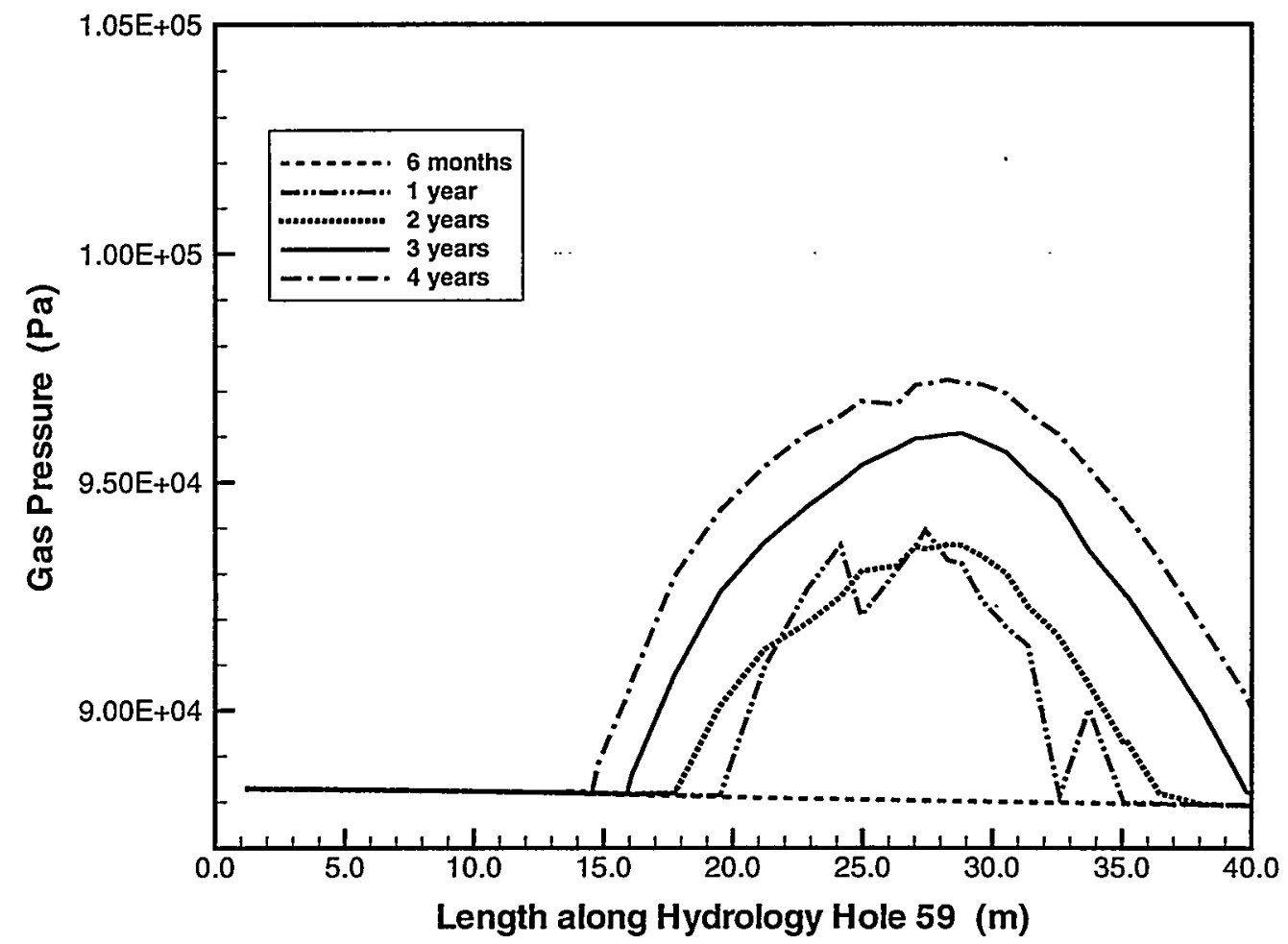

Figure A2-27 Gas pressure profile along borehole 59 at different times during heating period for $0.36 \mathrm{~mm} / \mathrm{yr}$ infiltration case (I year heating at 100\%, 3 years heating at 50\%). 


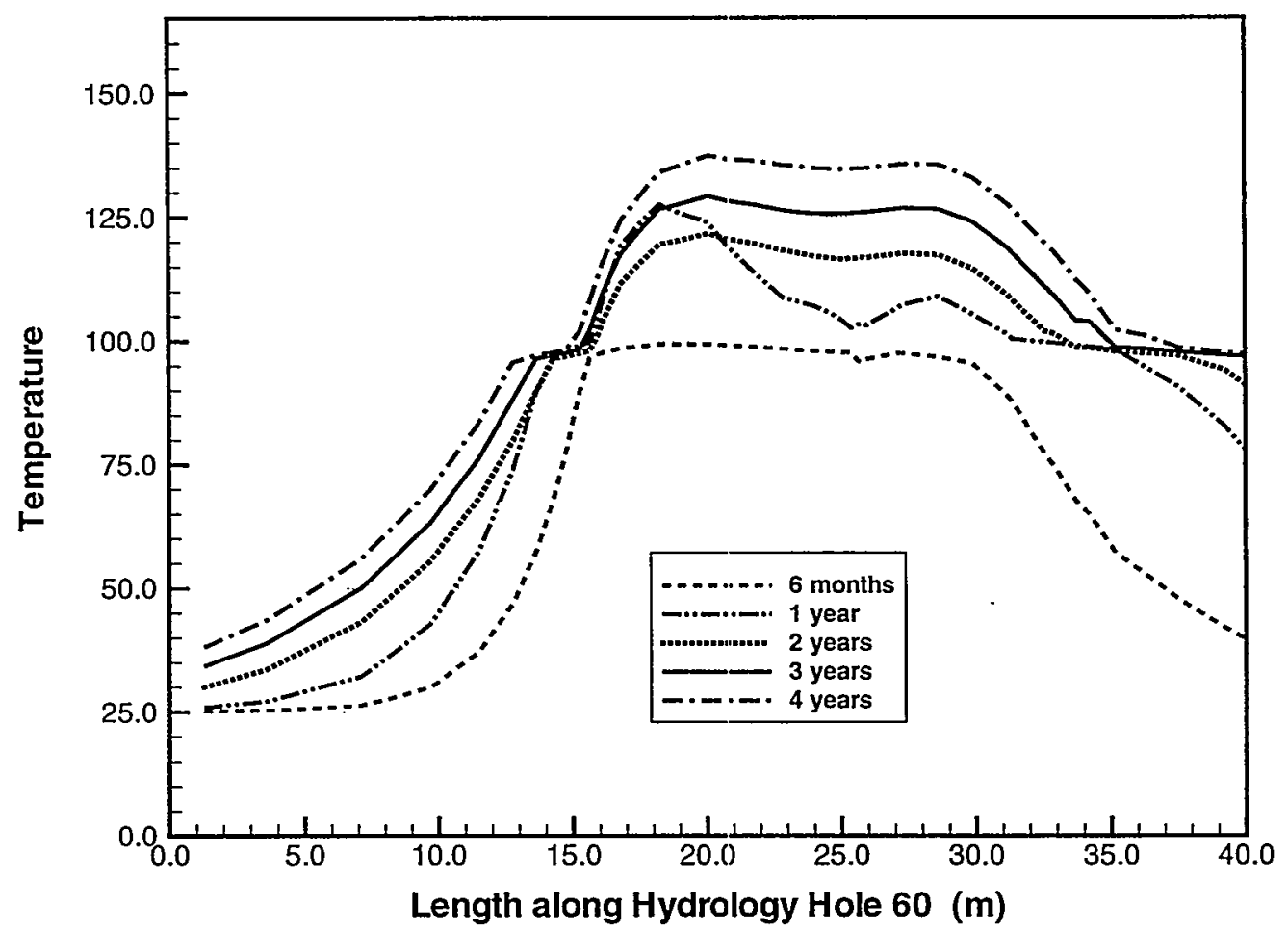

Figure A2-28 Temperature profile along borehole 60 at different times during heating period for $0.36 \mathrm{~mm} / \mathrm{yr}$ infiltration case (1 year heating at 100\%, 3 years heating at 50\%).

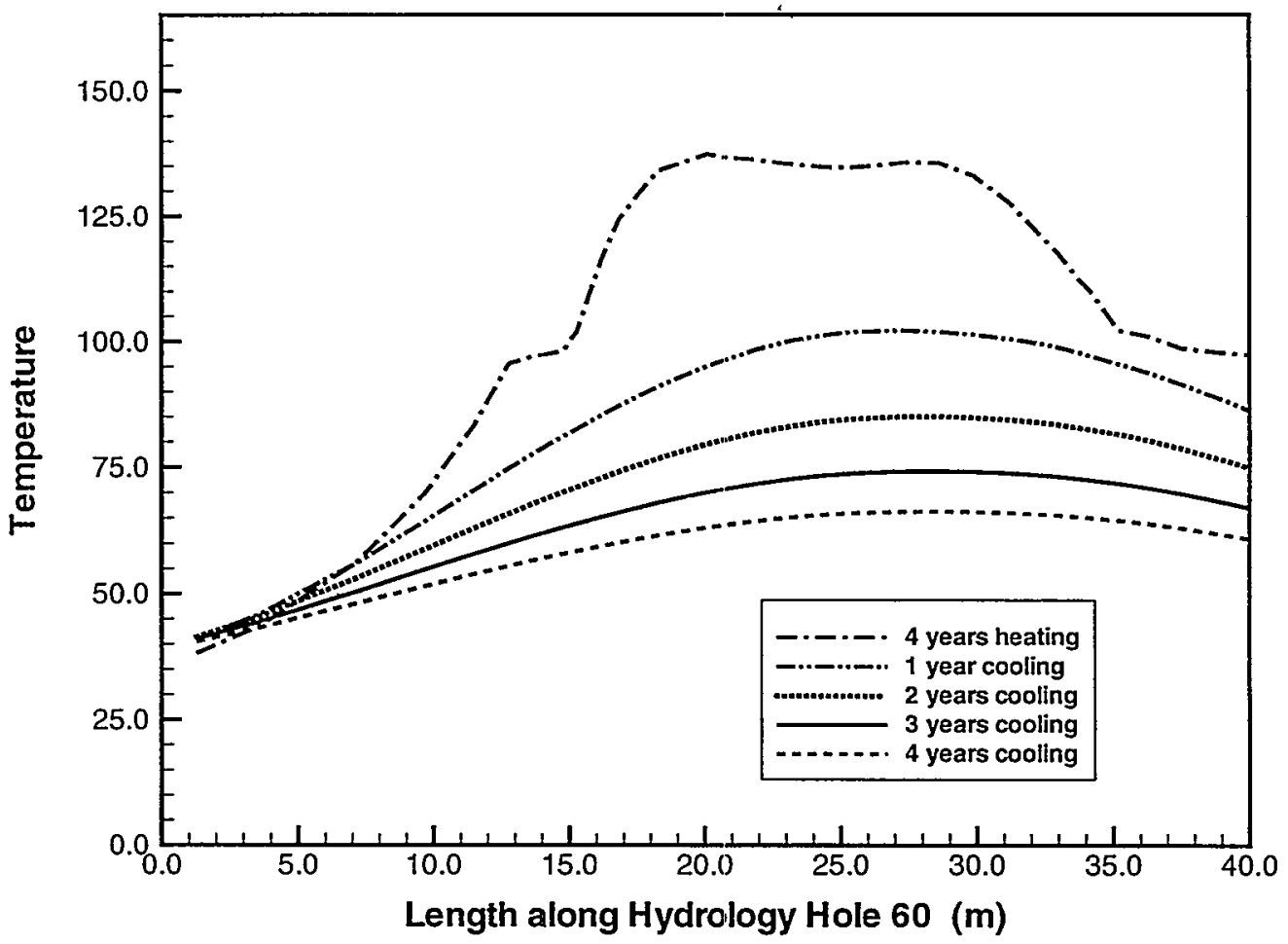

Figure A2-29 Temperature profile along borehole 60 at different times during cooling period for $0.36 \mathrm{~mm} / \mathrm{yr}$ infiltration case (1 year heating at $100 \%, 3$ years heating at $50 \%$ ). 


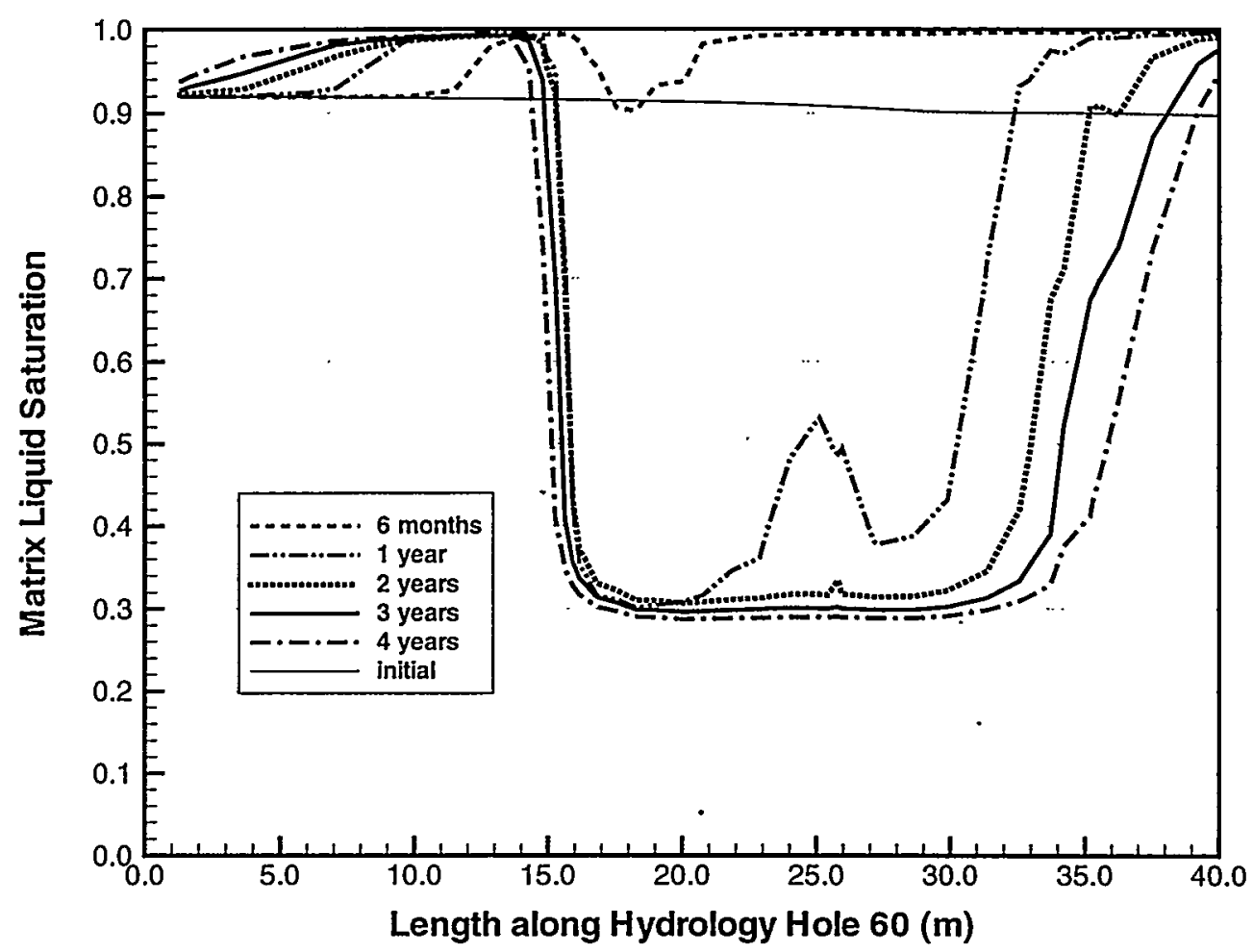

Figure A2-30 Matrix saturation profile along borehole 60 at different times during heating period for $0.36 \mathrm{~mm} / \mathrm{yr}$ infiltration case (I year heating at 100\%, 3 years heating at 50\%).

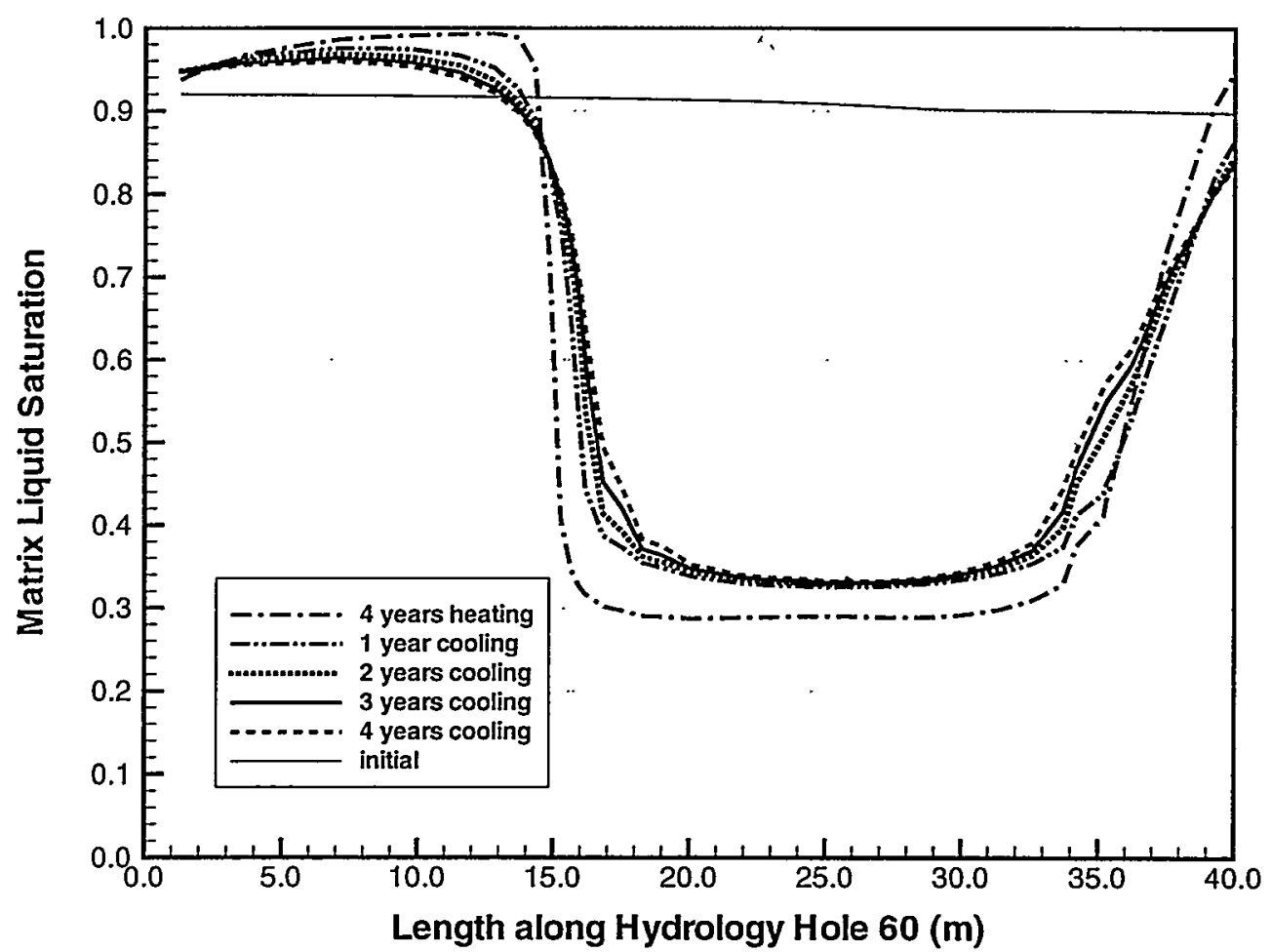

Figure A2-31 Matrix saturation profile along borehole 60 at different times during cooling period for $0.36 \mathrm{~mm} / \mathrm{yr}$ infiltration case (1 year heating at 100\%, 3 years heating at 50\%). 


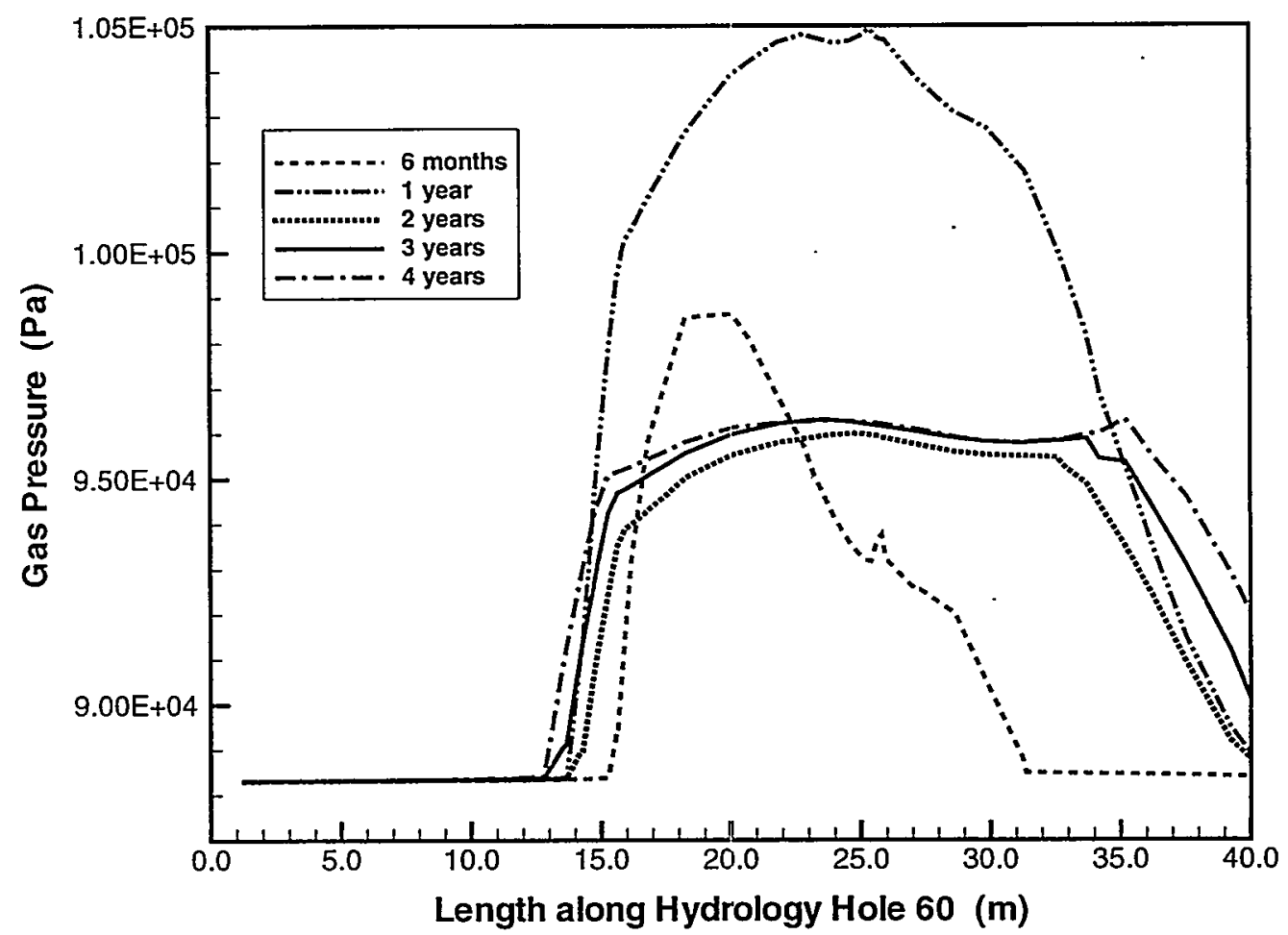

Figure A2-32 Gas pressure profile along borehole 60 at different times during heating period for $0.36 \mathrm{~mm} / \mathrm{yr}$ infiltration case (1 year heating at 100\%, 3 years heating at $50 \%$ ). 


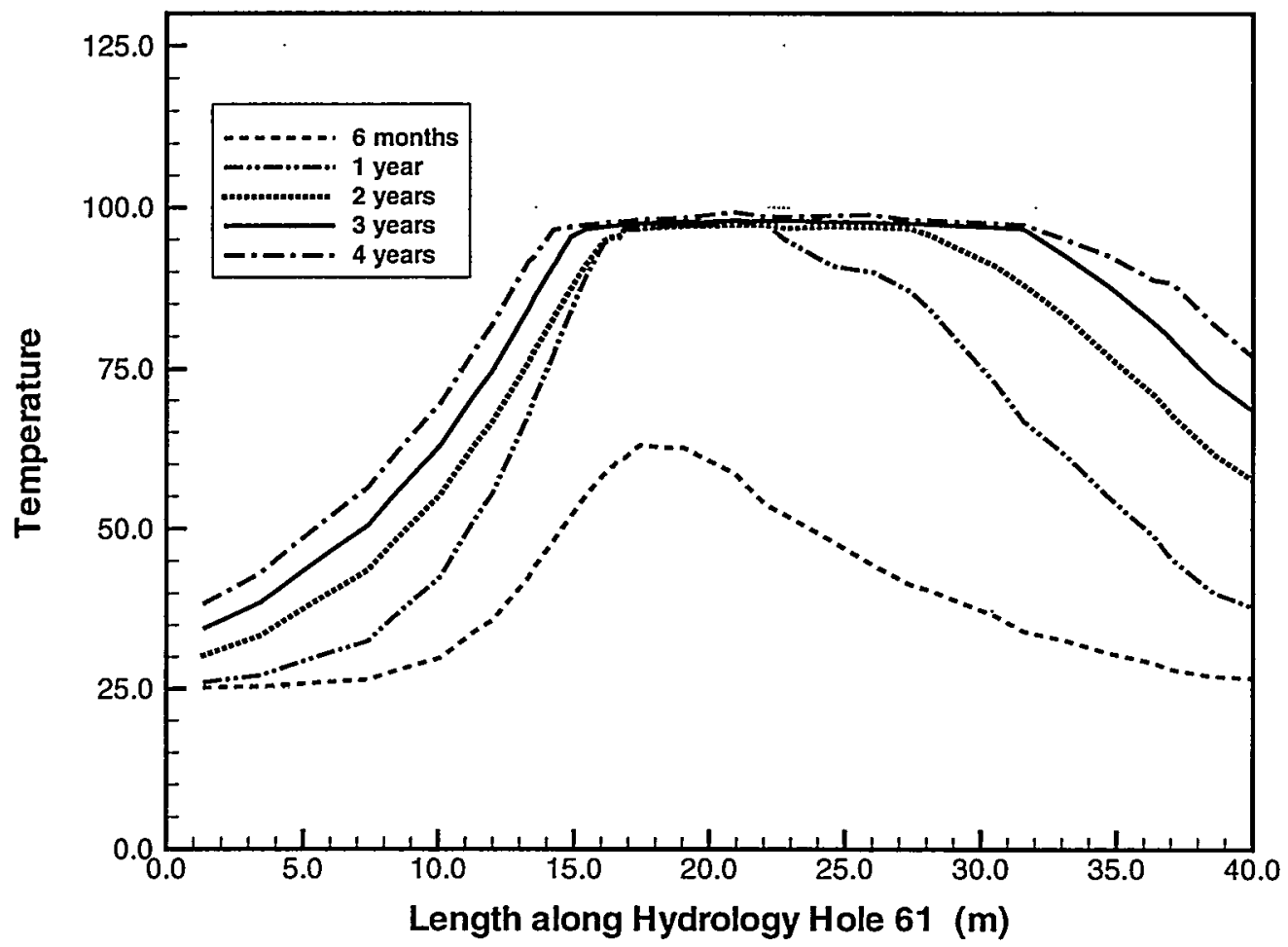

Figure A2-33 Temperature profile along borehole 61 at different times during heating period for $0.36 \mathrm{~mm} / \mathrm{yr}$ infiltration case (1 year heating at 100\%, 3 years heating at $50 \%$ ).

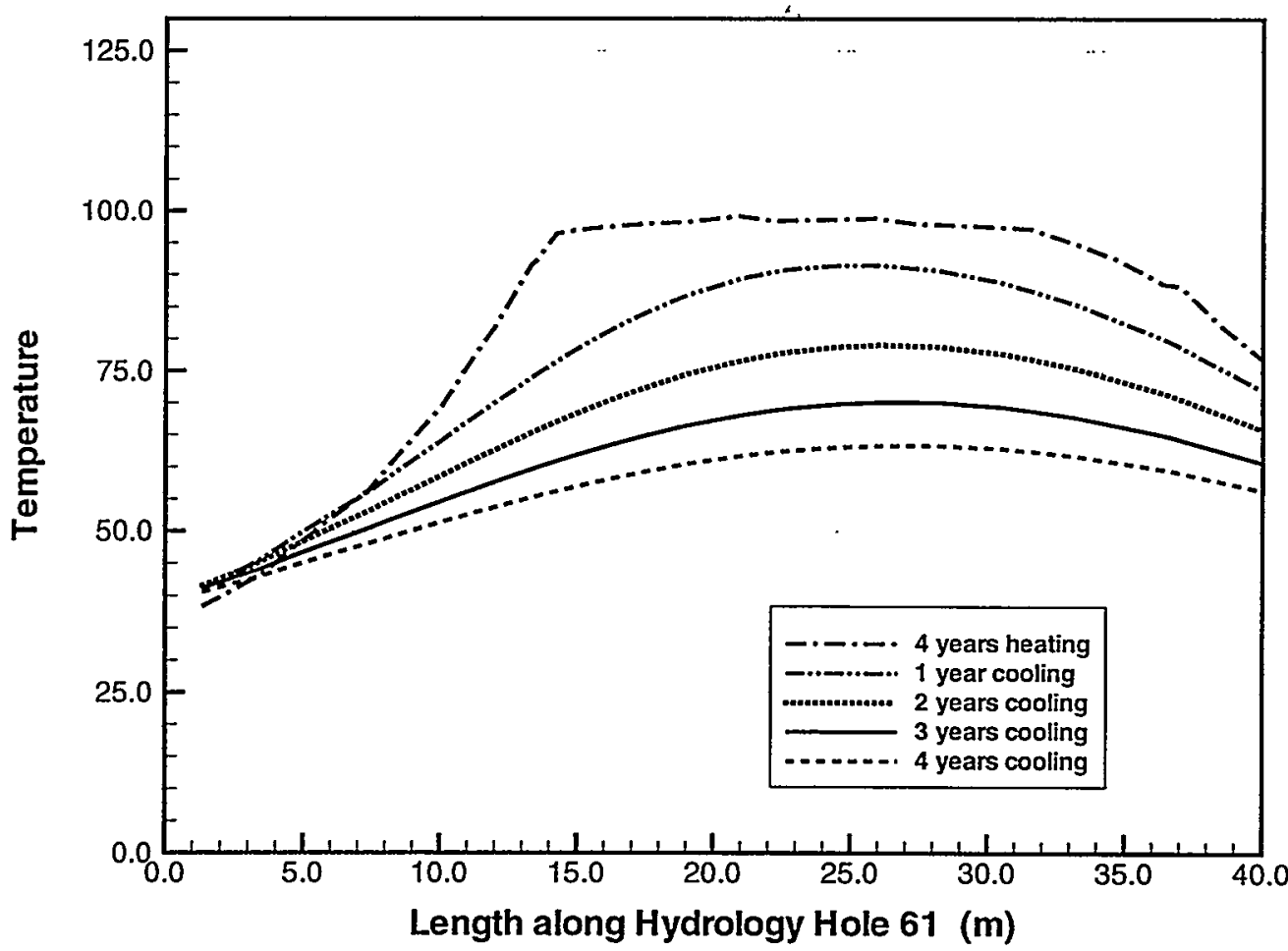

Figure A2-34 Temperature profile along borehole 61 at different times during cooling period for $0.36 \mathrm{~mm} / \mathrm{yr}$ infiltration case (1 year heating at 100\%, 3 years heating at $50 \%$ ). 


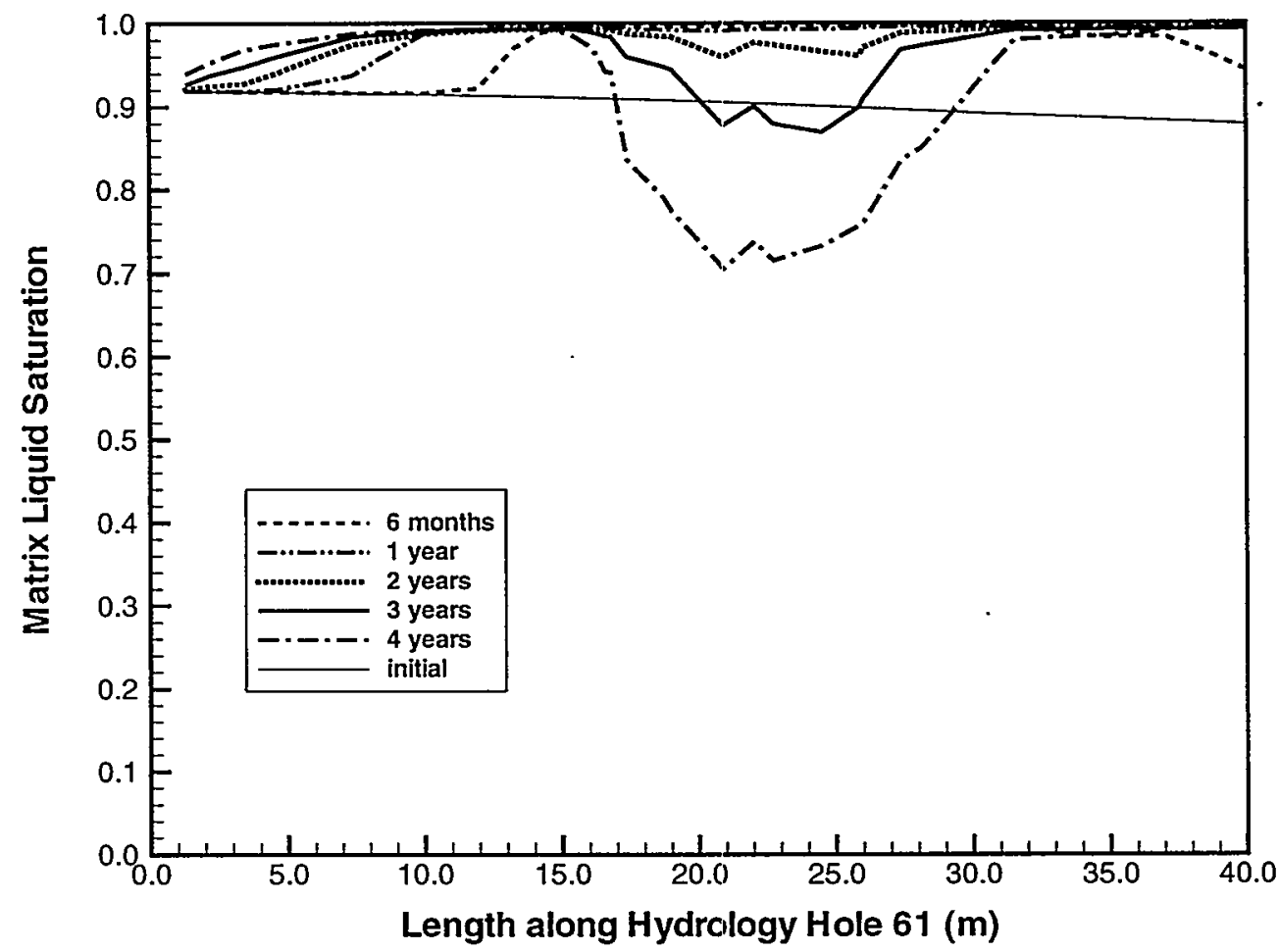

Figure A2-35 Matrix saturation profile along borehole 61 at different times during heating period for $0.36 \mathrm{~mm} / \mathrm{yr}$ infiltration case ( 1 year heating at 100\%, 3 years heating at 50\%).

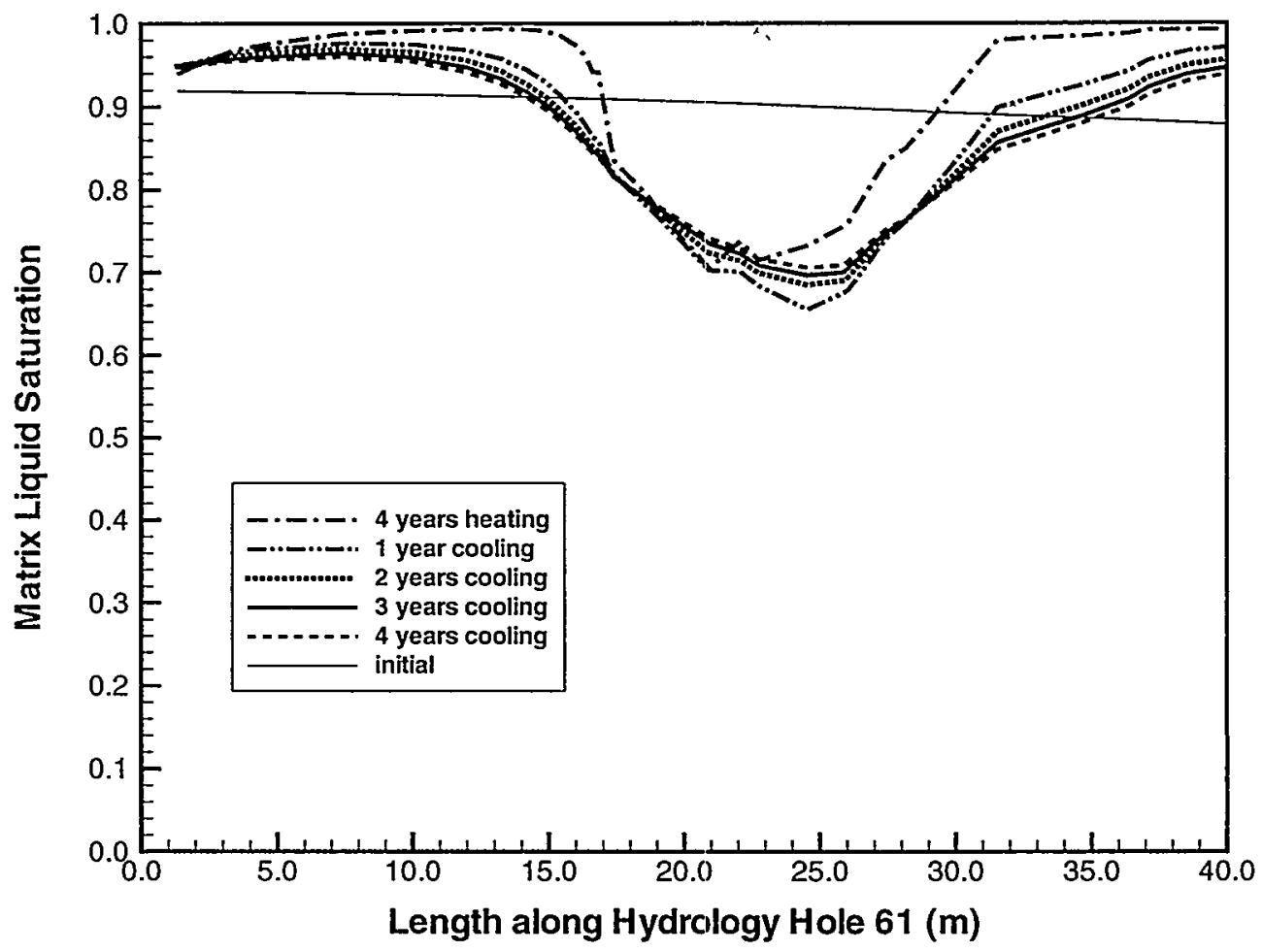

Figure A2-36 Matrix saturation profile along borehole 61 at different times during cooling period for $0.36 \mathrm{~mm} / \mathrm{yr}$ infiltration case ( 1 year heating at 100\%, 3 years heating at $50 \%$ ). 


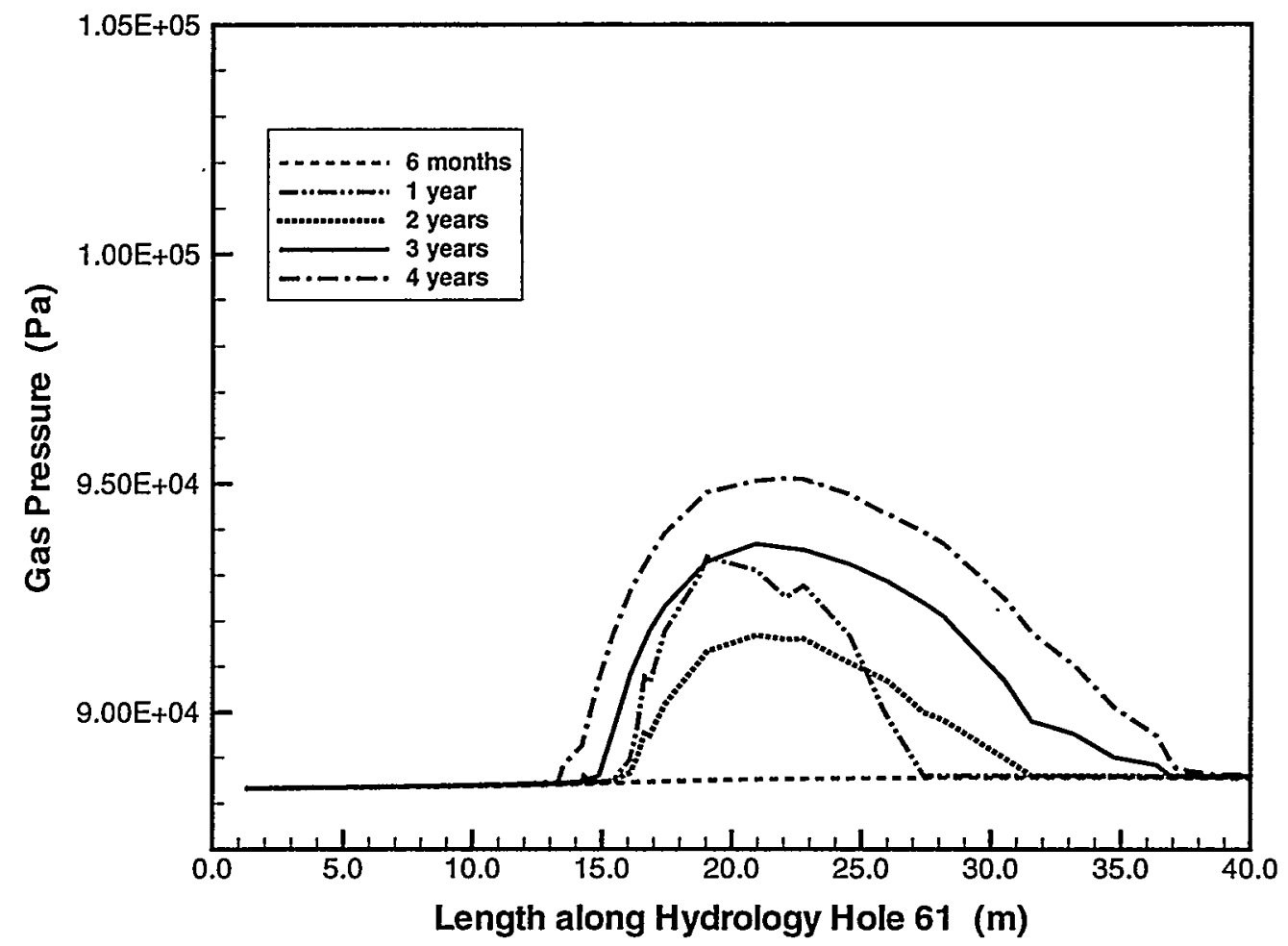

Figure A2-37 Gas pressure profile along borehole 61 at different times during heating period for $0.36 \mathrm{~mm} / \mathrm{yr}$ infiltration case ( 1 year heating at $100 \%, 3$ years heating at $50 \%$ ). 


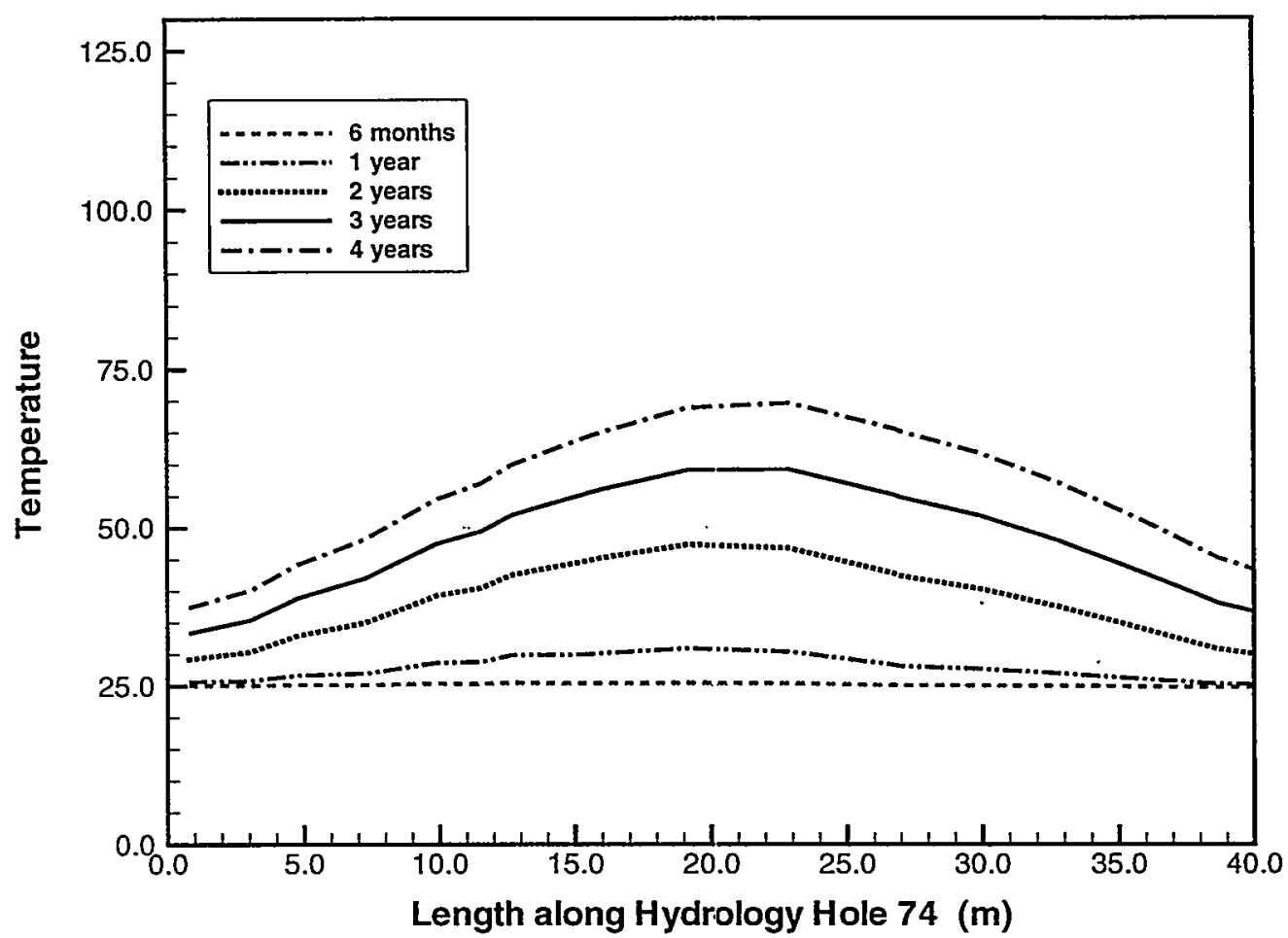

Figure A2-38 Temperature profile along borehole 74 at different times during heating period for $0.36 \mathrm{~mm} / \mathrm{yr}$ infiltration case (1 year heating at 100\%, 3 years heating at 50\%).

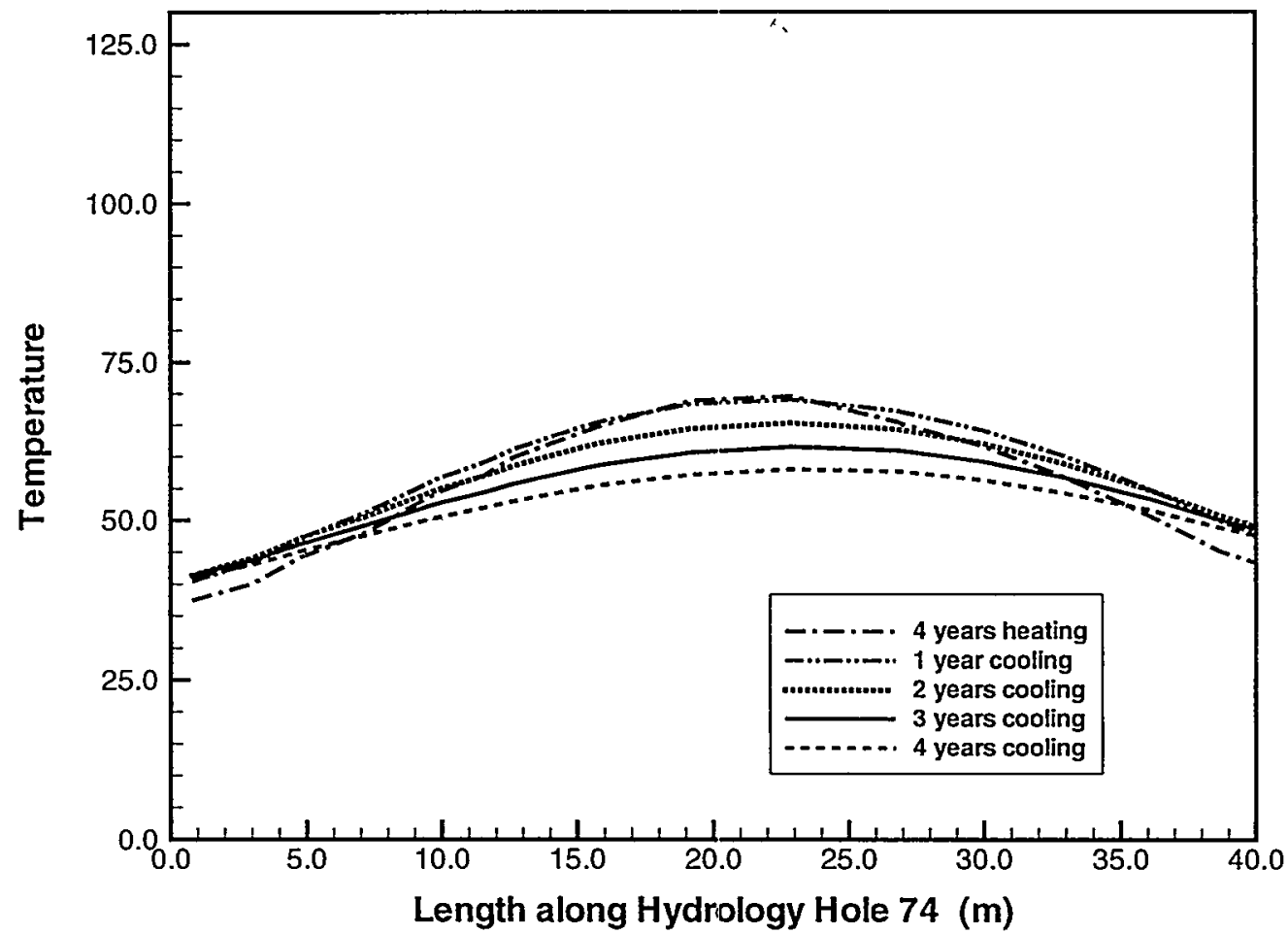

Figure A2-39 Temperature profile along borehole 74 at different times during cooling period for $0.36 \mathrm{~mm} / \mathrm{yr}$ infiltration case (1 year heating at 100\%, 3 years heating at $50 \%$ ). 


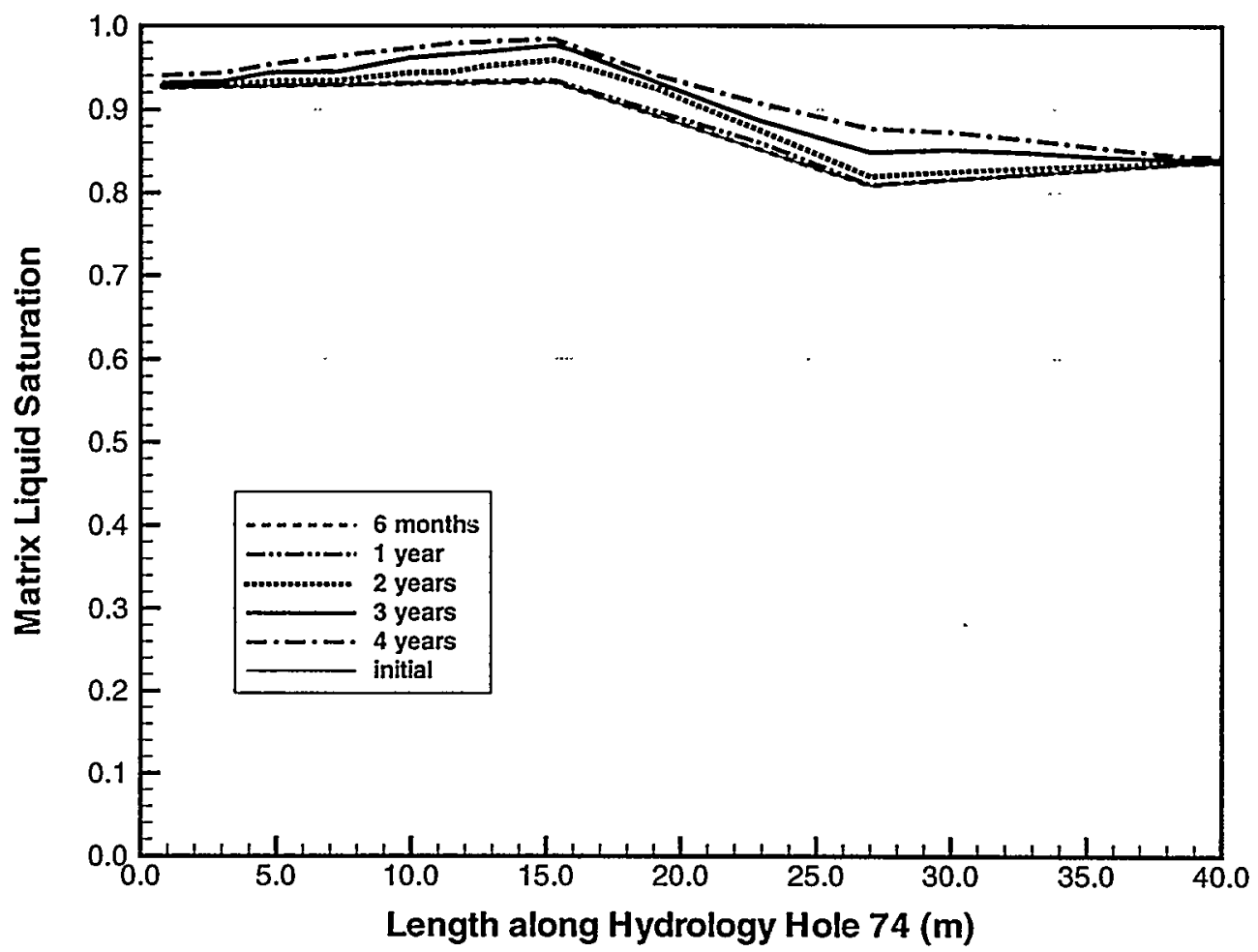

Figure A2-40 Matrix saturation profile along borehole 74 at different times during heating period for $0.36 \mathrm{~mm} / \mathrm{yr}$ infiltration case (1 year heating at 100\%, 3 years heating at $50 \%$ ).

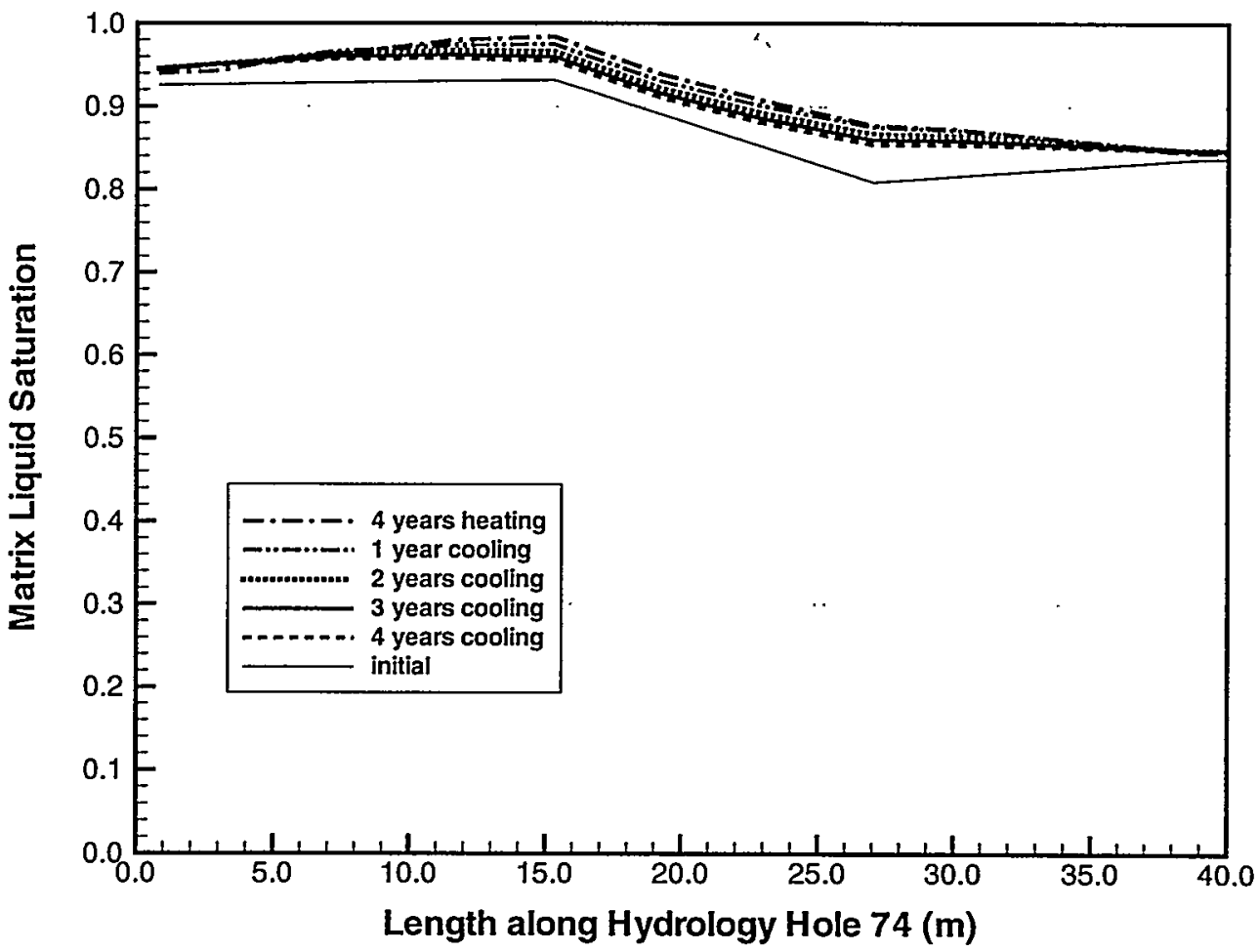

Figure A2-41 Matrix saturation profile along borehole 74 at different times during cooling period for $0.36 \mathrm{~mm} / \mathrm{yr}$ infiltration case (1 year heating at 100\%, 3 years heating at 50\%). 
Pretest Analysis of the Thermal-Hydrological Conditions of the ESF Drift Scale Test

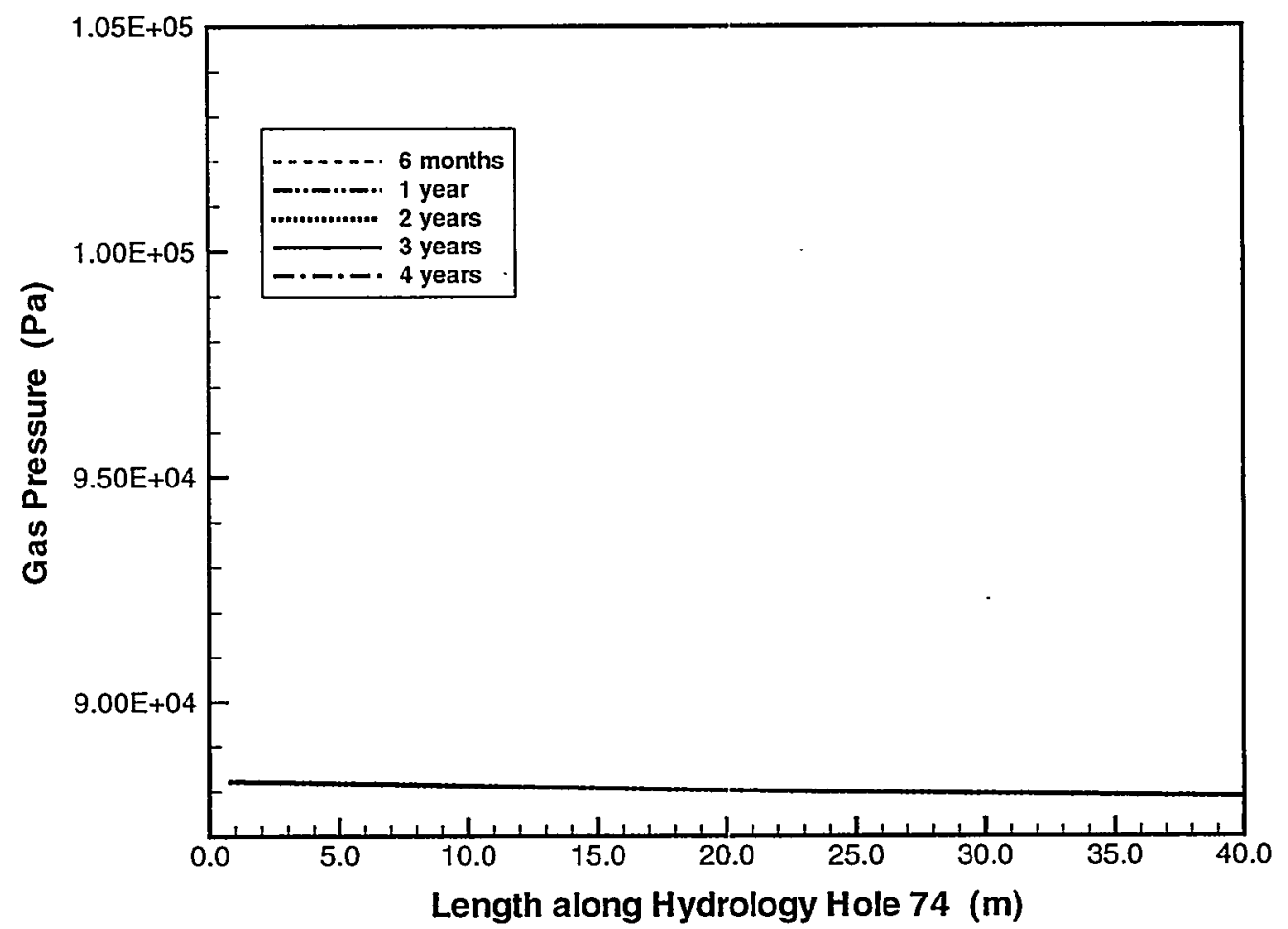

Figure A2-42 Gas pressure profile along borehole 74 at different times during heating period for $0.36 \mathrm{~mm} / \mathrm{yr}$ infiltration case (1 year heating at 100\%, 3 years heating at $50 \%$ ). 


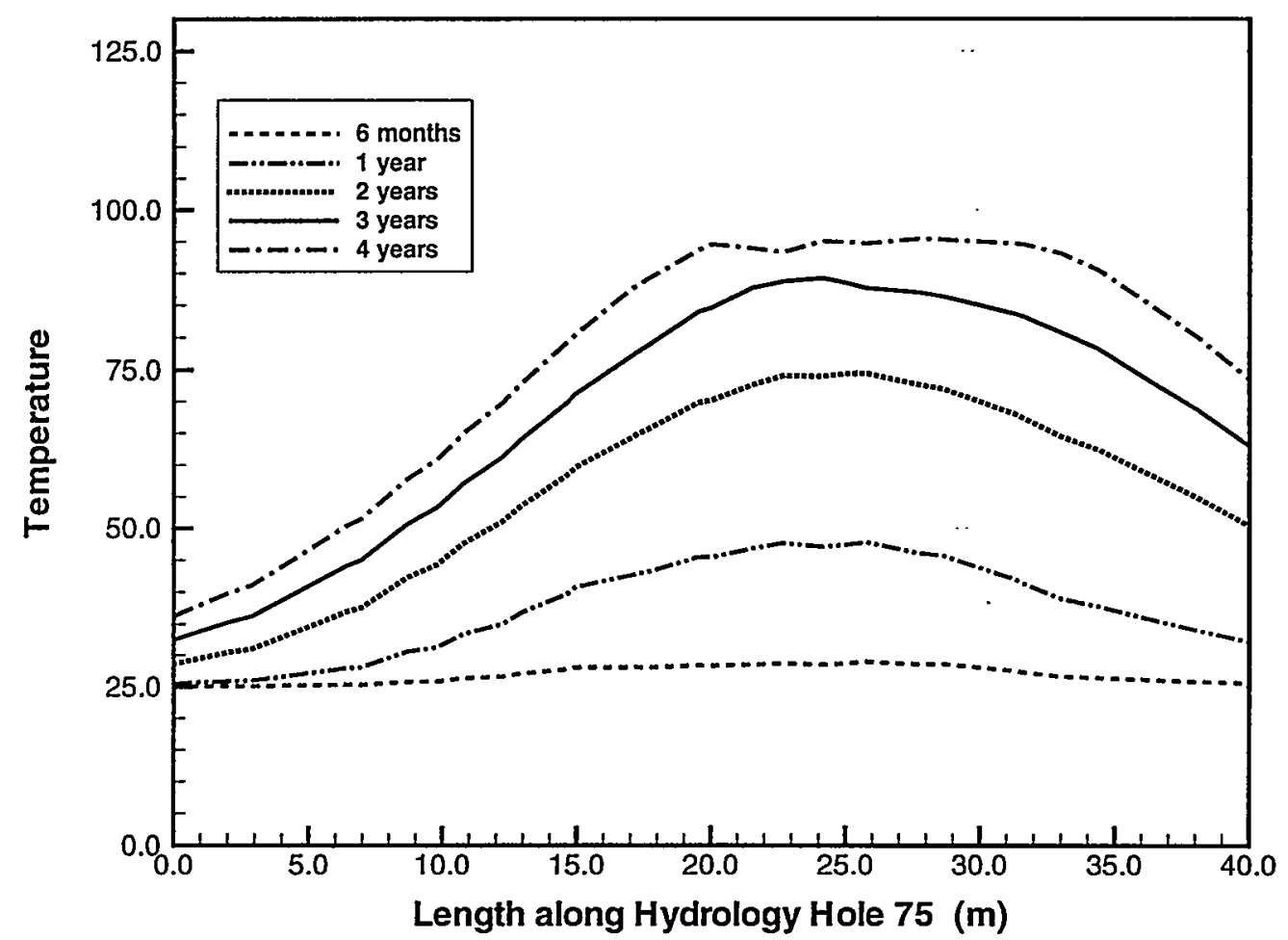

Figure A2-43 Temperature profile along borehole 75 at different times during heating period for $0.36 \mathrm{~mm} / \mathrm{yr}$ infiltration case (1 year heating at 100\%, 3 years heating at 50\%).

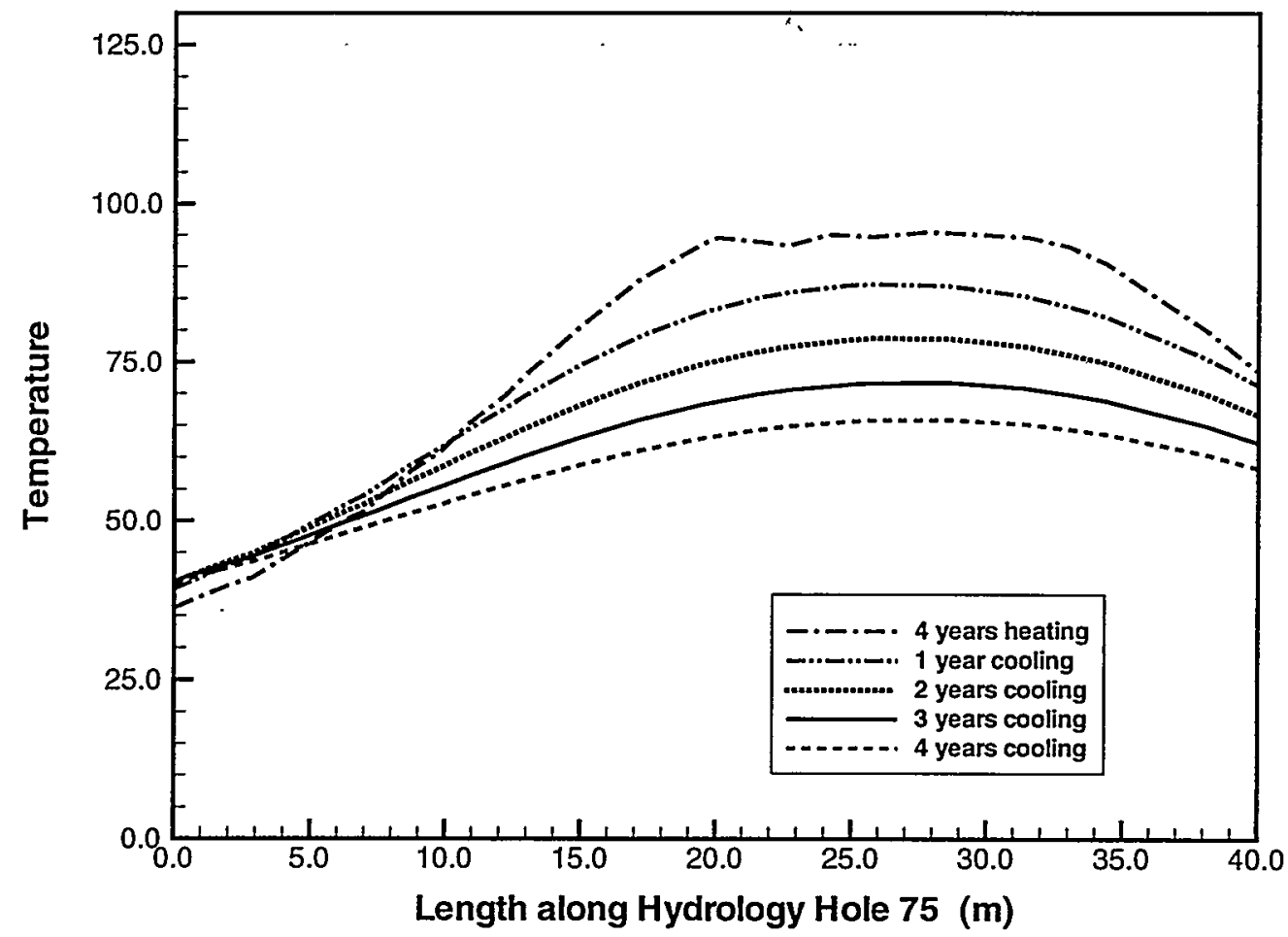

Figure A2-44 Temperature profile along borehole 75 at different times during cooling period for $0.36 \mathrm{~mm} / \mathrm{yr}$ infiltration case (1 year heating at 100\%, 3 years heating at $50 \%$ ). 


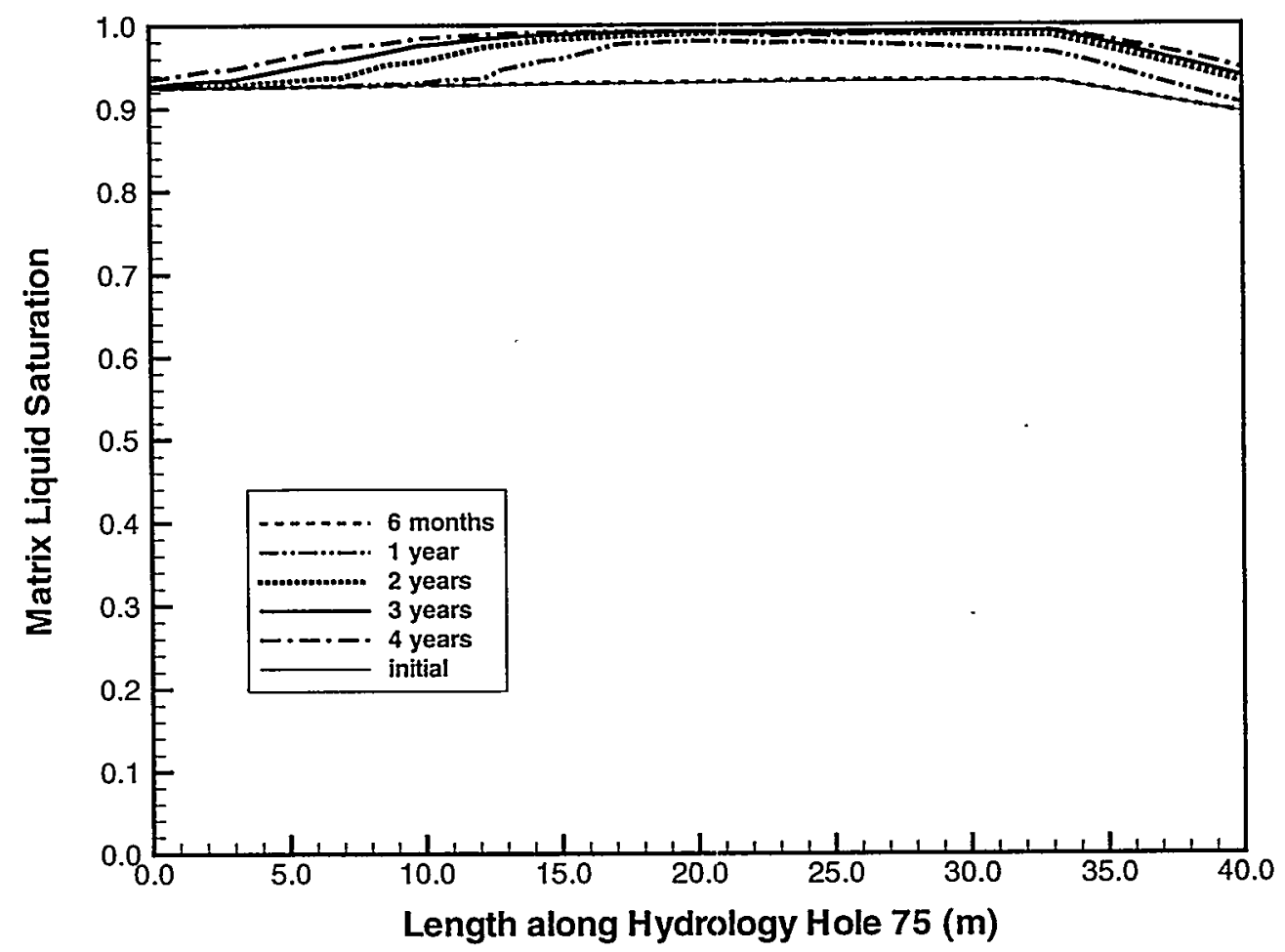

Figure A2-45 Matrix saturation profile along borehole 75 at different times during heating period for $0.36 \mathrm{~mm} / \mathrm{yr}$ infiltration case ( 1 year heating at 100\%, 3 years heating at $50 \%$ ).

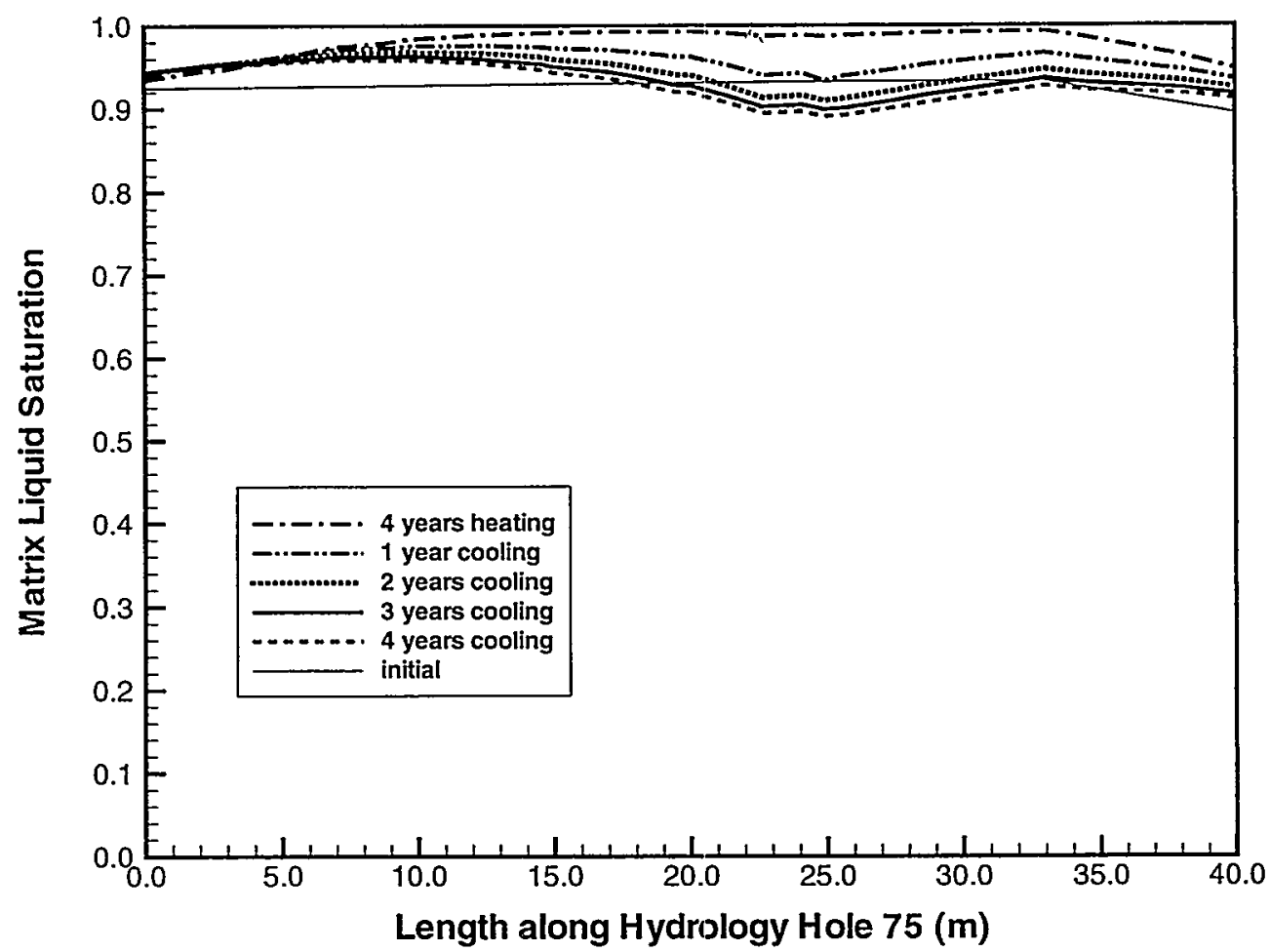

Figure A2-46 Matrix saturation profile along borehole 75 at different times during cooling period for $0.36 \mathrm{~mm} / \mathrm{yr}$ infiltration case (1 year heating at 100\%, 3 years heating at 50\%). 


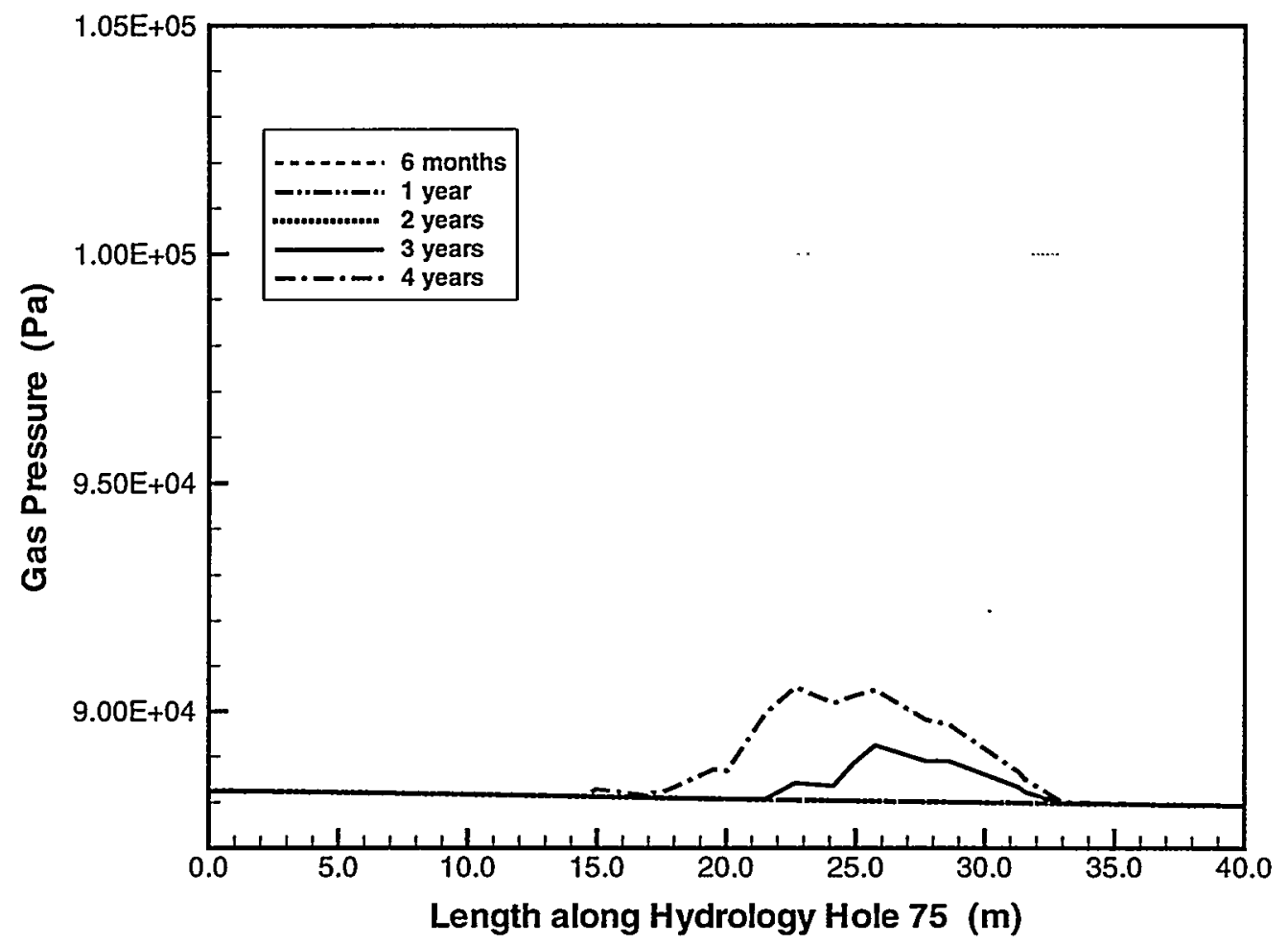

Figure A2-47 Gas pressure profile along borehole 75 at different times during heating period for $0.36 \mathrm{~mm} / \mathrm{yr}$ infiltration case (1 year heating at 100\%, 3 years heating at 50\%). 


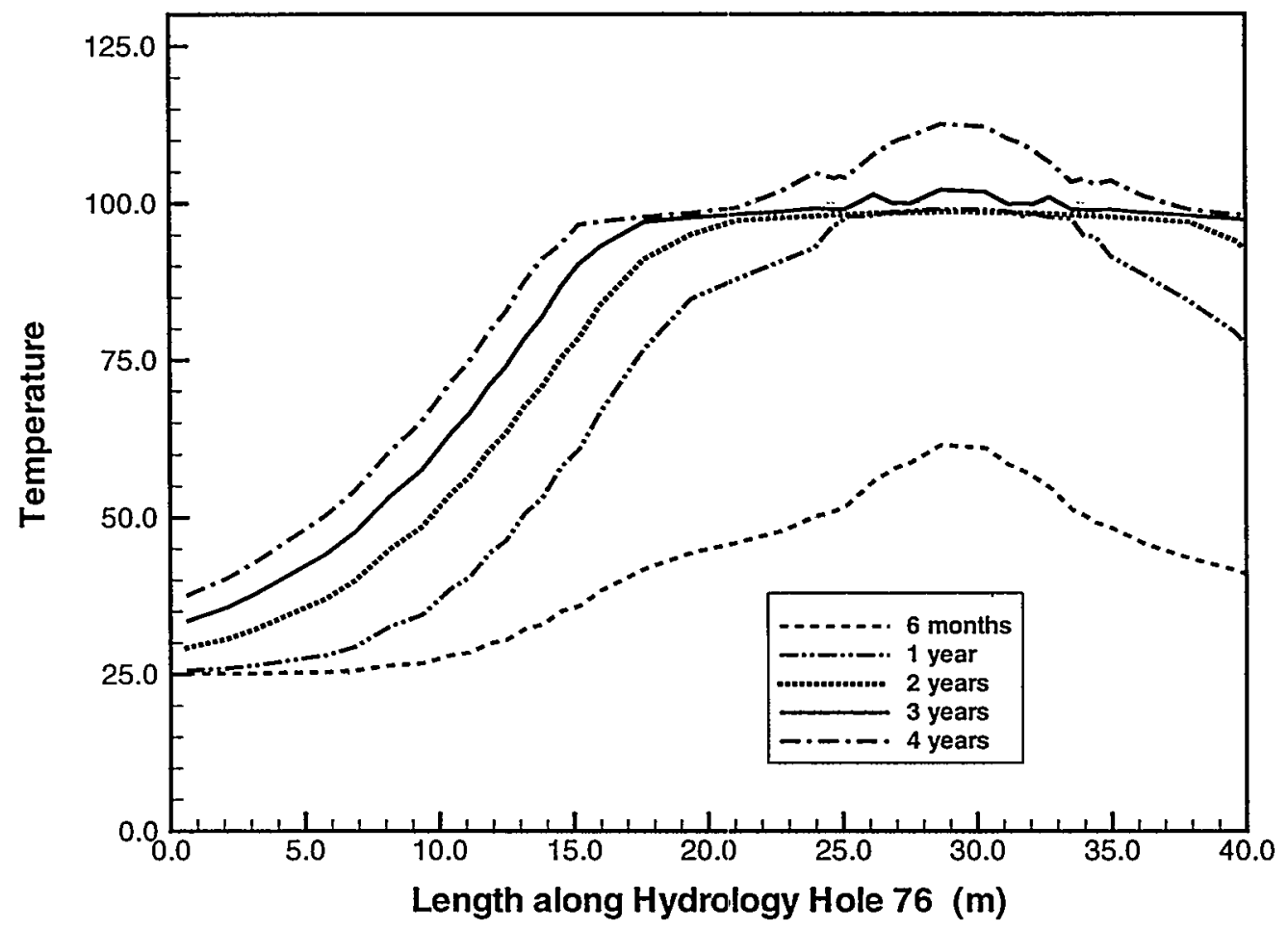

Figure A2-48 Temperature profile along borehole 76 at different times during heating period for $0.36 \mathrm{~mm} / \mathrm{yr}$ infiltration case (1 year heating at 100\%, 3 years heating at 50\%).

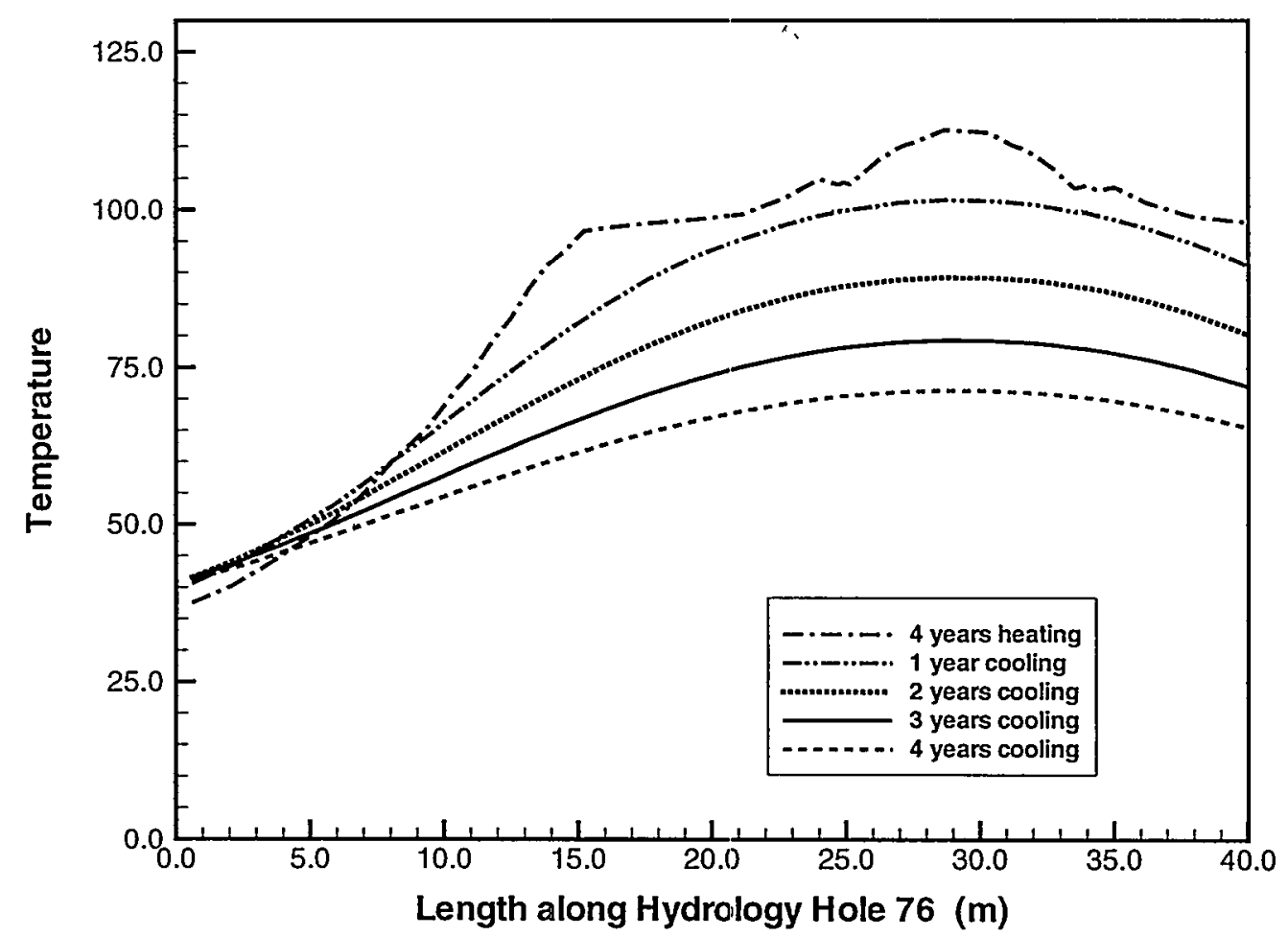

Figure A2-49 Temperature profile along borehole 76 at different times during cooling period for $0.36 \mathrm{~mm} / \mathrm{yr}$ infiltration case (I year heating at 100\%, 3 years heating at $50 \%$ ). 


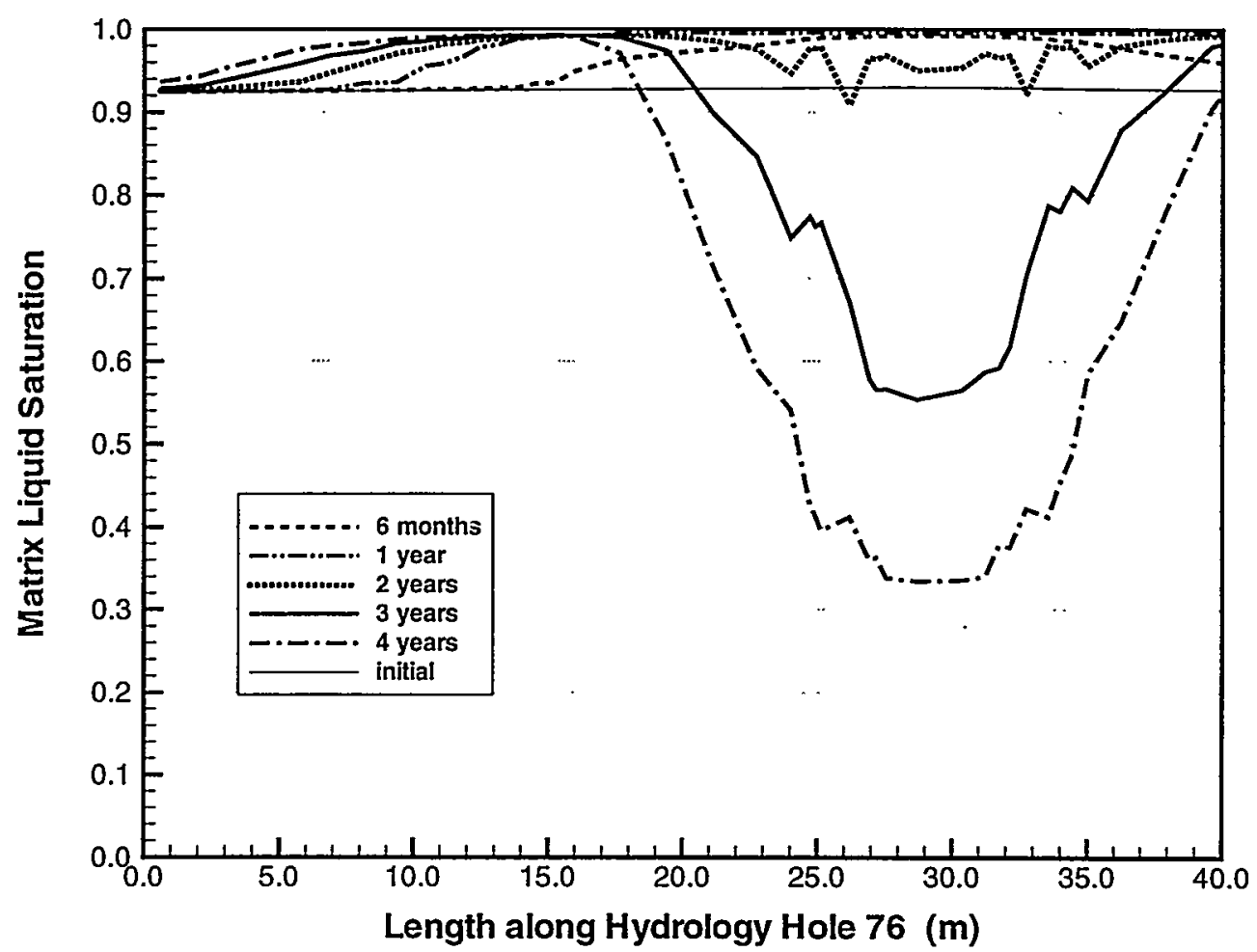

Figure A2-50 Matrix saturation profile along borehole 76 at different times during heating period for $0.36 \mathrm{~mm} / \mathrm{yr}$ infiltration case (1 year heating at 100\%, 3 years heating at 50\%).

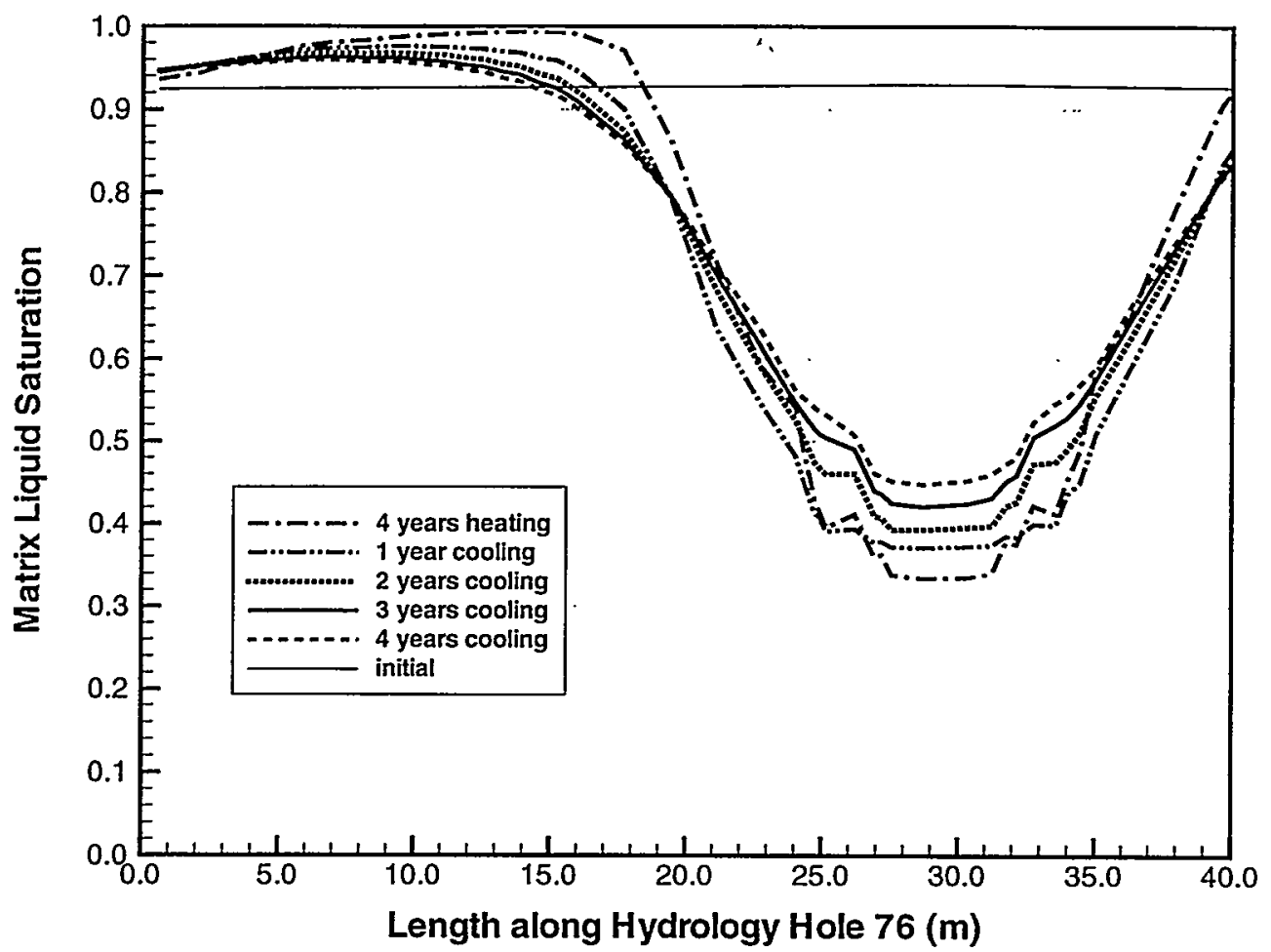

Figure A2-5I Matrix saturation profile along borehole 76 at different times during cooling period for $0.36 \mathrm{~mm} / \mathrm{yr}$ infiltration case (1 year heating at 100\%, 3 years heating at 50\%). 
Pretest Analysis of the Thermal-Hydrological Conditions of the ESF Drift Scale Test

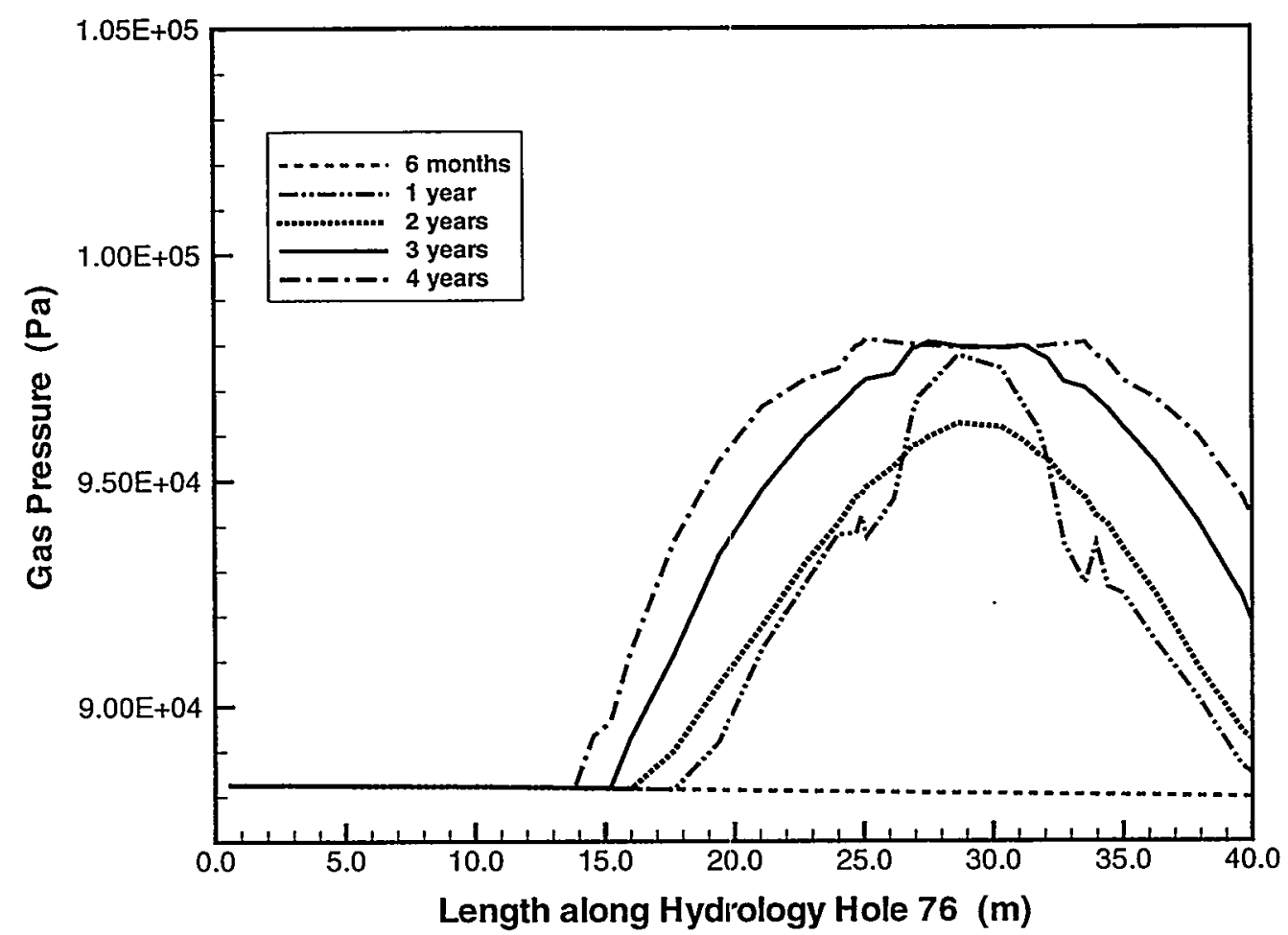

Figure A2-52 Gas pressure profile along borehole 76 at different times during heating period for $0.36 \mathrm{~mm} / \mathrm{yr}$ infiltration case (1 year heating at 100\%, 3 years heating at $50 \%$ ). 


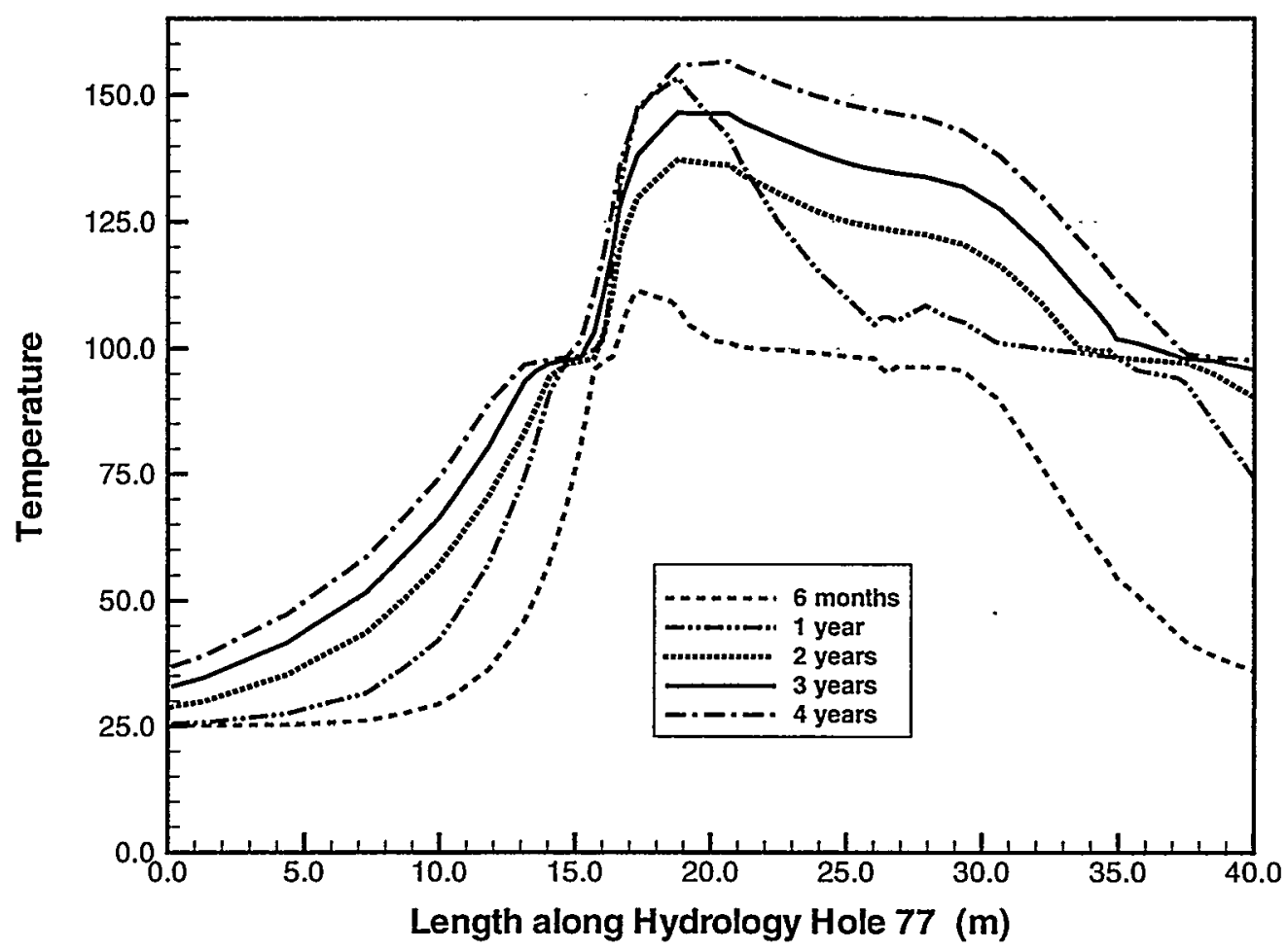

Figure A2-53 Temperature profile along borehole 77 at different times during heating period for $0.36 \mathrm{~mm} / \mathrm{yr}$ infiltration case (1 year heating at 100\%, 3 years heating at 50\%).

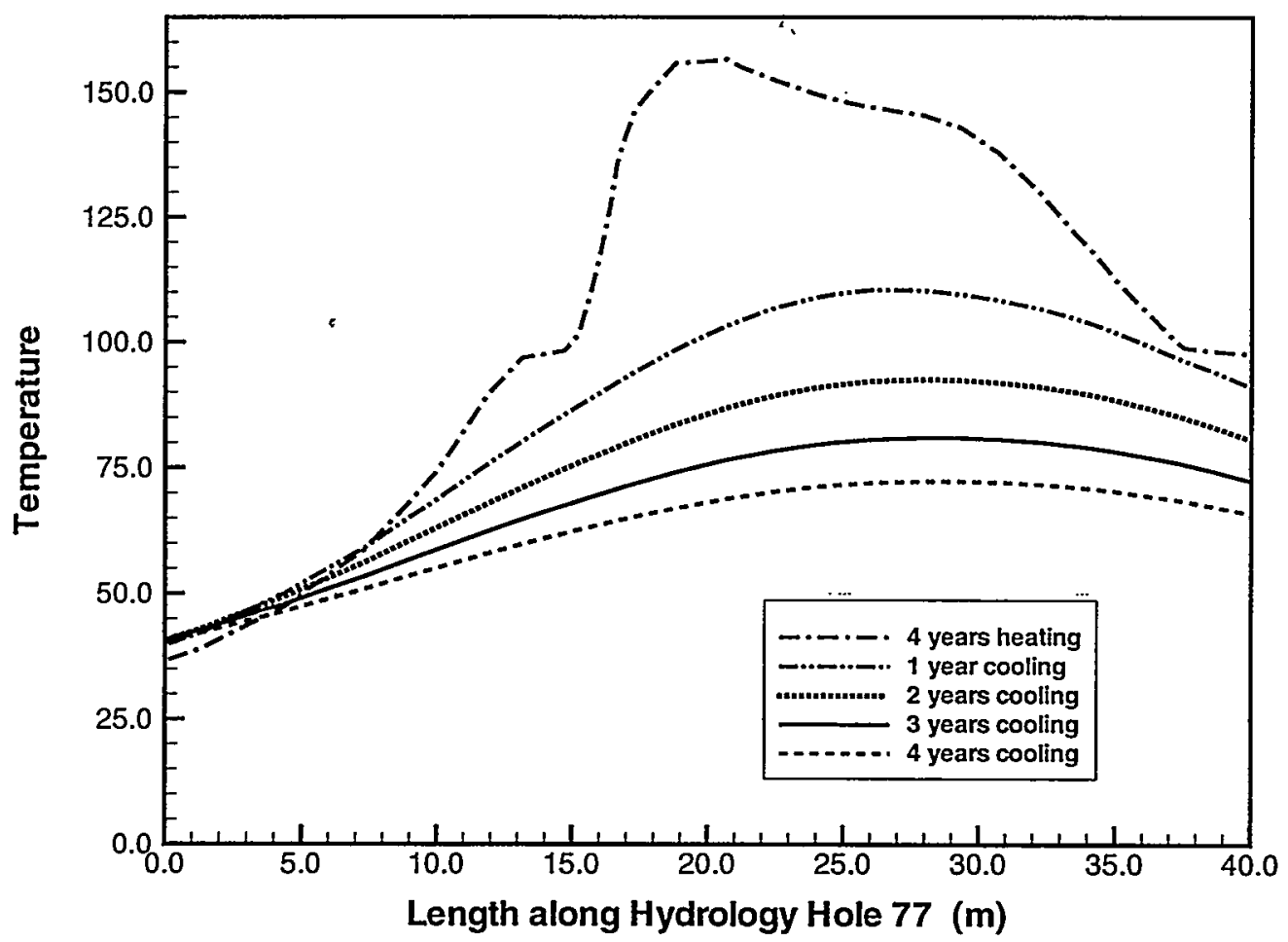

Figure A2-54 Temperature profile along borehole 77 at different times during cooling period for $0.36 \mathrm{~mm} / \mathrm{yr}$ infiltration case (1 year heating at 100\%, 3 years heating at 50\%). 


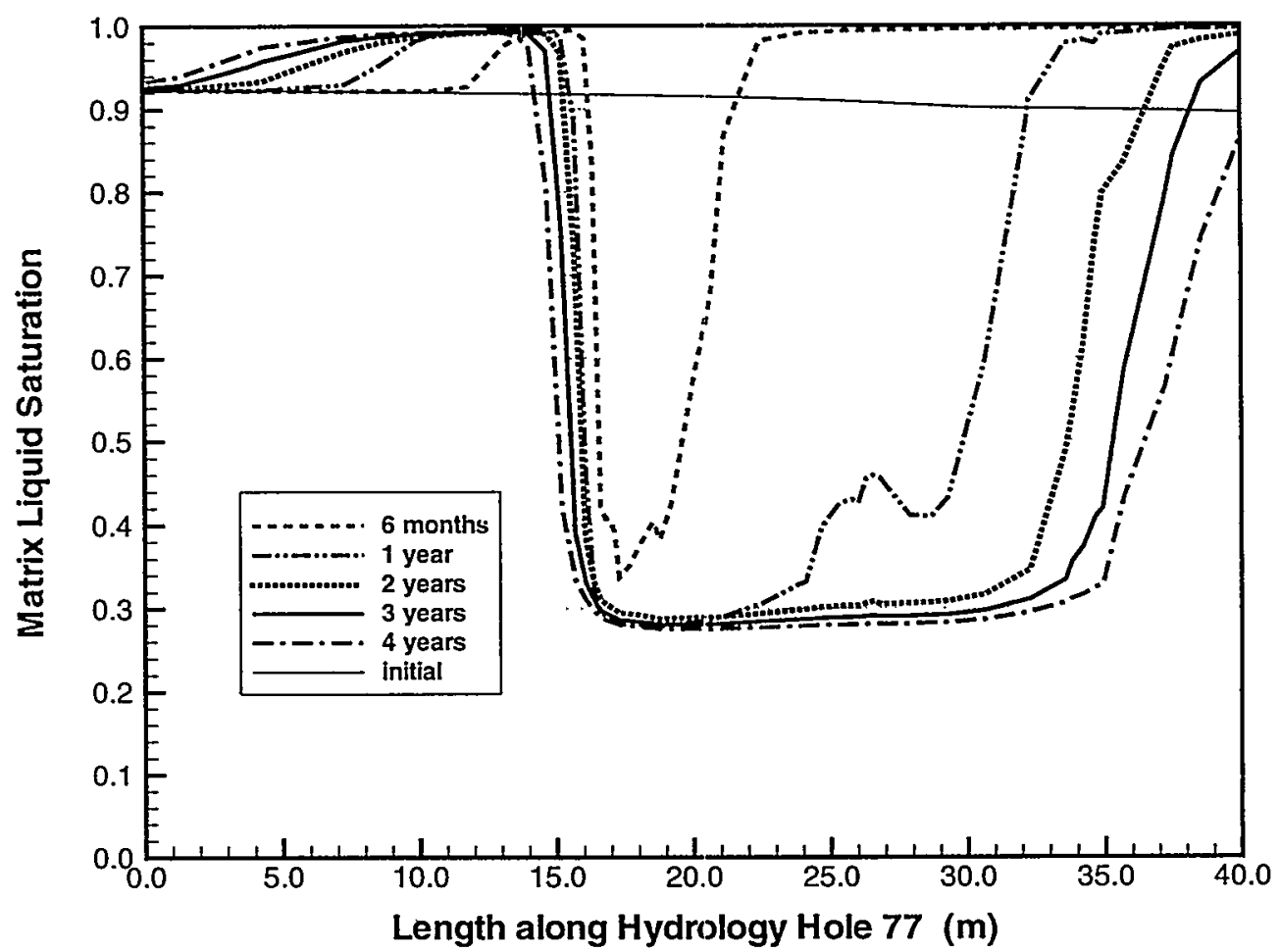

Figure A2-55 Matrix saturation profile along borehole 77 at different times during heating period for $0.36 \mathrm{~mm} / \mathrm{yr}$ infiltration case (1 year heating at 100\%, 3 years heating at $50 \%$ ).

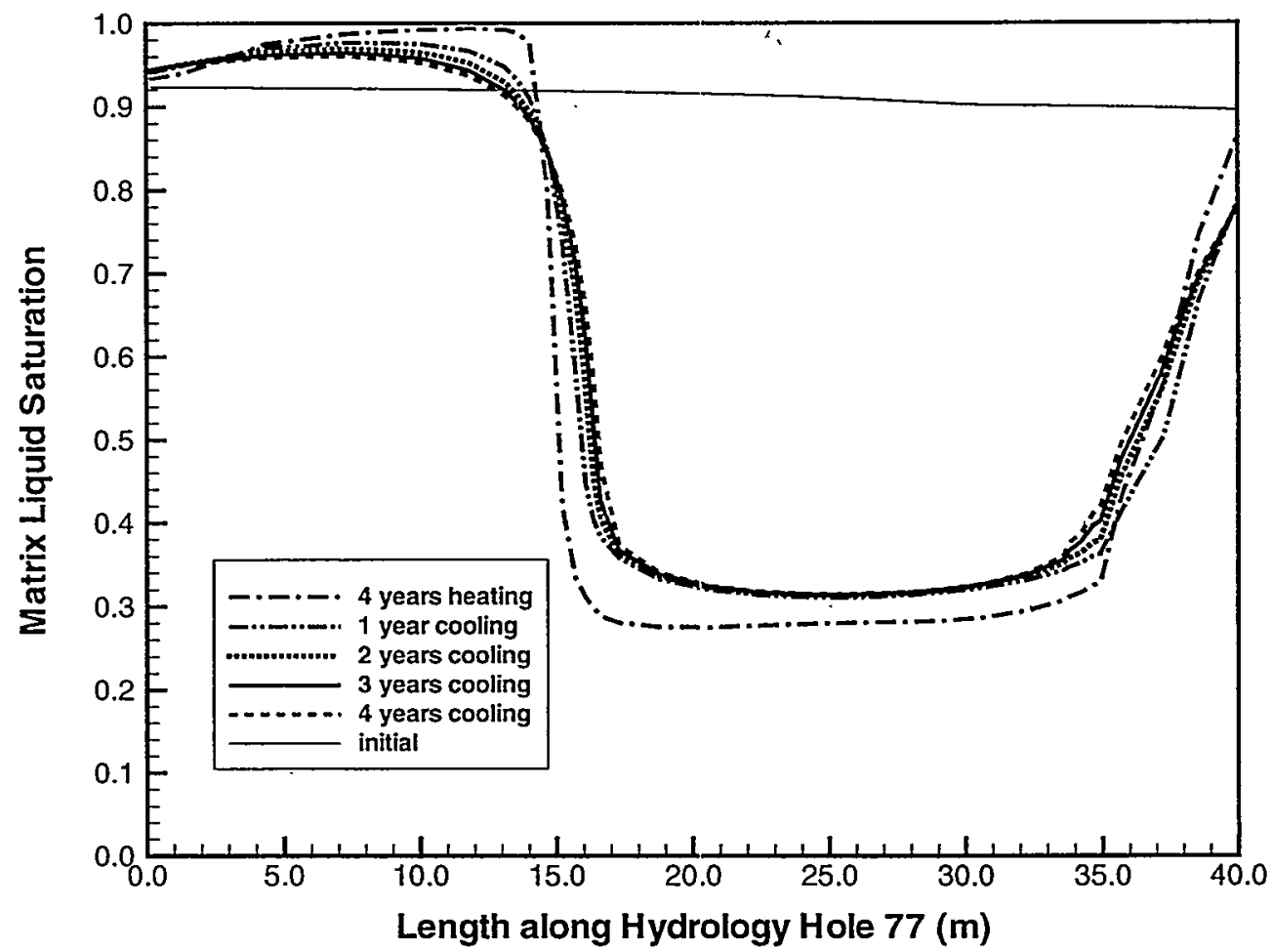

Figure A2-56 Matrix saturation profile along borehole 77 at different times during cooling period for $0.36 \mathrm{~mm} / \mathrm{yr}$ infiltration case (1 year heating at 100\%, 3 years heating at $50 \%$ ). 


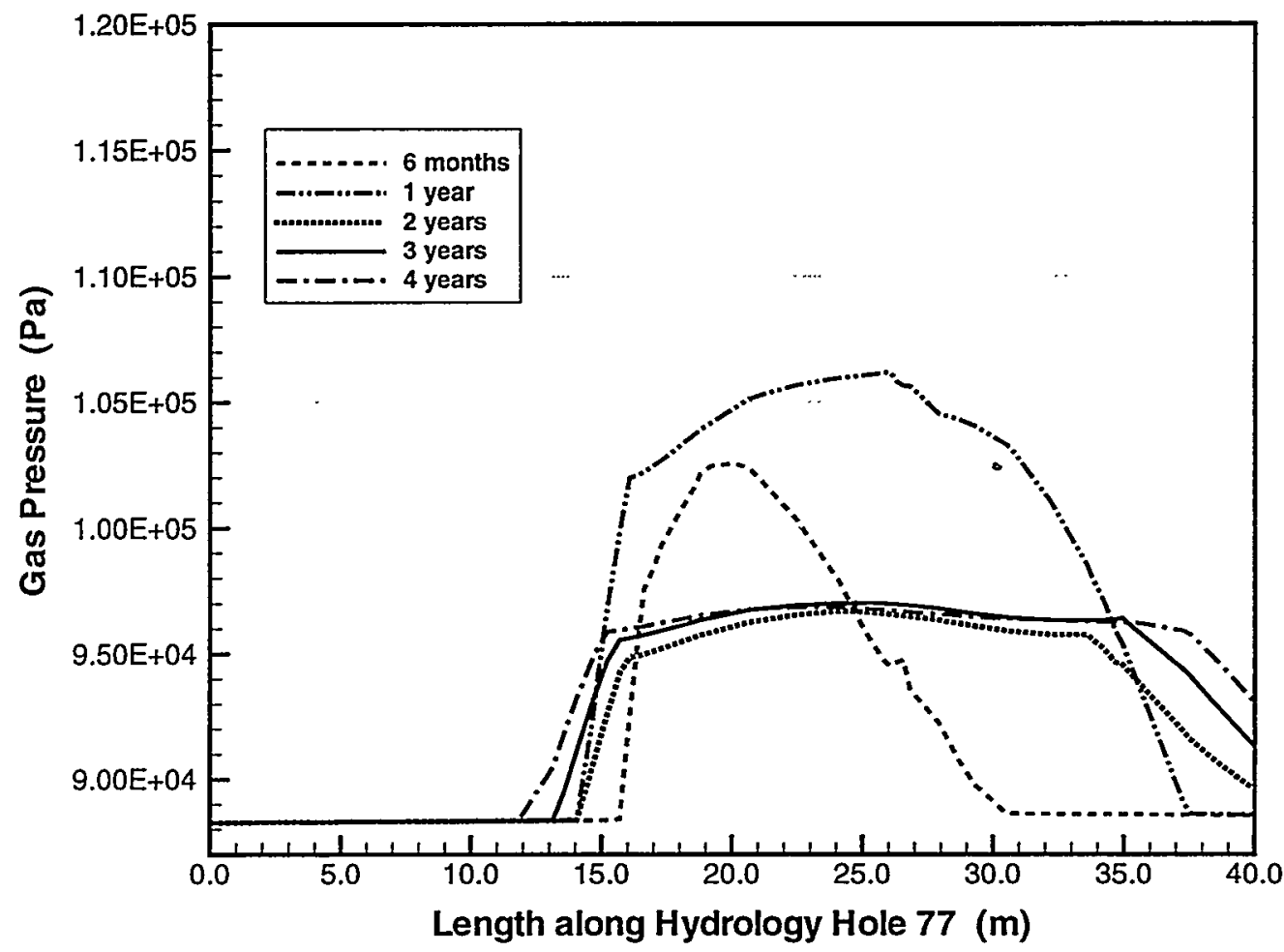

Figure A2-57 Gas pressure profile along borehole 77 at different times during heating period for $0.36 \mathrm{~mm} / \mathrm{yr}$ infiltration case (1 year heating at 100\%, 3 years heating at 50\%). 


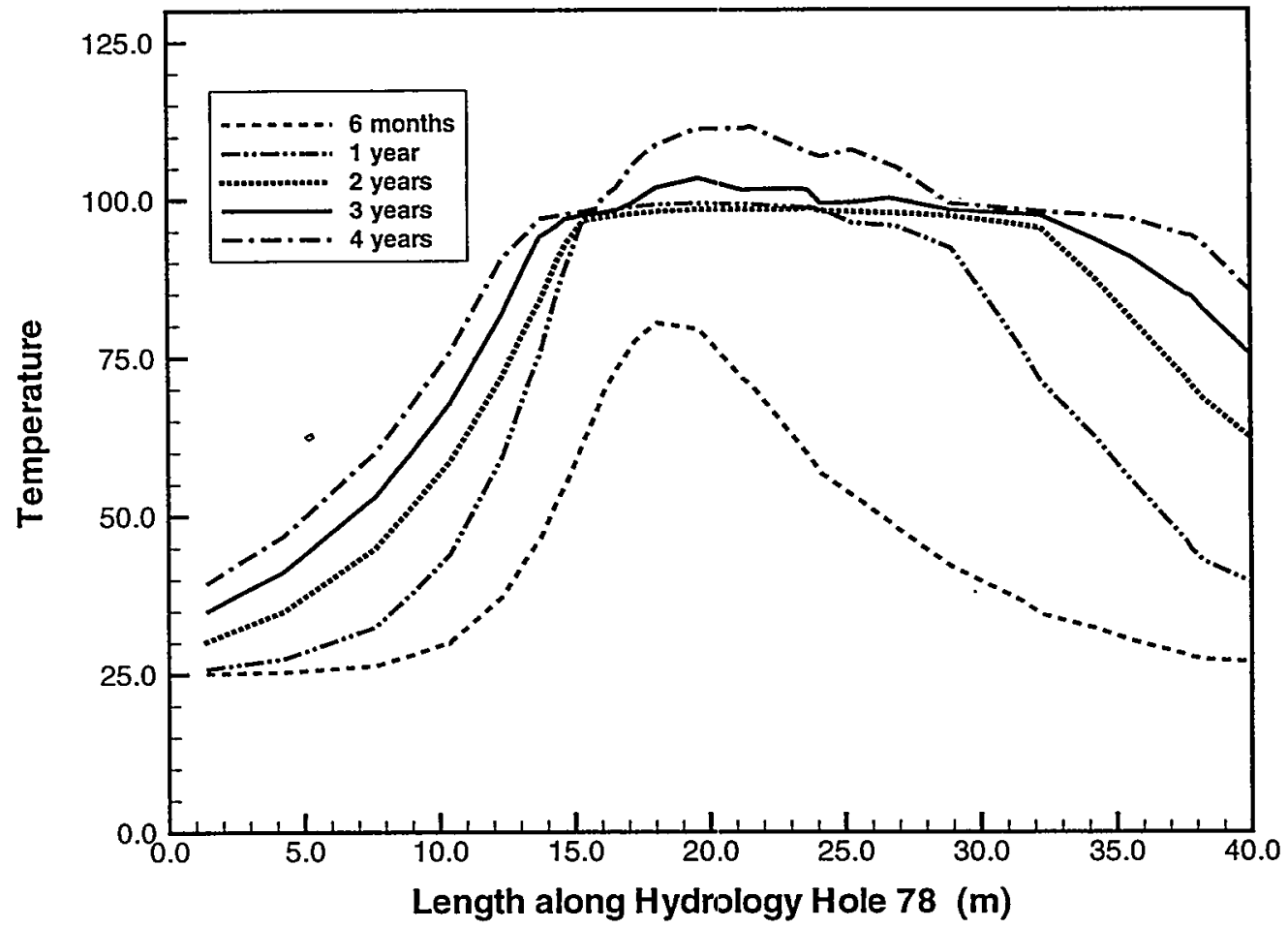

Figure A2-58 Temperature profile along borehole 78 at different times during heating period for $0.36 \mathrm{~mm} / \mathrm{yr}$ infiltration case (1 year heating at 100\%, 3 years heating at 50\%)

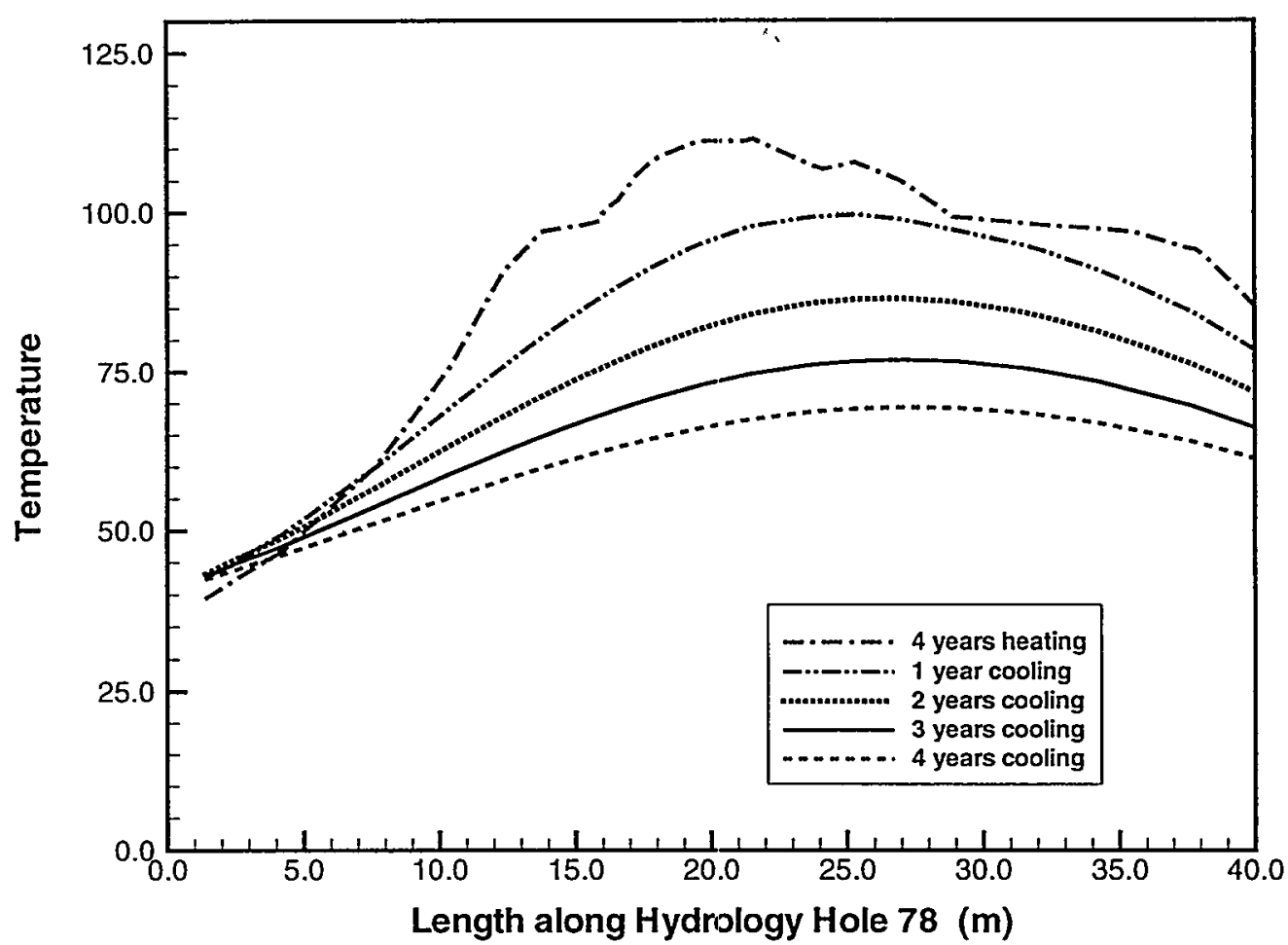

Figure A2-59 Temperature profile along borehole 78 at different times during cooling period for $0.36 \mathrm{~mm} / \mathrm{yr}$ infiltration case (1 year heating at 100\%, 3 years heating at 50\%). 


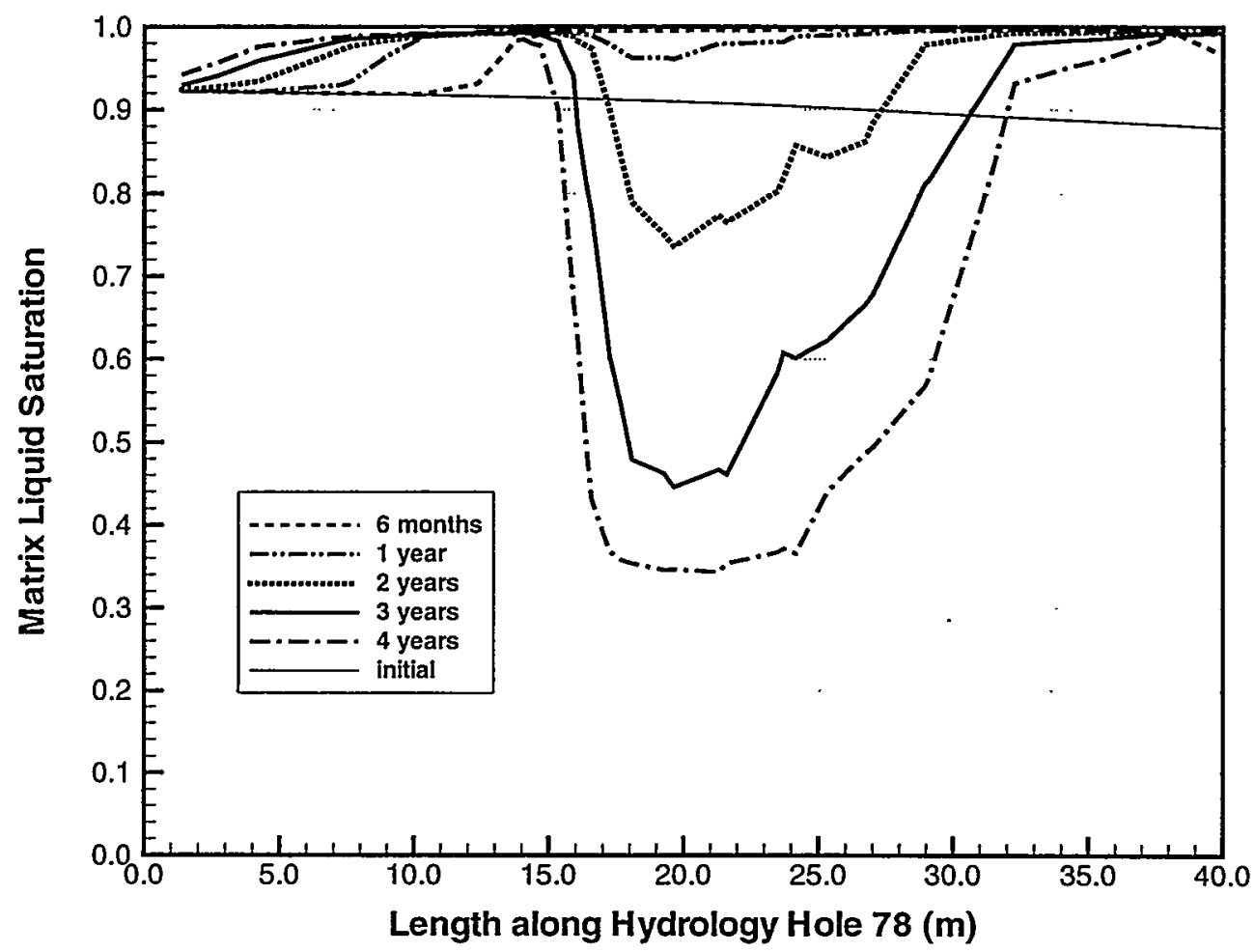

Figure A2-60 Matrix saturation profile.along borehole 78 at different times during heating period for $0.36 \mathrm{~mm} / \mathrm{yr}$ infiltration case (1 year heating at 100\%, 3 years heating at $50 \%$ ).

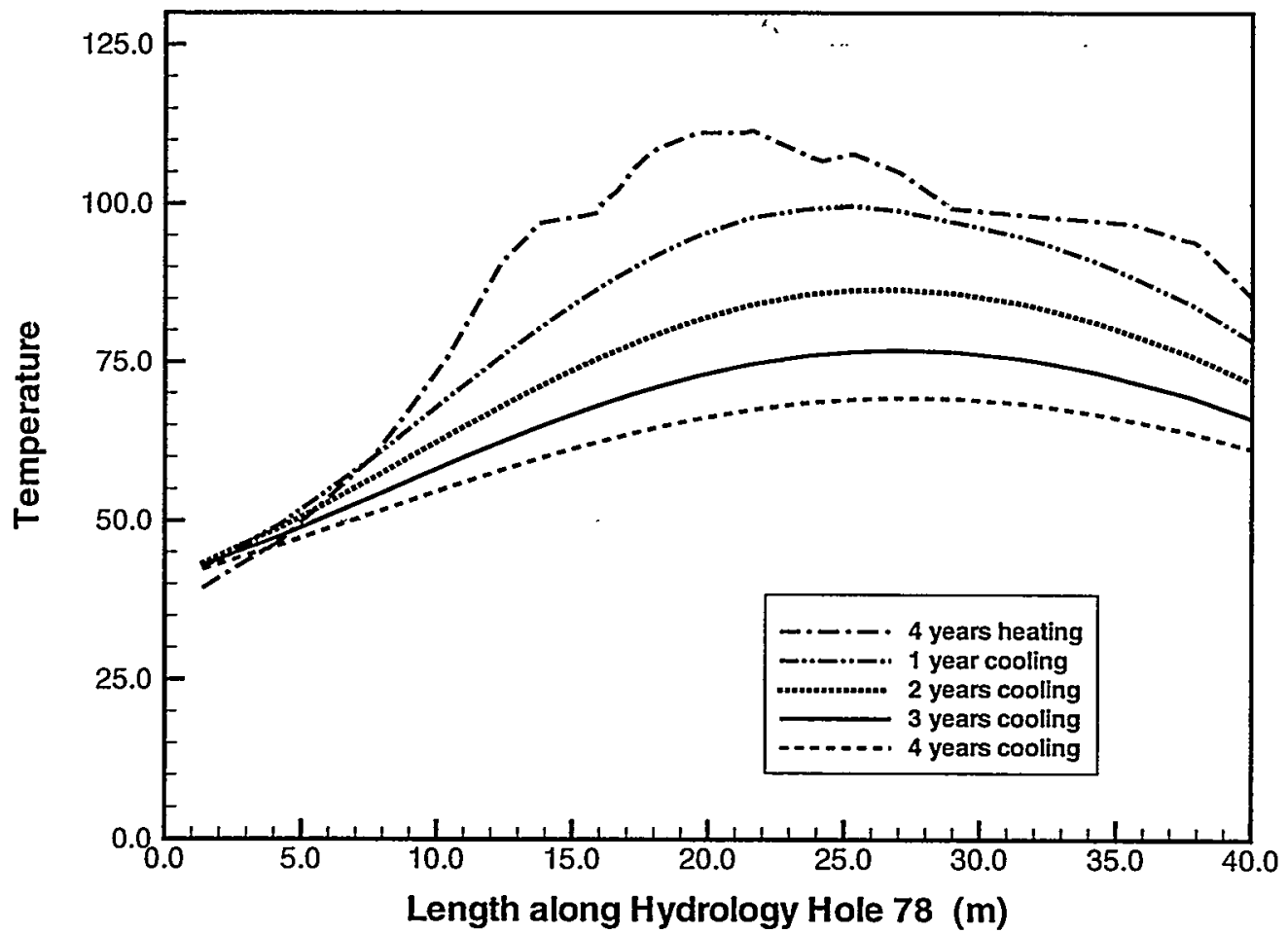

Figure A2-61 Matrix saturation profile along borehole 78 at different times during cooling period for $0.36 \mathrm{~mm} / \mathrm{yr}$ infiltration case (1 year heating at 100\%, 3 years heating at $50 \%$ ). 
Pretest Analysis of the Thermal-Hydrological Conditions of the ESF Drift Scale Test

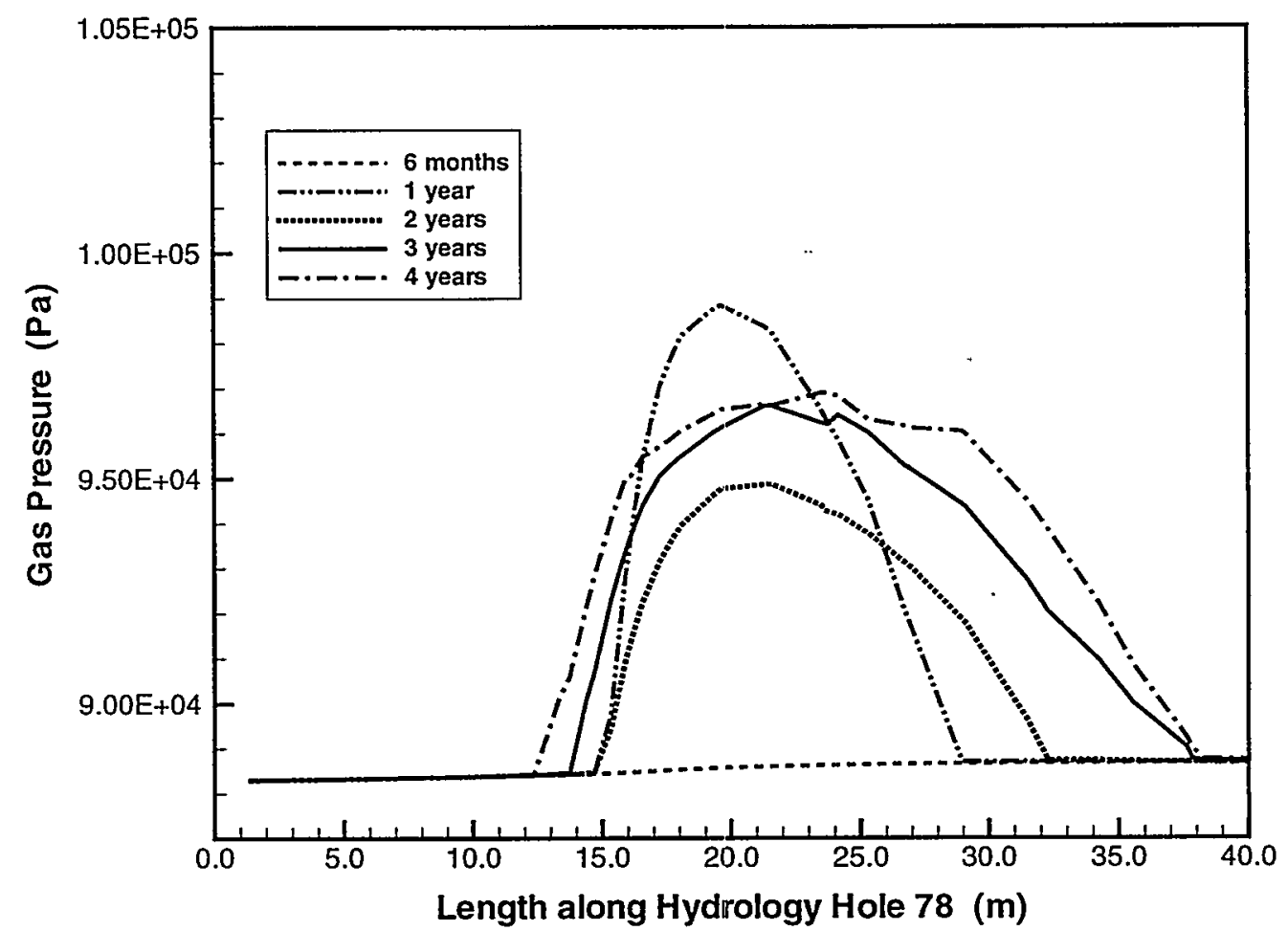

Figure A2-62 Gas pressure profile along borehole 78 at different times during heating period for $0.36 \mathrm{~mm} / \mathrm{yr}$ infiltration case (1 year heating at 100\%, 3 years heating at 50\%). 


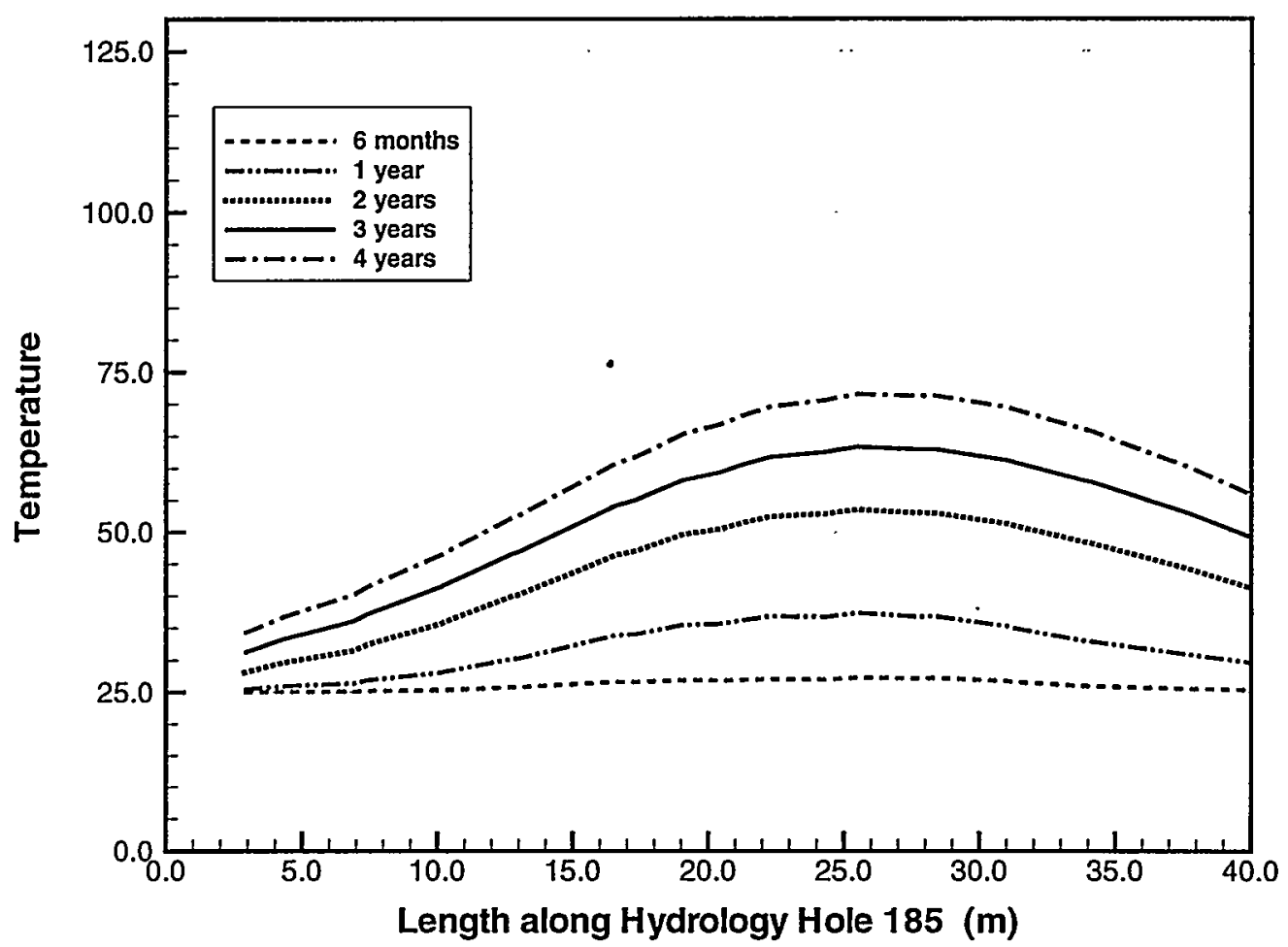

Figure A2-63 Temperature profile along borehole 185 at different times during heating period for $0.36 \mathrm{~mm} / \mathrm{yr}$ infiltration case (1 year heating at 100\%, 3 years heating at $50 \%$ ).

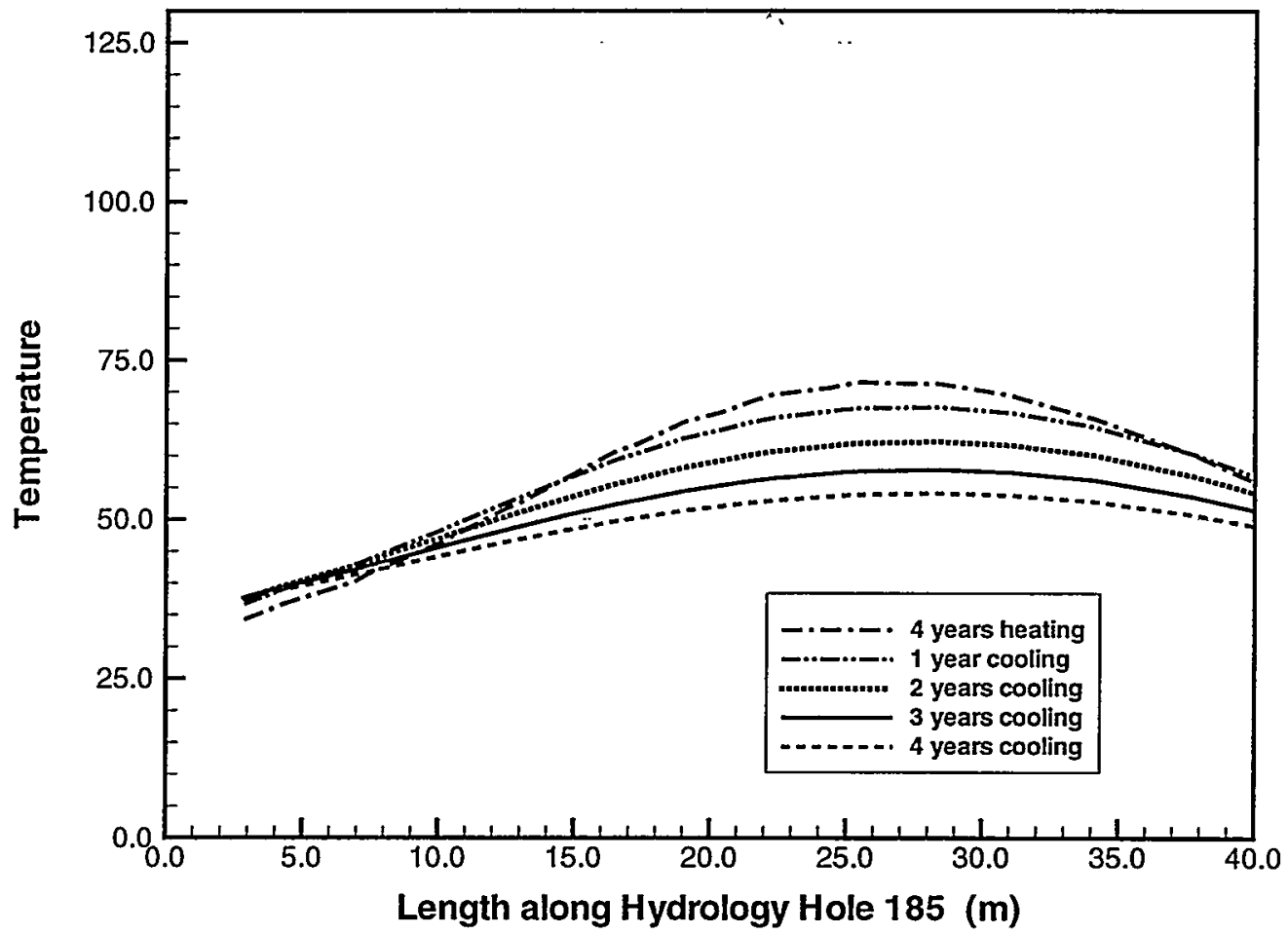

Figure A2-64 Temperature profile along borehole 185 at different times during cooling period for $0.36 \mathrm{~mm} / \mathrm{yr}$ infiltration case ( 1 year heating at 100\%, 3 years heating at $50 \%$ ). 


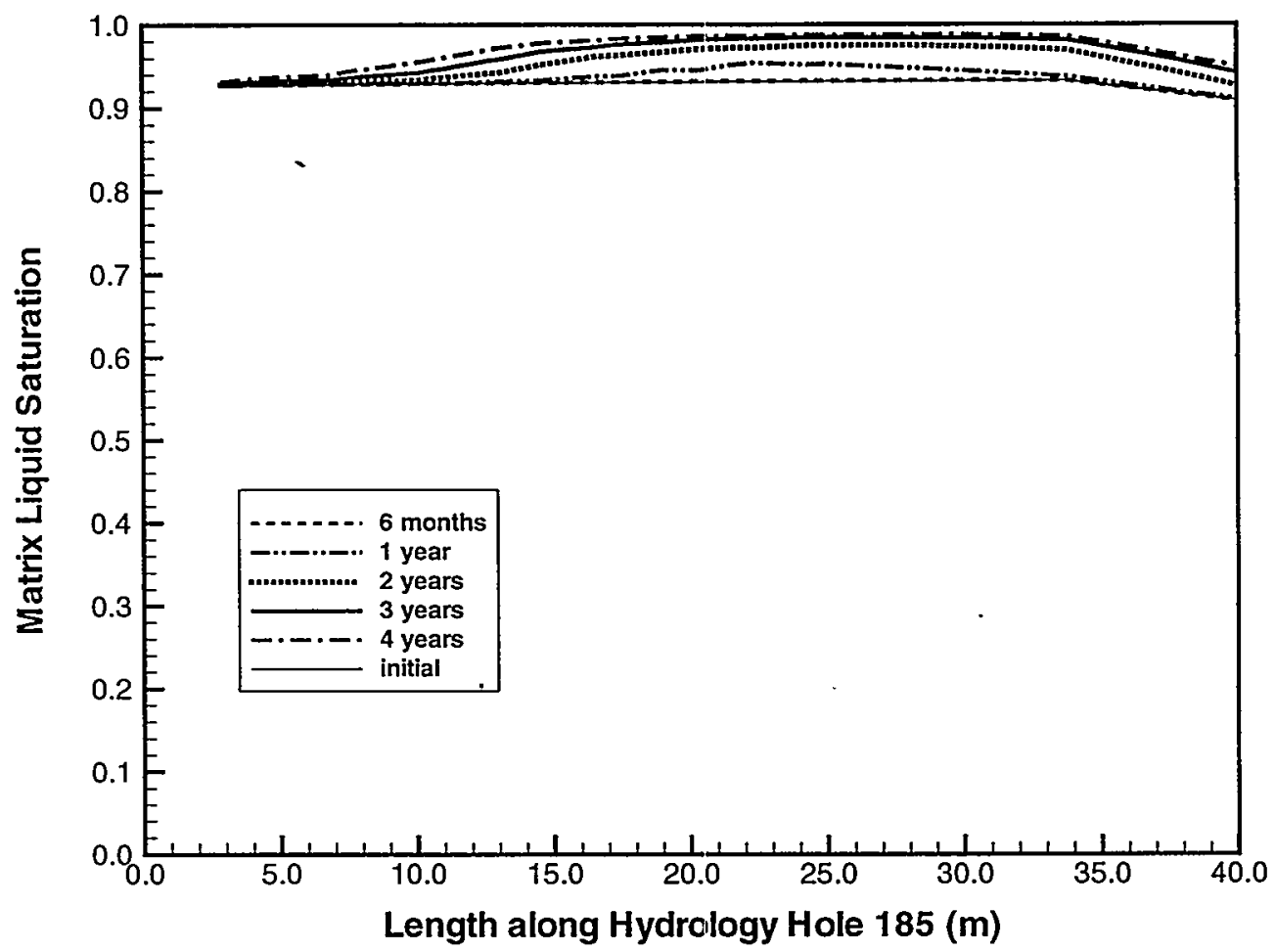

Figure A2-65 Matrix saturation profile along borehole 185 at different times during heating period for $0.36 \mathrm{~mm} / \mathrm{yr}$ infiltration case (1 year heating at $100 \%, 3$ years heating at $50 \%$ ).

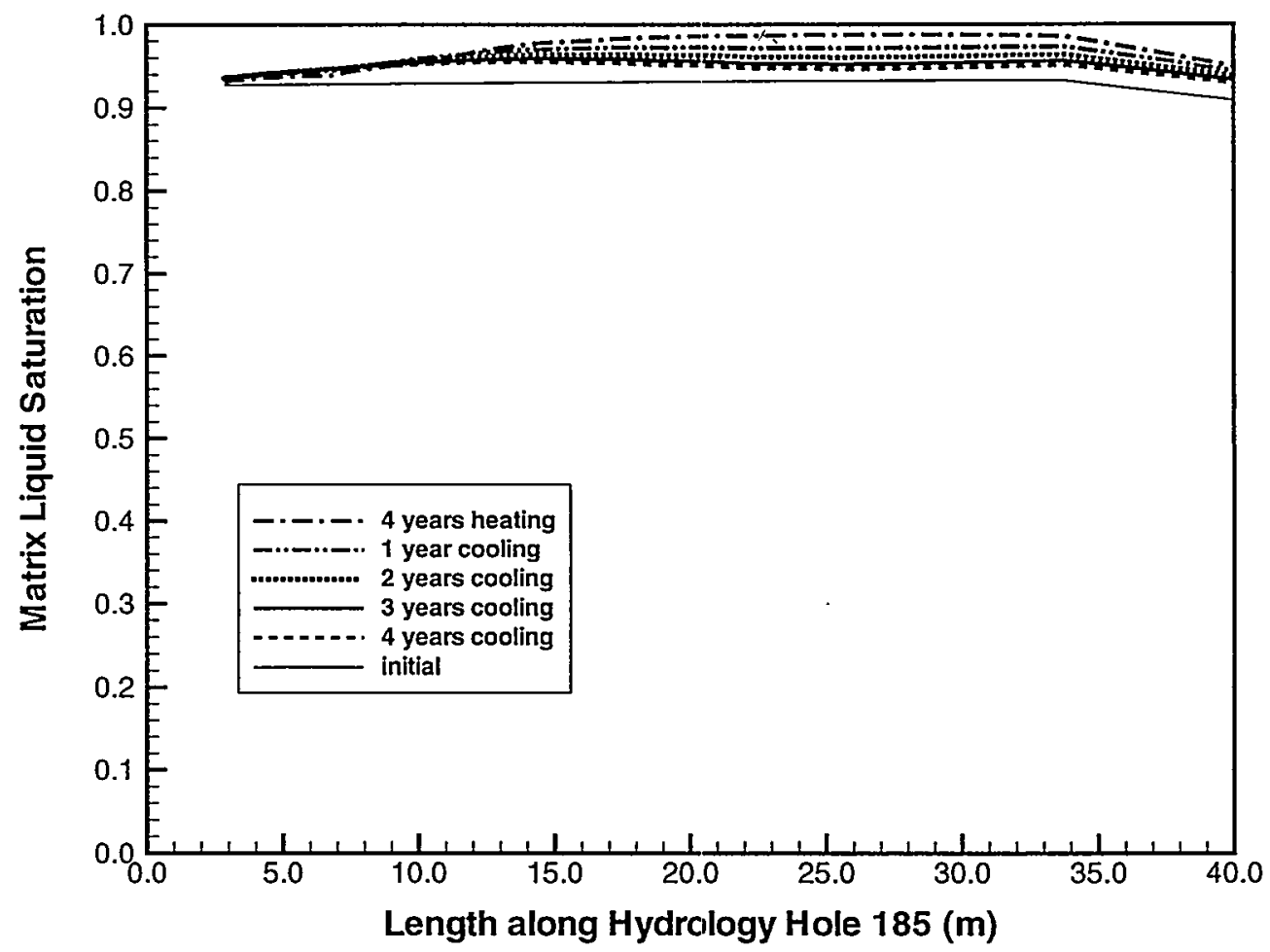

Figure A2-66 Matrix saturation profile along borehole 185 at different times during cooling period for $0.36 \mathrm{~mm} / \mathrm{yr}$ infiltration case (1 year heating at 100\%, 3 years heating at $50 \%$ ). 


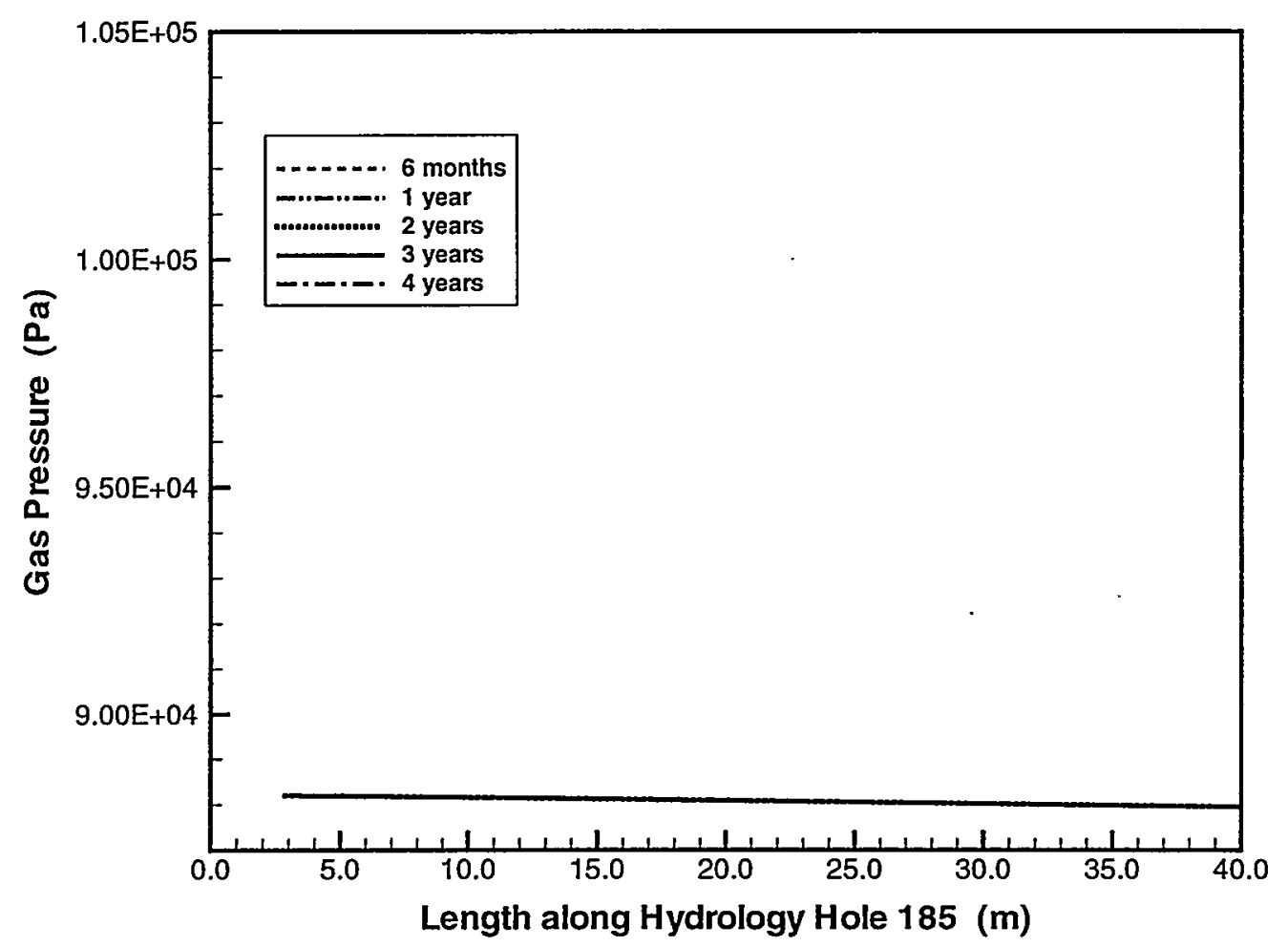

Figure A2-67 Gas pressure profile along borehole 185 at different times during heating period for $0.36 \mathrm{~mm} / \mathrm{yr}$ infiltration case (1 year heating at 100\%, 3 heating years heating at $50 \%$ ). 


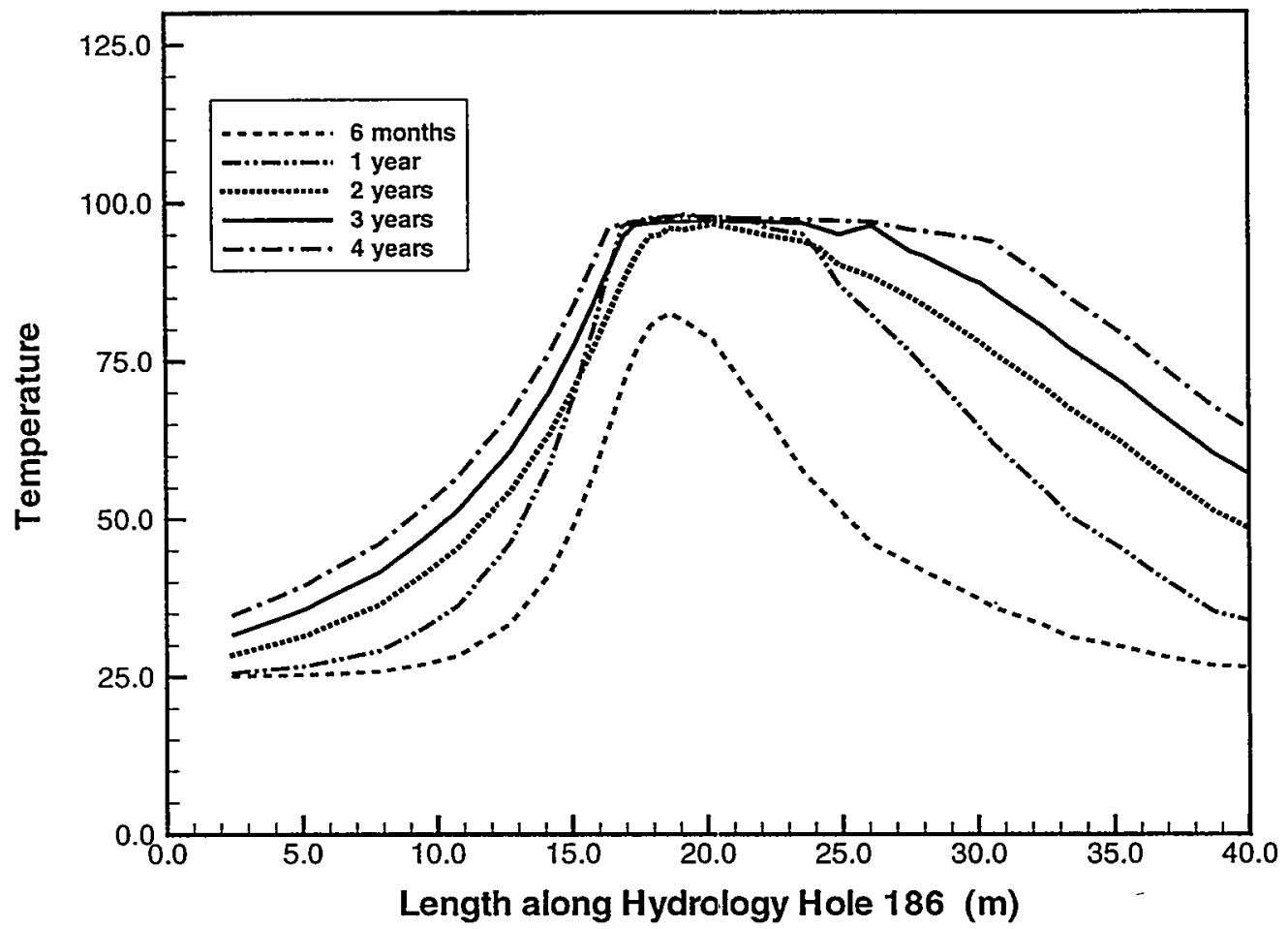

Figure A2-68 Temperature profile along borehole 186 at different times during heating period for $0.36 \mathrm{~mm} / \mathrm{yr}$ infiltration case (1 year heating at 100\%, 3 years heating at 50\%).

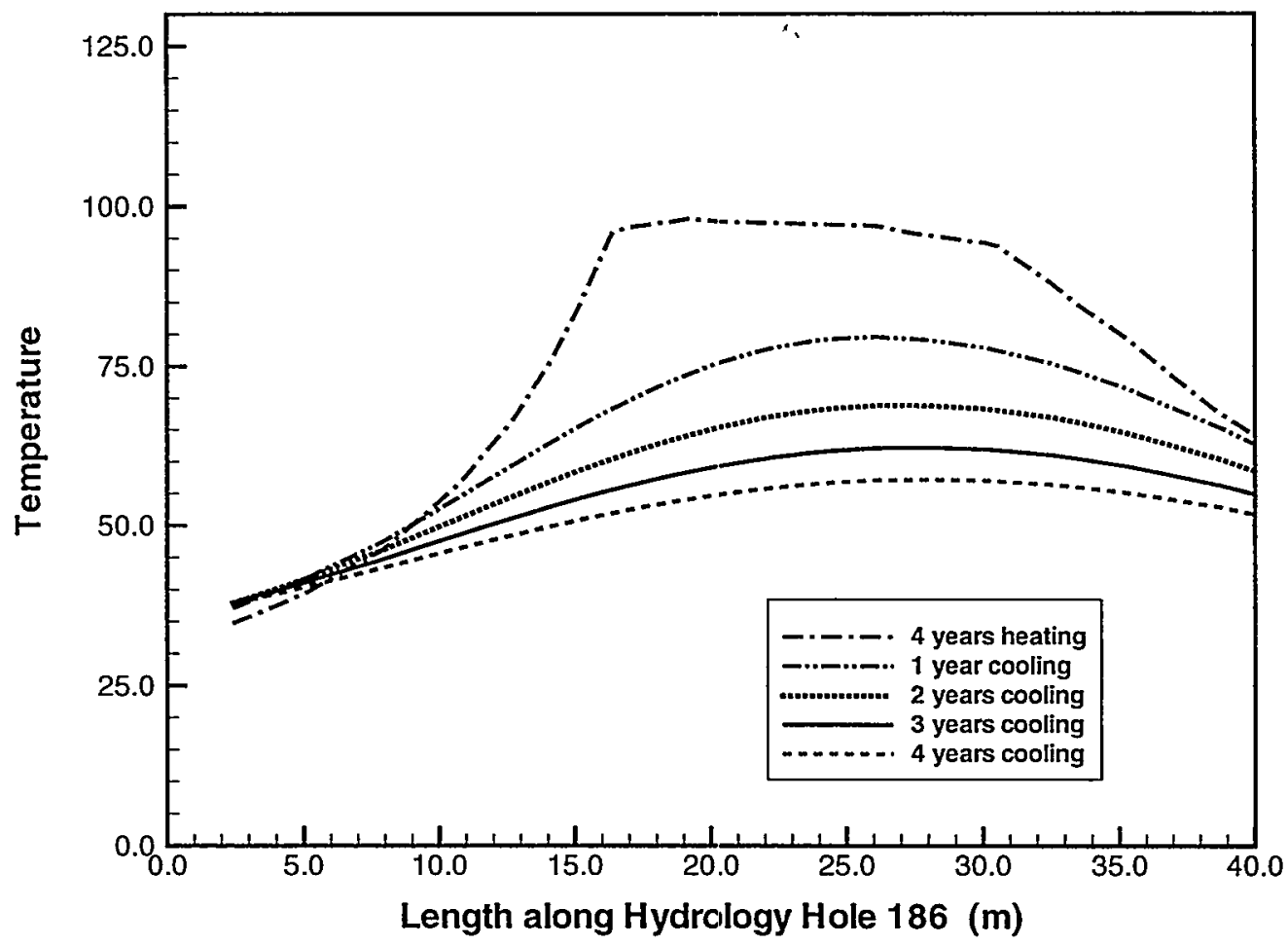

Figure A2-69 Temperature profile along borehole 186 at different times during cooling period for $0.36 \mathrm{~mm} / \mathrm{yr}$ infiltration case (1 year heating at 100\%, 3 years heating at $50 \%$ ). 


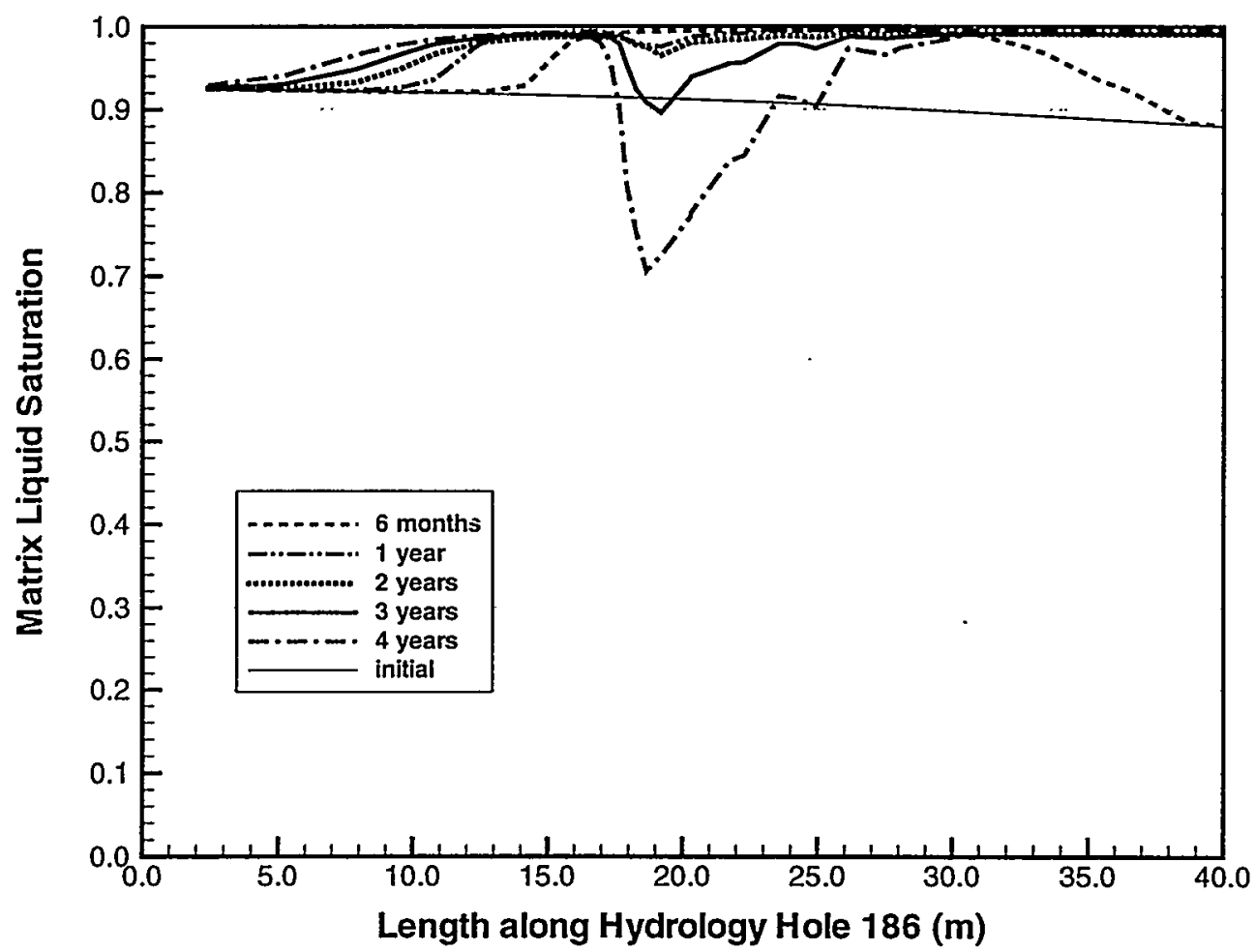

Figure A2-70 Matrix saturation profile along borehole 186 at different times during heating period for $0.36 \mathrm{~mm} / y$ r infiltration case (I year heating at 100\%, 3 years heating at 50\%).

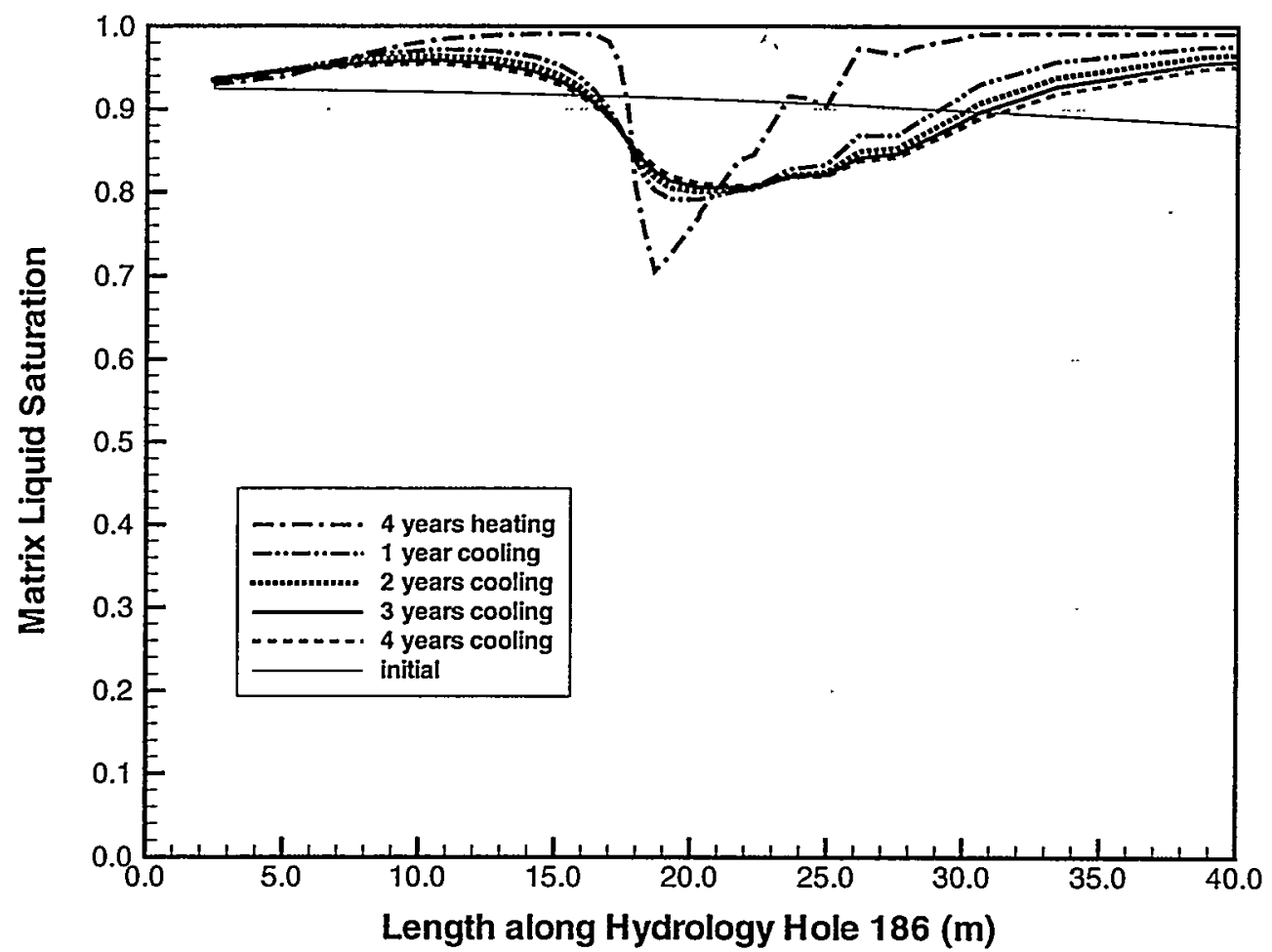

Figure A2-71 Matrix saturation profile along borehole 186 at different times during cooling period for $0.36 \mathrm{~mm} / \mathrm{yr}$ infiltration case (1 year heating at 100\%, 3 years heating at $50 \%$ ). 


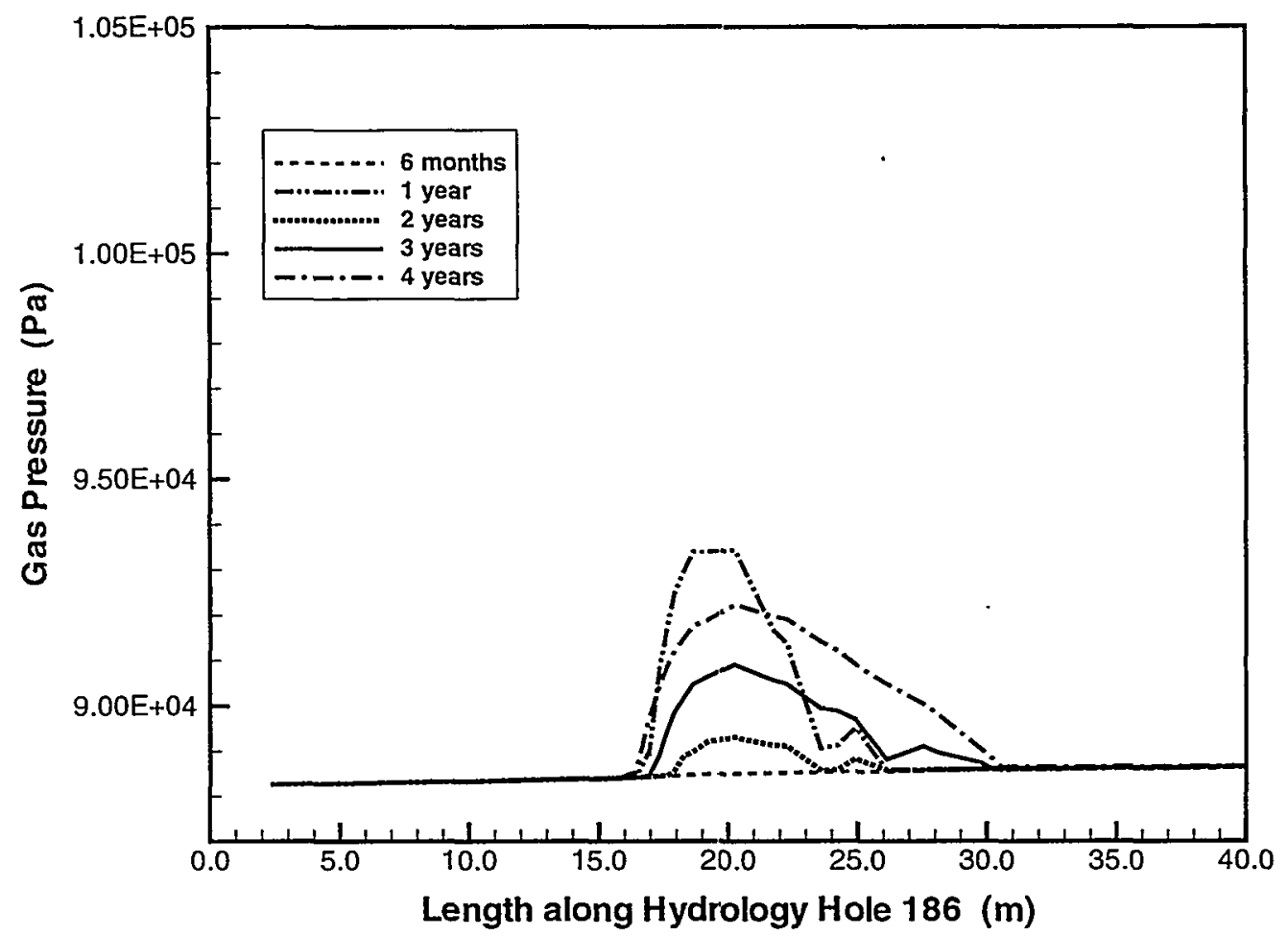

Figure A2-72 Gas pressure profile along borehole 186 at different times during heating period for $0.36 \mathrm{~mm} / \mathrm{yr}$ infiltration case (1 year heating at 100\%, 3 years heating at 50\%). 